UNIVERSIDADE DE SÃO PAULO

CAMPUS DE SÃO CARLOS

PROGRAMA DE PÓS-GRADUAÇÃo EM ENGENHARIA MECÂNICA

MARLON WESLEY MACHADO CUNICO

Desenvolvimento de nova tecnologia de manufatura aditiva baseado em formação seletiva de compósito

SÃO CARLOS

ABRIL - 2013 

MARLON WESLEY MACHADO CUNICO

\title{
Desenvolvimento de nova tecnologia de manufatura aditiva baseado em formação seletiva de compósito
}

\author{
Tese apresentada como requisito parcial à \\ obtenção do título de Doutor em Engenharia, \\ do Programa de Pós-Graduação em \\ Engenharia Mecânica do Campus de São \\ Carlos, da Universidade de São Paulo. \\ Área de Concentração em Projetos Mecânicos
}

Orientador: Prof. Jonas de Carvalho, Ph.D.

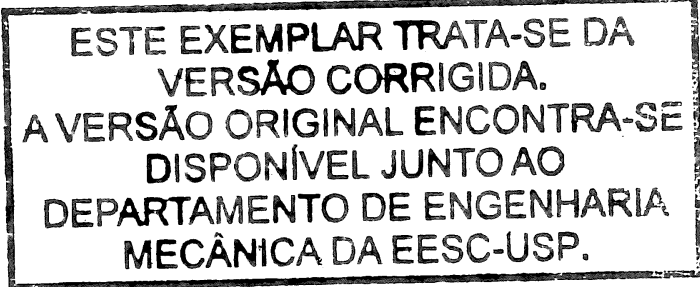

SÃO CARLOS

ABRIL - 2013 


\section{AUTORIZO A REPRODUC̃̃O TOTAL OU PARCIAL DESTE TRABALHO POR QUALQUER MEIO CONVENCIONAL OU ELETRÔNICO, PARA FINS DE ESTUDO E PESQUISA, DESDE QUE CITADA A FONTE.}

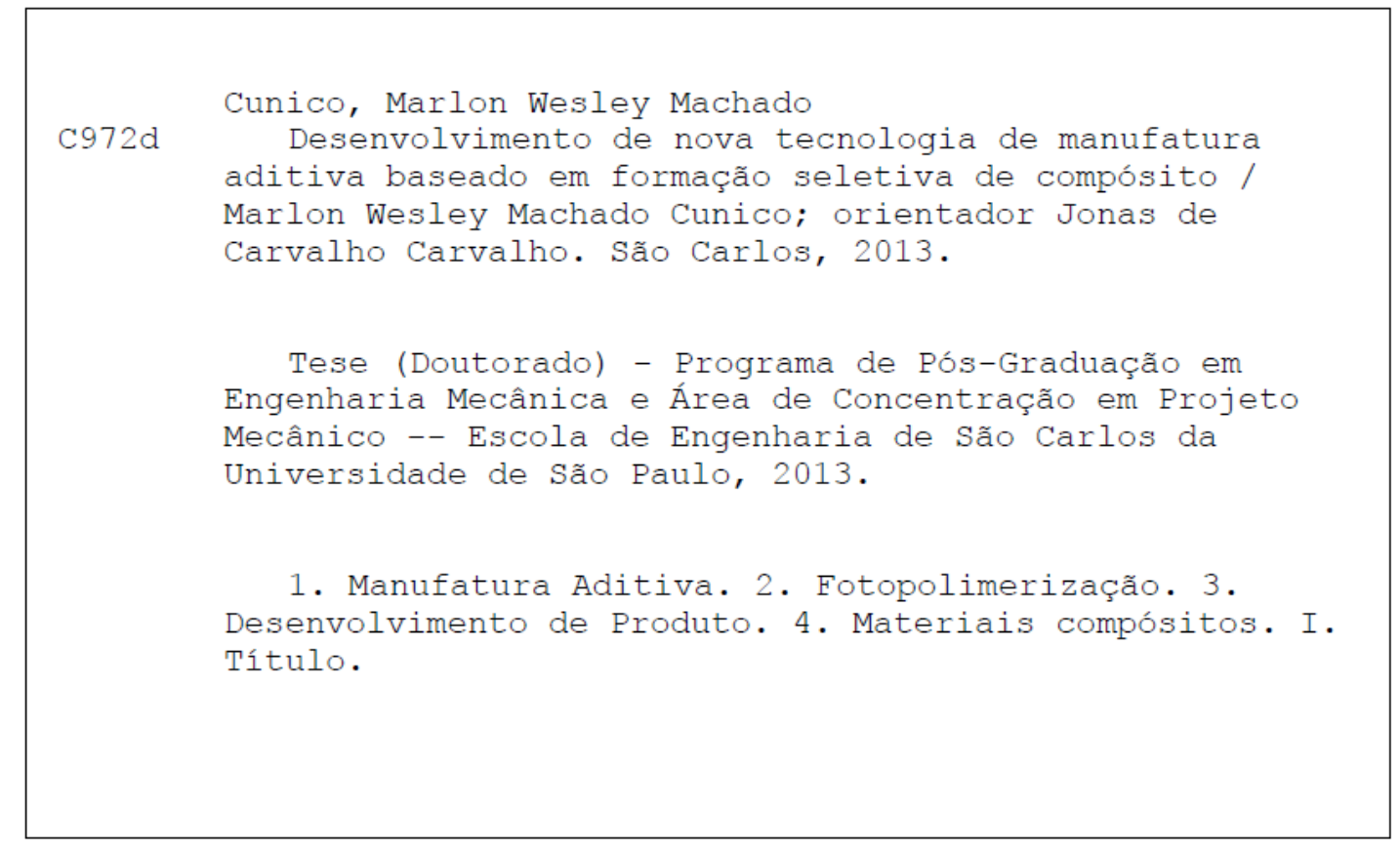




\section{FOLHA DE JULGAMENTO}

Candidato: Tecnólogo MARLON WESLEY MACHADO CÚNICO.

Título da tese: "Desenvolvimento de nova tecnologia de manufatura aditiva baseado em formação seletiva de compósito".

Data da defesa: $17 / 06 / 2013$

\section{Comissão Julgadora:}

Prof. Associado Jonas de Carvalho (Orientador)

(Escola de Engenharia de São Carlos/EESC)

Prof. Associado Glauco Augusto de Paula Caurin

(Escola de Engenharia de São Carlos/EESC)

Prof. Associado Antonio José Felix de Carvalho

(Escola de Engenharia de São Carlos/EESC)

Prof ${ }^{a}$. Drª . Cecília Amélia Carvalho Zavaglia

(Universidade Estadual de Campinas/UNICAMP)

Prof. Dr. Rodrigo Alvarenga Resende

(Centro de Tecnologia da Informação Renato Archer/CTI-Campinas)
Resultado:
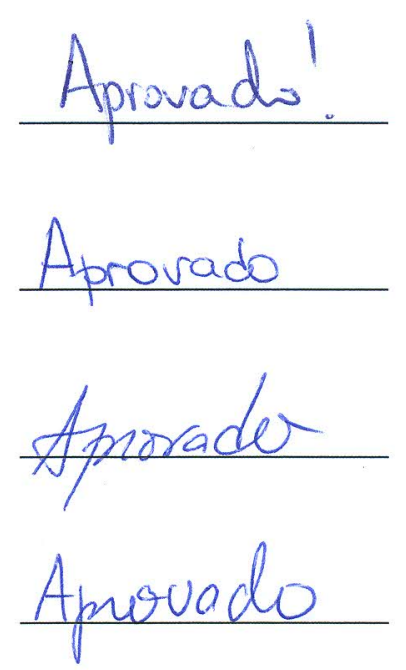

Coordenador do Programa de Pós-Graduação em Engenheira Mecânica:

Prof. Associado Marcelo Areias Trindade

Presidente da Comissão de Pós-Graduação:

Prof. Titular Denis Vinicius Coury 


\section{Dedicatória}

À minha querida e amada esposa Jennifer, pelo amor, carinho, paciência e dedicação, apoiando e incentivando ao longo deste trabalho Aos meus pais, Edimar e Miriam sempre presentes com muito amor. 


\section{AGRADECIMENTOS}

O autor deste trabalho agradece à Universidade de São Paulo pelo fornecimento de recursos necessários para realização deste trabalho. Adicionalmente, estende agradecimento à CAPES por auxilio financeiro e apoio à pesquisa e desenvolvimento.

Aos professores e orientador, também são oferecidos agradecimentos pelos conselhos e questionamentos. Enquanto para família, agradecimento por apoio e compreensão.

À minha esposa, agradecimento especial por suporte, apoio e compreensão.

Deus abençoe a todos. 
"A falsa ciência gera ateus; a verdadeira ciência leva os homens a se curvarem diante da divindade."

Voltaire 
CUNICO, Marlon Wesley Machado CUNICO, Marlon Wesley Machado, Desenvolvimento de nova tecnologia de manufatura aditiva baseado em formação seletiva de compósito, 2011, Tese de Doutorado, do Programa de PósGraduação em Engenharia Mecânica do Campus de São Carlos, da Universidade de São Paulo, 329p.

\section{RESUMO}

Nos últimos anos, a aplicação de tecnologias de manufatura aditiva tem crescido, estendendo seus benefícios para áreas diversas, como saúde, e encurtando o tempo de desenvolvimento de produto. Contudo, são encontrados apenas fabricantes nacionais de versões "open -source" de baixo custo de tecnologias de modelagem por fusão deposição (FDM), não existindo desenvolvedor de uma tecnologia nacional. Em função disto, o objetivo principal deste trabalho é apresentar e validar uma nova concepção de processo de fabricação aditiva. Esta proposta consiste na geração seletiva de compósito de celulose e acrílico através de fonte coerente de luz UV. Para isto, foram realizados estudos referentes a duas áreas principais, desenvolvimento de material e validação da concepção de processo proposto. Para o desenvolvimento de material, foram estudados materiais fotopoliméricos a base de acrilatos de forma a ser obtida uma formulação de material adequada para ser validado o processo. Da mesma forma, a seleção do material celulósico empregado foi realizado a partir da caracterização de materiais celulósicos laminados (papéis) comumente encontrados no mercado. Adicionalmente, foi identificado potencial de viabilidade preliminar da proposta ao longo da caracterização do compósito, visto que foi avaliada a aderência entre camadas, resistência mecânica à tração, resistência à água e microestrutura do compósito. Após o desenvolvimento do material, foi desenvolvido o projeto preliminar do equipamento de validação da proposta, assim como a fabricação de um protótipo e sua calibração. Foram realizados estudos de otimização para implementação do projeto do sistema de posicionamento, assim como dimensionamento de "error Budget" e custo relativo de equipamento. Foi também desenvolvido sistema de deposição de material polimérico, sistema de polimerização e alimentação de material, sendo realizados estudos de caracterização e validação do processo 
proposto. Foram identificados os efeitos principais dos principais parâmetros de processo para a largura da linha de polimerização, interferência da formação de compósito para camadas anteriores e, por fim a construção de corpo de prova. Através destes estudos, foi possível identificar a viabilidade funcional da proposta, sendo observadas as vantagens e desvantagens desta nova concepção em relação aos principais processos de fabricação aditiva no mercado.

Palavras-chave: Manufatura Aditiva, Fotopolimerização, Desenvolvimento de Produto, Materiais compósitos 


\section{CUNICO, Marlon Wesley Machado, Development of novel technology of additive} manufacturing based on selective composite formation, 2011, Ph.D. Thesis, Programa de Pós-Graduação em Engenharia Mecânica do Campus de São Carlos, da Universidade de São Paulo., 329p.

\section{ABSTRACT}

In recent years, the application of additive manufacturing technologies has grown, extending its benefits to diverse areas such as health, and shortening the time product development. However, national manufacturers are only found to provide versions of open-source and low cost FDM technologies, highlighting the absence of a national technology developer. Due to that, the main goal of this work is to present and evaluate a novel concept of additive manufacturing process. This proposal consists in selectively generate composite of cellulose and acrylic through a coherent UV light source. For this, studies have been conducted concerning two main areas, material development and validation of proposed process. For the development of material, we have studied photopolymeric materials based on acrylates so as to obtain a composition of material suitable for validating the process. Likewise, the selection of cellulosic substrate was made from the characterization of laminated cellulosic materials (sheet of paper) which are commonly found at market. Additionally, we identified the potential feasibility of the proposal along the preliminary characterization the composite, whereas it was evaluated the adhesion between layers, tensile strength, water resistance and microstructure of the composite. After development the material, it was developed a preliminary design of equipment for validation of proposal, in addition to fabricating and calibrating a prototype. Studies were performed to optimize and implement the mechanical design of the positioning system as well as sizing error Budget and relative cost of equipment. It was also developed the systems of poylmerization, photopolymeric material deposition, and feed of substrate, being conducted studies for the characterization and validation of proposed process. We identified the main effects of the main process parameters on the polymerization line width, interference of the formation of composite layers for and previous layers, and the construction of the test 
body. Through these studies, it was possible to identify the functional feasibility of the proposal, being observed the advantages and disadvantages of this novel design in comparison with the main additive manufacturing process in the market.

Keywords: Additive manufacturing, Photopolymerization, Product Development, composite materials 


\section{SUMÁRIO}

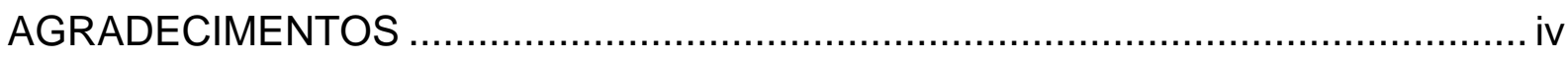

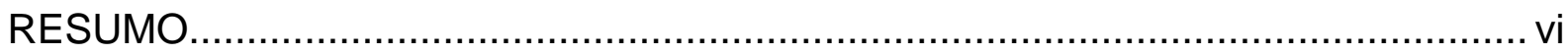

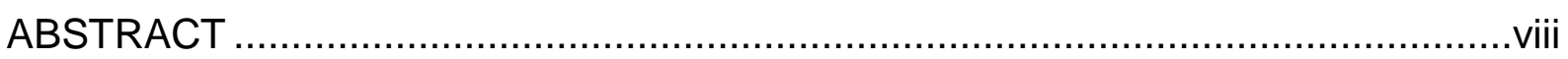

SUMÁRIO

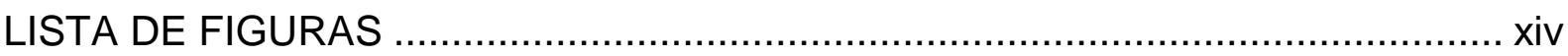

LISTA DE TABELAS …...........................................................................

LISTA DE ABREVIATURAS E SIGLAS .................................................xxxii

LISTA DE SÍMBOLOS........................................................................................

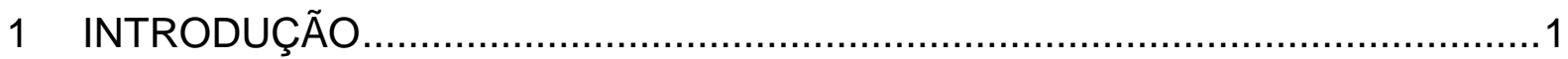

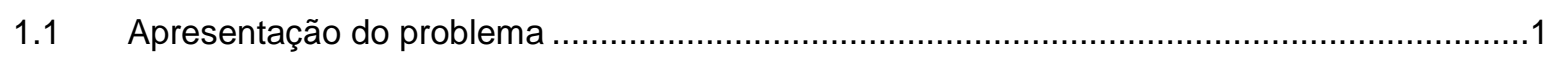

1.2 Relevância do tema......................................................................................

1.3 Oportunidade de desenvolvimento ..............................................................................

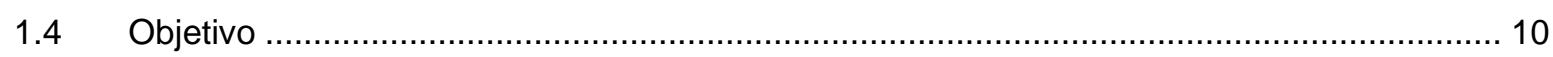

1.5 Objetivos específicos........................................................................................... 10

1.6 Estrutura da Pesquisa e do Trabalho ........................................................................ 10

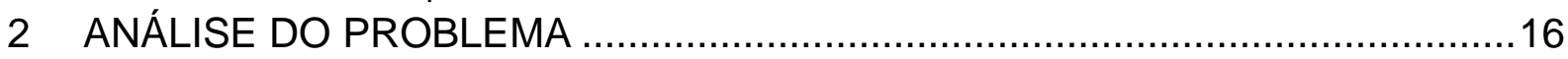

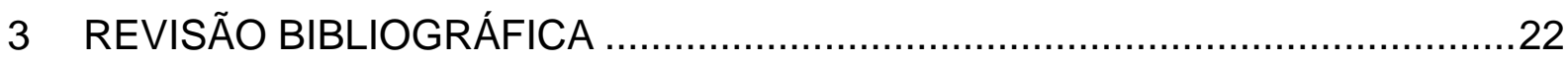

3.1 Tecnologias de Fabricação por Adição (Additive Manufacturing - AM) …………………. 22

3.1.1 Tecnologias a base de Polímeros Líquidos ............................................................. 22

3.1.2 Modelagem por Fusão e Deposição (Fused Deposition Modelling - FDM) ..................... 30

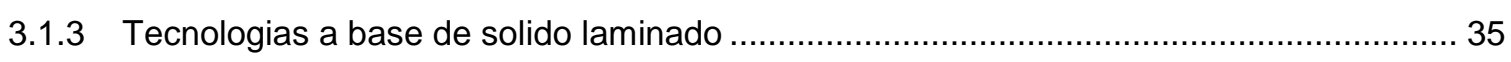

3.1.4 Tecnologias a base de Partículas Discretas ……………….................................... 38

3.1.5 Comparativo entre tecnologias ......................................................................... 41

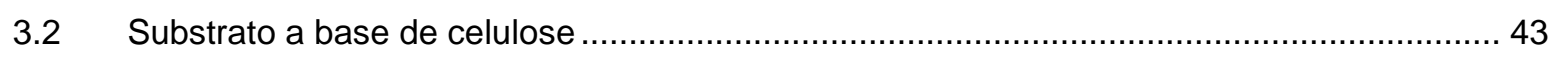

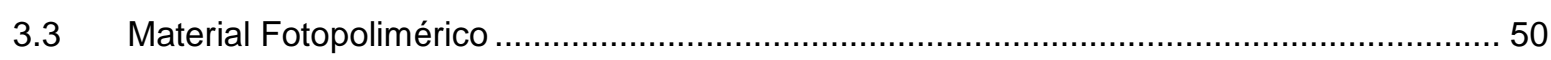

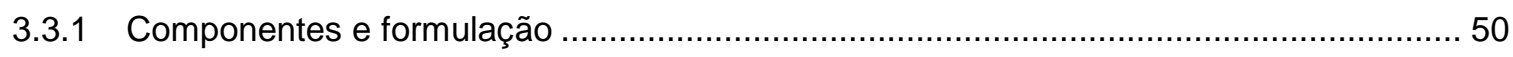

3.3.2 Processo de fotopolimerização ……………………………………………….... 55

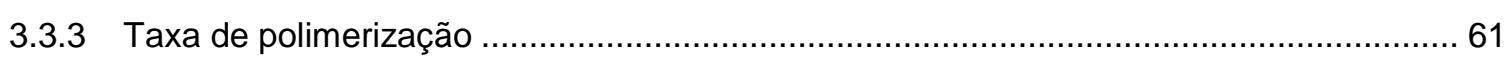

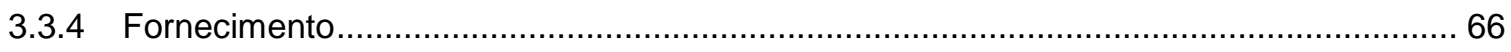

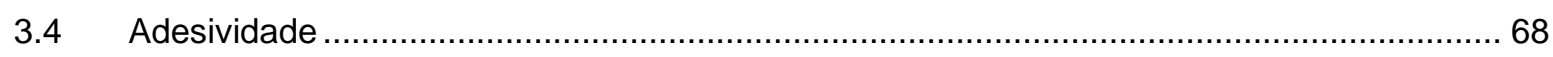

3.5 Sistema de Deposição ……………………………………………………….... 70

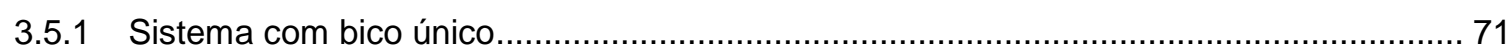

3.5.2 Sistema com múltiplos bicos ......................................................................... 72

3.5.3 Sistema de deposição por área............................................................................ 76

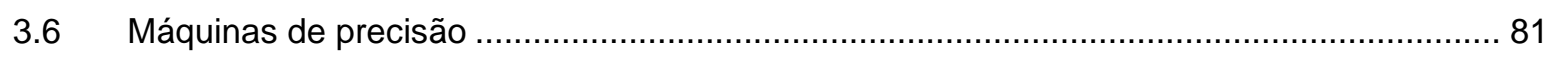

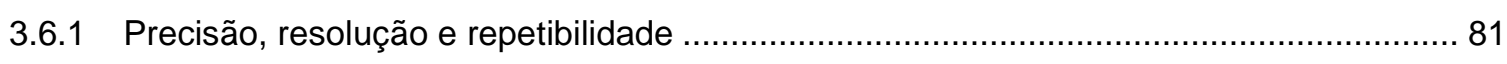

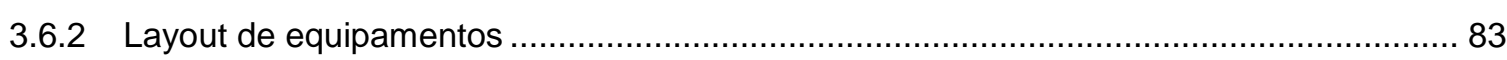

3.6.3 Estimativa de erros - "Error Budgeting" ................................................................. 84 


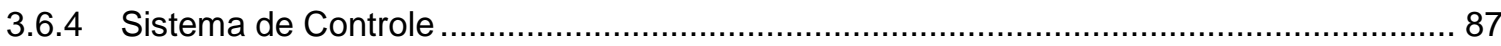

PARTE I - DESENVOLVIMENTO DE MATERIAL .......................................94

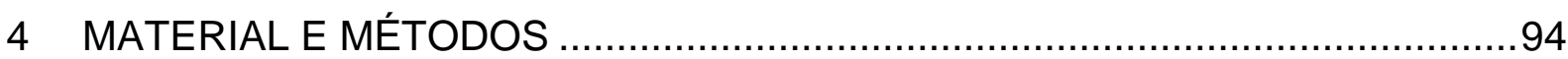

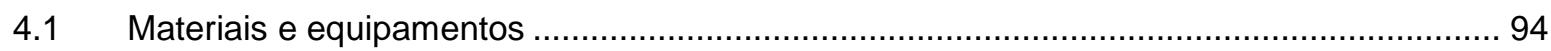

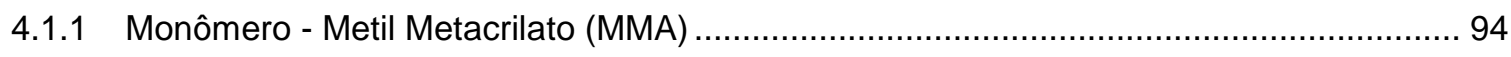

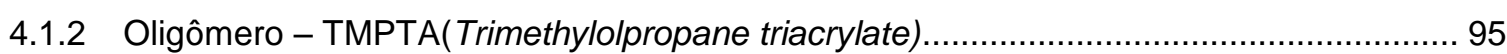

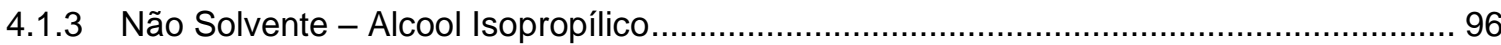

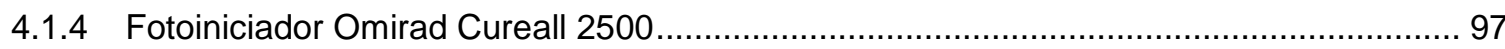

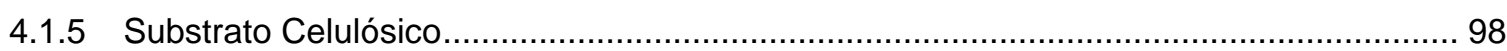

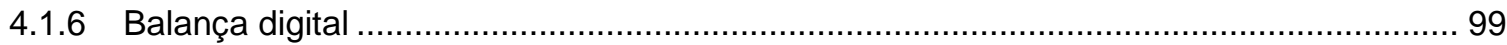

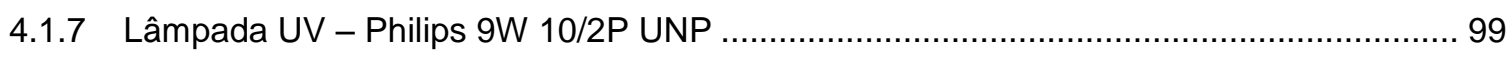

4.1.8 Fotodiodo Emissor Ultravioleta (Ultraviolet Light Emissior Diode - UV LED).................. 101

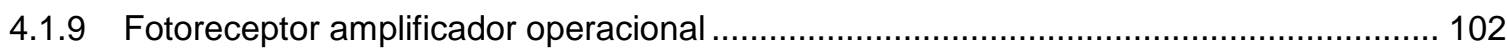

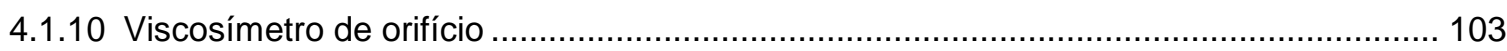

4.1.11 Fonte de alimentação regulável ....................................................................... 105

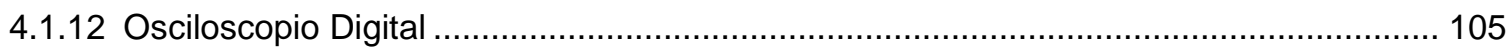

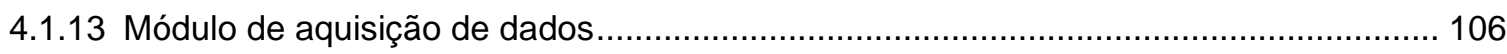

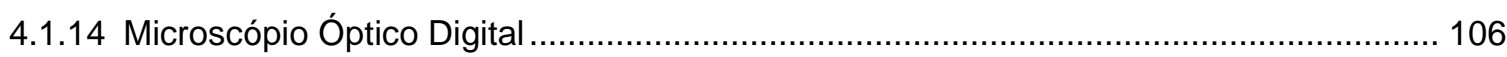

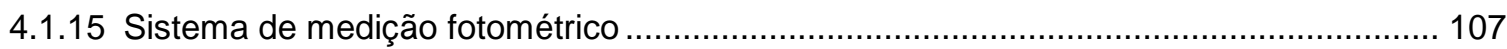

4.1.16 Sistema de medição de deflexão e temperatura de trabalho ........................................ 107

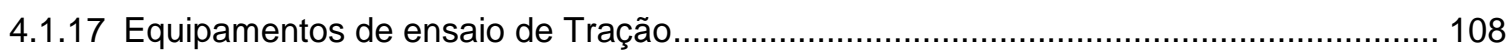

4.1.18 Equipamentos de ensaio de Tração para Papel ......................................................... 109

4.2 Confecção de Corpos de Prova ...................................................................................... 109

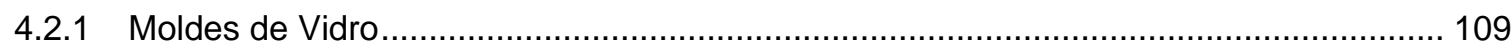

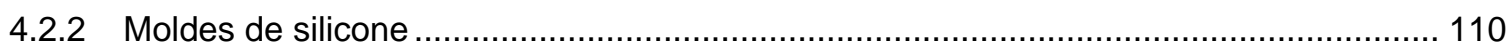

4.2.3 Corpo de prova de ensaio de tração de material Compósito ............................................ 112

4.2.4 Corpo de prova de ensaio de adesividade de material Compósito ................................ 113

4.3 Caracterização de material ................................................................................... 114

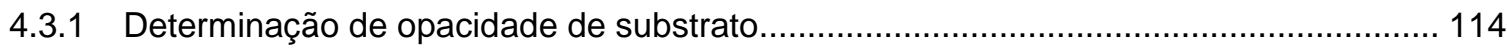

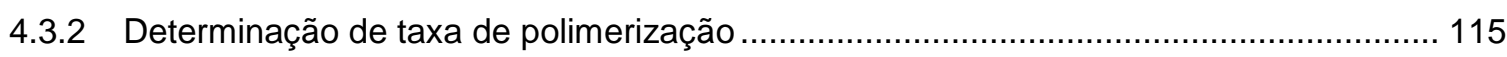

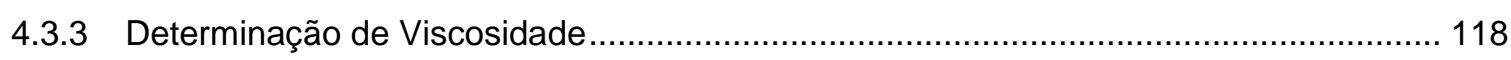

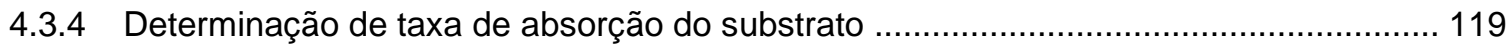

4.3.5 Determinação de temperatura de trabalho …......................................................... 120

4.3.6 Determinação de Módulo de elasticidade ................................................................... 123

4.3.7 Determinação de resistência mecânica a tração de material polimérico ......................... 124

4.3.8 Determinação de resistência mecânica a tração de material celulósico ......................... 125

4.3.9 Determinação de resistência mecânica a tração de material compósito .......................... 126

4.3.10 Determinação de resistência mecânica a tração de material compósito molhado .......... 127

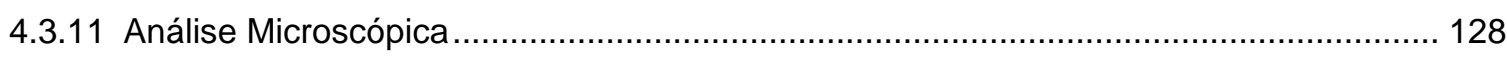


4.3.12 Determinação de adesividade entre camadas ........................................................ 129

4.3.13 Compatibilidade de resina com cabeçote jato de tinta................................................. 130

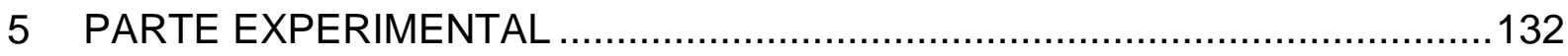

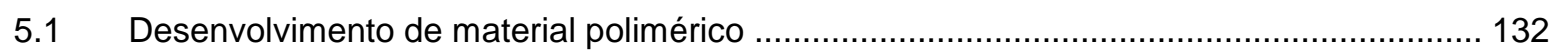

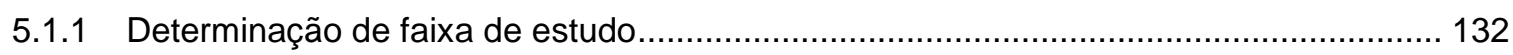

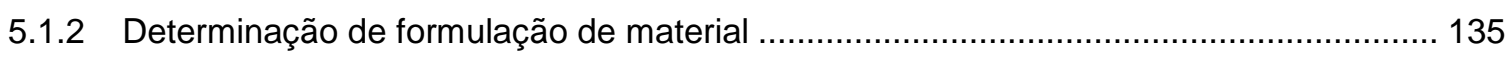

5.1.3 Compatibilidade com cabeçote jato de tinta ........................................................... 137

5.2 Desenvolvimento do material celulósico laminado (substrato) …..................................... 137

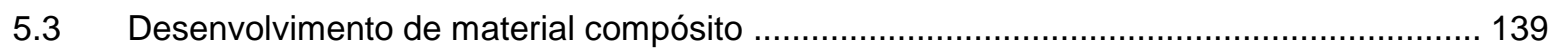

5.3.1 Influência de polímero sobre resistência mecânica ...................................................... 139

5.3.2 Determinação de Formulação do compósito .............................................................. 140

5.3.3 Caracterização de comportamento de polímero impregnado em substrato ..................... 142

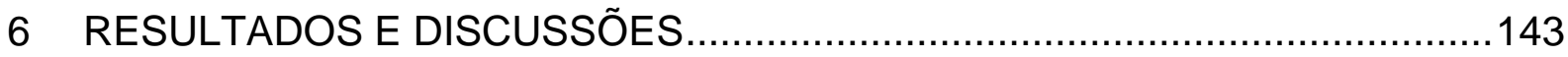

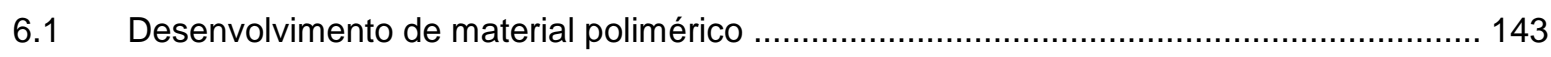

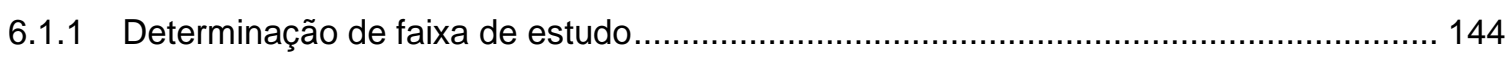

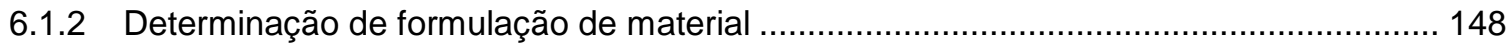

6.1.3 Compatibilidade entre material com tecnologia jato de tinta........................................ 168

6.2 Desenvolvimento de material celulósico laminado (Substrato) .......................................... 169

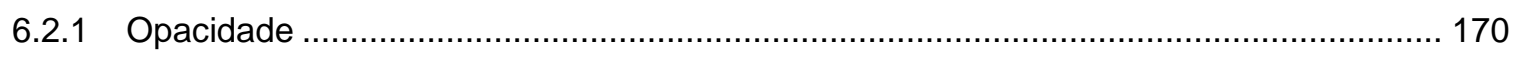

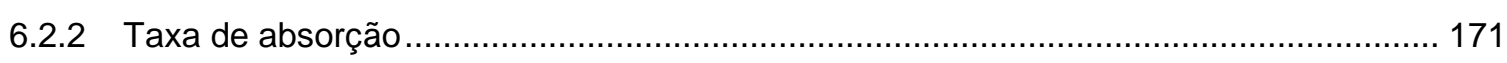

6.2.3 Resistência mecânica a tração de material celulósico................................................. 172

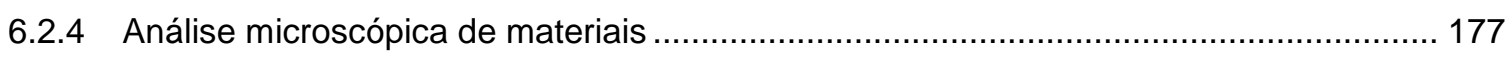

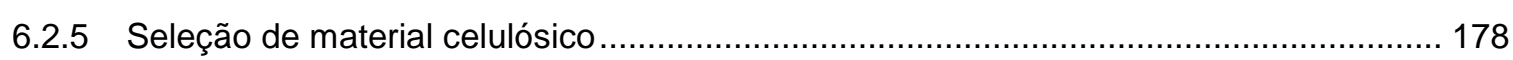

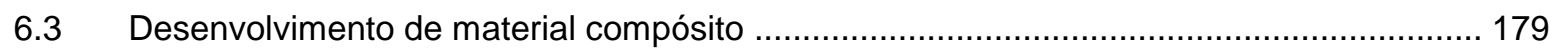

6.3.1 Resistência mecânica a tração em função de percentual de polímero ........................... 179

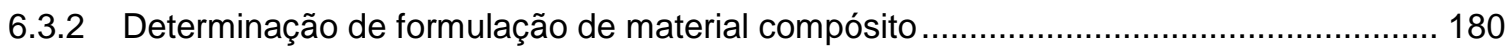

6.3.3 Comportamento de microestrutura de compósito .......................................................... 191

PARTE II - VALIDAÇÃO DE PROPOSTA DE PROCESSO ................................. 194

7 PROJETO CONCEITUAL DO EQUIPAMENTO ....................................... 194

7.1 Desenvolvimento Sistema de deposição ...................................................................... 194

7.2 Desenvolvimento de Sistema de alimentação de substrato ................................................ 198

7.3 Desenvolvimento de Sistema de posicionamento ........................................................ 201

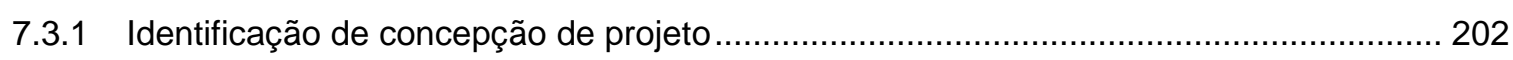

7.3.2 Levantamento de função de custo-tolerância ............................................................. 203

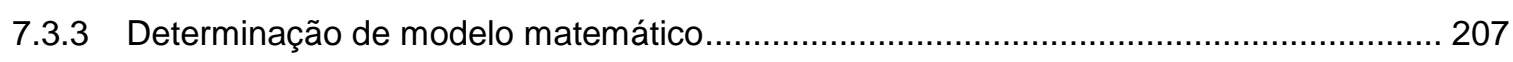

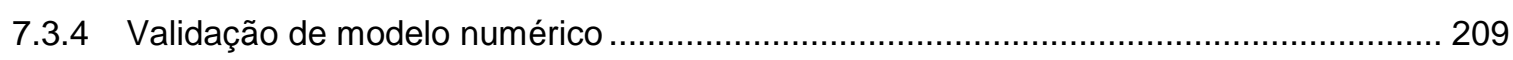

7.3.5 Otimização de sistema de posicionamento -"Cost and Error Budget" ............................ 211

7.4 Desenvolvimento de Sistema de Controle .............................................................. 213

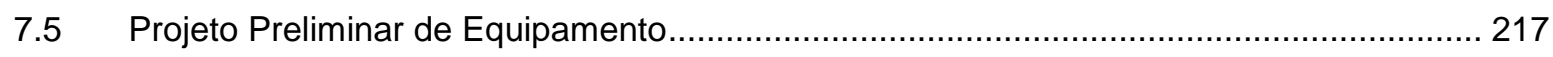

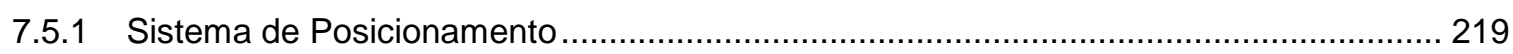




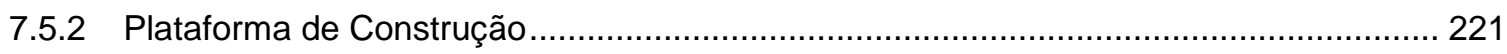

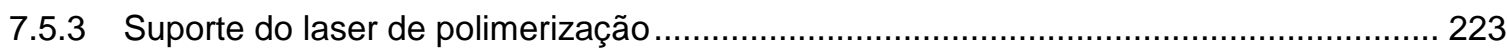

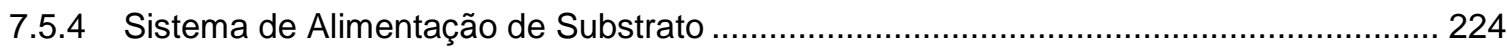

7.5.5 Sistema de Deposição de Material Fotopolimérico ……………………...................... 226

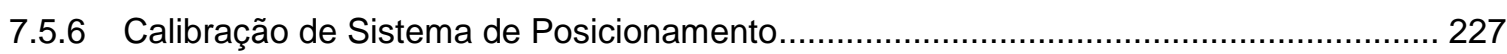

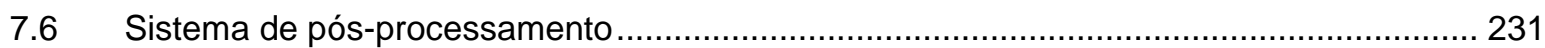

8 CARACTERICAÇÃO DA PROPOSTA ................................................232

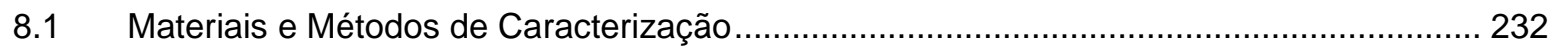

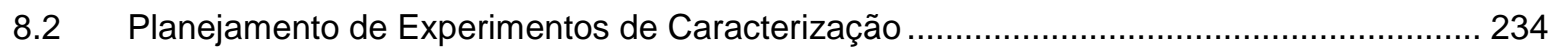

8.2.1 Caracterização de sistema de deposição ................................................................ 234

8.2.2 Caracterização de Formação de Compósito em uma Camada ........................................ 235

8.2.3 Caracterização de Formação de Compósito em para Múltiplas Camadas...................... 239

8.2.4 Caracterização de Funcionalidade de Conceito ........................................................ 241

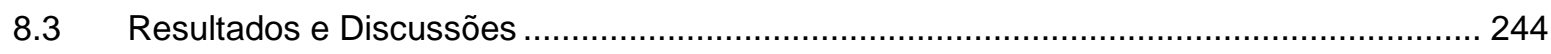

8.3.1 Caracterização de sistema de deposição ............................................................... 245

8.3.2 Caracterização de Formação de Compósito em uma Camada ........................................ 246

8.3.3 Caracterização de Formação de Compósito em Múltiplas Camadas .............................. 253

8.3.4 Caracterização de Funcionalidade de Conceito ........................................................ 254

9 ANÁLISE DE VIABILIDADE E FUNCIONALIDADE ...................................261

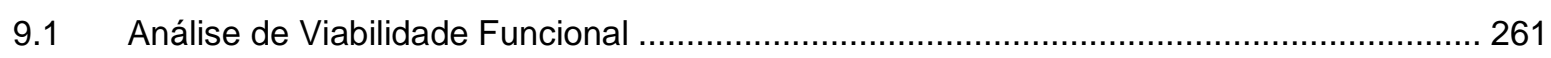

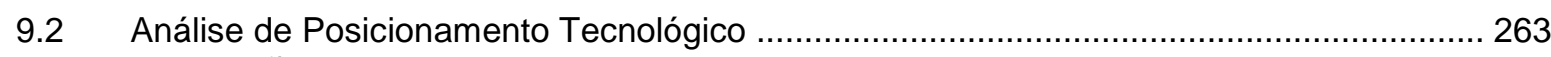

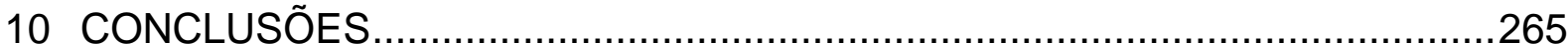

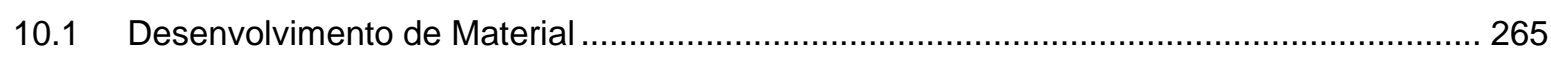

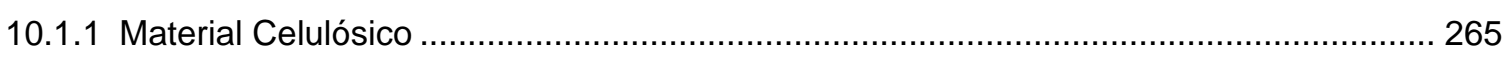

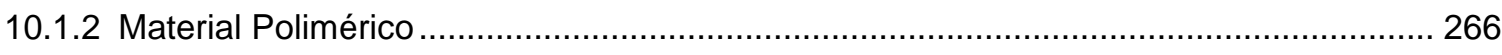

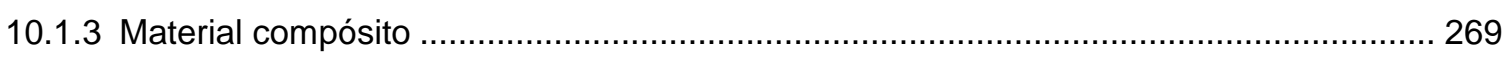

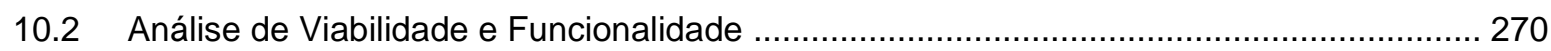

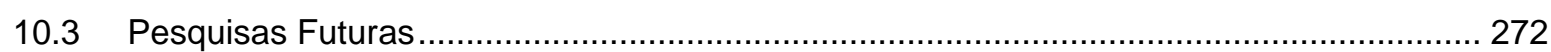

PRODUÇÃO CIENTÍFICA NO PERÍODO (fev 2010 - fev 2014) .........................274

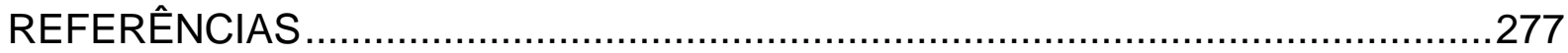




\section{LISTA DE FIGURAS}

Figura 1.1 - Representação esquemática de princípio básico de funcionamento de processos AM (VANDRESEN, 2004). 2

Figura 1.2 - Comparação entre tempo de comunicação na fase de projeto utilizando desenhos 2D, modelos CAD 3D e protótipos físicos (VOLPATO, 2007) 3

Figura 1.3 - Exemplo de reconstrução de espinha lombar fabricada por meio de tecnologia RP, sendo: a) modelo construído a partir de imagens obtidas de tomografia computadorizada; b) reconstrução fisica de modelo através de estereolitografia ("Stereolithography" - SLA) (GIBSON, 2005)

Figura 1.4 - Crescimento no numero de patentes relacionadas à manufatura aditiva (AM) - Classificação internacional de patentes (IPT) B29C, e das 5 principais empresas de AM (WIPO, 2011) .5

Figura 1.5 - Acompanhamento de preço de ações de empresa Stratasys (EDGAR, 2011)

Figura 1.6 - Relacionamento entre volume de pesquisa desenvolvida e crescimento econômico adaptado de (IMF, 2011; SCIMAGO, 2011)

Figura 1.7 - Esquemático simplificado de proposta de processo de fabrição por adição de material.

Figura 1.8 - Posicionamento de pesquisa de engenharia ou ciencia de aplicada em relação ao centro de atividades de engenharia de desenvolvimento (PAHL et al., 2007) 11

Figura 1.9 - Fluxo de processo básico de pesquisa de base (a) e desenvolvimento (b) (EEKELS e ROOZENBURG, 1991) ................................12

Figura 1.10 - Metodologia e Estrutura de Projeto ..............................................13

Figura 2.1 - Representação de determinação função global de produto ..................16

Figura 2.2 - Representação do primeiro nível de estratificação de funções especificas do projeto. 
Figura 2.3 - Representação de fluxo de processamento de segundo nível de estratificação da análise funcional de proposta de projeto 19

Figura 3.1 - Representação genérica de processo de Estereolitografia (SLA) (GIBSON et al., 2010)

Figura 3.2 - Representação genérica de perfil de cura gerados por deslocamento de laser (SLA) e interação entre filamentos, adaptado de (JACOBS et al., 1992; GIBSON et al., 2010) .24

Figura 3.3 - Representação genérica estrategias de geração de trajetorias de construção, sendo: a) malha (weave); b)malha 3D (star weave); c)contorno;d)varredura , adaptado de (JACOBS et al., 1992; GIBSON et al., 2010) .26

Figura 3.4 - Representação genérica da tecnologia máscara de projeção (GIBSON et al., 2010) .28

Figura 3.5 - Representação genérica da tecnologia IJP de fotopolimerizaveis (GIBSON et al., 2010) .30

Figura 3.6 - Representação esquemática de processo FDM (GIBSON, 2005) .32

Figura 3.7 - Representação esquemática estrategias básicas de geração construção de perfil de camada de processo FDM .33

Figura 3.8 - Foto of a)Fab@home and b)BitFromBytes FDM variations (MALONE e LIPSON, 2007; BITSFROMBYTES, 2011). .35

Figura 3.9 - Representação de princípio de funcionamento de processo LOM (GIBSON et al., 2010) .36

Figura 3.10 - llustração de posprocessamento de tecnologias LOM adaptado de (MORITA e SUGIYAMA, 2000) . .37

Figura 3.11 - llustração esquemática do processos de stratoconception e CAM-LEM (GIBSON et al., 2010) 37

Figura 3.12 - llustração esquemática do processos de consolidação ultrassônica (GIBSON et al., 2010) .38 
Figura 3.13 - Ilustração esquemática do processos de Si-nterização Seletiva a Laser (PRINZ et al., 1997)

Figura 3.14 - llustração esquemática do processos de impressão 3D (GIBSON et al., 2010)

Figura 3.15 -Empenamento de peça fabricada por processo FDM (MAHESH et al., 2004)

Figura 3.16 - Representação esquemática de geração de polpa de papel por processo mecânico (polpa mecânica) (KIRWAN, 2005)

Figura 3.17 - Representação esquemática de geração de polpa de papel por processo Quimico (polpa Química) (KIRWAN, 2005)

Figura 3.18 -Imagem micrografica $(400 x)$ de ruptura de papel sulfite (a), fabricado por processo quimico e papel higiênico popular (b), fabricado por processo mecânico.

Figura 3.19 - llustração esquemática dos processos de ramificação (Branching) e interligação das cadeias polimericas (crosslinking) (ODIAN, 2004) .52

Figura 3.20 - Representação de geração de fotofragmentação (MATYJASZEWSKI e DAVIS, 2002) 53

Figura 3.21 - Representação de processo de geração de radicais livres a partir de fotoiniciador radicalar do tipo II (MATYJASZEWSKI e DAVIS, 2002) 54

Figura 3.22 - Exemplo de amina terciária, Benzophenone/ N,N-dimethyl aniline (MATYJASZEWSKI e DAVIS, 2002) .55

Figura 3.23 - Representação esquemática do processo de fotopolimerização radicalar

Figura 3.24 - Representação de tipos de quebra de ligação, onde a)heterolítica; b) dupla ligação; c)homolítica (ODIAN, 2004) .58

Figura 3.25 - Representação de fases de polimerização iônica, propagação, transferência e terminação, respectivamente. .59

Figura 3.26 - Exemplos de grupos funcionais de polimerização por abertura de anéis (ODIAN, 2004) .60 
Figura 3.27 - Representação da propagação proveniente da abertura do anél epóxi (ODIAN, 2004) 61

Figura 3.28 - Espectro de absorção de IRGACURE 651, 99,9\%(JASTY, 1999) .64

Figura 3.29 - Representação de modos de falha de justas adesivas (ASTM, 2002) 70 Figura 3.30 - Representação de sistema de deposição de bico único com (a) ar comprimido (STRONG et al., 2007) e (b) atuador linear (PRINZ et al., 1997) ...71

Figura 3.31 - Representação de sistema de deposição jato de tinta (a) continuo (ClJ) e (b) deposição por demanda (DOD) (GIBSON et al., 2010) .73

Figura 3.32 - Esquema de tipos de cabeçotes jato de tinta e seus principais fornecedores (MAGDASSI, 2009)

Figura 3.33 - Classificação de principais tipos de impressão por matriz, elaborado a partir de (KIPPHAN, 2001; BLAYO, 2007) .76

Figura 3.34 -Esquemático de funcionamento de processo de litografia, baseado em (KIPPHAN, 2001; BLAYO, 2007) .77

Figura 3.35 -Esquemático de funcionamento de processo de rotogravura direta, baseado em (KIPPHAN, 2001; BLAYO, 2007). .78

Figura 3.36 -Esquemático de funcionamento de processo de tampografia, baseado em (KIPPHAN, 2001; BLAYO, 2007) .79

Figura 3.37 -Esquemático de funcionamento de processos de serigrafia:a) planoplano (flat-to-flat); b) plano-redondo (flat-to-round); c) redondo-redondo (round-toround); d) impressão de corpo (body printing) baseado em (KIPPHAN, 2001; BLAYO, 2007)

Figura 3.38 -Esquemático de funcionamento de processo de flexografia, baseado em (KIPPHAN, 2001; BLAYO, 2007)

Figura 3.39 - Representação de conceitos de precisão, repetibilidade e resolução (SLOCUM, 1992) .83

Figura 3.40 - Representação de sistema de controle de equipamentos de posicionamento com malha fechada (SUH et al., 2008) 88

Figura 3.41 - Ilustração de processo de interpolação linear (a) e circular (b) 89 
Figura 3.42 - Representação esquemática de acionamento de motores de passo unipolares, adaptado de (CONDIT e JONES, 2004)

Figura 3.43 - Representação esquemática de funcionamento de encoder linear absoluto (WEBSTER, 1999).

Figura 4.1 - Ilustração de estrutura molecular do Monômero MMA (Methyl Methacrylate) (SIGMA-ALDRICH, 2008a)

Figura 4.2 - Ilustração de estrutura molecular do oligômero CN501 ou TMPTA (Trimethylopropane triacrylate) (SIGMA-ALDRICH, 2008b). .96

Figura 4.3 - Ilustração de estrutura molecular de álcool Isopropílico (SIGMAALDRICH, 2011) .97

Figura 4.4 - Curva espectroscópica de fotoiniciador Omirad Cureall 2500 (IGM, 2005)

Figura 4.5 - Foto e esquemático dimensional de lâmpada UV PL-S 9W 10/2P UNP, sendo A - 129mm; B - 144.5mm; C167.5mm, D-21mm; e D1 - 13mm (PHILIPS, 2008) 100

Figura 4.6 - Espectro de emissividade de lâmpada UV PL-S 9W 10/2P UNP (PHILIPS, 2008) 100

Figura 4.7 - Demostração de variação de irradiação UV em função da distância a partir da lâmpada UV PL-S 9W 10/2P UNP (PHILIPS, 2006). 101

Figura 4.8 - Esquemático de dimensões gerais de UV LED (VCC, 2009). 102

Figura 4.9 - Espectro de emissividade de UV LED (VCC, 2009) 102

Figura 4.10 - Esquemático do circuito integrado e curva de resposta em função do comprimento do optoreceptor OPT101 (TEXAS, 1994) 103

Figura 4.11 - Foto(a) e esquemático de dimensões(b) de Copo Ford conforme ASTM D1200 (VISWANATH, 2007) 104

Figura 4.12 - Determinação numero de orifício de viscosímetro do tipo Copo Ford em função de viscosidade e tempo de escoamento conforme ASTM D1200 (VISWANATH, 2007). 105

Figura 4.13 - Esquemático de sistema de medição fotométrico 107 
Figura 4.14 - Esquemático de sistema de medição para determinação de Módulo de elasticidade por deflexão e temperatura de trabalho 108

Figura 4.15 - Representação de moldes de vidro, sendo a dimensão de espessura igual a $0.12 \mathrm{~mm}$ e $2 \mathrm{~mm}$

Figura 4.16 - Ilustração de variação do processo de RTV utilizado para a confecção dos corpos de prova fotopoliméricos adaptado de (PRINZ et al., 1997)

Figura 4.17 - Fotos de peças básicas utilizadas no processo de fabricação dos corpos de prova, sendo "a", "c" e "e "referentes ao ensaio de tração e "b", "d" e "f" ao ensaio de temperatura de trabalho e módulo de elasticidade. 112

Figura 4.18 - Fotos de amostra de corpo de prova de ensaio de resistência à tração de material compósito 113

Figura 4.19 - Fotos de amostra de corpo de prova de ensaio de adesividade 114

Figura 4.20 - Fluxograma dos procedimentos experimentais utilizadas para a determinação de opacidade de substrato celulósico

Figura 4.21 - Fluxograma dos procedimentos experimentais utilizadas para a determinação de grau de conversão por análise gravimetrica 116

Figura 4.22 - Fluxograma dos procedimentos experimentais utilizadas para a determinação de taxa de conversão baseado em fotometria 118

Figura 4.23 - Fluxograma dos procedimentos experimentais utilizadas para a determinação de taxa de absorção 119

Figura 4.24 - Fluxograma dos procedimentos experimentais utilizadas para a determinação de temperatura de trabalho 120

Figura 4.25 - Análise comparativa de deflexão proporcionada por de perda de módulo de elasticidade conforme carregamento indicado por método $A$ (1.82MPa) e método B (0.445MPa) da norma ASTM D648 e valores de espessura de corpo de prova de 3 e $13 \mathrm{~mm}$ 122

Figura 4.26 - Esquemático de funcionamento de determinação de módulo de elasticidade por deflexão, adaptado de (HUDGIN, 2006) 123 
Figura 4.27 - Desenho dimensional de corpo de prova tipo IV para ensaio de resistência mecânica à tração conforme norma ASTM D638

Figura 4.28 - Fluxograma dos procedimentos experimentais utilizadas para a determinação resistência a tração em função de absorção de água

Figura 4.29 - Fluxograma dos procedimentos experimentais utilizadas para a determinação resistência a tração de compósito em função de quantidade media de polímero 127

Figura 4.30 - Fluxograma dos procedimentos experimentais utilizadas para a determinação resistência média a tração de compósito em função de absorção de água 128

Figura 4.31 - Esquema de funcionamento de ensaio de arrancamento (adesividade) e dimensional de corpo de prova

Figura 4.32 - Fluxograma dos procedimentos experimentais utilizados para a determinação força de arrancamento (adesividade) entre camadas 130

Figura 4.33 - Fluxograma dos procedimentos experimentais utilizados para a determinação compatibilidade entre material e cabeçote jato de tinta

Figura 5.1 - llustração de grau de conversão em função de espessura de camada e concentração de iniciador 133

Figura 6.1 - Ilustração de grau de conversão em função de condições de otimização e espessura de camada 146

Figura 6.2 - Curvas de polimerização analíticas e experimentais de experimentos 2 e 4 147

Figura 6.3 - Diagrama de contorno de taxa de conversão em função de concentração de iniciador e espessura de camada .147

Figura 6.4 - Curva de polimerização de materiais A, B, C e D 149

Figura 6.5 - Curva de polimerização de materiais E, F, G e H 150

Figura 6.6 - Efeitos principais de componentes de material para conversão em 30 e 60 segundos 152 
Figura 6.7 - Efeitos secundarios de componentes de material para conversão em 30 e 60 segundos.

Figura 6.8 - Diagramas de contorno de conversão em 30 e 60 segundos em função de componentes de material polimérico

Figura 6.9 - Diagrama de contorno de conversão em 30 e 60 segundos em função de proporção monômero por oligômero (M/O) e concentração de iniciador ....155

Figura 6.10 - Diagramas de Efeito principal e Efeito secundário de viscosidade de material não polimerizado em função componentes do polímero 156

Figura 6.11 - Diagrama de contorno de viscosidade de material não polimerizado em função componentes do polímero

Figura 6.12 - Curva tensão de tração em função de deformação de materiais poliméricos

Figura 6.13 - Diagramas de Efeito principal e Efeito secundário de tensão de Ruptura e elongamento na ruptura em função de composição do material .....159

Figura 6.14 - Diagramas de contorno de tensão de Ruptura e elongamento na ruptura em função de composição do material 160

Figura 6.15 - Diagrama de efeitos principais e secundários de módulo de elasticidade por flexão em função de compostos de material 161

Figura 6.16 - Diagramas de contorno de módulo de elasticidade por flexão em função de composição do material. 162

Figura 6.17 - Relação de perda de módulo de elasticidade em função de temperatura de materiais 163

Figura 6.18 - Efeitos principais e secundários de componentes de material para a temperatura de trabalho (HDT) 164

Figura 6.19 - Diagrama de contorno de temperatura de trabalho (HDT) em função de componentes de material 165

Figura 6.20 - Diagrama de contorno de temperatura de trabalho (HDT) em função de relação M/O e concentração de iniciador . 165 
Figura 6.21 - Indicação de faixa de viabilidade às restrições do problema de otimização

Figura 6.22 - Levantamento de opacidade de materiais celulósicos em estado seco e em estado úmido (1 minuto de imersão em água)

Figura 6.23 - Levantamento de taxa de absorção de materiais celulósicos em função do tempo de imersão em água

Figura 6.24 - Levantamento de Diagrama de Whisker de tensão de ruptura de materiais celulósicos 172

Figura 6.25 - Determinação de resistência mecânica à tração de Papel Vegetal $\left(75 \mathrm{~g} / \mathrm{m}^{2}\right)$ em função de taxa de absorção de água (água por papel -W/P) 174

Figura 6.26 - Determinação de resistência mecânica à tração de Papel Sulfurizé $\left(35 \mathrm{~g} / \mathrm{m}^{2}\right)$ em função de taxa de absorção de água (água por papel -W/P) 174

Figura 6.27 - Determinação de resistência mecânica à tração de Papel Sulfite $\left(75 \mathrm{~g} / \mathrm{m}^{2}\right)$ em função de taxa de absorção de água (água por papel -W/P) 175

Figura 6.28 - Determinação de resistência mecânica à tração de Papel Seda $\left(18 \mathrm{~g} / \mathrm{m}^{2}\right)$ em função de taxa de absorção de água (água por papel -W/P) 176

Figura 6.29 - Apresentação comparativa entre resistência mecânica de materiais celulósicos, e perda de resistência dos materiais em função de 60 segundos de imersão em água 176

Figura 6.30 - Micrografia de materiais celulósicos, sendo a) papel vegetal $\left(75 \mathrm{~g} / \mathrm{m}^{2}\right)$; b)papel seda $\left(18 \mathrm{~g} / \mathrm{m}^{2}\right)$; c)papel sulfite $\left(75 \mathrm{~g} / \mathrm{m}^{2}\right)$; e d) papel sulfurizé $\left(35 \mathrm{~g} / \mathrm{m}^{2}\right) .177$

Figura 6.31 - Curva de tensão de ruptura de material Compósito em função do percentual de polímero impregnado em substrato celulósico, sendo composto por papel seda e material polimérico $B$ 180

Figura 6.32 - Diagramas de efeito principal e secundário de composição de material compósito para a tensão de ruptura. 181

Figura 6.33 - Diagramas de contorno de tensão de ruptura de material compósito em função de teor de componentes de sua formulação 182 
Figura 6.34 - Diagramas de contorno de tensão de ruptura de material compósito em função de relação monômero/oligômero e concentração de iniciador 183

Figura 6.35 - Diagramas de efeito principal e secundário de composição de material compósito para a tensão de ruptura em meio a água

Figura 6.36 - Diagramas de contorno de tensão de ruptura de material compósito em meio à água em função de teor de componentes de sua formulação 184

Figura 6.37 - Diagramas de contorno de tensão de ruptura de material compósito em presença de água em função de relação monômero/oligômero e concentração de iniciador. 185

Figura 6.38 - Foto de propagação de ruptura por a) borda de contorno de luz e b) homogênea

Figura 6.39 - Diagramas de Efeito principal e Efeito secundário de resistência de adesividade entre camadas em função de componentes de material

Figura 6.40 - Diagramas de contorno de resistência de adesividade entre camadas em função de componentes de material 188

Figura 6.41 - Diagramas de contorno de resistência de adesividade entre camadas em função de proporção entre monômero por oligômero e concentração de fotoiniciador 189

Figura 6.42 - Indicação de faixa de viabilidade às restrições do problema de otimização 190

Figura 6.43 - Imagens microscópicas de vista de topo de a) ruptura de substrato celulósico (papel seda); b) ruptura de material compósito com relação polímero/papel igual a 6,5 ; c) região central de material celulósico (papel seda); e d) região central de compósito com relação polímero/papel igual a 6,5 191

Figura 6.44 - Imagens microscópicas de seção transversal de a) material compósito e b) substrato celulósico (papel seda). 192

Figura 6.45 - Imagens microscópicas de seção transversal de material compósito com múltiplas camadas 
Figura 7.1 - Indicação de funções de sistema de deposição apresentado em análise funcional

Figura 7.2 - llustrações de concepções encontradas em matriz morfológica de sistema de deposição de material fotopolimérico, sendo: a) Concepção 1; b) Concepção 2; c) Concepção 3; d) Concepção 4

Figura 7.3 - Indicação de funções de sistema de alimentação de substrato celulósico apresentado em análise funcional. 199

Figura 7.4 - Ilustrações de concepções encontradas em matriz morfológica de sistema de alimentação de substrato, sendo: a) Concepção 1; b) Concepção 2; c) Concepção 3; d) Concepção 4 200

Figura 7.5 - llustração de concepção de sistema de posicionamento de primeiras gerações de processos FDM (CRUMP et al., 2009) 202

Figura 7.6 - Determinação de regressão exponencial de erro geral de guias de movimentação em função de custo de componente 205

Figura 7.7 - Determinação de regressão potência de erro geral de elementos de transmissão de movimento em função de custo de componente. .205

Figura 7.8 - Determinação de curva de tolerância em função do custo proporcional do processo de fabricação 206

Figura 7.9 - Determinação de sistemas de coordenada para cada eixo de movimentação do equipamento de posicionamento, baseado em primeiras gerações de FDM. 208

Figura 7.10 - Curva apresentando função de compromisso apresentando pontos de otimização balanceada e de concepção de Fortus 250mc 212

Figura 7.11 - Layout de interface de controle de sistema de posicionamento 216

Figura 7.12 - Vista isométrica de projeto preliminar de equipamento protótipo ......218

Figura 7.13 - Fluxograma de funcionamento de proposta de processo. 219

Figura 7.14 - Vista isométrica do sistema de posicionamento do projeto preliminar de equipamento protótipo. 220 
Figura 7.15 - Vista frontal de sistema de regulagem de nível e calibração de plataforma de construção do projeto preliminar de equipamento protótipo......222

Figura 7.16 - Desenho esquemático de suporte de laser de polimerização do projeto preliminar de equipamento protótipo 223

Figura 7.17 - Desenho esquemático de réguas de posicionamento e fixação de substrato do projeto preliminar de equipamento protótipo 224

Figura 7.18 - Desenho esquemático de sistema de alimentação de substrato do projeto preliminar de equipamento protótipo .225

Figura 7.19 - Desenho esquemático de sistema de deposição de material fotopolimérico do projeto preliminar de equipamento protótipo .226

Figura 7.20 - Esquamático de calibração de ortogonalidade entre eixos $X$ e $Y$ de sistema de posicionamento 228

Figura 7.21 - Esquamático de calibração de ortogonalidade entre eixo Z e plano XY de sistema de posicionamento e planicidade de plataforma de contrução 229

Figura 7.22 - Esquamático de calibração de planicidade de plataforma de construção em relação a suporte de laser (ferramenta) 230

Figura 7.23 - Sobreposição de foto e Padrão 45x25mm utilizado para a análise de precisão e repetibilidade planar de sistema de posicionamento .231

Figura 8.1 - Desenho esquemático de dispositivo de tampografia utilizado para deposição de material fotopolimérico em substrato 233

Figura 8.2 - Procedimento de fabricação de corpo de prova para estudo de formação seletiva de compósito em uma camada .237

Figura 8.3 - Ilustração e dimensionamento geral de trajetórias de deslocamento percorridas por laser de diâmetro de feixe $4 \mathrm{~mm}$ (a) e $2 \mathrm{~mm}$ (b), tipo de polimerização esperada (largura "w") e indicação de regiões de análise microscópica (marcações "A", "B" e "C") .238

Figura 8.4 - Procedimento de fabricação de corpo de prova para estudo de formação seletiva de compósito múltiplas camadas 241 
Figura 8.5 - Procedimento de fabricação de corpo de prova para estudo caracterização funcional de conceito

Figura 8.6 - Imagem microscópica de linha de deposição de experimento 3 (Laser $20 \mathrm{~mW}-1,591549 \mathrm{~mW} / \mathrm{mm}^{2}$, feixe $\varnothing 2 \mathrm{~mm}, \mathrm{Vd}-150 \mathrm{~mm} / \mathrm{min}$ ), onde a) é a imagem microscópica sem contraste e b) é a imagem microscópica com contraste

Figura 8.7 - Imagens microscópica de linhas de deposição de: a) experimento 16 (Laser - 100mW - 7,957745mW/mm², feixe $\varnothing 2 \mathrm{~mm}, \mathrm{Vd}-200 \mathrm{~mm} / \mathrm{min}$ ), e b) experimento 3 (Laser - $20 \mathrm{~mW}-1,591549 \mathrm{~mW} / \mathrm{mm}^{2}$, feixe $\varnothing 2 \mathrm{~mm}, \mathrm{Vd}-150$ $\mathrm{mm} / \mathrm{min}$ ), sendo que ambos apresentam mesmo grau de contraste 249

Figura 8.8 - Relação de largura de linha de polimerização em função de velocidade de deslocamento, intensidade de laser e diâmetro de feixe de laser 252

Figura 8.9 - Fotos de secção transversão de corpo de prova confeccionado com Intensidade $100 \mathrm{~mW}$, diâmetro de feixe de laser $2 \mathrm{~mm}$, velocidade de deslocamento $700 \mathrm{~mm} / \mathrm{min}$ e ângulo de orientação de varredura $90^{\circ}$ antes de remoção de material residual, onde a) parte interior do corpo deprova e b) parte superior do corpo de prova 255

Figura 8.10 - Representação genérica de perfil de cura gerados por deslocamento de laser em a) processo de formação seletiva de compósito (proposta do trabalho) e b) estereolitografia (SLA) .256

Figura 8.11 - Imagens de corpos de provas confeccionados com Intensidade 20mW, diâmetro de feixe de laser $2 \mathrm{~mm}$, velocidade de deslocamento $250 \mathrm{~mm} / \mathrm{min}$ e a) ângulo de orientação de varredura $90^{\circ}$; b) ângulo de orientação de varredura $0^{\circ}$; antes de remoção de material residual 257

Figura 8.12 - Imagens de foco de polimerização periférica em início de polimerização de corpos de provas confeccionados com Intensidade $20 \mathrm{~mW}$, diâmetro de feixe de laser $2 \mathrm{~mm}$, velocidade de deslocamento $250 \mathrm{~mm} / \mathrm{min}$ e ângulo de orientação de varredura $90^{\circ}$; antes de remoção de material residual 
Figura 8.13 - Curva de tensão-deformação de corpos de provas fabricados nos experimentos 3 e 5, sendo a variável de processo avaliada igual ao ângulo de varredura da trajetória do laser.

Figura 8.14 - Imagens de micro-bolhas observadas em corpos de prova 260 


\section{LISTA DE TABELAS}

Tabela 1.1 - Adaptação de matriz de relacionamento entre princípio de funcionamento e tecnologias de AM (GIBSON, 2005) ....................................

Tabela 2.1 - Especificação de Projeto

Tabela 3.1 - Relação de resolução, espessura de camada e faixa de custo de principais tecnologias de fabricação aditiva adaptado de (PHAM e GAULT, 1998; LIOU, 2007; KRUNIĆ et al., 2010)

Tabela 3.2 - Levantamento estatístico de divergências dimensionais de peças fabricadas pelos 4 principais processos aditivos, baseado em (MAHESH et al., 2004)

Tabela 3.3 - Relação dos principais tipos de papel e suas principais características e aplicações

Tabela 3.4 - Relação dos principais tipos de papel e suas principais características e aplicações (cont. I)

Tabela 3.5 - Relação dos principais tipos de papel e suas principais características e aplicações (cont. II)

Tabela 3.6 - Relação de fabricantes de monômeros e oligômeros (RADTECH, 2008)

Tabela 3.7 - Relação de fabricantes de aditivos (RADTECH, 2008)

Tabela 3.8 - Relação de fabricantes de fotoiniciadores para polimerização (RADTECH, 2008)

Tabela 3.9 - Relação de principais requisitos para tinta e cabeçotes jato de tinta (LINDQVIST et al., 2003)

Tabela 3.10 - Levantamento de principais concepções de equipamentos de posicionamento cartesianos com 3 eixos

Tabela 3.11 - Levantamento dos principais programas para implementação de arquitetura PC-NC 
Tabela 4.1 - Relação de plásticos de engenharia e seus valores de Tg, HDT 1.82 e HDT 0.445 (KELLY e ZWEBEN, 2000)

Tabela 5.1 - Matriz de planejamento de experimentos relacionados à determinação de formulação de material

Tabela 5.2 - Relação de ensaios realizados para obtenção dos fatores de resposta e indicativo de seção do trabalho onde esta localizada a descrição da confecção dos corpos de prova e procedimentos experimentais empregados 136

Tabela 5.3 - Relação de materiais celulósicos ensaiados e tempos de imersão.....138

Tabela 5.4 - Planejamento de experimento de estudo de influência de percentual de polímero para a resistência mecânica do material Compósito 140

Tabela 5.5 - Levantamento de ensaios e procedimentos para identificação dos fatores de resposta

Tabela 5.6 - Matriz de planejamento de experimentos relacionados à determinação de formulação de material Compósito

Tabela 6.1 - Relação de valores de otimização conforme espessura de camada, assim como valores de taxa de polimerização, absorbância potência de lâmpada e concetração de iniciador Omnirad cureall 2500

Tabela 6.2 - Relação de condições de otimização e tempo para $80 \%$ de polimerização em função da espessura de camada 145

Tabela 6.3 - Matriz de experimento de determinação de faixa de estudo e converão de material após 30 segundos de exposição

Tabela 6.4 - Relação entre composição de materiais e conversão de material em 30 e 60 segundos, Inibidor (TMQA), Constante $\frac{k p}{\sqrt{k t}}$ e mínimo quadrado $\left(\mathrm{r}^{2}\right)$

Tabela 6.5 - Relação entre composição de materiais e viscosidade 156

Tabela 6.6 - Relação entre composição de materiais módulo de elasticidade por flexão.

Tabela 6.7 - Relação entre composição de materiais temperatura de trabalho (HDT) 
Tabela 6.8 - Relação de materiais celulósicos e descrição de gramatura e espessura média

Tabela 6.9 - Relação de materiais celulósicos e descrição de gramatura e espessura média e estatística descritiva de tensão de ruptura 173

Tabela 6.10 - Matriz de análise relativa de materiais celulósicos 179

Tabela 6.11 - Relação de formulação de material, força de arrancamento, modo de falha e propagação de ruptura 187

Tabela 7.1 - Matriz morfológica de sistema de deposição, indicando concepções e suas principais aplicações. 196

Tabela 7.2 - Matriz de análise e seleção de concepções de sistema de deposição 198

Tabela 7.3 - Matriz morfológica de sistema de alimentação de substrato celulósico, indicando concepções e suas principais aplicações 199

Tabela 7.4 - Matriz de análise e seleção de concepções de sistema de alimentação de substrato celulósico, sendo apresentados os requisitos de projeto utilizados para seleção, assim como as ilustrações descritivas de concepções 201

Tabela 7.5 - Relação de principais elementos de transmissão e guia, sendo apresentado a grade de precisão, erro geral e custo relativo proporcionado por componente .204

Tabela 7.6 - Comparativo entre erro final estimado por modelo matemático e precisão anunciado por fabricante de equipamento Fortus 250mc (STRATASYS, 2011)

Tabela 7.7 - Relação de faixas de função de compromisso de estudo de otimização e elementos de máquina equivalentes .213

Tabela 7.8 - Matriz morfológica de sistema de controle, indicando concepções conforme combinações de funções exercidas pelo sistema .214

Tabela 7.9 - Matriz de análise e seleção de concepções de sistema de controle, sendo apresentados os requisitos de projeto utilizados para seleção, assim como as ilustrações descritivas de concepções. 
Tabela 7.10 - Relação de comandos de acionamento de equipamento e suas funcionalidades

Tabela 8.1 - Matriz de experimento de estudo de formação seletiva de compósito em uma camada .236

Tabela 8.2 - Matriz de experimento de estudo de formação seletiva de compósito em múltiplas camadas 239

Tabela 8.3 - Relação de valores de parâmetros utilizados no estudo de caracterização de funcionalidade de processo 242

Tabela 8.4 - Matriz de experimentos utilizados no estudo de caracterização de funcionalidade de processo $\left(2^{3-1}\right)$. .243

Tabela 8.5 - Relação de dados de estatística descritiva de estudo de caracterização de sistema de deposição manual (tampografia). 245

Tabela 8.6 - Relação de variáveis e resultados de estudos de formação de compósito em uma camada 248

Tabela 8.7 - Matriz de variáveis e resultado de número de camadas aderidas em passe único (profundidade de penetração) . 253

Tabela 8.8 - Relação de valores de respostas do estudo de caracterização de funcionalidade de conceito 258 


\section{LISTA DE ABREVIATURAS E SIGLAS}

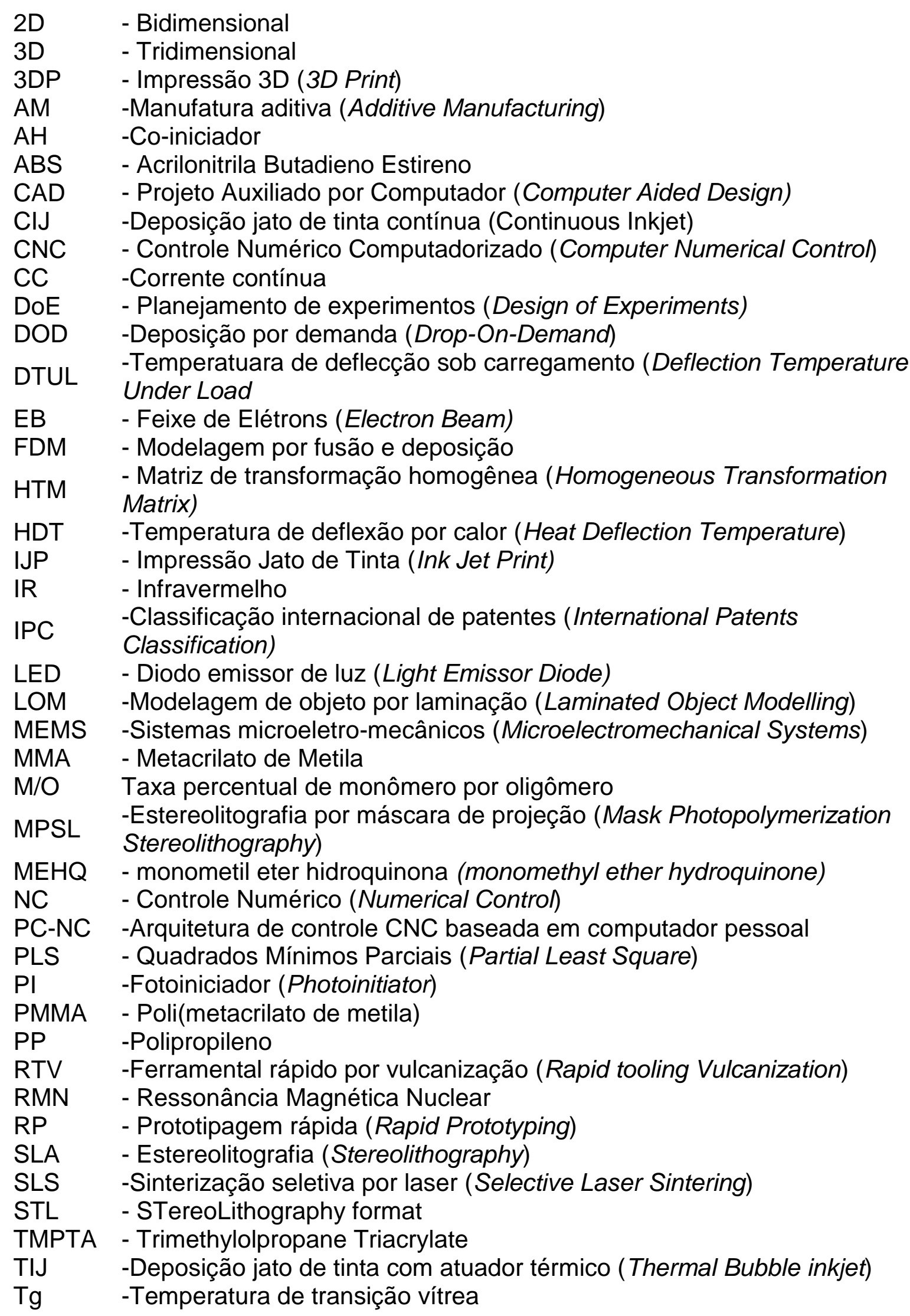


UFPR - Universidade Federal do Paraná

UV - Ultravioleta 


\section{LISTA DE SÍMBOLOS}

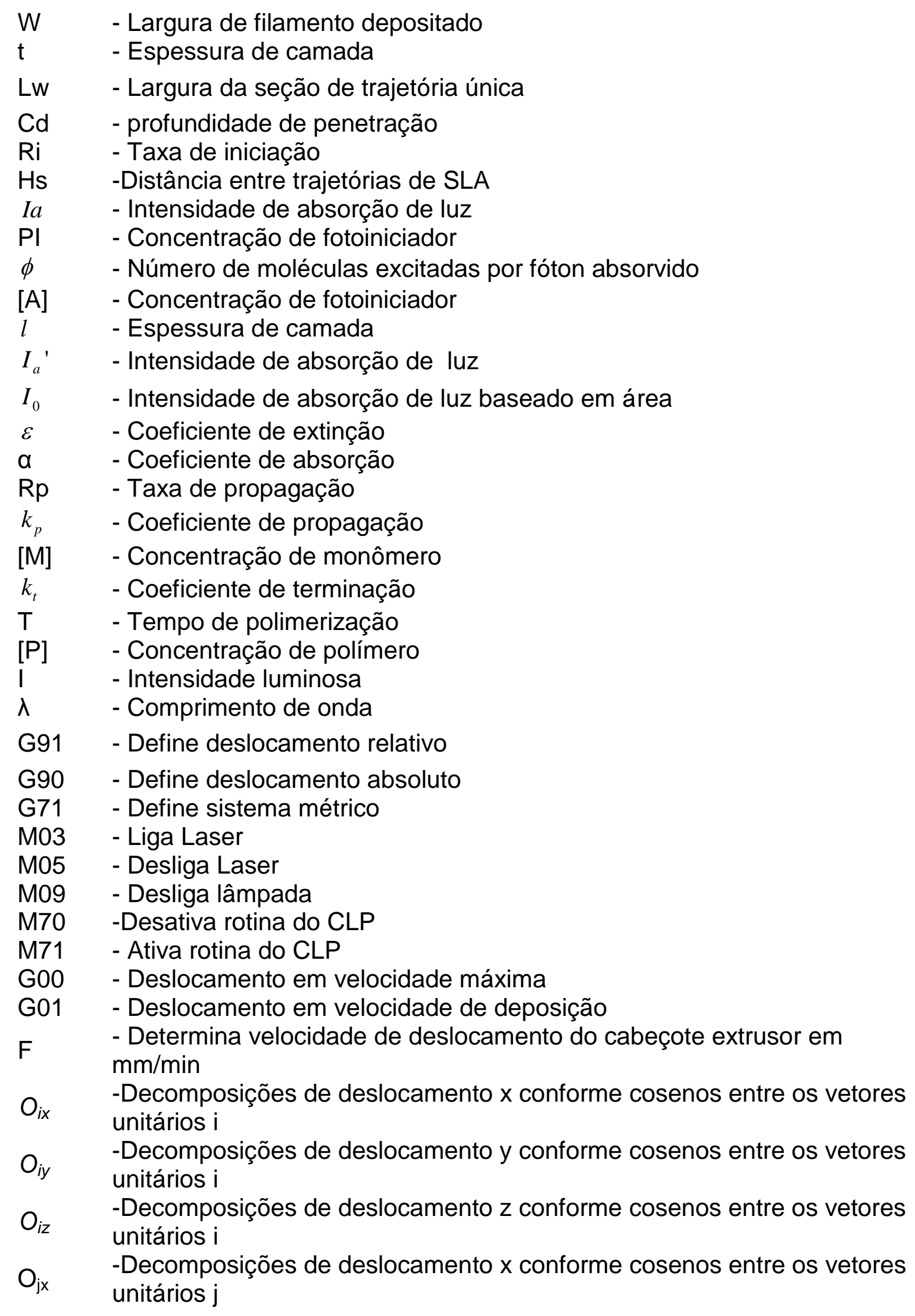




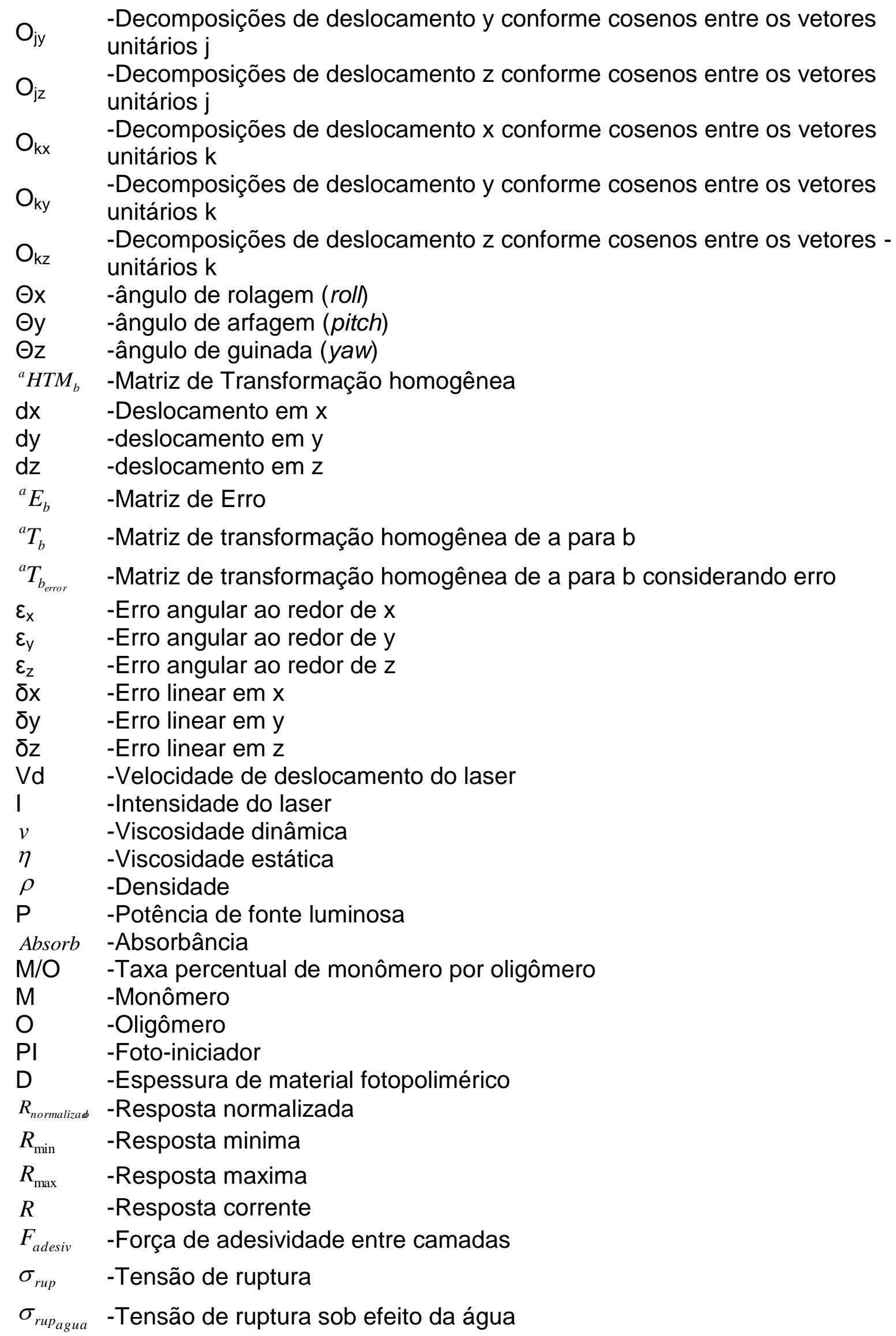


$C_{\text {total }} \quad$-Custo total

$C_{g_{x}} \quad$-custo das guias de movimentação $\mathrm{x}$

$N_{a_{x}} \quad$-Quantidade de guias de movimentação $\mathrm{x}$

$C_{g_{y}} \quad$-custo das guias de movimentação y

$N_{a_{y}} \quad$-Quantidade de guias de movimentação y

$C_{g_{z}} \quad$-custo das guias de movimentação z

$N_{a_{z}} \quad$-Quantidade de guias de movimentação z

$C_{t_{x}} \quad$-custo dos componentes de transmissão de movimento $\mathrm{x}$

$N_{b_{x}} \quad$-Quantidade de componentes de transmissão x

$C_{t_{\mathrm{y}}} \quad$-custo dos componentes de transmissão de movimento y

$N_{b_{y}} \quad$-Quantidade de componentes de transmissão y

$C_{t_{z}} \quad$-custo dos componentes de transmissão de movimento z

$N_{b_{z}} \quad$-Quantidade de componentes de transmissão z

$C_{m} \quad$-Custo de tolerância de manufatura

$w_{1} \quad$-Peso de importância de guia de movimentação

$w_{2} \quad$-Peso de importância de transmissão de movimento

$w_{3} \quad$-Peso de importância de tolerância de manufatura 


\section{INTRODUÇÃO}

O Capítulo 1 deste trabalho tem o objetivo principal de apresentar o cenário atual do mercado onde tecnologias de manufatura por adição de camadas ("Additive Manufacturing" - AM), também conhecidas como de tecnologias de Prototipagem Rápida ("Rapid Prototyping" - RP) estão inseridas. Neste capítulo, também são apresentados os benefícios e desvantagens proporcionados pela utilização de tais recursos.

Adicionalmente, são apresentados os objetivos principais e específicos deste trabalho, expondo um detalhamento das atividades necessárias e áreas envolvidas para o desenvolvimento deste projeto.

\subsection{Apresentação do problema}

Ao longo dos anos, em função da exigência de consumidores, as empresas foram impulsionadas a aumentar da complexidade de produtos. Em contra partida, para se manter competitividade, os prazos para desenvolvimento tiveram de ser reduzidos.

Com o objetivo de atenter a essas novas necessidades impostas pelo mercado, tecnologias de prototipagem rápida tiveram seu desenvolvimento iniciado a partir dos anos 80. Inicialmente, estas tecnologias tinham como objetivo principal, a construção de protótipos de maneira rápida, contudo, à medida da maturidade destas, seu número de aplicações se expandiu, chegando às áreas da saúde e de produção Em função disto, estas são atualmente relatadas como processos de fabricação por adição (Additive Manufacturing - $\mathrm{AM}$ ), devido às propriedades mecânicas e de acabamento das peças se aproximarem aos valores de processos convencionais (GIBSON, 2005; LIOU, 2007; VOLPATO, 2007; CUNICO, 2011).

Em geral, as tecnologias AM tem como princípio básico de funcionamento, a geração de objetos tridimensionais (3D) através de processo de adição de material camada por camada. Na Figura 1.1, é apresentado um esquemático simplificado 
deste processo, indicando as principais fases desde a criação do modelo computacional 3D até a finalização da fabricação da peça.

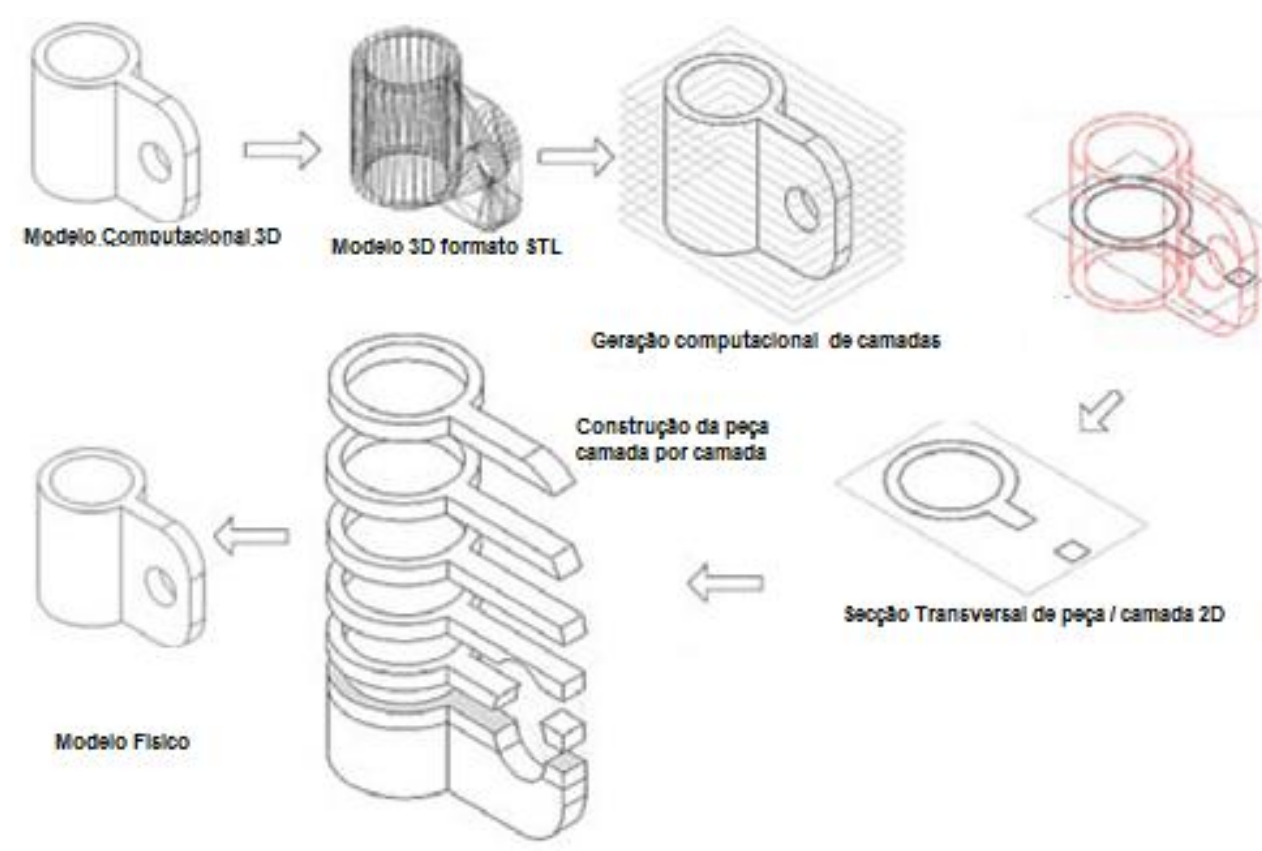

Figura 1.1 - Representação esquemática de princípio básico de funcionamento de processos AM (VANDRESEN, 2004)

Um exemplo que ilustra os benefícios gerados pela utilização de tecnologias AM pode ser encontrado num ambiente de pesquisa e desenvolvimento. Neste ambiente, as tecnologias AM proporcionam o aumento da agilidade de tomada de decisões, assim como auxilia na redução do tempo de desenvolvimento. Isto acontece em função da grande facilidade de obtenção de peças em fases iniciais do desenvolvimento de produto, onde as características mecânicas, em diversos casos, assemelham-se às de processos tradicionais (COOPER, 2001; FOGGIATTO et al., 2004; GIBSON, 2005; GIBSON et al., 2006; VOLPATO, 2007).

Na Figura 1.2 é apresentada uma relação do tempo despendido na tomada de decisão em projetos em função do tipo de recurso utilizado ao longo do processo de desenvolvimento de produto. Nesta figura, é comparada a aplicação de modelos bidimensionais (2D), Tridimensionais (3D) e prototipados fisicamente como ferramenta de desenvolvimento. Logo, pode-se observar que o baixo tempo de 
resposta destaca a vantagem de utilização de protótipos físicos sobre outros recursos.

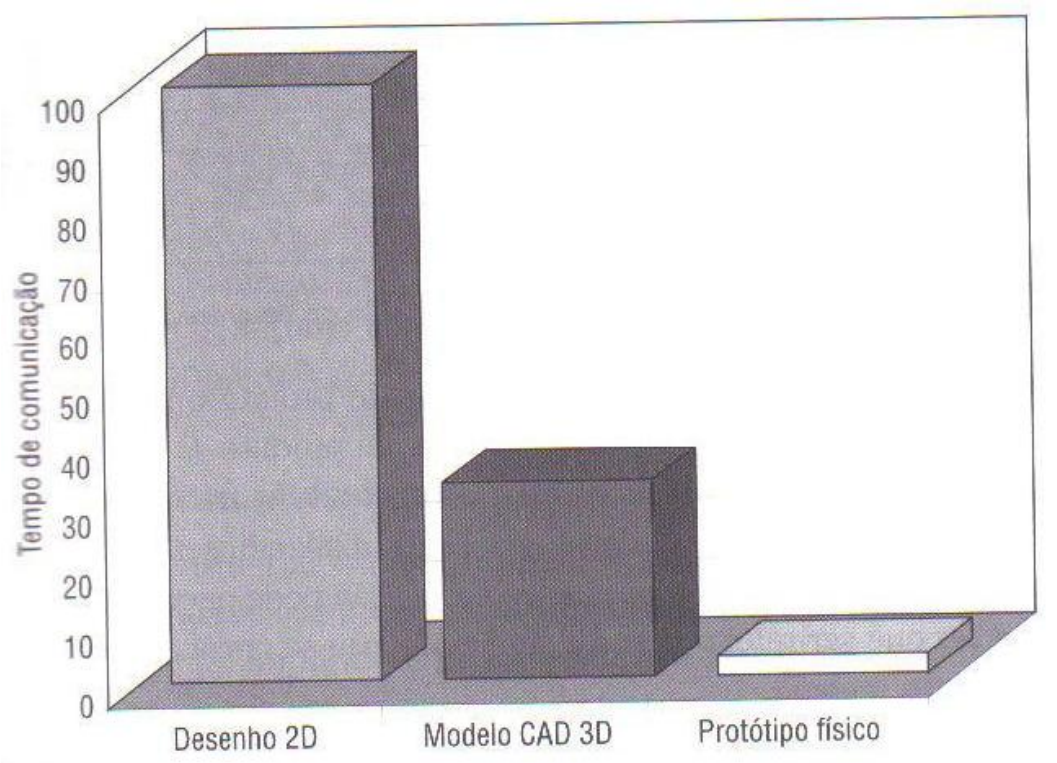

Figura 1.2 - Comparação entre tempo de comunicação na fase de projeto utilizando desenhos 2D, modelos CAD 3D e protótipos físicos (VOLPATO, 2007)

Por outro lado, em função das tecnologias AM permitirem a construção de formas muito mais livres que processos tradicionais e, em alguns casos, com resistência mecânica próximas das convencionais, o aumento na procura por estes processos em áreas da saúde se mostra eminente (COOPER, 2001; BIBB et al., 2006; GIBSON et al., 2006; LIOU, 2007).

Na Figura 1.3, é apresentado um exemplo de reconstrução de espinha lombar fabricada por meio de tecnologias AM, com o objetivo de auxiliar o planejamento cirúrgico. Nesta figura, é apresentada a imagem de um modelo eletrônico construído a partir de imagens obtidas por tomografia computadorizada, assim como do mesmo modelo, reconstruído físicamente através de estereolitografia ("Stereolithography" SLA). 


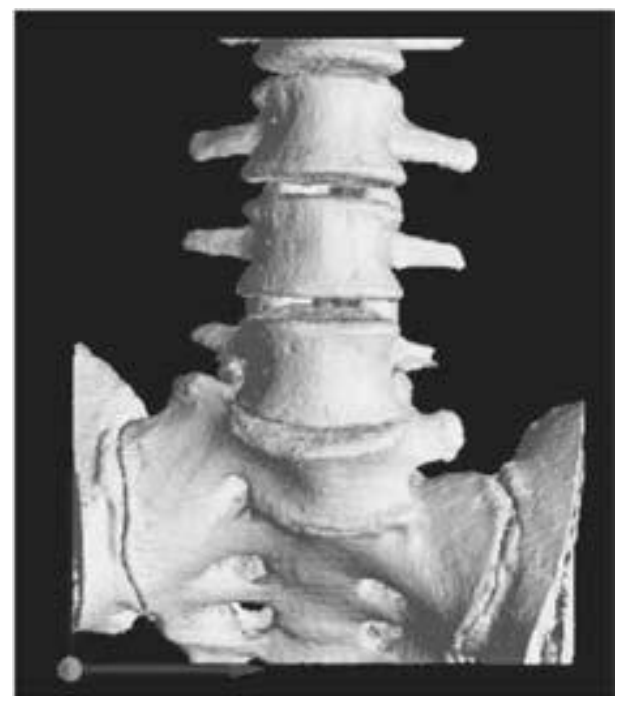

a)

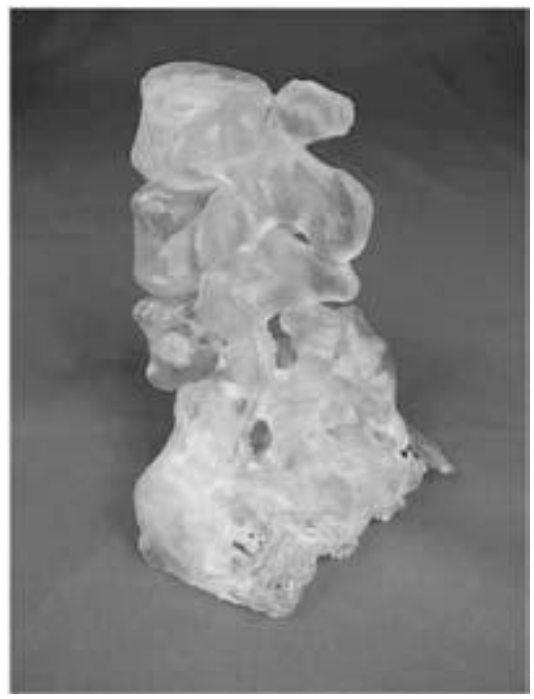

b)

Figura 1.3 - Exemplo de reconstrução de espinha lombar fabricada por meio de tecnologia RP, sendo: a) modelo construído a partir de imagens obtidas de tomografia computadorizada; b) reconstrução fisica de modelo através de estereolitografia ("Stereolithography" - SLA) (GIBSON, 2005)

Em contrapartida, apesar do grande numero de benefícios proporcionados por estes novos processos de fabricação, a sua utilização ainda mantém seu valor muito elevado devido, em grande parte, à falta de fabricantes de equipamentos e materiais em âmbito nacional (VOLPATO, 2007; CUNICO, 2011).

\subsection{Relevância do tema}

Além do atendimento da demanda nacional, outro aspecto que também deve ser ressaltado é o crescimento global na geração de patentes relacionadas à manufatura aditiva (AM). Neste caso, estas patentes podem ser identificadas conforme a classificação internacional de patentes (International Patents Classification - IPC) B29C (WIPO, 2011). Através do monitoramento desta secção, apresentado na Figura 1.4, torna-se possível identificar a progressão da quantidade de patentes relacionadas à tecnologias $\mathrm{AM}$ ao longo dos últimos dez anos. 
Adicionalmente, esta figura também apresenta a progressão do numero de patentes geradas pelas 5 principais empresas fornecedoras de equipamentos de AM.

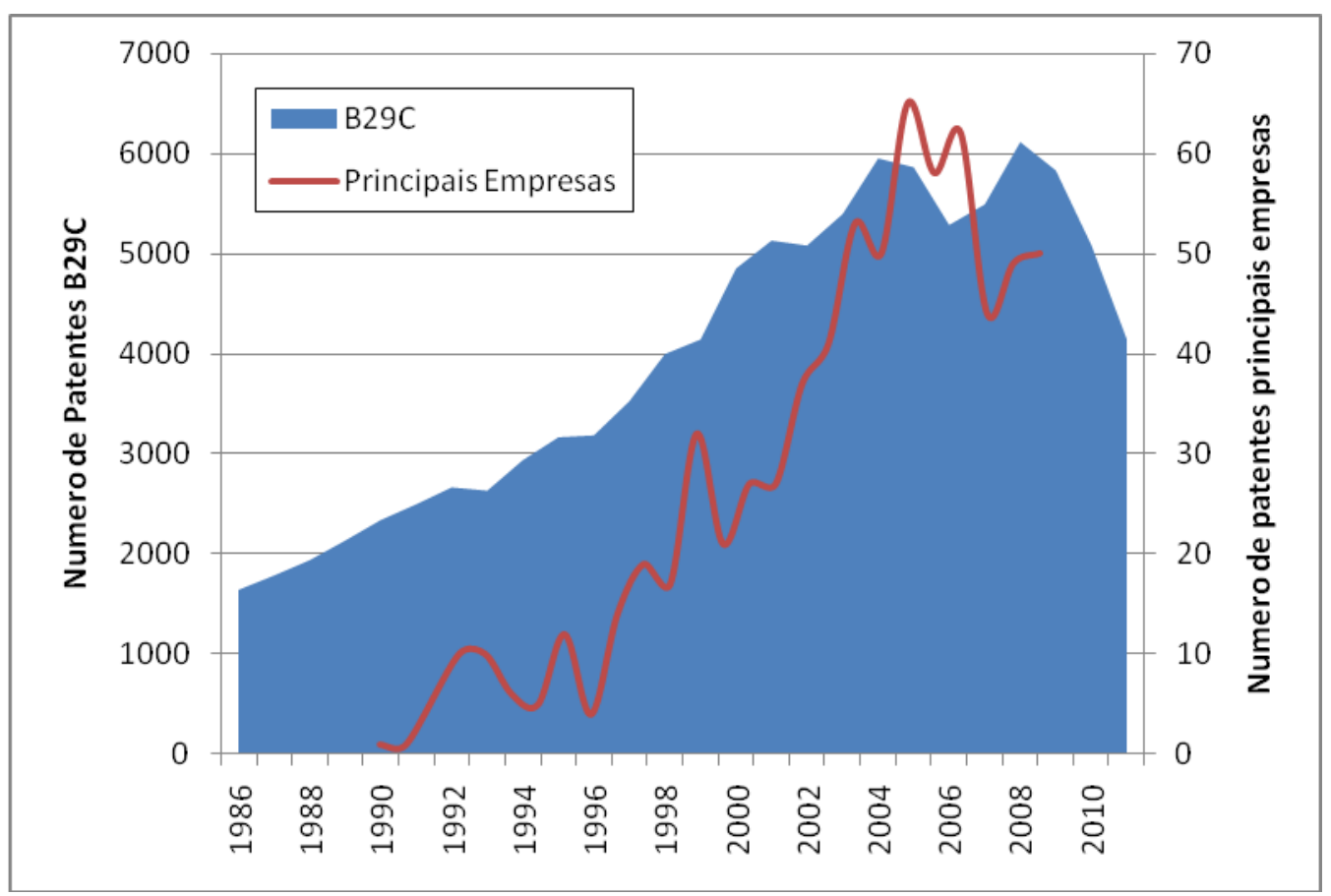

Figura 1.4 - Crescimento no numero de patentes relacionadas à manufatura aditiva (AM) - Classificação internacional de patentes (IPT) B29C, e das 5 principais empresas de AM (WIPO, 2011)

Este crescimento pode ser atribuído ao aumento da demanda na área, assim como à tendência de mercado para a utilização deste processo de fabricação, visto que a utilização do mesmo possibilita a redução do tempo de lançamento de produtos. Esta tendência também pode ser ilustrada através do acompanhamento das ações da empresa Stratasys, como pode ser observado na Figura 1.5. Nesta figura pode ser observado o aumento de aproximadamente $2000 \%$ das ações ao longo dos últimos 10 anos (EDGAR, 2011). 


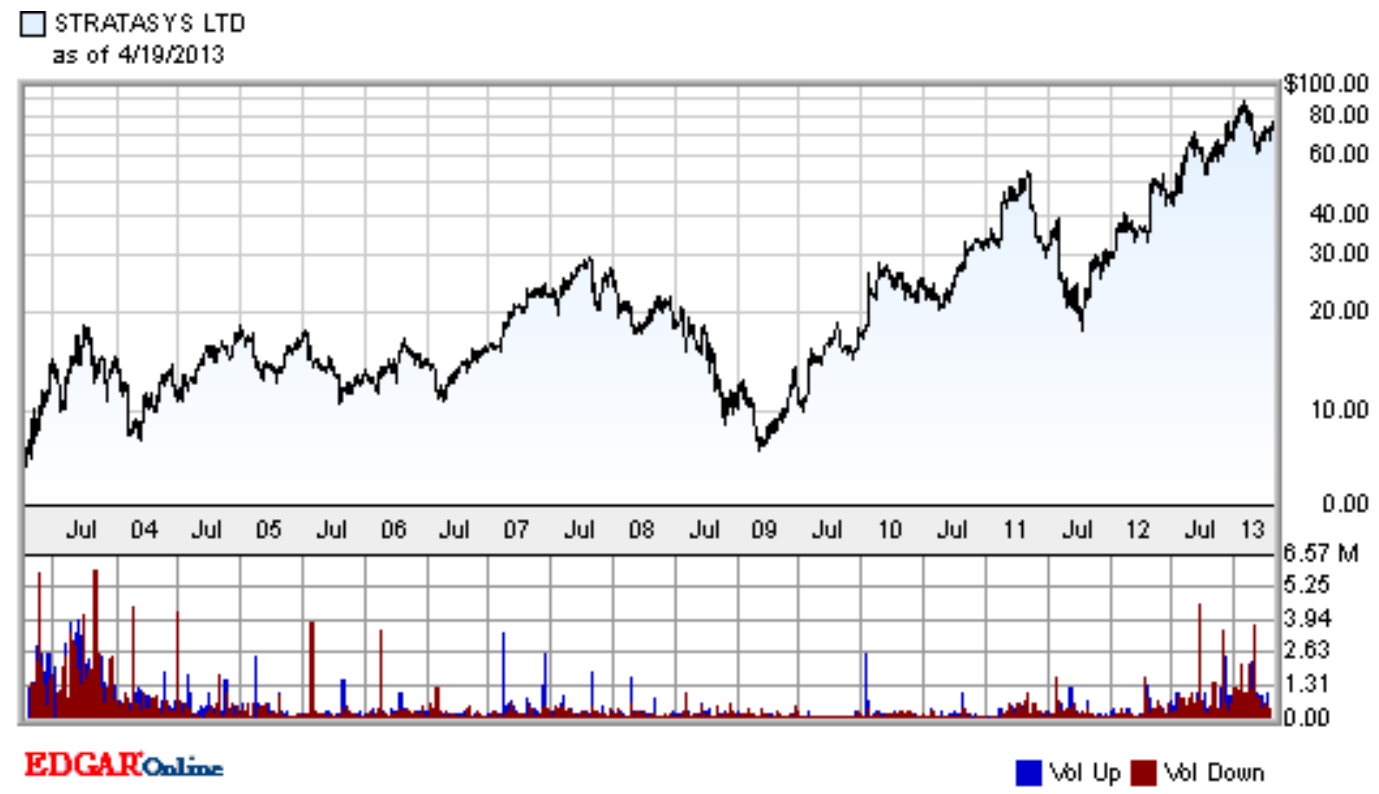

Figura 1.5 - Acompanhamento de preço de ações de empresa Stratasys (EDGAR, 2011)

Cabe também salientar que a contribuição de pesquisas ultrapassa somente o suprimento de uma necessidade local, este desenvolvimento contribui indiretamente para o crescimento de outras áreas. Desta forma, pode-se também associar o nível de crescimento da economia de um país ao volume de pesquisas desenvolvidas pelo mesmo, conforme apresentado na Figura 1.6.

Adicionalmente, esta figura apresenta um comparativo entre volume de pesquisa de países como China, Estados Unidos e Brasil, indicando o grande caminho a ser percorrido pelo Brasil a fim de alcançar margens semelhantes aos outros países analisados. Logo, pode-se ver claramente a relação entre os esforços empregados em pesquisa e desenvolvimento e o crescimento econômico do país. 


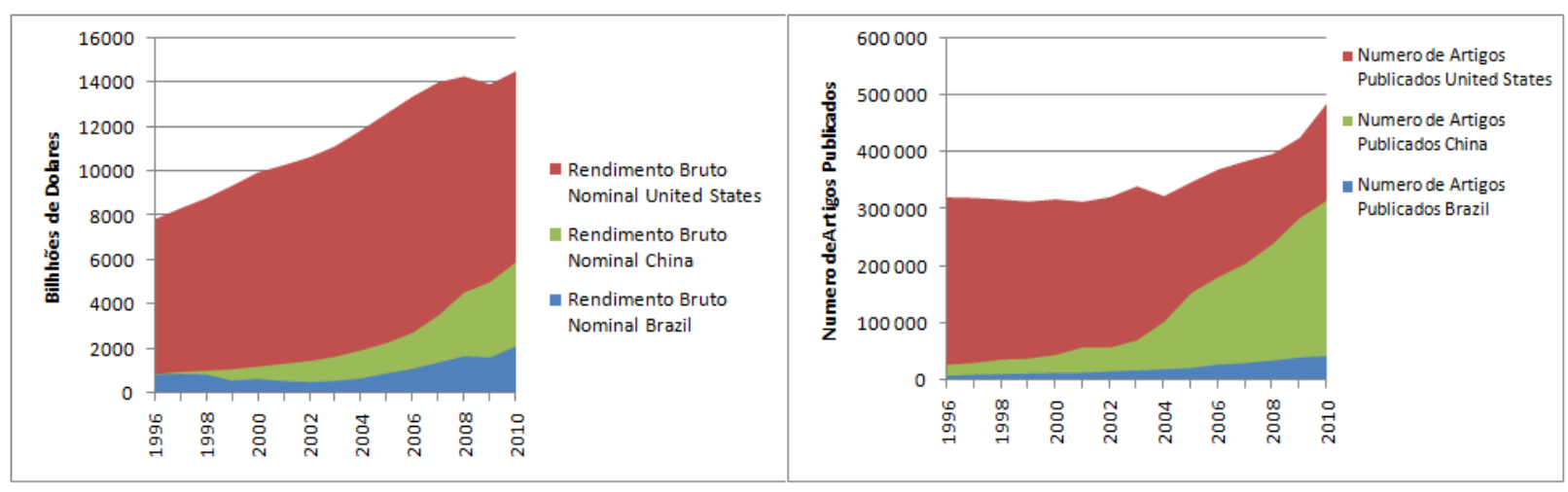

Figura 1.6 - Relacionamento entre volume de pesquisa desenvolvida e crescimento econômico adaptado de (IMF, 2011; SCIMAGO, 2011)

Em outras palavras, além de suprir uma demanda do mercado nacional, o desenvolvimento de uma tecnologia $A M$ inteiramente nacional contribui para desenvolvimento de outras áreas, e consequentemente para crescimento do país.

\subsection{Oportunidade de desenvolvimento}

Em face à relevância da problemática apresentada ao longo deste capítulo, pode-se ressaltar a importância da realização de projetos de pesquisa e desenvolvimento na área de fabricação por adição de material.

Logo, se considerar que estas tecnologias tiveram seu início nos anos 80, ainda há muitos desafios a serem superados. Da mesma forma, podem ser identificadas diversas oportunidades para desenvolvimento e geração de novos negócios.

Uma das formas de se observar os nichos de oportunidades em tecnologias AM é a classificação dos tipos de tecnologias conforme suas similaridades. Uma das formas de classificação destas tecnologias pode ser observada na Tabela 1.1, onde são relacionadas as principais tecnologias de $\mathrm{AM}$ e seus princípios de funcionamento. Nesta tabela, também são ressaltadas concepções ainda não exploradas, possibilitando identificar e posicionar a proposta de tecnologia apresentada neste trabalho. 
Apesar da Tabela 1.1 classificar as tecnologias através de materiais poliméricos líquidos e sólidos laminados, a proposta apresentada neste trabalho procura validar concepção hibrida. Onde é utilizado um material compósito baseado em substrato celulósico laminado e material polimérico no estado líquido.

Tabela 1.1 - Adaptação de matriz de relacionamento entre princípio de funcionamento e tecnologias de AM (GIBSON, 2005)

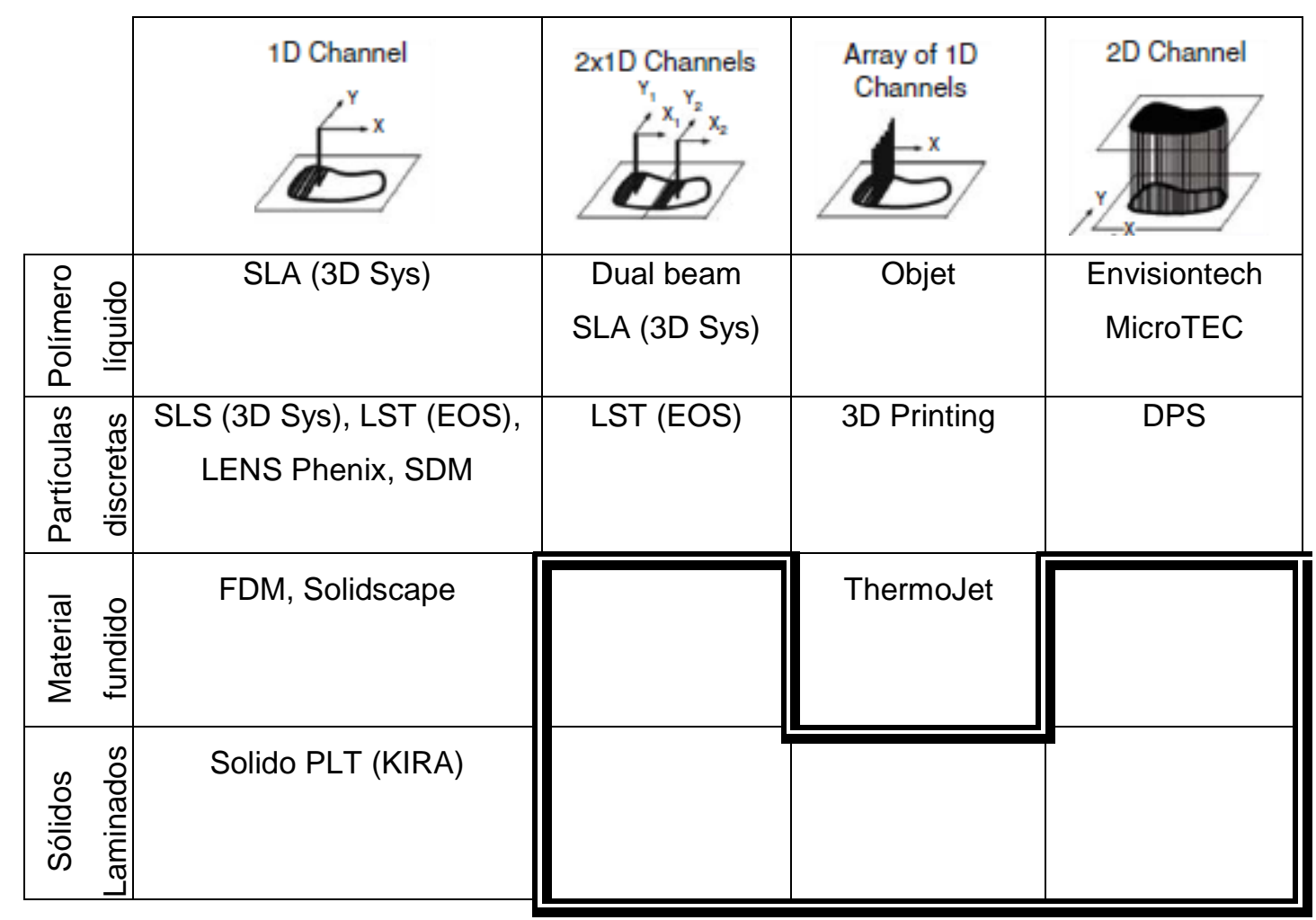

$\mathrm{Na}$ Figura 1.7, é apresentado um esquemático simplificado do processo de fabricação por adição de material proposto neste trabalho. Este processo consiste na fabricação de objetos tridimensionais através da adição de material compósito baseado em celulose e polímero líquido fotocurável. O princípio de funcionamento deste processo consiste na impregnação de polímero líquido em substrato celulósico laminado seguido da polimerizado seletiva do polímero de forma a construir o secção transversal de objeto 3D. Adicionalmente, é realizado o empilhamento das camadas de forma a construir um bloco de celulose cujo núcleo acomoda o objeto 
3D constituído de compósito de polímero e celulose. Por fim, é removida a celulose excedente por solvente ou água e finalizada a fabricação do objeto 3D.

Para a realização deste projeto, faz-se necessário o envolvimento de diversas áreas distintas, como o desenvolvimento de materiais, sistemas de controle, equipamento e processamento, sendo que o fluxo de desenvolvimento basea-se principalmente na determinação e processamento do material.

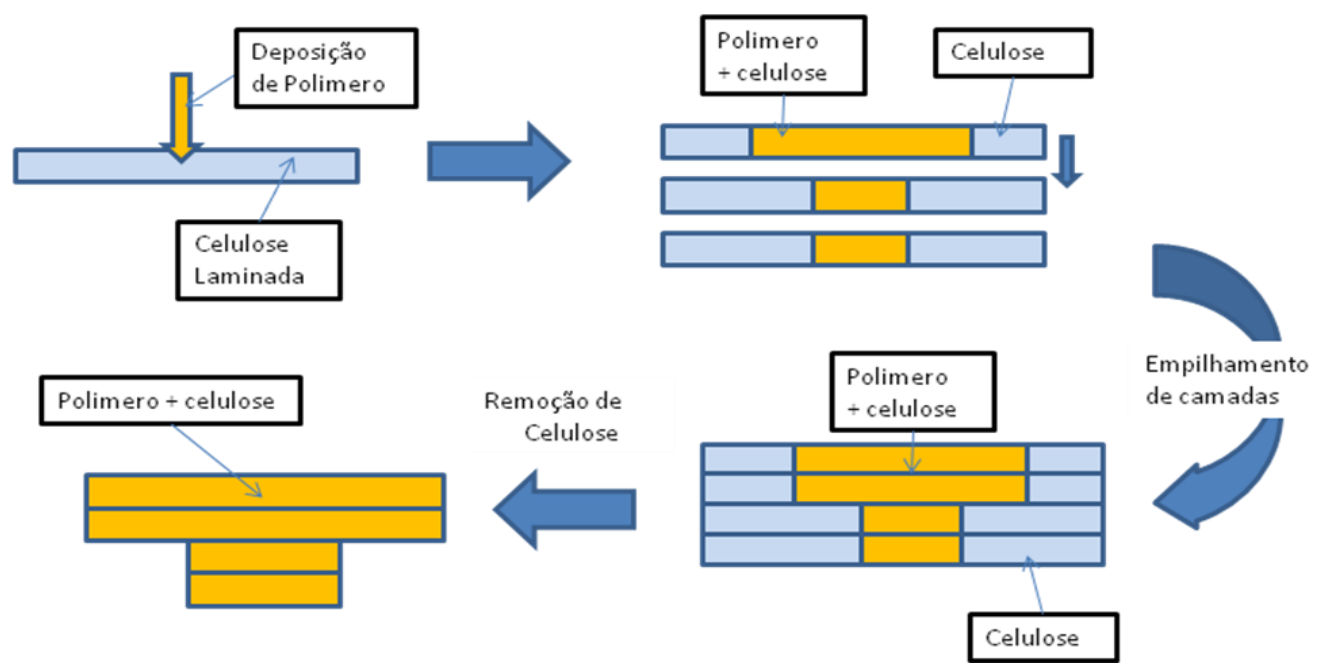

Figura 1.7 - Esquemático simplificado de proposta de processo de fabrição por adição de material

Sobretudo, além desta proposta de tecnologia se diferenciar de outras já existentes, esta apresenta uma combinação de características vantajosas de outros processos AM. Por exemplo, pretende-se utilizar materiais poliméricos líquidos, como em SLA, Objet IJP e Mask projection, em adição à aplicação de substrato celulósico, como no caso de Modelagem de objeto por laminação (LOM).

Desta forma, o processo proposto contemplaria a flexibilidade de material, como em processos baseados em polímeros líquidos, assim como a falta de necessidade de geração de material de suporte, como em processos baseados em substrato e pó, e por fim o incremento de resistência mecânica inerente às fibras de celulose. 


\subsection{Objetivo}

O Objetivo principal deste trabalho é o desenvolvimento de tecnologia de prototipagem rápida baseada em construção de camadas através de material compósito a base de celulose e polímero.

\subsection{Objetivos específicos}

Desenvolvimento de material compósito a base de celulose e polímero.

Projeto conceitual de equipamento e processo.

Projeto detalhado de equipamento protótipo.

Análise de viabilidade funcional de processo proposto.

Análise de viabilidade econômica de projeto.

\subsection{Estrutura da Pesquisa e do Trabalho}

Com finalidade de guiar o desenvolvimento deste trabalho, foi utilizada uma metodologia de pesquisa baseada no processo de desenvolvimento de produtos associado a metodologias de pesquisa aplicada (EEKELS e ROOZENBURG, 1991; HEVNER et al., 2004; ATTOH-OKINE e AYYUB, 2005; PAHL et al., 2007).

Isto se deve ao fato deste trabalho estar dividido entre pesquisa de base e engenharia de projetos, como pode ser observado na Figura 1.8. Assim, é necessário a utilização de metodologias hibridas para alcançar maior desempenho na realização dos estudos (KELLY, 2003).

Adicionalmente, pode-se salientar que apesar das metodologias de pesquisa de base e de desenvolvimento de produtos terem grandes semelhanças, sendo fundamentadas na solução de problemas, estas se diferenciam essencialmente pelos seus objetivos finais. No caso de pesquisa de base, os resultados obtidos implicam na geração conhecimento, enquanto em desenvolvimento de produto, em produtos comerciais. Entretanto, ambos os casos são mutuamente dependentes, 
visto que a utilização de conhecimento já existente é parte essencial para realização de desenvolvimento de produtos (EEKELS e ROOZENBURG, 1991; KELLY, 2003; HEVNER et al., 2004; ATTOH-OKINE e AYYUB, 2005; PAHL et al., 2007).

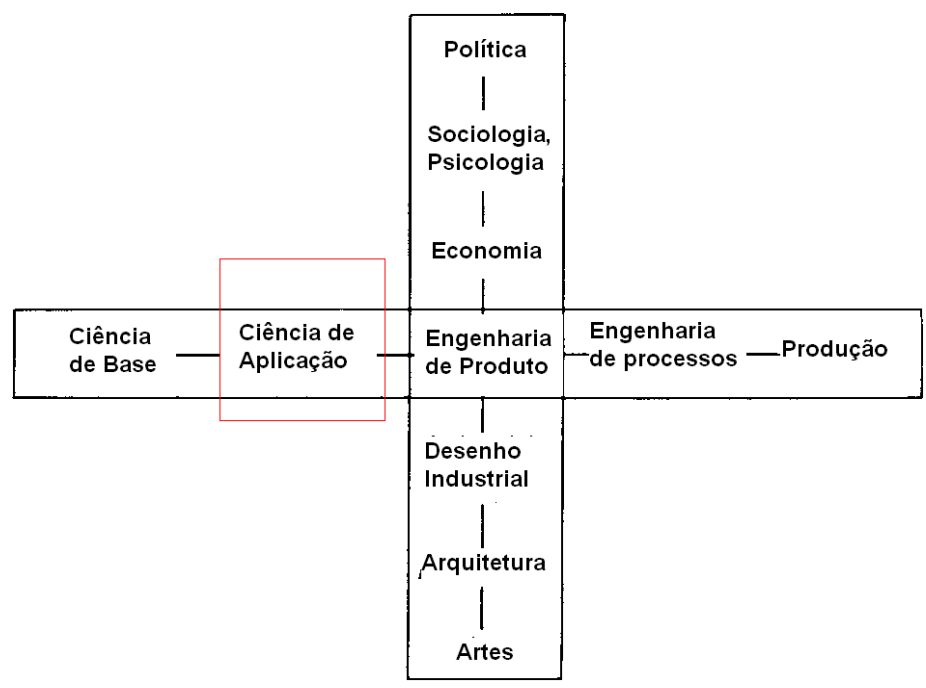

Figura 1.8 - Posicionamento de pesquisa de engenharia ou ciencia de aplicada em relação ao centro de atividades de engenharia de desenvolvimento (PAHL et al., 2007)

Como pode ser observado na Figura 1.9, entre os processos básicos de metodologias de pesquisa de base estão: definição da problema, gerado através de observação; geração de fatos, através de indução; criação de hipóteses, por meio de dedução; predição categórica gerada por testes e validação de modelos gerados por deduções e predições.

Nesta figura também é possível observar um processo simplificado de desenvolvimento, onde a definição de problema é gerada a partir da análise de mercado e de necessidades de clientes. Desta forma são definidos requisitos de projeto e, consequentemente a síntese funcional do produto, cujas propostas conceituais são simuladas e validadas através de predições condicionais, baseadas nos requisitos de projeto (EEKELS e ROOZENBURG, 1991; KELLY, 2003; PAHL et al., 2007).

A partir da análise do fluxo de atividades destas metodologias, assim como de suas similaridades e inter-relacionamentos, foi possível definir uma metodologia 
orientada ao desenvolvimento, contemplando atividades intrínsecas à pesquisa de base.

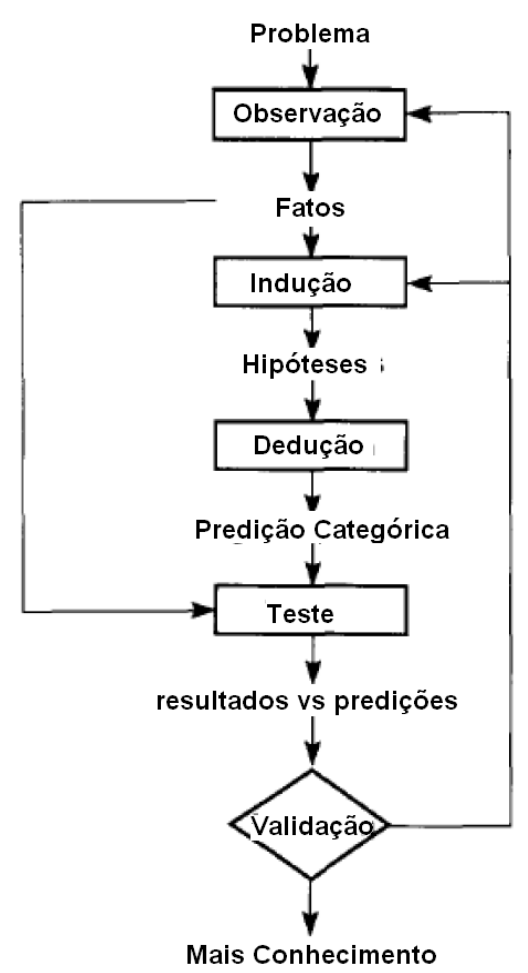

a)

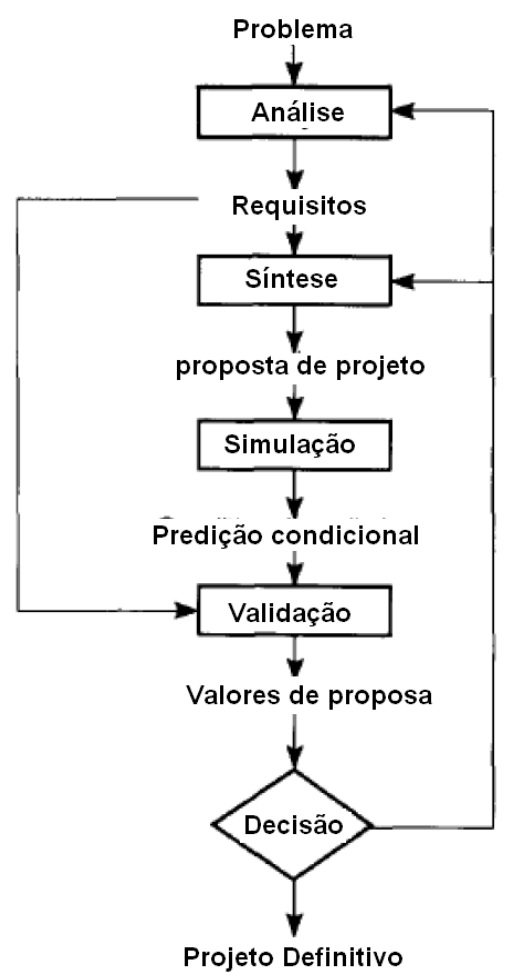

b)

Figura 1.9 - Fluxo de processo básico de pesquisa de base (a) e desenvolvimento (b) (EEKELS e ROOZENBURG, 1991)

Desta forma, foram determinadas quatro fases gerais de pesquisa, sendo: Definição de escopo de projeto; Pesquisas de apoio; Pesquisa de desenvolvimento; Conclusões, conforme é apresentado na Figura 1.10. Com referência à definição do escopo do projeto, foram determinadas as atividades de definição do problema, análise funcional, especificação de projeto e determinação de pesquisas de apoio. Enquanto para pesquisas de apoio, pesquisa literária; planejamento de estudos e desenvolvimento teórico; aquisição de dados; e análise de dados. 


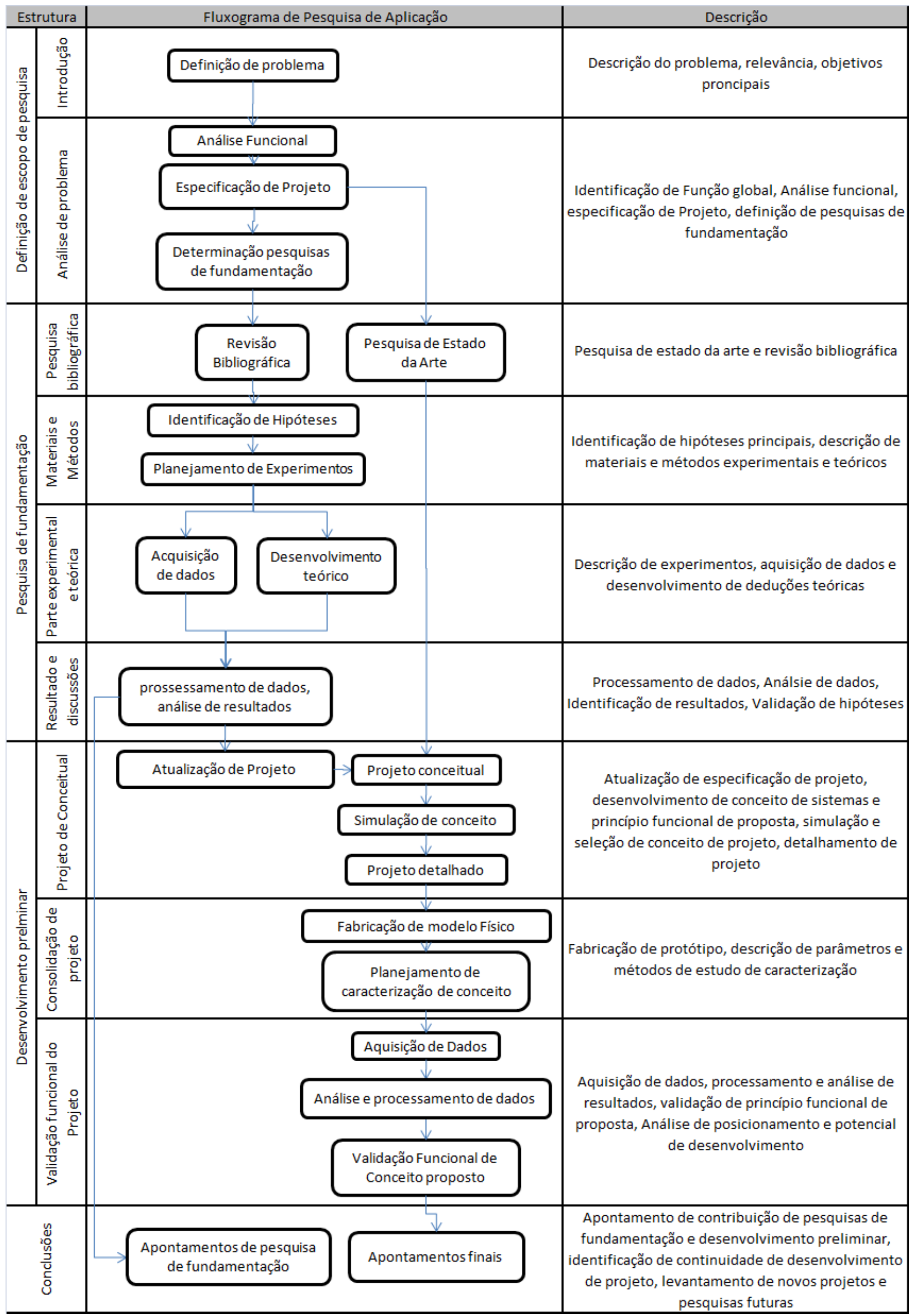


Por outro lado, a pesquisa de desenvolvimento é composta por: levantamento de estado da arte; desenvolvimento de modelo físico; caracterização de projeto; aquisição de dados; validação de resultados; e análise de viabilidade funcional. Adicionalmente, a interface entre estas fases inclui a atualização da especificação de projeto a partir dos resultados das pesquisas de apoio. Em conclusão, além da validade do projeto, pode-se identificar a contribuição das pesquisas de apoio.

Desta forma, este trabalho foi dividido em dez capítulos, conforme as fases da metodologia de pesquisa apresentada anteriormente. Adicionalmente este trabalho foi dividido em duas partes, sendo a primeira relacionada com o desenvolvimento de material (capítulos 4.5 e 6 ) e a segunda, com a validação da proposta de processo (capítulos 7, 8 e 9).

No capítulo 1, a problemática e relevância do tema são apresentados, assim como a definição do escopo de projeto e o objetivo deste trabalho.

No capítulo 2 é apresentada a análise funcional do projeto, assim como a especificação do projeto e definição de pesquisas de apoio.

Em relação à revisão bibliográfica, capítulo 3, são apresentadas pesquisas literárias, relacionadas às pesquisas de fundamentação, e o levantamento do estado da arte, para o desenvolvimento de produto.

Com relação ao capítulo 4, são apresentados os materiais e métodos utilizados para a realização de desenvolvimento de material (estudos de fundamentação). Este capítulo é marcado como o início da primeira parte desta pesquisa, onde é desenvolvido o material a ser utilizado na proposta de processo apresentada.

Por sua vez, o capítulo 5 apresenta o planejamento de experimentos realizados, assim como a aquisição destes dados empregados para o desenvolvimento de material .

No capítulo 6 são apresentadas as análises dos dados coletados para o desenvolvimento de material, assim como a validação destes resultados e seus respectivos modelos teóricos. Ao final deste capítulo, termina a parte do trabalho que se refere ao desenvolvimento de material 
A partir do capítulo 7, é apresentada uma atualização da especificação de projeto conforme os resultados da pesquisa de fundamentação. Este capítulo também apresenta 0 projeto conceitual do equipamento, assim como o dimensionamento de componentes e estudos de otimização de projeto preliminar de equipamento protótipo.

Em relação à caracterização do processo proposto, o Capítulo 8 mostra os estudos de caracterização do processo proposto. Desta forma, são apresentados os materiais, métodos e planejamento de experimentos utilizados nos estudos de caracterização, além dos resultados e discussões sobre os estudos realizados

A partir dos resultados obtidos da caracterização do projeto, o Capítulo 9 apresenta uma análise da funcionabilidade e viabilidade do projeto, assim como um comparativo entre a proposta deste trabalho e produtos comercializados atualmente.

Por fim, o Capítulo 10 apresenta as considerações finais relacionadas ao equipamento desenvolvido, assim como de trabalhos futuros. Também são apresentados apontamentos referentes aos resultados da pesquisa de fundamentação (desenvolvimento de material), em adição à sua relevância para outras linhas de pesquisa. 


\section{ANÁLISE DO PROBLEMA}

Inicialmente, foi identificada a função global do projeto com objetivo de determinar as principais entradas de material, energia e sinal, assim como as respectivas saídas proporcionadas pelo sistema, como pode ser observado na Figura 2.1.

\begin{tabular}{|c|c|c|}
\hline Celulose/Polimero & & Objeto 3D \\
\hline Energia eletrica & \multirow{2}{*}{$\begin{array}{l}\text { transformação de materiale } \\
\text { adição de camadas, conforme } \\
\text { geometria } 3 \mathrm{~d} / \mathrm{CNC}\end{array}$} & Energia mecanica \\
\hline Modelo 3D/stl & & Status completo \\
\hline
\end{tabular}

Figura 2.1 - Representação de determinação função global de produto

Pode-se observar que a função global indica as especificações primárias deste projeto, como a utilização de material a base de celulose e polímero, sendo que o equipamento é alimentado por energia elétrica. Adicionalmente, foi determinada como entrada para o sistema a utilização de modelos tridimensionais (3D) no formato STL (Stereolithography), que é um formato neutro amplamente utilizado em equipamentos de AM.

Num segundo momento, foi realizado o detalhamento desta função global em dois níveis de abstração. Em relação ao primeiro nível de abstração, são apresentadas as funções estratificadas a partir da função global do projeto. Adicionalmente, a Figura 2.2 apresenta funções principais utilizadas na caracterização da funcionalidade do sistema.

Nesta figura, é apresentada a relação entre funções ao longo do fluxo principal de processamento do sistema. Inicianlmente, foi determinada a geração de camadas, assim como a geração de instruções para o sistema. Constituindo uma função de laço, foram determinadas as funções: transformação de material, cuja entrada é o material composto por polímero e substrato celulósico; construção de 
perfil de camada, sendo o sistema de posicionamento nos eixos $\mathrm{x}$ e y realizado por comando numérico. Em relação a função aderência de camadas, o objetivo dela é proporcionar o mecanismo de adesividade entre camadas energia térmica e ou luminosa. Adicionalmente, a função de laço também recebe como entrada, a função de posicionamento no eixo $z$ através de comando numérico proporciona a repeteção do processo até a finalização do objeto 3D. Por último, ao final da construção do objeto 3D, foi identificada uma função de acabamento, onde é realizada a remoção de material não utilizado na construção do objeto, além do acabamento superficial da peça.

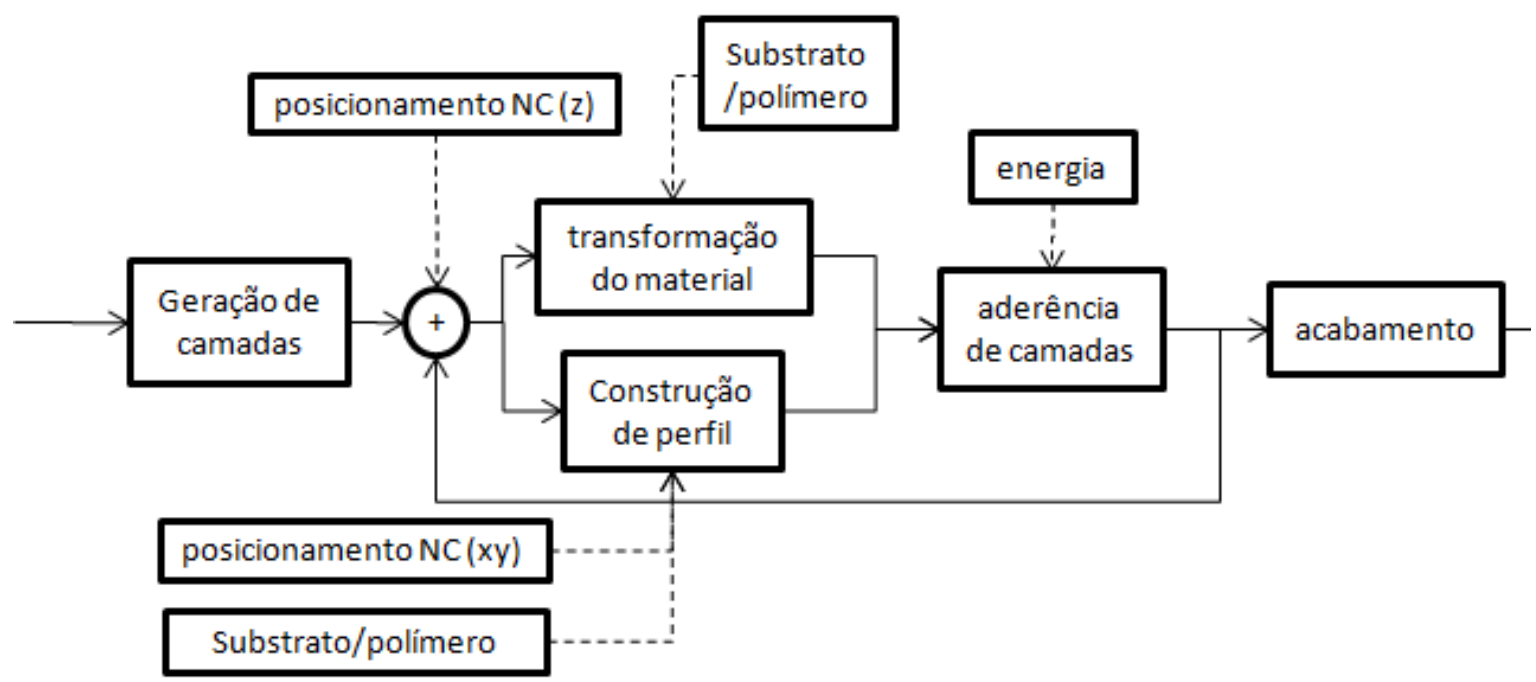

Figura 2.2 - Representação do primeiro nível de estratificação de funções especificas do projeto

No segundo nível de abstração, foram determinadas as funções especificas do projeto, assim como delineamento dos sistemas que compõem o equipamento, como pode ser observado na Figura 2.3.

Com isto, puderam ser determinadas as principais funções a serem descritas na especificação de projeto. E consequentemente, torna-se possível especificar as principais pesquisas de fundamentação a serem utilizadas no projeto.

Os principais sistemas delineados nesta análise funcional são: sistema de alimentação de substrato; sistema de deposição de material polimérico; software de 
processamento; sistema de controle e posicionamento; sistema de remoção de resíduo e acabamento; processo de formação de compósito; e mecanismo promotor de adesividade.

Em relação ao sistema computacional, foi identificada a necessidade de geração de camadas e estratégia de processamento através de arquivos STL, assim como o tratamento destas informações para a geração do código para o comando numérico.

Compondo o sistema de posicionamento e controle, foram identificadas as funções de posicionamento nos eixos $x, y$ e z, além da repetição do processo. Estas funções estão relacionadas com da comunicação entre comando numérico e sistema de controle do processo de deposição de polímero e fixação e posicionamento do substrato.

Com referência ao sistema de deposição, foram determinados os processos de alimentação de polímero assim como de deposição de material. Em paralelo a estes processos, foram também identificadas alimentação de substrato celulósico, e fixação e posicionamento de substrato como as funções que compõem o sistema de alimentação de substrato.

$\mathrm{Na}$ sequência de processamento, foram identificadas processos de transformação de material e mecanismo de adesividade. Estes processos são representados pelas funções de formação de compósito e aderência entre camadas, tendo energia térmica, mecânica (compressão) e ou luminosa como entradas.

Após a finalização da função de repetição de processo, foi identificada a função de pós-processamento e acabamento do objeto, sendo realizado por sistema independente do sistema de posicionamento e controle. Esta determinação foi realizada com o objetivo de permitir o equipamento a iniciar a construção de novos objetos enquanto o sistema de acabamento finaliza os objetos construídos anteriormente.

Com referência à especificação de projeto, a Tabela 2.1 apresenta uma relação das funções identificadas no primeiro e segundo nível da análise funcional do projeto. Adicionalmente, são também apresentadas descrições das funções, assim como os requisitos de projeto e as formas de implementação destas. 


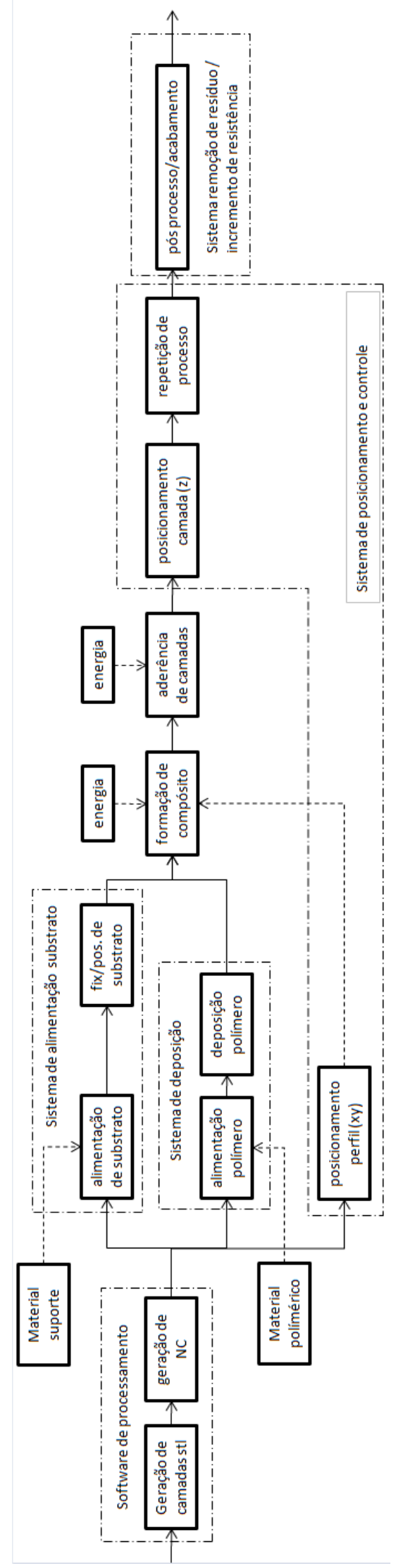

Figura 2.3 - Representação de fluxo de processamento de segundo nível de estratificação da análise funcional de proposta de projeto 
Em relação aos requisitos de projeto, foram determinados os principais delineamentos que o projeto deve atender. Entre estes, pode-se destacar a utilização de material compósito baseado em polímero e substrato celulósico, além do sistema de posicionamento e controle contemplar como entrada, a forma de comunicação via porta USB ou LPT. Isto permite a utilização de computador pessoal baseado na plataforma IBM para controle do equipamento.

Entre os outros requisitos de projeto, puderam ser também apresentados: utilização de substrato celulósico em forma laminada (folha ou rolo); utilização de código ISO ( $G$ code) como comando numérico padrão; Polímero líquido composto por monômero, oligômero e iniciador; resolução minima de $0.01 \mathrm{~mm}$ (xy) e 0.1 (z); resistência entre camadas mínima de $0.01 \mathrm{kgf}$; e área de contrução mínima de $100 \times 100 \times 20 \mathrm{~mm}$.

Similarmente, esta tabela também indica as formas de implementação do projeto, determinando, desta forma, as pesquisas de fundamentação deste trabalho. Entre estas, podem ser destacadas: o desenvolvimento de dispositivo de controle, desenvolvimento de material, desenvolvimento de sistema de deposição, desenvolvimento de sistema de alimentação e posicionamento de substrato, desenvolvimento de sistema de posicionamento, desenvolvimento de mecanismo de adesividade e desenvolvimento de processo e pos processo (acabamento).

Após a finalização da especificação de projeto, foi possível observar requisitos essenciais de cada função em relação às formas de implementação destas funções, permitindo prosseguir para as próximas etapas de desenvolvimento, conforme descrito anteriormente.

Como o conhecimento necessário para este desenvolvimento é diversificado e interdisciplinar, foram estipulados como assuntos principais de pesquisa: estado da arte de Tecnologias AM, Substrato a base de celulose, Sistemas de alimentação de substrato, processos de Polimerização, Adesividade, Sistema de deposição, Tinta para cabeçote jato de tinta e máquinas de precisão. 


\section{Tabela 2.1 - Especificação de Projeto}

\begin{tabular}{|c|c|c|c|c|}
\hline nivel & Processo/Funções & Descrição & Requisitos & Implementação \\
\hline 1 & $\begin{array}{l}\text { Geração de } \\
\text { camadas }\end{array}$ & $\begin{array}{l}\text { processo que proporciona a identificação de } \\
\text { geometrias } 3 \mathrm{~d} \text { computacionalmente e gerar } \\
\text { camadas e código de máquina }\end{array}$ & $\begin{array}{c}\text { interpretação de arquivo STL, } \\
\text { geração de perfil de camadas e } \\
\text { código NC }\end{array}$ & $\begin{array}{l}\text { Utilização de software RPCAM da empresa } \\
\text { MARCAM ou geração de código NC } \\
\text { manualmente para geometrias simples }\end{array}$ \\
\hline 2 & $\begin{array}{l}\text { Fatiamento de } \\
\text { objeto }\end{array}$ & $\begin{array}{l}\text { processo que gera secçóes transversais de } \\
\text { objeto conforme espessura determinada }\end{array}$ & \begin{tabular}{|c|}
$\begin{array}{c}\text { interpretação de arquivos STL, } \\
\text { determinação de espesura de } \\
\text { fatiamento }\end{array}$ \\
\end{tabular} & $\begin{array}{c}\text { utilização de software RPCAM ou determinação } \\
\text { manual de secção }\end{array}$ \\
\hline 2 & \begin{tabular}{|c|}
$\begin{array}{c}\text { Geração de código } \\
\text { NC }\end{array}$ \\
\end{tabular} & $\begin{array}{c}\text { processo de especificação de instruçôes para } \\
\text { equipamento através de código numérico }\end{array}$ & geração de código máquina G & $\begin{array}{c}\text { utilização de software RPCAM ou determinação } \\
\text { manual de código G }\end{array}$ \\
\hline 1 & $\begin{array}{l}\text { Repetição e } \\
\text { controle }\end{array}$ & $\begin{array}{l}\text { Proporciona o controle eletromecânico do } \\
\text { sistema a partir de código NC enviado por } \\
\text { computador }\end{array}$ & $\begin{array}{c}\text { Interpretação de código NC, } \\
\text { comunicação com PC através de } \\
\text { USB ou LPT }\end{array}$ & $\begin{array}{l}\text { Utilização de software TurboCNC ou Mach3, } \\
\text { desenvolvimento de dispositivo controle }\end{array}$ \\
\hline 2 & $\begin{array}{l}\text { processo de } \\
\text { repetição }\end{array}$ & $\begin{array}{l}\text { proporciona o sequencial de instruções para } \\
\text { realização de operações e posicionamento }\end{array}$ & $\begin{array}{l}\text { interpretação de código } \mathrm{Ge} \\
\text { comunicação através de porta } \\
\text { USB ou LPT }\end{array}$ & Utilização de software TurboCNC ou Mach3 \\
\hline 2 & Controle & $\begin{array}{l}\text { proporciona o controle do processo e } \\
\text { equipamento obtido de instruções }\end{array}$ & \begin{tabular}{|c|} 
Comunicação com PC através de \\
porta USB ou LPT, controle de \\
elementos eletromecânicos
\end{tabular} & Desenvolvimento de dispositivo de controle \\
\hline 1 & $\begin{array}{l}\text { Transformação do } \\
\text { material }\end{array}$ & $\begin{array}{c}\text { processo de transformação de materia-prima } \\
\text { em compósito }\end{array}$ & $\begin{array}{l}\text { Elementos de compósito a base } \\
\text { de fibra de celulose e polimero }\end{array}$ & Desenvolvimento de material \\
\hline 2 & $\begin{array}{l}\text { alimentação de } \\
\text { substrato }\end{array}$ & processo de alimentação de substrato & $\begin{array}{l}\text { Utilização de fibra de celulose } \\
\text { laminada (folhas ou bobinas) }\end{array}$ & $\begin{array}{c}\text { Desenvolvimento de Substrato e sistema de } \\
\text { alimentação }\end{array}$ \\
\hline 2 & $\begin{array}{c}\text { alimentação de } \\
\text { polímero }\end{array}$ & processo de alimentação de polímero & $\begin{array}{l}\text { utilização de monômero e } \\
\text { oligômero em estado líquido }\end{array}$ & Desenvolvimento de Polímero \\
\hline 2 & $\begin{array}{l}\text { formação de } \\
\text { compósito }\end{array}$ & processo de formação de compósito & $\begin{array}{c}\text { utilização de fibra de celulose } \\
\text { como substrato e polímero } \\
\text { como blinder }\end{array}$ & $\begin{array}{c}\text { Desenvolvimento de compósito, e mecanismo } \\
\text { de transformação }\end{array}$ \\
\hline 1 & $\begin{array}{l}\text { Construção do } \\
\text { perfil }\end{array}$ & $\begin{array}{c}\text { determinação seletiva de seç̧ão transversal } \\
\text { de objeto em espessura de camada } \\
\text { equivalente }\end{array}$ & - & Desenvolvimento de processo de deposição \\
\hline 2 & $\begin{array}{l}\text { fix/pos. de } \\
\text { substrato }\end{array}$ & $\begin{array}{c}\text { processo de posicionamento e fixação de } \\
\text { substrato em função de espessura e } \\
\text { deposição de material polimérico }\end{array}$ & $\begin{array}{c}\text { fixação de fibra de celulosa } \\
\text { laminada, sobre camada } \\
\text { anterior }\end{array}$ & desenvolvimento de sistema de fixação \\
\hline 2 & $\begin{array}{l}\text { deposição de } \\
\text { polimero }\end{array}$ & $\begin{array}{l}\text { processo de aplicação de polímero em } \\
\text { substrato }\end{array}$ & - & desenvolvimento de sistema de deposição \\
\hline 2 & $\begin{array}{c}\text { posicionamento } \\
\text { perfil (xy) }\end{array}$ & $\begin{array}{l}\text { processo de posicionamento seletivo entre } \\
\text { substrato e polímero }\end{array}$ & $\begin{array}{c}\text { resolução min de } 0.01 \mathrm{~mm} \text {, curso } \\
\text { min de } 100 \times 100 \mathrm{~mm}\end{array}$ & $\begin{array}{l}\text { Desenvolvimento de sistema de } \\
\text { posicionamento }\end{array}$ \\
\hline 2 & $\begin{array}{l}\text { posicionamento } \\
\text { camada }(z)\end{array}$ & $\begin{array}{c}\text { processo de posicionamento de nova camada } \\
\text { para inicio de processo de repetição }\end{array}$ & $\begin{array}{c}\text { resolução min de } 0.01 \mathrm{~mm} \text {, curso } \\
\text { min de } 20 \mathrm{~mm}\end{array}$ & $\begin{array}{l}\text { desenvolvimento de sistema de } \\
\text { posicionamento }\end{array}$ \\
\hline 1 & $\begin{array}{l}\text { aderência entre } \\
\text { camadas }\end{array}$ & $\begin{array}{l}\text { proporciona a adesividade entre camadas de } \\
\text { forma a empilhar secções da peça, obtendo, } \\
\text { assim, objeto final }\end{array}$ & \begin{tabular}{|c|}
$\begin{array}{c}\text { Desenvolvimento de material, } \\
\text { resistência mecânica } \mathrm{p} / \text { uma } \\
\text { camada superior a } 0.01 \mathrm{kgf}\end{array}$ \\
\end{tabular} & $\begin{array}{l}\text { Desenvolvimento de mecanismo promotor de } \\
\text { adesividade }\end{array}$ \\
\hline 1 & $\begin{array}{c}\text { Pós-processamento } \\
\text { e acabamento }\end{array}$ & $\begin{array}{l}\text { Processo de remoção de resíduos de } \\
\text { fabricação, incremento de resistência } \\
\text { mecânica e ajuste dimensional }\end{array}$ & - & Desenvolvimento de pós-processo \\
\hline
\end{tabular}




\section{REVISÃO BIBLIOGRÁFICA}

Conforme a diversidade de pesquisas de fundamentação levantadas anteriormente, os tópicos abordados ao longo deste capítulo relacionam os principais conteúdos levantados ao longo da pesquisa bibliográfica e do estado da arte. Entre estes, pode-se listar: o levantamento das principais tecnologias de fabricação aditiva (AM) atuais; materiais (substrato celulósico, polímero e Compósito), adesividade, sistemas de deposição e máquinas de precisão.

\subsection{Tecnologias de Fabricação por Adição (Additive Manufacturing - AM)}

Com referência às tecnologias de fabricação por adição (AM), também conhecidas como de prototipagem rapida $(\mathrm{RP})$, estas tem seu funcionamento fundamentado na criação de objetos 3D camada por camada através de adição de material (COOPER, 2001; GIBSON, 2005; VOLPATO, 2007; CUNICO, 2011).

Contudo, apesar da peculiaridade de cada tecnologia, é possível classificar estes processos em função do tipo de material utilizado na fabricação das peças, do tipo de energia utilizada para a transformação de material, ou até mesmo da forma de construção do perfil da camada, entre outros (GIBSON, 2005; WILLIAMS, 2008; MORTARA et al., 2009).

Por exemplo, ao considerar a classificação conforme tipo de material, pode-se identificar tecnologias baseadas em polímeros líquidos; material fundido, partículas discretas, e sólidos laminados (GIBSON, 2005; WILLIAMS, 2008; MORTARA et al., 2009).

\subsubsection{Tecnologias a base de Polímeros Líquidos}

Em relação às tecnologias baseadas em polímeros líquidos, estas tem como fator comum, a utilização de materiais fotopolimerizaveis, normalmente a base de 
acrilatos e epoxes. Adicionalmente, a cura destes materiais, ainda no estado líquido, ocorre normalmente através de ação de luz ou laser UV (PRINZ et al., 1997; COOPER, 2001; GIBSON, 2005; LIOU, 2007; GIBSON et al., 2010; CUNICO, 2011).

Entre estas, encontram-se a Estereolitografia (SLA), Fotopolimerização por máscara de projeção e a impressão jato de tinta (IJP), sendo as tecnologias mais conhecidas e expressivas desta classe (PRINZ et al., 1997; COOPER, 2001; GIBSON, 2005; LIOU, 2007; GIBSON et al., 2010; CUNICO, 2011).

\section{Estereolitografia (Stereolithography - SLA)}

A estereolitografia (stereolithography - SLA) é uma das mais difundidas tecnologia de prototipagem rápida, tendo sua comercialização feita inicialmente pela empresa 3D Systems. Apesar da validação de seu princípio funcional ter sido publicada por Kodama (1981) e por Herbert (1982), a tecnologia SLA teve como marco inicial a patente do fundador da 3D Systems somente em 1984 (HULL, 1986; PRINZ et al., 1997; GIBSON, 2005; GIBSON et al., 2010)

O princípio funcional deste processo consiste na cura localizada de resina fotosensível através de feixe de laser UV que se desloca ao longo dos eixos $\mathrm{X}$ e $\mathrm{Y}$. Este feixe incide sobre um recipiente imerso em resina a fim de construir a silueta da camada previamente calculada computacionalmente. Após a finalização de cada camada, uma plataforma de sustentação do material se desloca no eixo Z com o objetivo de iniciar a construção da nova camada, como pode ser observado na ilustração da Figura 3.1. Este processo se repete até a finalização da peça, quando é levantada a plataforma permitindo escorrer a resina não polimerizada (PRINZ et al., 1997; COOPER, 2001; GIBSON, 2005; GIBSON et al., 2006; LIOU, 2007; VOLPATO, 2007; GIBSON et al., 2010). 


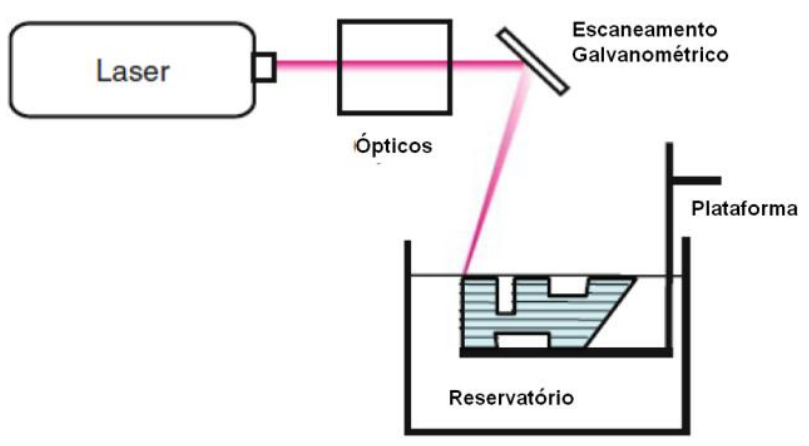

Figura 3.1 - Representação genérica de processo de Estereolitografia (SLA) (GIBSON et al., 2010)

Cabe ressaltar que, embora a concepção atual de SLA utilize laser UV, é possível o emprego de outras fontes promotoras da polimerização, como: feixe de elétrons (electron beam - EB), radiação, feixe de partículas de alta energia, raio-X, feixe de luz UV e luz UV convencional (HULL, 1986; WU et al., 2001).

Em relação ao comportamento da cura gerada ao longo do deslocamento do laser (Scan Pattern), a Figura 3.2 apresenta uma ilustração da secção transversal do filamento gerado por um deslocamento do laser ao longo de uma linha reta (JACOBS et al., 1992; COOPER, 2001; GIBSON et al., 2010).

Nesta figura, também é apresentada a interação entre filamentos gerados por varredura, indicando a existência de regiões não polimerizadas ao longo da construção da peça.
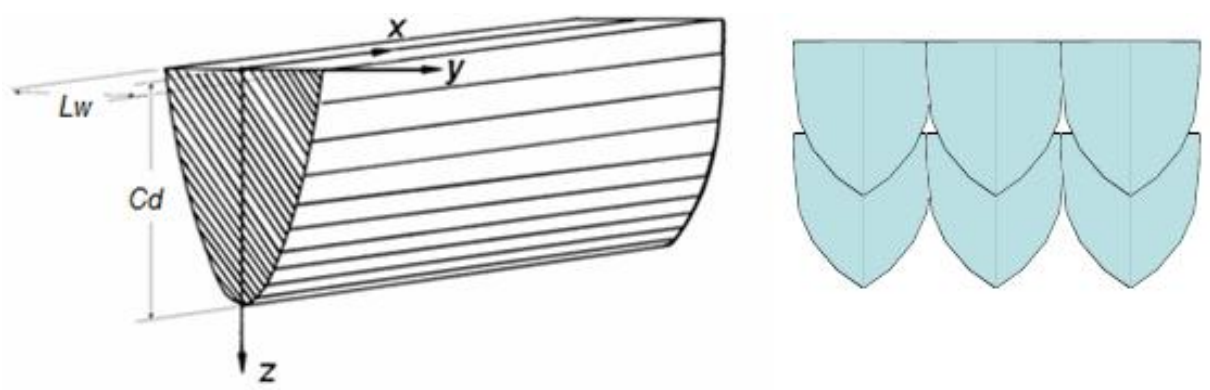

Figura 3.2 - Representação genérica de perfil de cura gerados por deslocamento de laser (SLA) e interação entre filamentos, adaptado de (JACOBS et al., 1992; GIBSON et al., 2010) 
Aliado à existência destas regiões não polimerizadas, o grau de polimerização da peça recém fabricada é de 80 a $90 \%$, implicando na realização de um pósprocessamento para finalização da polimerização e acréscimo de resistência mecânica. Nesta etapa, é mantida a peça finalizada mantida em forno com emissão de luz UV, assim como a remoção de material suporte (JACOBS et al., 1992; COOPER, 2001; LIOU, 2007; GIBSON et al., 2010).

Adicionalmente, a partir desta característica do processo, foi possível o desenvolvimento de estratégias de geração de trajetórias como: varredura, contorno, malha (weave) e malha tridimensional (star-weave). Na Figura 3.3 é apresentada uma ilustração destas estratégias de geração de tragetórias (JACOBS et al., 1992; COOPER, 2001; LIOU, 2007; GIBSON et al., 2010).

Os materiais tipicamente utilizados por este processo são baseados em acrilatos e epoxies, proporcionando para peças finais, uma resistência mecânica adequada para fabricação de peças funcionais. Em adição, representando quantativamente o nível de resistência mecânica, os valores de tensão de escoamento variam entre 28 a $78 \mathrm{MPa}$ (JACOBS et al., 1992; COOPER, 2001; LIOU, 2007; 3DSYSTEMS, 2008e; d; b; c; a; f; 2009; 2010b; a; GIBSON et al., 2010)

Em relação à precisão desta tecnologia, atualmente são encontrados valores de resolução de camada de até $50 \mu \mathrm{m}$, enquanto para precisão de varredura, podendo alcançar $25 \mu \mathrm{m}$. Neste caso, a velocidade de construção dos objetos pode alcançar até $35 \mathrm{~m} / \mathrm{s}$. Contudo, existem casos específicos, como microestereolitografia, cujos valores de resolução de camada $(z)$ e de precisão de varredura $(\mathrm{x}-\mathrm{y})$ podem alcançar respectivamente a 0,1 e $0,25 \mu \mathrm{m}$ (3DSYSTEMS, 2010b; GIBSON et al., 2010; 3DSYSTEMS, 2011b; a). 


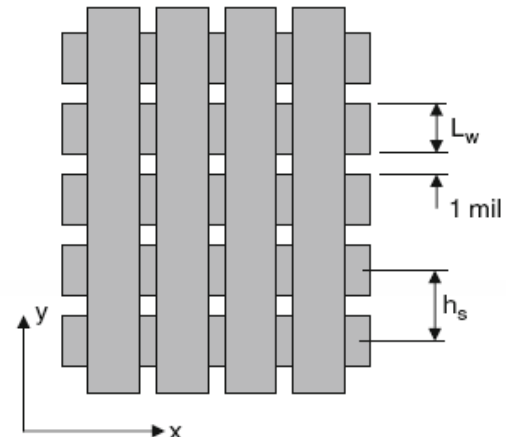

a
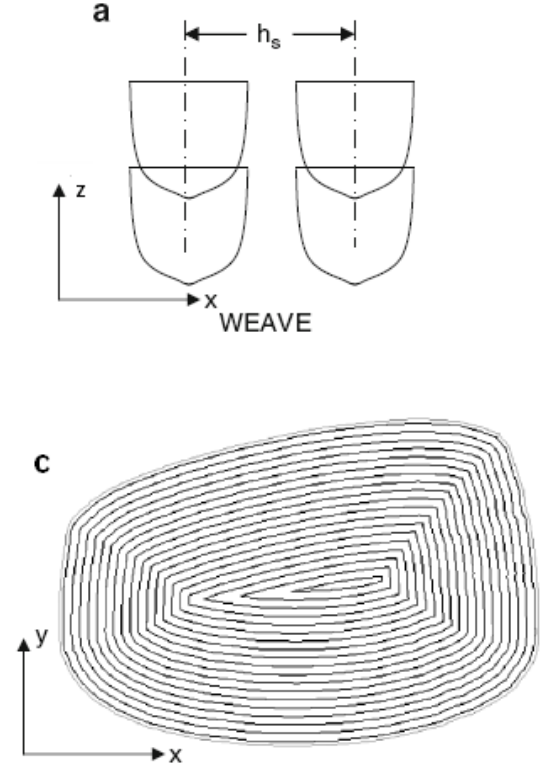

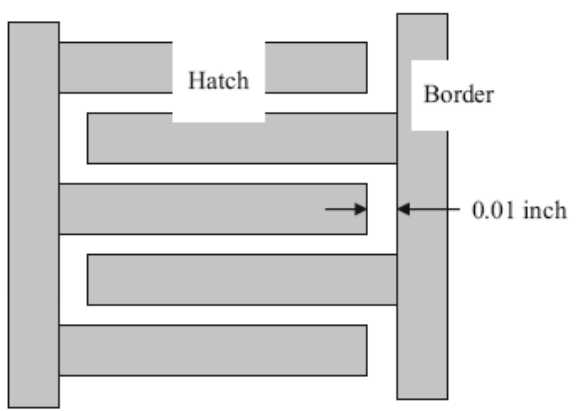

b

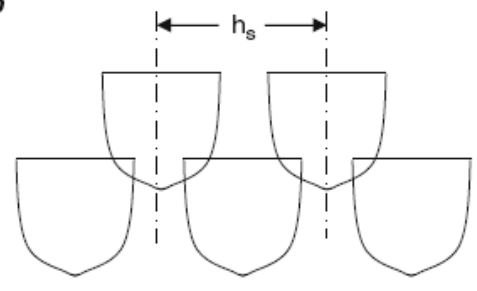

STAR-WEAVE

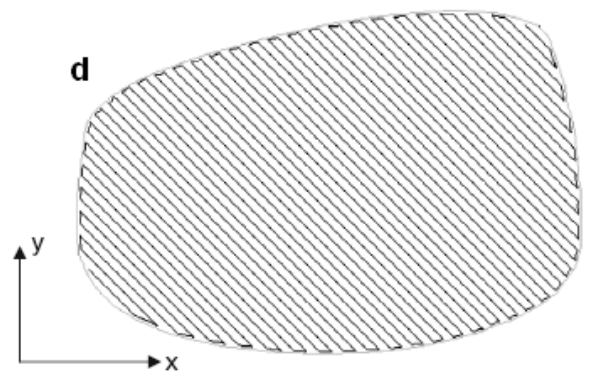

Figura 3.3 - Representação genérica estrategias de geração de trajetorias de construção, sendo: a) malha (weave); b)malha 3D (star weave); c)contorno;d)varredura , adaptado de (JACOBS et al., 1992; GIBSON et al., 2010)

Estereolitografia por máscara de projeção (Mask photopolymerization Stereolithography-MPSL)

Outra tecnologia de prototipagem rápida que utiliza materiais fotopolimerizáveis é o processo de estereolitografia por máscara de projeção (Mask photopolymerization Stereolithography - MPSL). Este processo, que também é conhecido como fotosolidificação (photosolidification), teve seu desenvolvimento iniciado em paralelo ao desenvolvimento de SLA, contudo, tendo início de 
comercialização de equipamentos em 1991 (PRINZ et al., 1997; GIBSON, 2005; GIBSON et al., 2010).

O funcionamento deste processo se destaca dos demais em função do modo de criação, visto que a camada é gerada em passo único (layer-wise), permitindo, assim, a redução do tempo de construção da peça e o aumento da homogeneidade das peças (PRINZ et al., 1997; GIBSON, 2005; GIBSON et al., 2010).

Um exemplo disto pode ser observado ao analisar a velocidade de fabricação do equipamento Perfactory ${ }^{\circledR}$ Standard UV, da EnvisionTec. Como este proporciona uma velocidade de fabricação de 200 camadas de $100 \mu \mathrm{m}$ de espessura por hora, a construção de uma peça de volume igual a $2484 \mathrm{cc}$ ocorreria em 11 horas. Em contraste, a construção de uma peça de mesmas proporções através de um processo SLA seria realizada no mesmo tempo, porém obtendo maior resolução de construção (PRINZ et al., 1997; GIBSON, 2005; ENVISIONTEC, 2009a; b; GIBSON et al., 2010; ENVISIONTEC, 2011f).

Para a construção de cada camada, é incidida luz UV através de uma máscara sob um recipiente preenchido de resina foto curável. Esta máscara permite somente a passagem de luminosidade no formato da camada, e por consequência, permitindo a polimerização de material no formato da camada. Em seguida, uma plataforma de sustentação do material se desloca no sentido vertical (eixo z) permitindo a construção da nova camada. Este processo se repete até a finalização da peça, quando é realizada pós-processamento da peça. Sendo possível observar na Figura 3.4 um desenho esquemático deste processo (PRINZ et al., 1997; GIBSON, 2005; GIBSON et al., 2010).

Embora diversos grupos venham continuamente estudando este processo, apenas duas empresas tem destaque na comercializam atualmente. A EnvisionTEC teve o lançamento de seus produtos a partir de 2003, enquanto a 3D System somente em 2008, com o equipamento V-Flash (PRINZ et al., 1997; GIBSON, 2005; GIBSON et al., 2010).

Em relação às propriedades mecânicas das peças fabricadas por este processo, os valores de tensão de escoamento podem chegar à $57 \mathrm{MPa}$, mantendo- 
se abaixo dos valores máximos de SLA (PRINZ et al., 1997; GIBSON, 2005; GIBSON et al., 2010; 3DSYSTEMS, 2011c; ENVISIONTEC, 2011e; a; b; d; c)

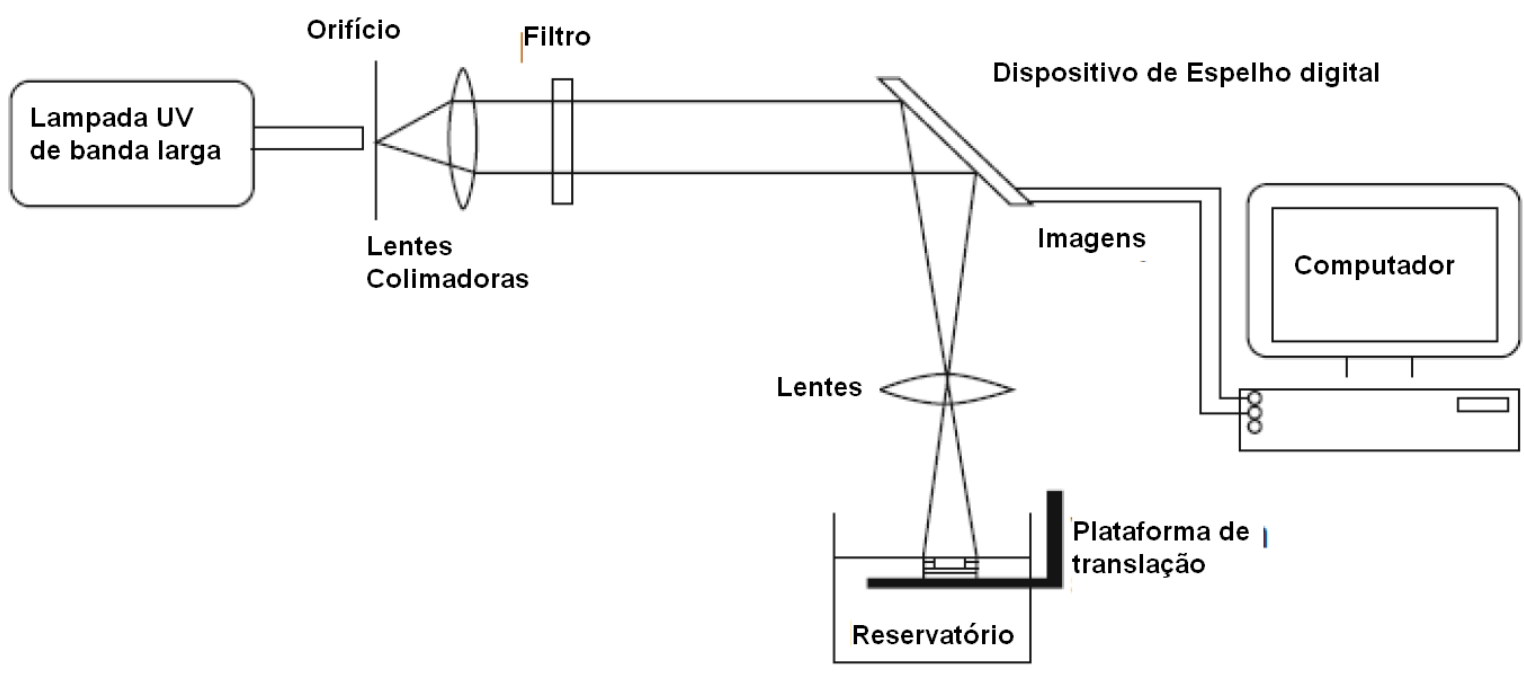

Figura 3.4 - Representação genérica da tecnologia máscara de projeção (GIBSON et al., 2010)

\section{Impressão Jato de Tinta (Inkjet Print - IJP)}

Com referência às tecnologias de prototipagem rápida baseadas em impressão jato de tinta (Inkjet Print - IJP), o princípio de funcionamento consistem na criação de camadas por deposição de gotas de material através de cabeçote jato de tinta. Esta tecnologia foi desenvolvida inicialmente pela empresa Sanders prototyping (Solid Scape) em 1994. Contudo, a utilização de jato de tinta em equipamentos AM tenha sido mais expressivamente somente a partir de 1999, quando foi patenteada a concepção empregada pela empresa israelense Objet Geometries (PRINZ et al., 1997; SANDERS et al., 1998; GOTHAIT, 2000; GIBSON et al., 2010).

No conceito inicial, apresentado pela Sanders Prototyping, é utilizado cabeçote jato de tinta térmico a fim de depositar seletivamente gotas de materiais a base de cera para construção de secção transversal de objetos 3D ao longo dos eixos $x$ e y. Após a finalização de cada camada, a plataforma de construçãose desloca em z 
proporcionando a construção da próxima camada, sendo que este processo se repete até a conclusão da peça (PRINZ et al., 1997; SANDERS et al., 1998; GIBSON et al., 2010).

Já na concepção adotada pela Objet, é utilizado cabeçote jato de tinta piezoelétrico para deposição de gotas de material fotocuravel no estado líquido sobre plataforma ou substrato ao longo dos eixos x-y. Simultaniamente, estas gotas são solidificadas devido à exposição a uma fonte de luz UV extensa. Após a finalização de cada camada, a plataforma de construção se desloca em z proporcionando o início de uma nova camada, como pode ser observado na Figura 3.5 (PRINZ et al., 1997; GOTHAIT, 2000; GIBSON et al., 2010).

Fazendo frenet à linha PolyJet da Objet, a empresa 3D Systems, através da linha Multi-jet, adotou uma variação da concepção desenvolvida pela Objet. No caso da desta concepção, em vez das gotas de material serem solidificadas simultaneamente, estas são curadas parcialmente por meio de flashes de luz UV ao final de cada camada (SCHMIDT, 2004; MARGOLIN, 2006).

Os tipos de materiais tipicamente utilizados são baseados em acrilatos, epoxes, termoplásticos e cera, sendo que estes se diferenciam pelo processo de solidificação do material. Isto permite dividir estas tecnologias em dois grupos: IJP de fotopolimerizaveis e IJP de termopolimerizáveis (VOLPATO, 2007; GIBSON et al., 2010).

Por exemplo, o equipamento EDEN, desenvolvida pela Objet, é um tipo de IJP de materiais fotopolimerizáveis, sendo que seu cabeçote jato de tinta deposita material através de 1536 bicos individuais dispostos em linha de forma simultânea em camadas de $15 \mu \mathrm{m}$. Neste caso, visto que a cura UV acontece de forma simultânea à deposição, não é identificada a necessidade de pós-processamento, como em outros processos baseados em líquidos (SLA e MPSL) (VOLPATO, 2007; GIBSON et al., 2010; OBJET, 2011). 


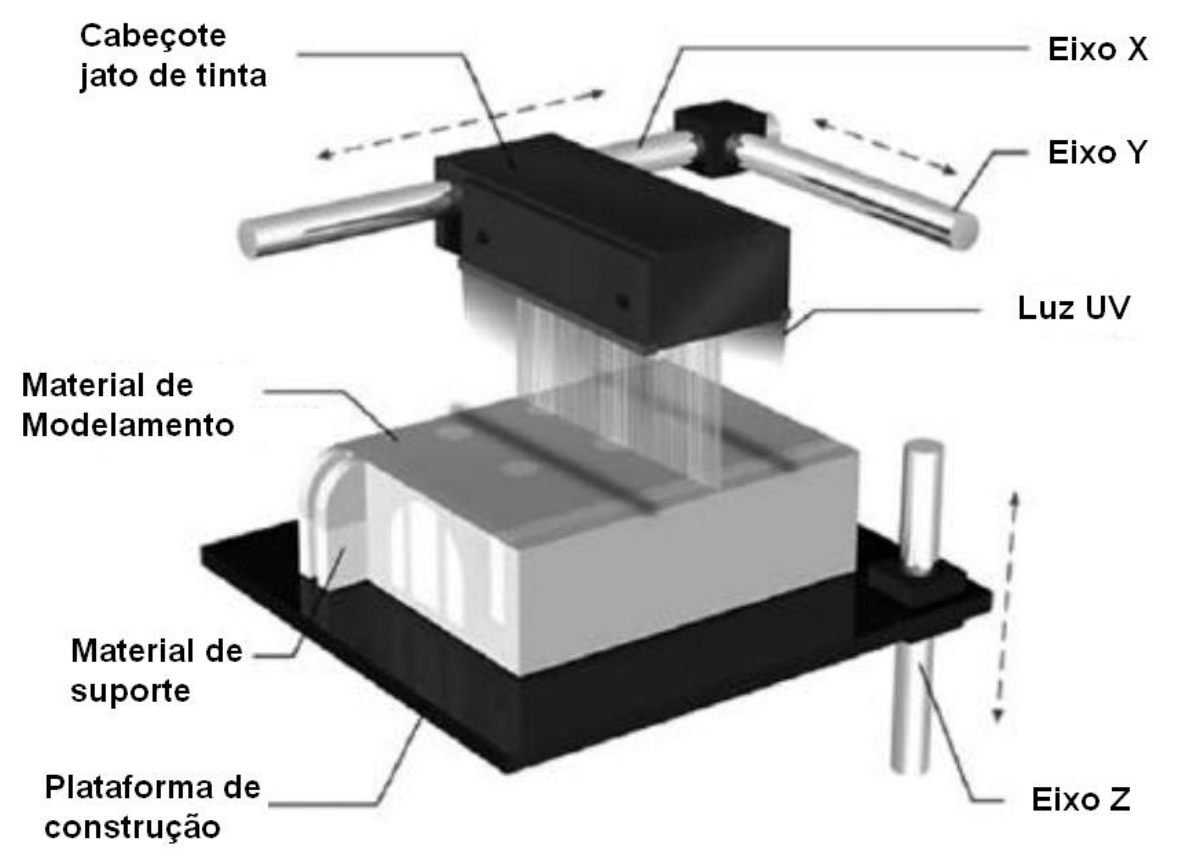

Figura 3.5 - Representação genérica da tecnologia IJP de fotopolimerizaveis (GIBSON et al., 2010)

Com relação às propriedades mecânicas proporcionadas por estes processos, são encontradas em tecnologias IJP de fotopolimerizaveis valores de a resistência a tração (tensão de escoamento) entre 30 a $76 \mathrm{Mpa}$, assim como precisão no sentido horizontal (x-y) de 600 dpi, que é equivalente a 42 m (VOLPATO, 2007; GIBSON et al., 2010).

\subsubsection{Modelagem por Fusão e Deposição (Fused Deposition Modelling - FDM)}

Outra classificação para tecnologias AM é referente à utilização de material fundido. Neste tipo de processo, o princípio de funcionamento consiste na deposição de material, normalmente termoplástico, através de um cabeçote extrusor. A fim de construir o perfil da camada, este cabeçote se desloca ao longo dos eixos $\mathrm{x}$ e y adicionando filamentos de material. Após a finalização de uma camada a plataforma de deposição se desloca no sentido $z$ com a finalidade de construção da próxima 
camada, de forma a repetir este procedimento até a finalização da peça (PRINZ et al., 1997; COOPER, 2001; GIBSON, 2005; LIOU, 2007; VOLPATO, 2007).

Entre as principais tecnologias comerciais que utilizam este princípio de funcionamento está a modelagem por fusão e deposição (Fused Deposition Modelling - FDM). Esta tecnologia, que é uma das mais difundidas no mercado, tem seu desenvolvimento realizado pela empresa Stratasys.

Visto que o desenvolvimento desta tecnologia teve como marco inicial, 0 depósito de patente de (CRUMP, 1989), esta tecnologia encontra-se como uma das pioneiras na área de fabricação aditiva (PRINZ et al., 1997; COOPER, 2001; GIBSON, 2005; LIOU, 2007; VOLPATO, 2007).

Contudo, a sua concepção se baseia na deposição de filamento individual, enquanto outras tecnologias, como a Thermojet da 3D Systems, proporcionam a deposição simultânea através de diversos bicos de deposição. Em contrapartida, o material utilizado nestes processos é baseado em cera (COOPER, 2001; GIBSON, 2005; LIOU, 2007).

Em relação aos processos básicos envolvidos na tecnologia FDM, podem ser descritos: carregamento de material; liquidificação do material, aplicação de pressão para impulsionar o material através do bico; extrusão; plotagem de acordo com trajetória predefinida pelos comandos numéricos; adesão entre material de construção; inclusão de estrutura de suporte para permitir a construção de geometrias negativas e complexas.

Na Figura 3.6, pode-se observar uma representação esquemática do processo FDM, onde um filamento de material termoplástico é movimentado para dentro da câmara de liquidificação por ação de rolos de alimentação (normalmente acionados por motores de passo). Ao redor desta câmara, são posicionadas resistências térmicas com a finalidade de elevar a temperatura do material até valores superiores ao do ponto de transição vítrea, no caso de plásticos.

Em contrapartida, podem se destacar variações baseadas em outros tipos materiais e outros princípios de solidificação de material. como Contour Craft, baseado em cerâmicos, Bioplotter, baseado em formação de gel, e FAB@HOME, baseado em silicone. 


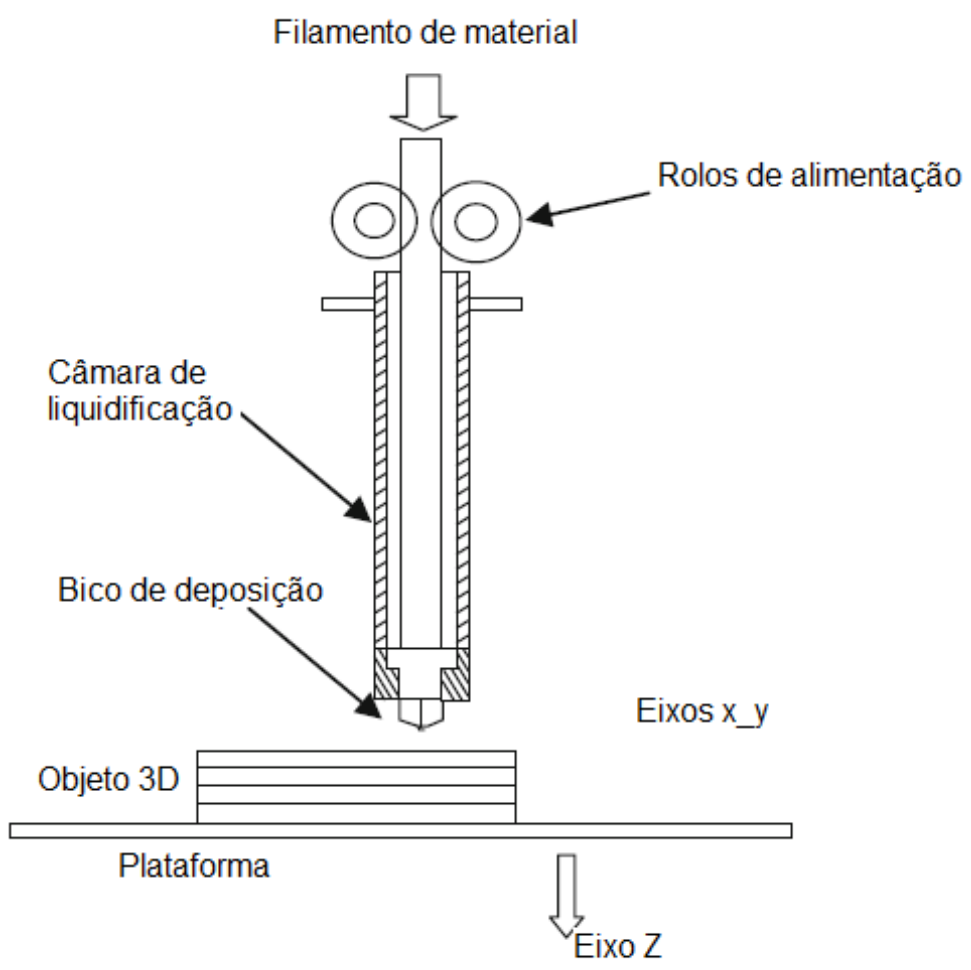

Figura 3.6 - Representação esquemática de processo FDM (GIBSON, 2005)

Em relação às estratégias básicas de geração de trajetórias, destacam-se varredura e contorno, como podem ser observadas na a Figura 3.7. Entre os principais parâmetros de varredura estão: distância entre filamentos, ângulo de varredura e angulação de rotação de varredura entre camadas. Contudo, cabe ressaltar que a varredura pode ser ter formatos diferenciados a fim de promover mesoestruturas (COOPER, 2001; GIBSON, 2005; GIBSON et al., 2006; WILLIAMS, 2008). 

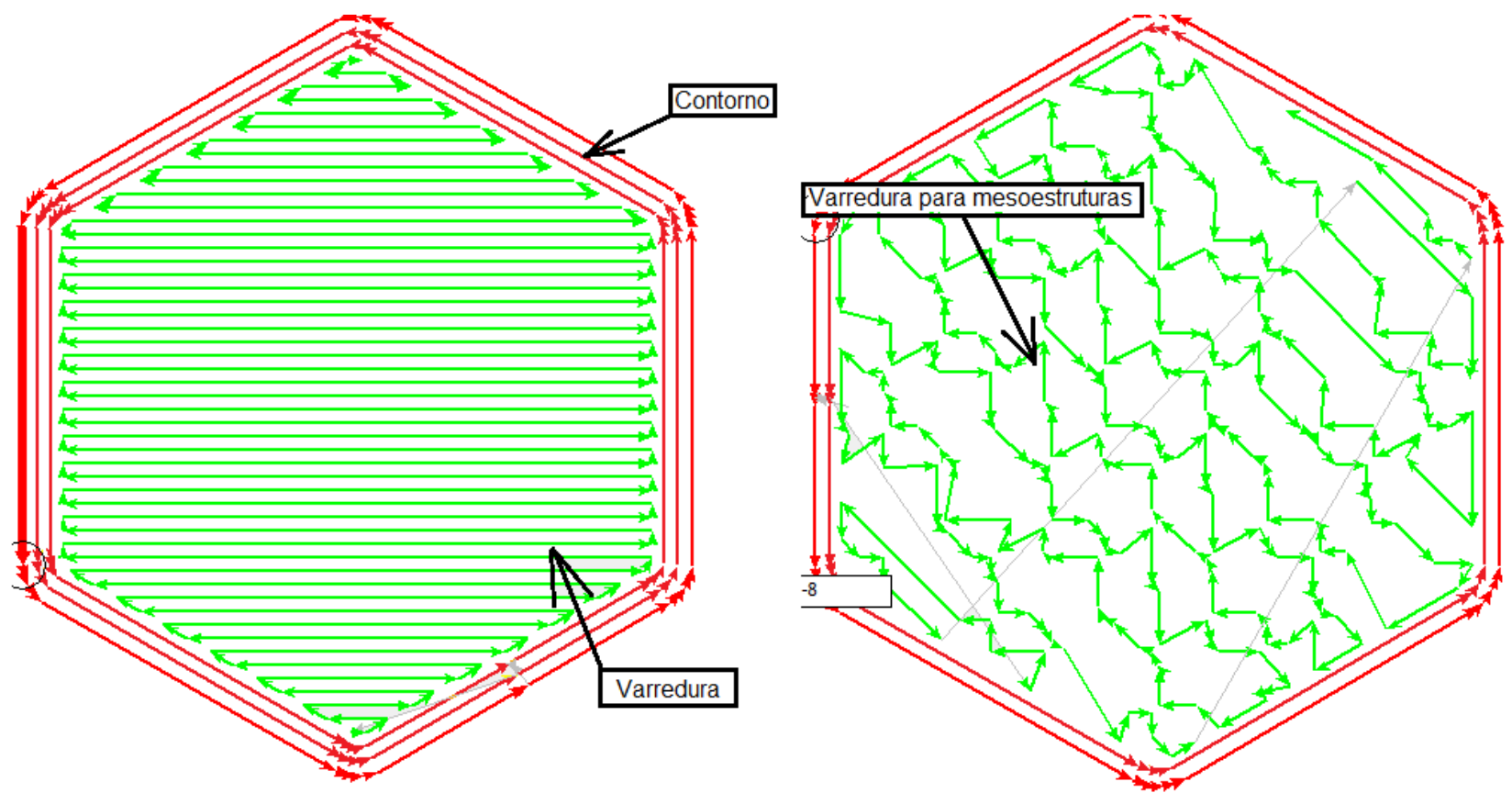

Figura 3.7 - Representação esquemática estrategias básicas de geração construção de perfil de camada de processo FDM

Além das trajetórias de deposição geradas por comando numérico, as principais variáveis que interferem neste processo são: temperatura de câmara de liquidificação, temperatura de ambiente de deposição, velocidade de rolos de alimentação, altura de deposição, velocidade de deposição e propriedades termomecânicas do material (GIBSON, 2005).

Aliado à quantidade de variáveis envolvidas, o comportamento de muitas destas não é linear. Desta forma, pode-se observar a dificuldade na identificação dos pontos de viabilidade do processo, assim como do controle do mesmo.

Apesar disto, ao longo dos últimos anos, puderam ser observar progressos significativos relacionados à obtenção final das peças. Por exemplo, podem ser encontrados atualmente alguns materiais utilizados para fabricação de peças em FDM cujos valores de resistência são até mesmo superiores aos de peças fabricadas por processos clássicos. Isto pode ser facilmente identificado ao comparar os valores de tensão de escoamento do material termoplásticos para FDM da Stratasys com os de materiais moldados. Enquanto os valores de materiais para 
FDM se mantém entre 22 e $71 \mathrm{MPa}$, os equivalentes para moldes de injeção se encontram entre 20 e 60 MPa (REDEYE, 2011).

Outra característica que também deve ser ressaltada deste processo é a precisão na construção de peças. Para equipamentos atuais, a espessura mínima de fabricação pode chegar até $0.127 \mathrm{~mm}$, Adicionalmente, a precisão ao longo da camada (xy) é descrita como $\pm 0.127 \mathrm{~mm}$ (GIBSON et al., 2010; REDEYE, 2011; STRATASYS, 2011) .

Apesar deste processo estar entre os mais baratos difundidos na indústria, o baixo nível de acabamento, a baixa densidade e os longos tempos de fabricação estão entre as principais limitações da utilização de tecnologias FDM (GIBSON et al., 2010).

Atualmente é possível encontrar diversas variações de baixo custo de equipamentos que utilizam processo de FDM, como, por exemplo, Fab@Home, que tem a base de seu desenvolvimento na universidade de Cornell e a recem aquisição da 3D System, Bitsfrombytes desenvolvida inicialmente na universidade de Bath (GIBSON, 2005; MALONE e LIPSON, 2007; GIBSON et al., 2010; BITSFROMBYTES, 2011).

$\mathrm{Na}$ Figura 3.8 são apresentadas imagens de duas variações de FDM, FAB@HOME e RapMan (BitsFromBytes). No primeiro exemplo, o material utilizado é silicone, sendo o sistema de deposição composto por seringa e atuador linear, sendo uma cópia de concepção patenteada pela Stratasys em 2008 (BATCHELDER, 2008). 


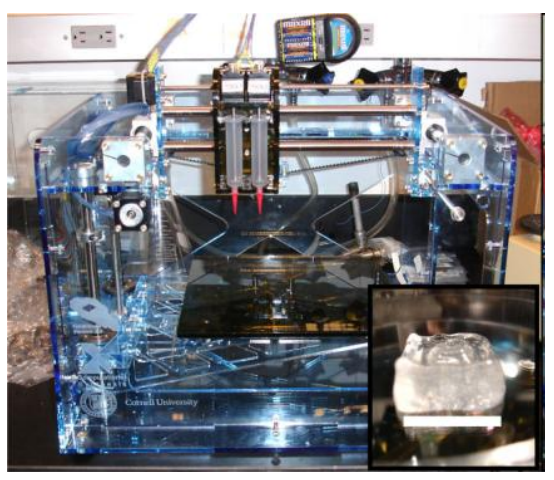

a)

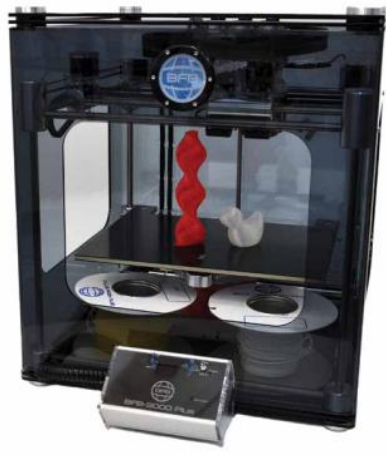

b)

Figura 3.8 - Foto of a)Fab@home and b)BitFromBytes FDM variations (MALONE e LIPSON, 2007; BITSFROMBYTES, 2011)

Já na segunda concepção, é utilizado o princípio de funcionamento atual de tecnologias FDM, utilizando ABS como material principal. Apesar do baixo custo de aquisição destes equipamentos, cujos valores são inferiores a 20 mil dólares americanos, estes proporcionam acabamento extremamente baixo, além de resistência mecânica utilizada somente em nível de protótipo (GIBSON et al., 2010).

\subsubsection{Tecnologias a base de solido laminado}

Outra categoria de processos por adição de material é baseada em sólidos laminados. Esta tecnologia AM foi uma das primeiras a serem comercializadas, tendo seu início em 1991. Inicialmente, o fornecedor desta tecnologia (Kira) a denominou de Laminated Object Modelling (LOM) (PRINZ et al., 1997; GIBSON, 2005; GIBSON et al., 2010).

O princípio de funcionamento deste processo baseia-se no corte e colagem de folhas de papel. Sendo a geração do perfil de camada realizado por meio de laser de $\mathrm{CO}_{2}$ que se desloca ao longo dos eixos xy. Adicionalmente, estas camadas são empilhadas através de cola termicamente ativada. Como pode ser observado na Figura 3.9, após a finalização de cada camada, uma plataforma é movimentada no eixo z, criando possibilidade para construção de novas camadas, sofrendo pressão e 
calor por ação de um rolo (PRINZ et al., 1997; COOPER, 2001; GIBSON, 2005; GIBSON et al., 2010).

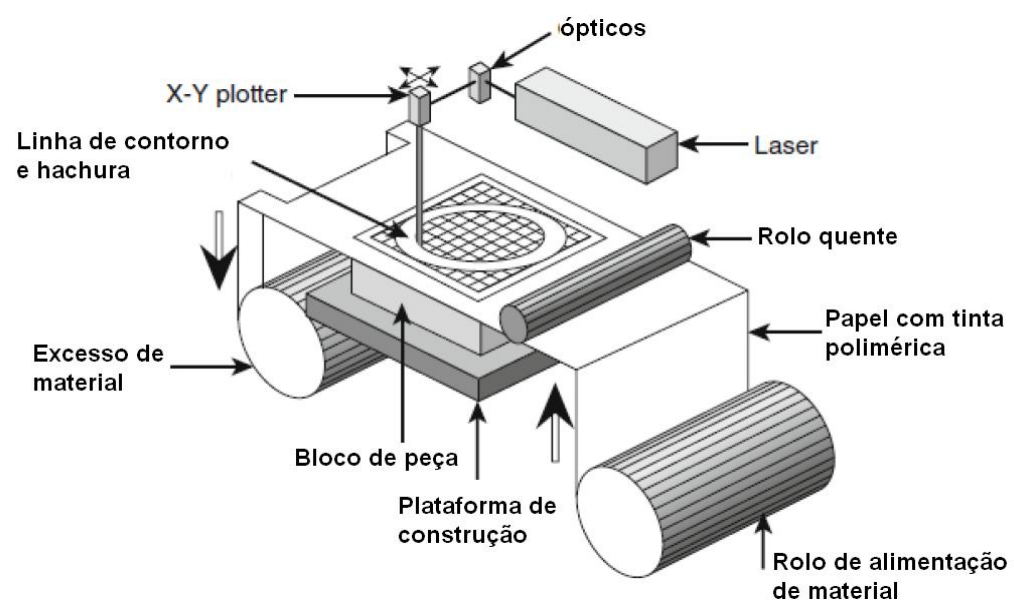

Figura 3.9 - Representação de princípio de funcionamento de processo LOM (GIBSON et al., 2010)

Por outro lado, o princípio básico de funcionamento sofreu ao longo do tempo algumas variações, como a utilização de lâmina para realização de corte. Outra subclassificação destas tecnologias pode ser identificada conforme a ordem de processamento, como corte-cola (Form-Then-Bond) e cola-corte (Bond-Then-Form). No caso de LOM da Helisys, KIRA e Solido, estes se baseam na classificação colacorta, utilizando, respectivamente, papel em bobina, papel em folhas, e bobina de Polipropileno (PRINZ et al., 1997; MORITA e SUGIYAMA, 2000; GIBSON, 2005).

Ao final da construção do objeto, é fornecido um bloco de celulose que necessita um processo de pos processamento para remoção das áreas que não fazem parte da peça como pode ser observado na Figura 3.10. 


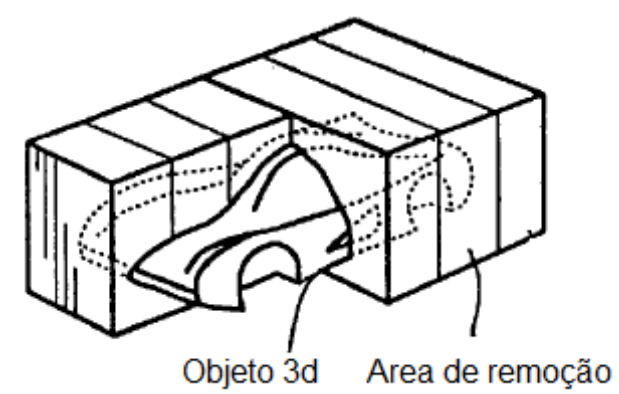

Figura 3.10 - llustração de posprocessamento de tecnologias LOM adaptado de (MORITA e SUGIYAMA, 2000)

Por outro lado, entre os principais processos baseados em corte-cola estão: Stratoconception; CAM-LEM e Offset Fabbing system, tendo respectivamente como materiais de base: chapas metálicas e cerâmicos (WEI et al., 2001; HOUTMANN et al., 2009; GIBSON et al., 2010; THABOUREY et al., 2010).

Na Figura 3.11 pode ser observada a ilustração esquemática dos processos stratoconception e CAM-LEM, sendo que é inicialmente cortadas as camadas do objeto $3 \mathrm{D}$ através de lazer ou CNC, sendo empilhadas e fixadas através de pinos de fixação. Então, após sofrer processo de brasagem é retirada a pinagem e finalizado o objeto 3D (GIBSON, 2005).

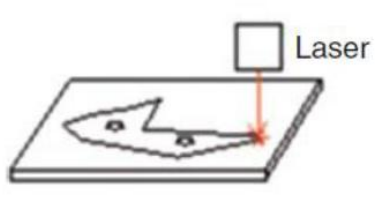

1. Corte de camada

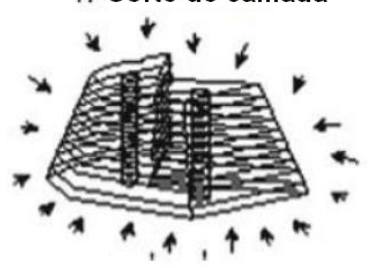

3. Laminação

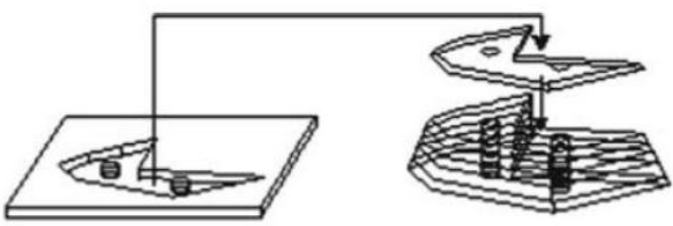

2. Empilhamento

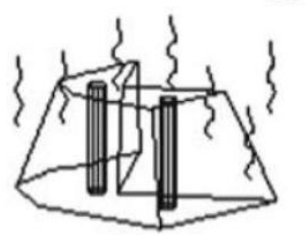

4. Remoção de ligante convencional e sinterização ou brasagem

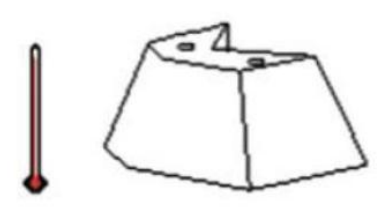

5. Acabamento de componente

Figura 3.11 - llustração esquemática do processos de stratoconception e CAMLEM (GIBSON et al., 2010) 
Por fim, outra variação da categoria corte-cola esta a consolidação ultrassônica, da Solidica Inc. Esta tecnologia se diferencia dos descritos anteriormente em função do processo de laminação, que é realizado por meio de solda ultrassônica, como pode ser observado na Figura 3.12 (GIBSON et al., 2010).
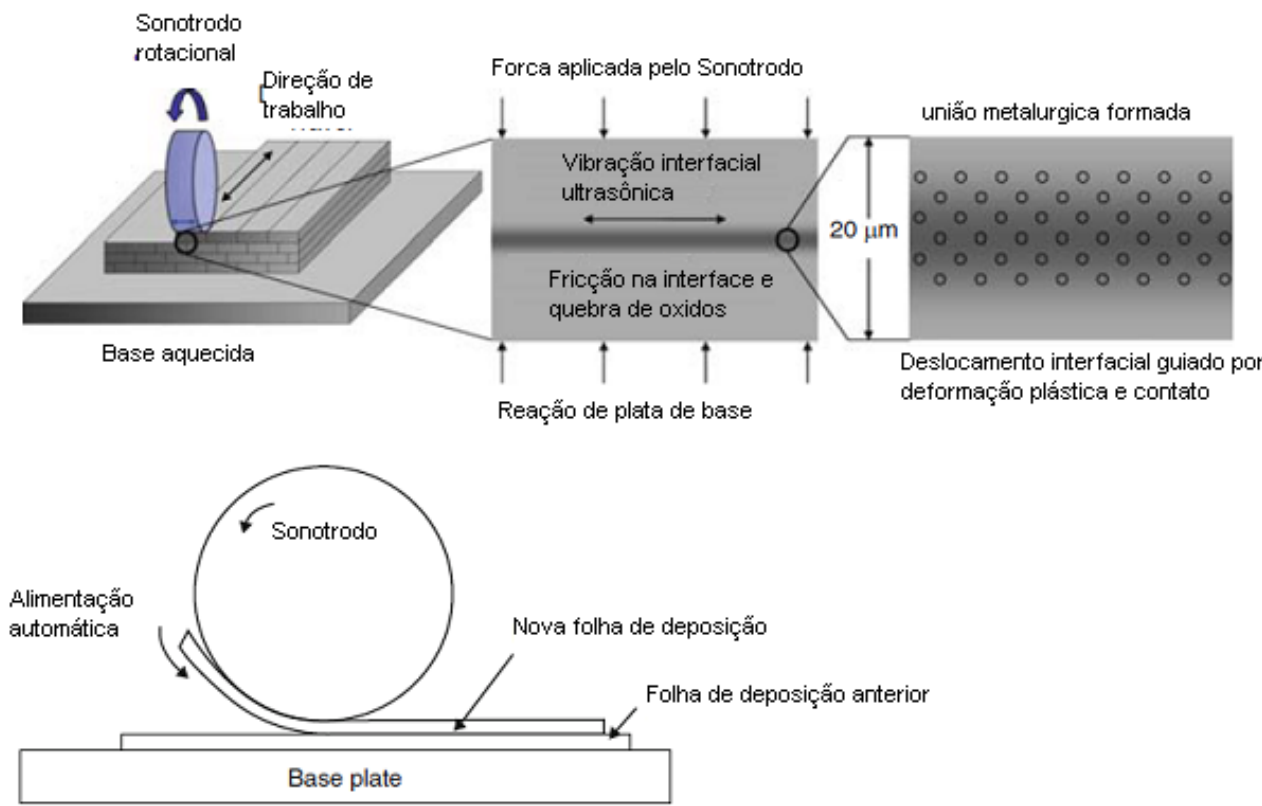

Figura 3.12 - Ilustração esquemática do processos de consolidação ultrassônica (GIBSON et al., 2010)

\subsubsection{Tecnologias a base de Partículas Discretas}

Outra classificação de tecnologias AM tem seu princípio de funcionamento fundamentado em materiais a base de partículas discretas. Entre estes processos estão a Sinterização Seletiva a Laser, e Impressão 3D. 


\section{Sinterização Seletiva a Laser (Selective Laser Sintering - SLS)}

Em relação ao processo de SLS, este teve seu desenvolvimento inicialmente na Universidade do Texas em Austin, Estados Unidos, iniciando sua comercialização em 1990 através da empresa DTM (PRINZ et al., 1997; GIBSON, 2005; GIBSON et al., 2010).

Esta tecnologia consiste na construção de objetos 3D através da sinterização de pó de material. O processo construção das camadas ocorre por meio de fusão do particulado metálico, cerâmico ou polimérico através de laser, que se desloca ao longo dos eixos xy. Após o termino de cada camada, a plataforma de construção se desloca no eixo z permitindo a alimentação de material na nova camada, como pode ser observado na Figura 3.13 (PRINZ et al., 1997; COOPER, 2001; GIBSON, 2005; LIOU, 2007; VOLPATO, 2007; GIBSON et al., 2010).
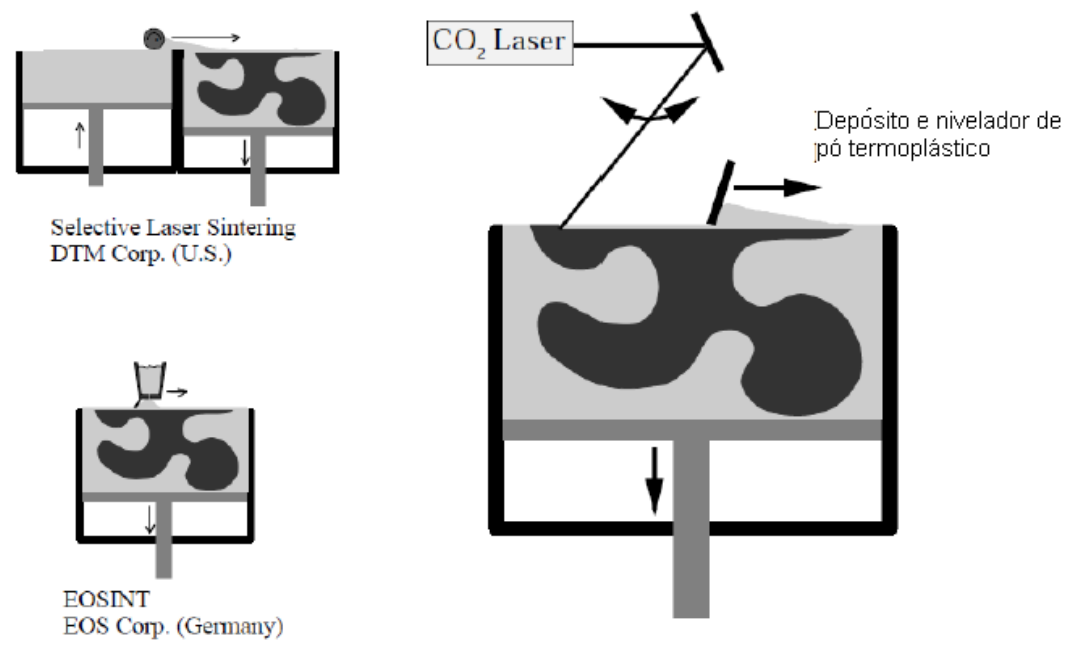

Figura 3.13 - llustração esquemática do processos de Si-nterização Seletiva a Laser (PRINZ et al., 1997)

Estes processos se repetem até o término da peça, que em diversos casos, necessita de um processo de pós-processamento para obtenção de resistência mecânica. Nestes casos, a peça que também é chamada de peça verde (Green Part) é infiltrada por material ligante, em adição à queima de material residual 
(PRINZ et al., 1997; COOPER, 2001; GIBSON, 2005; LIOU, 2007; VOLPATO, 2007; GIBSON et al., 2010).

Além de ser uma das primeiras tecnologias a serem comercializadas, esta tecnologia proporciona a maior variedade de material entre os processos de AM. Contudo, em função da grande quantidade de parâmetros envolvidos, ainda há muita variação nas características finais das peças (PRINZ et al., 1997; COOPER, 2001; MAHESH et al., 2004; GIBSON, 2005; GIBSON et al., 2010).

Adicionalmente, cabe ressaltar que esta tecnologia implica em fabricação de peças porosas, cujo nível de porosidade pode variar entre 50 e $90 \%$ da densidade do objeto final, de acordo com parâmetros de processo e propriedades do material particulado (PRINZ et al., 1997; COOPER, 2001; MAHESH et al., 2004; GIBSON, 2005; GIBSON et al., 2010).

Similarmente, as propriedades mecânicas proporcionadas por esta tecnologia se apresentam bem variadas. Por exemplo, ao analisar a variação da tensão de escoamento pode-se encontrar valores entre 5.5 e 90 MPa (EOS, 2011).

\section{Impresão 3D - (3D Printing - 3DP)}

Outra tecnologia baseada em materiais particulados é a impressão 3D, que é um processo inicialmente desenvolvido pela Universidade Tecnológica de Massachussets (MIT), sendo comercializada pela ZCorporation nos anos 90 (SACHS et al., 1989; GIBSON et al., 2010).

Esta tecnologia se baseia na deposição de uma material colante (blinder) sob camada de pó cerâmico, gerando um aglomerado. Neste processo, apresentado na Figura 3.14, um reservatório contendo pó eleva uma plataforma enquanto um rolo distribui sobre a plataforma de construção da peça. Para a geração de camada, um cabeçote jato de tinta se desloca em $x-y$ imprimindo o material colante sobre a camada de pó. Este processo se repete até a finalização da peça, quanto é utilizado um jato de ar para retirar o pó excedente da peça (SACHS et al., 1989; COOPER, 2001; GIBSON, 2005; LIOU, 2007; VOLPATO, 2007; GIBSON et al., 2010). 


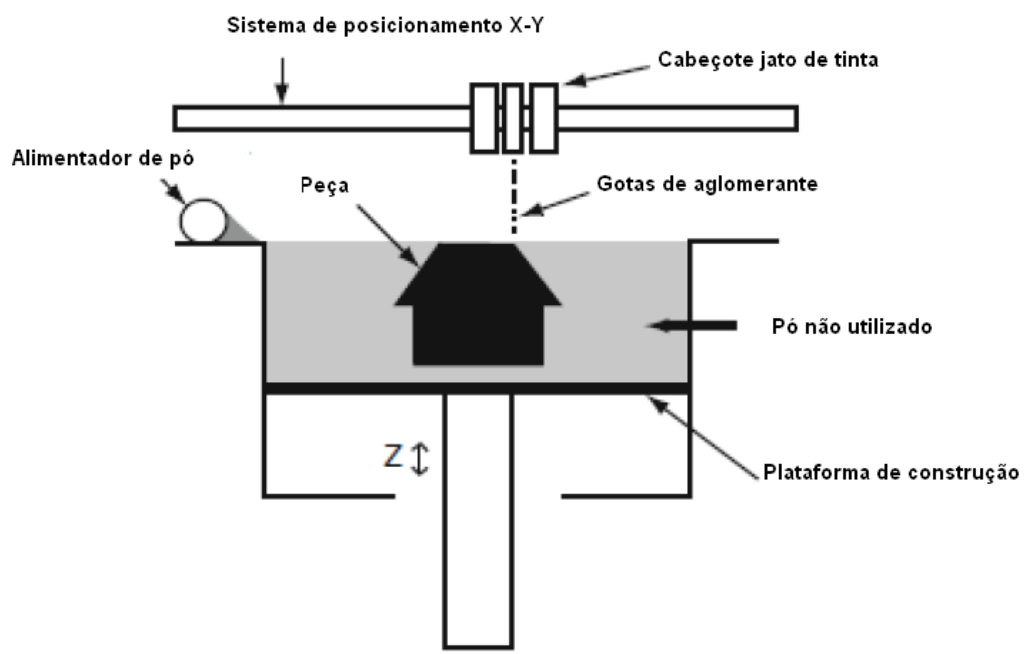

Figura 3.14 - llustração esquemática do processos de impressão 3D (GIBSON et al., 2010)

Em relação à espessura de deposição, esta tecnologia proporciona entre de 0,089 a $0,2 \mathrm{~mm}$, enquanto a resolução se encontra entre $600 \times 540 \mathrm{DPI}$. Adicionalmente, pode-se dizer que esta precisão geral de aproximadamente 0,125mm (GIBSON et al., 2010).

Além da velocidade de fabricação desta tecnologia chegar a 4 camadas por minuto, este processo proporciona a característica peculiar de gerar peças coloridas em até 24 bits de cores (GIBSON et al., 2010).

Adicionalmente, a fim de adquirir resistência mecânica, é realizado um processo de infiltração e, em alguns casos, através de sinterização indireta, podendo implicar em tensões de escoamento na ordem de $400 \mathrm{MPa}$ (EXONE, 2011).

\subsubsection{Comparativo entre tecnologias}

De forma geral, cada processo de fabricação aditiva proporciona características interessantes e singulares. Assim, através da análise comparativa entre estas tecnologias, torna-se possível identificar os principais benefícios e desvantagens enrte cada um destes processos. A Tabela 3.1 apresenta um levantamento das 
principais tecnologias comercializadas na Europa, sendo expostas faixas de custo e resolução.

Tabela 3.1 - Relação de resolução, espessura de camada e faixa de custo de principais tecnologias de fabricação aditiva adaptado de (PHAM e GAULT, 1998; LIOU, 2007; KRUNIĆ et al., 2010)

\begin{tabular}{|l|c|c|c|r|}
\hline Tecnologia & Resolução $(\mathrm{x}-\mathrm{y})$ & Espessura de camada $(\mathrm{z})$ & \multicolumn{2}{|c|}{${ }^{*}$ Custo aproximado } \\
\hline SLA & $\pm 100 \mu \mathrm{m}$ & $50 \mu \mathrm{m}$ & $\mathrm{R} \$ 420.000,00$ & $\mathrm{R} \$ 1.092 .000,00$ \\
\hline FDM & $\pm 127 \mu \mathrm{m}$ & $50-762 \mu \mathrm{m}$ & $\mathrm{R} \$ 33.600,00$ & $\mathrm{R} \$ 224.000,00$ \\
\hline LOM & $\pm 127 \mu \mathrm{m}$ & $76-150 \mu \mathrm{m}$ & $\mathrm{R} \$ 16.800,00$ & $\mathrm{R} \$ 280.000,00$ \\
\hline SLS & $\pm 51 \mu \mathrm{m}$ & $100-150 \mu \mathrm{m}$ & $\mathrm{R} \$ 420.000,00$ & $\mathrm{R} \$ 2.240 .000,00$ \\
\hline 3DP & $\pm 127 \mu \mathrm{m}$ & $250 \mu \mathrm{m}$ & $\mathrm{R} \$ 33.600,00$ & $\mathrm{R} \$ 182.000,00$ \\
\hline Polyjet & $\begin{array}{c}600-1600 \mathrm{dpi} \\
(15-42 \mu \mathrm{m})\end{array}$ & $16-32 \mu \mathrm{m}$ & $\mathrm{R} \$ 70.000,00$ & $\mathrm{R} \$ 700.000,00$ \\
\hline $\begin{array}{l}\text { Envisiontec } \\
\text { DLP }\end{array}$ & $\begin{array}{c}1280 \times 1024 \mathrm{dpi} \\
(19 \times 25 \mu \mathrm{m})\end{array}$ & $15-100 \mu \mathrm{m}$ & $\mathrm{R} \$ 70.000,00$ & $\mathrm{R} \$ 700.000,00$ \\
\hline
\end{tabular}

*Taxa de conversão cambial $-1 €=R \$ 2,80$

Adicionalmente, pode-se observar que apesar da alta resolução, estas tecnologias estão sujeitas a variações de processo, acarretando em distorções dimensionais no produto final. Esta análise pode ser claramente observada na Figura 3.15, onde é apresentado o empenamento de uma peça fabricada por FDM ao final do processo de fabricação (MAHESH, 2004).

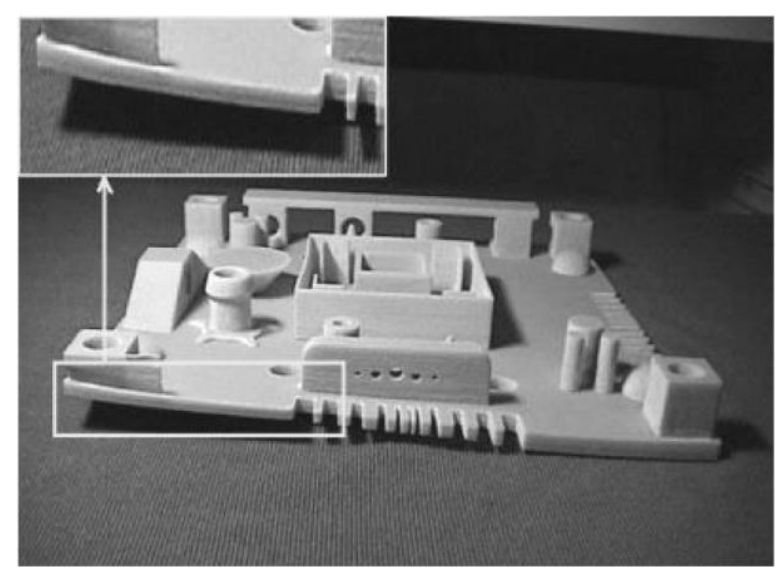

Figura 3.15 -Empenamento de peça fabricada por processo FDM (MAHESH et al., 2004) 
No estudo realizado por (MAHESH, 2004), é possível identificar divergências dimensionais proporcionadas pelos 4 processos AM mais difundidos atualmente. Com objetivo de condensar as principais informações contidas neste estudo, foi elaborado um apanhado dos principais resultados encontrados, sendo adicionalmente realizado um processamento estatístico destes. Na Tabela 3.2, é apresentada esta análise, onde é indicada a estereolitografia como o processo com maior precisão entre os estudados.

Tabela 3.2 - Levantamento estatístico de divergências dimensionais de peças fabricadas pelos 4 principais processos aditivos, baseado em (MAHESH et al., 2004)

\begin{tabular}{|l|r|r|r|r|}
\cline { 2 - 5 } \multicolumn{1}{c|}{} & \multicolumn{4}{c|}{ Processos Aditivos } \\
\hline $\begin{array}{l}\text { Percentual deDivergência } \\
\text { dimensional }\end{array}$ & SLA & \multicolumn{1}{l|}{ SLS } & LOM & FDM \\
\hline Média & $1,33 \%$ & $4,39 \%$ & $5,10 \%$ & $8,88 \%$ \\
\hline Mediana & $5,00 \%$ & $15,00 \%$ & $10,00 \%$ & $12,50 \%$ \\
\hline Máximo & $15,00 \%$ & $25,00 \%$ & $25,00 \%$ & $50,00 \%$ \\
\hline Minimo & $5,00 \%$ & $5,00 \%$ & $5,00 \%$ & $5,00 \%$ \\
\hline Desvio Padrão & $0,93 \%$ & $3,93 \%$ & $5,59 \%$ & $19,93 \%$ \\
\hline
\end{tabular}

\subsection{Substrato a base de celulose}

O material substrato a base de celulose é um produto derivado da polpa madeira, sendo também chamado de papel, no caso de produtos laminados. Sua aplicação tem uma ampla diversidade, variando desde produtos de higiene pessoal a produtos industriais (D'ALMEIDA e PAPEL, 1981; SMOOK, 2002; HOCKING, 2005; KIRWAN, 2005; BRACELPA, 2010).

Entre os produtos derivados da polpa de madeira, destacam-se os laminados, podendo ser divididos conforme seu processo de fabricação e sua aplicação. Com relação à classificação relacionada à fabricação da polpa, destacam-se os processos mecânicos e os químicos. Adicionalmente os processos Kraft (processo a base de sulfato) e os sulfites são os principais processos quimicos utilizados atualmente 
(D'ALMEIDA e PAPEL, 1981; SMOOK, 2002; HOCKING, 2005; KIRWAN, 2005; BRACELPA, 2010).

Com relação a estes processos, a Figura 3.16 e Figura 3.17apresentam um esquemático apresentando as principais etapas de cada um destes tipos de processo.

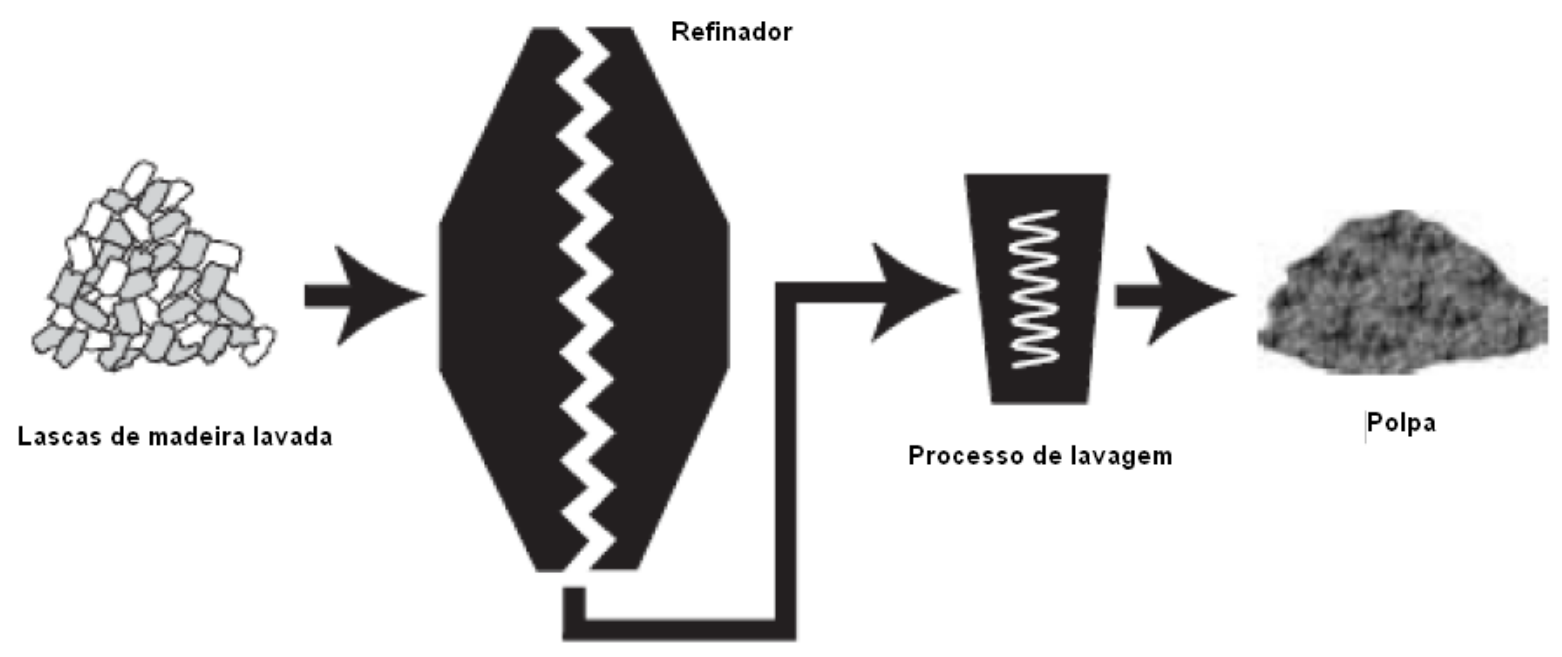

Figura 3.16 - Representação esquemática de geração de polpa de papel por processo mecânico (polpa mecânica) (KIRWAN, 2005) 


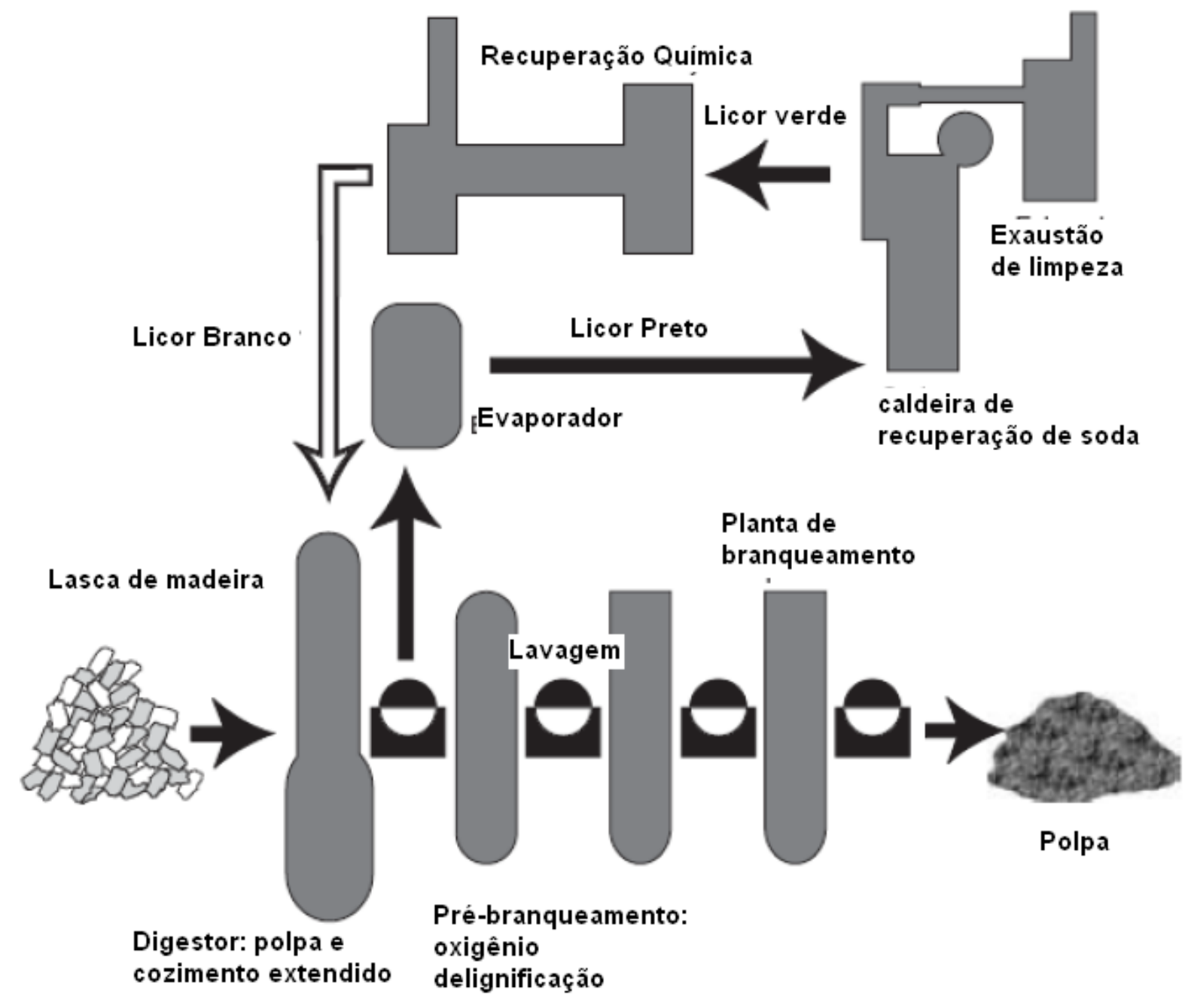

Figura 3.17 - Representação esquemática de geração de polpa de papel por processo Quimico (polpa Química) (KIRWAN, 2005)

Com relação aos produtos gerados por processo mecânico, são encontrados valores de densidade baixa e fibras longas. Este processo também proporciona baixos valores de resistência mecânica, devido à baixa aderência entre fibras (D'ALMEIDA e PAPEL, 1981; SMOOK, 2002; HOCKING, 2005; KIRWAN, 2005; BRACELPA, 2010).

Em contrapartida, os processos químicos proporcionam valores de densidade maiores e fibras longas. Em adição, são encontrados valores de resistência mecânica superiores aos do processo mecânico, devido ao alto grau de aderência entre fibras. Apesar disto, estes processos necessitam realizar o 
branqueamento (bleeching) da polpa, visto que resíduos de madeira e lignina proporcionam à polpa um aspecto amarelado. Normalmente, em conjunto com este processo, são introduzidos elementos que proporcionam características especiais, como redução da absorção do papel e proteção contra luz UV (D'ALMEIDA e PAPEL, 1981; SMOOK, 2002; HOCKING, 2005; KIRWAN, 2005; BRACELPA, 2010).

Esta diferença proporcionada por processos mecânicos e quimicos pode ser facilmente evidenciada na Figura 3.18. Nesta figura são apresentadas imagens micrograficas (magnitude de 400x) de ruptura de papel sulfite, fabricado por processo químico, e papel higiênico popular, fabricado por processo mecânico. Através dessas imagens, são evidenciados os comprimentos das fibras, assim como o espaçamento entre estas. Adicionalmente, pode-se observar a maior densidade e opacidade do papel sulfice em comparação ao higiênico popular.

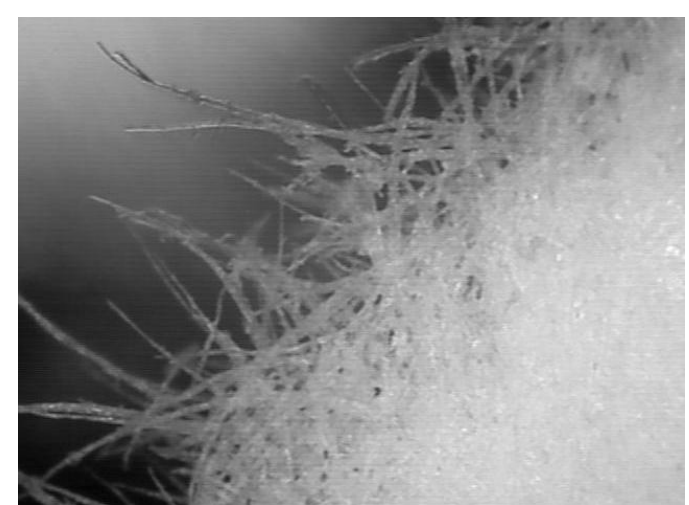

a)

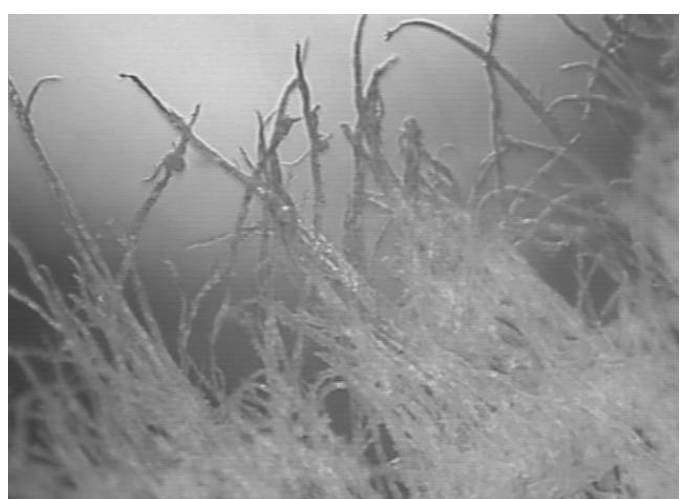

b)

Figura 3.18 -Imagem micrografica (400x) de ruptura de papel sulfite (a), fabricado por processo quimico e papel higiênico popular (b), fabricado por processo mecânico

Entre as principais propriedades encontradas em papéis, podem ser listadas: gramatura, espessura, acabamento superficial, coloração, reflexibilidade, opacidade, printabilidade, absorção, resistência mecânica à tração, elongamento, resistência à rasgo, resistência a estouro, rigidez, resistência a compreção e resistência à queima (D'ALMEIDA e PAPEL, 1981; SMOOK, 2002; HOCKING, 2005; KIRWAN, 2005; BRACELPA, 2010). 
Pode ser observado na Tabela 3.3, Tabela 3.4 e Tabela 3.5, os principais tipos de papel, assim como suas classificações, principais características e aplicações. Entre estes podem ser destacados os papéis para impressão, papéis para escrever e os papéis de embrulho leves, visto que estes são os mais comuns e de fácil aquisição (BRACELPA, 2010).

Tabela 3.3 - Relação dos principais tipos de papel e suas principais características e aplicações

\begin{tabular}{|c|c|c|}
\hline Classe & Tipo & Características \\
\hline \multirow{8}{*}{ 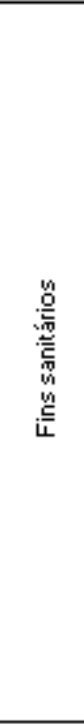 } & Higiênico popular & $\begin{array}{l}\text { Papel fabricado com pasta mecânica ełou aparas, em folha única, natural ou em } \\
\text { cores com gramatura ao redor de } 35 \mathrm{glm} 2 \text {. }\end{array}$ \\
\hline & Higiênico folha simples de boa qualidade & $\begin{array}{l}\text { Papel fabricado com celulose química ełou PAR não branqueada efou pasta } \\
\text { mecânica ełou aparas de boa qualidade - tratadas quimicamente, em folha única, } \\
\text { semibranco ou em cores, nas gramaturas de } 25 \text { a } 30 \mathrm{~g} / \mathrm{m} 2 \text {. }\end{array}$ \\
\hline & Higiênico folha simples de alta qualidade & $\begin{array}{l}\text { Papel fabricado com celulose química branqueada ełou PAR branqueada aparas de } \\
\text { boa qualidade - tratadas quimicamente, macio, em folha única, branco ou em cores, } \\
\text { nas gramaturas de } 25 \text { a } 28 \mathrm{~g} / m 2 \text {. }\end{array}$ \\
\hline & Higiênnico folha dupla de alta qualidade & $\begin{array}{l}\text { Papel fabricado com celulose química branqueada efou PAR branqueada, incluindo } \\
\text { ou nẫo aparas de boa qualidade tratadas quimicamente, macio, nas gramaturas de } 16 \\
\text { a } 18 \mathrm{glm} 2 \text {, para uso em folha dupla, branco ou em cores. }\end{array}$ \\
\hline & Toalha de cosinha e de mão & $\begin{array}{l}\text { Papel fabricado para fim específico, natural ou em cores, nas gramaturas entre } 25 \text { e } \\
50 \mathrm{glm} 2 \text {. Usado em folha única ou dupla }\end{array}$ \\
\hline & Guardanapo & $\begin{array}{l}\text { Papel crepado ou não, fabricado com pasta química branqueada, incluindo ou nẫo } \\
\text { aparas de boa qualidade tratadas quimicamente, para fim específico, nas gramaturas } \\
\text { de } 18 \text { a } 25 \text { gim2, para uso em folha única ou dupla, branco ou em cores. }\end{array}$ \\
\hline & Lenço & $\begin{array}{l}\text { Papel fabricado com pasta química branqueada, incluindo ou não aparas de boa } \\
\text { qualidade tratadas quimicamente, nas gramaturas de } 15 \text { a } 18 \mathrm{glm} 2 \text {, para uso em folhas } \\
\text { múltiplas na confeção de lenços faciais e de bolso, branco ou em cores. }\end{array}$ \\
\hline & Lençol hospitalar & $\begin{array}{l}\text { Papel fabricado com pasta química branqueada, incluindo ou não aparas de boa } \\
\text { qualidade tratadas quimicamente, nas gramaturas de } 15 \text { a } 30 \mathrm{grm} 2 \text {, para uso } \\
\text { específico. }\end{array}$ \\
\hline \multirow{6}{*}{ 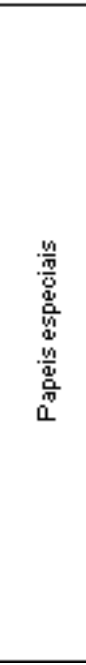 } & Base para carbono & $\begin{array}{l}\text { Papel para fim específico, fabricado com pasta química, geralmente com gramaturas } \\
\text { até } 24 \mathrm{~g}+\mathrm{m} 2 \text {, branco ou em cores. Usado como base para fabricação de papel } \\
\text { carbono. }\end{array}$ \\
\hline & cigarros e afins & $\begin{array}{l}\text { Papel para fim específico, fabricado com pasta química branqueada, de fibras têxteis } \\
\text { ełou madeira, geralmente contendo carga mineral até } 26 \% \text {, nas gramaturas de } 13 \text { a } 25 \\
\text { głm2, nấo colado, de alta opacidade, com marca d'água, "velin" ou marca filigrana, } \\
\text { com combustibilidade controlada, com ou sem impregnantes. Usado em bobinas } \\
\text { para confeção mecânica de cigarros ou em resmas e mortalhas, quando para } \\
\text { confecção manual. }\end{array}$ \\
\hline & crepado & $\begin{array}{l}\text { Papel para fins específicos, com crepagem obtida durante a fabricaçẫo para } \\
\text { aumentar sua elasticidade e maciez, fabricado essencialmente com pasta química. } \\
\text { Usado para reforço de costura em sacos multifolhados, base para fitas adesivas, } \\
\text { germinação de sementes, base para lençóis plásticos, etc. }\end{array}$ \\
\hline & desenho & $\begin{array}{l}\text { Papel para fim específico, fabricado com pasta química, geralmente nas gramaturas } \\
\text { de } 100 \text { a } 280 \text { glm2, com acabamento de máquina e tratado na massa ou na superfície, } \\
\text { de modo a resistir a açâo da borracha. }\end{array}$ \\
\hline & heliografico & $\begin{array}{l}\text { Papel para fim específico, fabricado com pasta química branqueada, com baixo teor } \\
\text { de ferro, com absorção uniforme, nas gramaturas de } 40 \text { a } 120 \mathrm{glm} 2 \text {, bem colado, } \\
\text { alisado, branco ou levemente colorido. }\end{array}$ \\
\hline & absorvente e filtrante & $\begin{array}{l}\text { Papel fabricado geralmente com pasta química, nas gramaturas de } 80 \text { a } 400 \mathrm{~g} / \mathrm{m} 2 \text {, } \\
\text { com características definidas quanto ao uso. }\end{array}$ \\
\hline
\end{tabular}




\section{Tabela 3.4 - Relação dos principais tipos de papel e suas principais características e aplicações (cont. I)}

\begin{tabular}{|c|c|c|}
\hline Classe & Tipo & Características \\
\hline \multirow{7}{*}{ 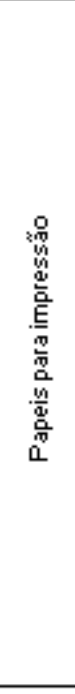 } & Bíblia & $\begin{array}{l}\text { Papel fabricado com pasta química branqueada, gramatura máxima de } 50 \mathrm{~g} / \mathrm{m} 2 \text {, com } \\
\text { alto teor de carga mineral e elevada opacidade. Usado para impressão de bíbliase } \\
\text { similares, podendo conter ou nẫo linhas d'água. }\end{array}$ \\
\hline & Bouffant & $\begin{array}{l}\text { Papel fabricado essencialmente com pasta química branqueada, não colado, com } \\
\text { alta carga mineral (mais de } 10 \% \text { ), bem encorpado e absorvente. Usado para } \\
\text { impressâo de livros, serviços tipográficos e cópias mimeográficas, podendo ter ou } \\
\text { nấo linhas d'água. }\end{array}$ \\
\hline & Couché & $\begin{array}{l}\text { Papel de impressẫo, que possui o máximo das qualidades necessárias para a } \\
\text { reprodução perfeita de "clichés", resultante do seu revestimento com cargas } \\
\text { minerais em uma ou duas faces. }\end{array}$ \\
\hline & Imprensa & $\begin{array}{l}\text { Papel de impressẫo de jornais e periódicos, fabricado principalmente com pasta } \\
\text { mecânica ou mecanoquímica, com } 45 \text { a } 56 \mathrm{~g} \text { 'm } 2 \text {, com ou sem linhas d'água no } \\
\text { padrấo fiscal, com ou sem colagem superficial. }\end{array}$ \\
\hline & Jornal & $\begin{array}{l}\text { Papel de impressẫo, similar ao "Imprensa", porém, sem limitação de gramatura, } \\
\text { alisado ou monolúcido. Usado para impressos comerciais, blocos de rascunho etc. }\end{array}$ \\
\hline & Monolúcido & $\begin{array}{l}\text { Papel fabricado essencialmente com pasta química branqueada ou mecânica, com } \\
\text { brilho em uma das faces. Usado para rótulos, cartazes, sacolas, embalagens e papéis } \\
\text { fantasia. }\end{array}$ \\
\hline & Offset & $\begin{array}{l}\text { Papel de impressấ, fabricado essencialmente com pasta química branqueada com } \\
\text { elevada resistência da superfície. Usado geralmente para impressâo em "Offset". }\end{array}$ \\
\hline \multirow{3}{*}{ 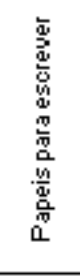 } & $\begin{array}{l}\text { Apergaminhado com marca (bond com } \\
\text { marca) }\end{array}$ & $\begin{array}{l}\text { Papel fabricado essencialmente com pasta química branqueada, com marca d'água, } \\
\text { alisado, colado e com boa opacidade. Usado geralmente para correspondência. }\end{array}$ \\
\hline & apergaminhado(bond) & $\begin{array}{l}\text { Papel fabricado essencialmente com pasta química branqueada, alisado, colado e } \\
\text { com boa opacidade. Usado para correspondência em geral, formulários, impressos, } \\
\text { cadernos escolares e envelopes. }\end{array}$ \\
\hline & 2as vias ["flor post"] & $\begin{array}{l}\text { Papel fabricado essencialmente com pasta química branqueada, geralmente com } \\
\text { gramatura até } 32 \mathrm{~g} \mathbf{m} 2 \text {, branco ou em cores. Usado geralmente para segundas-vias } \\
\text { em correspondência ou formulários impressos. }\end{array}$ \\
\hline \multirow{11}{*}{ 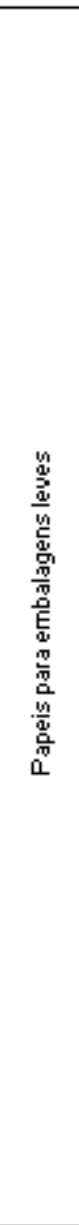 } & Estiva e maculatura & $\begin{array}{l}\text { Papel fabricado essencialmente com aparas, em cor natural, acinzentada, geralmente } \\
\text { nas gramaturas de } 70 \text { a } 120 \text { glm2. Usado para embrulhos que não requerem } \\
\text { apresentação, podendo atingir até } 400 \text { głm } 2 \text { para tubetes e conicais. }\end{array}$ \\
\hline & Manilhinha (padaria) & $\begin{array}{l}\text { Papel fabricado com aparas, pasta mecânica ou semiquímica, em geral nas } \\
\text { gramaturas de } 40 \text { a } 45 \text { głm } 2 \text {, monolúcido ou não, geralmente na cor natural e em } \\
\text { follhas dobradas. Usado essencialmente nas padarias. }\end{array}$ \\
\hline & Manilhinha -HD & $\begin{array}{l}\text { Papéis fabricados com aparas, pasta mecânica edou semiquímica, em geral nas } \\
\text { gramaturas de } 40 \text { a } 100 \mathrm{~g} \mathrm{tm} 2 \text {, monolúcidos em cores características ou cor natural. } \\
\text { Usado para embrulhos nas lojas, indústrias e congêneres }\end{array}$ \\
\hline & Tecido & $\begin{array}{l}\text { Papel de embalagem, fabricado com pasta química e pasta mecânica ou aparas } \\
\text { limpas, nas gramaturas de } 70 \text { a } 120 \text { grm } 2 \text {, com boa resistência mecânica e geralmente } \\
\text { nas cores creme, bege e azul. Usado essencialmente para embrulho de tecidos e na } \\
\text { fabricacão de envelopes. }\end{array}$ \\
\hline & Fósforo & $\begin{array}{l}\text { Papel de embalagem, essencialmente fabricado com pasta química, com } 40 \mathrm{glm} 2 \text {, } \\
\text { monolúcido ou não, na cor azul característica. Usado essencialmente para forrar } \\
\text { cainas de fósforos. }\end{array}$ \\
\hline & Strong & $\begin{array}{l}\text { Papel de embalagem, fabricado com pasta química ou mecânica geralmente sulfito } \\
\text { etou aparas de cartốes perfurados, com } 40 \text { a } 80 \text { glm2, geralmente monolúcido, } \\
\text { branco ou em cores claras. Usado essencialmente para a fabricação de sacos de } \\
\text { pequeno porte, forro de sacos e para embrulhos. }\end{array}$ \\
\hline & Seda & $\begin{array}{l}\text { Papel de embalagem, fabricado com pasta química branqueada ou nâo, com } 20 \text { a } 27 \\
\text { grm2, branco ou em cores. Usado para embalagens leves, embrulhos de objetos } \\
\text { artísticos, intercalaçâo, enfeites, proteção de frutas, etc. }\end{array}$ \\
\hline & Glassine, pergaminho, cristal & $\begin{array}{l}\text { Papel fabricado com pasta química branqueada, trabalhada com elevado grau de } \\
\text { refinação, para que em conjunto com a supercalandragem obtenha sua } \\
\text { característica típica, que é a transparência. Quando tornado opaco com cargas } \\
\text { minerais, adquire aspecto leitoso translúcido. Fabricado geralmente a partir de } 30 \\
\text { głm2 e com impermeabilidade elevada. Usado essencialmente para embalagens de } \\
\text { alimentos, base de papel auto-adesivo, proteção de frutas nas árvores, etc. }\end{array}$ \\
\hline & Giranado & $\begin{array}{l}\text { Papel similar ao "Glassine, Cristal ou Pergaminho", porém com menor transparência } \\
\text { e impermeabilidade que estes, devido à presença de outras pastas. Fabricado } \\
\text { também em cores. }\end{array}$ \\
\hline & Greaseproof & $\begin{array}{l}\text { Papel de elevadíssima impermeabilidade às gorduras, fabricado com pasta química } \\
\text { branqueada, geralmente nas gramaturas de } 30 \text { a } 80 \text { grm2. Translúcido, sem super- } \\
\text { calandragem e de coloraçâo branca ou ligeiramente amarelada. Usado } \\
\text { essencialmente para embalagens de substâncias gordurosas. }\end{array}$ \\
\hline & Fosco & $\begin{array}{l}\text { Papel de baixa impermeabilidade, fabricado com pasta química, geralmente a partir de } \\
40 \text { glm } 2 \text {, translúcido, sem supercalandragem, de coloração natural. Usado para } \\
\text { desenho, embalagem descartável para alimentos, etc. }\end{array}$ \\
\hline
\end{tabular}


Tabela 3.5 - Relação dos principais tipos de papel e suas principais características e aplicações (cont. II)

\begin{tabular}{|c|c|c|}
\hline Classe & | Tipo & Características \\
\hline \multirow{10}{*}{ 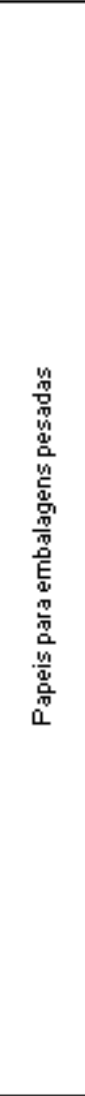 } & Kraft Natural para sacos multifolhados & $\begin{array}{l}\text { Papel fabricado com pasta química sulfato nẫo-branqueada, essencialmente de fibra } \\
\text { longa, geralmente nas gramaturas de } 80 \text { a } 90 \mathrm{gtm} 2 \text {. Altamente resistente ao rasgo e } \\
\text { com boa resistência ao estouro. Usado essencialmente para sacos e embalagens } \\
\text { industriais de grande porte. }\end{array}$ \\
\hline & Kraft Extensível & $\begin{array}{l}\text { Fabricado com pasta química sulfato ou soda não branqueada, essencialmente de } \\
\text { fibra longa, geralmente nas gramaturas de } 80 \text { a } 100 \mathrm{glm} 2 \text {. Altamente resistente ao } \\
\text { rasgo e a energia absorvida na tração. Possui alongamento no sentido longitudinal } \\
\text { maior ou igual a } 8 \% \text { Usado para embalagem de sacos de papel. }\end{array}$ \\
\hline & $\begin{array}{l}\text { Kraft natural ou em cores para outros } \\
\text { fins }\end{array}$ & $\begin{array}{l}\text { Fabricado com pasta química sulfato, nâo-branqueada, essencialmente de fibra } \\
\text { longa, geralmente com } 30 \text { a } 150 \text { głm } 2 \text {, monolúcido ou alisado, com características de } \\
\text { resistência mecânica similar ao "Kraft Natural para Sacos Multifolhados". Usado } \\
\text { para a fabricacẫo de sacos de pequeno porte, sacolas e para embalagens em geral }\end{array}$ \\
\hline & Kraft branco ou em cores & $\begin{array}{l}\text { Fabricado com pasta química sulfato branqueada, essencialmente de fibra longa, } \\
\text { geralmente com } 30 \text { a } 150 \text { glm2, monolúcido ou alisado. Usado como folha externa } \\
\text { em sacos multifolhados, sacos de açúcar e farinha, sacolas e, nas gramaturas mais } \\
\text { baixas, para embalagens individuais de balas etc. }\end{array}$ \\
\hline & Tipo Kraft de 1a & $\begin{array}{l}\text { Papel de embalagem, semelhante ao "Kraft Natural ou em Cores", porém com } \\
\text { menor resistência mecânica que este, fabricado com pelo menos } 50 \% \text { de pasta } \\
\text { química, geralmente com mais de } 40 \mathrm{~g} \mathrm{tm} 2 \text {, monolúcido ou não. Usado geralmente } \\
\text { para saquinhos etc. }\end{array}$ \\
\hline & Tipo Kraft de 2a & $\begin{array}{l}\text { Papel semelhante ao "Tipo Kraft de 1a.", porém com resistência mecânica inferior, } \\
\text { geralmente com mais de } 40 \text { grm2, monolúcido ou nấo. Usado para embrulhos e } \\
\text { embalagens em geral. }\end{array}$ \\
\hline & Miolo (fluting) & $\begin{array}{l}\text { Papel fabricado com pasta semiquímica elou mecânica elou aparas, geralmente } \\
\text { com } 120 \text { a } 150 \mathrm{glm} 2 \text {. Usado para ser ondulado na fabricação de papelấo ondulado. }\end{array}$ \\
\hline & Capa de 1a (kraftliner) & $\begin{array}{l}\text { Papel fabricado com grande participaçấo de fibras virgens, geralmente com } 120 \mathrm{~g} / \mathrm{m} 2 \\
\text { ou mais, atendendo as especificaçốes de resistência mecânica requeridas para } \\
\text { constituir a capa ou forro das cainas de papelấo ondulado }\end{array}$ \\
\hline & Capa de 2a & $\begin{array}{l}\text { Papel semelhante ao "Capa de 1a.", porém com propriedades mecânicas inferiores, } \\
\text { consequentes da utilização de matérias-primas recicladas em alta proporçăo. }\end{array}$ \\
\hline & White Top Liner & $\begin{array}{l}\text { Papel fabricado com grande participação de fibras virgens, geralmente com } 150 \text { a } 385 \\
\text { grm2, atendendo as especificaçốes de resistência mecânica requeridas para } \\
\text { constituir parte das cainas de papelấo ondulado. }\end{array}$ \\
\hline \multirow{5}{*}{ 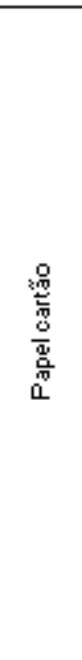 } & Papel Cartão & $\begin{array}{l}\text { O papelcartão é um produto resultante da uniẫo de várias camadas de papel e } \\
\text { sobrepostas, iguais ou distintas, que se adere por compressão. Nessas camadas } \\
\text { pode ser utilizada celulose virgem (recursos renováveis) e materiais celulósicos } \\
\text { recicláveis. Independente do tipo, o papelcartão é fabricado na faixa de gramatura de } \\
200 \text { a } 500 \text { grm2, com ou sem revestimento superficial. }\end{array}$ \\
\hline & Cartolina para copos & $\begin{array}{l}\text { Produzida por massa única (mono camada) com ou sem revestimento superficial, } \\
\text { pode apresentar-se em várias cores. Rigidez controlada, resistente a recravagem, } \\
\text { com alta colagem, fabricado com pasta química branqueada, nas gramaturas de } 150 \\
\text { a } 270 \text { głm2, para confecção de copos (fundo e corpo) }\end{array}$ \\
\hline & Cartolina branca para impressos & $\begin{array}{l}\text { Cartolina fabricada essencialmente com pasta química branqueada, em uma só } \\
\text { massa e uma só camada, com ou sem tratamento superficial, alisado ou super } \\
\text { calandrado, com gramaturas de } 120 \text { a } 290 \mathrm{glm} 2 \text {, usado para impressos, pastas para } \\
\text { arquivos, cartốes de visita e comerciais, confeccão de fichas e similares. }\end{array}$ \\
\hline & Papelấo laminado & $\begin{array}{l}\text { Papelấo fabricado essencialmente de aparas, obtido por colagem de folhas } \\
\text { sobrepostas, não revestidos na superfície, gramaturas de } 349 \text { a } 1749 \mathrm{glm} 2 \text {, em } \\
\text { folhas. }\end{array}$ \\
\hline & Polpa moldada & $\begin{array}{l}\text { Produto obtido a partir da desagregação ou separação das fibras de aparas de jornal } \\
\text { e outras em geral, que misturadas a água e produtos químicos, formam uma massa } \\
\text { natural ou em cores, que dará origem a produtos como: bandejas para } \\
\text { acondicionamento, transporte e proteção de hortifrutigranjeiros, calços para } \\
\text { lâmpadas, celulares, geladeiras e fogôes. }\end{array}$ \\
\hline
\end{tabular}

Adicionalmente, cabe ressaltar que entre estes, o tipo de papel que apresenta menor faixa de gramatura é o tipo seda, que consequentemente apresenta menor espessura. Como este papel é fabricado por processo químico, sendo ou não 
realizado branqueamento, é pertinente salientar que para aplicações onde são necessários valores de opacidade e absorção de UV baixos, não se deve optar por processos de branqueamento. Além disto, o processo de branqueamento reduz a taxa de absorção do papel, em função da carga de aditivos inseridos à pasta ao longo deste processo (D'ALMEIDA e PAPEL, 1981; SMOOK, 2002; HOCKING, 2005; KIRWAN, 2005; BRACELPA, 2010).

\subsection{Material Fotopolimérico}

Com referência ao desenvolvimento de materiais, foi optado por utilizar material fotopolimérico no estado líquido. Desta forma, foram levantadas informações sobre o estado da arte esta tecnologia, como compostos químicos, propriedades físicoquímicas, fornecimento, e processos constitutivos.

Assim como outros polímeros do tipo aditivo, os materiais fotopoliméricos são macromoléculas formadas pela adição de moléculas menores através de ligações intermoleculares. Adicionalmente, os processos relacionados a estas ligações são iniciadas ou induzidas pela ação de luz visível ou radiação (JONSSON et al., 1996; CALLISTER, 2003; ODIAN, 2004; DROBNY, 2010).

Entre os principais tipos de sistemas fotopoliméricos ou fotoinduzidos, destacam-se: polimerização radicalar; polimerização iônica e polimerização por abertura de anéis. Contudo, cada um destes sistemas é constituido normalmente por monômeros; oligômeros; iniciadores e aditivos, sendo em alguns casos utilizados sensibilizadores ou co-iniciadores (RODRIGUES e NEUMANN, 2003; SARTOMER, 2004; DROBNY, 2010).

\subsubsection{Componentes e formulação}

Com relação à formulação dos materiais fotopoliméricos, a variação do teor de seus compostos afeta diretamente a propriedades físicas, químicas e mecânicas do material. Contudo, para aplicações relacionadas a tintas, são utilizados 
normalmente: 15 a 60\% no peso de monômero; 25 a 90\% no peso de oligômero; 1 a $15 \%$ no peso de fotoiniciador; 1 a $3 \%$ no peso de co-iniciador e 1 a $50 \%$ no peso de aditivos (RODRIGUES e NEUMANN, 2003; SARTOMER, 2004).

\section{Monômeros}

Os monômeros são os compostos básicos da formulação de polímeros, visto que são caracterizados por serem as moléculas elementares (meros) que se ligam a fim de formar uma macromolécula (BRANDRUP et al., 1999; CALLISTER, 2003; ODIAN, 2004; SPERLING, 2006).

No que se refere à forma que estas ligações acontecem (polimerização), cada tipo de monômero apresenta um ou mais tipos de mecanismos. Por exemplo, no caso do metacrilato de metila (MMA), a polimerização pode ocorrer de forma radicalar de adição ou iônica de adição, sendo ambas detalhadas ao longo desta seção (ANDREAJEWSKA, 2001; FOUASSIER, J. P. et al., 2003; ODIAN, 2004; KRICHELDORF et al., 2005).

Uma forma de identificação da capacidade de um monômero polimerizar por ação de luz (fotopolimerizar) é através dos grupos funcionais presentes na molécula, como por exemplo, duplas ligações entre atomos de carbono e anéis epóxi. Entre estes grupos, ressaltam-se os acrilatos e epoxes, sendo os mais empregados em tecnologias AM a base de materiais líquidos (JACOBS et al., 1992; BARTON e FULTON, 2000; ODIAN, 2004; DROBNY, 2010; GIBSON et al., 2010).

\section{Oligômeros}

Em contrapartida, os oligômeros são compostos viscosos cujo grau de polimerização se encontra num nível intermediário, entre monômeros e polímeros. Em outras palavras, os oligômeros podem ser caracterizados através do numero de moléculas elementares (meros) presentes em sua cadeia molecular, variando entre 2 e 20 meros. Todavia, pode-se também classificar os oligômeros por meio de seu 
peso molecular, tendo seu limite em $8000 \mathrm{~g} / \mathrm{mol}$ (SARTOMER, 1998; JASTY, 1999; CALLISTER, 2003; SARTOMER, 2004).

Em função do comprimento de cadeia apresentado por oligômeros, são encontrados, muitas vezes, oligômeros que apresentam mais de um grupo funcional ao longo de suas cadeias. Isto possibilita o aumento da velocidade de polimerização, assim como a ramificação (branching) e a interligação entre cadeias poliméricas (crosslinking), visto que a direção de crescimento da cadeia molecular acontece em mais de uma direção (ANDRZEJEWSKA, 2001; DECKER, C et al., 2001; ODIAN, 2004; DROBNY, 2010).

Um exemplo deste processo é ilustrado na Figura 3.19,

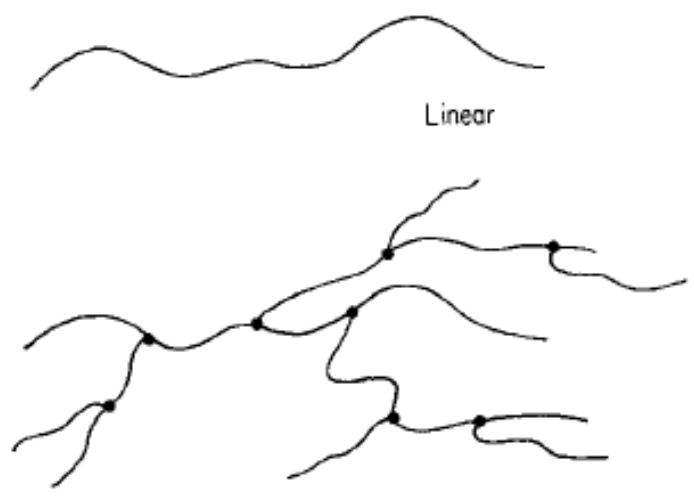

Ramificação

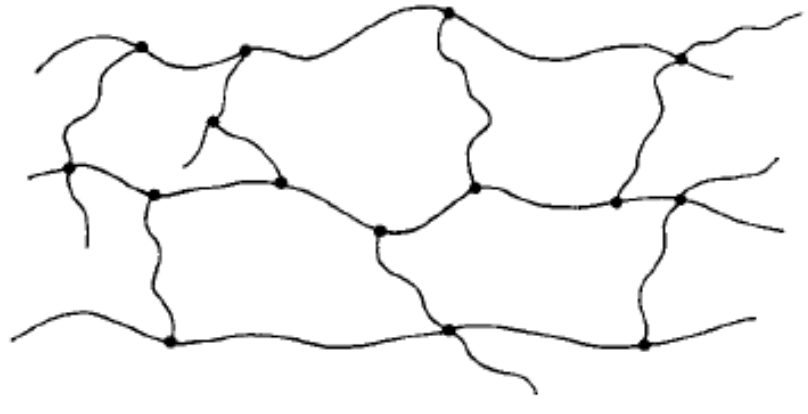

Interligação (crosslinking)

Figura 3.19 - Ilustração esquemática dos processos de ramificação (Branching) e interligação das cadeias polimericas (crosslinking) (ODIAN, 2004)

\section{Iniciadores e co-iniciadores}

Outro componente encontrado em sistemas de fotopolimerização são os fotoiniciadores, cuja função principal é de iniciar o processo polimerização. Estes componentes podem ser classificados conforme o mecanismo de polimerização que é induzido pelo mesmo. Contudo, destacam-se os fotopolimerizadores radicalares do tipo I, do tipo II; e os fotopolimerizadores iônicos. (JASTY, 1999; MATYJASZEWSKI 
e DAVIS, 2002; YURTERI, SEDA et al., 2002; CIBA, 2003; RODRIGUES e NEUMANN, 2003; ODIAN, 2004; KRICHELDORF et al., 2005).

Enquanto o fotopolimerizador radicalar do tipo I gera radicais livres através de fotofragmentação direta de moléculas (Figura 3.20), o fotoiniciador do tipo II realiza reações bimoleculares. Neste caso, faz-se necessário a inclusão de outro componente no sistema, o co-iniciador ou também chamado fotosensibilizador (JASTY, 1999; MATYJASZEWSKI e DAVIS, 2002; YURTERI, SEDA et al., 2002; CIBA, 2003; RODRIGUES e NEUMANN, 2003; ODIAN, 2004; KRICHELDORF et al., 2005).

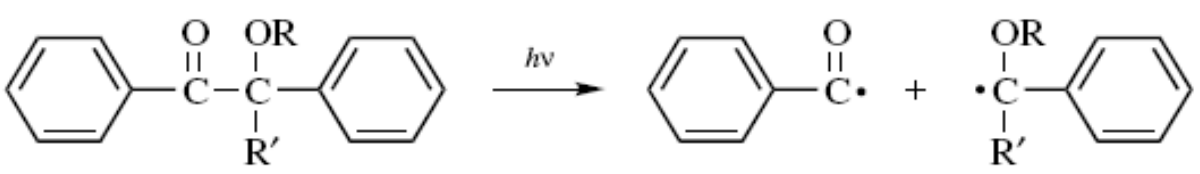

Figura 3.20 - Representação de geração de fotofragmentação (MATYJASZEWSKI e DAVIS, 2002)

Adicionalmente, é apresentada, na Figura 3.21, uma representação do processo de geração de radicais livres a partir de fotoiniciadores radicalares do tipo II. No exemplo apresentado, o fotoiniciador (Benzofenona) em conjunto com um sensibilizador a base de amina é exposto à radiação UV, onde o co-iniciador abstrai um átomo de hidrogênio do iniciador. Por meio desta abstração, é formado um radical livre a partir do fotoiniciador (ANDRZEJEWSKA, 2001; MATYJASZEWSKI e DAVIS, 2002; ODIAN, 2004; DROBNY, 2010). 


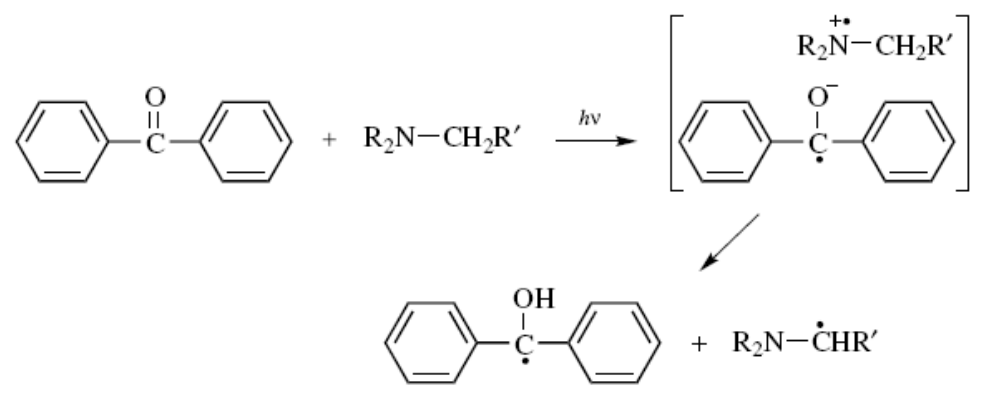

Figura 3.21 - Representação de processo de geração de radicais livres a partir de fotoiniciador radicalar do tipo II (MATYJASZEWSKI e DAVIS, 2002)

Além dos fotoiniciadores radicalares, outro tipo de iniciador que se destaca é fotopolimerizador iônico. Assemelhando-se ao fotopolimerizador radicalar do tipo II, este iniciador também realiza reações bimoleculares. Contudo, a exposição à radiação UV induz a geração de íons, em vez de radicais livres. Neste caso, este tipo de iniciador ainda pode ser dividido conforme o tipo de íon gerado na reação, podendo, assim, ser classificado como fotoiniciador catiônico ou aniônico. (ANDRZEJEWSKA, 2001; MATYJASZEWSKI e DAVIS, 2002; ODIAN, 2004; DROBNY, 2010).

Por outro lado, estes tipos de iniciadores promovem o aumento da cadeia polimérica através da transferência de um elétron doador, implicando em velocidades altas de polimerização. Em contrapartida, o controle deste processo se torna muito dificil e de baixa repetibilidade (ANDRZEJEWSKA, 2001; MATYJASZEWSKI e DAVIS, 2002; ODIAN, 2004; DROBNY, 2010)..

Em relação aos co-iniciadores, estes são compostos utilizados em conjunto com o iniciador a fim de proporcionar a geração de radicais livres ou íons. Entre os diversos tipos de co-iniciador, o utilizado mais regularmente com fotoiniciadores do tipo II são as aminas. Em adição, pode-se também atrelar a eficiência do sistema de polimerização de acordo com a ordem da amina, ou seja, de acordo com o numero de Carbonos ligados a átomos de Nitrogênio (JASTY, 1999; ANDREAJEWSKA, 2001; MATYJASZEWSKI e DAVIS, 2002; ODIAN, 2004; KRICHELDORF et al., 2005).

Por exemplo, a Figura 3.22 apresenta a representação estrutural de uma amina terciária, Benzophenone/ N,N-dimethyl aniline. 


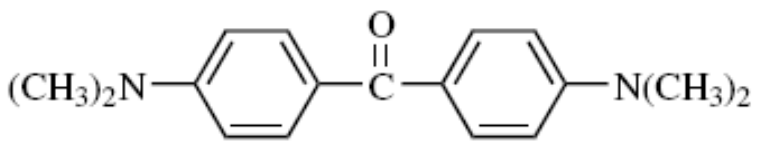

Figura 3.22 - Exemplo de amina terciária, Benzophenone/ N,N-dimethyl aniline (MATYJASZEWSKI e DAVIS, 2002)

Contudo, os outros tipos co-iniciadores que também são utilizados em conjuto com iniciadores do Tipo II são: álcool, amidas, aminoácidos e eters (ODIAN, 2004). Enquanto para fotocura iônica, os co-iniciadores mais comuns são sais de ônio (MALMSTRIJM et al., 1995; JASTY, 1999; YURTERI, S. et al., 2002; CIBA, 2003; ODIAN, 2004; KABATC e PACZKOWSKI, 2006).

\section{Aditivos}

Aditivos são componentes químicos que auxiliam a melhorar as propriedades mecânicas e químicas dos materiais (RODRIGUES e NEUMANN, 2003; SARTOMER, 2004).

\subsubsection{Processo de fotopolimerização}

Em contraste com métodos de polimerização tradicionais, a fotopolimerização é um tipo de polimerização por adição que se mostra mais vantajosa quanto : a) à velocidade de polimerização; b) ao alto peso molecular gerado; c) às taxas de conversão próximas a 100\%; d) ao fácil controle atmosférico; e) à baixa energia de polimerização. Entretanto a fotocura é limitada pela baixa penetração da energia luminosa através da espessura de material (BRANDRUP et al., 1999; MATYJASZEWSKI e DAVIS, 2002; RODRIGUES e NEUMANN, 2003; ODIAN, 2004). 
Em geral, os principais tipos de fotopolimerização podem ser divididos em: radicalar; iônica, e abertura de anéis, devido ao tipo de cinética de processamento que estas apresentam (BRANDRUP et al., 1999; JASTY, 1999; MATYJASZEWSKI e DAVIS, 2002; FOUASSIER, J. P. et al., 2003; ODIAN, 2004; KRICHELDORF et al., 2005).

\section{Fotopolimerização radicalar}

Em relação à polimerização do tipo radicalar, pode-se caracterizar o seu processo em função da adição de moléculas por meio de reações de fotofragmentação e abstração de hidrogênio promovidas por fotoiniciadores e coiniciadores apresentam (BRANDRUP et al., 1999; JASTY, 1999; MATYJASZEWSKI e DAVIS, 2002; FOUASSIER, J. P. et al., 2003; ODIAN, 2004; KRICHELDORF et al., 2005).

As principais fases deste processo de polimerização podem ser divididas em iniciação, propagação, transferência e terminação. Na fase de iniciação, é evidenciada a geração de espécies ativas provenientes do iniciador, enquanto na propagação, a quebra da dupla ligação dos monômeros ou oligômeros. Adicionalmente, na fase de transferência são acrescidas moléculas às cadeias poliméricas até a inibição das espécies ativas (fase de terminação), como pode ser observada na Figura 3.23 (BRANDRUP et al., 1999; ANDREAJEWSKA, 2001; MATYJASZEWSKI e DAVIS, 2002; FOUASSIER, J. P. et al., 2003; ODIAN, 2004; KRICHELDORF et al., 2005) 


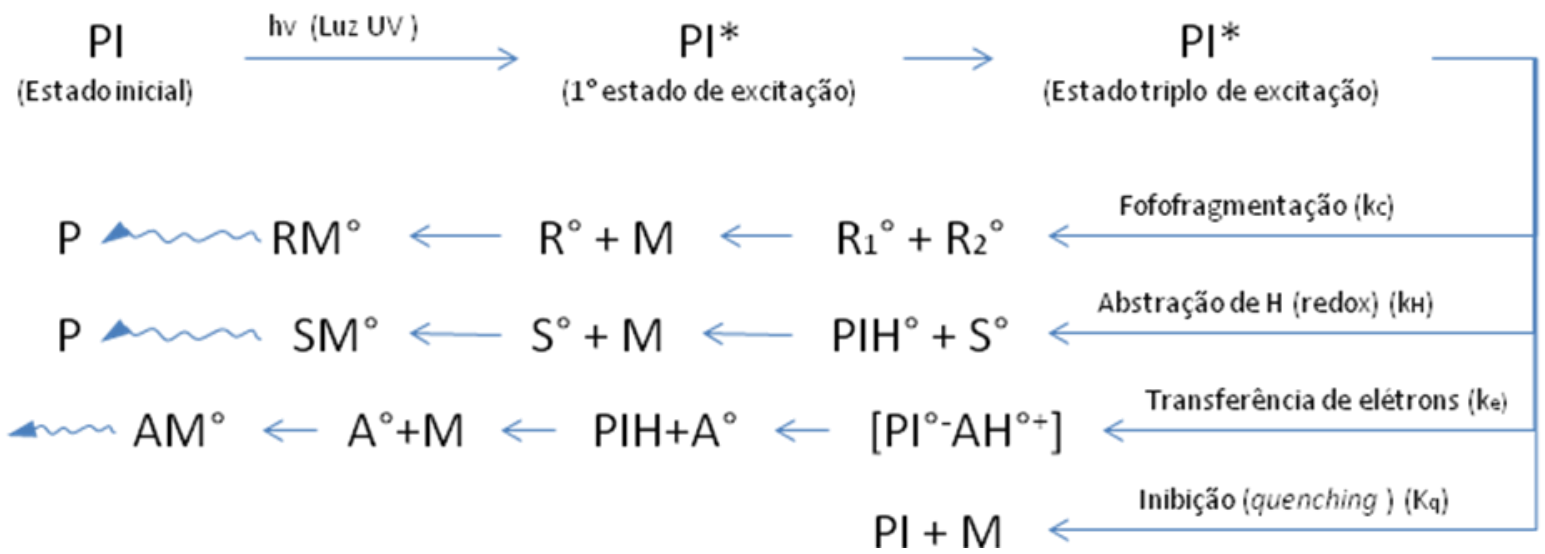

Figura 3.23 - Representação esquemática do processo de fotopolimerização radicalar

Nesta Figura, pode-se observar que o fotoiniciador (PI) é o excitado pela ação da luz gerando uma espécie ativa $\left(\mathrm{PI}^{*}\right)$, que, por sua vez, pode iniciar diversas reações. No caso de fotoiniciadores do tipo I, ocorre a fotofragmentação deste iniciador, gerando radicais livres $\left(\mathrm{R} 1^{*}, \mathrm{R} 2^{*}\right)$. Estes, por sua vez, quebram as duplas ligações dos monômeros e oligômeros, iniciando o processo de polimerização (BRANDRUP et al., 1999; JASTY, 1999; MATYJASZEWSKI e DAVIS, 2002; FOUASSIER, J. P. et al., 2003; ODIAN, 2004; KRICHELDORF et al., 2005).

Já para o caso dos fotoiniciadores do tipo II, faz-se necessária a inclusão de outro componente ao sistema, o co-iniciador ( $\mathrm{AH}$ ) ou sensibilizador (S). Neste caso, podem ocorrer dois tipos de processo: a abstração de hidrogênio, que também é conhecida como redox, e a transferência de elétrons (BRANDRUP et al., 1999; JASTY, 1999; MATYJASZEWSKI e DAVIS, 2002; FOUASSIER, J. P. et al., 2003; ODIAN, 2004; KRICHELDORF et al., 2005).

Em relação ao processo de abstração de hidrogênio (redox), a ocorrência deste processo é evidenciada quando a espécies ativa $\left(\mathrm{PI}^{*}\right)$ incorpora um hidrogênio da molécula do componente sensibilizador gerando radicais livres $\left(\mathrm{PIH}^{\circ}, \mathrm{S}^{\circ}\right)$. A partir destes radicais, é promovida a quebra das duplas ligações do monômero ou olgômero, iniciando o processo de polimerização (BRANDRUP et al., 1999; JASTY, 1999; MATYJASZEWSKI e DAVIS, 2002; FOUASSIER, J. P. et al., 2003; ODIAN, 2004; KRICHELDORF et al., 2005). 
Em contrapartida, o processo de transferência de elétrons é promovido pela adição de um co-iniciador $(\mathrm{AH})$ ao sistema. Neste caso, as espécies ativas $\left(\mathrm{PI}^{*}\right)$ incorporam o co-iniciador implicando em moléculas polares instáveis. Consequentemente, estas moléculas se dividem ocasionando radicais livres $\left(A^{\circ}\right)$, iniciando o processo de polimerização (BRANDRUP et al., 1999; JASTY, 1999; MATYJASZEWSKI e DAVIS, 2002; FOUASSIER, J. P. et al., 2003; ODIAN, 2004; KRICHELDORF et al., 2005).

Outro processo que também ocorre em ambos os tipos de iniciador é a inibição do sistema (quenching), sendo ocasionado pela perda energética das espécies ativas que retornam ao seu estado inicial. Este processo é muitas vezes proporcionado por componentes inibidores, visto que estes absorvem a energia luminosa, fazendo com que o fotoiniciador não consiga alcançar o estado triplo de excitação (BRANDRUP et al., 1999; JASTY, 1999; MATYJASZEWSKI e DAVIS, 2002; FOUASSIER, J. P. et al., 2003; ODIAN, 2004; KRICHELDORF et al., 2005).

\section{Polimerização iônica}

Com referência ao processo de polimerização iônica, esta é caracterizada pela forma que é ocasionada a quebra das duplas ligações. Ao contrário do processo radicalar, que promove a quebra de forma homolitica, o processo iônico realiza a quebra das duplas ligações por meio heterilítico, como é representado na Figura 3.24 (ANDREAJEWSKA, 2001; MATYJASZEWSKI e DAVIS, 2002; RODRIGUES e NEUMANN, 2003; ODIAN, 2004; KRICHELDORF et al., 2005)

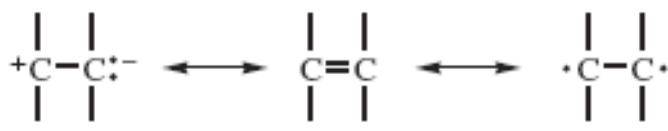
a)
b)
c)

Figura 3.24 - Representação de tipos de quebra de ligação, onde a)heterolítica; b) dupla ligação; c)homolítica (ODIAN, 2004) 
Embora a polimerização iônica proporcione velocidades de polimerização superiores às encontradas em processos radicalares, este processo ainda acarreta num controle mais difícil, assim como num baixo nível de repetibilidade. Isto é ocasionado em função da alta sensibilidade do sistema perante a presença de impurezas (ANDREAJEWSKA, 2001; ARCHER, 2001; YURTERI, S. et al., 2002; ODIAN, 2004).

Em relação à cinética deste processo, a Figura 3.25 apresenta uma representação das reações e etapas encontradas neste tipo de fotopolimerização. Nesta figura, pode ser observado que após a geração das espécies ativas $\left(\mathrm{PI}^{\star}\right), 0$ sensibilisador é incorporado à molécula do iniciador, implicando num elemento polar. Logo, a quebra das duplas ligações do monômero ou oligômero ocorre de forma heterogência, iniciando, desta forma, o processo de polimerização (ANDREAJEWSKA, 2001; ARCHER, 2001; YURTERI, S. et al., 2002; ODIAN, 2004).

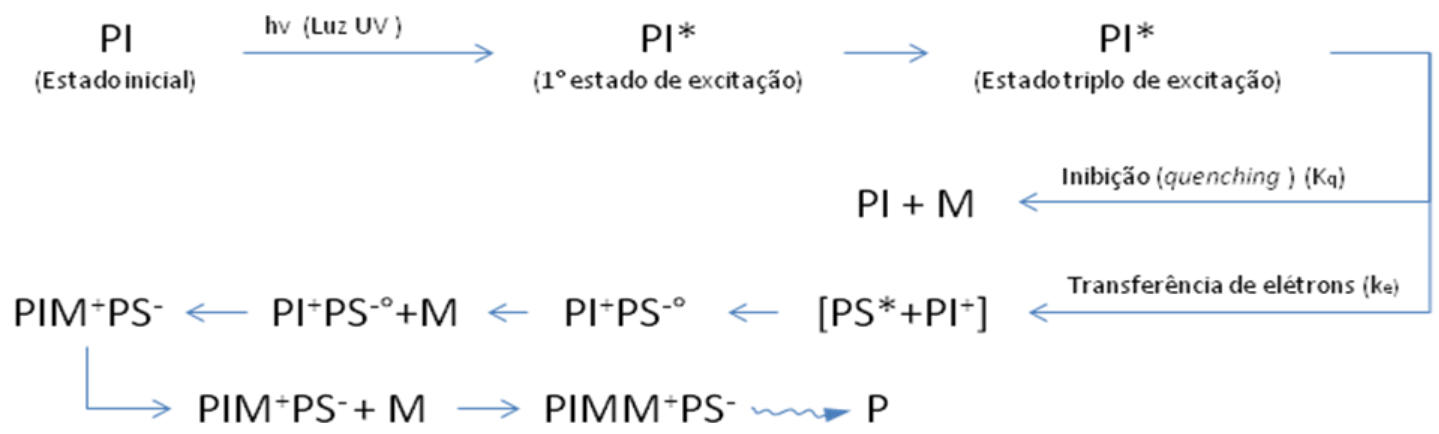

Figura 3.25 - Representação de fases de polimerização iônica, propagação, transferência e terminação, respectivamente

\section{Polimerização por abertura de anel}

Outro tipo de polimerização que também é amplamente utilizado é a polimerização por abertura de anéis (ring-openning polymerization). Entre os principais grupos funcionais utilizados neste processo, destacam-se os éteres (epoxes), cetais, amidas (lactams), ésteres (lactones), siloxanos, aminas, sulfetos e olefinas. Contudo, os mais empregados em materiais destinados à 
manufatura aditiva (AM) são os éteres, apresentados na Figura 3.26. Adicionalmente, esta figura também expõe outros exemplos de grupos funcionais que proporcionam a fotopolimerização por abertura de aneis (MUKHERJEE, 1978; ANDREAJEWSKA, 2001; ARCHER, 2001; MATYJASZEWSKI e DAVIS, 2002; ODIAN, 2004; KRICHELDORF et al., 2005).

Em geral, este tipo de polimerização pode ser iniciado através dos mesmos mecanismos encontrados em processos de polimerização iônica, embora seja realizada a abertura do anel em vez da quebra das duplas ligações. Com referência aos processos de iniciação, propagação, transferência e terminação, estes podem ser obsevados através da ilustração apresentada na Figura 3.27 (MATYJASZEWSKI e DAVIS, 2002; ODIAN, 2004; KRICHELDORF et al., 2005).

Assim como os processos iônicos, estes tipos de polimerização apresentam taxas de polimerização superiores às taxas dos radicalares, tendo como principal material o baseado em epóxi (éter) (DECKER, C. et al., 2001).

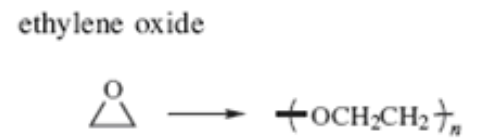

trioxane

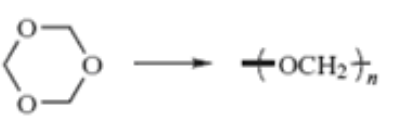

octamethylcyclotetrasiloxane:

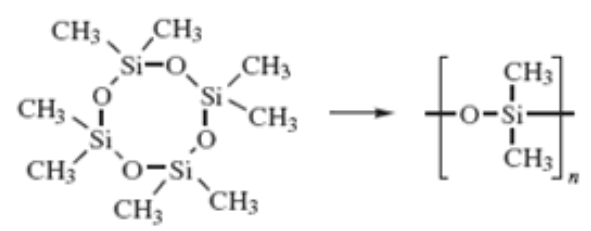

E-caprolactam

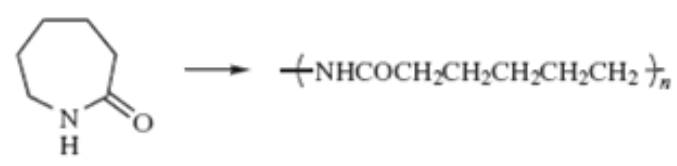

Figura 3.26 - Exemplos de grupos funcionais de polimerização por abertura de anéis (ODIAN, 2004) 


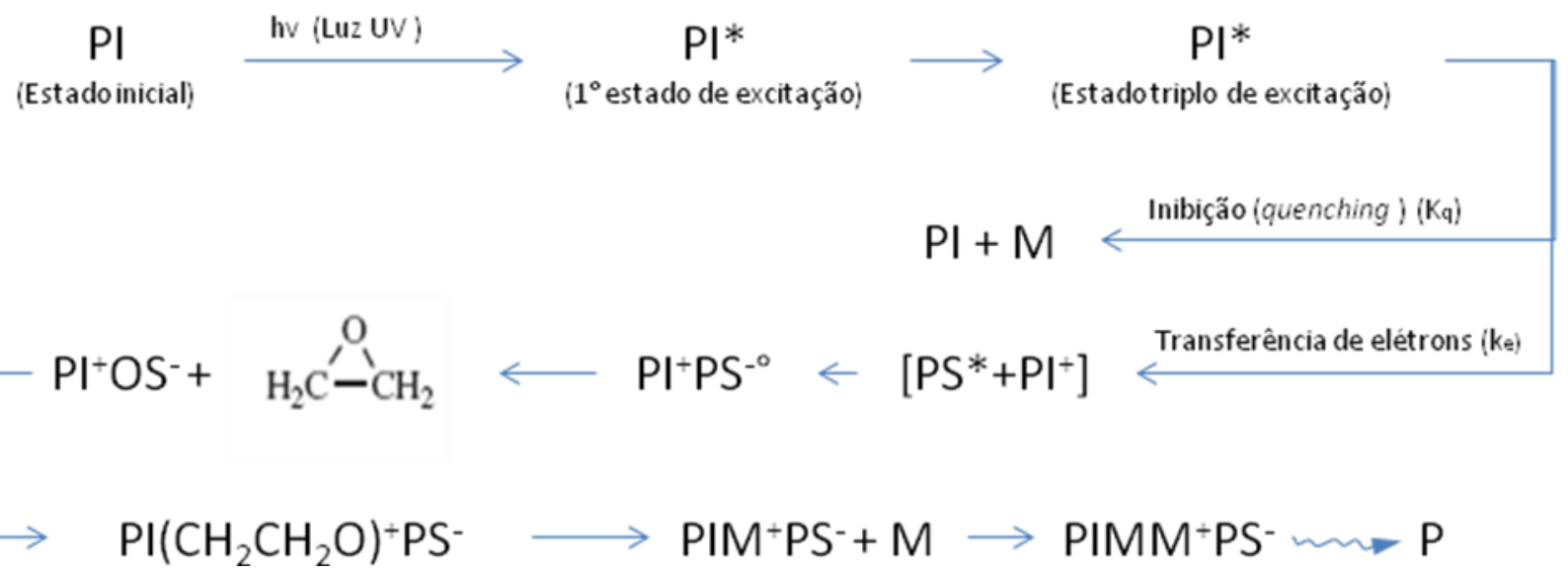

Figura 3.27 - Representação da propagação proveniente da abertura do anél epóxi (ODIAN, 2004)

\subsubsection{Taxa de polimerização}

Em relação à velocidade de aumento da cadeia polimérica, também chamada de taxa de polimerização, esta é uma das propriedades mais importantes do material, para aplicação em tecnologias AM (Gibson, Jacobs, Foussier, Drobny).

Através das leis fundamentais da fotoquímica (Lamber Law) Equação (3.2), pode-se definir a intensidade de luz absorvida por uma solução em um segundo, e assim o número de moléculas iniciadas por segundo, conforme é apresentado na Equação (3.1). A partir destas definições pode-se encontrar a taxa de iniciação da polimerização induzida por luz (MUKHERJEE, 1978; COYLE, 1986; MEZAKI e MA, 1997; MATYJASZEWSKI e DAVIS, 2002; RODRIGUES e NEUMANN, 2003; ODIAN, 2004)

$$
\begin{aligned}
& R i=2 \cdot \phi \cdot I_{a} \\
& I_{a}{ }^{\prime}=I_{0} \cdot\left(1-10^{\varepsilon[C] \cdot l}\right)
\end{aligned}
$$


Nestas equações, $R_{i}$ representa a taxa de iniciação, enquanto $I_{a}$ a intensidade de luz absorvida por mol em 1 segundo. Já $\phi$ representa o número de moléculas excitadas por fóton absorvido, sendo este valor igual a 1 para fontes extensas de luz e 2 para lasers. Adicionalmente, [C] é a concentração de fotoiniciador, com unidade $\frac{g}{m o l}$ e $l$ é a espessura de camada, em centimetros (MUKHERJEE, 1978; COYLE, 1986; MEZAKI e MA, 1997; MATYJASZEWSKI e DAVIS, 2002; RODRIGUES e NEUMANN, 2003; ODIAN, 2004).

Nestas fórmulas, $I_{a}{ }^{\prime} \mathrm{e}{ }^{I_{0}}$, são intensidades baseadas em área (com unidade $\mathrm{mol} /\left(\mathrm{cm}^{2} . \mathrm{s}\right)$ ), enquanto $l_{a}$, Equações (3.1) e (3.3), apresenta a intensidade baseada no volume (com unidade $\mathrm{mol} /\left(\mathrm{cm}^{2} . \mathrm{s}\right)$ ou $\mathrm{mol} /(\mathrm{L} . \mathrm{s})$ ). Outra variável encontrada neste processo é o coeficiente de extinção $(\varepsilon)$, que é um coeficiente baseado na absorção de fótons proporcionada pelo iniciador, Equação (3.4) (MUKHERJEE, 1978; COYLE, 1986; MEZAKI e MA, 1997; MATYJASZEWSKI e DAVIS, 2002; RODRIGUES e NEUMANN, 2003; ODIAN, 2004).

$$
\begin{aligned}
& I_{a}=\frac{d I_{a}{ }^{\prime}}{d l}=\alpha \cdot[C] \cdot I_{0} \cdot 10^{3} \cdot e^{-\alpha \cdot[C] \cdot l} \\
& \varepsilon=\frac{\alpha}{2.303}
\end{aligned}
$$

A partir destas definições, torna-se possível identificar a taxa de polimerização em função da concentração de monômero e iniciador, profundidade de penetração (espessura e camada) e intensidade luminosa, Equação (3.5) (MUKHERJEE, 1978; COYLE, 1986; MEZAKI e MA, 1997; JASTY, 1999; LEMEE et al., 1999; MATYJASZEWSKI e DAVIS, 2002; RODRIGUES e NEUMANN, 2003; ODIAN, 2004). 


$$
R_{p}=k_{p} \cdot[M] \cdot\left(\frac{\phi \cdot \alpha \cdot[C] \cdot I_{0} \cdot 10^{3} \cdot e^{-\alpha \cdot[C] \cdot l}}{k_{t}}\right)^{\frac{1}{2}}
$$

Logo, para identificação do tempo de polimerização pode ser encontrado a partir da Equação (3.6), onde [P] é a concentração de polímero após exposição em UV.

$$
\int d t=-\frac{1}{R_{p}} \cdot \int d M \rightarrow T=\frac{[P]}{R_{p}}
$$

Como a maioria das fontes luminosas definirem o fluxo de luz em potência $\left(W=\frac{J}{s}\right)$, a intensidade de luz $\left(\frac{q u a n t u m}{m^{2} \cdot s}\right)$ pode ser definida através das Equações (3.7), (3.8) e (3.9) (MUKHERJEE, 1978; COYLE, 1986; MEZAKI e MA, 1997; JASTY, 1999; LEMEE et al., 1999; MATYJASZEWSKI e DAVIS, 2002; RODRIGUES e NEUMANN, 2003; ODIAN, 2004).

$$
\begin{aligned}
& I\left[\frac{\text { einstein }}{m^{2} \cdot s}\right]=8,36 \cdot \lambda[\mathrm{nm}] \cdot \text { Potência }[\mathrm{W}] \\
& I\left[\frac{\text { quanta }}{m^{2} \cdot s}\right]=5,03 \cdot 10^{24} \cdot \lambda[\mathrm{nm}] \cdot \text { Potência }[\mathrm{W}] \\
& I_{a}=\frac{1,196 \cdot 10^{8}}{\lambda}\left[\frac{\text { einstein }}{m^{2} \cdot s}\right]
\end{aligned}
$$

Outra característica de grande importância no processo de fotopolimerização é a faixa de comprimento de onda da luz, visto que o coeficiente de extinção é dependente desta variável do processo. Adicionalmente, em função de cada iniciador ter um comportamento diferenciado em relação à absorbância luminosa, a análise da curva espectroscópica do composto se torma fundamental para a determinação do comprimento de onda mais apropriado para a fonte luminosa. Um exemplo disso é apresentado na Figura 3.28, onde a curva espectroscópica indica a 
maior absorbância do iniciador no comprimento de onda $260 \mathrm{~nm}$ (MUKHERJEE, 1978; COYLE, 1986; MEZAKI e MA, 1997; JASTY, 1999; LEMEE et al., 1999; MATYJASZEWSKI e DAVIS, 2002; RODRIGUES e NEUMANN, 2003; ODIAN, 2004).

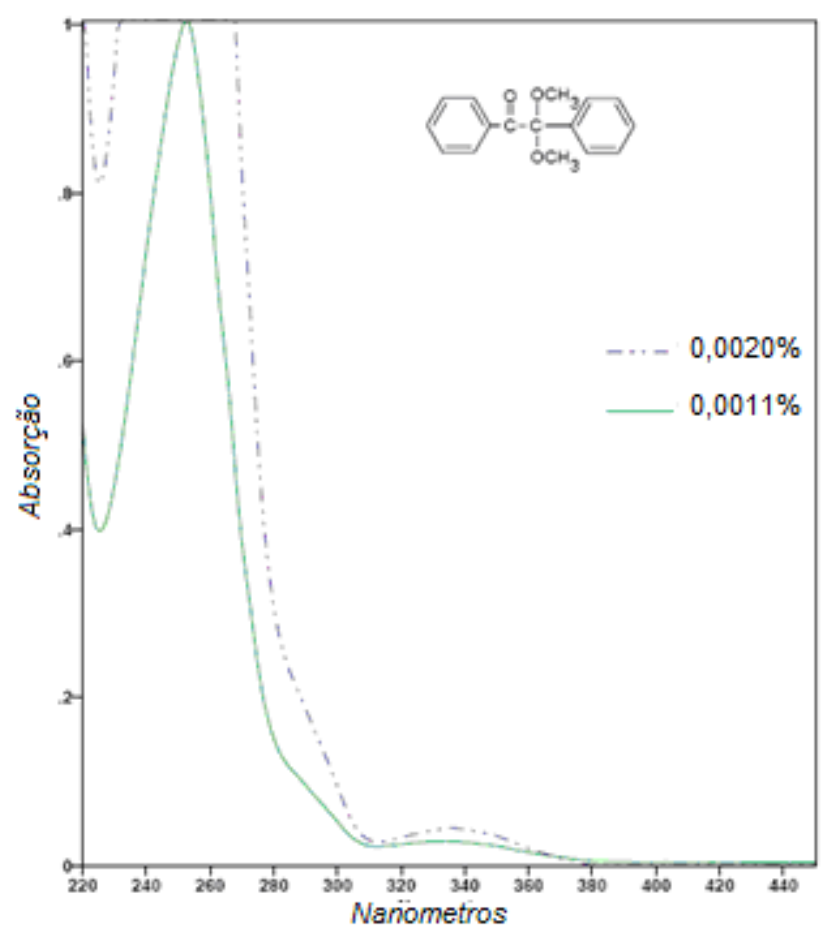

Figura 3.28 - Espectro de absorção de IRGACURE 651, 99,9\%(JASTY, 1999)

\section{Determinação e controle de Taxa de polimerização}

Em face à importância da taxa de polimerização nos processos de fotopolimerização, faz-se necessário ressaltar as metodologias de determinação e controle experimental desta propriedade. Entre as diversas formas de identificação e controle, destacam-se a gravimetria, espectroscopia, dilatometria e a calorimetria. Contudo, variações de espectroscopia, como fotometria, permitem o monitoramento simultânio do processo através de soluções de baixo custo (ODIAN, 2004; CUNICO e CARVALHO, 2011). 


\section{Gravimetria}

A gravimetria é um método de determinação de taxa de polimerização que consiste na identificação a da variação de massa de monômero convertido em polímero através da coleta de amostras de material expostas à luz UV ao longo do tempo. Após a exposição destas amostras à radiação UV, o polímero é isolado por precipitação através de adição de um não-solvente à solução. A quantidade de polímero gerado é encontrada após secagem de alíquotas destas amostras por meio de filtragem. Adicionalmente, cabe salientar que apesar desta técnica ser uma das mais utilizadas em pesquisas em função da facilidade encontrada (DROBNY, 2010)na realização do ensaio, o tempo de aquisição dos dados costumam ser altos (MUKHERJEE, 1978; MATYJASZEWSKI e DAVIS, 2002; RODRIGUES e NEUMANN, 2003; ODIAN, 2004; SPERLING, 2006).

\section{Espectroscopia}

Outro método de levantamento da velocidade de polimerização é realizado por meio de análises espectroscópicas. Este método é baseado no monitoramento do aparecimento de polímero ou desaparecimento de monômero através de infravermelho (IR), UV ou ressonância magnética nuclear (RMN), entre outras espectrometrias. Um exemplo disso é o escaneamento do desaparecimento de duplas ligações em um período de tempo, no caso de polímeros vinílicos (MUKHERJEE, 1978; MATYJASZEWSKI e DAVIS, 2002; JUNIOR et al., 2003; LEE et al., 2003; MIYASAKA et al., 2003; RODRIGUES e NEUMANN, 2003; ODIAN, 2004; SPERLING, 2006).

Apesar da grande difusão deste método, assim como da precisão proporcionada, são requeridos custos elevados para a implementação desta técnica. Outro fator também relevante é que o emprego deste método não pode ser realizado simultaneamente ao processo (in loco), implicando na coleta de amostras para a análise do material (CUNICO e CARVALHO, 2011). 


\section{Fotometria}

Com relação à metodologia de determinação de taxa de polimerização e conversão baseada em análise fotométrica, esta tem seu princípio de funcionamento similar ao de métodos espectroscópicos. Porém sua forma de aquisição de dados tem custo baixo e proporciona monitoramento de conversão em tempo real. Adicionalmente, esta técnica se diferencia conceitualmente de outras em função da faixa de comprimento de onda analisada ser fixa (CUNICO e CARVALHO, 2011).

\section{Dilatometria/Calorimetria}

Outros dois métodos também amplamente utilizados, tanto sozinhos quanto em conjunto com outros métodos, como espectrometria, são a dilatometria, onde é observada a dilatação da solução enquanto está polimerizando, e a calorimetria, que relaciona a energia emanada pela solução em um período estipulado com a concentração de polímero formada (MUKHERJEE, 1978; MATYJASZEWSKI e DAVIS, 2002; RODRIGUES e NEUMANN, 2003; ODIAN, 2004; SPERLING, 2006).

\subsubsection{Fornecimento}

Com referência às companhias envolvidas com a comercialização de produtos utilizados em processos de fotopolimerização, as Tabela 3.6,Tabela 3.7 e Tabela 3.8 apresentam algumas empresas envolvidas no processo de fabricação e fornecimento de matéria-prima. 
Tabela 3.6 - Relação de fabricantes de monômeros e oligômeros (RADTECH, 2008)

\begin{tabular}{|c|c|c|c|c|c|c|c|c|c|}
\hline \multicolumn{10}{|c|}{ Monômero/oligômero } \\
Empresa & Basf ag & $\begin{array}{c}\text { Cognis } \\
\text { france }\end{array}$ & $\begin{array}{c}\text { Hang cheung } \\
\text { petrochemical } \\
\text { limited }\end{array}$ & $\begin{array}{c}\text { Igm } \\
\text { resins } \\
\text { bv }\end{array}$ & $\begin{array}{c}\text { Jobachem } \\
\text { gmbh }\end{array}$ & $\begin{array}{c}\text { Lambson } \\
\text { group Itd }\end{array}$ & $\begin{array}{c}\text { Mirage } \\
\text { inks Itd }\end{array}$ & $\begin{array}{c}\text { Rahn } \\
\text { ag }\end{array}$ & $\begin{array}{c}\text { Sartomer } \\
\text { europe }\end{array}$ \\
\hline Pais & Alemanha & França & China & Holanda & Alemanha & Inglaterra & Inglaterra & Suécia & Itália \\
\hline
\end{tabular}

Tabela 3.7 - Relação de fabricantes de aditivos (RADTECH, 2008)

\begin{tabular}{|l|c|c|c|c|c|c|c|c|c|}
\hline & & Ciba & & Aditivos & & & \\
\hline Empresas & $\begin{array}{c}\text { Byk- } \\
\text { chemie }\end{array}$ & $\begin{array}{c}\text { Spec. } \\
\text { Chemicals }\end{array}$ & $\begin{array}{l}\text { Cognis } \\
\text { france }\end{array}$ & $\begin{array}{c}\text { ag tego } \\
\text { coating }\end{array}$ & $\begin{array}{c}\text { Grace } \\
\text { gmbh }\end{array}$ & $\begin{array}{c}\text { Hang cheung } \\
\text { petrochemical } \\
\text { limited }\end{array}$ & $\begin{array}{c}\text { Kromachem } \\
\text { Itd }\end{array}$ & $\begin{array}{c}\text { Lambson } \\
\text { group Itd }\end{array}$ & $\begin{array}{c}\text { Mirage } \\
\text { inks Itd }\end{array}$ \\
\hline Pais & Alemanha & Holanda & França & Alemanha & Alemanha & China & Inglaterra & Inglaterra & Inglaterra \\
\hline
\end{tabular}

Além destas empresas citadas existem companhias que, embora não sejam especializadas em fotopolimerização, são fabricantes de produtos químicos, e conseqüentemente fornecedodores de compostos utilizados em fotopolimerização.

Tabela 3.8 - Relação de fabricantes de fotoiniciadores para polimerização (RADTECH, 2008)

\begin{tabular}{|c|c|c|c|c|c|c|c|}
\hline \multicolumn{8}{|c|}{ Fotoiniciador } \\
\hline Empresa & Pais & Empresa & Pais & Empresa & Pais & Empresa & Pais \\
\hline Akzo Nobel & Dinamarca & $\begin{array}{l}\text { Lambson } \\
\text { group Itd }\end{array}$ & Inglaterra & $\begin{array}{c}\text { Jobachem } \\
\text { gmbh }\end{array}$ & Alemanha & $\begin{array}{c}\text { Ciba specialités } \\
\text { chimiques sa }\end{array}$ & França \\
\hline Basf ag & Alemanha & Rahn ag & Suécia & $\begin{array}{l}\text { Lamberti } \\
\text { spa }\end{array}$ & Itália & $\begin{array}{l}\text { Ciba spec. } \\
\text { Chemicals }\end{array}$ & Brasil \\
\hline $\begin{array}{l}\text { Dow } \\
\text { europe } \\
\text { gmbh }\end{array}$ & Suécia & $\begin{array}{l}\text { Shinyoung } \\
\text { rad. Chem. } \\
\text { Ltd. }\end{array}$ & Coréa & $\begin{array}{c}\text { Lamberti } \\
\text { spa }\end{array}$ & Itália & $\begin{array}{c}\text { Prod.chim.auxil.et } \\
\text { synthèse }\end{array}$ & França \\
\hline $\begin{array}{c}\text { Igm resins } \\
\text { bv }\end{array}$ & Holanda & Akzo nobel & Dinamarca & $\begin{array}{l}\text { Lamberti } \\
\text { spa }\end{array}$ & Itália & $\begin{array}{l}\text { Ciba spec. } \\
\text { Chemicals }\end{array}$ & Holanda \\
\hline $\begin{array}{c}\text { Jobachem } \\
\text { gmbh }\end{array}$ & Alemanha & $\begin{array}{l}\text { Ciba spec. } \\
\text { Chemicals }\end{array}$ & Itália & $\begin{array}{l}\text { Lambson } \\
\text { group Itd }\end{array}$ & Inglaterra & Lambson group Itd & Inglaterra \\
\hline
\end{tabular}




\subsection{Adesividade}

A adesividade é um processo de união entre materiais onde um adesivo é posto em contato com superfícies aderentes (substrato) a fim de produzir a ligação entre os mesmo após solidificação do material adesivo (LIGHT e KWUN, 1989; VESELOVSKIĬ e KESTEL'MAN, 2002; PIZZI e MITTAL, 2003; MUELLER, 2004; PACKHAM, 2005; HUDGIN, 2006; BANEA e DA SILVA, 2009).

Entre as diversas aplicações de adesivos, destacam-se as juntas adesivas, visto que esta proporciona baixo peso, custo de fabricação reduzido e melhora na tolerância a danos (LIGHT e KWUN, 1989; VESELOVSKIĬ e KESTEL'MAN, 2002; PIZZI e MITTAL, 2003; MUELLER, 2004; PACKHAM, 2005; HUDGIN, 2006; BANEA e DA SILVA, 2009).

Em relação às principais etapas do processo de adesividade, podem ser listados: preparação superficial de substratos, aplicação de adesivo, união entre substratos e solidificação (cura) de material adesivo (LIGHT e KWUN, 1989; VESELOVSKIĬ e KESTEL'MAN, 2002; PIZZI e MITTAL, 2003; MUELLER, 2004; PACKHAM, 2005; HUDGIN, 2006; BANEA e DA SILVA, 2009).

Com relação aos tipos de mecanismos promotores de aderência, estes podem ser classificados conforme a forma de solidificação do material adesivo, como por exemplo: não-poliméricos ou diretos(adesivo não está polimerizado) e poliméricos ou indiretos (adesivo já está polimerizado). Entre os processos não poliméricos (diretos), podem-se listar os emolsivos, térmocuráveis e os curáveis por radiação (Luz UV e Feixe de Electrons). Por outro lado, os processos poliméricos (indiretos) se restringem a polímeros termoplásticos (LIGHT e KWUN, 1989; VESELOVSKII e KESTEL'MAN, 2002; PIZZI e MITTAL, 2003; MUELLER, 2004; PACKHAM, 2005; HUDGIN, 2006; BANEA e DA SILVA, 2009).

Adicionalmente, os principais processos promotores de aderência entre superfícies podem ser referenciados como: interamarração mecânica; difusão e adsorção (LIGHT e KWUN, 1989; VESELOVSKIĬ e KESTEL'MAN, 2002; PIZZI e MITTAL, 2003; MUELLER, 2004; PACKHAM, 2005; HUDGIN, 2006; BANEA e DA SILVA, 2009). 
A interamarração mecânica consiste na solidificação de material que penetra em irregularidades e porosidades, proporcionando, desta forma, a força de ligação entre as superfícies. Já o processo de difusão é caracterisado pela solubilisação de ambos os materiais da junta adesiva (substrato e adesivo), proporcionando a mobilidade mutua de macromoléculas alongo da junta (LIGHT e KWUN, 1989; VESELOVSKIII e KESTEL'MAN, 2002; PIZZI e MITTAL, 2003; MUELLER, 2004; PACKHAM, 2005; HUDGIN, 2006; BANEA e DA SILVA, 2009).

Com referência ao processo de adsorção, a força de atração entre camadas é proporcionado por ação de átomos entre as duas superfícies gerando ligações de Van Der Waals. Estas ligações são atribuídas basicamente à força de disperção e força polar, sendo induzidas por ação do material adesivo (LIGHT e KWUN, 1989; VESELOVSKIĬ e KESTEL'MAN, 2002; PIZZI e MITTAL, 2003; MUELLER, 2004; PACKHAM, 2005; HUDGIN, 2006; BANEA e DA SILVA, 2009).

Outro aspecto que também é relevante no desenvolvimento de materiais adesivos é o modo de falha da junta adesiva. Através desta característica, é possível identificar a qualidade da união, sendo caracterizados sete tipos de modos de falha: falha adesiva, falha coesiva, falha coesiva e camada fina; falha substrato, falha leve de substrato; falha de rompimento de haste, e falha mista. Adicionalmente, estes modos de falha, ilustrados na Figura 3.29, nos permitem mensurar a eficácia da adesividade entre adesivo e substrato, assim como a fragilização do substrato. 


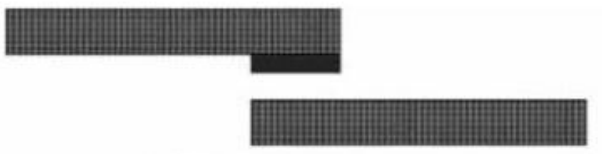

a) Falha adesiva

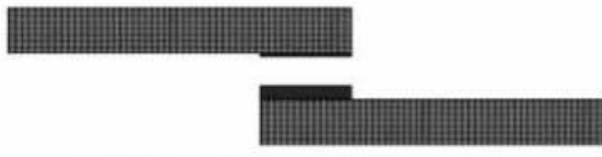

c) Falha coesiva superficial

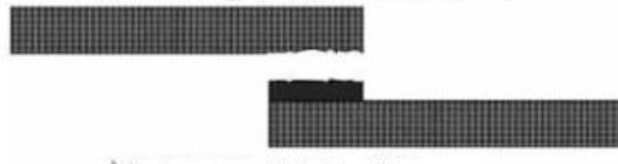

e) Falha superficial de fibra

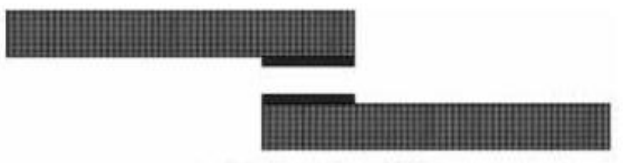

b) Falha Coesiva

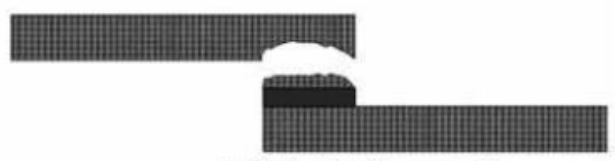

d) Falha de fibra parcial

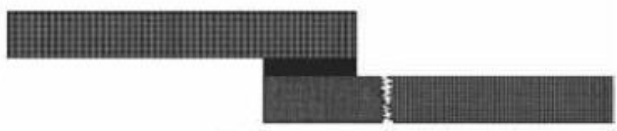

f) Falha de ruptura de peça

Figura 3.29 - Representação de modos de falha de justas adesivas (ASTM, 2002)

\subsection{Sistema de Deposição}

Entre os principais sistemas de deposição de líquidos, destacam-se os sistemas com bico único, os sistemas de múltiplos bicos e os sistemas de deposição por área. No caso de sistemas de bico único, a deposição é realizada, em geral, de forma contínua, sendo forçado o movimento do fluido através de um orifício (bico de deposição) (PRINZ et al., 1997; VOZZI et al., 2002; BATCHELDER, 2008).

Já no caso de sistemas com múltiplos bicos, os sistemas mais expressivos atualmente são os cabeçotes jato de tinta, cujo princípio funcional consiste deposisão de fluido através da formação de gotas, podendo depositar até a magnitude de 60 milhões de gotas por segundo (KIPPHAN, 2001; KLANG, J. e BALCERSKI, J., 2002; LINDQVIST et al., 2003; NAOMI LUFT, 2005; DONG, 2006; OHTA e ROSEN, 2006; BLAYO, 2007).

De forma geral, os sistemas de deposição por área, ou por contato, se baseiam na transferência de material, resina ou tinta aderida ou obstruida por superfície de matriz para substrato (KIPPHAN, 2001; KIRWAN, 2005; TRACTON, 2005; OHTA e ROSEN, 2006; BLAYO, 2007). 


\subsubsection{Sistema com bico único}

Atualmente, as concepções de sistema com bico único mais utilizadas são caracterizadas por apresentar como elementos fundamentais, reservatório, orifício (bico de deposição) e atuador. Sendo que as principais variações de atuadores são: atuadores lineares (sendo utilizados fusos ou cremalheiras), ar comprimido, pressurização de fluido (spray ou aerosol) (WESTON, 1993; PRINZ et al., 1997; VOZZI et al., 2002; SCHMIDT, 2004; BURWASH et al., 2006; STRONG et al., 2007; BATCHELDER, 2008).

Na Figura 3.30, esta concepção de sistema de deposição é exemplificada, sendo apresentadas concepções de (a) dispenser de adesivo ou resina e (b) sistema de deposição de processo alemão de AM MJS (Multiphase Jet Solidification) (PRINZ et al., 1997) .

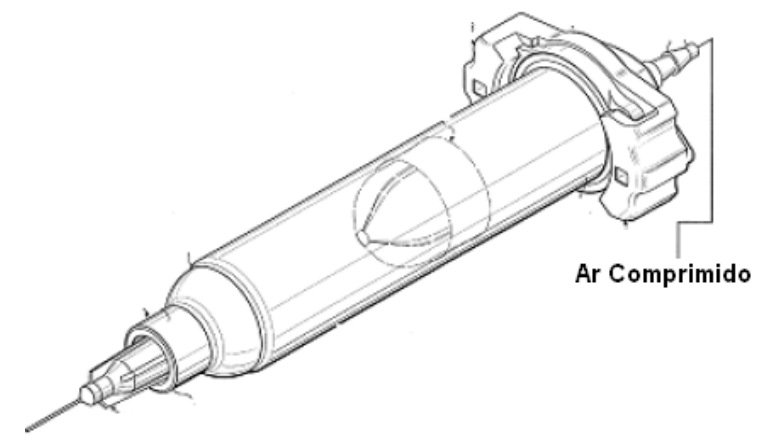

a)

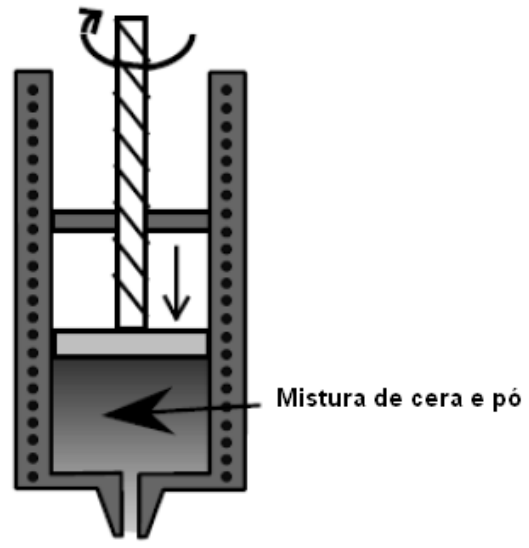

b)

Figura 3.30 - Representação de sistema de deposição de bico único com (a) ar comprimido (STRONG et al., 2007) e (b) atuador linear (PRINZ et al., 1997) 
Entre as vantagens proporcionadas por estes sistemas de deposição, estão: baixa restrição quanto a viscosidade de fluido, alta resistência à corrosão, e fácil implementação.

Com relação ao acionamento destes sistemas, ambos necessitam de controle de vazão, contudo o sistema que utiliza ar comprimido tende a proporcionar uma deposição mais contínua.

\subsubsection{Sistema com múltiplos bicos}

Apesar das diversas concepções de sistemas de deposição com múltiplos bicos, atualmente os que são utilizados mais amplamente são os cabeçotes jato de tinta (KLANG, J. e BALCERSKI, J., 2002; LINDQVIST et al., 2003; DONG, 2006; OHTA Q ROSEN, 2006).

Ao contrário dos sistemas de deposição apresentados anteriormente, estes sistemas se baseiam na deposição de fluido através de gotas, exigindo, em muitos casos, que o fluido (tinta) tenha propriedades químicas e mecânicas especiais (KLANG, J. e BALCERSKI, J., 2002; LINDQVIST et al., 2003; DONG, 2006; OHTA e ROSEN, 2006).

\section{Tipos de Cabeçotes jato de tinta}

Em contraste com a grande variedade de cabeçotes jato de tinta, estes sistemas podem ser classificados em processos contínuos (continuous inkjet - ClJ) e deposição por demanda (drop-on-demand - DOD) (KLANG, J. e BALCERSKI, J., 2002; LINDQVIST et al., 2003; DONG, 2006; OHTA e ROSEN, 2006).

Com relação aos cabeçotes CIJ, estes são marcados pela geração contínua de gotas, que são selecionadas através de alteração de campo magnético. Uma ilustração deste tipo de sistema é apresentado na Figura 3.31, onde é exposto um 
esquemático do conceito deste tipo de cabeçote (KLANG, J. e BALCERSKI, J., 2002; LINDQVIST et al., 2003; DONG, 2006; OHTA e ROSEN, 2006; BLAYO, 2007).

Cabe ressaltar que o funcionamento deste sistema necessita que o material a ser depositado apresente propriedades condutivas, visto que as paletas de defleção, encontradas no bico, alteram a direção das gotas, que são impulsionadas para um reservatório ou para fora do cabeçote (KLANG, J. e BALCERSKI, J., 2002; LINDQVIST et al., 2003; DONG, 2006; OHTA e ROSEN, 2006; BLAYO, 2007).

Nesta figura, é também apresentado um esquemático de funcionamento de sistemas DOD, sendo que, neste caso, as gotas são geradas de forma seletiva, conforme a necessidade (KLANG, J. e BALCERSKI, J., 2002; LINDQVIST et al., 2003; DONG, 2006; OHTA e ROSEN, 2006; BLAYO, 2007).

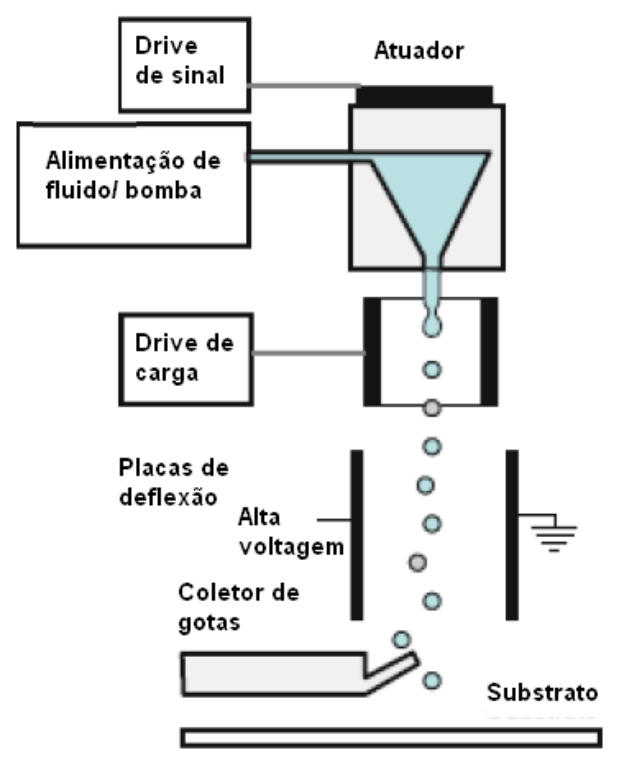

a)

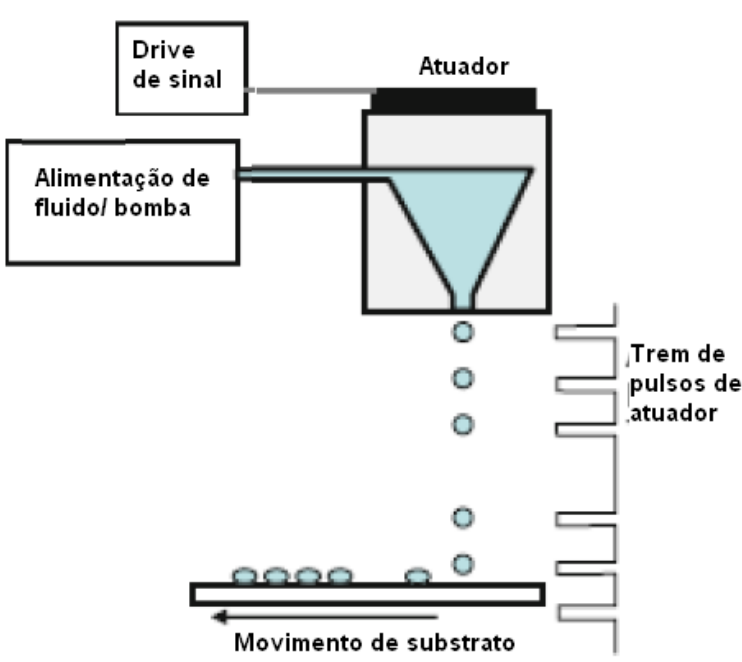

b)

Figura 3.31 - Representação de sistema de deposição jato de tinta (a) continuo (ClJ) e (b) deposição por demanda (DOD) (GIBSON et al., 2010)

Adicionalmente, os sistemas DOD podem ser subdivididos conforme 0 mecanismo de formação das gotas de aproximadamente 1pL, como: atuador Térmico (Thermal bubble Jet - TIJ), atuadores piezoelétricos, atuadores eletro- 
estáticos e sistemas microeletro-mecânicos (Microelectromechanical Systems MEMS. Pode ser observada na Figura 3.32, uma relação dos principais fornecedores destes sistemas, assim como a classificação destes.

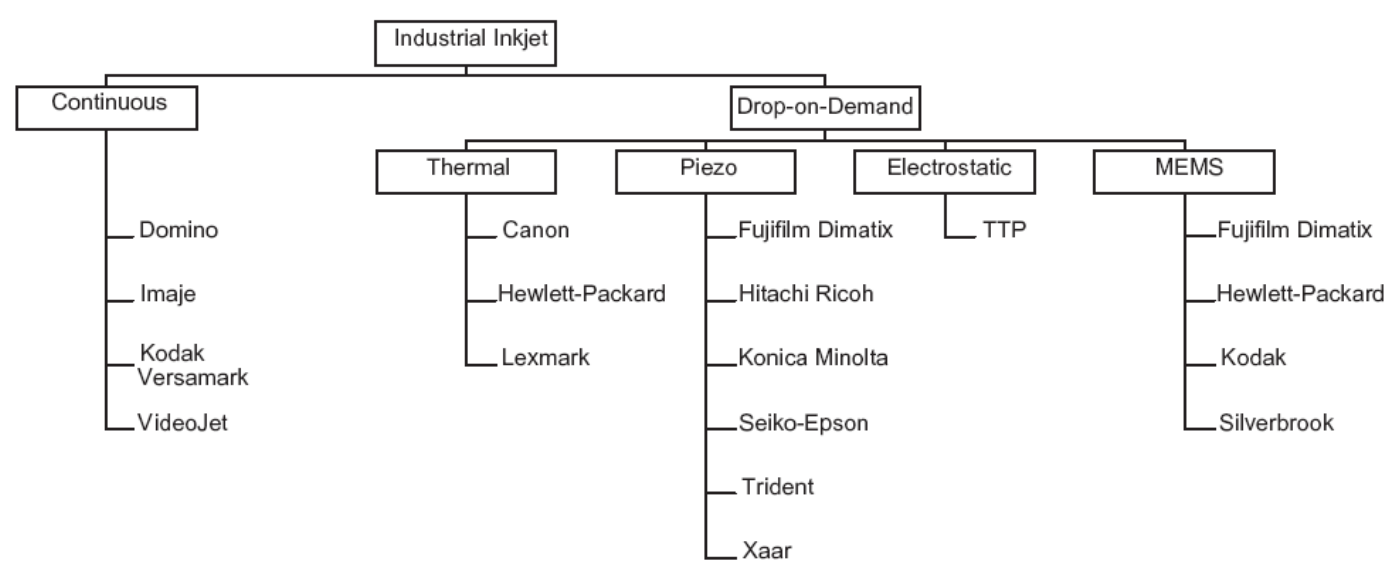

Figura 3.32 - Esquema de tipos de cabeçotes jato de tinta e seus principais fornecedores (MAGDASSI, 2009)

\section{Tinta para cabeçote Jato de Tinta}

Em relação aos tipos de tinta para sistemas jato de tinta, estes podem ser dividitos em: Soluveis ou pigmentadas; Solventes ou a base de água; tintas termofundidas (hot-melt inks) e tintas UV (JONSSON et al., 1996; KLANG, J. e BALCERSKI, J., 2002; KLANG, J. A. e BALCERSKI, J. S., 2002; LINDQVIST et al., 2003; DONG, 2006; DEVONALD, 2006 ; BEY-OUESLATI et al., 2008; MAGDASSI, 2009).

As tintas Soluveis ou pigmentadas são tintas normalmente utilizadas em sistemas $\mathrm{ClJ}$, tendo seu princípio funcional na secagem po evaporação e infiltração. Já as tintas a base de água, além de apresentar o mesmo princípio funcional, esta apresenta baixos nível de viscosidade variando entre 2 e $8 \mathrm{cP}$. Adicionalmente, pode-se dizer que as tintas a base de água foram introduzidas para atender basicamente a mercado de escritório, sendo utilizadas em tecnologias TIJ e DOD (JONSSON et al., 1996; KLANG, J. e BALCERSKI, J., 2002; KLANG, J. A. e 
BALCERSKI, J. S., 2002; LINDQVIST et al., 2003; DONG, 2006; DEVONALD, 2006 ; BEY-OUESLATI et al., 2008; MAGDASSI, 2009).

Com relação às tintas termofundidas, esta são depositadas de forma a sua fluidez aumentar em função de aumento de temperatura, sendo solidificadas as gotas através da perda energética em função da temperatura ambiente (JONSSON et al., 1996; KLANG, J. e BALCERSKI, J., 2002; KLANG, J. A. e BALCERSKI, J. S., 2002; LINDQVIST et al., 2003; DONG, 2006; DEVONALD, 2006 ; BLAYO, 2007; BEY-OUESLATI et al., 2008; MAGDASSI, 2009).

Por fim, as tintas UV ou fotocuraveis são tintas que apresentam características peculiares, como a sua cura ou solidificação por meio de incidência de Luz UV sobre a amostra (JONSSON et al., 1996; KLANG, J. e BALCERSKI, J., 2002; KLANG, J. A. e BALCERSKI, J. S., 2002; LINDQVIST et al., 2003; DONG, 2006; DEVONALD, 2006 ; BEY-OUESLATI et al., 2008; MAGDASSI, 2009).

Em face à necessidade de utilização de cabeçotes jato de tinta para deposição de materiais fotopoliméricos no estado líquido, buscou-se identificar as principais restrições dos diferentes tipos de sistemas, como é apresentado na Tabela 3.9.

Tabela 3.9 - Relação de principais requisitos para tinta e cabeçotes jato de tinta (LINDQVIST et al., 2003)

\begin{tabular}{|c|c|c|c|c|c|}
\hline Propriedades de tinta & CIJ Binario & $\begin{array}{c}\text { CIJ } \\
\text { multideflexão }\end{array}$ & DOD Piezo & Valve jet & TIJ \\
\hline Aplicação & A;S & A;S & A;S;HM;UV & A;S & A;S \\
\hline Viscosidade (cP) & $\sim 1,5$ & $3-8$ & $8-12$ & $<2$ & $\sim 1,5$ \\
\hline $\begin{array}{c}\text { Tensão superficial } \\
(\mathrm{mN} / \mathrm{m})\end{array}$ & $>35$ & $25-40$ & $>32$ & $>24$ & $>35$ \\
\hline $\begin{array}{c}\text { Tamanho max de } \\
\text { partícula }(\mu \mathrm{m})\end{array}$ & 1 & 3 & 1 & 5 & 0,2 \\
\hline $\begin{array}{c}\text { condutividade } \\
(\mu \text { Siemens) }\end{array}$ & $>500$ & $>1000$ & \multicolumn{2}{|c|}{ desnecessário } \\
\hline $\begin{array}{c}\text { Nível de Sais Cloridicos } \\
(\mathrm{ppm})\end{array}$ & $<100$ & $<100$ & $<10$ & $<100$ & $<100$ \\
\hline
\end{tabular}

A- Base de Água; S- Solventes; UV- Tintas UV; HM - Termofundidas (hot-melt inks) 


\subsubsection{Sistema de deposição por área}

Entre as formas mais comuns de sistemas de deposição por área, destacam-se a litografia (offset), a serigrafia, a flexografia, a rotogravura (tampografia). Estes processos de impressão basicamente consitem na deposição de tinta/material em substrato de forma a transmitir geometria previamente determinada (informação) com repetibilidade (KIPPHAN, 2001; KLANG, J. e BALCERSKI, J., 2002; LINDQVIST et al., 2003; NAOMI LUFT, 2005; DONG, 2006; OHTA e ROSEN, 2006; BLAYO, 2007).

De forma geral, estes processos são considerados processos convencionais de impressão podem ser classificados pela existência de matriz de deposição, também conhecida como "master". Contudo, todos estes depositam material líquido em substrato(KIPPHAN, 2001; KLANG, J. e BALCERSKI, J., 2002; LINDQVIST et al., 2003; NAOMI LUFT, 2005; DONG, 2006; OHTA e ROSEN, 2006; BLAYO, 2007).

Na Figura 3.33, é apresentada uma relação dos quatro principais processos de impressão baseados em matriz de impressão: Flexografia (letterpress), rotogravura, litografia (offset) e serigrafia.

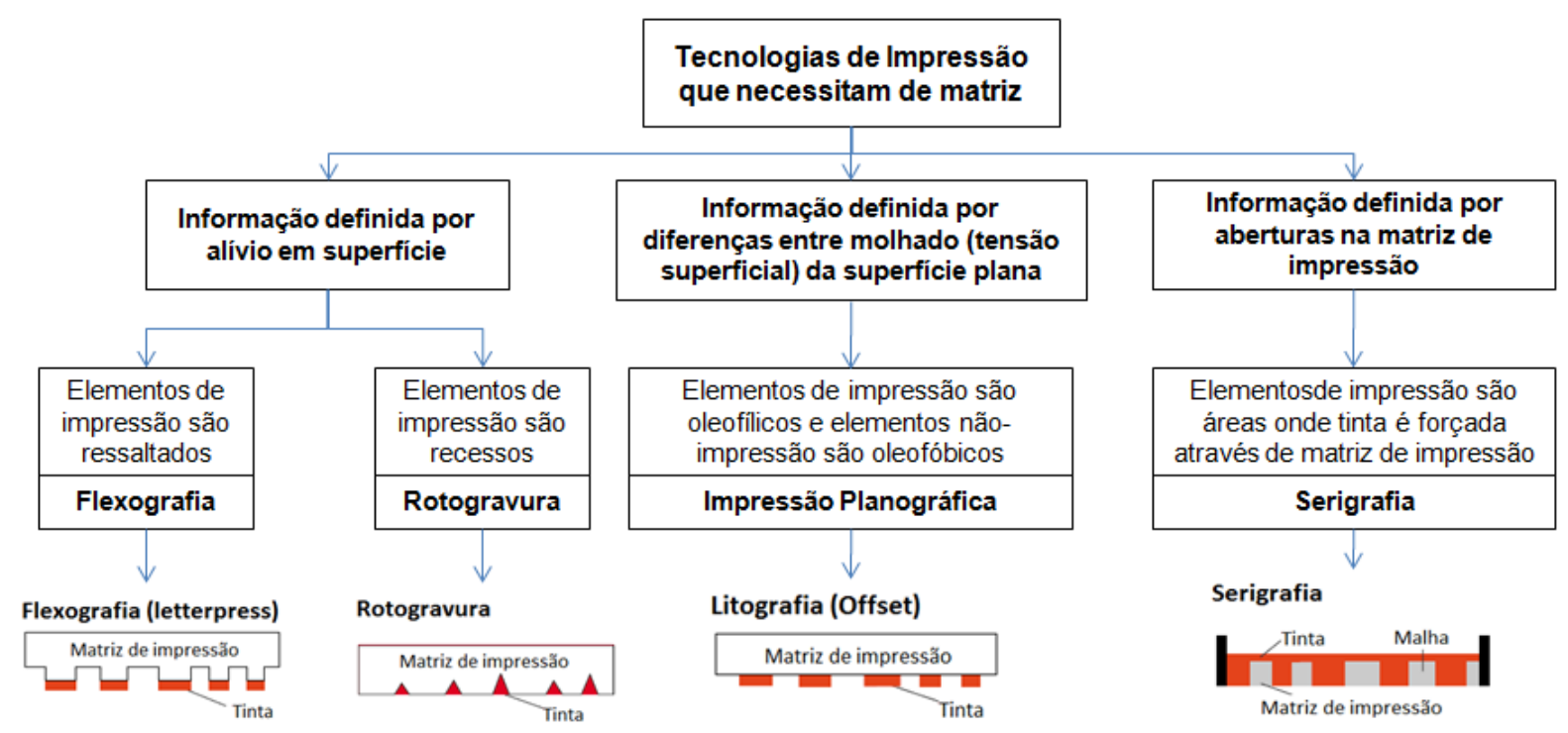

Figura 3.33 - Classificação de principais tipos de impressão por matriz, elaborado a partir de (KIPPHAN, 2001; BLAYO, 2007) 


\section{Litografia (Offset)}

O processo de litografia, também conhecido como offset é um tipo de impressão planográfica. Ou seja, não há recessos, ressaltos ou clichês para formação de geometria/informação (KIPPHAN, 2001; BLAYO, 2007).

Assim, para a delimitação de região de impressão, é necessário que sejam definidos alguns elementos básicos deste processo para melhor compreensão da essência do processo (Figura 3.34): elementos de impressão, elementos de nãoimpressão, sistema de tintagem, e sistema de ancoragem (KIPPHAN, 2001; BLAYO, 2007).

O sistema de tintagem proporciona o transporte e dosagem da tinta/material para o cilindro de chapa, onde a tinta se deposita em regiões de impressão. Adicionalmente o sistema de ancoragem proporciona em paralelo a transporte de uma solução de ancoramento nas regiões de não-impressão devido ao caráter hidrofílico destas regiões (KIPPHAN, 2001; BLAYO, 2007).

Após a deposição de material de ancoragem e tinta no cilindro de chapa, é depositada tinta no cilindro de cobertura que realizará a impregnação no substrato (KIPPHAN, 2001; BLAYO, 2007).

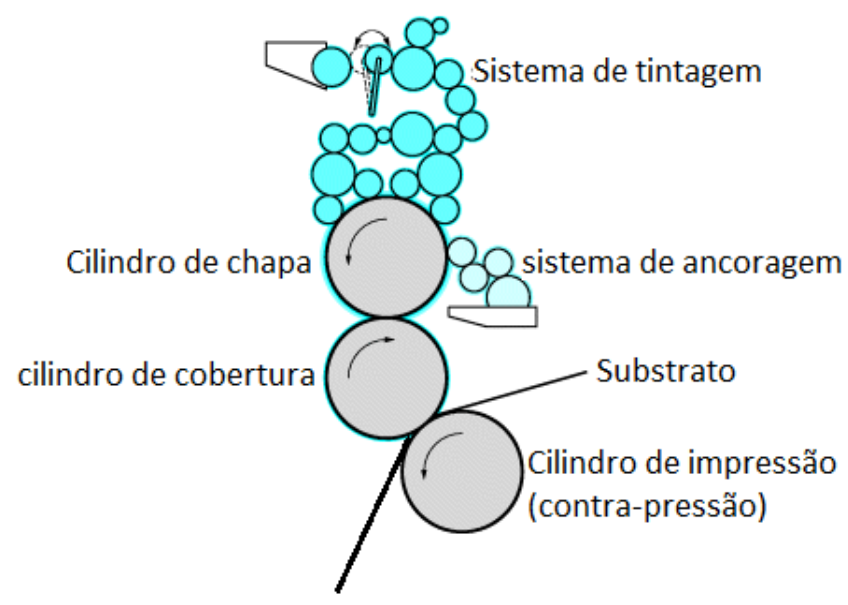

Figura 3.34 -Esquemático de funcionamento de processo de litografia, baseado em (KIPPHAN, 2001; BLAYO, 2007) 


\section{Rotogravura (Tampografia)}

No caso da rotogravura, o processo de deposição de tinta/material para o substrato é proporcionado pela transferência de material acumulado nos rebaixos existentes no cilindro de rotogravura (KIPPHAN, 2001; BLAYO, 2007).

De forma básica, o processo de rotogravura consite em três etapas: imersão do cilindro de rotogravura em reservatório de tinta ou material, remoção do excesso de material através de lâmina, transferência de material para substrato. Na Figura 3.35, além de serem ilustradas estas etapas, são também expostos os tipos de rebaixos utilizados para transporte e delimitação do material para o substrato. Neste caso, o volume de material a ser depositado é determinado pela profundidade e área dos rebaixos (KIPPHAN, 2001; BLAYO, 2007).

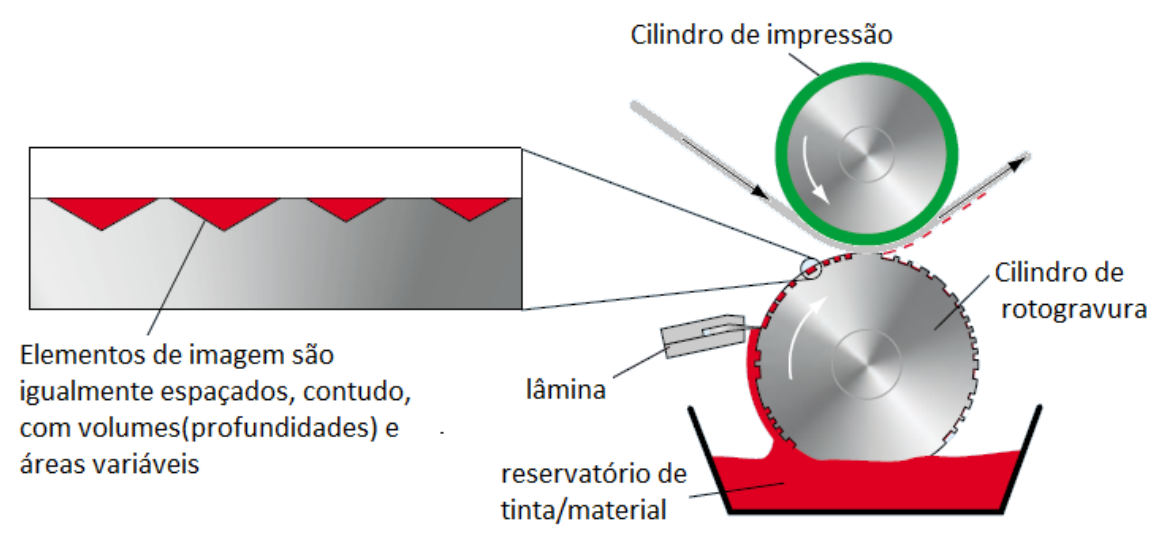

Figura 3.35 -Esquemático de funcionamento de processo de rotogravura direta, baseado em (KIPPHAN, 2001; BLAYO, 2007)

Outro caso específico de rotogravura (indireta) é a tampografia. Este processo é caracterizado pela utilização de carimbos semelhantes a almofadas que coletam a tinta/material contida em matriz transferindo e depositando em substrato ou superfície desejada. Este processo pode ser observado na Figura 3.36, onde é apresentado um esquemático de funcionamento de sistema de tampografia (KIPPHAN, 2001; BLAYO, 2007). 


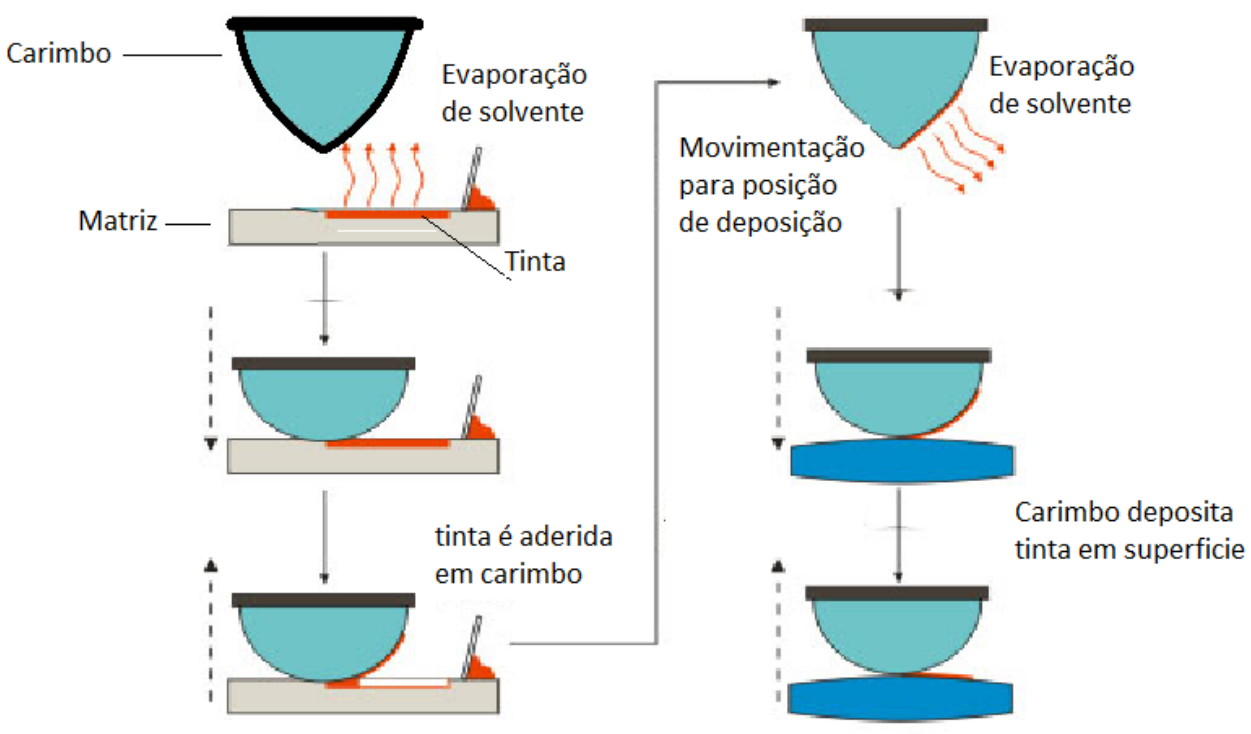

Figura 3.36 -Esquemático de funcionamento de processo de tampografia, baseado em (KIPPHAN, 2001; BLAYO, 2007)

\section{Serigrafia}

A serigrafia é um processo de impressão que se baseia na deposição de tinta/material em substrato através de orifícios da matriz de impressão, também conhecida como clichê. Neste processo, a tinta é previamente depositada sobre posição determinada do clichê, enquanto uma lâmina espalha a tinta sobre o clichê e transfere a tinta para substrato (KIPPHAN, 2001; BLAYO, 2007).

Os principais tipos deste processo podem ser classificados por meio do tipo de placa de base e tela. Desta forma, podendo ser: a) plano-plano(flat-to-flat); b) planoredondo (flat-to-round); c) redondo-redondo (round-to-round) ou d) impressão de corpo (body printing) (KIPPHAN, 2001; BLAYO, 2007). Um esquemático destes processos é apresentada na Figura 3.37. 


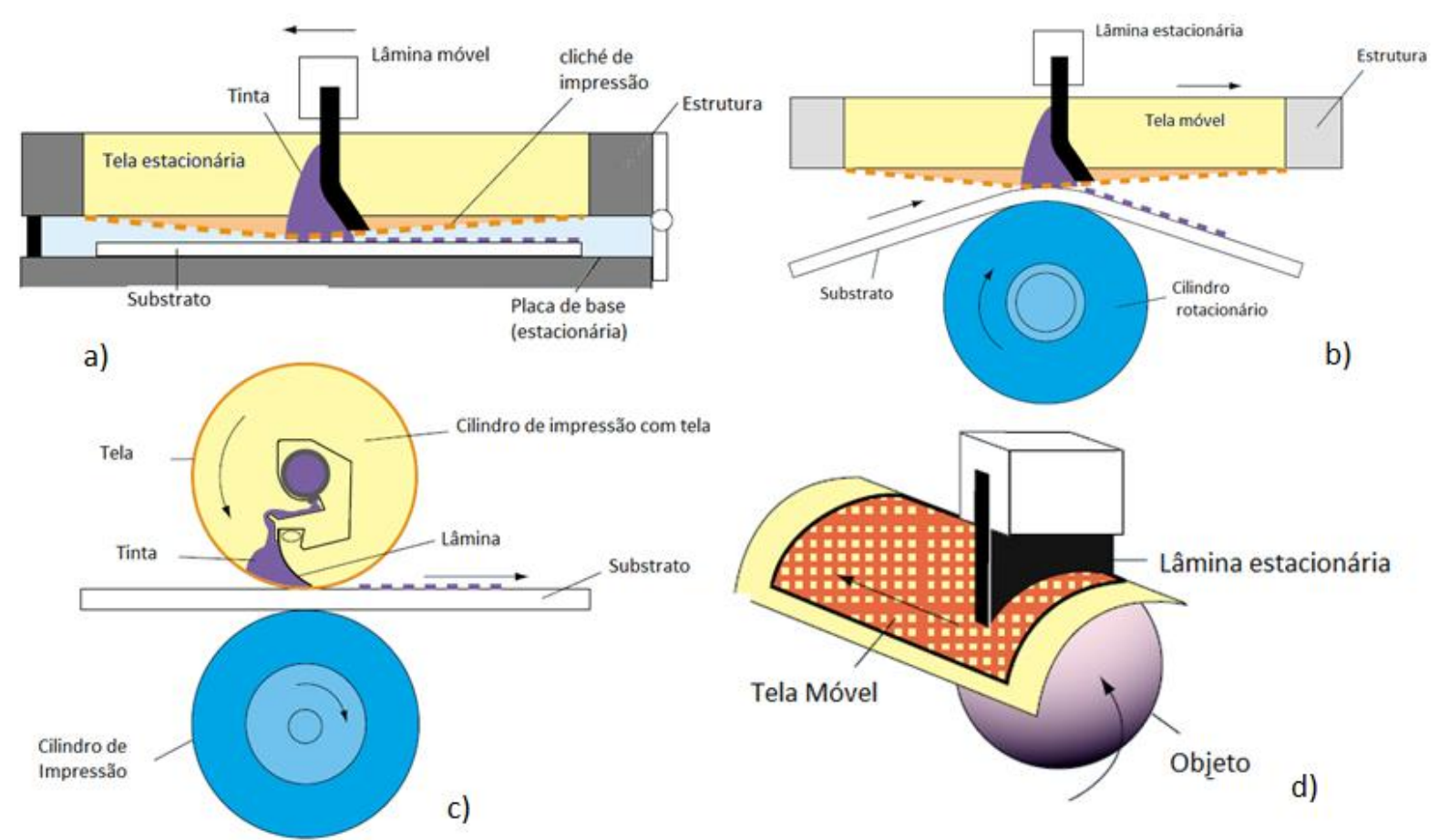

Figura 3.37 -Esquemático de funcionamento de processos de serigrafia:a) planoplano(flat-to-flat); b) plano-redondo (flat-to-round); c) redondo-redondo (round-toround); d) impressão de corpo (body printing) baseado em (KIPPHAN, 2001; BLAYO, 2007)

\section{Flexografia}

Ao contrario de processo de rotogravura, o processo de impressão por flexografia tem como forma de transferência e deposição de tinta/material ressaltos. Esta característica pode ser vista na Figura 3.38, onde é apresentado um esquemático simplificado de funcionamento deste processo (KIPPHAN, 2001; BLAYO, 2007).

Basicamente, as principais etapas da flexografia são transferência de tinta do reservatório para cilindro chapa e deposição da tinta do cilindro chapa para substrato (KIPPHAN, 2001; BLAYO, 2007).

Para a transferência da tinta para o cilindro chapa, um sistema de tintagem constituído por reservatório de tinta e unidade de rolos de tintagem transfere a 
tinta/material para chapa de impressão. Esta chapa de impressão é localizada no cilindro de chapa e contém ressaltos que delimitam a forma das geometrias/informações a serem depositadas em substrato. Em seguida, a tinta aderida na chapa de impressão é depositada no substrato, que é pressionado contra o cilindro de chapa (KIPPHAN, 2001; BLAYO, 2007).

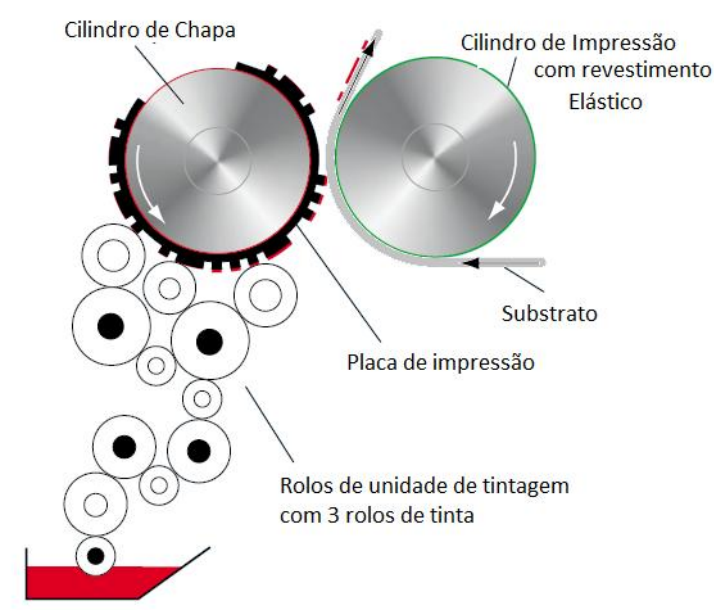

Figura 3.38 -Esquemático de funcionamento de processo de flexografia, baseado em (KIPPHAN, 2001; BLAYO, 2007)

\subsection{Máquinas de precisão}

Em função da importância do desenvolvimento de sistema de posicionamento para este projeto, as principais caracteristicas encontradas em projetos de máquinas ferramenta e máquinas de precisão são expostas nesta seção.

Além dos conceitos essenciais de sistemas de posicionamento, são também abordados, nesta seção, sistemas de controle e estimativa de erros.

\subsubsection{Precisão, resolução e repetibilidade}

Entre os conceitos fundamentais de projetos de equipamentos de precisão, encontram-se a precisão, a repetebilidade e a resolução. Estes conceitos podem ser 
observados graficamente na Figura 3.39, onde a precisão é definida como a diferenca entre a posição calculada e a posição real encontrada na ponta da ferramenta (BERG, 1965; SLOCUM, 1992; HALE, 1999; DORNFELD e LEE, 2007; TAN et al., 2008; VENKATESH e IZMAN, 2008).

Por outro lado, a repetebilidade (precisão) é determinada pelo erro (desvio padrão) entre posições reais da ferramenta ao longo de um numero consecutivo de tentativas do equipamento voltar para a mesma posição. Este conceito é também ilustrado graficamente na Figura 3.39, sendo marcada pelo raio da circunferência circunscrita aos pontos gerados por cada tentativa (BERG, 1965; SLOCUM, 1992; HALE, 1999; DORNFELD e LEE, 2007; TAN et al., 2008; VENKATESH e IZMAN, 2008).

Adicionalmente, cabe ressaltar que um dos maiores fatores que colaboram para este erro é a folga axial dos fusos (lead screw backlash), sendo evidenciada através da mudança do sentido de deslocamento (BERG, 1965; SLOCUM, 1992; HALE, 1999; DORNFELD e LEE, 2007; TAN et al., 2008; VENKATESH e IZMAN, 2008).

Já a resolução é marcada por ser o deslocamento mínimo proporcionado pelo equipamento de forma controlada. Em geral, considera-se como requisito de projeto que a resolução seja 10 vezes superior à precisão esperada no projeto. Logo, para equipamentos com precisão de $100 \mu \mathrm{m}$, por exemplo, a resolução adequada para

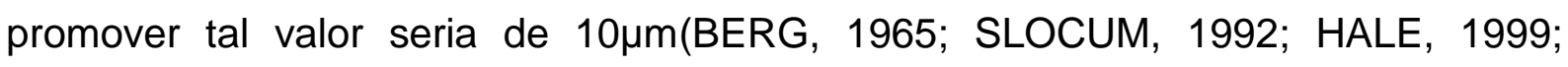
DORNFELD e LEE, 2007; TAN et al., 2008; VENKATESH e IZMAN, 2008). 


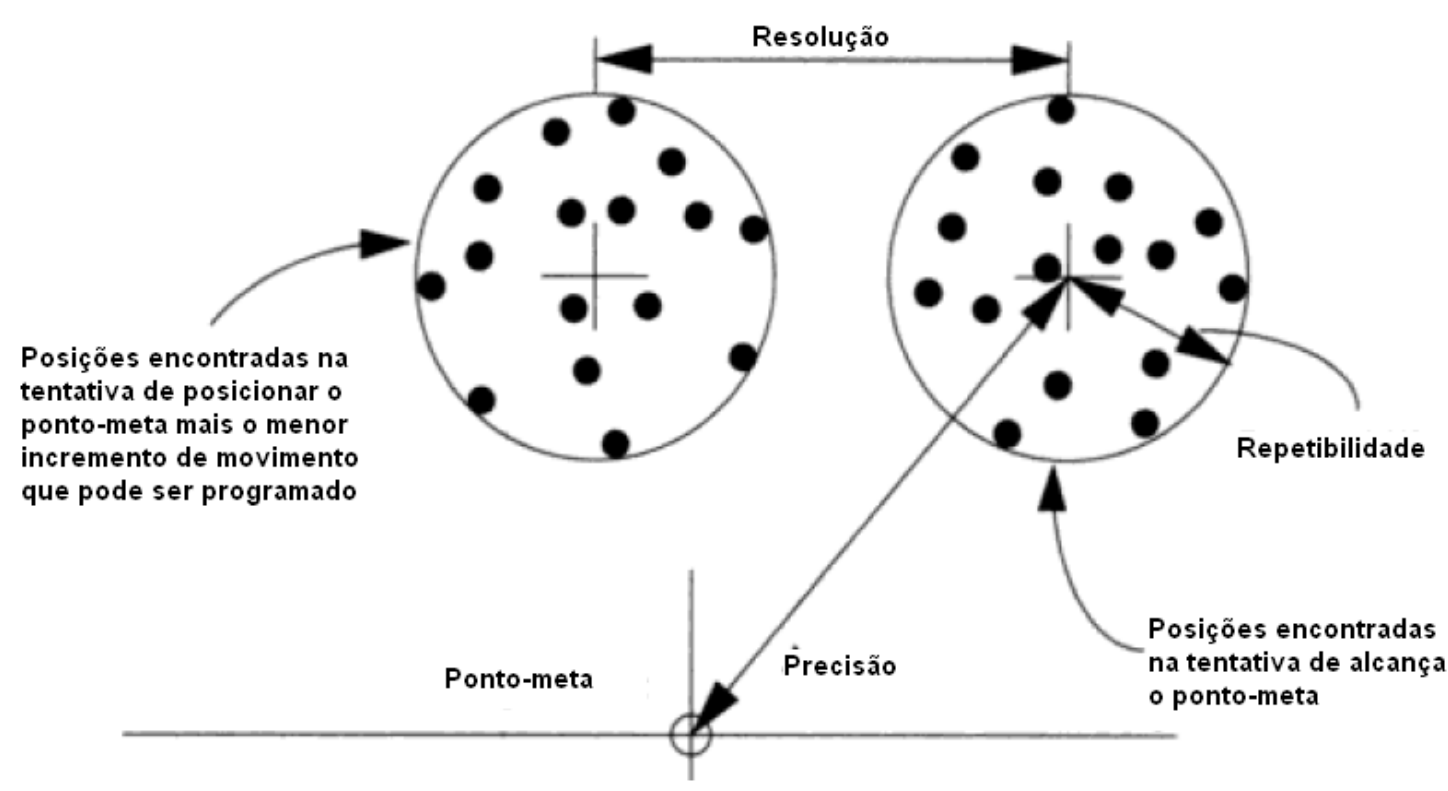

Figura 3.39 - Representação de conceitos de precisão, repetibilidade e resolução (SLOCUM, 1992)

\subsubsection{Layout de equipamentos}

Entre os principais conceitos de equipamentos de posicionamento abordados neste estudo, destatam-se os cartesianos baseados em deslocamento linear em 3 direções (3 eixos). Isto se deve em função do conceito fundamental de processo de fabricação aditiva (AM) ser atendido com equipamentos $2 \frac{1}{2}$ eixos, contudo, podendo ser estendido à 3 eixos.

Logo, pode-se listar as principais concepções de máquinas ferramentas com deslocamento em 3 eixos conforme a disposição de seus elementos básicos: mesa eixos, cabeçote de ferramenta. Na Tabela 3.10 são apresentadas as principais concepções utilizadas para máquinas ferramentas.

Adicionalmente, destaca-se, entre estas, a concepção de mesa móvel vertical, pois esta é amplamente empregada para tecnologias $A M$, como em tecnologias FDM, 3DP, SLS e LOM (SACHS et al., 1989; BEAMAN e DECKARD, 1990; PRINZ et al., 1997; MORITA e SUGIYAMA, 2000; CRUMP et al., 2009). 
Tabela 3.10 - Levantamento de principais concepções de equipamentos de posicionamento cartesianos com 3 eixos

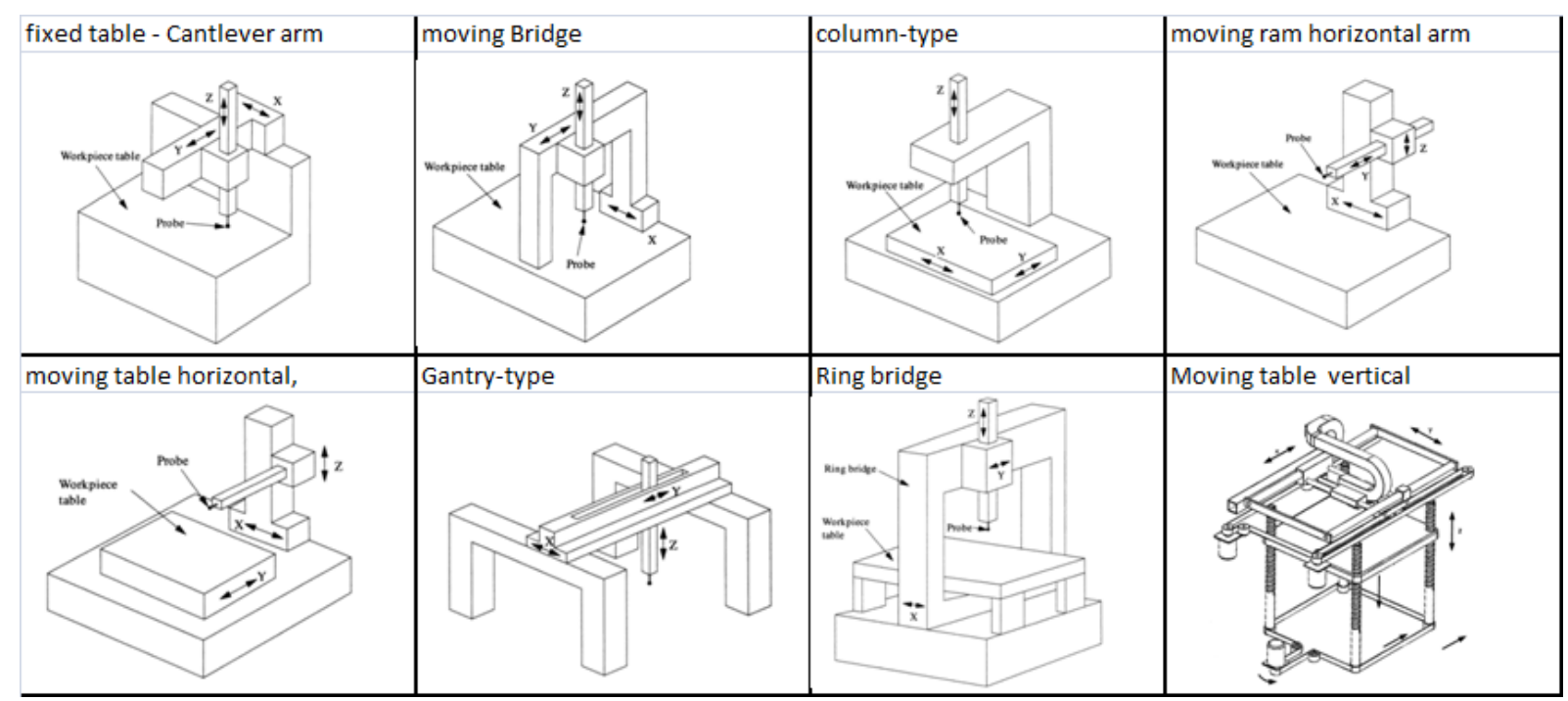

\subsubsection{Estimativa de erros - "Error Budgeting"}

Com referência à estimativa de erros, deve-se ressaltar a sua importância, visto que a determinação de custos, processos de fabricação, tolerância de componentes e precisão final do equipamento pode ser realizada através testa análise, ainda em fases iniciais do projeto. Adicionalmente, esta técnica permite a identificação de erros de equipamentos já finalizados, e consequentemente possibilitando a compensação destes erros por meio de software (BERG, 1965; SLOCUM, 1992; HALE, 1999; RAMESH et al., 2000; TONG et al., 2003; TONG et al., 2004; DORNFELD e LEE, 2007; TAN et al., 2008; TONG et al., 2008; VENKATESH e IZMAN, 2008).

Para a determinação do modelo matemático dos erros do equipamento, são utilizadas matrizes de transformação homogênea (Homogeneous Transformation Matrix - HTM) de cada um dos eixos ou montagens principais, conforme Equação (3.10) (BERG, 1965; SLOCUM, 1992; HALE, 1999; RAMESH et al., 2000; 
TONG et al., 2003; TONG et al., 2004; DORNFELD e LEE, 2007; TAN et al., 2008; TONG et al., 2008; VENKATESH e IZMAN, 2008).

$$
{ }^{a} H T M_{b}=\left[\begin{array}{cccc}
O_{i x} & O_{i y} & O_{i z} & d x \\
O_{j x} & O_{j y} & O_{j z} & d y \\
O_{k x} & O_{k y} & O_{k z} & d z \\
0 & 0 & 0 & 1
\end{array}\right]=\left[\begin{array}{cccc}
\cos \theta y+\cos \theta z & -\sin \theta & \sin \theta y & d x \\
\sin \theta z & \cos \theta x+\cos \theta & -\sin \theta x & d y \\
-\sin \theta y & \sin \theta x & \cos \theta x+\cos \theta y & d z \\
0 & 0 & 0 & 1
\end{array}\right]
$$

Nesta equação, $d x$, dy e dz são as coordenadas de deslocamento do eixo de referência para o novo eixo, enquanto $O_{i x}, O_{i y}, O_{i z}, O_{j x}, O_{j y}, O_{j z}, O_{k x}, O_{k y}$ e $O_{k z}$ são decomposições das direções conforme cosenos entre os vetores unitários i, j, k. Adicionalmente, esta decomposição pode ser ilustrada em função do deslocamento angular nas direções $\mathrm{x}, \mathrm{y}, \mathrm{z}$ ( $\theta \mathrm{x}$ - rolagem (roll), $\theta \mathrm{y}$ - arfagem (pitch) e $\theta \mathrm{z}-$ guinada (yaw) ) (BERG, 1965; SLOCUM, 1992; HALE, 1999; DORNFELD e LEE, 2007; TAN et al., 2008; VENKATESH e IZMAN, 2008).

Adicionalmente, para cada conjunto ou eixo, são incluídos individualmente os erros relacionados aos mesmos, implicando na determinação do erro final entre o sistema de cordenadas de referência e o sistema de coordenadas da ferramenta. As Equações (3.11)e (3.12) apresentam a inclusão do erro para cada eixo, assim como HTM geral do equipamento. Através desta HTM, torna-se possível identificar o erro final entre do ponto de referência (workpiece) e ferramenta (BERG, 1965; SLOCUM, 1992; HALE, 1999; DORNFELD e LEE, 2007; TAN et al., 2008; VENKATESH e IZMAN, 2008).

${ }^{a} T_{b_{\text {error }}}={ }^{a} T_{b} \cdot{ }^{a} E_{b}=\left[\begin{array}{cccc}1 & 0 & 0 & X \\ 0 & 1 & 0 & Y \\ 0 & 0 & 1 & Z \\ 0 & 0 & 0 & 1\end{array}\right] \cdot\left[\begin{array}{cccc}1 & -\varepsilon_{z} & \varepsilon_{y} & \delta x \\ \varepsilon_{z} & 1 & -\varepsilon_{x} & \delta y \\ -\varepsilon_{y} & \varepsilon_{x} & 1 & \delta z \\ 0 & 0 & 0 & 1\end{array}\right]=\left[\begin{array}{cccc}1 & -\varepsilon_{z} & \varepsilon_{y} & X+\delta x \\ \varepsilon_{z} & 1 & -\varepsilon_{x} & Y+\delta y \\ -\varepsilon_{y} & \varepsilon_{x} & 1 & Z+\delta z \\ 0 & 0 & 0 & 1\end{array}\right]$

Sendo, $X, Y, Z$ posições de deslocamento entre eixos; $\varepsilon_{x}$, $\varepsilon_{y}$ e $\varepsilon_{z}$ erros angulares e $\delta x, \delta y$ e $\delta z$ erros lineares nos sentidos $x, y, z$, respectivamente. 


$$
{ }^{R} T_{z_{\text {error }}}={ }^{T} T_{x_{\text {error }}}{ }^{y} T_{y_{\text {error }}}{ }^{z} T_{z_{\text {error }}}
$$

Entre as diversas fontes de erro encontradas em sistemas de posicionamento, pode-se dividir os tipos de erro em erros sistêmicos, aleatórios e de histerese. Contudo, as principais fontes de erros determinadas na fase de projeto mecânico são sistêmicas, como por exemplo (BERG, 1965; SLOCUM, 1992; HALE, 1999; RAMESH et al., 2000; TONG et al., 2003; TONG et al., 2004; DORNFELD e LEE, 2007; TAN et al., 2008; TONG et al., 2008; VENKATESH e IZMAN, 2008):

- Errors mecânicos Quasi-estáticos

- Erros Geometricos

- Erros Cinemáticos

- Erros induzidos por forças externas

- Erros causados por força gravitacional

- Erros causados por aceleração dos eixos

- Eixos causados por forças de corte

- Erros induzidos por esforços de montagem de equipamento

- Erros ocasionados por expansão térmica

- Erros ocasionados por instabilidade de material

○ Erros de instrumentação

- Errors mecânicos ocasionados por forças dinâmicas

○ Vibração estrutural

○ Fricção

Sobretudo, as fontes de erro mais relevantes para o desenvolvimento de equipamentos AM são erros geométricos, cinemáticos e os ocasionados por aceleração dos eixos. Isto se deve ao fato de sistemas AM, em sua maioria, não apresentar forças de corte, assim como baixas temperaturas (BERG, 1965; 
SLOCUM, 1992; HALE, 1999; DORNFELD e LEE, 2007; TAN et al., 2008; VENKATESH e IZMAN, 2008).

Em adição, erros aleatórios podem incluídos no modelo matemático através de acrécimos percentuais aos erros sistêmicos, possibilitando ajustar o modelo matemático ao real (BERG, 1965; SLOCUM, 1992; HALE, 1999; DORNFELD e LEE, 2007; TAN et al., 2008; VENKATESH e IZMAN, 2008).

\subsubsection{Sistema de Controle}

Um dos elementos mais importantes para equipamentos de posicionamento é o sistema de controle, proporcionando o acionamento dos atuadores, monitoramento de parâmetros de processos e monitoramento do deslocamento, no caso de sistemas com malha fechada (BERG, 1965; SLOCUM, 1992; HALE, 1999; RAMESH et al., 2000; TONG et al., 2003; WILLIAMS, 2003; TONG et al., 2004; DORNFELD e LEE, 2007; SUH et al., 2008; TAN et al., 2008; TONG et al., 2008; VENKATESH e IZMAN, 2008).

Os principais elementos encontrados em sistema de controle de equipamentos de posicionamento são: controlador, sensores, atuadores e drives de acionamento. Contudo, o controlador a peça chave para a implementação destes sistemas, visto que este é quem realiza o processamento das interpolações e sinais provenientes dos sensores, assim como o acionamento de atuadores (BERG, 1965; SLOCUM, 1992; HALE, 1999; RAMESH et al., 2000; TONG et al., 2003; WILLIAMS, 2003; TONG et al., 2004; DORNFELD e LEE, 2007; ALBERT, 2008; SUH et al., 2008; TAN et al., 2008; TONG et al., 2008; VENKATESH e IZMAN, 2008).

Como pode ser observado na Figura 3.40, um sistema de controle realiza essencialmente a transmissão de instruções de posicionamento vindas do programa NC para os drives de acionamento. Adicionalmente, este sistema promove o monitoramento dos atuadores em função de ajustar posicionamento, caso necessário. Nesta figura é apresentada uma ilustração simplificada de sistema de 
controle em malha fechada, sendo utilizada uma encoder linear incremental, como sensor de posicionamento, e fuso acionado por servomotor, como atuador linear.

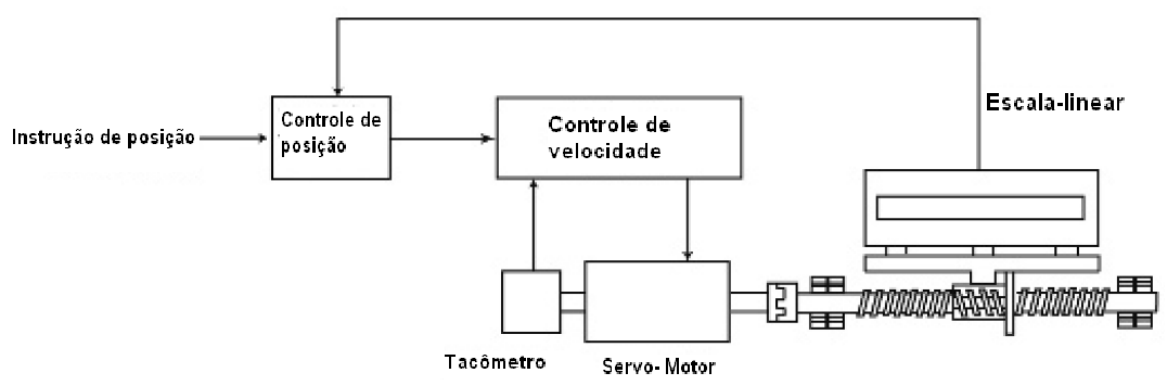

Figura 3.40 - Representação de sistema de controle de equipamentos de posicionamento com malha fechada (SUH et al., 2008)

Visto que os equipamentos de posicionamento proporcionam deslocamentos restritos a uma resolução determinada, cabe também ao controlador gerar o encadeiamento de movimentos entre os eixos de forma a gerar uma trajetória (linear, circular, curvas cônicas) de forma fiel. Este encadeiamento de movimentos é chamado de interpolação, sendo apresentados, na Figura 3.41, exemplos de interpolação linear e circular (SUH et al., 2008).

Como estas interpolações, muitas vezes, demandam um tempo de processamento longo, podem ser observadas descontinuidades do movimento da trajetória, Em função disto a determinação de controladores deve prever o tipo de interpolação suportada, velocidade de processamento e memória de armazenamento de comandos (buffer) (SUH et al., 2008). 


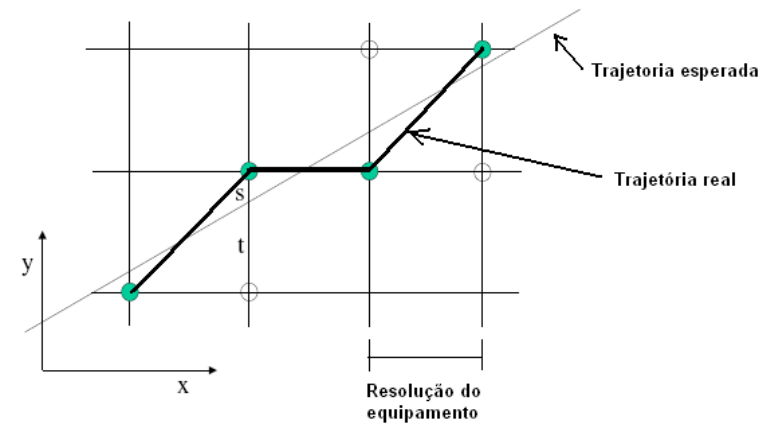

a)

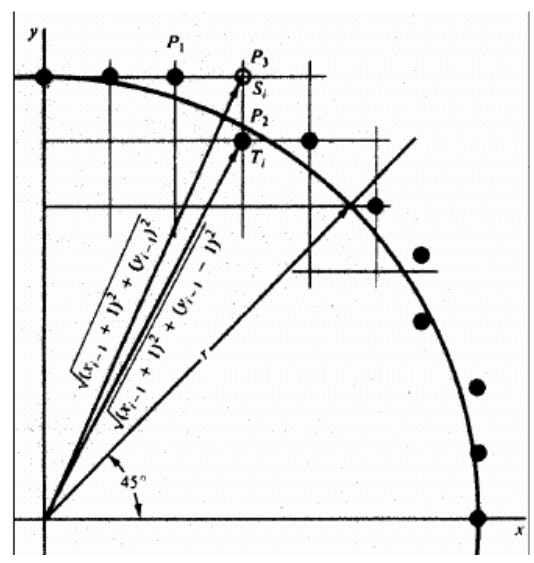

b)

Figura 3.41 - llustração de processo de interpolação linear (a) e circular (b)

No caso do controle do equipamento ser realizado por computadores pessoais (arquiteturas PC-NC), o sistema de controle pode ser dividido em: software de controle, interface de comunicação, interface de potência, atuadores e sensores. (WILLIAMS, 2003; ALBERT, 2008; SUH et al., 2008).

Atualmente, os principais softwares de controle CNC são apresentados na Tabela 3.11, proporcionando comunicação através de porta paralela (LPT) ou USB. Logo, a interface de comunicação tem por objetivo principal, a interpretação dos sinais enviados pela porta paralela (LPT)/USB do computador, convertendo e transmitindo para drives de acionamento. Em adição, esta interface deve realizar a leitura dos sensores, transmitindo para o software de controle processar os valores recalculando os novos valores a serem enviados. 
Tabela 3.11 - Levantamento dos principais programas para implementação de arquitetura PC-NC

\begin{tabular}{|l|l|l|}
\hline Programas & Sistema operacional & Porta de comunicação \\
\hline EMC2 & Linux & Paralela (LPT) \\
\hline KCAM & Windows 98 & Paralela (LPT) \\
\hline TurboCNC & MS-DOS & Paralela (LPT) \\
\hline Mach2/3 & Windows XP & Paralela (LPT) \\
\hline DeskCNC & Windows XP & Paralela (LPT) \\
\hline CNCZeus & MS-DOS & Paralela (LPT) \\
\hline Master5 & Windows 98 & Paralela (LPT) \\
\hline DesKAM & Windows XP/MS-DOS & Paralela (LPT) \\
\hline CNCPro & MS-DOS & Paralela (LPT) \\
\hline USBCNC & Windows XP & USB \\
\hline CNCDudez & Windows XP & USB \\
\hline EMC2Arduino & Linux & Arduino-USB \\
\hline ReplicatorG & Windows & Arduino-USB \\
\hline
\end{tabular}

Cabe também ressaltar que a determinação dos drives de acionamento é diretamente relacionada ao tipo do atuador a ser controlado. Logo, apesar dos atuadores lineares serem essencialmente mecânicos, como por exemplo, fusos, roscas e correias, o acionamento destes mecanismos é proporcionado por meio de motores elétricos. Entre os principais motores utilizados em sistemas de posicionamento, destacam-se os motores de passo, os motores de corrente contínua (CC) e os servomotores (WILLIAMS, 2003; ALBERT, 2008; SUH et al., 2008).

Em relação aos motores de passo, este é o tipo de motor mais empregado em sistemas de posicionamento com malha de controle aberta, em função de seu princípio de funcionamento. Ao contrário de motores de corrente contínua (CC), que giram indeterminadamente quando energizados, o motore de passo proporciona movimentos fracionados (WILLIAMS, 2003; ALBERT, 2008; SUH et al., 2008).

Conforme é ilustrado na Figura 3.42, o acionamento de motores de passo são realizados conforme a combinação de acionamentos das bobinas do estator (CONDIT e JONES, 2004; SUH et al., 2008). 


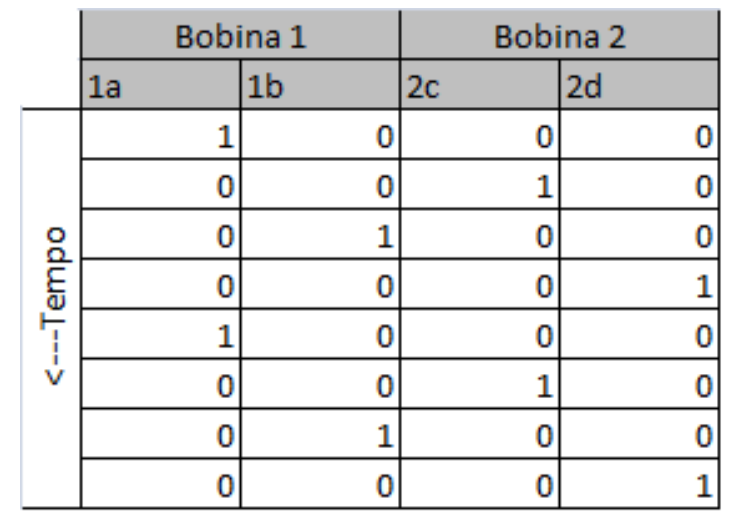
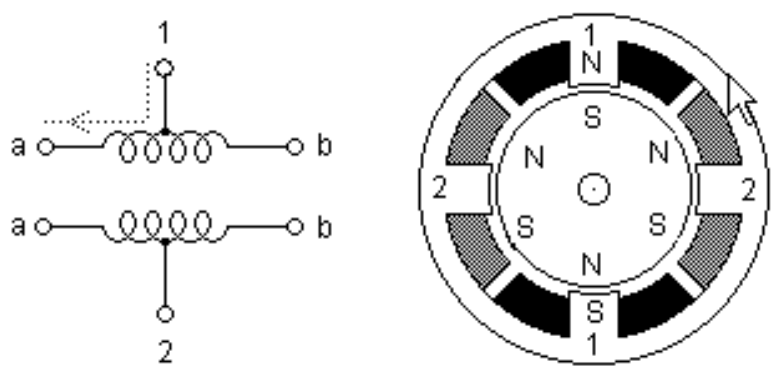

Figura 3.42 - Representação esquemática de acionamento de motores de passo unipolares, adaptado de (CONDIT e JONES, 2004)

No caso exemplificado nesta figura, é apresentado um motor de passo unipolar com deslocamento angular de $36^{\circ}$ por passo. Contudo, os motores de passo são divididos em dois grupos, os unipolares, que permitem serem controlados por acionamento direto das bobinas, e os bipolares, cujo controle é realizado por meio de pontes $\mathrm{H}$, presentes em drive de acionamento (DRURY e ENGINEERS, 2001; CONDIT e JONES, 2004).

Cabe também ressaltar que o acionamento de motores de passo pode ser classificado em passo cheio (full-step mode), meio passo (half-step mode), e passos fracionados ou micropassos (microstepping mode). Neste caso, com o auxilio de drives de acionamento, o motor de passo proporciona o deslocamento angular equivalente à fração do passo cheio. Ou seja, para um motor de 200 passos por revolução ou $1,8^{\circ}$ por passo, um drive que proporciona um fracionamento de 1/256 permite ao motor realizar um deslocamento de $0.007^{\circ}$ por passo (DRURY e ENGINEERS, 2001; CONDIT e JONES, 2004; ATHANI, 2007).

Em contraste, servomotores de rotação livre são motores de CC cujo controle é realizado por meio de sistema de malha fechada, sendo composto por drive de controle e encoder. Neste caso, o posicionamento angular do motor é determinado pelo encoder, enquanto a velocidade de rotação é controlada por meio de modulação por largura de pulso (Pulse Width Moduling - PWM) (DRURY e ENGINEERS, 2001; WILLIAMS, 2003; ATHANI, 2007; ALBERT, 2008; SUH et al., 2008). 
Já em relação aos principais sensores utilizados em sistemas de posicionamento, destacam-se os encoders, resolvers, capacitivos, indutivos e chaves fim de curso. Sobretudo, os encoders lineares tomam papel mais relevante na composição de sistemas de controle de equipamentos de posicionamento (BERG, 1965; SLOCUM, 1992; HALE, 1999; WILLIAMS, 2003; DORNFELD e LEE, 2007; ALBERT, 2008; SUH et al., 2008; TAN et al., 2008; VENKATESH e IZMAN, 2008).

Estes sensores são caracterizados por conversão de deslocamento de forma discreta através de transdudores óticos. A concepção deste tipo de sensor é composta por receptor ótico, emissor luminoso e obstrusor (régua linear). Neste caso, a regua linear proporciona a obstrução da luz vinda do emissor conforme distâncias pré-estabelecidas A contagem do numero de pulsos proporcionados pelo movimento do atuador linear determina o deslocamento deste. Este processo pode ser observado na Figura 3.43, onde é apresentado um esquemático de funcionamento de encoder linear absoluto (WEBSTER, 1999).

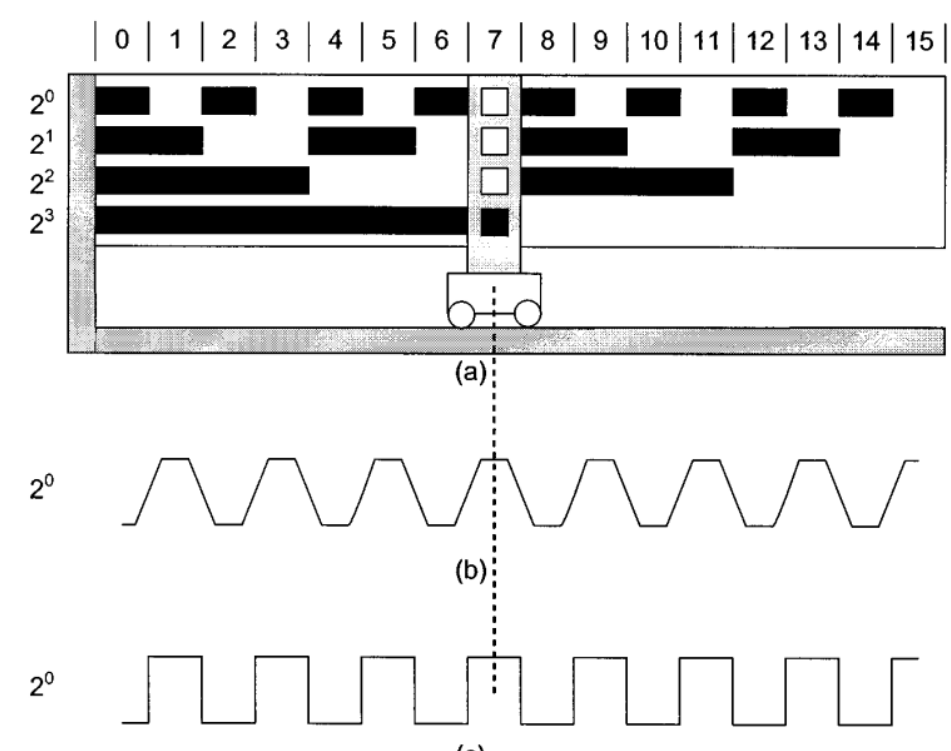

(c)

Figura 3.43 - Representação esquemática de funcionamento de encoder linear absoluto (WEBSTER, 1999) 
Em relação aos sensores capacitivos, indutivos e óticos, em geral estes tem função similar as chaves de fim de curso, permitindo adicionalmente a indicação de proximidade do sensor. Contudo, estes podem ser também utilizados para determinação de distâncias, espessuras, rugosidade e opacidade, entre outras aplicações (BERG, 1965; SLOCUM, 1992; HALE, 1999; WILLIAMS, 2003; DORNFELD e LEE, 2007; ALBERT, 2008; SUH et al., 2008; TAN et al., 2008; VENKATESH e IZMAN, 2008). 


\section{PARTE I - DESENVOLVIMENTO DE MATERIAL}

\section{MATERIAL E MÉTODOS}

Neste Capítulo, são apresentados os principais métodos e materiais empregados para a realização das pesquisas de fundamentação. Adicionalmente, os tópicos abordados neste capítulo foram divididos em materiais e equipamentos, processo de fabricação de corpos de prova e caracterização de material.

\subsection{Materiais e equipamentos}

Nesta seção, são apresentados os principais materiais utilizados ao longo deste trabalho, assim como os principais equipamentos empregados para realização dos ensaios.

\subsubsection{Monômero - Metil Metacrilato (MMA)}

Para a composição do material foi escolhido e utilizado como monômero, o componente químico Metil Metacrilato, tendo objetivo de geração do material PMMA (Poli-Metil Metacrilato).

Este composto, cuja representação de estrutura molecular é apresentada na Figura 4.1, tem massa molecular de 100.12 e pressão de vapor de $29 \mathrm{mmHg}\left(20^{\circ} \mathrm{C}\right)$. Como pode ser observado nesta figura, este monômero apresenta um grupo funcional acrilato em sua estrutura molecular (SIGMA-ALDRICH, 2008a). 


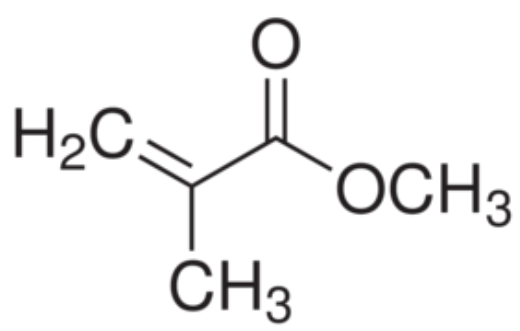

Figura 4.1 - Ilustração de estrutura molecular do Monômero MMA (Methyl Methacrylate) (SIGMA-ALDRICH, 2008a)

Contudo, para garantir a estabilidade do material ao longo do transporte e estocagem, este composto químico apresenta $30 \mathrm{ppm}$ do inibidor MEHQ (monomethyl ether hydroquinone) (SIGMA-ALDRICH, 2008a).

Cabe ressaltar que apesar da presença do inibidor, segundo (POLYSCIENCES, 2009), não há a necessidade de remoção do inibidor por meio de destilação para aplicações onde material pode apresentar coloração amarelada. Logo, a compensação do desempenho da cura do material pode ser realizado pelo iniciador.

\subsubsection{Oligômero - TMPTA(Trimethylolpropane triacrylate)}

Em relação ao oligômero escolhido para compor o material polimérico, foi escolhido o CN501 da Sartomer (SARTOMER, 2007; 2008). Este oligômero é também conhecido como TMPTA (Trimethylopropane triacrylate), apresentando 3 grupos funcionais de acrilatos em sua estrutura molecular, como pode ser observado na Figura 4.2. 


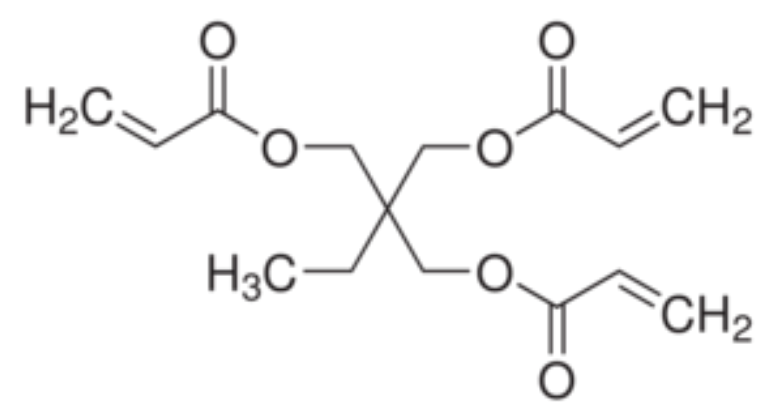

Figura 4.2 - llustração de estrutura molecular do oligômero CN501 ou TMPTA (Trimethylopropane triacrylate) (SIGMA-ALDRICH, 2008b)

Este composto químico, apresentando massa molecular de 296.32, promove o fenômeno de grafitização e a interamarração (crosslinking) entre as cadeias poliméricas em função de proporcionar o crescimento das cadeias poliméricas em 3 direções. Em função disto, este oligômero de baixa viscosidade (64000cP) proporciona rápida resposta de cura assim como altos valores de adesividade e dureza (SARTOMER, 2007; 2008; SIGMA-ALDRICH, 2008b).

Contudo, com objetivo de estabilização do composto durante armazenamento, pode ser encontrado 100ppm do inibidor MEHQ (monomethyl ether hydroquinone).

\subsubsection{Não Solvente - Alcool Isopropílico}

Entre os diversos compostos químicos que se comportam como não solventes para polímeros a base de metacrilato de metila, foi utilizado álcool isopropílico como não solvente. Este álcool, cuja ilustração da estrutura molecular é apresentada na Figura 4.3, tem massa molecular de 60.10 , enquanto pressão de vapor de $33 \mathrm{mmHg}$ $\left(20^{\circ} \mathrm{C}\right)$. 


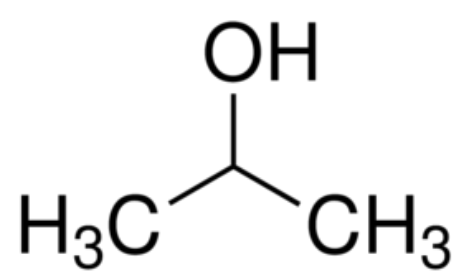

Figura 4.3 - Ilustração de estrutura molecular de álcool Isopropílico (SIGMAALDRICH, 2011)

\subsubsection{Fotoiniciador Omirad Cureall 2500}

Em relação ao iniciador utilizado para o desenvolvimento deste trabalho, foi selecionado o fotoiniciador Omirad Cureall 2500 da IGM, em função do ser alto valor de absorbância na faixa de 400nm de comprimento de onda de luz.

Este valor pode ser observado na Figura 4.4, onde é apresentada a curva espectroscópica do iniciador. Pode-se observar que para o comprimento de onda de 400nm, a absorbância proporcionada pelo componente químico é de aproximadamente $1.5 \mathrm{ml} / \mathrm{gr}$. Em adição, este valor de absorbância é encontrada para uma concentração de iniciador de $0.1 \mathrm{mg} / \mathrm{ml}$ em tolueno (IGM, 2005). 


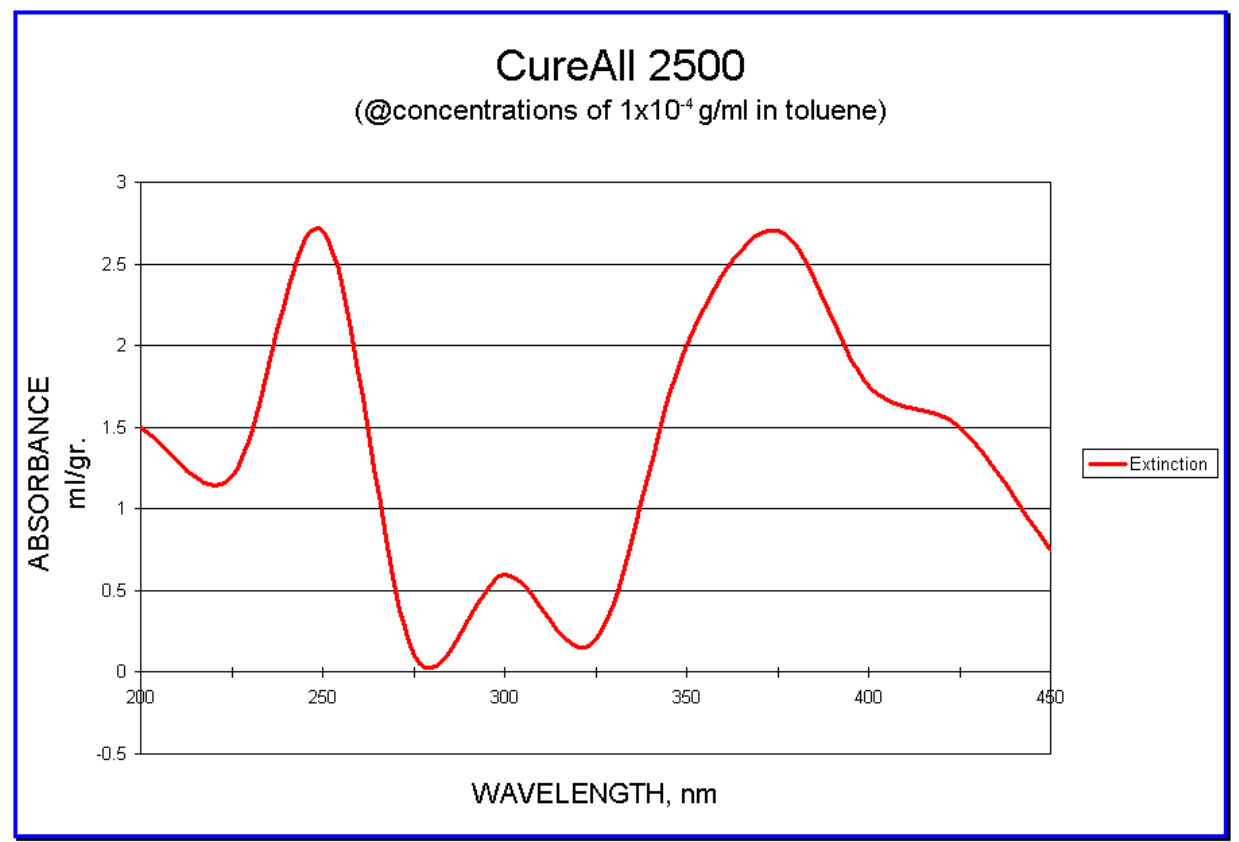

Figura 4.4 - Curva espectroscópica de fotoiniciador Omirad Cureall 2500 (IGM, 2005)

Adicionalmente, este iniciador tem massa molecular de 246, enquanto os teores percentuais para aplicação recomendados pelo fornecedor são de 1 a $3 \%$; para tintas de pintura (camadas espessas) e de 4 a 10\%, para tintas de impressão (camadas finas) (IGM, 2005).

\subsubsection{Substrato Celulósico}

Em relação aos materiais celulósicos estudados neste trabalho, foram utilizados 4 tipos de papel representando as principais classes de papel utilizadas comercialmente no Brasil. Entre estes tipos de papel estão: papel sulfite, papel sulfurizé, papel vegetal, papel seda.

O papel sulfite escolhido para ser estudado neste trabalho é fornecido em folhas pela empresa Internacional Paper, tendo gramatura de $75 \mathrm{~g} / \mathrm{m}^{2}$ (INTERNATIONALPAPERS, 2011), enquanto o papel Vegetal escolhido tem 
gramatura de $75 \mathrm{~g} / \mathrm{m}^{2}$ e é fornecidoem folhas ou bobina pela empresa Spiral do Brasil.

Já o papel de seda, é fornecido em bobina pela empresa M. SASSO, tendo gramatura de $18 \mathrm{~g} / \mathrm{m}^{2}$, enquanto o papel sulfurizé é fornecido em folhas pela empresa Graffiti Artes, sendo a sua gramatura igual a $35 \mathrm{~g} / \mathrm{m}^{2}$.

\subsubsection{Balança digital}

Para realização das medições de massa, tanto para formulação do material como de outros experimentos realizados neste trabalho, foi utilizada uma balança digital de precisão igual a $1 \mathrm{mg}$.

\subsubsection{Lâmpada UV - Philips 9W 10/2P UNP}

Ao longo deste trabalho foram utilizadas duas fontes de luz UV, sendo uma destas fontes, uma lâmpada UV de 9W de potência. Esta lâmpada (PL-S 9W 10/2P UNP) tem como seu fornecedor a empresa Philips, tendo como dimensões maximas iguais a 167.5x28x13mm (PHILIPS, 2008).

$\mathrm{Na}$ Figura 4.5, pode ser observado uma foto e um esquemático com as principais dimensões desta lâmpada. O comprimento de onda emitido por esta lâmpada se encontra dentro da faixa UVA, permitindo, desta forma, a exposição a esta lâmpada de forma segura (PHILIPS, 2008).

Adicionalmente, o espectro de emissividade desta lâmpada pode ser observado na Figura 4.6, onde é exposto o pico de emissividade para o comprimento de onda de 380nm (PHILIPS, 2008). 

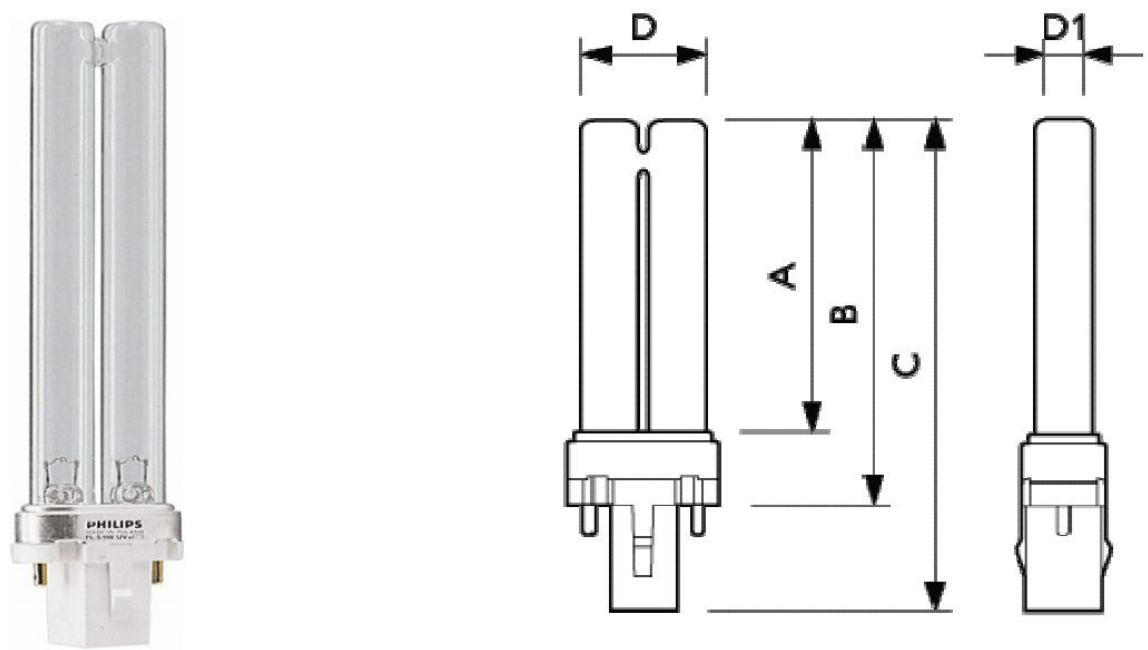

Figura 4.5 - Foto e esquemático dimensional de lâmpada UV PL-S 9W 10/2P UNP, sendo A - 129mm; B - 144.5mm; C167.5mm, D-21mm; e D1 - 13mm (PHILIPS, 2008)

Por outro lado, cabe destacar que a intensidade luminosa proporcionada por esta lâmpada é variável em função da distância a partir da lâmpada, proporcionando uma intensidade luminosa média de $22 \mu \mathrm{W} / \mathrm{cm}^{2}$, a uma distância de 1 metro (PHILIPS, 2006).

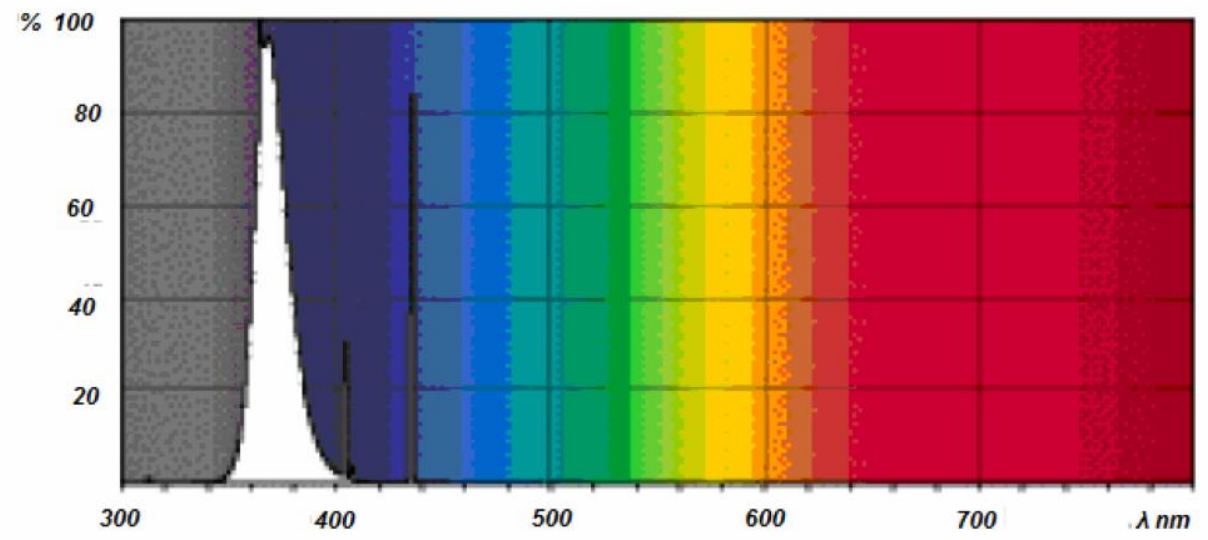

Figura 4.6 - Espectro de emissividade de lâmpada UV PL-S 9W 10/2P UNP (PHILIPS, 2008) 
Pode-se adicionalmente identificar a irradiação promovida por esta fonte luminosa em função da distância a partir da lâmpada, conforme pode ser observado na Figura 4.7.

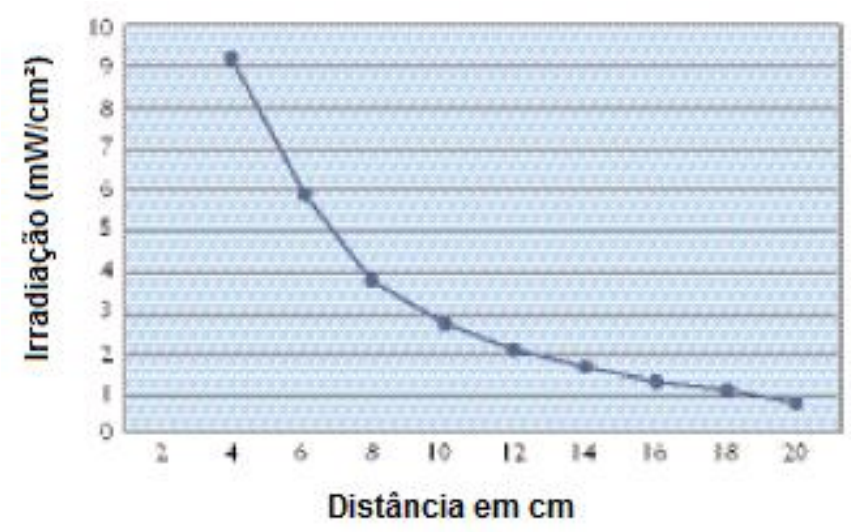

Figura 4.7 - Demostração de variação de irradiação UV em função da distância a partir da lâmpada UV PL-S 9W 10/2P UNP (PHILIPS, 2006).

\subsubsection{Fotodiodo Emissor Ultravioleta (Ultraviolet Light Emissior Diode - UV LED)}

A segunda fonte de luz UV utiizada neste trabalho foi um fotodiodo emissor de luz ultravioleta (UV LED), fabricado pela empresa VCC Optoelectronics. Este LED tem como dimensões fundamentais $8 \mathrm{~mm}$ de comprimento e $\varnothing 5 \mathrm{~mm}$, como pode ser observado na Figura 4.8 (VCC, 2009).

Em relação ao espectro de emissividade desta fonte luminosa, este pode ser observado na Figura 4.9. Nesta figura, pode ser observado o pico de emissividade do LED para o comprimento de onda de 400nm (VCC, 2009).

Adicionalmente, a potência luminosa proporcionada por este LED é de 120mW, ou 200 mcd, sendo emitida num ângulo de abertura de feixe de $15^{\circ}$. Cabe também ressaltar que estes valores de potencia são proporcionais a uma corrente de alimentação de 20mA a uma tensão de 5V (VCC, 2009). 

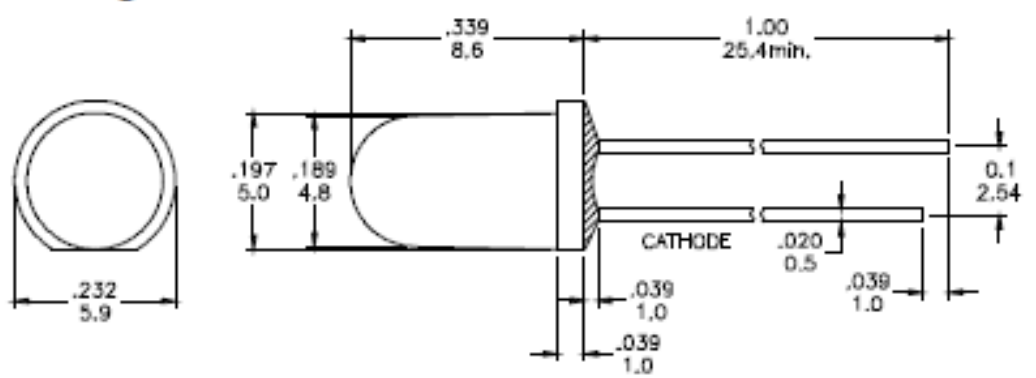

Figura 4.8 - Esquemático de dimensões gerais de UV LED (VCC, 2009)

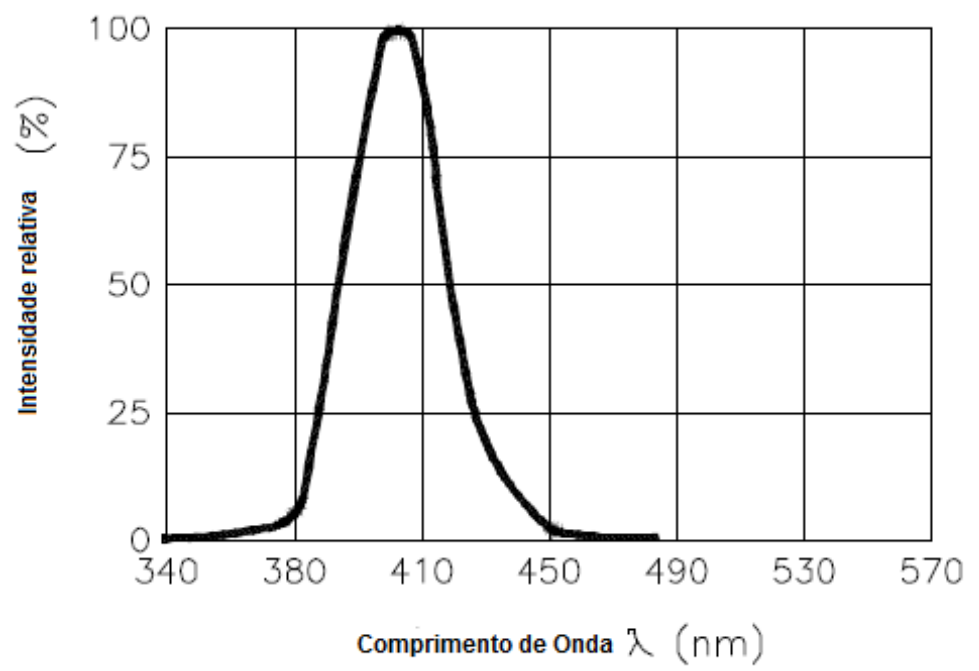

Figura 4.9 - Espectro de emissividade de UV LED (VCC, 2009)

\subsubsection{Fotoreceptor amplificador operacional}

Em relação ao optoreceptor utilizado nos estudos fotométricos para determinação de taxa de polimerização e determinação de opacidade, foi utilizado um OPT101 fabricado pela Texas instrument. Este sensor é um circuito integrado composto por um fotodiodo receptor ligado num amplificador operacional, conforme apresentado na Figura 4.10 (TEXAS, 1994). 

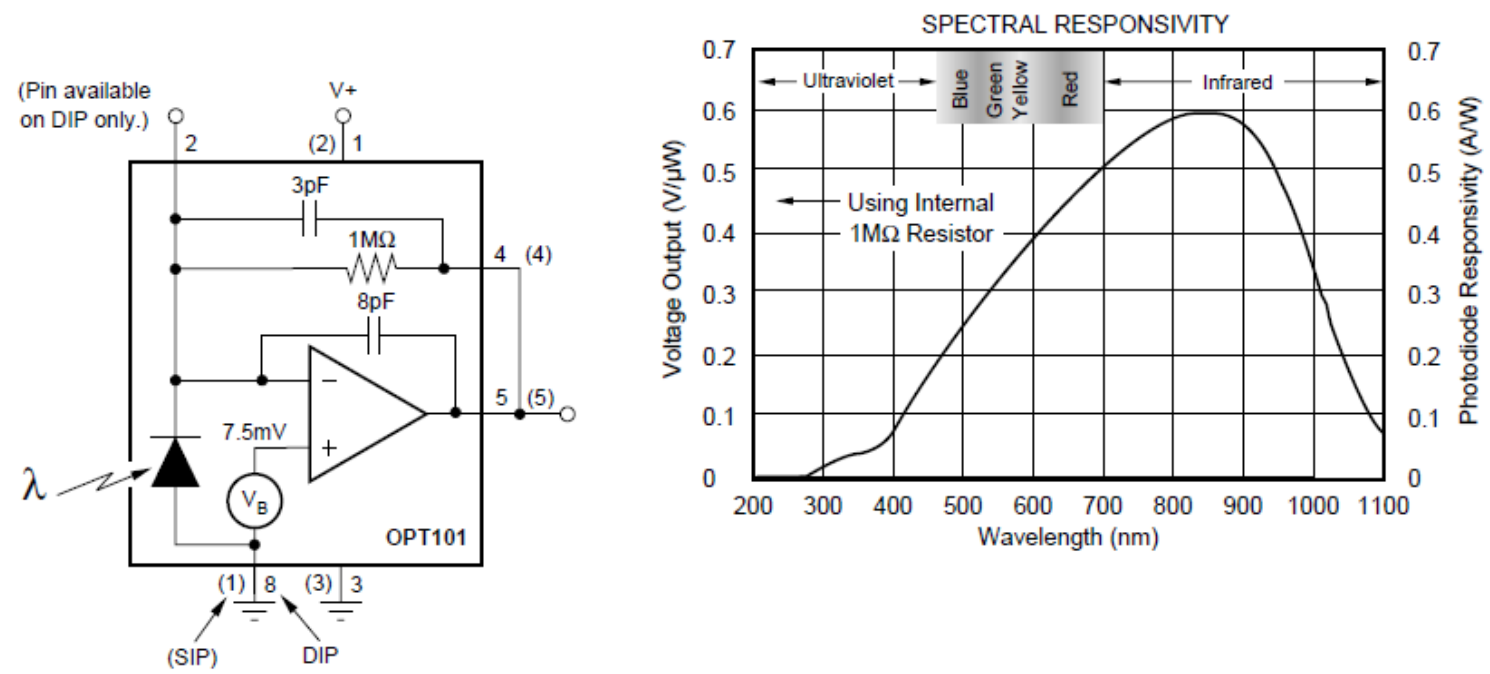

Figura 4.10 - Esquemático do circuito integrado e curva de resposta em função do comprimento do optoreceptor OPT101 (TEXAS, 1994)

\subsubsection{Viscosímetro de orifício}

Para determinação da viscosidade do material polimérico em estado líquido, foi utilizado um viscosímetro de orifício do tipo Copo Ford. Sendo que um esquemático com as principais dimensões é apresentado na Figura 4.11 


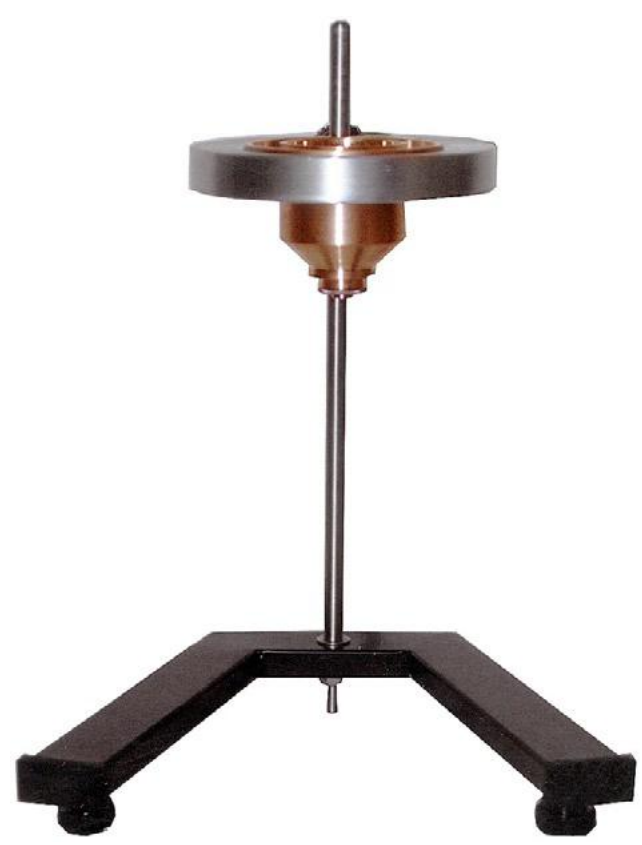

a)

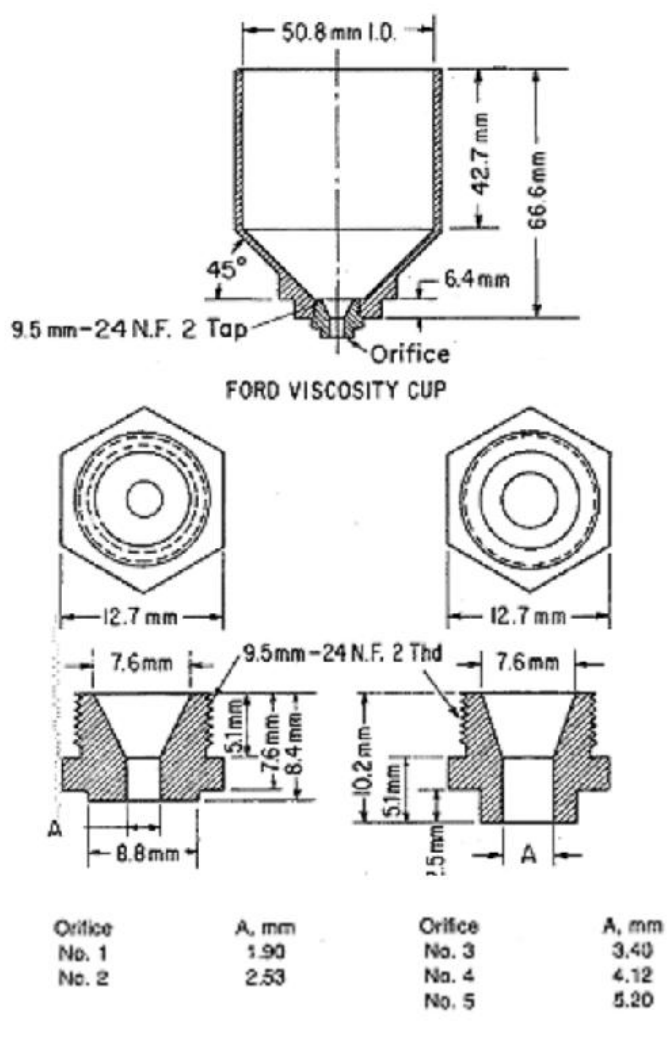

b)

Figura 4.11 - Foto(a) e esquemático de dimensões(b) de Copo Ford conforme ASTM D1200 (VISWANATH, 2007)

Adicionalmente, a determinação do tipo de orifício a ser utilizado é realizada em função do tempo necessário para o escoamento completo do fluido, como pode ser observado na Figura 4.12 


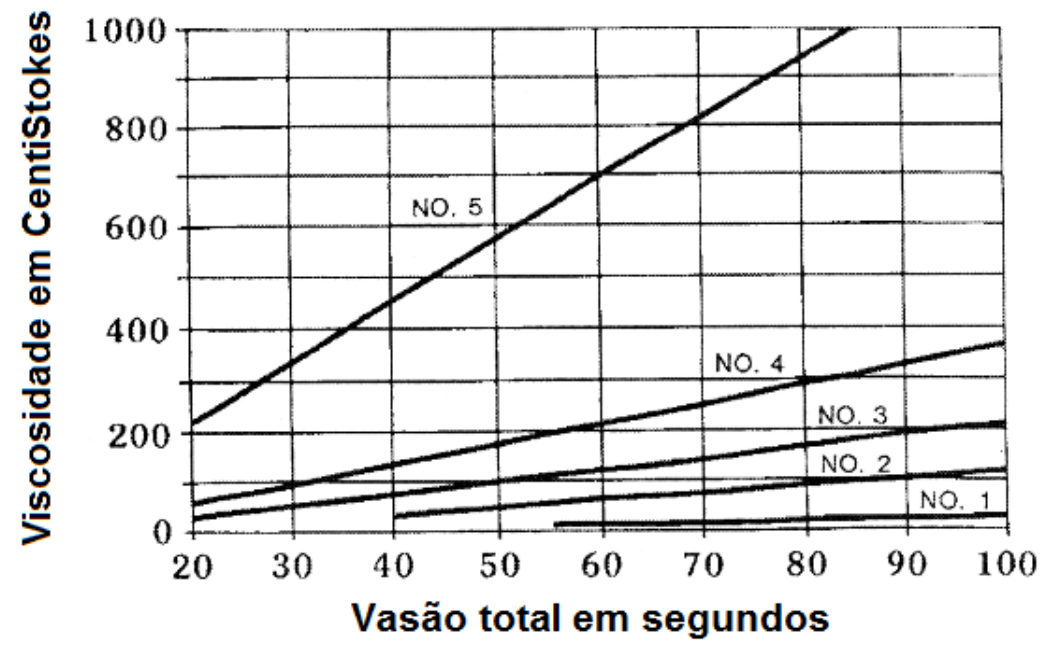

Figura 4.12 - Determinação numero de orifício de viscosímetro do tipo Copo Ford em função de viscosidade e tempo de escoamento conforme ASTM D1200 (VISWANATH, 2007)

\subsubsection{Fonte de alimentação regulável}

Com o objetivo de alimentar os instrumentos de medição com interface eletrônica de forma precisa, foi utilizada uma fonte regulável MLP-1305M, fornecido pela empresa Minipa (MINIPA, 2011).

Esta fonte de alimentação fornece tensão máxima de $32 \mathrm{~V}$ e $5 \mathrm{~A}$, podendo ser ajustada com precisão de $0.1 \mathrm{~V}$ e $0.1 \mathrm{~A}$, além de apresentar proteção contra sobrecarga e inversão de polaridade (MINIPA, 2011).

\subsubsection{Osciloscopio Digital}

Para realização das medições dos sensores de interface eletrônica, foram utilizados osciloscópios digitais com o objetivo de processar os sinais analógicos provenientes dos sensores. 
Os osciloscópios utilizados neste trabalho podem ser divididos conforme a portabilidade dos mesmos, sendo um osciloscópio de bancada (Siglent SDS1000CM serial) e um osciloscópio portátil (SeedStudio DSO 201).

Em relação ao osciloscópio de bancada Siglent SDS1000CM serial, tem largura de banda igual a $150 \mathrm{MHz}$, tempo de amostragem de $1 \mathrm{GSamples} / \mathrm{s}$ e impedância de $1 \mathrm{M} \Omega$ e 17pf. Adicionalmente este osciloscópio proporciona uma sensibilidade vertical de $2 \mathrm{mV}$ a $10 \mathrm{~V} /$ div através de 8bits (SIGLENT, 2011).

Por outro lado, o osciloscópio portátil SeedStudio DSO 201 proporciona largura de banda de até $1 \mathrm{MHz}$, tendo taxa de amostragem máxima de 1 Msamples/s, impedância de $500 \mathrm{k} \Omega$ e sensibilidade vertical de $0.5 \mathrm{mV}$ a $10 \mathrm{~V} /$ div através de $12 \mathrm{bits}$ (SEEDSSTUDIO, 2009).

\subsubsection{Módulo de aquisição de dados}

Para realização de aquisição de dados obtidos ao longo do trabalho, foi utilizado um módulo de aquisição de dados fornecido pela empresa Dataq. Este módulo ( DI-158) proporciona a aquisição de até 4 canais analogicos com resoloção de 12 bits, tendo porta USB como meio de comunicação com computador pessoal. Este dispositivo também permite a medição de faixa de tensões entre 0 e $10 \mathrm{~V}$, tendo 4 entradas digitais e 2 saidas analógicas (DATAQ, 2011).

Adicionalmente, pode-se ressaltar a taxa de aquisição de dados na faixa de $14.4 \mathrm{kHz}$, assim como a impedância de $500 \mathrm{k} \Omega$, visto que estes valores são inferiores aos proporcionados nos osciloscópios utilizados neste trabalho (DATAQ, 2011).

\subsubsection{Microscópio Óptico Digital}

Para a identificação do comportamento microestrutural dos materiais, foi utilizado um Microscópio Ótico Digital Avangard Optics AN-E500. Este microscópio 
portátil permite a amplificação de até $500 x$ de magnitude, sendo a aquisição e processamento das imagens micrograficasrealizadas através do software MATLAB.

\subsubsection{Sistema de medição fotométrico}

Para realização dos ensaios levantamento de taxa de polimerização por análise fotométrica e determinação de opacidade de substrato celulósico, foi desenvolvido um dispositivo composto essensialmente por LED UV e Optoreceptor, conforme apresentado na Figura 4.13. Adicionalmente, a medição dos sinais vindos do optoreceptor é realizada por meio de osciloscópio ou módulo de aquisição de dados (Data Acquisition - DAQ), enquanto a fonte de alimentação regulavel proporciona a alimentação do LED e do optoreceptor de forma precisa e estável.

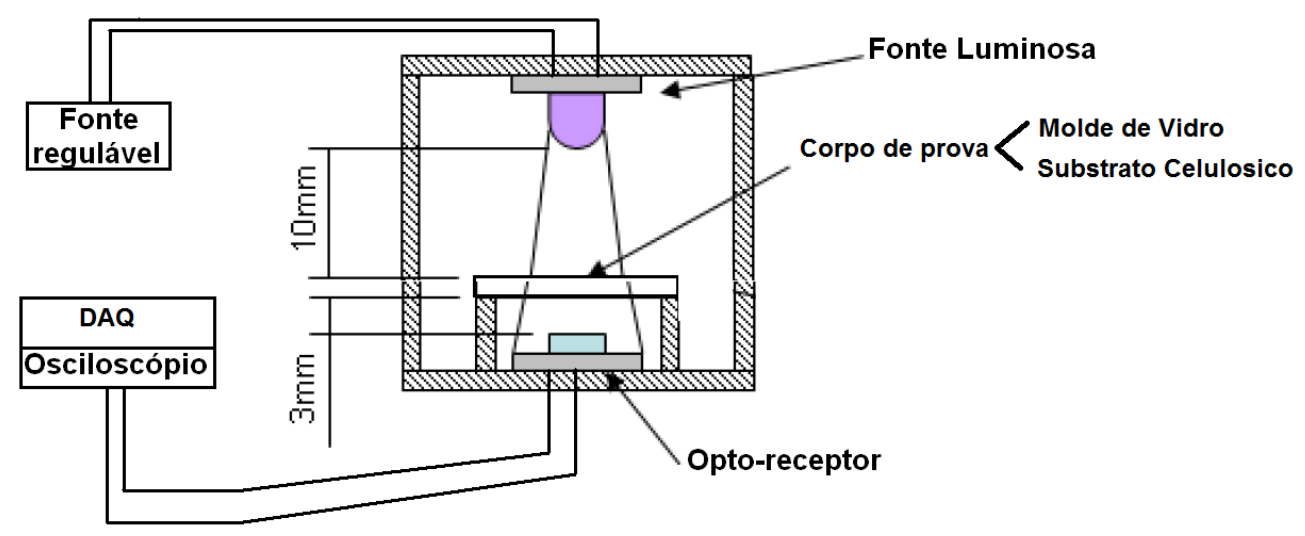

Figura 4.13 - Esquemático de sistema de medição fotométrico

\subsubsection{Sistema de medição de deflexão e temperatura de trabalho}

Em relação aos ensaios relacionados à determinação de temperatura de trabalho e do módulo de elasticidade. Foi desenvolvido um sistema baseado nas 
ASTM D790 e D648. Contudo este sistema de medição permite a realização de

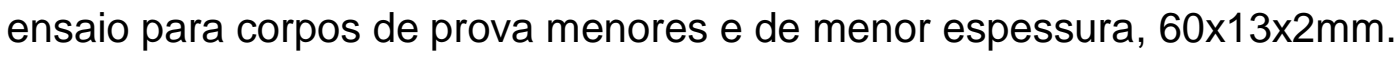

Como pode ser observado na Figura 4.14, este dispositivo monitora a temperatura e deslocamento do mecanismo de carregamento através de osciloscópios ou módulo de aquisição de dados.

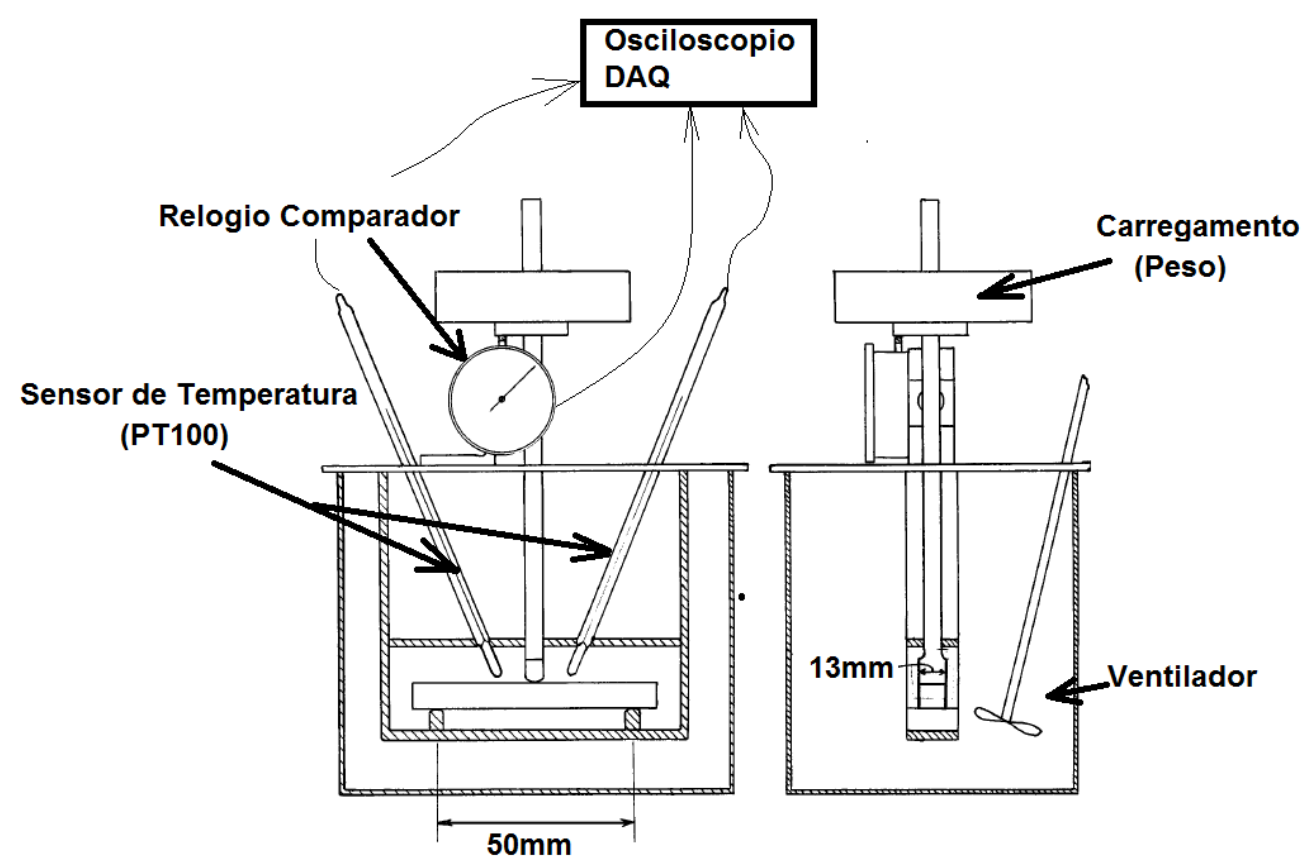

Figura 4.14 - Esquemático de sistema de medição para determinação de Módulo de elasticidade por deflexão e temperatura de trabalho

\subsubsection{Equipamentos de ensaio de Tração}

Para realização dos ensaios de resistência macânica à tração dos materiais poliméricos, foi utilizada um equipamento de ensaio universal da empresa EMIC (DL10000).

Este equipamento é caracterizado por proporcionar força de tração ou compreção de até $100 \mathrm{kN}$, tendo a velocidade de deslocamento entre $0.01 \mathrm{e}$ 
$500 \mathrm{~mm} / \mathrm{min}$ e resolução de deslocamento de $0.01 \mathrm{~mm}$. Adicionalmente, a medição de força segue a classe 1 da norma NM ISO7500-1, proporcionando uma resolução de 10N (EMIC, 2011).

\subsubsection{Equipamentos de ensaio de Tração para Papel}

Para realização do ensaio de tração para substratos celulósicos (papel), foi utilizada uma máquina de ensaio que atendia os requisitos encontrados nas normas Tappi T481 e T494. Neste caso, o principal requisito encontrado é a resolução de medição de força igual a $0.1 \mathrm{~N}$. Adicionalmente, este equipamento eletromecânico (UEC 1005), proporciona velocidade de deslocamento entre 5 e $250 \mathrm{~mm} / \mathrm{min}$, assim como carga máxima de 600N (UEC, 2011).

Cabe também ressaltar que a utilização deste equipamento foi realizada no laboratório de Polpa e Papel do Departamento de Engenharia madereira e Florestal da Universidade Federal do Parana.

\subsection{Confecção de Corpos de Prova}

Ao longo desta seção, são apresentados os procedimentos utilizados para fabricação dos corpos de prova para realização dos ensaios de resistência mecânica à tração de materiais fotopoliméricos e compósitos, assim como de corpos de prova para determinação de temperatura de trabalho e módulo de elasticidade. Adicionalmente, são apresentados os moldes de vidro utilizados na determinação de taxa de polimerização.

\subsubsection{Moldes de Vidro}

Com relação aos estudos de determinação de taxa de polimerização, foram utilizados moldes de vidro de $99 \%$ de transparência, possibilitando a restrição da 
espessura de camada e volume. Na Figura 4.15, pode ser observado a representação do molde com suas principais dimensões.

Para a confecção do molde de vidro de espessura $0.12 \mathrm{~mm}$, foram utilizadas lamínulas coladas por cola epóxi, enquanto para o molde de $2 \mathrm{~mm}$ de espessura, foram utilizadas lâminas de vidro coladas por cola acrílica.

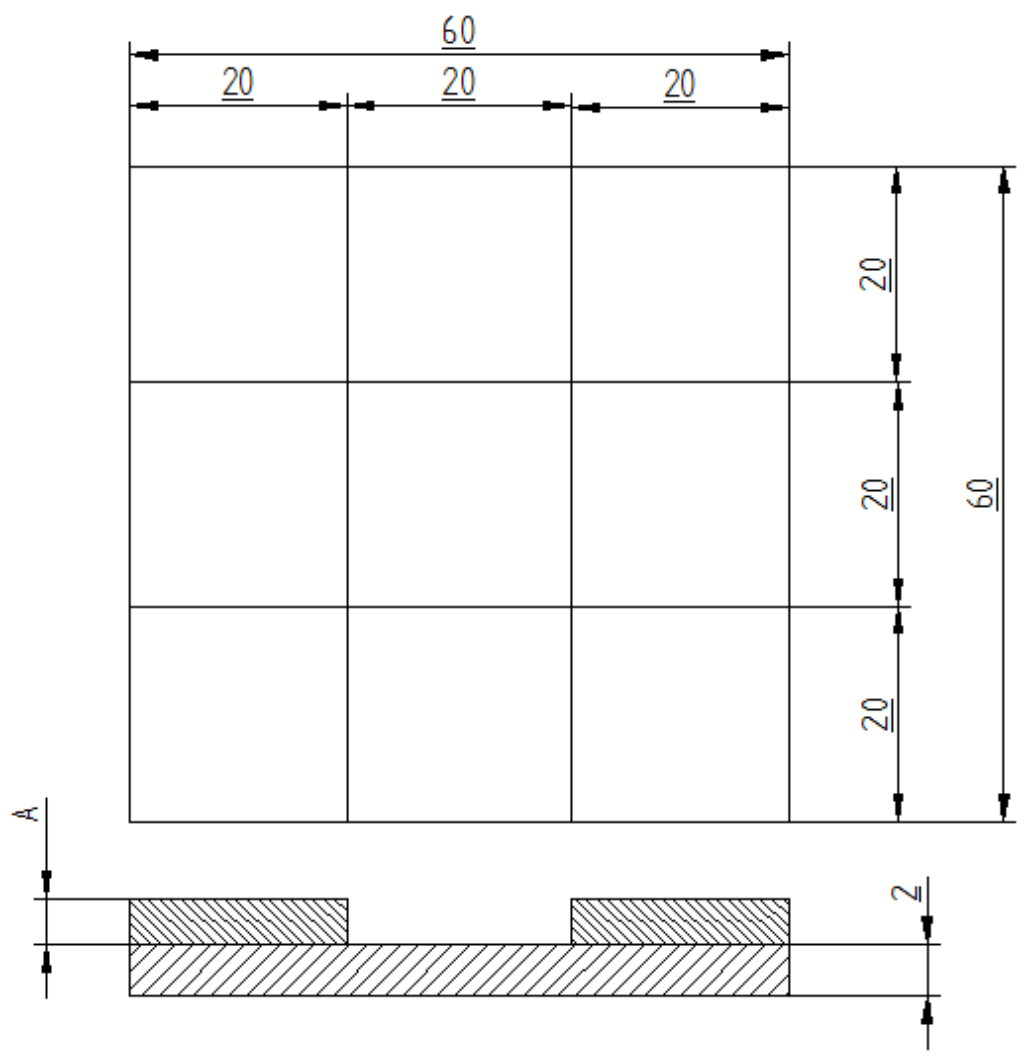

Figura 4.15 - Representação de moldes de vidro, sendo a dimensão de espessura igual a $0.12 \mathrm{~mm}$ e $2 \mathrm{~mm}$

\subsubsection{Moldes de silicone}

Em função de materiais acrílicos promoverem altos valores de aderência, a fabricação de corpos de prova para ensaios de caracterização termo-mecânica dos materiais fotopoliméricos foi realizada por meio de moldes de silicone. 
Para a fabricação destes corpos de prova, foi empregado o processo de ferramental rápido RTV (Silicone Rubber Tooling), cujo procedimento pode ser observado na Figura 4.16.

Molde reverso (basico) Modelo basico Modelo basico Molde reverso (basico)

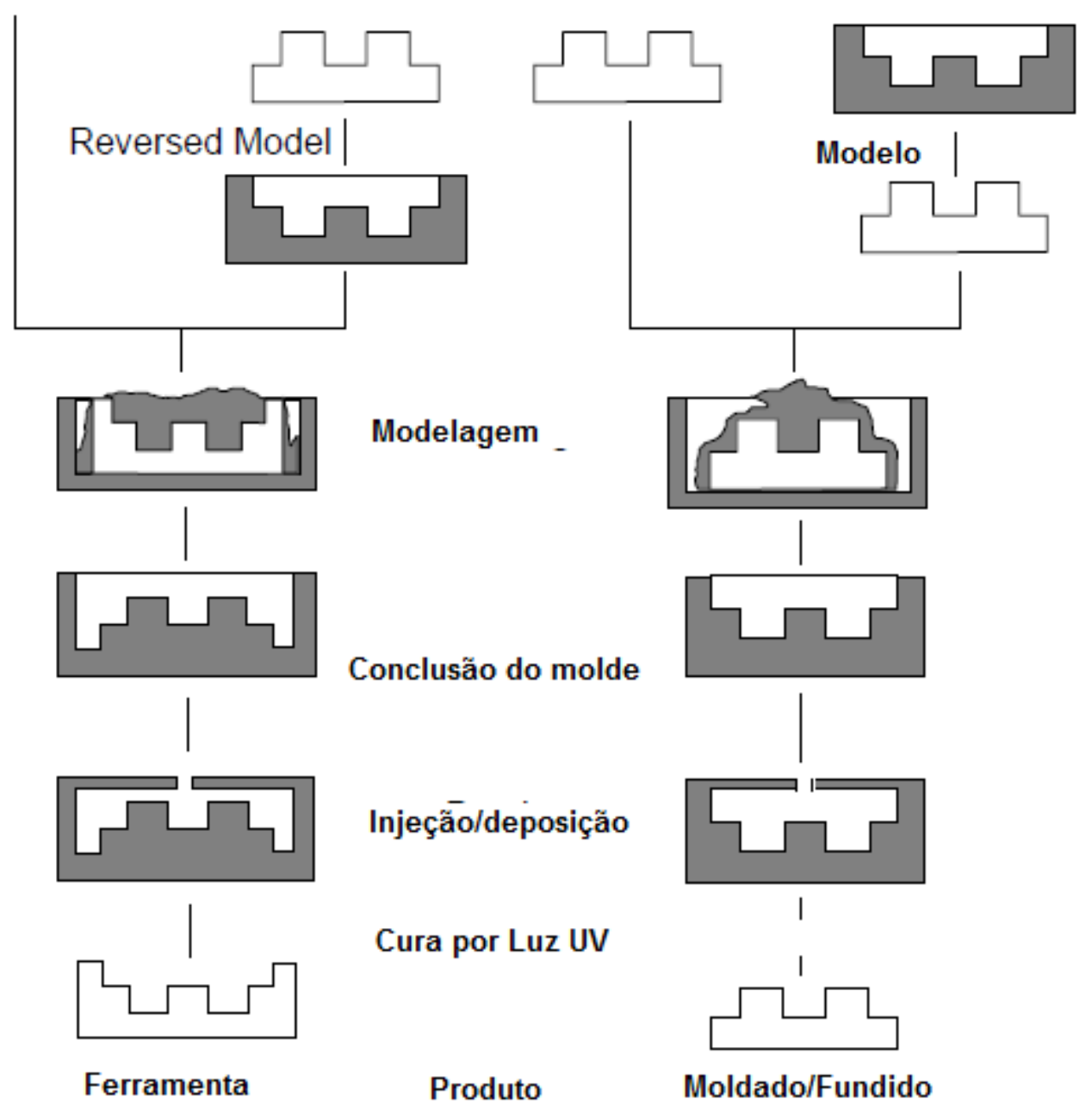

Figura 4.16 - Ilustração de variação do processo de RTV utilizado para a confecção dos corpos de prova fotopoliméricos adaptado de (PRINZ et al., 1997)

Nesta figura, são apresentadas as principais etapas realizadas para a fabricação dos corpos de prova, sendo empregado o processo FDM para a construção da peça básica ou negativa utilizada para a confecção do molde.

Adicionalmente, a Figura 4.17 apresenta fotos das peças básicas utilizadas e moldes de silicone utilizados para a confecção dos corpos de prova. Cabe ressaltar 
que estes moldes possuem cavidades abertas a fim de que os materiais depositados nestes possam ser expostos à luz UV.

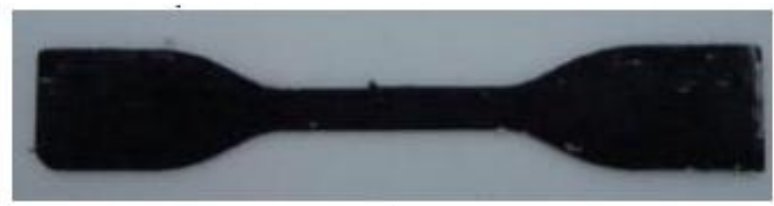

a)

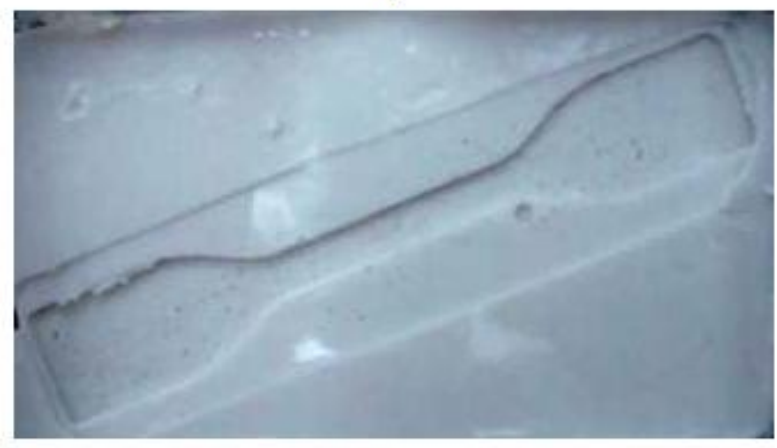

c)

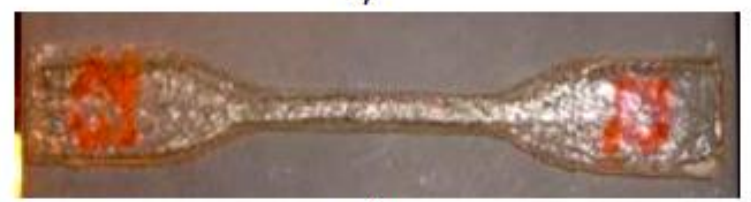

e)

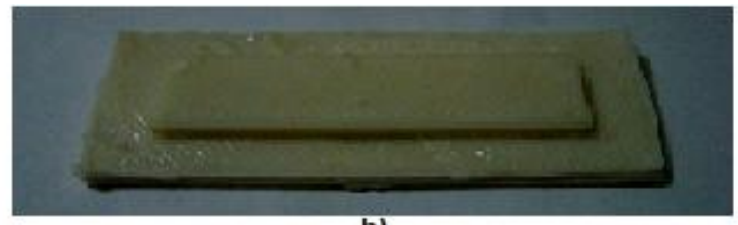

b)

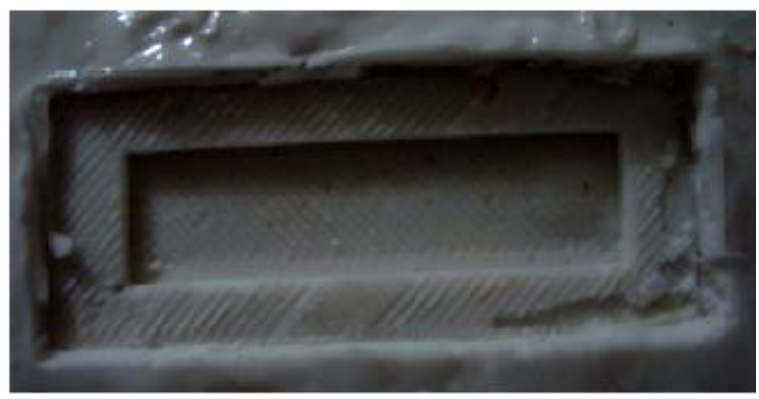

d)

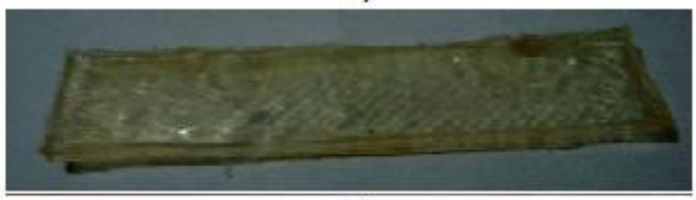

f)

Figura 4.17 - Fotos de peças básicas utilizadas no processo de fabricação dos corpos de prova, sendo "a", "c" e "e " referentes ao ensaio de tração e "b", "d" e "f" ao ensaio de temperatura de trabalho e módulo de elasticidade

\subsubsection{Corpo de prova de ensaio de tração de material Compósito}

Para a confecção dos corpos de prova do material compósito, foi utilizaddo como matriz celulósica tiras de papel de seda de dimensões iguais a $20 \times 50 \mathrm{~mm}$. Adicionalmente, foi depositado material de forma que a sua quantidade pudesse ser mensurada por meio de balança de precisão.

Por fim este corpo de prova é exposto à luz emitida pela lâmpada UV por período de $30 \mathrm{~min}$. Na Figura 4.18, pode ser observada a foto de um dos corpos de 
prova utilizados na determinação da resistência mecânica média à tração do material compósito desenvolvido.

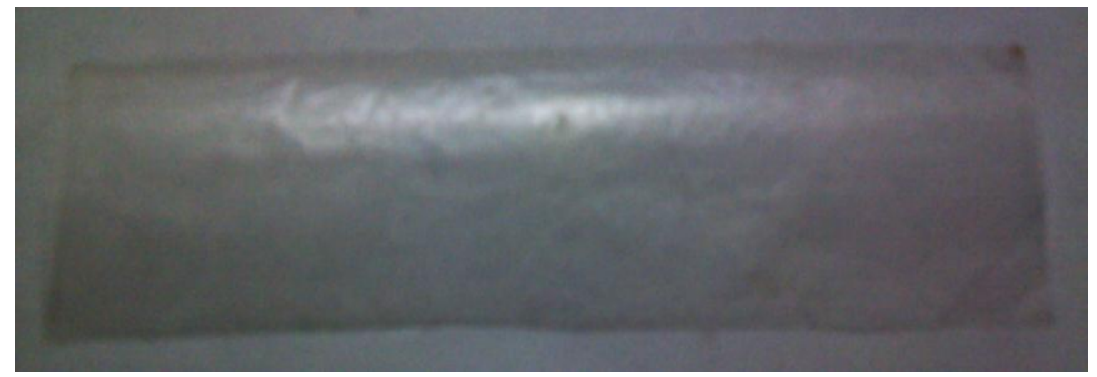

Figura 4.18 - Fotos de amostra de corpo de prova de ensaio de resistência à tração de material compósito

\subsubsection{Corpo de prova de ensaio de adesividade de material Compósito}

Outro corpo de prova confeccionado para a caracterização do material compósito tem como objetivo, a determinação da aderência entre camadas de material. Este corpo de prova do tipo "T peeling" é composto de duas folhas de papel seda de $25 \times 50 \mathrm{~mm}$, sendo impregnados simultaneamente por material fotopolimérico até a sua metade. Após o processo de deposição, o corpo de prova é exposto a luz do LED UV, de forma a ser curado até aproximadamente $60 \%$ de conversão.

Adicionalmente; cabe ressaltar a utilização do LED UV em vez da lâmpada UV teve objetivo de identificar os modos de fratura da junta adesiva em função do tipo de material e gradiente de polimerização. Isto se deve ao fato que o LED UV proporciona intensidade luminosa variável, tendo seu pico no centro da circunferência de incidência.

Por fim, a Figura 4.19 apresenta a foto de um dos corpos de prova confeccionados para a identificação da aderência entre camadas de material compósito. 


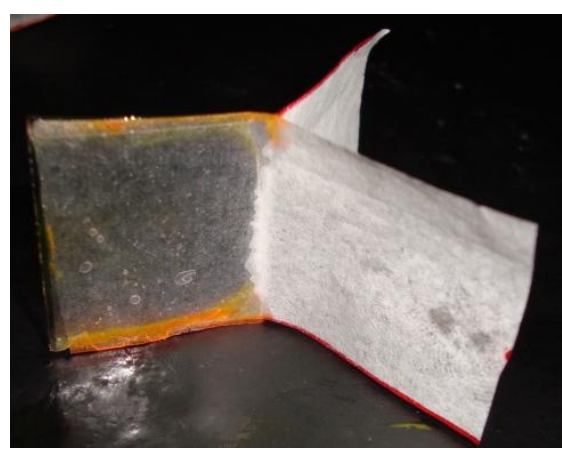

Figura 4.19 - Fotos de amostra de corpo de prova de ensaio de adesividade

\subsection{Caracterização de material}

Com relação à caracterização do material desenvolvido neste trabalho, foram realizados estudos com objetivo de identificação do comportamento da matéria prima do material (substrato e polímero) quanto aos processos de transformação de material. Adicionalmente, foram realizados estudos intencionando a caracterização do compósito, como por exemplo, aderência entre camadas.

\subsubsection{Determinação de opacidade de substrato}

Para determinação de opacidade do substrato, foi utilizado um método baseado nas normas TAPPI T 519 e ASTM D589, sendo utilizados: um Optoreceptor, um emissor de LED UV, uma fonte de alimentação regulavel e um osciloscópio conforme apresentado na Seção 4.1.15.

O procedimento utilizado para a realização deste ensaio pode ser observado na Figura 4.20. Neste procedimento, a calibração do instrumento de medição é realizada sem substrato e tendo 30 minutos como tempo de estabilização do equipamento (warming up).

Este procedimento também comprende as etapas de monitoramento da intensidade luminosa após exposição do substrado à fonte de luz, tendo estes valores coletados e processados. 


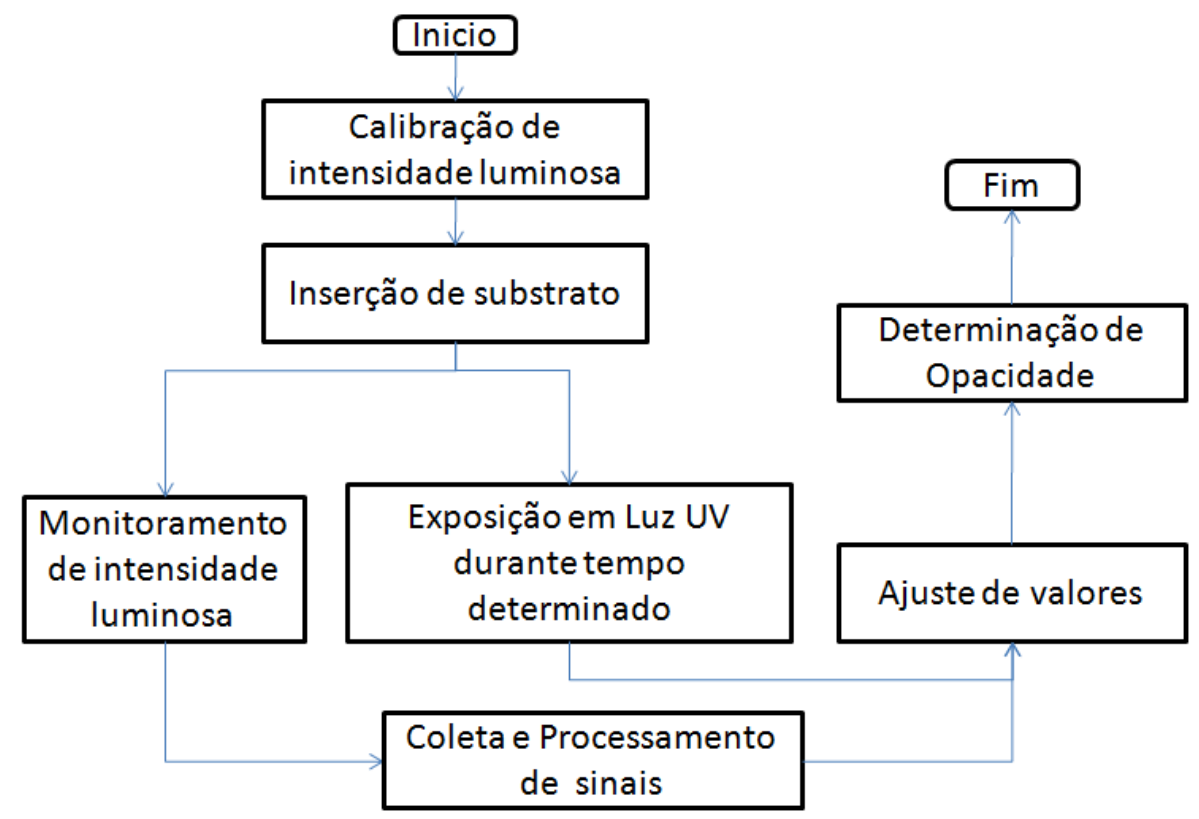

Figura 4.20 - Fluxograma dos procedimentos experimentais utilizadas para a determinação de opacidade de substrato celulósico

Por fim, foi realizado o ajuste dos valores obtidos pelo opto-receptor (Volts) para percentual de intensidade luminosa passante(\%), de acordo com valores de calibração obtidos no início do experimento.

Com relação aos corpos de prova, estes tiveram suas dimensões estabelecidas em 20x20mm, em função do diâmetro de incidência da fonte luminosa. Adicionalmente, todos os corpos de prova foram mantidos em ambiente controlado a $20^{\circ} \mathrm{C}$ e umidade relativa de $50 \%$.

\subsubsection{Determinação de taxa de polimerização}

Em relação à determinação da taxa de polimerização, foi utilizada metodologia baseada na em análise fotométrica, sendo ajustados valores adquiridos através de calibração realizada por meio de levantamento gravimétrico. 


\section{Gravimetria}

Com referência ao levantamento gravimétrico da conversão polimérica, podese dizer que este processo é um dos mais utilizados em âmbito laboratorial. Este processo é caracterizado pela determinação de grau de conversão e taxa de polimerização de polímeros através do levantamento mássico de quantida de material convertido em polímero.

Para realização deste ensaio, foram utilizados moldes de vidro com dimensões $20 \times 20 \times 0,12 \mathrm{~mm}$ e $20 \times 20 \times 2 \mathrm{~mm}$, proporcionando respectivamente volume de $48 \mathrm{~mm}^{3} \mathrm{e}$ $800 \mathrm{~mm}^{3}$. Adicionalmente, o procedimento utilizado para garantir a repetibilidade, apresentado na Figura 4.21.

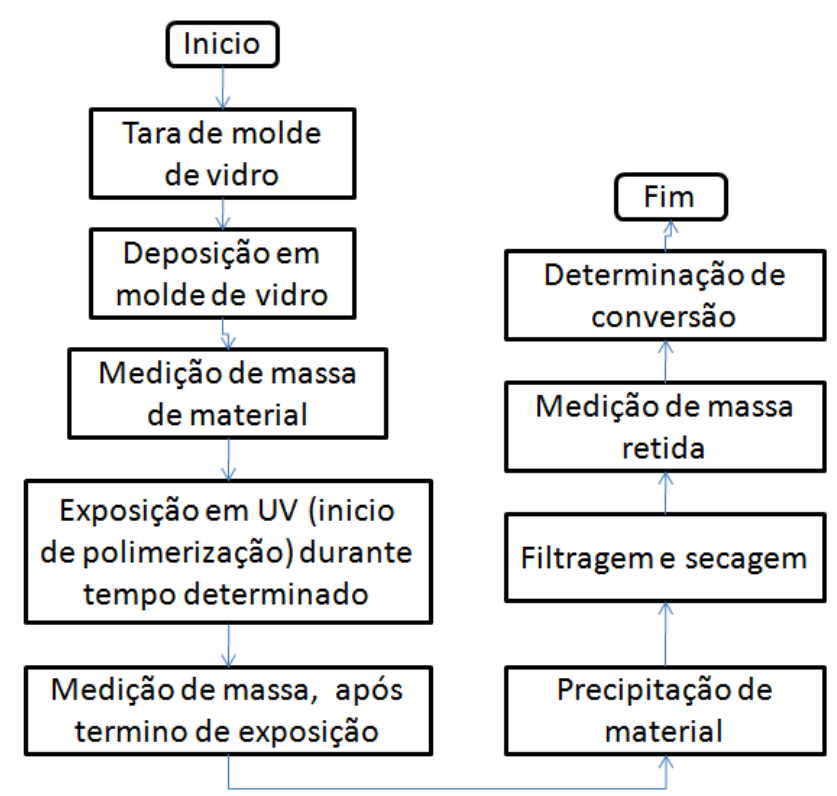

Figura 4.21 - Fluxograma dos procedimentos experimentais utilizadas para a determinação de grau de conversão por análise gravimetrica

Neste processo, após pesagem inicial do material não polimerizado, este é exposto à luz UV (LED UV), iniciando o processo de polimerização de durante período determinado. Para a precipitação das cadeias poliméricas, foi utilizado álcool isopropílico como não-solvente, sendo as amostras submetidas a processo de filtragem e secagem ao longo de 3 horas. 
Após a finalização do processo de secagem, foi realizada a medição da massa de material retido no filtro, sendo considerado material convertido em polímero.

\section{Fotometria}

Para a realização do ensaio referente à determinação de grau de conversão por análise fotométrica, foi utilizado um sistema de medição composto por fotoemisor, opto-receptor e módulo de aquisição de dados, conforme apresentado na Seção 4.1.15. Adicionalmente, foram utilizados moldes de vidro para delimidação de volume e espessura de amostras.

Este método consiste no monitoramento da intensidade de luminosa emitida através do material, conforme lei de Lamber, Equação (3.2). Desta forma, pode-se observar a progressão da conversão do material em polímero ao longo do tempo através da variação de intensidade luminosa incidida no opto-receptor, Equação (4.1) (MILLER, 2005).

conversão $(\%)=\log \left(1-\frac{I_{i}}{I_{o}}\right) \cdot 100$

Com o objetivo de garantir a repetibilidade do ensaio, foi estipulado um procedimento para a realização deste ensaio, conforme apresentado na Figura 4.22. Nesta figura, é apresentado um fluxograma das etapas realizadas para a obtenção dos dados, e consequentemente, a determinação da curva de conversão polimérica do material. Adicionalmente, foi realizada a aferição do processo de medição através de determinação gravimétrica da amostragem. 


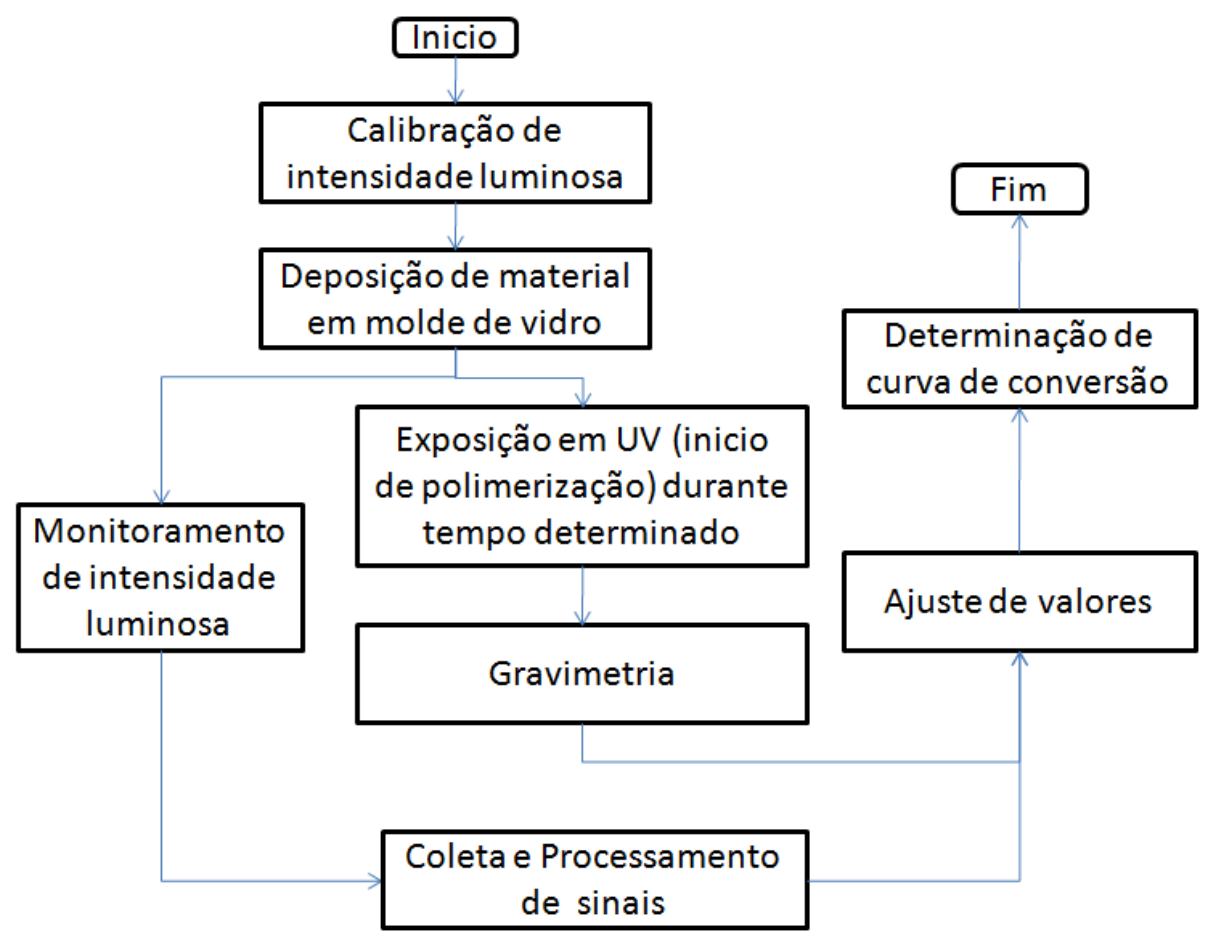

Figura 4.22 - Fluxograma dos procedimentos experimentais utilizadas para a determinação de taxa de conversão baseado em fotometria

\subsubsection{Determinação de Viscosidade}

Em face à necessidade de identificação de viscosidade do material nãopolimerizado, foi utilizado um método de determinação por copo de orifício conforme norma ASTM D1200.

Este método consiste na determinação de viscosidade cinematica de fluidos Newtoneanos através de tempo de escoamento do fluido contido em recipiente com orifício padronizado. Adicionalmente, a viscosidade pode ser determinada através da Equação (4.2), onde $\mathrm{k}$ e $\mathrm{K}$ são constantes intrínsecas à perda de carga proporcionada pelo copo e orifício, e $\Delta \mathrm{t}$ o tempo decorrido ao longo do escoamento de $100 \%$ do fluido contido no copo. 


$$
v=\frac{\eta}{\rho}=k \cdot \Delta t-\frac{K}{\Delta t}
$$

\subsubsection{Determinação de taxa de absorção do substrato}

Para a determinação da taxa de absorção do substrato, foi realizada uma análise gravimétrica da água absorvida pelo substrado ao longo do tempo. O procedimento utilizado para a realização deste ensaio pode ser observado na Figura 4.23, onde são apresentadas as principais etapas realizadas neste ensaio, que se baseia nas normas ASTM D 3285, D 824.

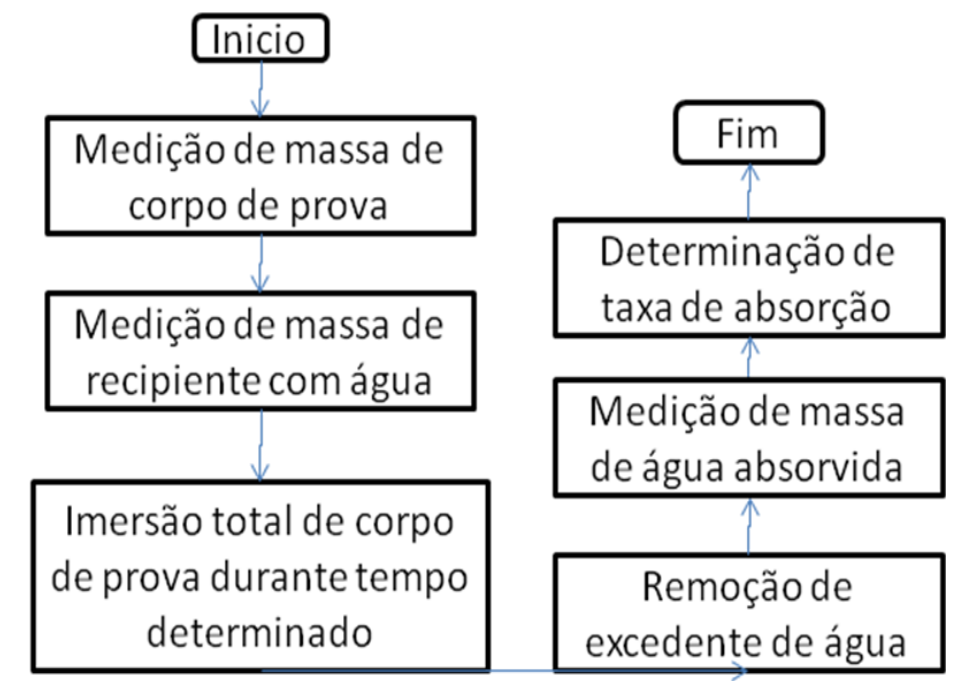

Figura 4.23 - Fluxograma dos procedimentos experimentais utilizadas para a determinação de taxa de absorção

Para a realização deste ensaio, foi utilizado balança de precisão igual a $0.01 \mathrm{~g}$, enquanto as dimensões do corpo de prova foram definidas como $25 \times 50 \mathrm{~mm}$. Adicionalmente, este ensaio é caracterizado pelo monitoramento da quantidade da água absorvida pelo papel em função do tempo de imersão.

Neste processo, é inicialmente mensurada a massa do substrato (papel), que é subsequentemente mantido imerso durante período determinado. Após o termino do 
processo de imersão do substrato, é retirado o excedente de água por um período de $1 \mathrm{~min}$, sendo mensurada a massa da água absorvida pelo substrato.

\subsubsection{Determinação de temperatura de trabalho}

Com objetivo de identificar a temperatura de trabalho, também conhecida como temperatuara de deflecção sob carregamento (Deflection Temperature Under LoadDTUL) ou temperatura de deflexão por calor (Heat Deflecion Temperature - HDT) foi elaborado um ensaio baseado na norma ASTM D648, como pode ser observado na Figura 4.24.

Esta adaptação se deve à necessidade de identificação destes valores de temperatura para a espessuras inferiores a $3 \mathrm{~mm}$, visto que esta norma contempla somente valores de espessura entre 3 e $13 \mathrm{~mm}$.

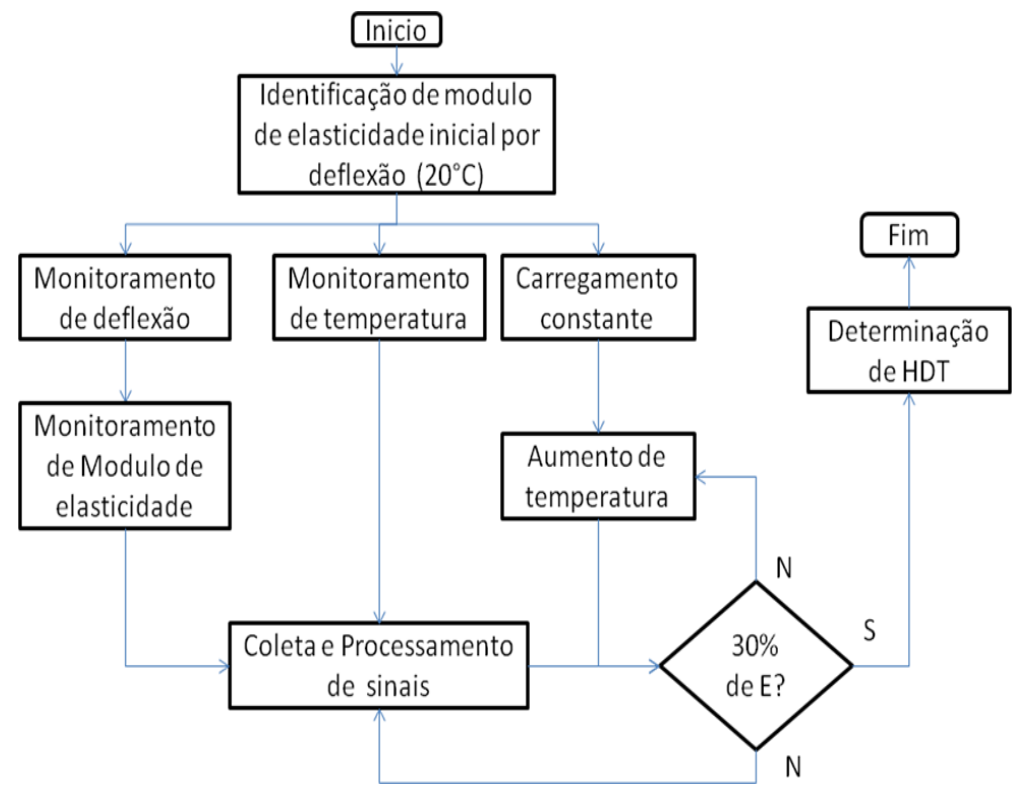

Figura 4.24 - Fluxograma dos procedimentos experimentais utilizadas para a determinação de temperatura de trabalho 
Em geral, este método consiste na identificação da temperatura em que o corpo de prova proporciona valor incremental de deflexão igual a $0.25 \mathrm{~mm}$ (conforme ASTM D648). Neste caso, os valores de carregamento são determinados em função da tensão proporcionada pelo carregamento, podendo ser 1.82MPa ou 0.445MPa.

Contudo, ao observar os valores de DTUL ou HDT (Heat Deflection Temperature) em comparação com os valores de transição vítrea ( $\mathrm{Tg}$ ), pode-se identificar grandes digergências, como pode ser observado na Tabela 4.1.

Tabela 4.1 - Relação de plásticos de engenharia e seus valores de Tg, HDT 1.82 e HDT 0.445 (KELLY e ZWEBEN, 2000)

\begin{tabular}{|l|r|r|r|}
\cline { 2 - 4 } \multicolumn{1}{c|}{} & \multicolumn{3}{c|}{ Ensaio } \\
\hline Material & $\begin{array}{l}\text { TG }( \\
\left.{ }^{\circ} \mathrm{C}\right)\end{array}$ & $\begin{array}{l}\text { HDT 1.82 Mpa } \\
\left({ }^{\circ} \mathrm{C}\right)\end{array}$ & $\begin{array}{l}\text { HDT 0.445 Mpa } \\
\left({ }^{\circ} \mathrm{C}\right)\end{array}$ \\
\hline ABS & 100 & 93 & 104 \\
\hline PVC & 85 & 60 & 77 \\
\hline PMMA & 100 & 68 & 100 \\
\hline PET & 80 & 21 & 66 \\
\hline PETG & 80 & 63 & 66 \\
\hline Nylon 66 & 70 & 75 & 104 \\
\hline Nylon 6 & 60 & 68 & 95 \\
\hline PC & 150 & 121 & 132 \\
\hline HIPS & 100 & 77 & 96 \\
\hline PS & 100 & 76 & 94 \\
\hline
\end{tabular}

Isto se deve ao fato desta norma atualmente identificar a temperatura de trabalho conforme valor fixo de deflexão. Adicionalmente, esta norma ainda apresenta dois métodos distintos para identificação da temperatura em questão, proporcionando valores diferenciados para o mesmo material.

Em função da falta de confiabilidade nos resultados obtidos por esta norma, foram realizados estudos relacionados à viabilização deste método de ensaio.

Considerando o conceito físico deste ensaio, pode-se identificar que este pode ser compreendido pelo variação do módulo de elasticidade (Young's modulus) em função da temperatura. Sendo possível identificar a perda ocorrida no módulo de elasticidade em função da deflexão. 
$\mathrm{Na}$ Figura 4.25 é apresentado um exemplo da digerência entre valores encontrados através dos métodos $1.82 \mathrm{MPa}$ e $0.445 \mathrm{MPa}$, assim como da diferença de resultados obtidos a partir de diferentes espessuras contempladas pela norma.

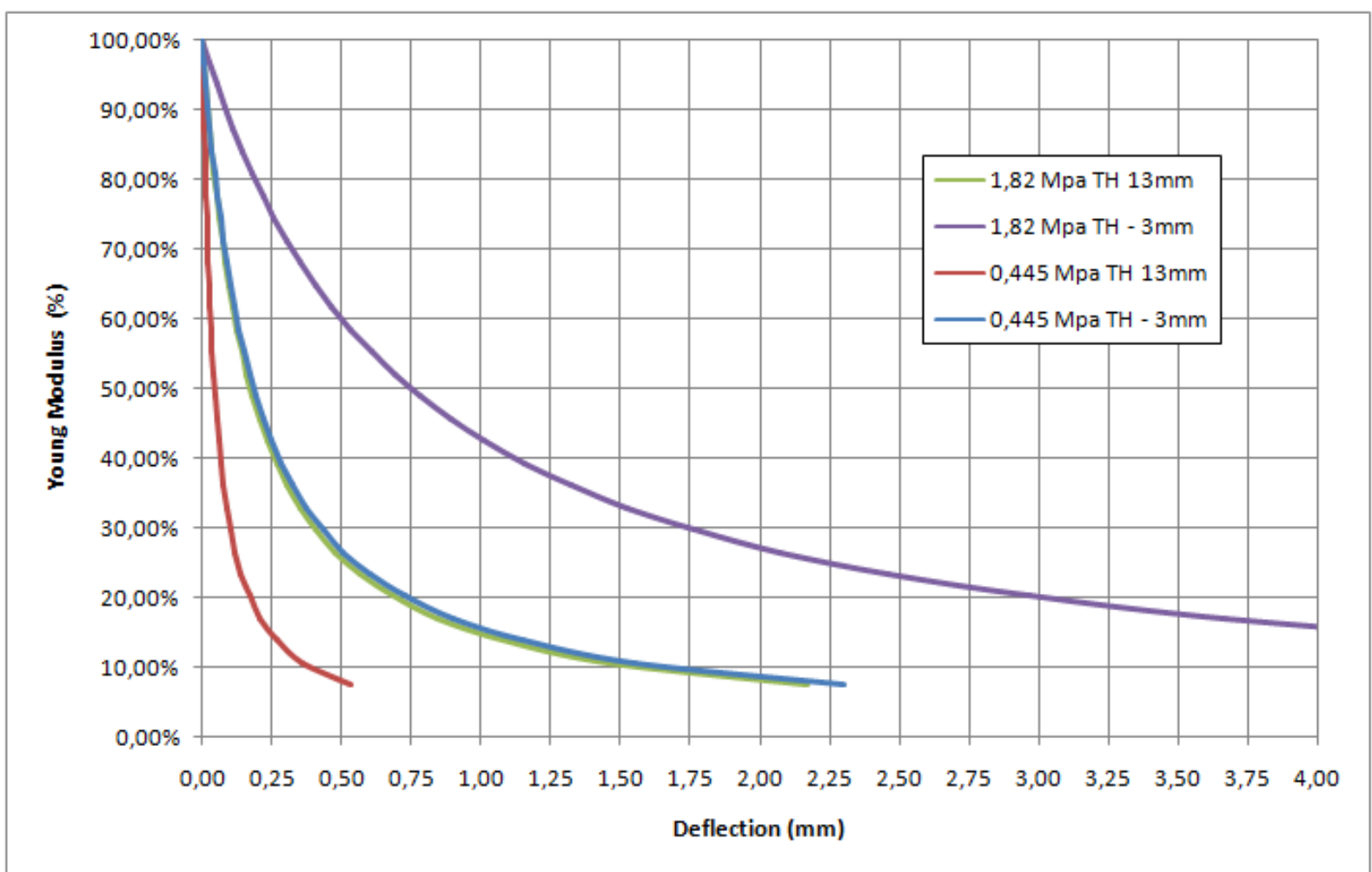

Figura 4.25 - Análise comparativa de deflexão proporcionada por de perda de módulo de elasticidade conforme carregamento indicado por método $\mathrm{A}$ (1.82MPa) e método B (0.445MPa) da norma ASTM D648 e valores de espessura de corpo de prova de 3 e $13 \mathrm{~mm}$

Neste exemplo foi utilizado um material termoplástico amorfo (ABS) com módulo de elasticidade igual a $1.35 \mathrm{GPa}$ em $20^{\circ} \mathrm{C}$. Contudo, esta figura evidencia que para as quatro situações limite encontradas na norma, o valor de deflexão corresponde a perdas de módulo de elasticidade distintas, variando entre 15 e 75\%.

Em função disto, para a determinação do HDT do material, foi definido que o este valor é determinado através da temperatura em que módulo de elasticidade sofre perda igual a $70 \%$. Este valor de perda no módulo é equivalente à perda observada na temperatura de transição vítrea $(\mathrm{Tg})$ de termoplásticos amorfos. 
Adicionalmente, como este procedimento é baseado na perda do módulo de elasticidade, foi utilizado o procedimento experimental apresentado na Figura 4.24. Onde são expostas as principais etapas decorridas para a realização de deste ensaio.

Por fim, a confecção do corpo de prova foi realizada através de molde de silicone, sendo determinados os valores dimensionais iguais a $60 \times 25 \times 2 \mathrm{~mm}$.

\subsubsection{Determinação de Módulo de elasticidade}

Para a determinação do módulo de elasticidade do material polimérico, foi utilizada uma variação do método relatado na norma ASTM D790. Este método é caracterizado por identificar o módulo de elasticidade do material em função da deflecção de um corpo de prova de dimensões 100×25×2mm após carregamento de uma força determinada.

Na Figura 4.26, é apresentado um esquemático do ensaio, sendo a força e a medição da deflecção realizada por meio de um sistema de medição apresentado na Seção 4.1.16.

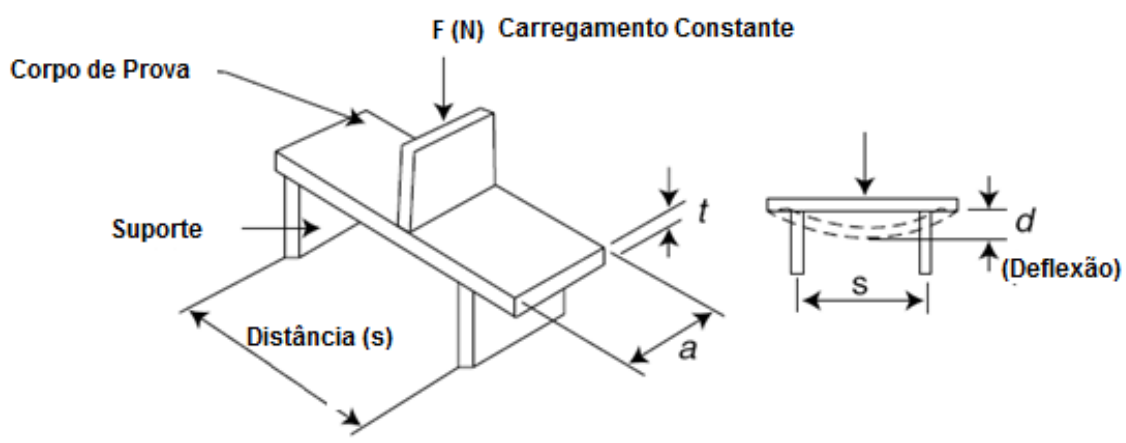

Figura 4.26 - Esquemático de funcionamento de determinação de módulo de elasticidade por deflexão, adaptado de (HUDGIN, 2006) 
Para a confecção destes corpos de prova, foi fabricado molde de silicone a partir de corpo de prova padrão fabricado através de processo aditivo FDM (Seção 4.2.2). Subsequentemente, o material depositado no molde foi exposto à luz UV durante período de $30 \mathrm{~min}$, de forma a garantir a um alto grau de conversão para todos os corpos de prova.

\subsubsection{Determinação de resistência mecânica a tração de material polimérico}

Para a determinação da resistência mecânica à tração do material polimérico, foi utilizado um equipamento de ensaio universal EMIC (Seção 4.1.17), sendo utilizados os parâmetros de experimentação em concordância com norma ASTM D638.

Em adição, o corpo de prova utilizado para a realização deste ensaio foi estipulado como sendo do Tipo IV, cujos valores dimensionais destes corpos de prova podem ser observados na Figura 4.27.

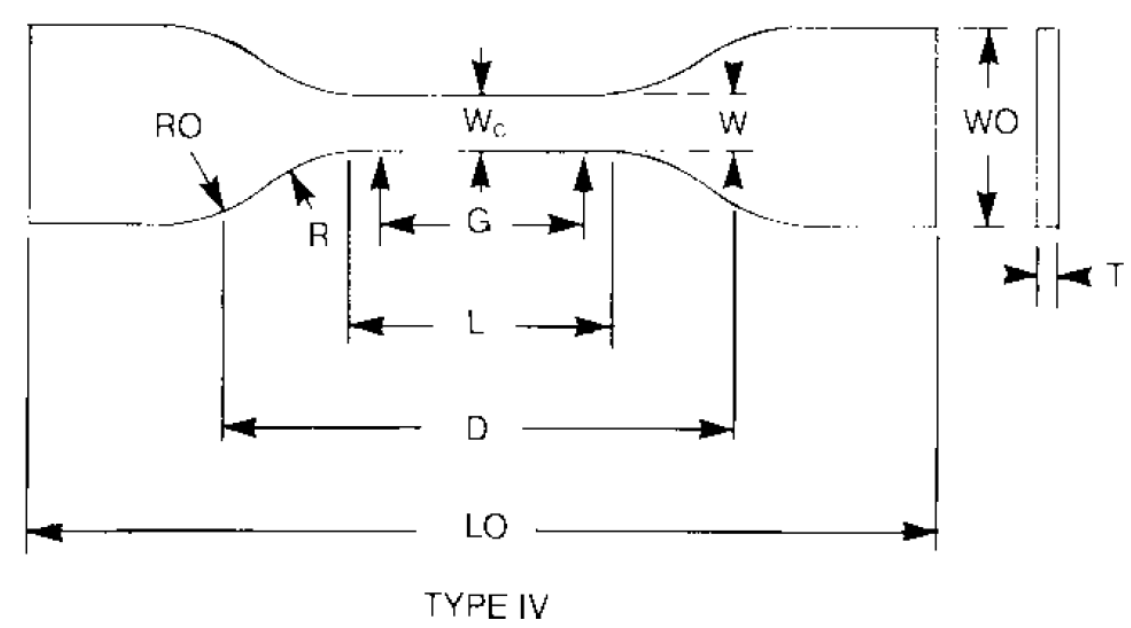

Figura 4.27 - Desenho dimensional de corpo de prova tipo IV para ensaio de resistência mecânica à tração conforme norma ASTM D638 
Para a confecção destes corpos de prova, foi fabricado molde de silicone a partir de corpo de prova padrão (Seção 4.2.2). fabricado através de processo aditivo FDM. Subsequentemente, o material depositado no molde foi exposto à luz UV durante período de $30 \mathrm{MIN}$, de forma a garantir a um alto grau de conversão para todos os corpos de prova.

\subsubsection{Determinação de resistência mecânica a tração de material celulósico}

Em contrapartida, para a determinação da resistência mecânica a tração do material celulósico, foi utilizado um equipamento de ensaio de tração destinado a papel (Seção 4.1.18), conforme norma Tappi T 494 e ASTM 828. Isto se deve em função dos baixos valores de força proporcionados por estes materiais.

Da mesma forma, esta norma foi utilizada para a confecção dos corpos de prova com dimensões iguais a 24,5x254mm e tolerância de +/- 0,5mm. Adicionalmente, foi realizado o corte dos corpos de prova no sentido longitudinal (sentido de fabricação do papel) em função da maior resistência proporcionada pelo alinhamento das fibras.

Para a realização dos ensaios, os corpos de prova foram mantidos em ambiente controlado $\left(20^{\circ} \mathrm{C}\right.$ e Umidade relativa de $\left.30 \%\right)$ durante 24 horas a fim de garantir repetibilidade e uniformidade do material no momento do ensaio.

Outro ensaio realizado para a caracterização do material celulósico é relacionado à resistência mecânica do material em função da quantidade de água absorvida.

Para a realização deste ensaio, foram utilizados procedimentos fundamentados nas normas TAPPI 456, e ASTM D829. Contudo, ao contrario da proposta das normas, este estudo proporcionou a determinação de resistência mecânica à tração (ASTM D828 e TAPPI 494) de materiais com diversos níveis de absorção de água. 
O procedimento utilizado para a realzação deste estudo pode ser observado na Figura 4.28, onde é apresentado o processo de determinação da quantidade de água absorvida antes da realização do ensaio de tração.

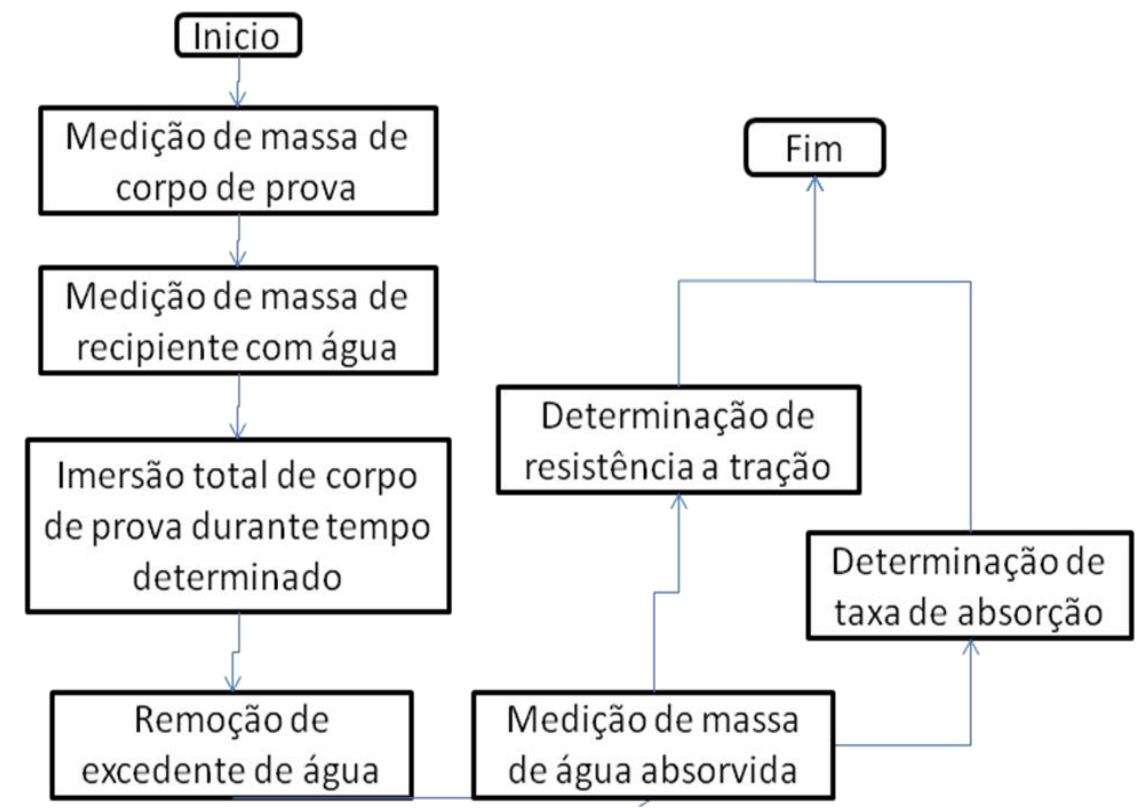

Figura 4.28 - Fluxograma dos procedimentos experimentais utilizadas para a determinação resistência a tração em função de absorção de água

\subsubsection{Determinação de resistência mecânica a tração de material compósito}

Em relação à resistência mecânica à tração do material compósito, foram utilizados procedimentos similares aos empregados na caracterização do substrato (ASTM D828 e TAPPI 494). Contudo, para este caso, a preparação dos corpos de prova apresenta o processo de impregnação e cura de polímero depositado no substrato, como pode ser observado na Figura 4.29 


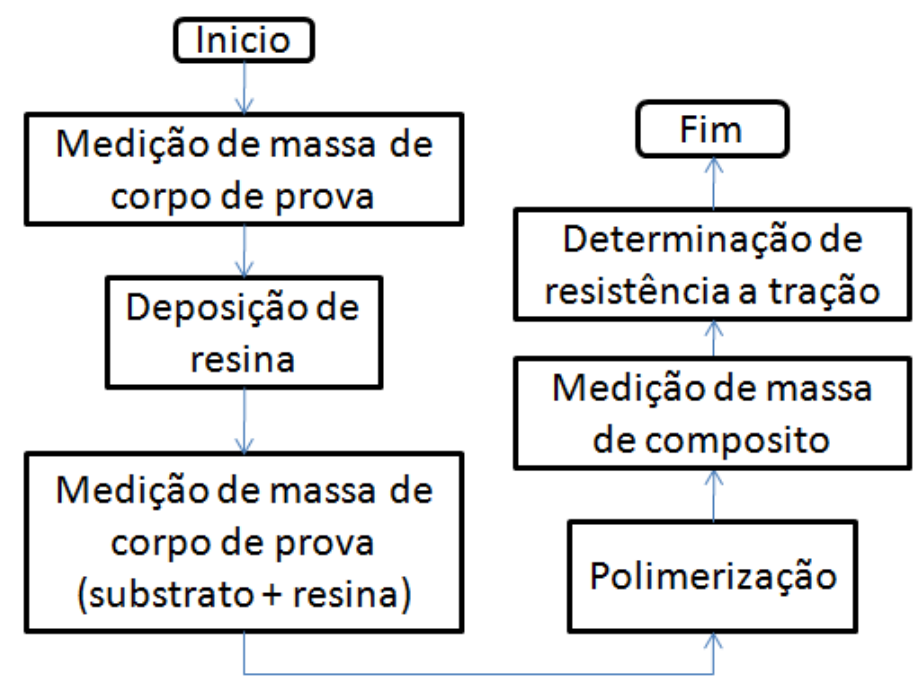

Figura 4.29 - Fluxograma dos procedimentos experimentais utilizadas para a determinação resistência a tração de compósito em função de quantidade media de polímero

Para a confecção dos corpos de prova, foi utilizado o procedimento apresentado na Seção 4.2.3, onde são mostrados os passos realizados para a fabricação do compósito. Adicionalmente, as dimensões definidas para estes corpos de prova são iguais a $20 \times 50 \mathrm{~mm}$.

Para a determinação da quantidade de material polimérico depositado no substrato, foi utilizada uma balança com $0,01 \mathrm{~g}$ de precisão, enquanto os corpos de prova tiveram sua parte polimérica curada através da Lâmpada UV durante tempo fixo. Enquanto para o ensaio de tração foi utilizada um equipamento de ensaio EMIC, sendo a velocidade de deslocamento igual a $100 \mathrm{~mm} / \mathrm{min}$.

\subsubsection{Determinação de resistência mecânica a tração de material compósito molhado}

Outro ensaio realizado para a caracterização do material compósito é a resistência a tração do material compósito em função da exposição à água.

Neste caso, além dos procedimentos já expostos na Secção 4.3.9, foram empregados procedimentos relacionados à determinação de percentual de água absorvido pelo compósito, como pode ser observado na Figura 4.30. 
Para realização deste procedimento, cabe ressaltar que o tempo utilizado para cura da parte polimérica do compósito foi considerado uma constante, sendo realizada por meio de lâmpada UV. Adicionalmente, foi o processo de remossão de água excedente teve duração de 1 minuto, enquanto a taxa de deslocamento do equipamento de ensaio de tração foi de $100 \mathrm{~mm} / \mathrm{min}$.

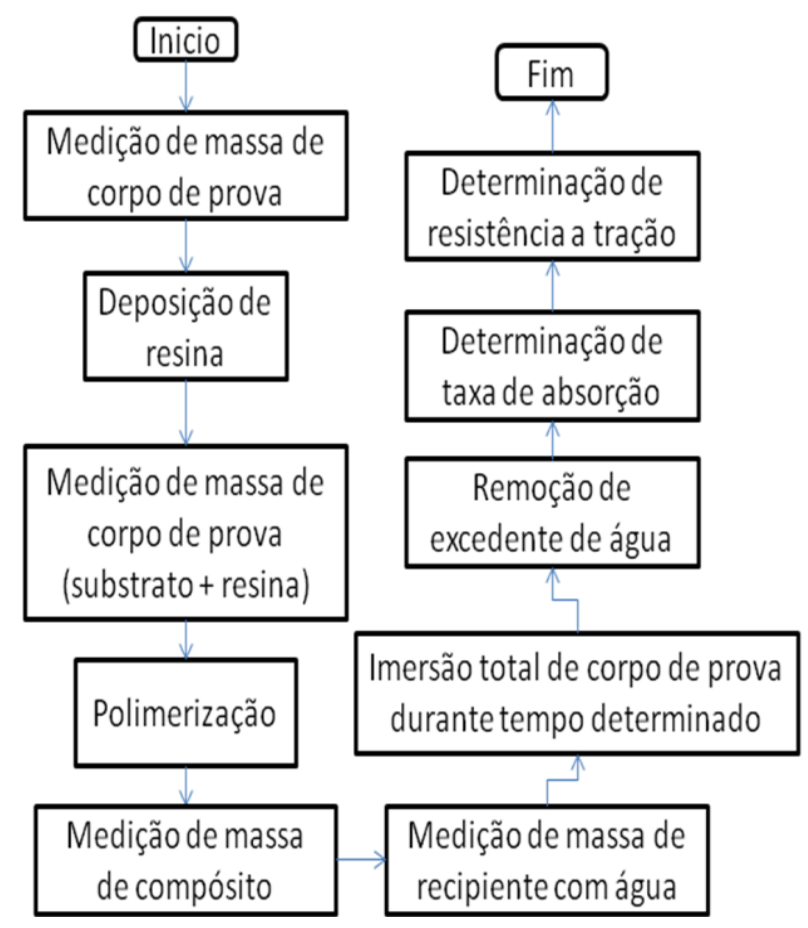

Figura 4.30 - Fluxograma dos procedimentos experimentais utilizadas para a determinação resistência média a tração de compósito em função de absorção de água

Através deste ensaio, torna-se possível identificar a taxa de absorção do compósito, além de determinar a resistência mecânica média do material à tração.

\subsubsection{Análise Microscópica}

Com referência a análise microscópica utilizada na caracterização do material, foi utilizado um microscópio ótico de magnitude igual a 400x. Este valor de 
magnitude proporciona evidenciar microestruturas com até $10 \mu \mathrm{m}$ de magnitude, como fibras, rugosidade superficial.

Para a realização desta análise, foram utilizadas corpos de prova de dimensões iguais a $20 \times 20 \mathrm{~mm}$, enquanto a iluminação empregada para a análise microscópica foi do tipo direta.

\subsubsection{Determinação de adesividade entre camadas}

Com relação à identificação da adesividade entre camadas, foi realizado procedimento baseado na norma ASTM D1876, onde é determinada a resistência a tração de uma junta em "T" (Peeling Test), como pode ser observado na Figura 4.31.

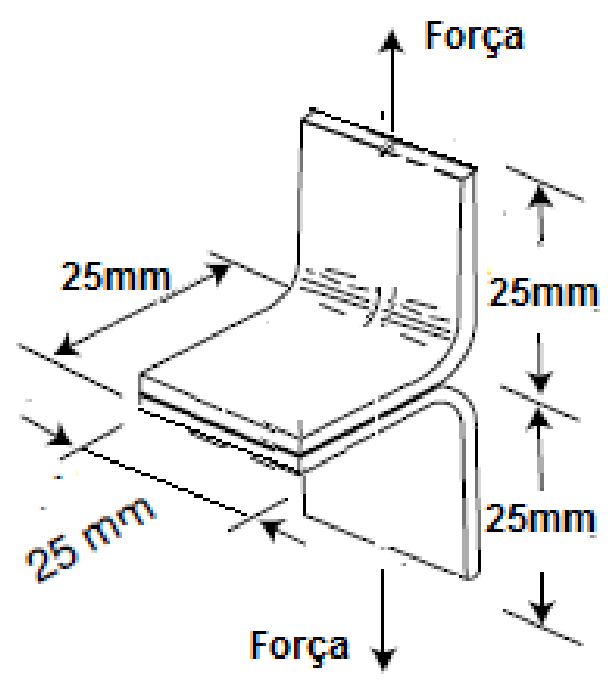

Figura 4.31 - Esquema de funcionamento de ensaio de arrancamento (adesividade) e dimensional de corpo de prova

Nesta figura, é possível também observar as dimensões básicas do corpo de prova, que é constituído por duas folhas de 25×50. Para a preparação do corpo de 
prova, a deposição da resina é realizada somente em metade das folhas, tendo sua polimerização realizada por meio de luz UV.

Adicionalmente, o tempo de exposição em UV foi especificado conforme grau de conversão de $60 \%$ do material polimérico. Ou seja, para cada material polimérico, foi identificado o tempo necessário para ser proporcionado $60 \%$ de conversão através da curva de polimerização do material.

Em relação ao procedimento realizado para a execução deste ensaio, a Figura 4.32 apresenta um fluxograma contendo as principais etapas realizadas neste ensaio. Após o término de ensaio de arrancamento, é realizada a determinação do modo de falha da junta adesiva através de análise microscópica, permitindo identificar a colaboração de cada elemento do compósito para a resistência mecânica do compósito.

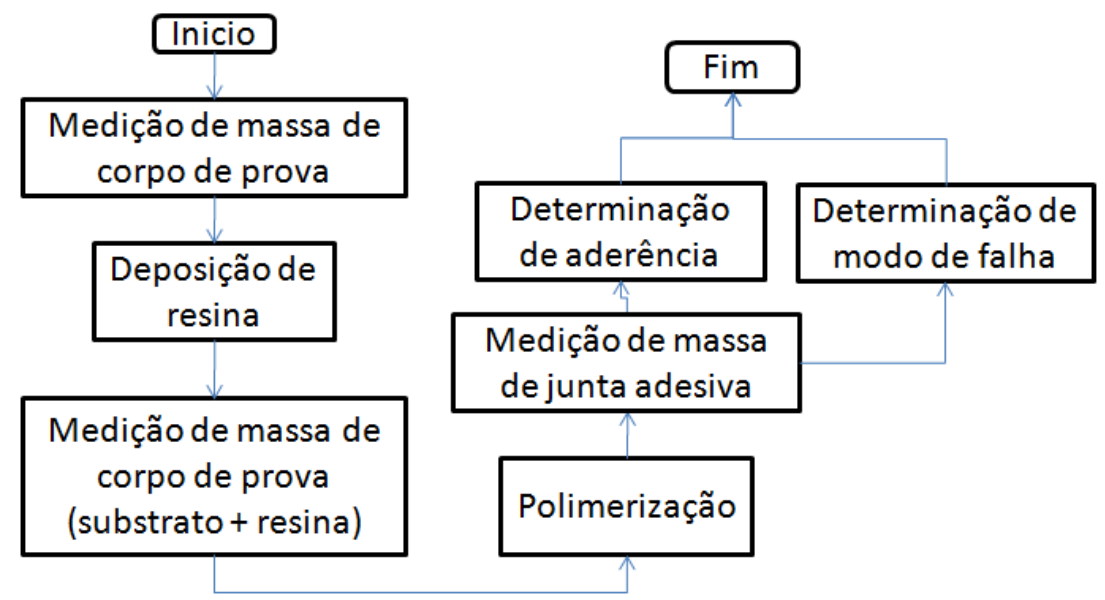

Figura 4.32 - Fluxograma dos procedimentos experimentais utilizados para a determinação força de arrancamento (adesividade) entre camadas

\subsubsection{Compatibilidade de resina com cabeçote jato de tinta}

Para identificação da compatibilidade das resinas com cabeçotes jato de tinta, foi elaborado um ensaio para determinação das principais características envolvidas no processo de impressão. Neste ensaio, foram determinadas como principais 
caracteristicas, a capabilidade de impressão e a quantidade de material depositado por gravimetria de substrato, conforme apresentado na Figura 4.33.

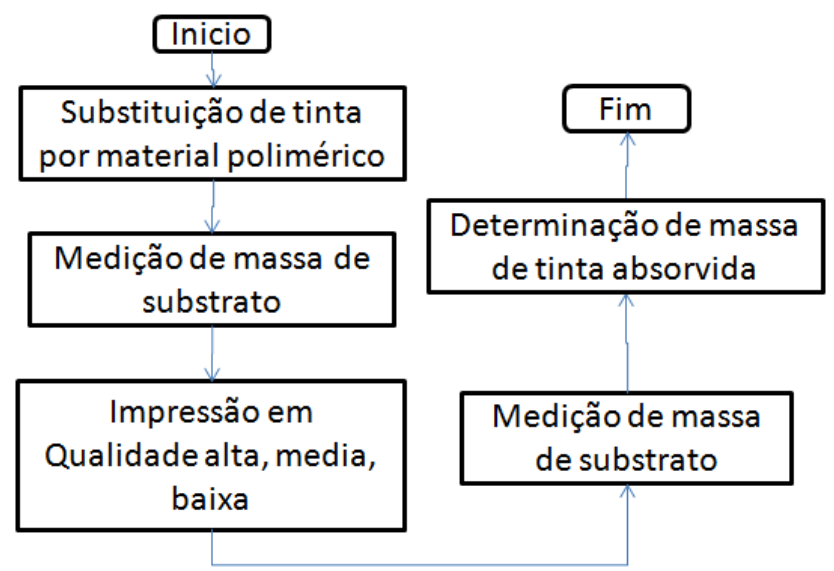

Figura 4.33 - Fluxograma dos procedimentos experimentais utilizados para a determinação compatibilidade entre material e cabeçote jato de tinta

Após limpeza de tinta remanecente de cabeçote jato de tinta, é estabelecido um padrão de impressão para forma geometrica retangular de dimensões 100x50mm. Em seguida é realizado o levantamento a identificação da quantidade de material depositado no substrato através de análise gravimétrica. 


\section{PARTE EXPERIMENTAL}

Neste capítulo, são apresentadas as principais considerações e planejamentos dos estudos de apoio realizados ao longo deste trabalho. Adicionalmente, os principais estudos necessários para suportar o desenvolvimento da tecnologia proposta neste trabalho são relacionados à caracterização de material polimérico, substrato celulósico e compósito.

\subsection{Desenvolvimento de material polimérico}

Para a identificação do material polimérico adequado para ser utilizado neste projeto, foram realizados estudos de caracterização relacionados às principais funções que este material deve proporcionar, assim como da determinação da formulação do material.

Para a realização deste projeto, foram escolhidos materiais a base de acrilatos, cuja formulação é composta de Metacrilato de Metila (monômero), Trimethylolpropane triacrylate (TMPTA) ou Sartomer CN501 (oligômero) e Omnirad Cureall 2500 (iniciador).

\subsubsection{Determinação de faixa de estudo}

Os sistemas de polimerização estudados apresentam múltiplas variáveis de controle, assim como um comportamento não linear em relação à formulação do material e espessura de camada, conforme apresentado na Figura 5.1. Em função disto, foi realizado um estudo inicial, com o objetivo de determinação da faixa de valores a ser estudada. 


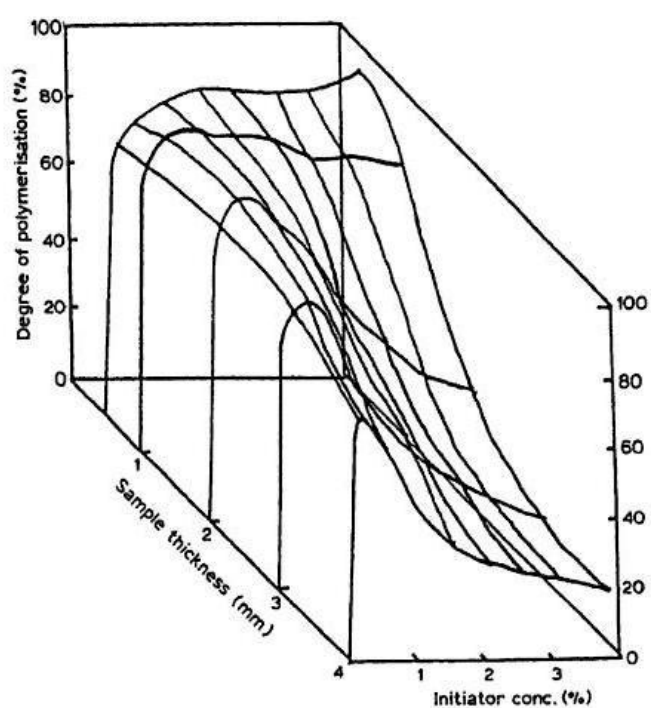

Figura 5.1 - llustração de grau de conversão em função de espessura de camada e concentração de iniciador

Neste estudo, foram avaliados os principais parâmetros de controle de processos de fotopolimerização, como: comprimento de onda da fonte luminosa, potência de fonte luminosa, absorbância de iniciador, concentração de iniciador e espessura de polimerização.

Adicionalmente, para realização deste estudo, foram considerados monômeros unifuncionais, sendo utilizados valores de constantes de propagação e terminação relativos ao metacrilato de metila (MMA).

Com o objetivo de identificar a faixa de valores mais adequada para ser utilizada em sistemas de cura de camadas espessas ou camadas finas, foram empregados métodos de otimização não linear com múltiplas variáveis aliado à validação experimental por meio de planejamento fatorial. Neste estudo, foram levantados e otimizados seis cenários de sistemas de polimerização com distintas espessuras de camada $(0,12 ; 0,5 ; 1 ; 2 ; 3 ; 4 \mathrm{~mm})$. Adicionalmente, foram consideradas como variáveis, a potência da fonte luminosa, o comprimento de onda da luz e a concentração de iniciador.

Logo, o problema de otimização pode ser descrito como: 


$$
\operatorname{Max} \rightarrow \operatorname{Rp}(\lambda, P, A)
$$

Submetido à:

$0.12 \leq P \leq 13[W]$

$325 \leq \lambda \leq 400[\mathrm{~nm}]$

$0.5 \leq A \leq 10[\%]$

Em relação às restrições da otimização, os valores de comprimento de onda e potência de fonte luminosa foram escolhidos de forma a atender às especificações encontradas em fotodiodos (LEDs) e lâmpadas UV de médio porte (PHILIPS, 2006; VCC, 2009). Adicionalmente, a faixa comprimento de onda foi também determinada a fim de atender proporcionar uma absorbância do fotoiniciador entre 0 e 1.

Por outro lado, a determinação da concentração do iniciador foi fundamentada a extrapolação dos valores máximos e mínimos recomendados pelo fornecedor. Sendo que o objetivo principal desta escolha foi de verificar se a recomendação do formecedor era aplicável para camadas espessas.

Para resolução da otimização, foi utilizado o método Newton Modificado, sendo os valores iniciais do estudo iguais a $4 \%$ para concentração de iniciador, $5 \mathrm{~W}$ para potência de fonte luminosa, e $380 \mathrm{~nm}$ para comprimento de onda.

Em relação ao erro de convergência, foi estipulado o valor de 0,01 , enquanto os valores de absorbância do iniciador foram obtidos através de regressão polinomial de curva espectrométrica do iniciador Omirad cureall 2500. Em adição, pode-se ressaltar esta regressão, apresentada na Equação (5.5), refere-se à faixa de comprimento de onda estipulada neste estudo (325 e 400nm).

$$
\text { Absorb }=3,53 \cdot 10^{4}-4,63 \cdot 10^{2} \cdot \lambda+2,43 \cdot \lambda^{2}-6,32 \cdot 10^{-3} \cdot \lambda^{3}+8,18 \cdot 10^{-6} \cdot \lambda^{4}-4,23 \cdot 10^{-9} .
$$


Para validar os resultados obtidos analiticamente, foi realizado um estudo experimental realizando planejamento fatorial das duas variáveis independentes da fonte luminosa (espessura de camada e concentração de iniciador). Neste estudo, foi considerado como fator de resposta, o grau de conversão após 40 segundos de exposição em luz UV.

Em relação aos valores dos fatores de controle, foram utilizados 0,12 a $2 \mathrm{~mm}$, para espessura de camada, e 1 a 10\% no peso, para concentração de iniciador. Onde, o controle da espessura foi realizado através de moldes de vidro, conforme apresentado na Seção 4.2.1.

Para determinação do grau de conversão, foi realizada uma análise fotométrica, conforme procedimentos apresentados na Seção 4.3.2. Em adição, foi realizada a análise gravimétrica (ajuste de curva de conversão) ao final de 40 segundos de exposição.

Por fim, além de serem identificados os efeitos principais da espessura de camada e da concentração do iniciador para o grau de conversão do sistema, foi determinada uma janela de processamento do processo através de diagrama de contorno.

\subsubsection{Determinação de formulação de material}

Para determinação da formulação mais adequada para o projeto, foi realizado um estudo experimental multivariado com múltiplos objetivos. Neste estudo, foi utilizado o método de planejamento de experimentos (Design of Experiment - DoE), sendo determinados como fatores de controle, os teores de monômero, oligômero e iniciador, conforme apresentado na Tabela 5.1. Nesta tabela, são apresentados os níveis e valores de cada fator de controle, sendo o DoE do tipo completo sem pontos centrais $\left(2^{3}\right)$. 
Tabela 5.1 - Matriz de planejamento de experimentos relacionados à determinação de formulação de material

\begin{tabular}{|c|c|c|c|c|c|c|c|c|c|c|}
\hline \multirow[b]{2}{*}{ material } & \multirow[b]{2}{*}{$\exp$} & \multicolumn{9}{|c|}{ Fatores de Controle } \\
\hline & & \multicolumn{3}{|c|}{ Monomero (ml) } & \multicolumn{3}{|c|}{ Oligomero } & \multicolumn{3}{|c|}{ Fotoiniciator } \\
\hline$A$ & 1 & - & $5 \mathrm{ml}$ & $62,50 \%$ & - & $3 \mathrm{ml}$ & $37,50 \%$ wt & - & $0,16 \mathrm{ml}$ & $2,00 \% \mathrm{wt}$ \\
\hline B & 2 & + & $10 \mathrm{ml}$ & $76,92 \%$ & - & $3 \mathrm{ml}$ & $23,08 \% w t$ & - & $0,253 \mathrm{ml}$ & $2,00 \% \mathrm{wt}$ \\
\hline C & 3 & - & $5 \mathrm{ml}$ & $50,00 \%$ & + & $5 \mathrm{ml}$ & $50,00 \%$ wt & - & $0,204 \mathrm{ml}$ & $2,00 \% \mathrm{wt}$ \\
\hline D & 4 & + & $10 \mathrm{ml}$ & $66,67 \%$ & + & $5 \mathrm{ml}$ & $33,33 \% \mathrm{wt}$ & - & $0,297 \mathrm{ml}$ & $2,00 \% \mathrm{wt}$ \\
\hline$E$ & 5 & - & $5 \mathrm{ml}$ & $62,50 \%$ & - & $3 \mathrm{ml}$ & $37,50 \%$ wt & + & $0,399 \mathrm{ml}$ & $5,00 \%$ wt \\
\hline $\mathrm{F}$ & 6 & + & $10 \mathrm{ml}$ & $76,92 \%$ & - & $3 \mathrm{ml}$ & $23,08 \%$ wt & + & $0,633 \mathrm{ml}$ & $5,00 \%$ wt \\
\hline G & 7 & - & $5 \mathrm{ml}$ & $50,00 \%$ & + & $5 \mathrm{ml}$ & $50,00 \%$ wt & + & $0,509 \mathrm{ml}$ & $5,00 \%$ wt \\
\hline $\mathrm{H}$ & 8 & + & $10 \mathrm{ml}$ & $66,67 \%$ & + & $5 \mathrm{ml}$ & $33,33 \%$ wt & + & $0,743 \mathrm{ml}$ & $5,00 \% \mathrm{wt}$ \\
\hline
\end{tabular}

Com relação aos fatores de resposta, foram espeficidados os valores de resistência mecânica à tração, taxa de polimerização (grau de conversão), viscosidade, temperatura de deflexão sobre carregamento (DTUL ou HDT) e módulo de elasticidade.

Em relação aos fatores de resposta deste estudo, é possível observar na Tabela 5.2, um levantamento dos ensaios realizados para a identificação destes fatores, assim como a seção onde estes procedimentos estão descritos.

Tabela 5.2 - Relação de ensaios realizados para obtenção dos fatores de resposta e indicativo de seção do trabalho onde esta localizada a descrição da confecção dos corpos de prova e procedimentos experimentais empregados

\begin{tabular}{|c|c|c|}
\hline Ensaio & Confecção de Corpo de prova & Procedimento experimental \\
\hline Viscosidade & - & Seção 4.3.3 \\
\hline Taxa de polimerização & Seção 4.2.1 & Seção 4.3.2 \\
\hline $\begin{array}{c}\text { Resistência mecânica à } \\
\text { tração }\end{array}$ & Seção 4.2.2 & Seção 4.3.7 \\
\hline $\begin{array}{c}\text { Determinação de Módulo de } \\
\text { elasticidade }\end{array}$ & Seção 4.2.2 4.3.6 \\
\hline $\begin{array}{c}\text { Temperatura de trabalho - } \\
\text { (DTUL ou HDT) }\end{array}$ & Seção 4.2.2 & Seção 4.3.5 \\
\hline
\end{tabular}




\subsubsection{Compatibilidade com cabeçote jato de tinta}

Com relação à compatibilidade do material com cabeçote jato de tinta, foi determinado através de estudos de otimização, Seção 6.1.2, formulação de material a ser testado em duas tecnologias de jato de tinta comerciais. A primeira testada é a tecnologia bubblejet da empresa HP, enquanto a segunda é a piezo da empresa Seiko Epson.

Neste ensaio, foi identificada a compatibilidade entre o material polimérico estudado e os cabeçotes jato de tinta através dos procedimentos apresentados na Seção 4.3.13. Adicionalmente, foram identificadas as respectivas taxas de deposição de material em função do tipo de qualidade de impressão selecionada (baixa, média, alta).

\subsection{Desenvolvimento do material celulósico laminado (substrato)}

Com o objetivo de identificar o material celulósico laminado mais adequado para a realização deste projeto, foram estipulados como critério de seleção de material, a gramatura, espessura, opacidade, taxa de absorção, resistência mecânica à tração e microestrutura.

Entre as demais propriedades de materiais celulósicos, estas foram selecionadas em importância das mesmas para a viabilização do projeto. Adicionalmente, foram caracterizados 4 tipos de material comerciais de classificação distinta, como: papel sulfite (folhas), papel sulforizé (folha), papel seda (bobina) e papel vegetal (folha).

Para a determinação da gramatura e espessura de material, foram identificados valores de espessura e gramatura 10 amostras de cada um dos materiais, sendo mensurados e confrontados os valores de gramatura obtidos experimentalmente com valores especificados por fabricante.

Em contrapartida, o levantamento da taxa de absorção do material foi realizado conforme procedimentos apresentados na Seção 4.3.4. Sendo identificada a quantidade de água absorvida em função do tempo de imersão do material. Neste 
estudo, foram ensaiadas 5 amostras de cada material conforme apresentado na Tabela 5.3. Nesta tabela, pode-se observar o tempo de imersão de cada amostra assim como do tipo de papel e sua gramatura.

Tabela 5.3 - Relação de materiais celulósicos ensaiados e tempos de imersão

\begin{tabular}{|c|c|c|c|c|}
\hline $\begin{array}{l}\text { Tempo de } \\
\text { imersão (s) }\end{array}$ & \multicolumn{4}{|c|}{ Tipo de substrato } \\
\hline 0 & \multirow{6}{*}{ 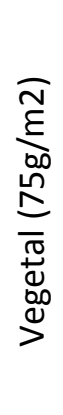 } & \multirow{6}{*}{ 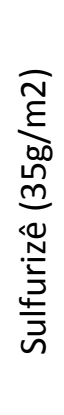 } & \multirow{6}{*}{ 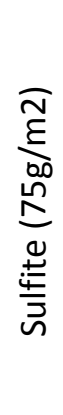 } & \multirow{6}{*}{ 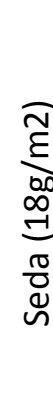 } \\
\hline 15 & & & & \\
\hline 30 & & & & \\
\hline 60 & & & & \\
\hline 150 & & & & \\
\hline 300 & & & & \\
\hline
\end{tabular}

Em relação à determinação da opacidade dos materiais, foram ensaiadas 4 amostras de cada material, sendo utilizados os procedimentos descritos na Seção 4.3.1. Neste estudo, além da opacidade do material seco, foram identificados os valores de opacidade dos materiais após absorção de água durante período de 120 segundos. Desta forma, torna-se possível identificar a influência da absorção de fluidos para a opacidade do material.

Similarmente, foi determinada a resistência mecânica à tração dos materiais em função da quantidade de água absorvida. Neste caso, foram realizadas uma amostragem de 8 valores para cada material, permitindo levantar uma curva de resistência em função da absorção.

Com objetivo de explicar o comportamento do material, foi realizada uma análise da microestrutura de cada um dos materiais. Desta forma, sendo possível identificar o tipo de fibra presente, assim como o tipo de tratamento empregado. 


\subsection{Desenvolvimento de material compósito}

Com o objetivo de identificar o comportamento do material compósito, assim como da potencialidade de viabilização deste projeto, foram realizados estudos referentes ao comportamento mecânico do material em função do percentual de polímero impregnado no substrato. Da mesma forma, foi estudada a influência do polímero para a taxa de absorção e perda de resistência por absorção de água.

Adicionalmente, foi identificada a adesividade entre camadas de material compósito, assim como dos modos de falha proporcionados por gradientes de polimerização.

\subsubsection{Influência de polímero sobre resistência mecânica}

Com relação ao desenvolvimento da formulação do material compósito, foi inicialmente realizado um estudo referente à resistência mecânica média à tração em função do percentual de polímero impregnado no substrato. Através deste estudo, torna-se possível identificar a possibilidade de fabricação de um material com gradiente funcional.

Para este estudo, foi considerado como variável, a quantidade de polímero depositado em substrato, formando corpos de prova de dimensões iguais $25 \times 50$, conforme apresentado na Seção 4.2.3. Adicionalmente, foram submetidos a ensaio de tração (Seção 4.3.9), 5 corpos de prova de cada percentual de polímero depositado em subtrato, sendo identificada a variação da taxa polímero/substrato (\%) pela tensão máxima de tração (Mpa).

$\mathrm{Na}$ Tabela 5.4, pode-se observar o planejamento dos experimentos deste estudo, sendo apresentados 5 percentuais de polímero.

Cabe também ressaltar que a determinação da formulação de material fotopolimerica utilizada para este estudo teve como critério a resistência mecânica à tração do polímero, enquanto o tempo de polimerização foi considerado uma constante do estudo. 
Tabela 5.4 - Planejamento de experimento de estudo de influência de percentual de polímero para a resistência mecânica do material Compósito

\begin{tabular}{|c|c|c|c|}
\hline Material & Polímero/Substrato & Substrato & Polimerização \\
\hline \multirow{6}{*}{ 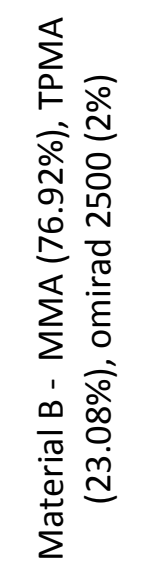 } & 0 & \multirow{6}{*}{ 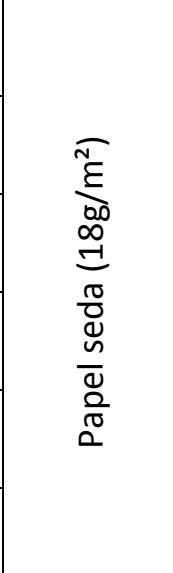 } & \multirow{6}{*}{ 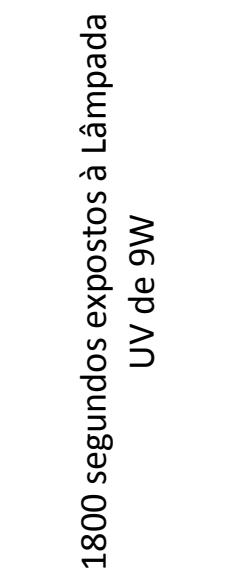 } \\
\hline & 0.5 & & \\
\hline & 1 & & \\
\hline & 1.5 & & \\
\hline & 2 & & \\
\hline & 2.5 & & \\
\hline
\end{tabular}

\subsubsection{Determinação de Formulação do compósito}

Outro estudo relacionado à caracterização do material compósito tem como objetivo, a identificação da contribuição da formulação do material polimérico para a resistência mecânica do compósito em presença de água, assim como para a aderência entre camadas.

Para realização deste estudo, foi utilizado um planejamento de experimentos completo $\left(2^{3}\right)$ sem pontos centrais cujos fatores de controle são: monômero, oligômero, iniciador e percentual de polímero/substrato. Neste caso, foram considerados como fatores de resposta, a resistência mecânica do material à tração em presença ou não de água, taxa de absorção de água e aderência entre camadas.

Em relação aos ensaios realizados ao longo deste estudo, assim como os procedimentos empregados para a sua realização, a Tabela 5.5 apresenta as seções deste trabalho onde estes procedimentos são descritos. Em adição, também são apresentados os principais parâmetros utilizados na realização deste estudo. 
Tabela 5.5 - Levantamento de ensaios e procedimentos para identificação dos fatores de resposta

\begin{tabular}{|c|c|c|c|}
\hline & \multicolumn{3}{|c|}{ Fatores de Resposta } \\
\hline & 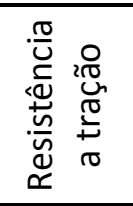 & 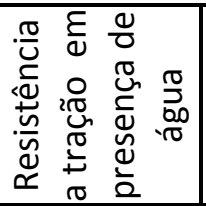 & 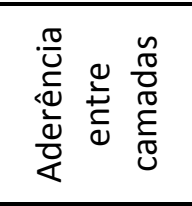 \\
\hline Confecção dos corpos de prova & \multicolumn{2}{|c|}{ Seção 4.2 .3} & Seção 4.2.4 \\
\hline \multirow{2}{*}{ Procedimento experimental } & Seção & Seção & Seção \\
\hline & 4.3.10 & 4.3.11 & 4.3.13 \\
\hline Tempo de cura & \multicolumn{2}{|c|}{30 minutos } & $\begin{array}{c}\text { Equivalente à } \\
60 \% \text { de } \\
\text { conversão }\end{array}$ \\
\hline Fonte luminosa & \multicolumn{2}{|c|}{ Lâmpada UV } & Led UV \\
\hline Velocidade de deslocamento & \multicolumn{3}{|c|}{$100 \mathrm{~mm} / \mathrm{min}$} \\
\hline
\end{tabular}

Outro ponto que também pode ser salientado é que a determinação de tempo de exposição de 1800 segundos para ensaios de resistência de tração em presença ou não de água se deve à necessidade de todos os materiais estarem com grau de conversão acima de $90 \%$.

Contudo, cabe ressaltar que o tempo de polimerização utilizado para a determinação da aderência entre camadas foi estipulado em função desta taxa de polimerização promover o mesmo critério para comparação entre diferentes formulações de matéria (diferentes taxas de polimerização). Em adição, buscou-se realizar este ensaio com valores inferiores a $80 \%$, com o objetivo de identificar a relação entre os modos de falha da junta adesiva e dogradiente de polimerização gerado pelo LED UV.

Com relação ao planejamento experimental deste estudo, a Tabela 5.6 apresenta a matriz de experimentos realizados, indicando adicionalmente os níveis empregados no DoE. 
Tabela 5.6 - Matriz de planejamento de experimentos relacionados à determinação de formulação de material Compósito

\begin{tabular}{|l|r|c|c|c|c|c|c|}
\hline material & exp & \multicolumn{2}{|c|}{ Monomer (ml) } & \multicolumn{2}{|c|}{ Oligomer (ml) } & \multicolumn{2}{|c|}{ Photoinitiator (\% wt) } \\
\hline A & 1 & - & 5 & - & 3 & - & $2.00 \%$ \\
B & 2 & + & 10 & - & 3 & - & $2.00 \%$ \\
C & 3 & - & 5 & + & 5 & - & $2.00 \%$ \\
D & 4 & + & 10 & + & 5 & - & $2.00 \%$ \\
E & 5 & - & 5 & - & 3 & + & $5.00 \%$ \\
F & 6 & + & 10 & - & 3 & + & $5.00 \%$ \\
G & 7 & - & 5 & + & 5 & + & $5.00 \%$ \\
H & 8 & + & 10 & + & 5 & + & $5.00 \%$ \\
\hline
\end{tabular}

\subsubsection{Caracterização de comportamento de polímero impregnado em substrato}

Outra abordagem utilizada neste trabalho para caracterização do material compósito é a análise microscópica. Neste caso foram consideradas amostras de material compósito conforme apresentado na Seção 4.3.11, sendo analisadas amostras frontais e transversais dos corpos de prova.

Cabe também ressaltar que, foram observadas regiões de borda e de deposição, assim como de seção transversal entre camadas de material. Através disto, busca-se o entendimento do comportamento do material de torma mais clara. 


\section{RESULTADOS E DISCUSSÕES}

Neste capítulo, são apresentados resultados das pesquisas de fundamentação realizadas ao longo deste trabalho. Adicionalmente, estes resultados são discutidos a fim de identificar um material viável para ser utilizado neste projeto.

Entre estes estudos, podem ser divididos em desenvolvimento de material polimérico, desenvolvimento de material celulósico e desenvolvimento de material compósito, de forma a identificar os requisitos necessários para utilização e processamento destes materiais.

\subsection{Desenvolvimento de material polimérico}

Com referência ao desenvolvimento do material polimérico, foi identificada a colaboração dos componentes químicos para as propriedades finais do material.

Contudo, em função do comportamento não linear do material, foi realizado um estudo inicial para determinação da faixa a ser estudada, como é descrito na Seção 5.1.1.

Após determinada a faixa de estudo, foi empregada a metodologia de planejamento de experimentos, como é apresentado na Seção 5.1, para a identificação do material a ser utilizado no projeto.

Adicionalmente, foram identificados como fatores de resposta, a taxa de polimerização do material, viscosidade do material não polimerizado, resistência a tração, módulo de elasticidade, temperatura de trabalho e compatibilidade com cabeçote jato de tinta. 


\subsubsection{Determinação de faixa de estudo}

Em relação às respostas obtidas neste estudo inicial, foram confrontados resultados de estudo de otimização numérica, sendo estes valores validados experimentalmente.

Para os resultados do estudo de otimização, foram encontrados valores otimizados para 6 espessuras de camada distintas, como pode ser observado na Tabela 6.1.

Nesta tabela pode ser observado que a concentração de iniciador aumenta conforme a redução da espessura de camada, enquanto a potência da lâmpada se manteve constante. Adicionalmente, pode-se observar que houve a redução do comprimento de onda para valores de espessura de camada menores, e consequentemente o aumento da absorbância do iniciador.

Tabela 6.1 - Relação de valores de otimização conforme espessura de camada, assim como valores de taxa de polimerização, absorbância potência de lâmpada e concetração de iniciador Omnirad cureall 2500

\begin{tabular}{|r|r|l|r|r|r|r|r|}
\hline $\begin{array}{l}\text { Condição } \\
\text { otimização }\end{array}$ & $\mathrm{T}(80 \%)$ & $\mathrm{Rp}$ & $\lambda(\mathrm{nm})$ & absorbancia & $\mathrm{P}(\mathrm{W})$ & $\mathrm{A}(\%)$ & $\begin{array}{l}\mathrm{D} \\
(\mathrm{mm})\end{array}$ \\
\hline $\mathrm{A}$ & 0.204135 & 2.299632 & $\begin{array}{r}378.55 \\
554\end{array}$ & 2.590395 & 13 & $10.00 \%$ & 0.12 \\
\hline $\mathrm{B}$ & 0.391584 & 1.198814 & 400 & 1.860031 & 13 & $4.97 \%$ & 0.5 \\
\hline $\mathrm{C}$ & 0.553783 & 0.84769 & 400 & 1.860031 & 13 & $2.48 \%$ & 1 \\
\hline $\mathrm{D}$ & 0.783168 & 0.599407 & 400 & 1.860031 & 13 & $1.24 \%$ & 2 \\
\hline $\mathrm{E}$ & $\begin{array}{r}0.959181 \\
572\end{array}$ & 0.489414 & 400 & 1.860031 & 13 & $0.83 \%$ & 3 \\
\hline $\mathrm{F}$ & 1.107567 & 0.423845 & 400 & 1.860031 & 13 & $0.62 \%$ & 4 \\
\hline
\end{tabular}

Com o objetivo de identificar o comportamento do material em diferentes condições, foram submetidas as condições de otimização A-F às 5 outras espessuras de camada estudadas, como pode ser observado na Tabela 6.2. 
Nesta tabela, é apresentado o tempo necessário para polimerização de $80 \%$ do material exposto a radiação UV em função da espessura de camada e condições de otimização identificadas anteriormente.

Consequentemente, pode-se observar que para condições de otimização realizadas para camadas mais espessas, como por exemplo $\mathrm{F}$, a diferença de tempo de polimerização entre camadas finas e espessas é reduzido ( 0.40 segundos). Em contrapartida, as condições de otimização obtidas para espessuras finas (A e B), apresentaram diferença grandes, como 10000 segundos.

Tabela 6.2 - Relação de condições de otimização e tempo para 80\% de polimerização em função da espessura de camada

\begin{tabular}{|c|c|c|c|c|c|c|}
\hline & \multicolumn{6}{|c|}{ Tempo (s) para 80\% de de polimerização conforme Condições de } \\
otimização & \multicolumn{7}{c|}{ de } \\
\hline D (mm) & A & B & C & D & E & F \\
\hline 0.12 & 0.204136 & 0.267789 & 0.356656897 & 0.489482 & 0.593525 & 0.681926 \\
\hline 0.5 & 0.592191 & 0.391584 & 0.431287209 & 0.538263 & 0.632331 & 0.715099 \\
\hline 1 & 2.404762 & 0.645613 & 0.553783739 & 0.609932 & 0.687284 & 0.761219 \\
\hline 2 & 39.65444 & 1.754959 & 0.913035031 & 0.783168 & 0.81193 & 0.862574 \\
\hline 3 & 653.9004 & 4.770473 & 1.505340279 & 1.005608 & 0.959182 & 0.977425 \\
\hline 4 & 10782.79 & 12.96749 & 2.481886542 & 1.291227 & 1.133139 & 1.107567 \\
\hline
\end{tabular}

Adicionalmente este comportamento pode ser observado graficamente na Figura 6.1, onde é apresentado o tempo de polimerização de $80 \%$ do material conforme espessura de camada para condições de otimização $B(0.5 \mathrm{~mm})$ e $F(4 \mathrm{~mm})$.

Através desta figura, pode-se observar que condições de otimização para espessuras finas tendem a proporcionar grande contração na peça, em função do gradiente de polimerização proporcionado ao longo da espessura de camada.

Em contraste, baixas concentrações de iniciador ( condições de otimização F) proporcionam maior homogeneidade do material ao longo da espessura de camada. 


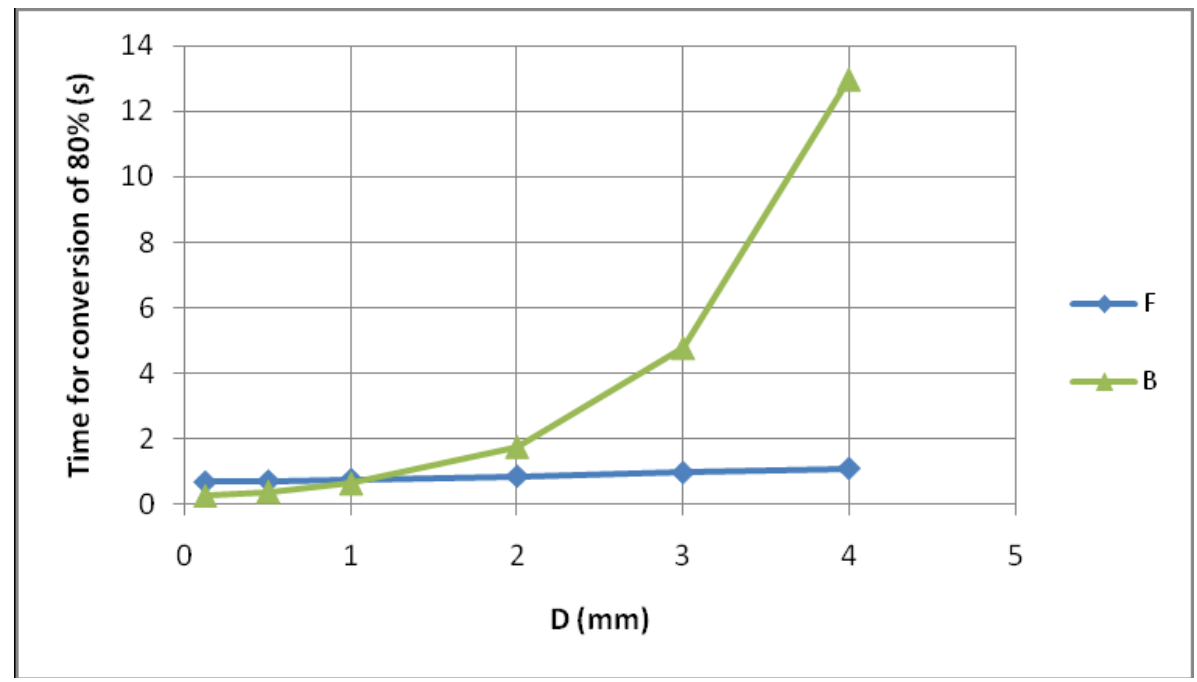

Figura 6.1 - llustração de grau de conversão em função de condições de otimização e espessura de camada

Com o intuito de validar experimentalmente os resultados obtidos neste estudo, foi realizado um planejamento de experimentos de duas variáveis, conforme apresentado na Seção 5.1.1. Neste estudo, foram consideradas como variáveis, a espessura de camada e concentração de iniciador, como pode ser observado na Tabela 6.3.

Tabela 6.3 - Matriz de experimento de determinação de faixa de estudo e converão de material após 30 segundos de exposição

\begin{tabular}{|c|l|l|l|}
\hline & \multicolumn{3}{|c|}{ Matriz de experimentos } \\
\hline $\begin{array}{l}\text { Exp } \\
\text { No }\end{array}$ & Espessura de camada (mm) & Concentração de iniciador (\% wt) & Conversão (\%) \\
\hline 1 & $(-) 0,12$ & $(-) 1$ & $45.45 \%$ \\
\hline 2 & $(-) 0,12$ & $(+) 10$ & $75.00 \%$ \\
\hline 3 & $(+) 2$ & $(-) 1$ & $33.65 \%$ \\
\hline 4 & $(+) 2$ & $(+) 10$ & $27.27 \%$ \\
\hline
\end{tabular}

Estes valores de conversão foram identificados através de análise fotométrica, sendo apresentado na Figura 6.2, as curvas de polimerização de experimentos cuja formulação de material apresentavam 10\% de iniciador. 


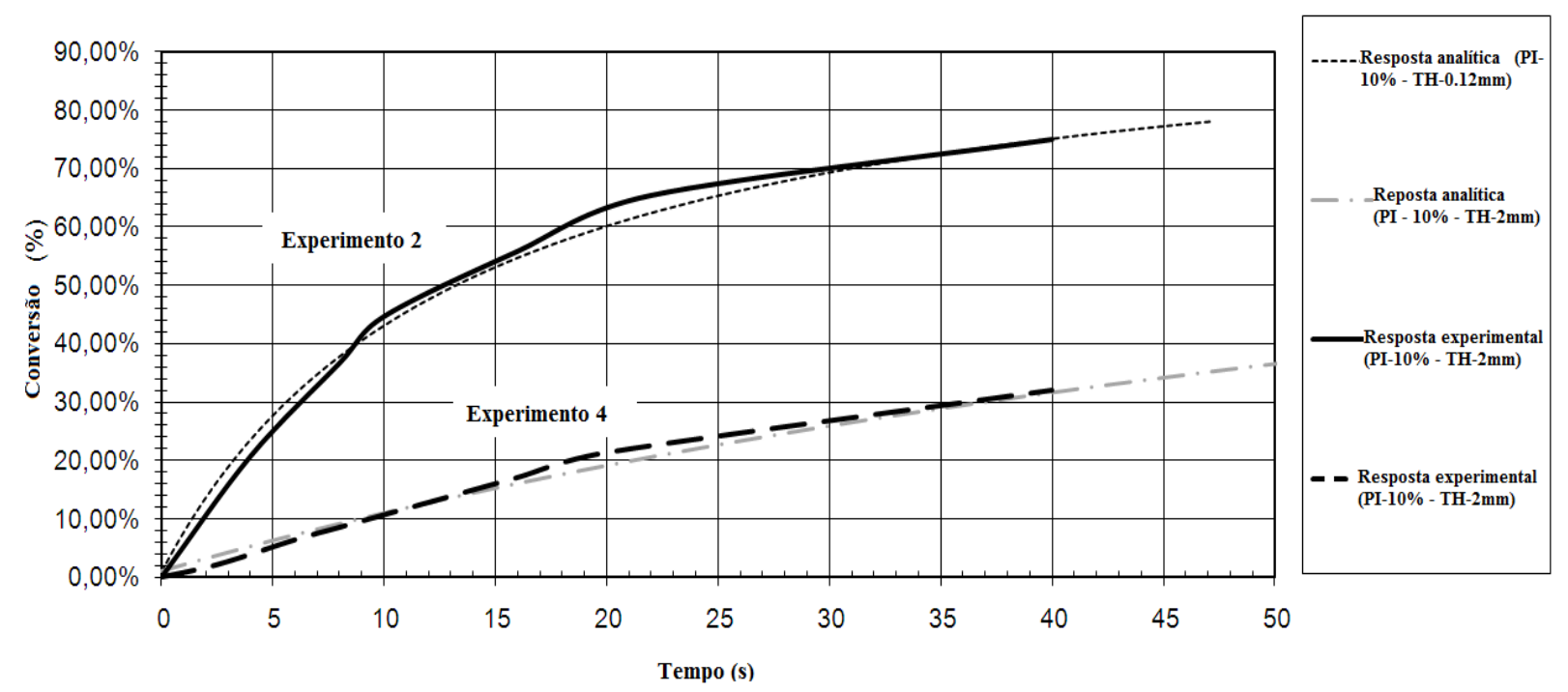

Figura 6.2 - Curvas de polimerização analíticas e experimentais de experimentos 2 e 4

Pode-se ver que para camadas espessas (experimento 4) occorre uma estagnação da taxa de polimerização em 20 segundos, confirmando os resultados obtidos analiticamente.

Em adição, foi elaborado o diagrama de contorno deste estudo, Figura 6.3, onde pode ser observado comportamento da conversão do material em 30 segundos de exposição em função da espessura de camada e concentração de iniciador.
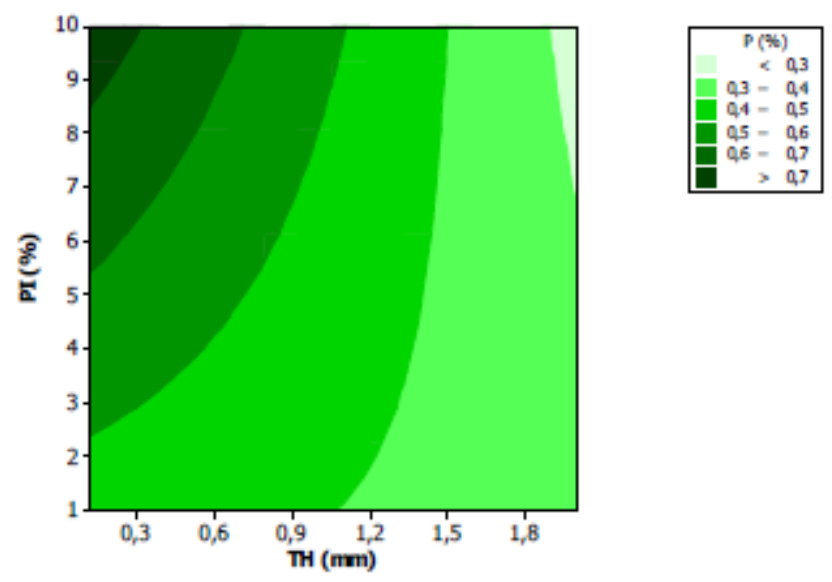

Figura 6.3 - Diagrama de contorno de taxa de conversão em função de concentração de iniciador e espessura de camada 
Em face à necessidade de espessura mínima de $2 \mathrm{~mm}$ para a caracterização do material, em adição aos levantamentos realizados nestes estudos, pode-se identificar como faixa adequada para a determinação da formulação de material, os valores de concentração de iniciador entre 2 e 5\%. Da mesma forma, foi estipulada o comprimento de onda de luz UV igual a $400 \mathrm{~nm}$, devido à facilidade de implementação de fontes luminosas nesta faixa.

\subsubsection{Determinação de formulação de material}

Para a determinação da formulação do material polimérico, foi realizado um estudo multivariável aplicando planejamento de experimentos, conforme apresentado na Seção 5.1.2.

Neste estudo, foram identificados como fatores de resposta, a taxa de polimerização, viscosidade de material não polimerizado, resistência mecânica média a tração, módulo de elasticidade e temperatura de trabalho (HDT).

\section{Taxa de polimerização do Material}

Para a identificação da taxa de polimerização do material, foi realizada uma análise fotométrica dos materiais, conforme apresentado na Seção 4.3.2. Sendo apresentadas as curvas de conversão dos materiais estudados na Figura 6.4 e Figura 6.5.

A partir destas curvas torna-se possível identificar a constante $\left(\frac{k p}{\sqrt{k t}}\right)$ do modelo matemático da cinética de polimerização baseado na Equação (6.1). Neste modelo, esta constante representa a taxa de propagação e terminação do processo, sendo ligada diretamente às propriedades do material. Esta equação destaca que a taxa de polimerização pode ser identificada através da quebra das duplas ligações de carbono das moléculas de monômero e oligômero (FOUASSIER e RABEK, 1993; BRANDRUP et al., 1999; ANDRZEJEWSKA, 2001; MATYJASZEWSKI e DAVIS, 
2002; FOUASSIER, J. et al., 2003; LOVESTEAD et al., 2003; ODIAN, 2004; BODDAPATl et al., 2011).

$$
R p=\frac{k p}{\sqrt{k t}} \cdot[M] \cdot\left(I_{o} \cdot \alpha \cdot \phi \cdot[A] \cdot e^{-\alpha \cdot[A] \cdot D}\right)^{1 / 2}=\frac{k p}{\sqrt{k t}} \cdot[C=C] \cdot\left(I_{o} \cdot \alpha \cdot \phi \cdot[A] \cdot e^{-\alpha \cdot A] \cdot D}\right)^{1 / 2}
$$

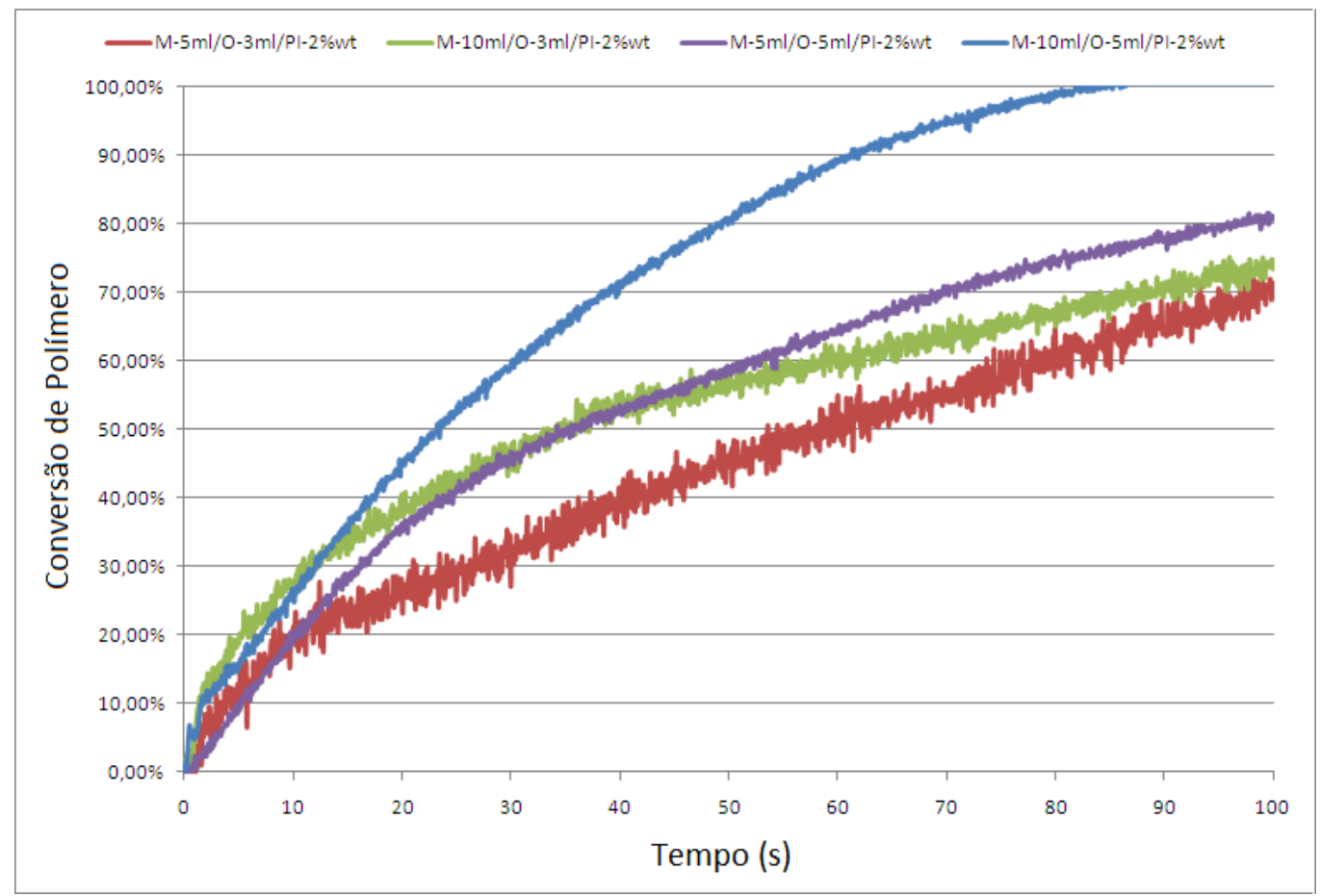

Figura 6.4 - Curva de polimerização de materiais A, B, C e D 


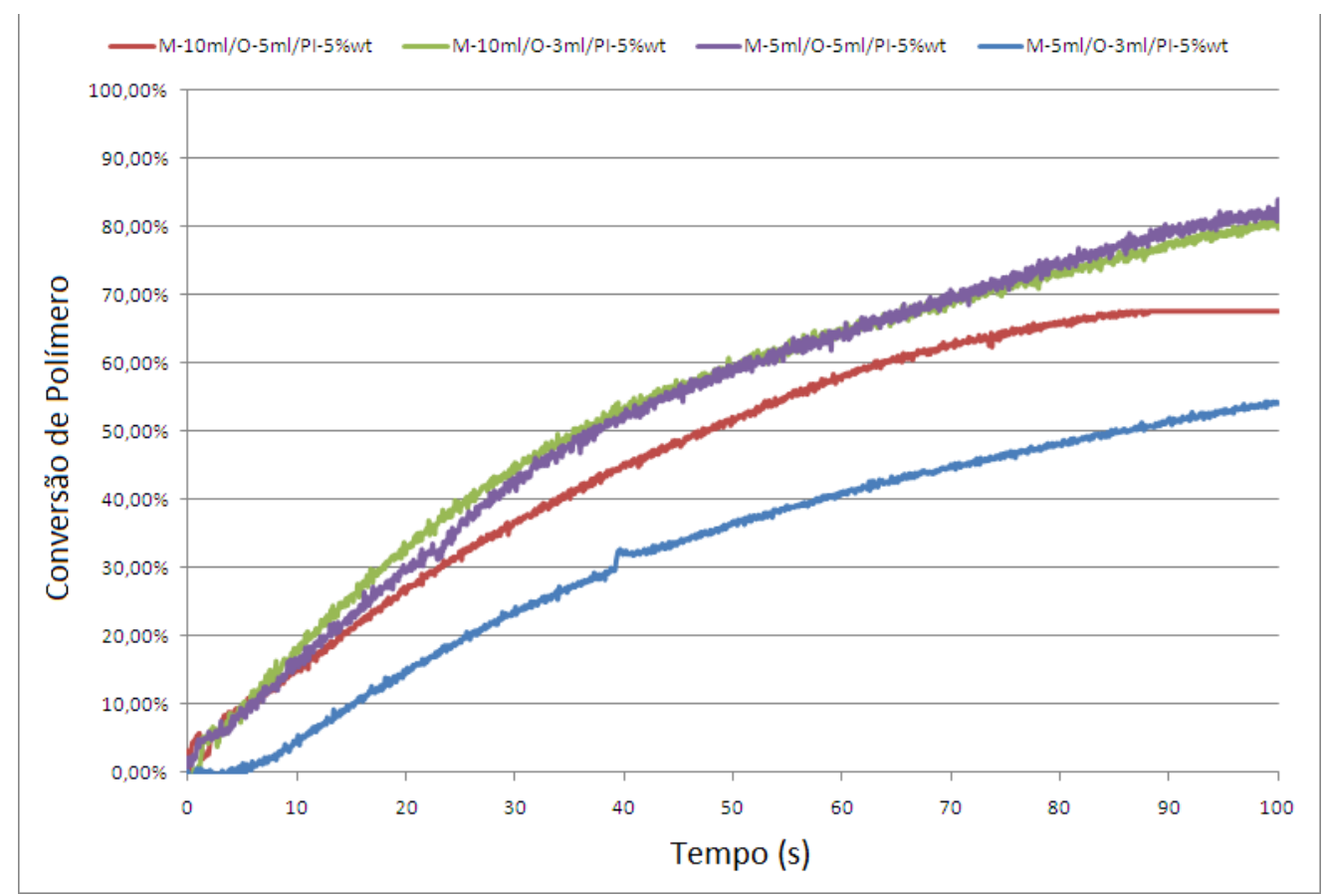

Figura 6.5 - Curva de polimerização de materiais E, F, G e H

Adicionalmente, a Tabela 6.4 apresenta a relação entre formulação do material e conversão do material em 30 e 60 segundos de exposição em radiação de LED UV. Adicionalmente, esta tabela apresenta o percentual de inibidor presente na formulação dos materiais, assim como os valores das constantes de polimerização das formulações de material $\left(\frac{k p}{\sqrt{k t}}\right)$ e dos mínimos quadrados equivalentes do ajuste de regressão não linear (Goodness Fit Test). Nesta tabela, os valores de resposta experimentais e os valores teóricos baseados no modelo matemático são também apresentados. 
Tabela 6.4 - Relação entre composição de materiais e conversão de material em 30 e 60 segundos, Inibidor (TMQA), Constante $\frac{k p}{\sqrt{k t}}$ e mínimo quadrado $\left(\mathrm{r}^{2}\right)$

\begin{tabular}{|c|c|c|c|c|c|c|c|c|c|c|}
\hline \multirow{3}{*}{ ষ̃ } & \multicolumn{4}{|c|}{ Fatores de controle } & \multicolumn{6}{|c|}{ Fatores de Resposta } \\
\hline & \multirow{2}{*}{$\begin{array}{c}\text { Mon. } \\
\mathrm{ml}\end{array}$} & \multirow{2}{*}{$\begin{array}{c}\text { Olig. } \\
\mathrm{ml}\end{array}$} & \multirow{2}{*}{$\begin{array}{c}\mathrm{PI} \\
\% \mathrm{wt}\end{array}$} & \multirow{2}{*}{$\begin{array}{c}\text { TMQA } \\
\mathrm{ppm}\end{array}$} & \multicolumn{2}{|c|}{ Valor Experimental } & \multicolumn{2}{|c|}{ Valor Teórico } & \multirow{2}{*}{$\frac{k p}{\sqrt{k t}}$} & \multirow{2}{*}{$r^{2}$} \\
\hline & & & & & $30 \mathrm{~s}$ & $60 \mathrm{~s}$ & $30 \mathrm{~s}$ & $60 \mathrm{~s}$ & & \\
\hline 1 & 5 & 3 & 2 & 450 & $27.06 \%$ & $55.00 \%$ & $30.60 \%$ & $51.85 \%$ & 3.7069 & 0.9603 \\
\hline 2 & 10 & 3 & 2 & 600 & $45.79 \%$ & $60.00 \%$ & $38.99 \%$ & $62.78 \%$ & 5.0137 & 0.8066 \\
\hline 3 & 5 & 5 & 2 & 650 & $46.77 \%$ & $65.00 \%$ & $41.95 \%$ & $66.30 \%$ & 5.5171 & 0.9847 \\
\hline 4 & 10 & 5 & 2 & 800 & $59.45 \%$ & $89.00 \%$ & $63.06 \%$ & $86.36 \%$ & 9.7127 & 0.9813 \\
\hline 5 & 5 & 3 & 5 & 450 & $23.71 \%$ & $41.00 \%$ & $22.41 \%$ & $39.80 \%$ & 2.6576 & 0.9874 \\
\hline 6 & 10 & 3 & 5 & 600 & $45.42 \%$ & $65.00 \%$ & $41.29 \%$ & $65.54 \%$ & 5.5787 & 0.9891 \\
\hline 7 & 5 & 5 & 5 & 650 & $44.19 \%$ & $65.00 \%$ & $40.97 \%$ & $65.15 \%$ & 5.5211 & 0.9977 \\
\hline 8 & 10 & 5 & 5 & 800 & $36.90 \%$ & $58.03 \%$ & $34.26 \%$ & $56.78 \%$ & 4.3933 & 0.9810 \\
\hline
\end{tabular}

Em relação ao efeito principal proporcionado pelos fatores de controle para a taxa de polimerização, foi analisada a conversão do polímero no tempo de 30 e 60 segundos. Desta forma, evidenciando a contribuição dos componentes do material para a fase inicial e final da polimerização.

Estes efeitos podem ser observados na Figura 6.6, onde é indicado o iniciador como o componente que proporciona maior efeito. Pode-se também observar o aumento do efeito do oligômero ao longo do tempo, assim como a redução da contribuição do monômero. 

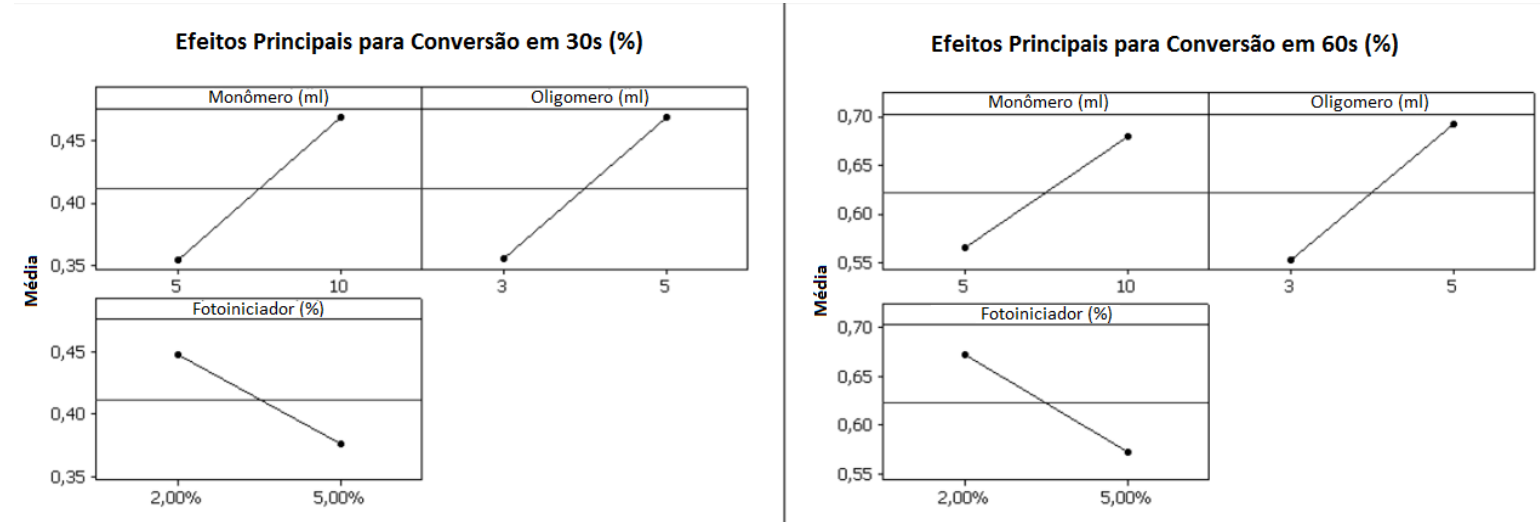

Figura 6.6 - Efeitos principais de componentes de material para conversão em 30 e 60 segundos

Logo, pode-se indicar que, para esta faixa de valores, o monômero contribui para o início da polimerização, enquanto o oligômero, para propagação e terminação.

Outro aspecto também observado nesta figura é a redução da conversão para níveis altos de iniciador. Este fenômeno pode ser explicado pelo fato da polimerização ser realizada em presença do ar, assim como de inibidor encontrado no monômero e oligômero. Neste caso, o iniciador absorve energia suficiente para somente alcançar o primeiro nível de excitação, gerando espécies inibidoras.

Em relação aos efeitos secudários, pode-se observar a maior contribuição da interação entre monômero, oligômero e iniciador, como o termo que proporciona a segunda maior contribuição para o fim da polimerização, Figura 6.7. Adicionalmente, este termo tem seu efeito reduzido no início do processo de polimerização. 

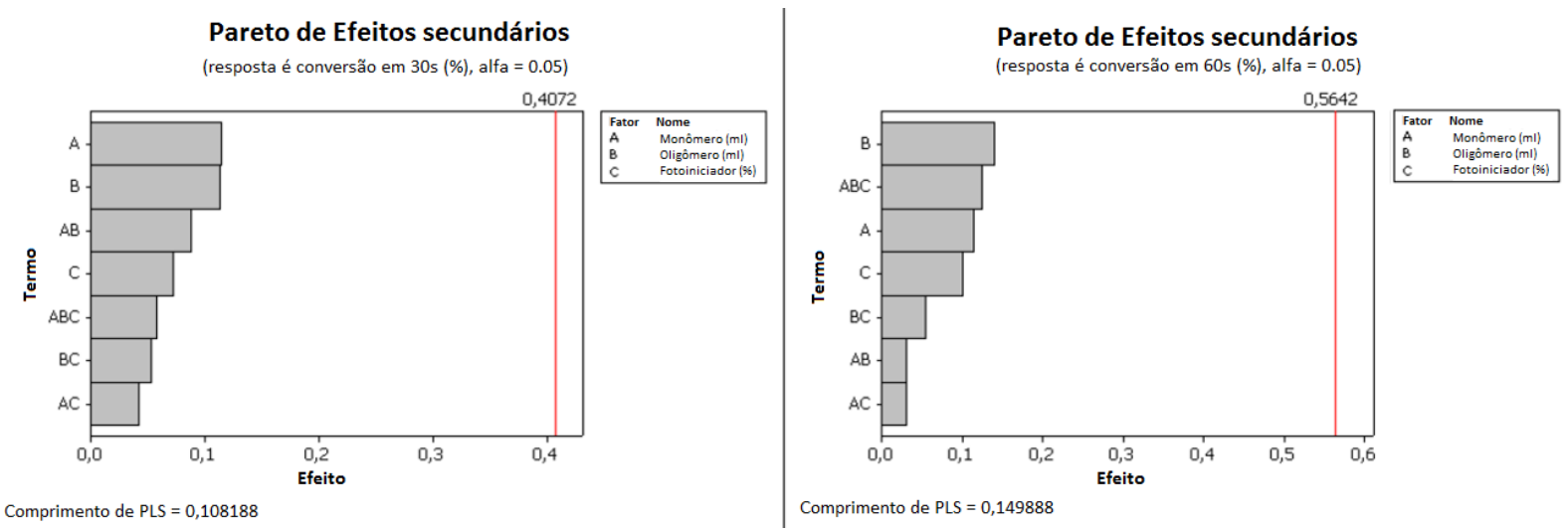

Figura 6.7 - Efeitos secundarios de componentes de material para conversão em 30 e 60 segundos

Adicionalmente, foram identificados diagramas de contorno relacionando o teor dos componentes do material e o grau de conversão do polímero, conforme apresentado na Figura 6.8. Neste caso, pode-se observar a similaridade de comportamento do material para diferentes tempos de polmerização.

Nesta figura, pode-se observar níveis altos de polimerização para valores baixos de iniciador e altos de oligômero, sendo adicionalmente evidenciado que estes valores são encontrados para teores maiores de iniciador em função de altos níveis de oligômero.

Outro aspecto que também é importante de ser salientado é relacionado à proporção de monômero por oligômero, visto que pode ser observada uma inversão de comportamento do material para faixas distintas de teores de monômeros e oligômeros. 


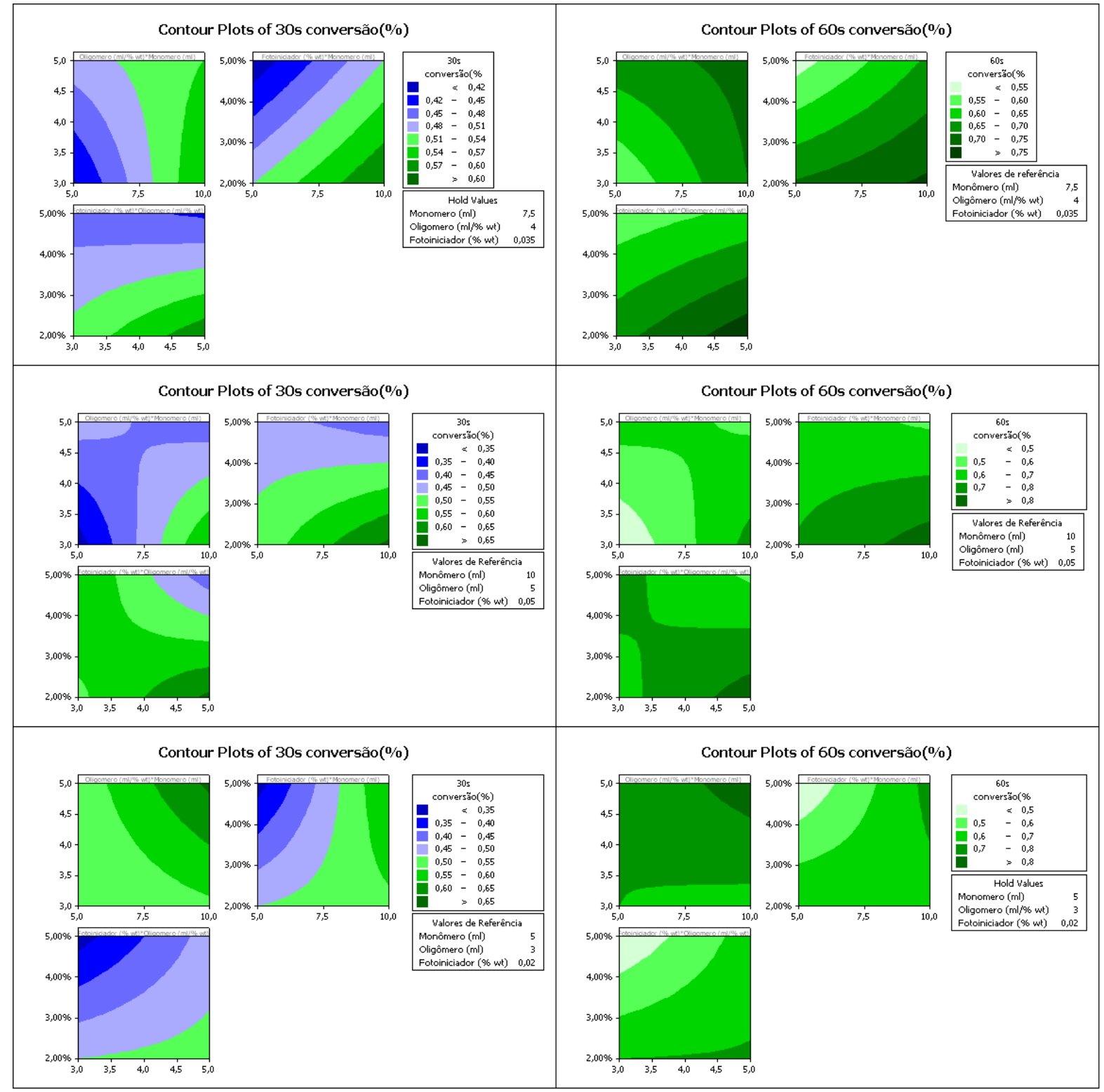

Figura 6.8 - Diagramas de contorno de conversão em 30 e 60 segundos em função de componentes de material polimérico

Neste caso, com o objetivo de identificar o comportamento do material em função desta proporção, foi identificado um diagrama de contorno relacionando a proporção Monômero/Oligômero (M/O), iniciador e grau de conversão, conforme apresentado na Figura 6.9.

Através desta figura, pode-se observar que a conversão de material atinge valores mínimos para proporção $\mathrm{M} / \mathrm{O}$ inferior a 2, quando utilizada concentração alta de iniciador. Em contrapartida, podem ser observados valores máximos de 
conversão para a faixas de valores de M/O superiores a 3 e inferiores a 1,5 e nível baixo de iniciador.
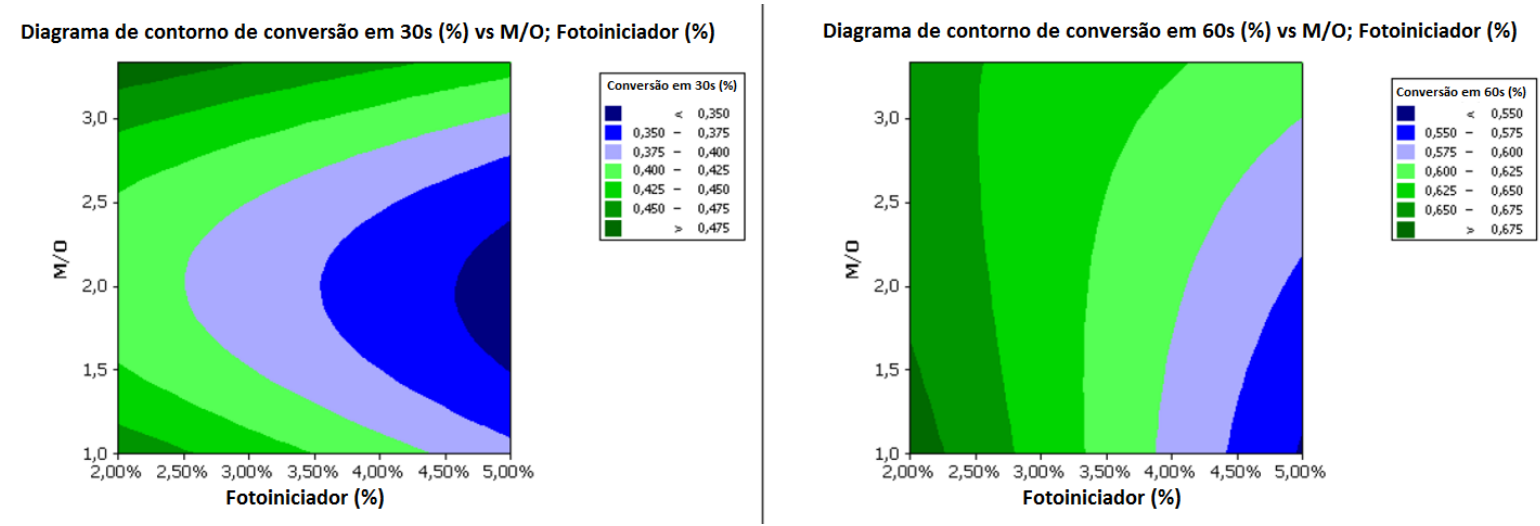

Figura 6.9 - Diagrama de contorno de conversão em 30 e 60 segundos em função de proporção monômero por oligômero $(\mathrm{M} / \mathrm{O})$ e concentração de iniciador

\section{Viscosidade de material não polimerizado}

Como resultado da determinação da viscosidade dos materiais não polimerizados, foram encontrados valores de viscosidade inferiores a $5 \mathrm{cP}$, permitindo a utilização destes em cabeçotes jato de tinta piezoelétricos.

O resultado destes estudo pode ser observado na Tabela 6.5, onde pode ser identificado o valor máximo de viscosidade para materiais $C$ e $G$, tendo em ambos os casos sua composição $50 \%$ de oligômero. O caso contrario também pode ser observado, onde a menor viscosidade é identificada para percentuais de monômero iguais a $76.92 \%$. 
Tabela 6.5 - Relação entre composição de materiais e viscosidade

\begin{tabular}{|l|r|c|c|c|c|c|c|c|c|c|c|c|}
\hline material & exp & \multicolumn{3}{|c|}{ Monomero $(\mathrm{ml} / \% \mathrm{wt})$} & \multicolumn{3}{|c|}{ Oligomero (ml/\% wt) } & \multicolumn{3}{|c|}{ Fotoiniciador (ml/\% wt) } & Visc \\
\hline $\mathrm{A}$ & 1 & - & 5 & $62.50 \%$ & - & 3 & $37.50 \%$ & - & 0.1596 & $2.00 \%$ & 1.900856 \\
$\mathrm{~B}$ & 2 & + & 10 & $76.92 \%$ & - & 3 & $23.08 \%$ & - & 0.2532 & $2.00 \%$ & 1.524699 \\
$\mathrm{C}$ & 3 & - & 5 & $50.00 \%$ & + & 5 & $50.00 \%$ & - & 0.2036 & $2.00 \%$ & 2.958819 \\
$\mathrm{D}$ & 4 & + & 10 & $66.67 \%$ & + & 5 & $33.33 \%$ & - & 0.2972 & $2.00 \%$ & 1.524699 \\
$\mathrm{E}$ & 5 & - & 5 & $62.50 \%$ & - & 3 & $37.50 \%$ & + & 0.399 & $5.00 \%$ & 2.264255 \\
$\mathrm{~F}$ & 6 & + & 10 & $76.92 \%$ & - & 3 & $23.08 \%$ & + & 0.633 & $5.00 \%$ & 1.524699 \\
$\mathrm{G}$ & 7 & - & 5 & $50.00 \%$ & + & 5 & $50.00 \%$ & + & 0.509 & $5.00 \%$ & 2.958819 \\
$\mathrm{H}$ & 8 & + & 10 & $66.67 \%$ & + & 5 & $33.33 \%$ & + & 0.743 & $5.00 \%$ & 1.776974 \\
\hline
\end{tabular}

Em relação ao efeito principal e secundário proporcionado pelos componentes de material para viscosidade do material não polimerizado, pode-se indicar, conforme observado na Figura 6.10, o monômero como o fator de maior efeito para esta resposta. Neste caso, o aumento percentual de monômero implica em redução de viscosidade, enquanto o aumento de oligômero, no ganho de viscosidade.

Apesar de apresentar efeito muito baixo, cabe adicionalmente ressaltar que 0 percentual de iniciador contribui diretamente para viscosidade.

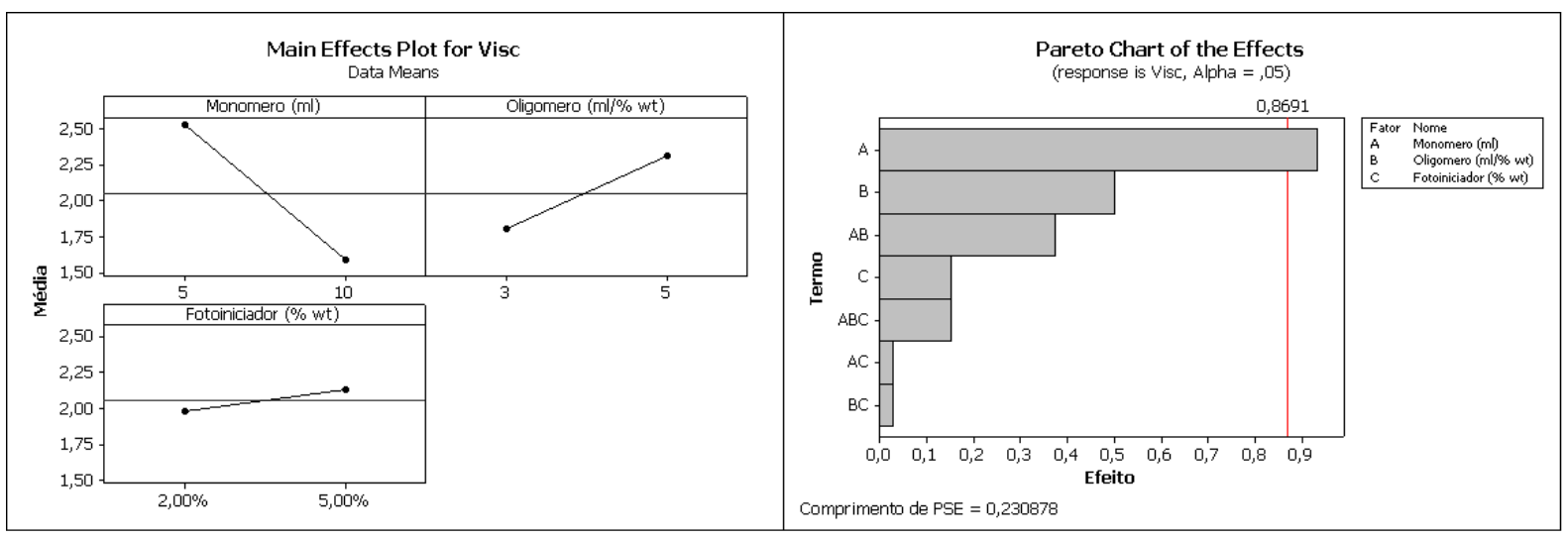

Figura 6.10 - Diagramas de Efeito principal e Efeito secundário de viscosidade de material não polimerizado em função componentes do polímero

Adicionalmente, foram encontrados diagramas de contorno, apresentados na Figura 6.11, com o objetivo de identificar este comportamento do material. Neste 
caso, torna-se possível identificar menores valores de viscosidade para volumes altos de monômero,assim como valores baixos de oligômero e iniciador.

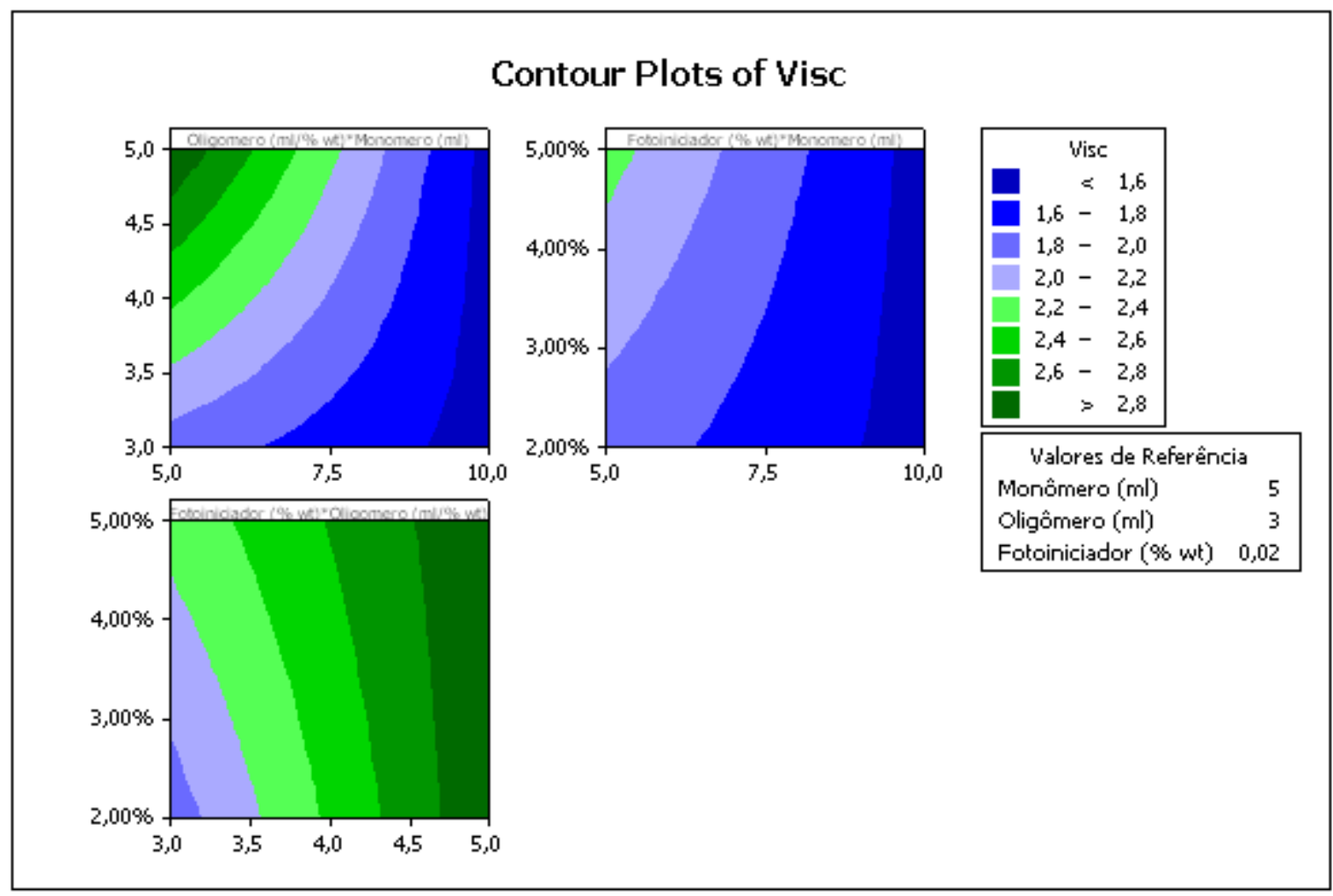

Figura 6.11 - Diagrama de contorno de viscosidade de material não polimerizado em função componentes do polímero

\section{Resistência mecânica à tração}

Em relação à determinação da resistência mecânica à tração do material polimérico, foram submetidas as formulações de materiais ao ensaio de tração conforme apresentado na Seção 4.3.7.

Como resultado destes ensaios, a Figura 6.12 apresenta a curva de tensão de tração em função da deformação dos materiais poliméricos estudados neste trabalho. 


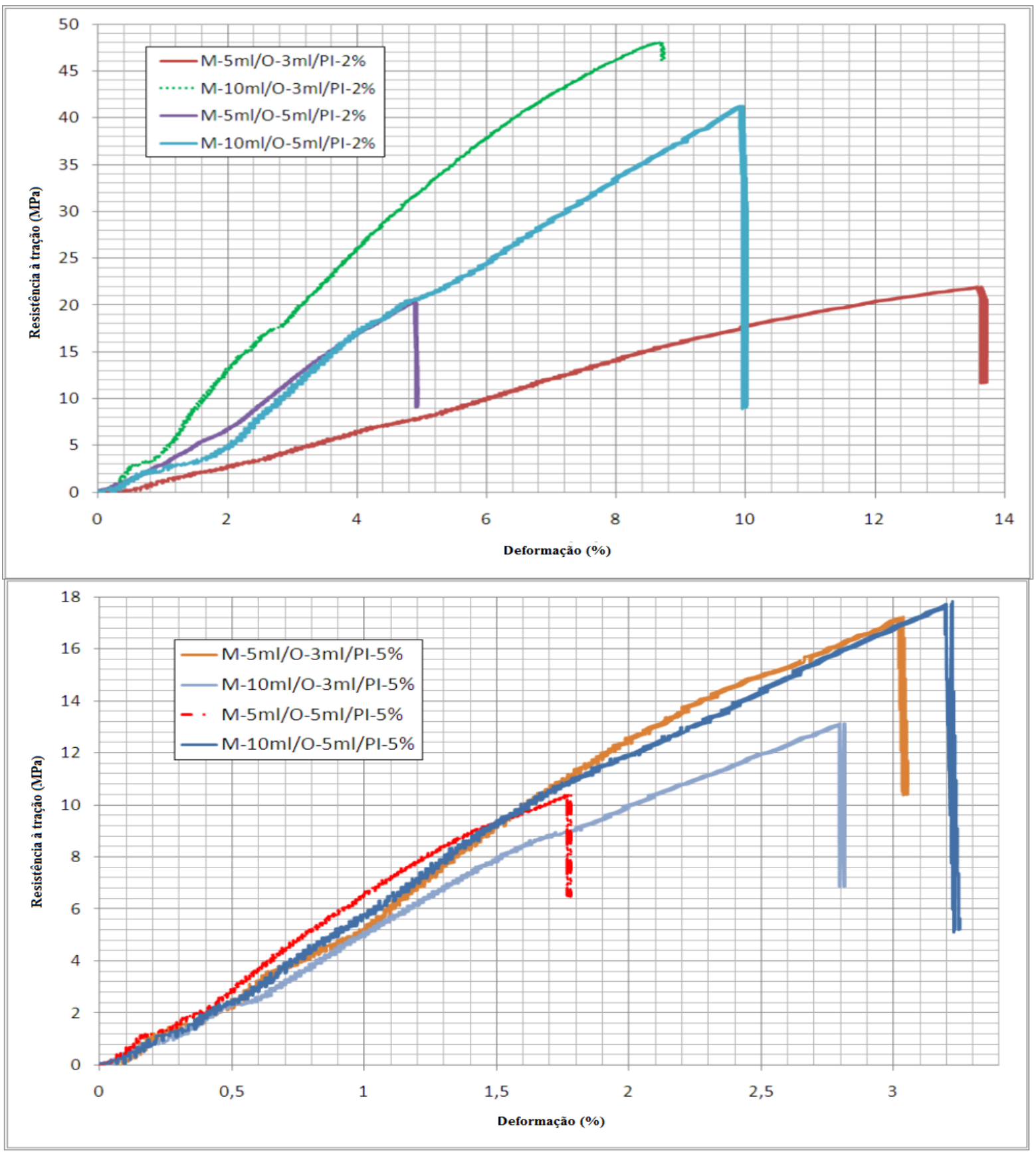

Figura 6.12 - Curva tensão de tração em função de deformação de materiais poliméricos

Ao observar estas curvas, pode-se observar o comportamento frágil para estas formulações de polímero. Sendo identificadas as maiores valores de resistência para os materiais que apresentaram maior percentual de monômero em adição a baixos valores de iniciador. 
Para identificar a contribuição dos componentes para a resistência mecânica do material à tração, foram encontrados os efeitos principais e secundários destes componentes para este fator de resposta, como pode ser observado na Figura 6.13.

Nesta figura, são apresentados os gráficos de efeitos principais e secundários dos componentes do material para a tensão de ruptura e elongamento do material. Nestes gráficos, pode-se observar que o fator de controle que proporcionou maior efeito para a resistência mecânica à tração, é o iniciador. Em contrapartida, o elongamento do material teve maior influência do monômero.

Para este caso, em face ao comportamento frágil do material, pode-se ser relacionada à resistência mecânica do material, a taxa de polimerização e percentual de monômero presente na formulação.

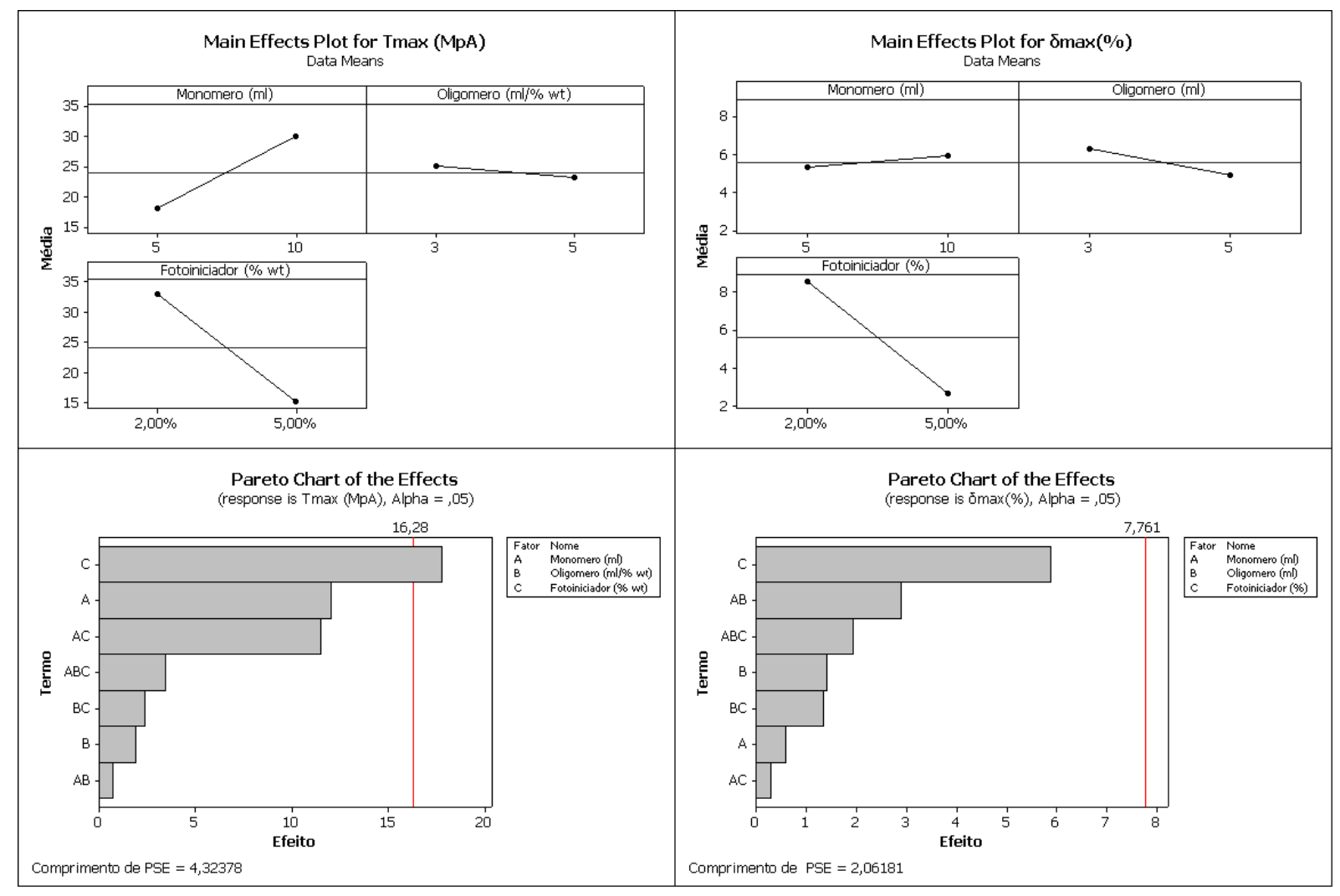

Figura 6.13 - Diagramas de Efeito principal e Efeito secundário de tensão de Ruptura e elongamento na ruptura em função de composição do material 
Pode-se também observar a tendência de aumento da resistência mecânica à tração do material em função da redução dos percentuais de oligômero e iniciador. Ao analisar os diagramas de contorno deste estudo, Figura 6.14, pode-se adicionalmente identificar a contribuição do iniciador para a ductilidade do material, sendo encontrados menores valores de deformação na ruptura para índices elevados de iniciador.

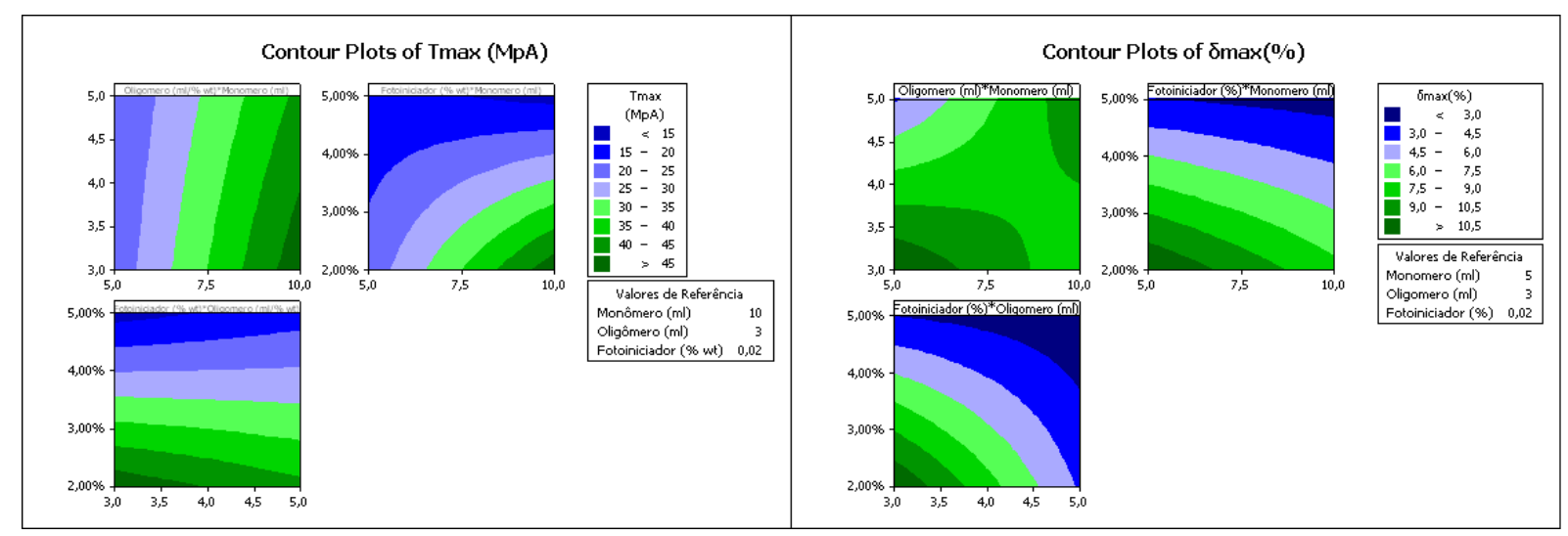

Figura 6.14 - Diagramas de contorno de tensão de Ruptura e elongamento na ruptura em função de composição do material

Similarmente, a proporção de monômero por oligômero apresentou comportamento linear quanto à resistência mecânica, tendo seu aumento proporcional ao aumento desta proporção.

\section{Módulo de elasticidade}

Em relação à determinação do módulo de elasticidade por flexão, foram utilizados os procedimentos descritos na Seção 4.3.6, sendo encontrados os valores conforme apresentados na Tabela 6.6.

Nesta tabela são relacionados os módulos de elasticidade e a composição de material, sendo indicado que o material $F$ apresenta maior módulo de elasticidade (8.66 GPa). Em Contrapartida, o material A apresentou o menor módulo, sendo seu valor igual a $361 \mathrm{MPa}$. 
Tabela 6.6 - Relação entre composição de materiais módulo de elasticidade por flexão

\begin{tabular}{|c|c|c|c|c|c|c|c|c|c|}
\hline mat & exp & \multicolumn{2}{|c|}{ Monomero (ml) } & \multicolumn{2}{|c|}{ Oligomero (ml) } & \multicolumn{2}{|c|}{ Fotoiniciador (\%) } & $\begin{array}{c}\text { E(Gpa) - Flexão } \\
\text { média }\end{array}$ & $\begin{array}{c}\text { desvio padrão } \\
\text { (Gpa) }\end{array}$ \\
\hline A & 1 & - & 5 & - & 3 & - & $2,00 \%$ & 1,616719348 & 0,115564196 \\
\hline B & 2 & + & 10 & - & 3 & - & $2,00 \%$ & 5,511218829 & 0,444614885 \\
\hline C & 3 & - & 5 & + & 5 & - & $2,00 \%$ & 4,120259956 & 0,492172385 \\
D & 4 & + & 10 & + & 5 & - & $2,00 \%$ & 4,111242789 & 1,106869825 \\
\hline E & 5 & - & 5 & - & 3 & + & $5,00 \%$ & 5,630222317 & 0,464628337 \\
\hline F & 6 & + & 10 & - & 3 & + & $5,00 \%$ & 4,657029074 & 3,873549417 \\
G & 7 & - & 5 & + & 5 & + & $5,00 \%$ & 5,845204965 & 0,625007738 \\
\hline H & 8 & + & 10 & + & 5 & + & $5,00 \%$ & 5,451347713 & 0,468168871 \\
\hline
\end{tabular}

Em relação aos efeitos principais e secundários proporcionados pela formulação do material para o módulo de elasticidade pela flexão, pode-se constatar, conforme observado na Figura 6.15, que o maior efeito é proporcionado pelo iniciador. Nesta figura, pode ser também indicado o aumento do módulo de elasticidade em função da concentração de iniciador.

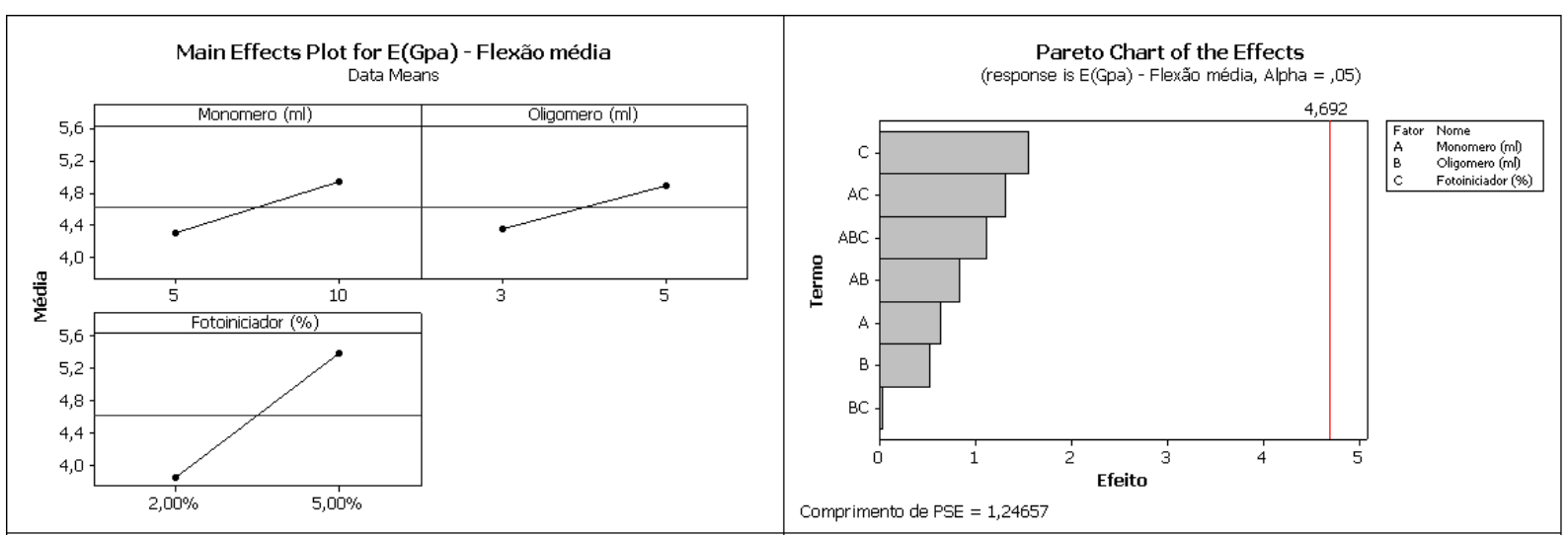

Figura 6.15 - Diagrama de efeitos principais e secundários de módulo de elasticidade por flexão em função de compostos de material

Secundariamente, foi identificado que a interação entre monômero e fotoiniciador apresenta o segundo maior efeito sobre o módulo de elasticidade na flexão. 
Adicionalmente, pode ser observado no diagrama de conforno (Figura 6.16) que o módulo de elasticidade apresenta um comportamento não linear em função do monômero e iniciador para níveis baixos de oligômero (3ml). Em contraste, para níveis altos de oligômero, este comportamento se mostra mais linear.

Nesta figura, foi também observada a tendência do aumento do módulo de elasticidade para valores maiores de iniciador e de oligômero. Situação que evidenciou o fenômeno de interamarração das cadeias poliméricas (crosslinking) devido aos múltiplos grupos funcionais encontrados no oligômero.

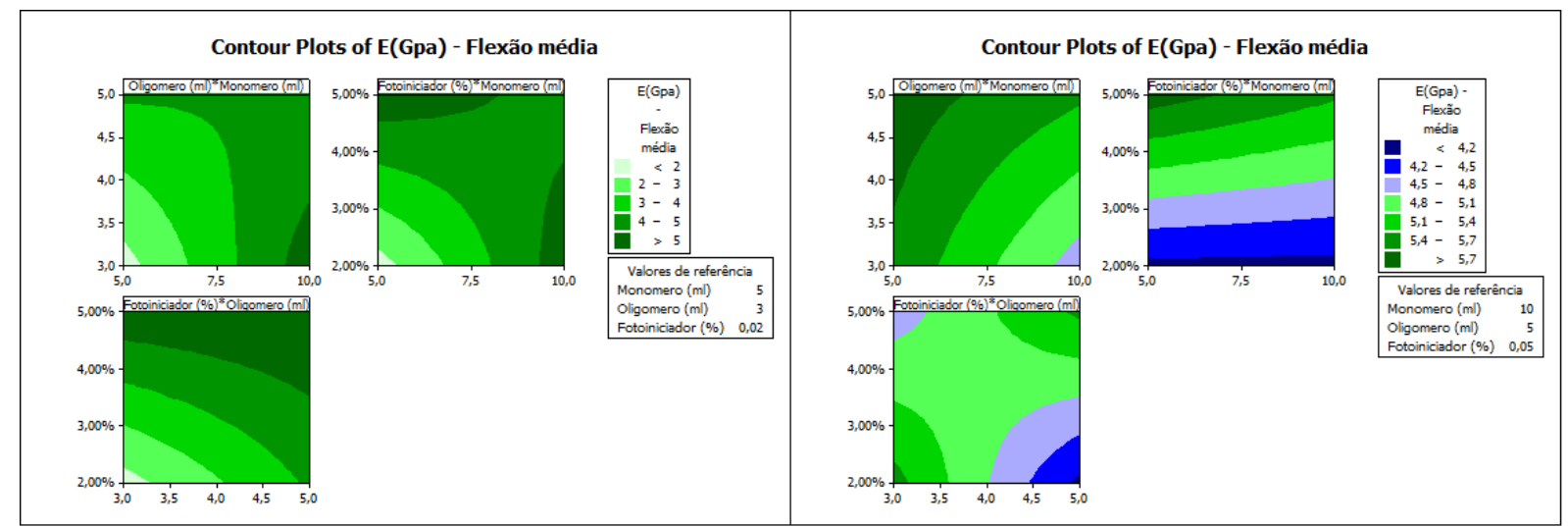

Figura 6.16 - Diagramas de contorno de módulo de elasticidade por flexão em função de composição do material

\section{Temperatura de trabalho (HDT)}

Com referência à temperatura de trabalho, foi identificada perda percentual do módulo de elasticidade inicial $\left(20^{\circ} \mathrm{C}\right)$ em função da temperatura, conforme ensaio descrito na Seção 5.1.2.

$\mathrm{Na}$ Figura 6.17, pode-se observar a progressão desta perda de rigidez do material, sendo apresentadas as curvas do percentual do módulo de elasticidade em função da temperatura. 


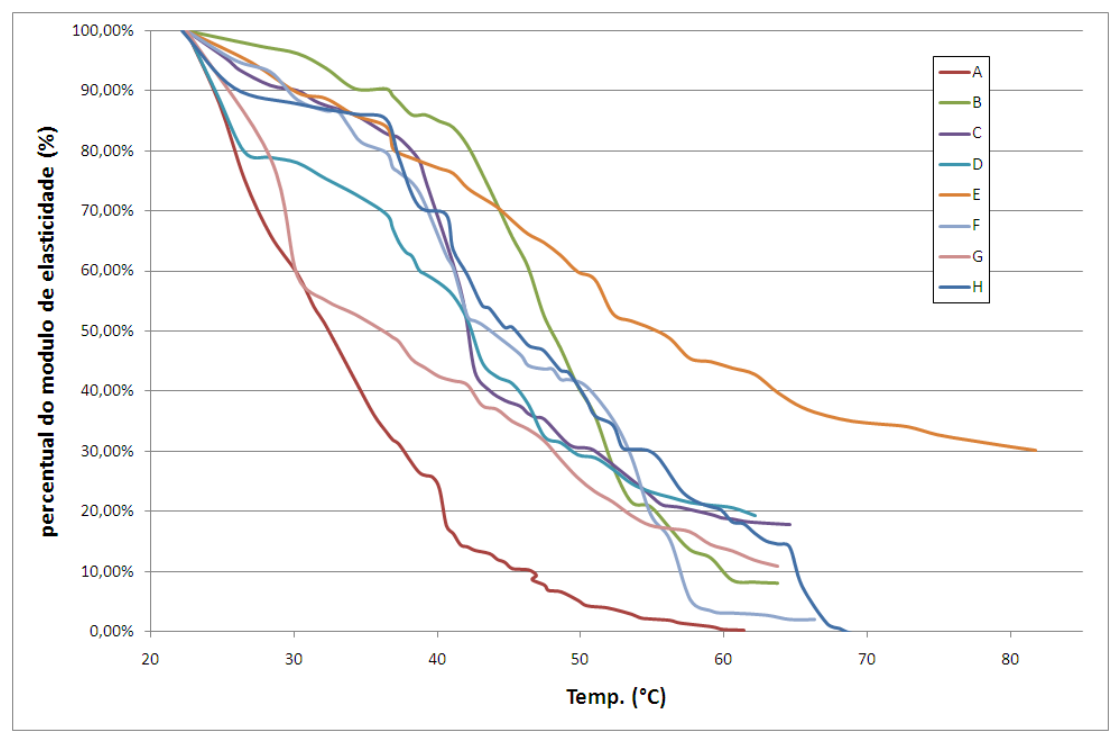

Figura 6.17 - Relação de perda de módulo de elasticidade em função de temperatura de materiais

Nesta figura, pode-se também observar o comportamento do material perante à temperatura, indicando o nível de cristalinidade dos material. Como exemplo, é possível indicar um comportamento amorfo para os materiais $\mathrm{A}$ e $\mathrm{E}$, em contraste ao comportamento mais cristalino para os materiais $\mathrm{B}$ e $\mathrm{C}$. No caso dos materiais $\mathrm{A}$ e $\mathrm{E}$, pode-se associar seus comportamentos a um maior nível de interamarração entre cadeias poliméricas, devido à maior linearidade do módulo de elasticidade em função da temperatura.

Adicionalmente, conforme apresentado na Seção 4.3.5, foi estipulado que o critério para determinação da temperatura de trabalho (HDT) é referente à temperatura onde o material proporciona $30 \%$ de seu módulo de elasticidade inicial $\left(20^{\circ} \mathrm{C}\right)$. Neste caso, pode-se observar a relação entre formulação do material e temperatura de trabalho na Tabela 6.7. 
Tabela 6.7 - Relação entre composição de materiais temperatura de trabalho (HDT)

\begin{tabular}{|c|c|c|c|c|c|c|c|c|}
\hline mat & exp & \multicolumn{2}{|c|}{ Monômero (ml) } & \multicolumn{2}{|c|}{ Oligômero (ml) } & \multicolumn{2}{|c|}{ Fotoiniciador (\%) } & HDT 30\% $\left({ }^{\circ} \mathrm{C}\right)$ \\
\hline A & 1 & - & 5 & - & 3 & - & $2,00 \%$ & 37,50 \\
B & 2 & + & 10 & - & 3 & - & $2,00 \%$ & 51,50 \\
C & 3 & - & 5 & + & 5 & - & $2,00 \%$ & 51,00 \\
D & 4 & + & 10 & + & 5 & - & $2,00 \%$ & 49,00 \\
E & 5 & - & 5 & - & 3 & + & $5,00 \%$ & 81,00 \\
F & 6 & + & 10 & - & 3 & + & $5,00 \%$ & 53,00 \\
G & 7 & - & 5 & + & 5 & + & $5,00 \%$ & 48,00 \\
H & 8 & + & 10 & + & 5 & + & $5,00 \%$ & 54,00 \\
\hline
\end{tabular}

Nesta tabela, pode-se observar o maior valor de HDT para o material E, enquanto o menor valor foi encontrado para o material $A$. Em relação à diferença entre a formulação destes material, destaca-se a concentração de iniciador, sendo $2 \%$ para $A$ e $5 \%$.para $E$.

Em relação aos efeitos proporcionados pelos componentes do material para a temperatura de trabalho (HDT), apresentados na Figura 6.18, pode-se identificar o maior efeito principal proveniente do iniciador, enquanto a interação entre os três componentes do material proporcionam maior efeito secundário.

Nesta figura, pode-se também relacionar o aumento da temperatura de trabalho em função do aumento da concentração de iniciador.

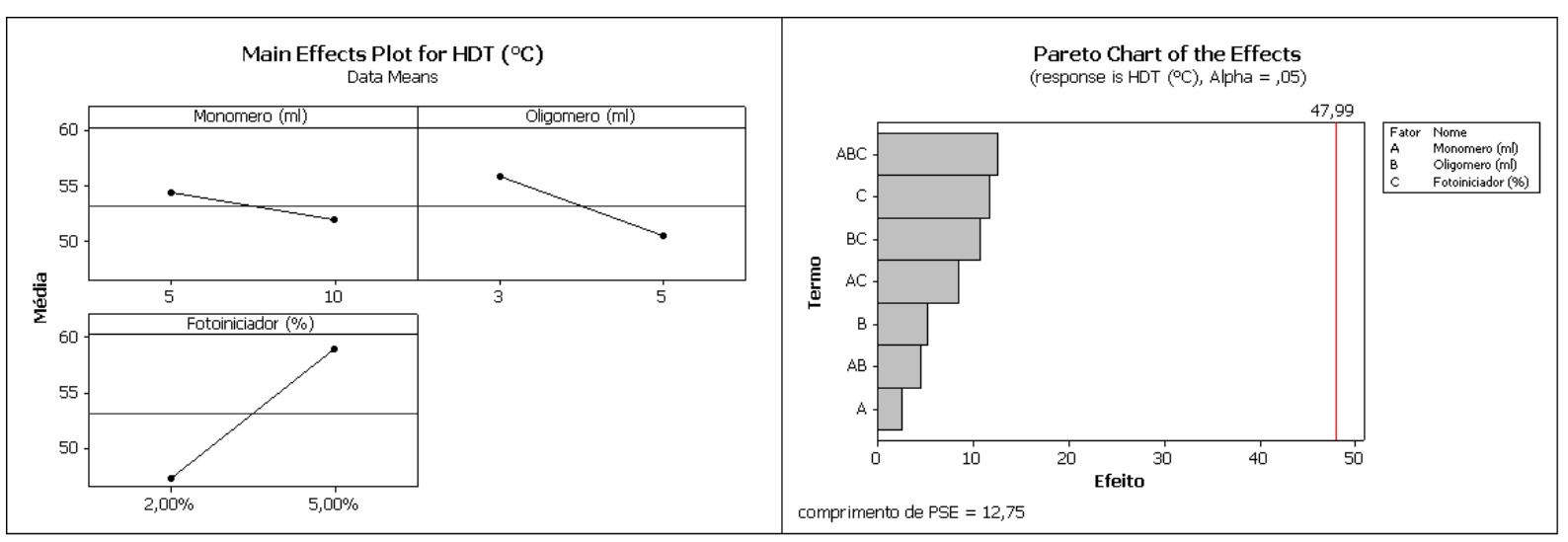

Figura 6.18 - Efeitos principais e secundários de componentes de material para a temperatura de trabalho (HDT) 
Adicionalmente, foi identificado através dos diagramas de contorno (Figura 6.19), que os valores de HDT são encontrados conforme redução de volume de oligômero.

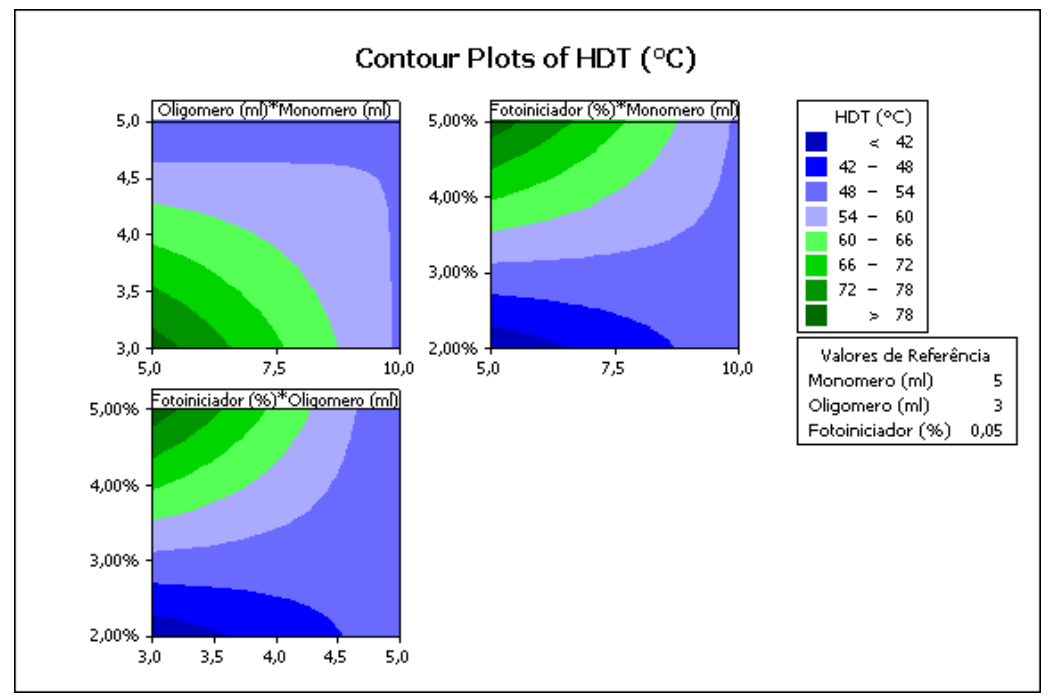

Figura 6.19 - Diagrama de contorno de temperatura de trabalho (HDT) em função de componentes de material

Adicionalmente, ao analisar temperatura de trabalho (HDT) em função da relação monômero por oligômero (M/O) e concentração de iniciador (Figura 6.20), pode-se identificar maiores valores de para concentrações altas de iniciador, assim como para relação M/O em torno de 2.

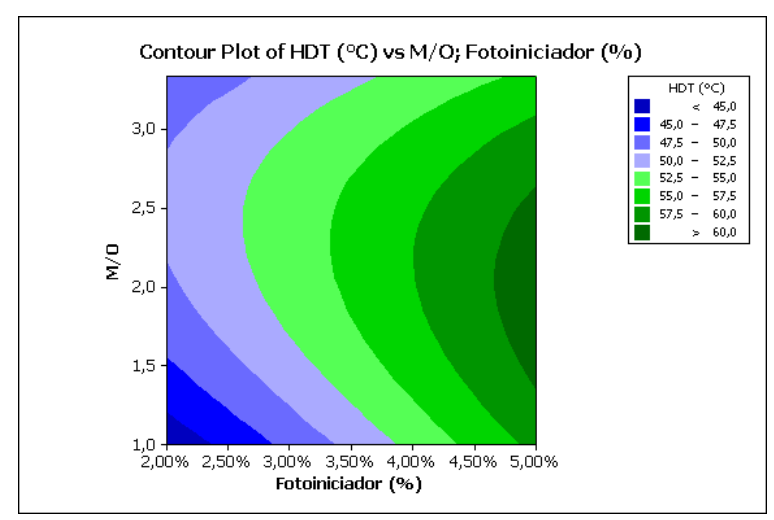

Figura 6.20 - Diagrama de contorno de temperatura de trabalho (HDT) em função de relação $\mathrm{M} / \mathrm{O}$ e concentração de iniciador 


\section{Otimização de material}

Com finalidade de identificação da formulação mais adequada para ser utilizada neste projeto, foi realizada uma otimização estatística com múltiplos objetivos, a partir do planejamento de experimentos (DoE).

Para realização deste estudo, foi definido como problema de otimização, a minimização da viscosidade e maximização de tensão de ruptura, conversão de material em 60 segundos, Módulo de elasticidade e temperatura de amolecimento (HDT em $30 \%$ de rigidez). Logo, a função de custo pode ser observada na equação (6.3).

Adicionalmente esta equação apresenta constantes de normalização de fatores de resposta, conforme apresentado na equação (6.2).

$$
R_{\text {normalizad }}=\frac{R-R_{\min }}{R_{\max }-R_{\min }}
$$

Onde:

$R$ é o valor corrente de resposta

$R_{\min }$ é o valor mínimo das respostas

$R_{\max }$ é o valor máximo das respostas

$R_{\text {normalizad }}$ é o valor de resposta normalizado

Desta forma, este estudo de otimização pode ser descrito como: 
Minimizar:

$$
f\left(\text { Conv }, \sigma_{\text {break }}, E, T s, v\right)=w_{1} \cdot \frac{1}{\frac{\text { Conv }}{0.48}-0.854}+w_{2} \cdot \frac{1}{\frac{\sigma_{\text {break }}}{40}-0.25}+w_{3} \cdot \frac{1}{\frac{E}{5}-4.23}+w_{4} \cdot \frac{1}{\frac{T s}{80}-44}+w_{5} \cdot\left(\frac{v}{2.5}-1.5\right)
$$

Submetido à:

$$
\begin{aligned}
& 5 m l<M<10 m l \\
& 3 m l<O<5 m l \\
& 2 \% w t l<P I<5 \% w t
\end{aligned}
$$

Adicionalmente, a Figura 6.21 apresentada a região de viabilidade proporcionada pelas restrições impostas na otimização, sendo destacada em branco.
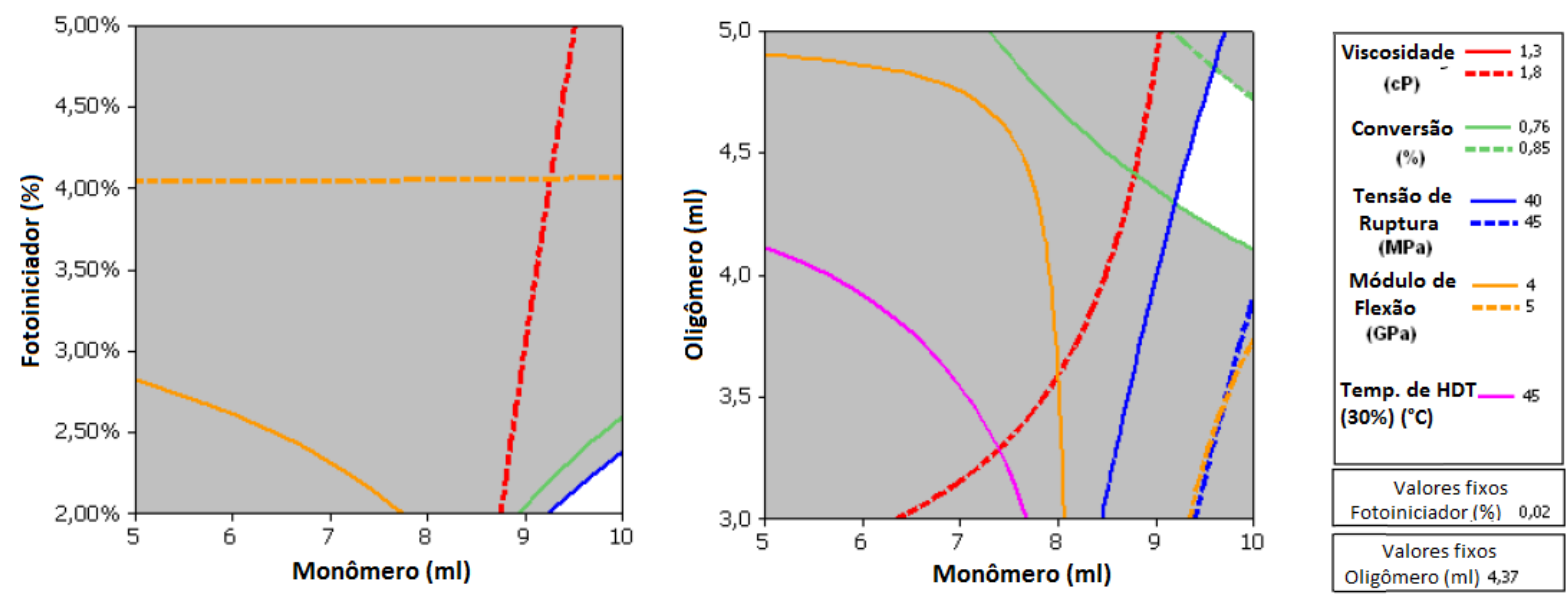

Figura 6.21 - Indicação de faixa de viabilidade às restrições do problema de otimização

Por fim, foi encontrada a como formulação de material otimizada: $10 \mathrm{ml}$ para monômero, 4,37374 ml para oligômero e $2 \%$ para iniciador, proporcionando valores de viscosidade de 1,53cP, conversão em 60 segundos de 79,92\%, resistência 
mecânica à tração de 43,39 MPa, Módulo de flexão de 4,55 GPa e Temperatura de $\operatorname{HDT}(30 \%)$ de $49,79^{\circ} \mathrm{C}$.

\subsubsection{Compatibilidade entre material com tecnologia jato de tinta}

Em relação à determinação da compatibilidade entre o material polimérico desenvolvido e tecnologia jato de tinta, foram realizados os estudos de compatibilidade conforme apresentado na Seção 5.1.3.

Neste estudo, não foi possível observar a capabilidade de impressão para nenhuma das duas tecnologias jato de tinta. Contudo, ao observar o princípio funcional destas tecnologias, pode-se identificar causas de não-compatibilidade.

Para a tecnologia BubbleJet da HP, tem-se como princípio funcional o aquecimento do material gerando uma bolha de vapor que pressiona o material para fora do cabeçote jato de tinta. Neste caso, pode-se ressaltar que há a necessidade de inserção de componentes adicionais ao material polimérico, evidenciando que a formulação atual não proporciona as condições necessárias para seu funcionamento correto.

Por outro lado, a tecnologia piezo tem como princípio funcional, a utilização de atuador piezoelétrico para geração de pressão negativa para puxar o material para a câmara de impressão e positiva para movimentação do material para fora da cabeça de impressão. Neste caso, a não compatibilidade do material se deve possivelmente à tensão superficial do material, em conjunto com características dinâmicas do fluido.

Embora estes aspectos não tenham sido considerados no desenvolvimento do material, cabe realizar futuramente estudos com objetivo de identificar formulação adequada deste tipo de material para ser utilizada em tecnologias jato de tinta. 


\subsection{Desenvolvimento de material celulósico laminado (Substrato)}

Para a determinação do material celulósico adequado para ser utilizado neste projeto, foram analisadas as principais propriedades de 4 tipos de papel, como é descrito na Seção 5.2. Entre estas propriedades, pode ser listada a gramatura, espessura, opacidade, taxa de absorção de água, resistência mecânica à tração de material seco e resistência mecânica à tração de material em função de absorção de água.

$\mathrm{Na}$ Tabela 6.8, pode ser observada a descrição dos materiais celulósicos estudados, assim suas respectivas gramaturas e espessuras médias. Desta forma, sendo possível relacionar a gramatura com a espessura, como pode ser observado na Equação (6.7).

Tabela 6.8 - Relação de materiais celulósicos e descrição de gramatura e espessura média

\begin{tabular}{|c|c|c|}
\hline Material & Gramatura & Espessura \\
\hline Papel Vegetal & $75 \mathrm{~g} / \mathrm{m}^{2}$ & $0,10 \mathrm{~mm}$ \\
\hline Papel Sulfurizê & $35 \mathrm{~g} / \mathrm{m}^{2}$ & $0,05 \mathrm{~mm}$ \\
\hline Papel Sulfite & $75 \mathrm{~g} / \mathrm{m}^{2}$ & $0,10 \mathrm{~mm}$ \\
\hline Papel Seda & $18 \mathrm{~g} / \mathrm{m}^{2}$ & $0,03 \mathrm{~mm}$ \\
\hline
\end{tabular}

Nesta tabela, pode ser também observado o menor valor de espessura para o papel seda, assim como a menor gramatura. Isto se deve em função da relação direta da gramatura com a espessura.

Esp $=$ Gramatura $\cdot 1,34 \cdot 10^{-3}$ 


\subsubsection{Opacidade}

Em relação à opacidade dos materiais, esta foi determinada em duas condições distintas, considerando o substrato molhado (1 min de imersão em água) e seco, conforme descrito na Seção 4.3.1.

Na Figura 6.22, pode-se observar a menor opacidade no papel vegetal, sendo cujos valores de opacidade iguais a $63,75 \%$ para o material seco e $54,68 \%$ para o material mohado. Neste caso, é possível identificar uma perdade 9,06\%.

Em contrapartida, o papel seda apresentou o segundo menor valor de opacidade, sendo de aproximadamente $83 \%$ para o papel seco e de $63 \%$ para o material molhado. Neste caso, foi possível identificar uma perda de opacidade 19\%, sendo o valor de opacidade do papel seda molhado equivalente ao do papel vegetal seco.

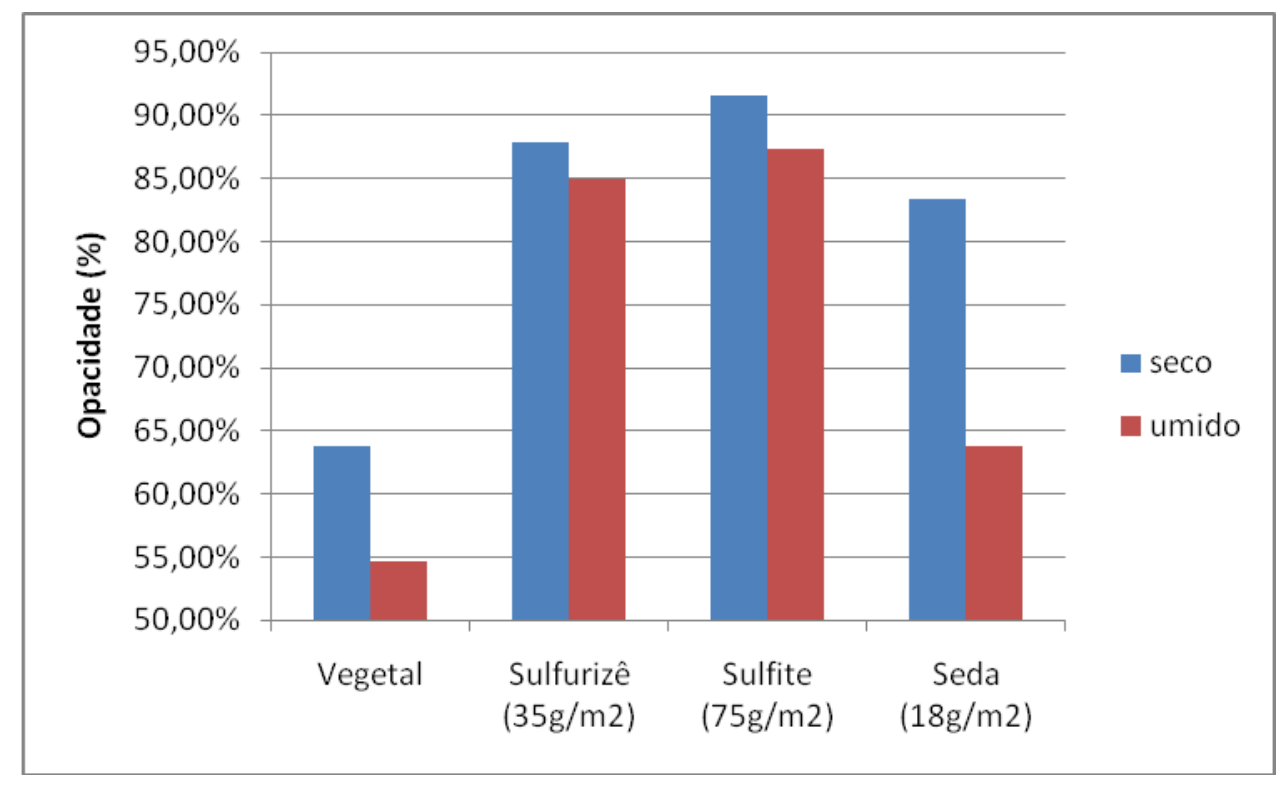

Figura 6.22 - Levantamento de opacidade de materiais celulósicos em estado seco e em estado úmido (1 minuto de imersão em água)

Já em relação à opacidade dos papéis sulfite e sulfurizé, estes apresentaram valores superiores a $85 \%$, mesmo quando molhados, indicando uma restrição destes quanto à polimerização de polímero impregnado através de luz UV. 


\subsubsection{Taxa de absorção}

Em relação à determinação da taxa de absorção de água dos materiais celulósicos, este estudo teve como objetivo, a identificação do percentual de água absorvida pelo papel em função do tempo de imersão em água, sendo seus procedimentos descritos na Seção 4.3.4.

Como pode ser observado na Figura 6.23, pode-se indicar o papel seda como o material que proporciona maior percentual de absorção, podendo absorver até 4 vezes sua massa.

Cabe também ressaltar que o comportamento do papel seda ao longo do tempo se mostrou mais linear que os outros tipos de papel, sendo adicionalmente evidenciados percentuais de absorção inferiores a 2 e saturação dos níveis de absorção.

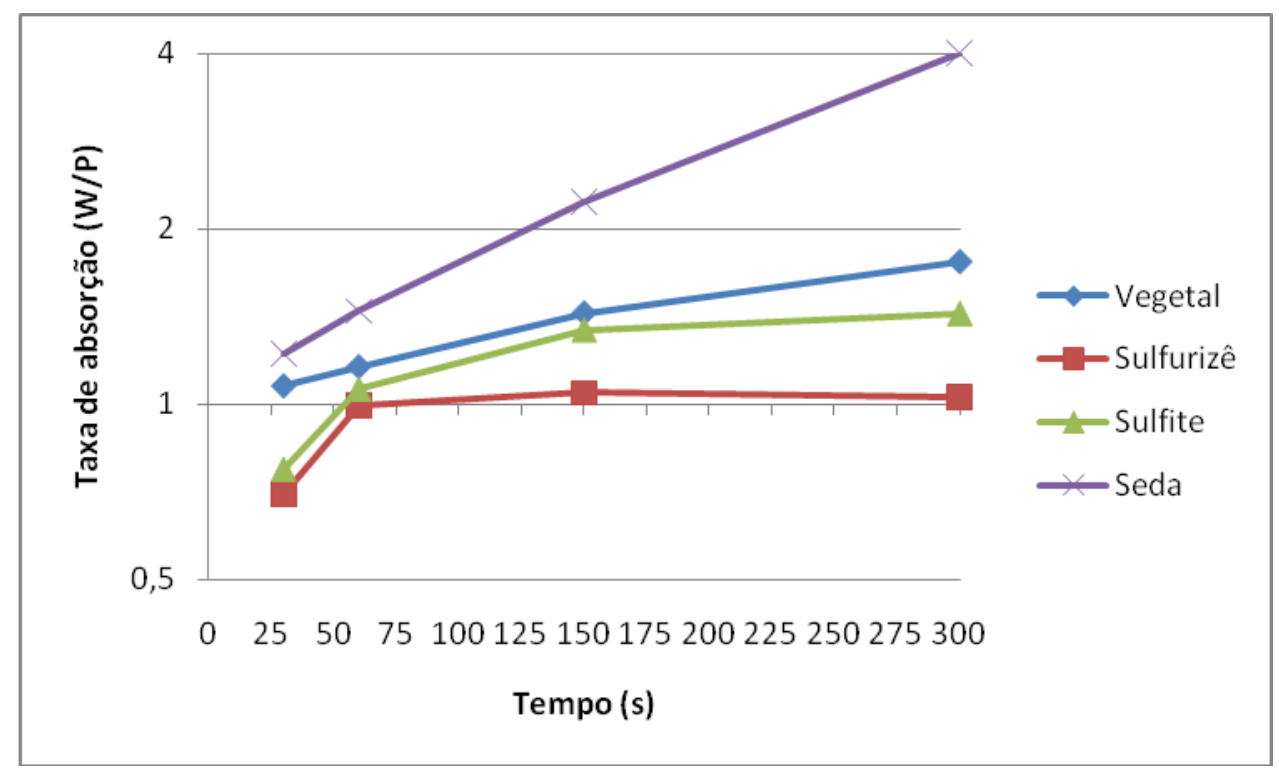

Figura 6.23 - Levantamento de taxa de absorção de materiais celulósicos em função do tempo de imersão em água 
Pode-se também salientar que, com exceção do papel seda, os valores de absorção dos materiais se mostraram próximos a 1 num tempo de 60 segundos. Logo, é possível indicar a potencialidade da utilização do papel seda quanto à absorção de material polimérico.

\subsubsection{Resistência mecânica a tração de material celulósico}

Com relação à determinação da resistência mecânica média à tração dos materiais secos, foram realizados ensaios conforme apresentado na Seção 5.2. Os resultados deste estudo são apresentados graficamente na Figura 6.24. Nesta figura, através do diagrama de whisker (plot-box), são indicados visualmente os principais elementos de estatística descritiva, como desvio padrão, mediana, $1^{\circ}$ e $3^{\circ}$ quartil e curtose.

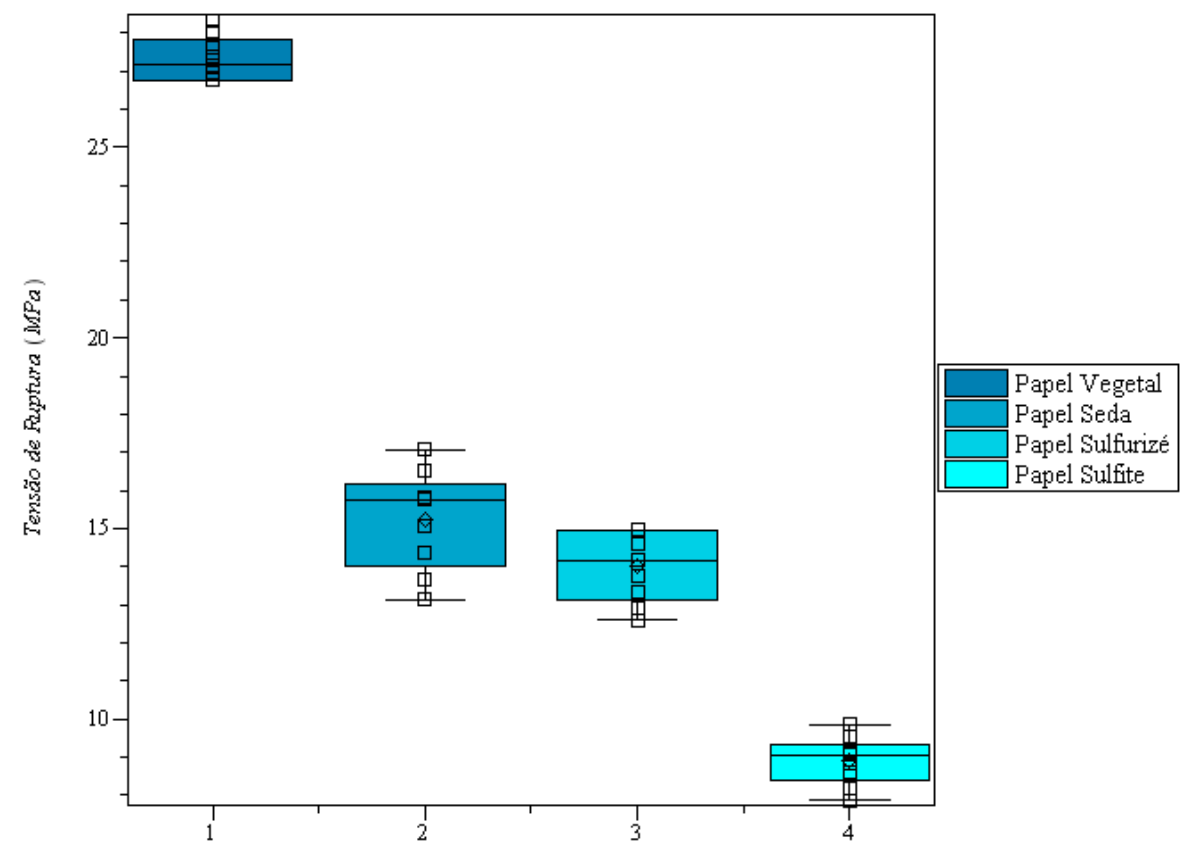

Figura 6.24 - Levantamento de Diagrama de Whisker de tensão de ruptura de materiais celulósicos 
Nessa figura foi possível identificar o papel vegetal como o material que apresentou maior resistência mecânica à tração, sendo seu valor médio igual à 27,32 MPa.

Adicionalmente, a Tabela 6.9 também apresenta os valores de desvio padrão e mediana encontrados neste estudo. Nesta tabela, pode ser identificado o maior desvio padrão para o papel seda, cuja tensão de ruptura média apresenta 0 sengundo maior valor entre os materiais estudados.

Tabela 6.9 - Relação de materiais celulósicos e descrição de gramatura e espessura média e estatística descritiva de tensão de ruptura

\begin{tabular}{|c|c|c|c|c|c|}
\cline { 3 - 6 } \multicolumn{2}{c|}{} & \multicolumn{3}{c|}{ Tensão de Ruptura } \\
\hline Material & Gramatura & Espessura & Média & Mediana & Desvio Padrão \\
\hline Papel Vegetal & $75 \mathrm{~g} / \mathrm{m} 2$ & $0,10 \mathrm{~mm}$ & $27,32 \mathrm{Mpa}$ & $27.16 \mathrm{Mpa}$ & $0.66 \mathrm{Mpa}$ \\
\hline Papel Sulfurizê & $35 \mathrm{~g} / \mathrm{m} 2$ & $0,05 \mathrm{~mm}$ & $14,02 \mathrm{Mpa}$ & $14.17 \mathrm{Mpa}$ & $1.03 \mathrm{Mpa}$ \\
\hline Papel Sulfite & $75 \mathrm{~g} / \mathrm{m} 2$ & $0,10 \mathrm{~mm}$ & $8,90 \mathrm{Mpa}$ & $9.05 \mathrm{Mpa}$ & $0.71 \mathrm{Mpa}$ \\
\hline Papel Seda & $18 \mathrm{~g} / \mathrm{m} 2$ & $0,03 \mathrm{~mm}$ & $15,22 \mathrm{Mpa}$ & $15.75 \mathrm{Mpa}$ & $1.50 \mathrm{Mpa}$ \\
\hline
\end{tabular}

Em relação à resistência mecânica à tração do material em função da taxa de abosorção de água, a Figura 6.25 apresenta um gráfico expondo a tensão de ruptura do Papel Vegetal em função da taxa de absorção. Nesta figura, pode ser observado o comportamento do material através da regressão de potencia, que apresentou mínimo quadrado igual a 0,9922. Este valor indica uma confiabilidade superior a $95 \%$. 


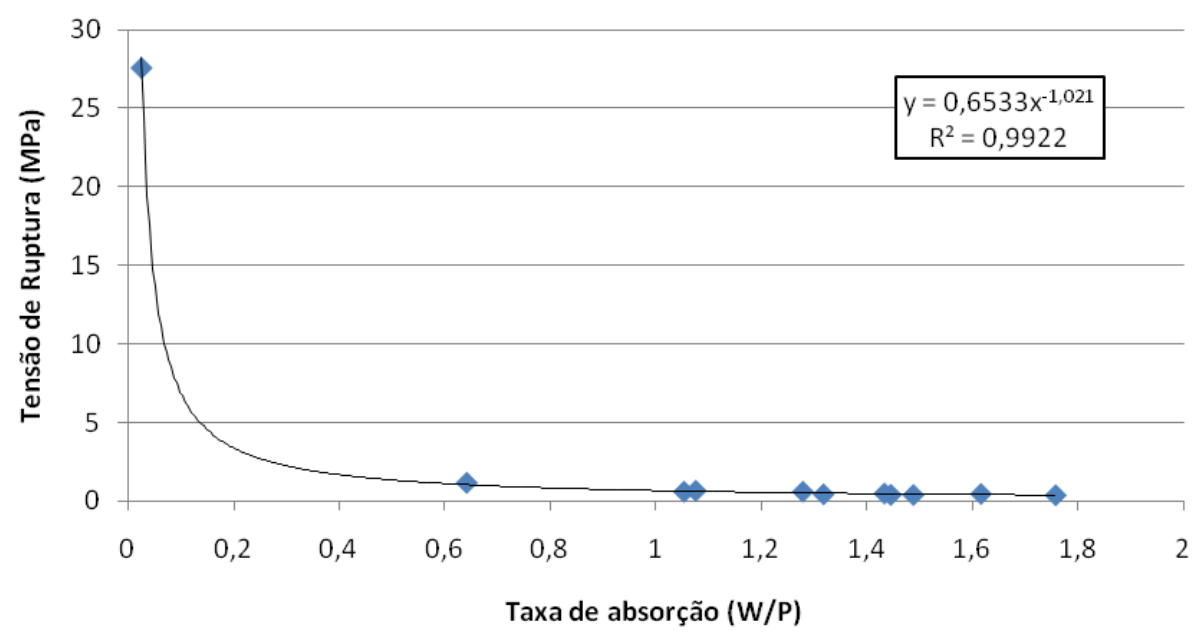

Figura 6.25 - Determinação de resistência mecânica à tração de Papel Vegetal $\left(75 \mathrm{~g} / \mathrm{m}^{2}\right)$ em função de taxa de absorção de água (água por papel $\mathrm{W} / \mathrm{P})$

Da mesma forma, o papel sulforizé (Figura 6.26) apresentou comportamento similar, contudo, apresentando mínimos quadrado igual a 0,975.

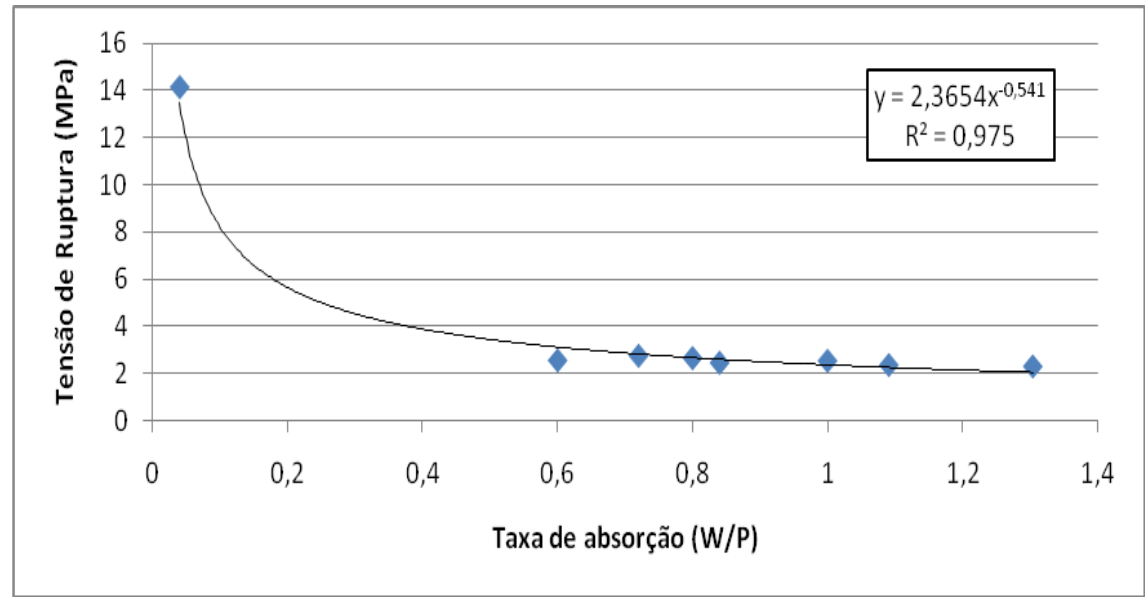

Figura 6.26 - Determinação de resistência mecânica à tração de Papel Sulfurizé $\left(35 \mathrm{~g} / \mathrm{m}^{2}\right)$ em função de taxa de absorção de água (água por papel W/P)

Em relação ao papel sulfite, os valores de resistência mecânica à tração para taxa de absorção superiores à 0,5 se apresentaram em torno de $1 \mathrm{MPa}$. Este valor indica uma perda de resistência de 8 vezes. 


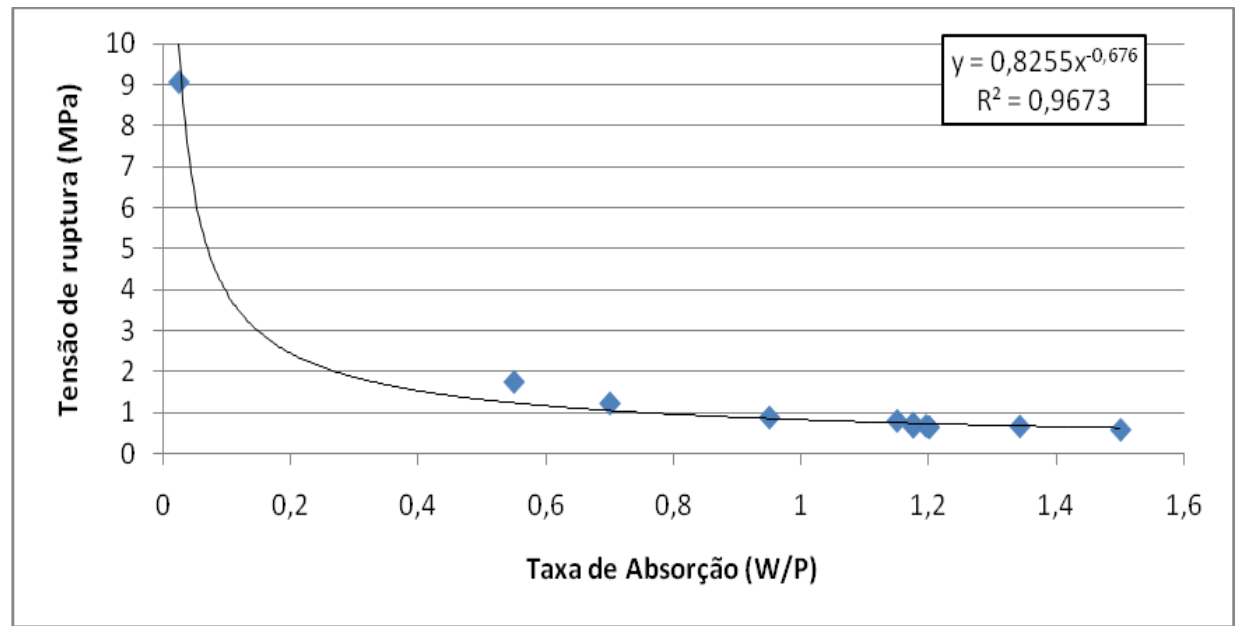

Figura 6.27 - Determinação de resistência mecânica à tração de Papel Sulfite $\left(75 \mathrm{~g} / \mathrm{m}^{2}\right)$ em função de taxa de absorção de água (água por papel $\mathrm{W} / \mathrm{P})$

Por fim, o papel seda, cuja curva de tensão de ruptura em função da taxa de absorção é apresentada na Figura 6.28, também apresentou comportamento diferenciado dos outros materiais celulósicos. Visto que foi encontrado valor de mínimo quadrado igual a 0,988 para a regressão logaritimica dos valores estudados.

Neste grafico, pode ser também ser observada a redução de aproximadamente 50 vezes na resistência mecânica do material em função da ação da água.

Adicionalmente, pode-se observar que o papel seda proporciona praticamente a mesma perda de resistência mecânica em função da taxa de absorção que o papel sulfite. Enquanto a maior perda de resistência foi encontrada para o papel vegetal, como pode ser observado na Figura 6.29. 


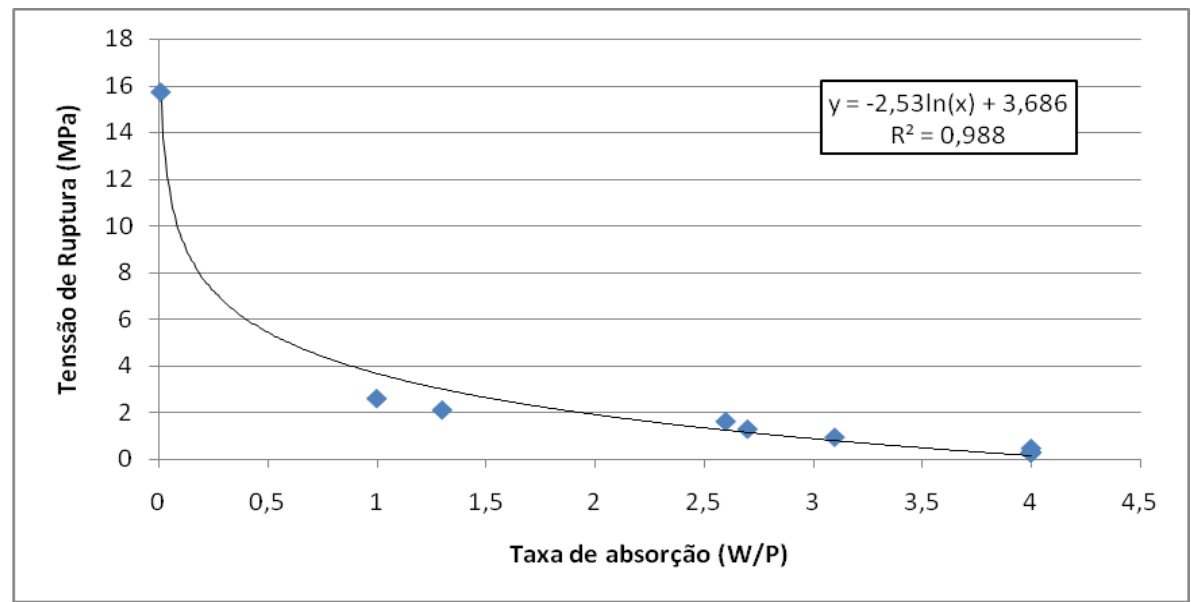

Figura 6.28 - Determinação de resistência mecânica à tração de Papel Seda $\left(18 \mathrm{~g} / \mathrm{m}^{2}\right)$ em função de taxa de absorção de água (água por papel $\mathrm{W} / \mathrm{P})$

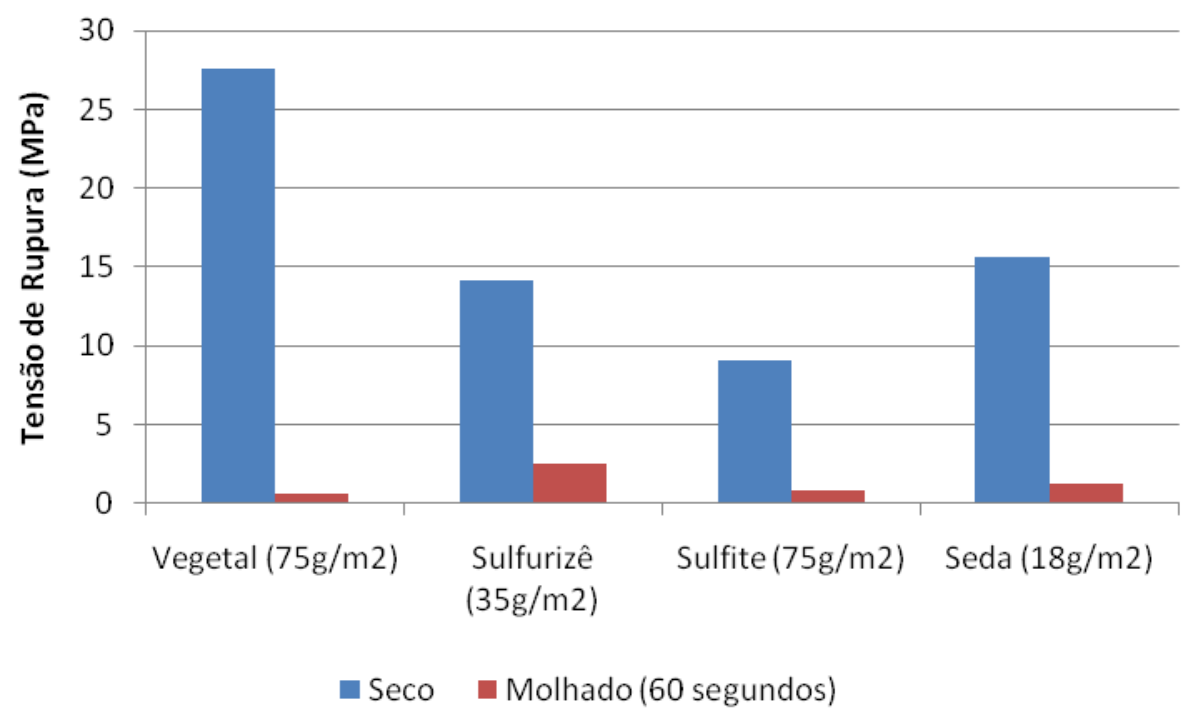

Figura 6.29 - Apresentação comparativa entre resistência mecânica de materiais celulósicos, e perda de resistência dos materiais em função de 60 segundos de imersão em água 


\subsubsection{Análise microscópica de materiais}

Tendo o objetivo de justificar o comportamento do material, foi realizada uma análise micrográfica do rompimento dos 4 tipos de papel, conforme apresentado na Figura 6.30.

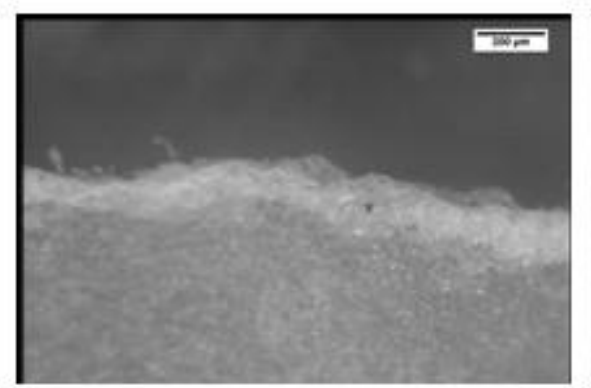

a)

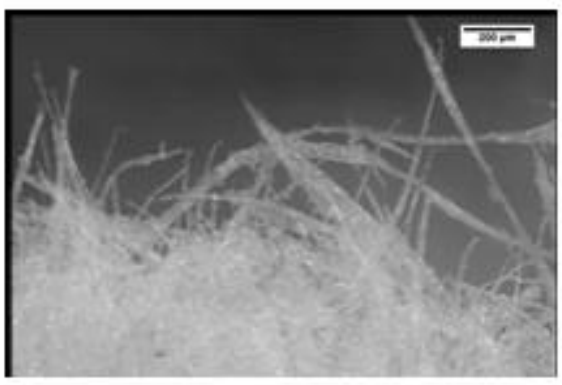

c)

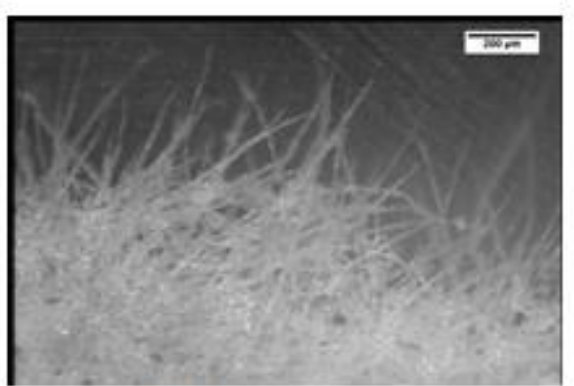

b)

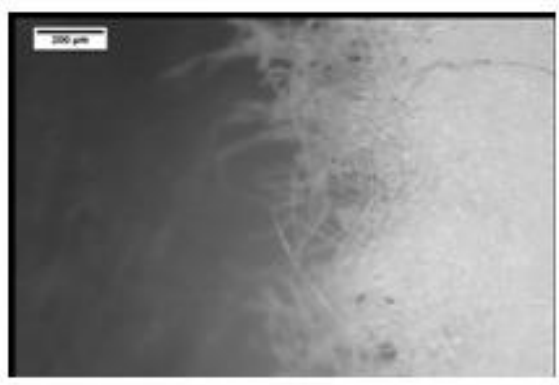

d)

Figura 6.30 - Micrografia de materiais celulósicos, sendo a) papel vegetal $\left(75 \mathrm{~g} / \mathrm{m}^{2}\right)$; b)papel seda $\left(18 \mathrm{~g} / \mathrm{m}^{2}\right)$; c)papel sulfite $\left(75 \mathrm{~g} / \mathrm{m}^{2}\right)$; e d) papel sulfurizé $\left(35 \mathrm{~g} / \mathrm{m}^{2}\right)$

Ao analisar esta figura, pode-se identificar que foi empregado de tratamento químico para os papéis vegetal (a), sultife (c) e sulfurizé (d), enquanto para o papel seda (b) foi realizado tratamento mecânico da polpa de papel. Também é possível identificar que os papéis sulfite e sulfurizé sofreram processo de branqueamento (bleaching), sendo o nível branqueamento maior para o papel sulfurizé.

Adicionalmente, pode-se observar uma densidade elevada para o papel Vegetal $(75 \mathrm{~g} / \mathrm{m} 2)$, sendo identificadas fibras curtas, ao contrário do papel 
Sulfite $(75 \mathrm{~g} / \mathrm{m} 2)$, que apresentou ser constituído de fibras longas. Já os papéis Sulfurizé e Seda, apresentaram fibras médias.

Atentando-se a este fato, aliado à resistência mecânica destes materiais, podese identificar que os tipos de papel que apresentavam fibras curtas proporcionaram maior resistência. Contudo, este resultado pode ser atribuído ao tipo de madeira utilizado na fabricação do papel, assim como processo de fabricação de polpa, quantidade de lignina e tipo de branqueamento.

Por outro lado, ao analisar a taxa de absorção destes materiais, pode-se identifcar que o processo de branqueamento proporcionou maior resistência à absorção de água. Em adição, foi identificado que o processo de fabricação mecânico de polpa (Papel Seda) promoveu maior taxa de absorção, devido à alta porosidade encotrada neste material.

\subsubsection{Seleção de material celulósico}

Em conclusão, para a seleção do material celulósico utilizado neste projeto, foi utilizada uma matriz de análise relativa (Tabela 6.10), de forma a identificar o tipo de material mais adequado para esta aplicação.

Nesta tabela, são relacionados os principais requisitos identificados no material celulósico de forma a permitir a implementação da concepção proposta deste trabalho. Adicionalemente, como resultado desta análise, é indicado o papel seda como para ser utilizado neste projeto.

Desta forma, a partir da seleção deste material, foi possível desenvolver a formulação do material compósito, assim como o processamento do mesmo. 
Tabela 6.10 - Matriz de análise relativa de materiais celulósicos

\begin{tabular}{|c|c|c|c|c|c|c|c|c|}
\hline \multirow{3}{*}{$\begin{array}{c}\text { Propriedades } \\
\text { Espessura de } \\
\text { camada }\end{array}$} & \multicolumn{8}{|c|}{ Materiais } \\
\hline & \multicolumn{2}{|c|}{ Papel Vegetal } & \multicolumn{2}{|c|}{ Papel Sulfurizé } & \multicolumn{2}{|c|}{ Papel Sulfite } & \multicolumn{2}{|c|}{ Papel seda } \\
\hline & \multirow{6}{*}{ 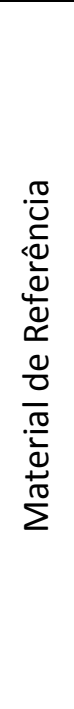 } & 0,1 & 1 & 0,05 & 0 & 0,1 & 1 & 0,03 \\
\hline $\begin{array}{l}\text { Opacidade de } \\
\text { material seco }\end{array}$ & & $63,75 \%$ & -1 & $87,92 \%$ & -1 & $91,54 \%$ & -1 & $83,38 \%$ \\
\hline $\begin{array}{c}\text { Opacidade de } \\
\text { material Molhado }\end{array}$ & & $54,68 \%$ & -1 & $84,89 \%$ & -1 & $87,31 \%$ & 0 & $63,75 \%$ \\
\hline $\begin{array}{c}\text { Taxa de absorção } \\
\text { (1 min) }\end{array}$ & & 1,2 & -1 & 1,08 & -1 & 0,89 & 1 & 2,5 \\
\hline $\begin{array}{c}\text { Resistência } \\
\text { mecânica à tração } \\
\text { de material seco }\end{array}$ & & $\begin{array}{l}27,32 \\
\text { Mpa }\end{array}$ & -1 & $\begin{array}{l}14,02 \\
\mathrm{Mpa}\end{array}$ & -1 & $\begin{array}{l}8,90 \\
\text { Mpa }\end{array}$ & -1 & 15,22 Mpa \\
\hline $\begin{array}{c}\text { Resistência } \\
\text { mecânica à tração } \\
\text { de material } \\
\text { molhado (1 } \mathrm{min})\end{array}$ & & $\begin{array}{l}\text { 0,59 } \\
\text { Mpa }\end{array}$ & 1 & 2,54 Mpa & -1 & $\begin{array}{l}0,88 \\
\text { Mpa }\end{array}$ & 1 & 2,62 Мра \\
\hline Análise Total & 0 & pontos & -2 & pontos & -5 & pontos & 1 & pontos \\
\hline
\end{tabular}

\subsection{Desenvolvimento de material compósito}

Com relação ao desenvolvimento do material compósito, foram realizados estudos relacionados à identificação da formulação do material compósito, assim como de seu comportamento em função da quantidade de polímero impregnado, e do teor dos componentes do material polimérico. Adicionalmente, esta seção apresenta um estudo visando validar o princípio funcional do processo proposto neste trabalho, sendo identificada a adesividade entre camadas. Por fim, foi realizado um estudo de otimização que busca maximizar a resistência mecânica do compósito assim como a força de arrancamento do ensaio de adesividade.

\subsubsection{Resistência mecânica a tração em função de percentual de polímero}

Com objetivo de identificação do comportamento mecânico do material compósito em função do percentual de polímero. Foi realizado um estudo relacionando a resstência mecânica média à tração do material compósito, como pode é descrito na Seção 5.3.1. 
Neste estudo, foi observada a tensão de ruptura do material compósito para 5 valores percentuais de polímero, como pode ser observado na Figura 6.31. Neste estudo, foi optado por utilizar o material $B$, visto que este material apresentou a maior resistência mecâica à tração, entre os materiais estudados.

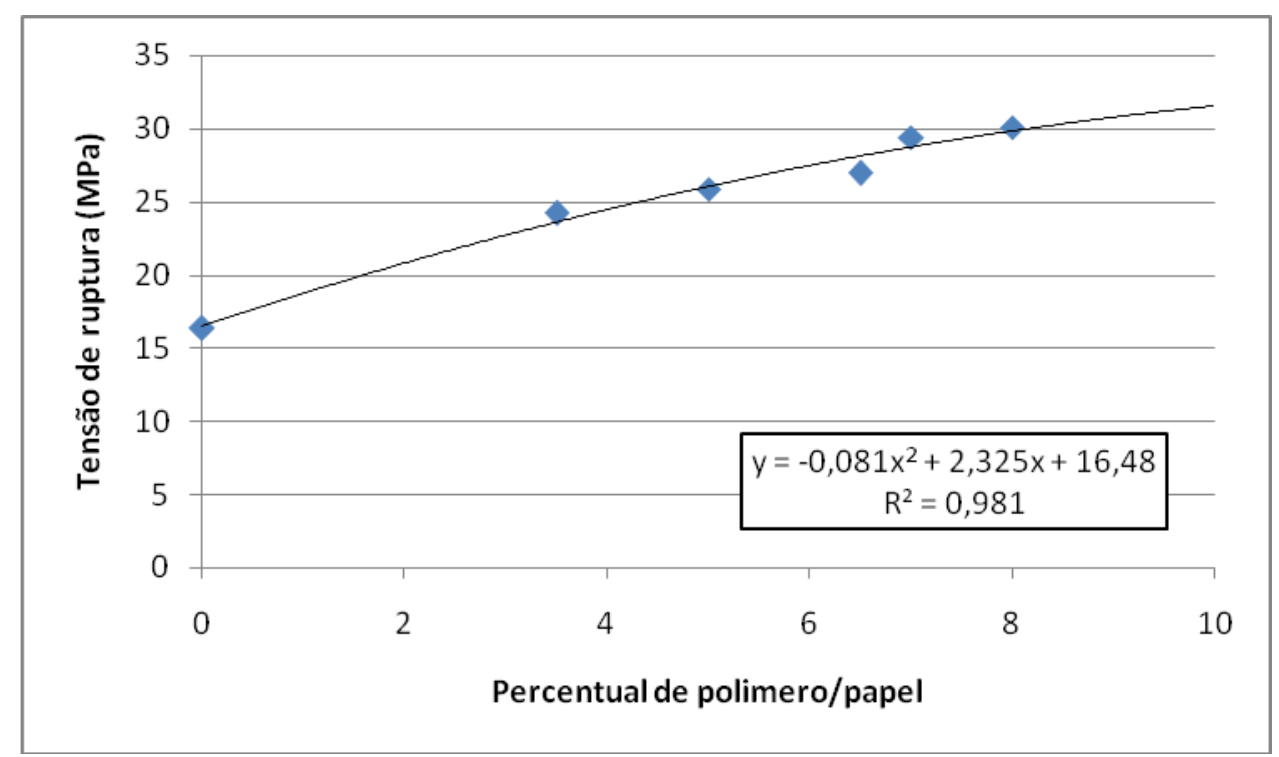

Figura 6.31 - Curva de tensão de ruptura de material Compósito em função do percentual de polímero impregnado em substrato celulósico, sendo composto por papel seda e material polimérico $B$

Através desta curva, torna-se possível identificar uma faixa de contribuição do polímero para a resistência mecânica entre 0 e 8 . Neste caso, foi possível identificar que o aumento da resistência mecânica à tração do material compósito é promovido pelo percentual de polímero impregnado em papel, seguindo como padrão, uma regressão polinomial de segunda ordem.

\subsubsection{Determinação de formulação de material compósito}

Com o objetivo de identificar uma formulação do material compósito adequada para ser utilizada na validação da proposta deste projeto. Foi realizado um planejamento de experimentos, conforme apresentado na Seção 5.3. 
Neste estudo, foram considerados como fatores de resposta, a taxa de absorção do material compósito, a resistência mecânica média a tração e aderência entre camadas.

\section{Resistência mecânica média à tração}

Em relação à resistência média à tração do material compósito, foi estudada a contribuição do material polimérico para a resistência mecânica do compósito através de planejamento de experimentos (DoE), conforme apresentado na Seção 5.3.2. Adicionalmente, foi determinada para a realização deste estudo a relação polímero/papel entre 4,5 e 5,5, de modo a manter o mesmo parâmetro de comparação.

Na Figura 6.32, foi possível observar que tanto o efeito principal quanto o efeito secundário, indicam o fotoiniciador como o principal componente que contribui para o aumento da resistência mecânica do compósito à tração.

Nesta figura, torna-se também possível identificar que 0 aumento da concentração de iniciador proporciona a queda dos valores de resistência.

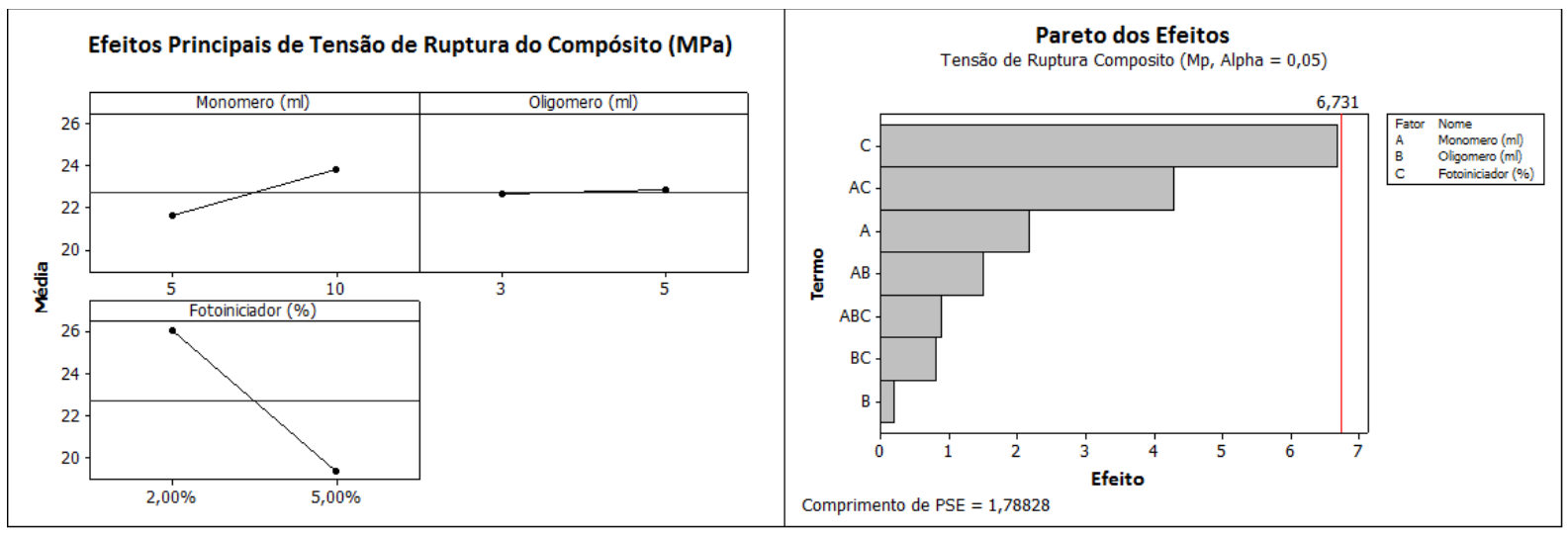

Figura 6.32 - Diagramas de efeito principal e secundário de composição de material compósito para a tensão de ruptura

Já ao analisar o diagrama de contorno da tensão de ruptura em função da composição do material (Figura 6.33), pode-se identificar valores altos de tensão para concentrações baixas de iniciador. Cabe ressaltar que para estes níveis de 
concentração, foram encontrados os maiores valores de conversão, indicando a grande relação da resistência mecânica com a taxa de polimerização.

Pode também ser observado nesta figura, que o aumento de oligômero na formulação proporciona maiores valores resistência para concentrações maiores de iniciador.
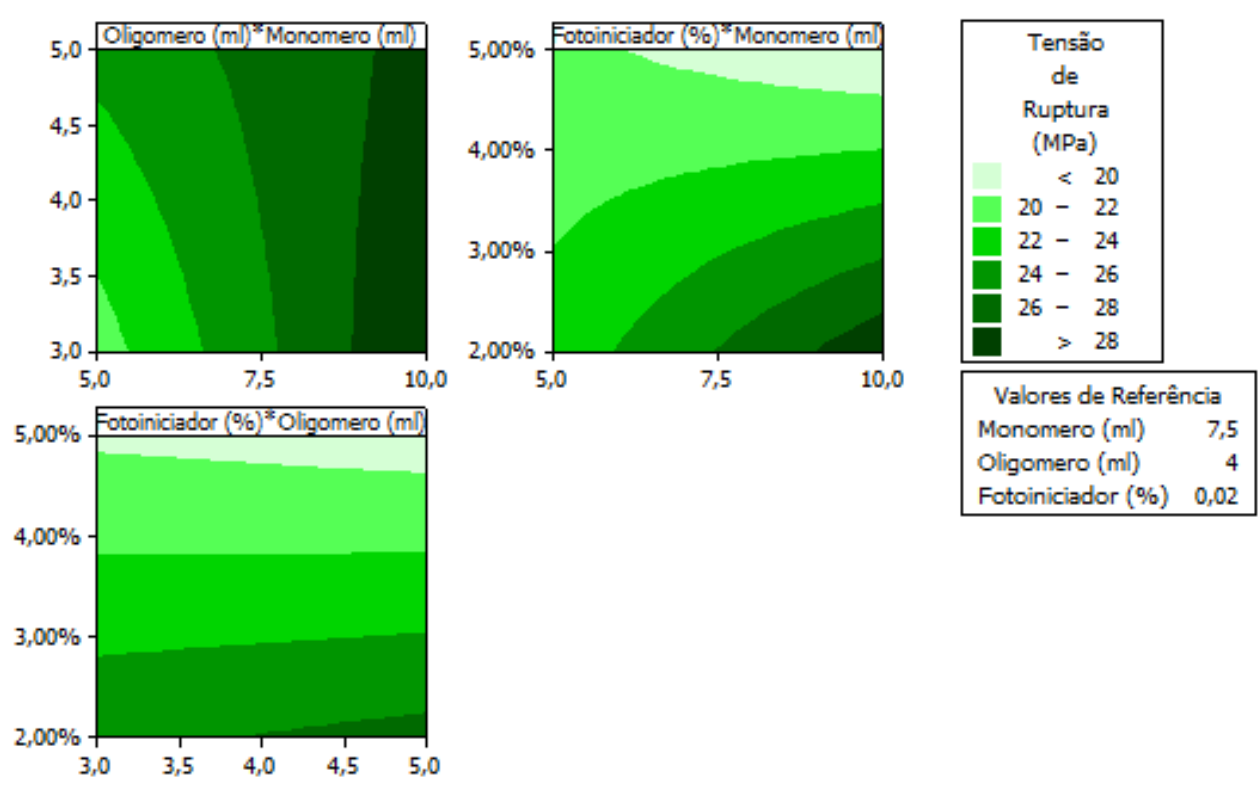

Figura 6.33 - Diagramas de contorno de tensão de ruptura de material compósito em função de teor de componentes de sua formulação

Contudo, ao observar a o diagrama de contorno da tensão de rompimento em função da relação entre monômero e oligômero $(M / O)$ e da concentração de iniciador (Figura 6.34), pode-se identificar que os maiores valores de resistência mecânica à tração foram encontrados para níveis altos de monômero e concentrações baixas de iniciador. 

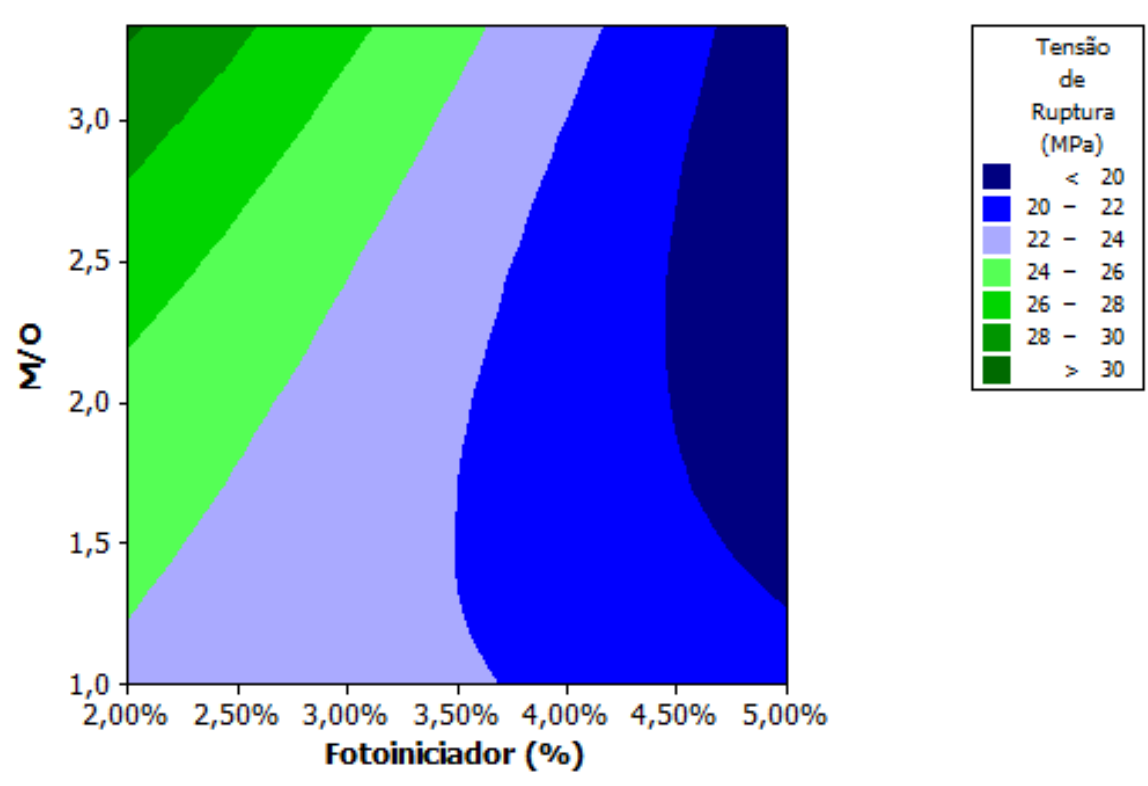

Figura 6.34 - Diagramas de contorno de tensão de ruptura de material compósito em função de relação monômero/oligômero e concentração de iniciador

\section{Resistência mecânica média à tração em meio à água}

Visto que a concepção apresentada neste trabalho contempla a remoção de material residual através de solvente (água), foi realizado um estudo identificando a perda de resistência do material compósito em função da taxa de absorção de água, conforme descrito na Seção 5.3.2.

Neste caso, foram encontrados valores de absorção de água para tempo de imersão de 60 segundos, sendo levatados em seguida os valores de tensão de ruptura em presença de água. Neste caso, não foi observadas diferenças entre os valores de absorção dos materiais estudados, tendo suas taxas de absorsão iguais a $30 \%$ do compósito.

Em relação aos efeitos principais e secundários encontrados neste estudo, a Figura 6.35 indica o maior efeito proporcionado pelo iniciador. Pode-se também observar que as maiores perdas de resistência foram encontradas nos materiais com concentrações altas de iniciador, chegando à perda de $77 \%$ da resistência original. 


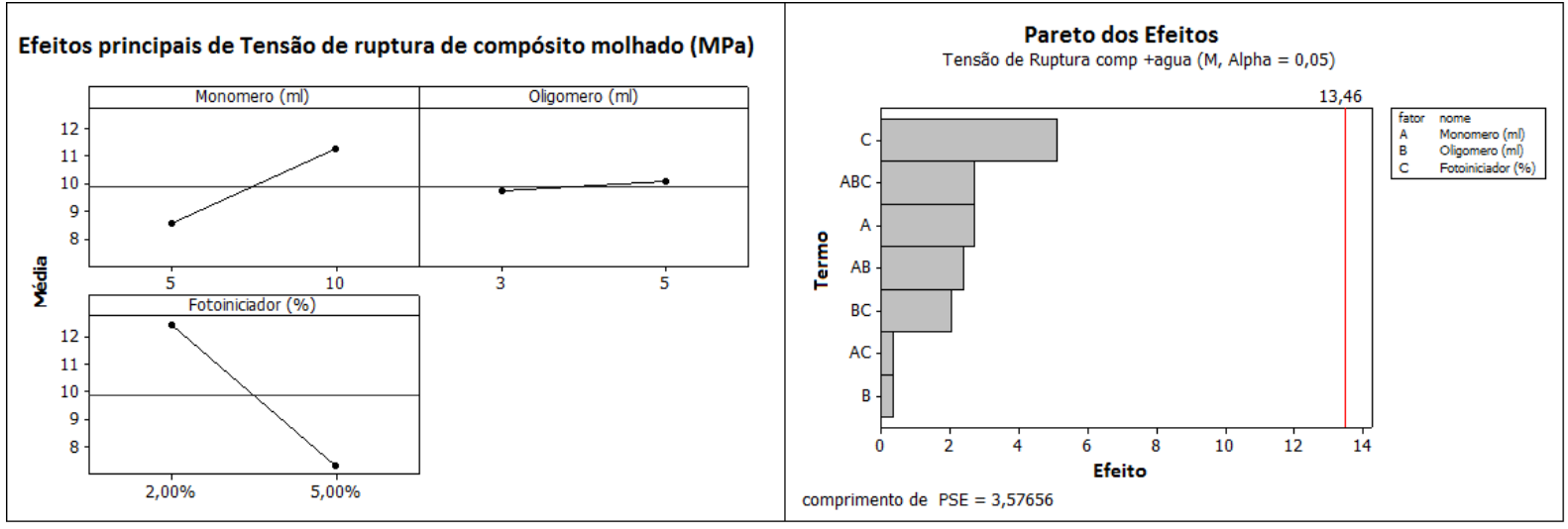

Figura 6.35 - Diagramas de efeito principal e secundário de composição de material compósito para a tensão de ruptura em meio a água

Com relação à tensão de ruptura do material compósito em presença de água em função da composição do material, pode ser observado na Figura 6.36 que são obtidos valores de resistência superiores para valores altos de monômero. Contudo, torna-se também possível observar a tendência do aumento da resistência em função da redução de iniciador, situação onde foi observada maiores valores de conversão polimérica.
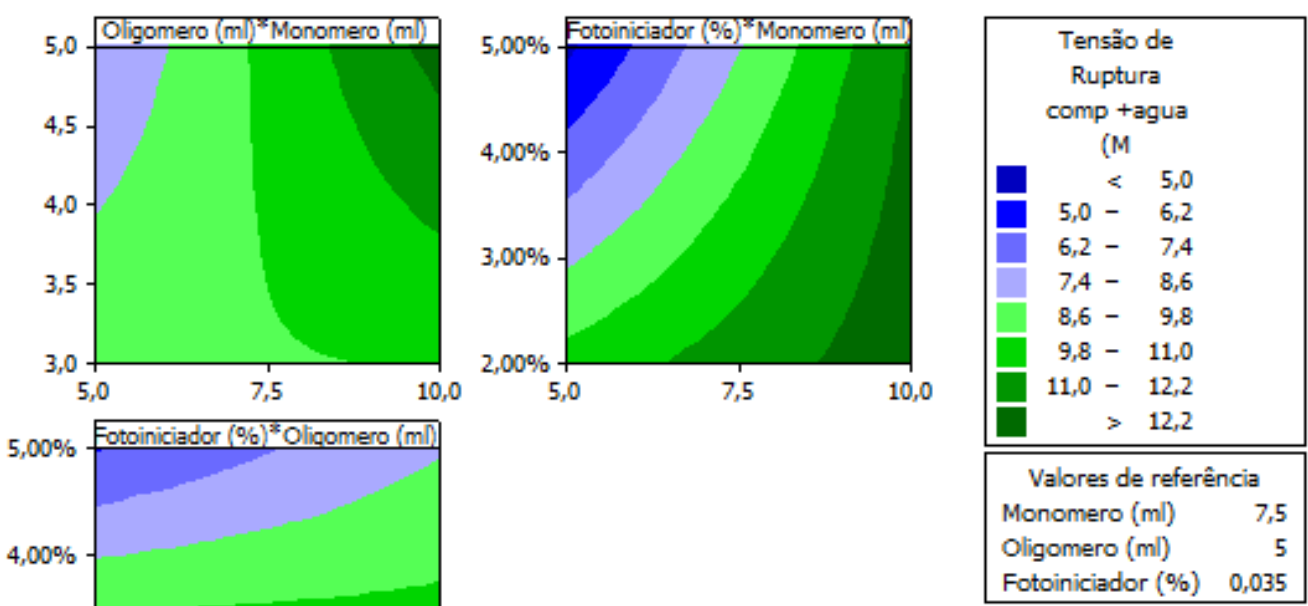

Figura 6.36 - Diagramas de contorno de tensão de ruptura de material compósito em meio à água em função de teor de componentes de sua formulação 
Como observado ao longo deste trabalho, pode-se observar a direta relação entre monômero e oligômero para a determinação do comportamento do material. Desta forma, pode-se observar como contraste aos altos valores de resistência à tração do compósito, que a taxa de monômero por oligômero $(\mathrm{M} / \mathrm{O})$ apresenta maiores valores de perda percentual de resistência para concentrações baixas de iniciador.
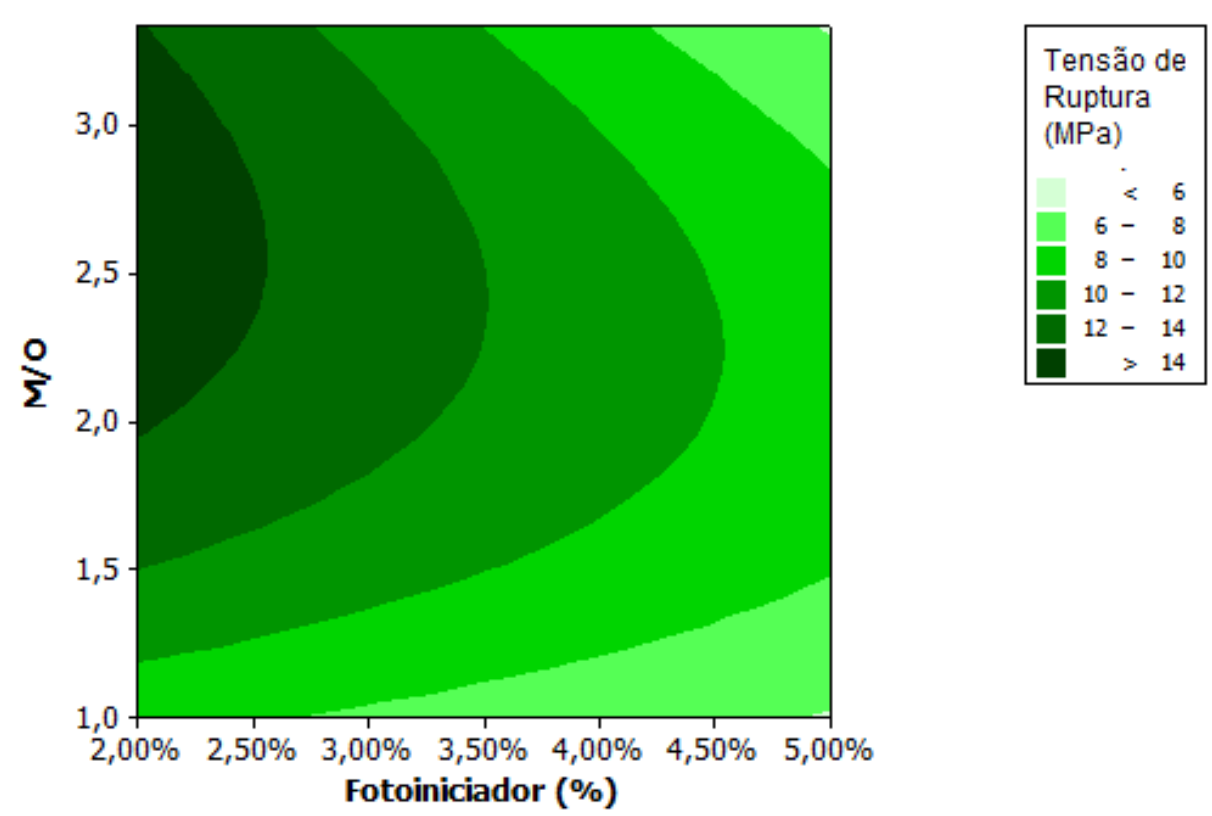

Figura 6.37 - Diagramas de contorno de tensão de ruptura de material compósito em presença de água em função de relação monômero/oligômero e concentração de iniciador

\section{Aderência entre camadas}

Em relação à determinação da aderência entre camadas de compósito, foram realisados estudos conforme descrito na Seção 4.3.12. O objetivo principal deste estudo é de identificar a resistência mecânica da junta adesiva formada entre camadas, e considerando um grau de conversão de $60 \%$. 
Adicionalmente, foram analisados os modos de falha proporcionados por cada formulação de material, sendo relacionada esta falha com o gradiente de polimerização proporcionado pelo LED UV.

Este relacionamento pode ser observado através da Figura 6.38, onde são apresentadas as formas de propagação da falha, podendo ser homogênea ou ao longo da borda de contorno da luz emitida pelo LED UV.

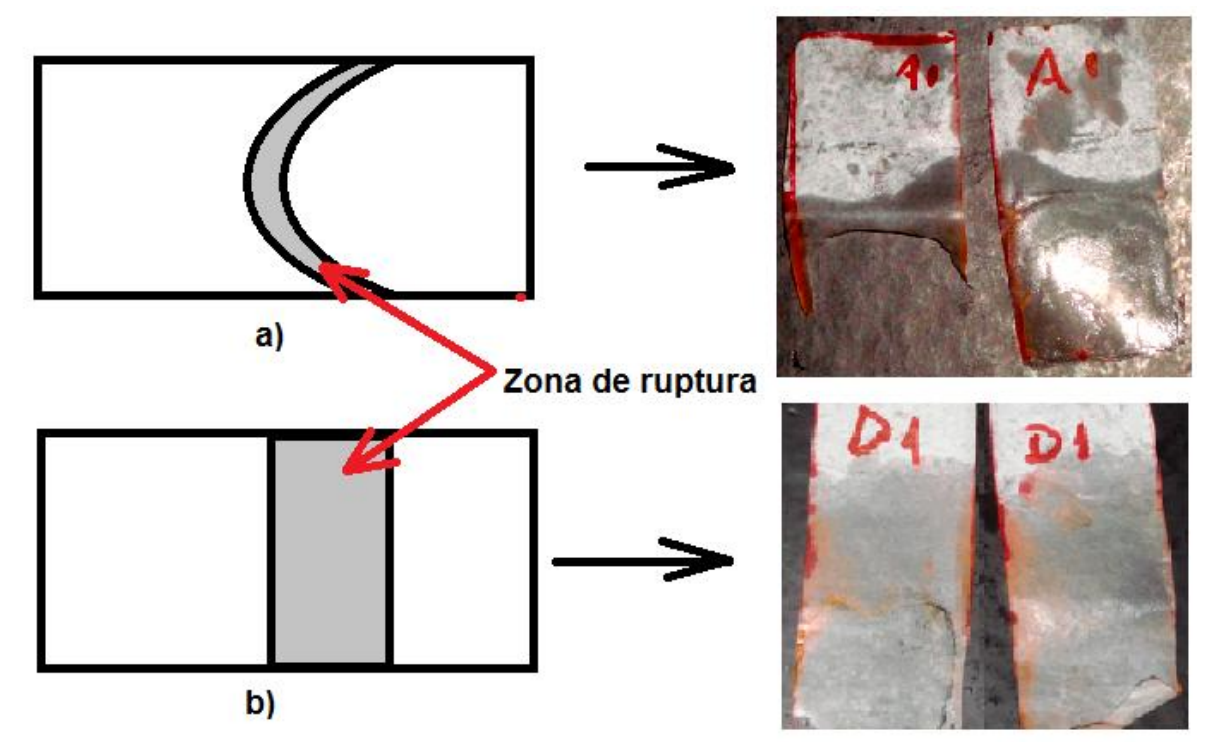

Figura 6.38 - Foto de propagação de ruptura por a) borda de contorno de luz e b) homogênea

Na Tabela 6.11, podeser observada a relação entre composição de material, tempo de exposição em UV, resistência mecânica à arrancamento (aderência), modo de falha observado e relação com gradiente de polimerização. 
Tabela 6.11 - Relação de formulação de material, força de arrancamento, modo de falha e propagação de ruptura

\begin{tabular}{|c|c|c|c|c|c|c|c|c|c|c|}
\hline \multirow{2}{*}{$\frac{\text { mat }}{\mathrm{A}}$} & \multirow{2}{*}{\begin{tabular}{|c|}
$\exp$ \\
1
\end{tabular}} & \multicolumn{2}{|c|}{ Monomero (ml) } & \multicolumn{2}{|c|}{ Oligomero (ml) } & \multicolumn{2}{|c|}{ Fotoiniciador (\%) } & \multirow{2}{*}{$\begin{array}{c}\text { Aderência (kgf) } \\
0.135\end{array}$} & \multirow{2}{*}{$\frac{\text { Modo de Falha }}{\widetilde{2}}$} & \multirow{2}{*}{$\begin{array}{l}\text { Propagação de ruptura } \\
\text { Borda de contorno de luz }\end{array}$} \\
\hline & & - & 5 & - & 3 & - & $2.00 \%$ & & & \\
\hline $\mathrm{B}$ & 2 & + & 10 & - & 3 & - & $2.00 \%$ & 0.125 & & Borda de contorno de luz \\
\hline $\mathrm{C}$ & 3 & - & 5 & + & 5 & - & $2.00 \%$ & 0.14 & 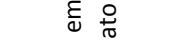 & Homogêneo \\
\hline $\mathrm{D}$ & 4 & + & 10 & + & 5 & - & $2.00 \%$ & 0.135 & $\stackrel{乛}{=} \stackrel{0}{=}$ & Homogêneo \\
\hline$E$ & 5 & - & 5 & - & 3 & + & $5.00 \%$ & 0.12 & 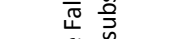 & Homogêneo \\
\hline $\mathrm{F}$ & 6 & + & 10 & - & 3 & + & $5.00 \%$ & 0.125 & $\frac{0}{0} \frac{0}{0}$ & Borda de contorno de luz \\
\hline G & 7 & - & 5 & + & 5 & + & $5.00 \%$ & 0.1175 & $\frac{0}{0}$ & Homogêneo \\
\hline $\mathrm{H}$ & 8 & + & 10 & + & 5 & + & $5.00 \%$ & 0.1375 & & Borda de contorno de luz \\
\hline
\end{tabular}

Em relação aos efeitos principais proporcionados pela formulação do material para a aderência, pode-se constatar, conforme observado na Figura 6.39, que o maior efeito é proporcionado pela concentração de iniciador. Contudo, esta figura ainda indica a interação entre monômero e iniciador como o termo que promove maior contribuição para a aderência entre camadas.

Neste caso, pode-se observar que com o aumento de oligômero e redução de iniciador, pode-se observar o aumento dos valores de adesividade.

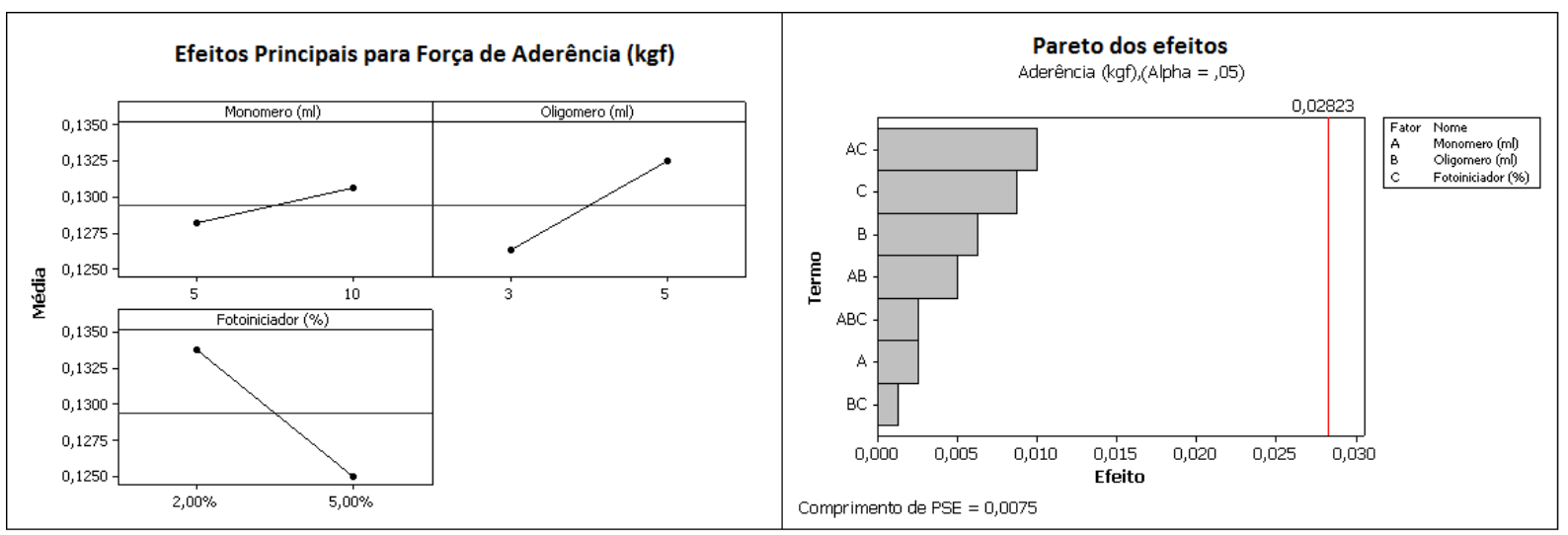

Figura 6.39 - Diagramas de Efeito principal e Efeito secundário de resistência de adesividade entre camadas em função de componentes de material

Esta propriedade também pode ter seu comportamento analisada através da Figura 6.40, que apresenta diagramas de contorno da adesividade média em função da formulação de material polimérico. 
Através desta figura, pode-se identificar que para concentrações baixas de iniciador, obtém-se o aumento da adesividade em função da redução de monômero e aumento de oligômero. Em contrapartida, se forem consideradas concentrações altas de iniciador, esta resposta é obtida através do aumento simultâneo de monômero e oligômero.
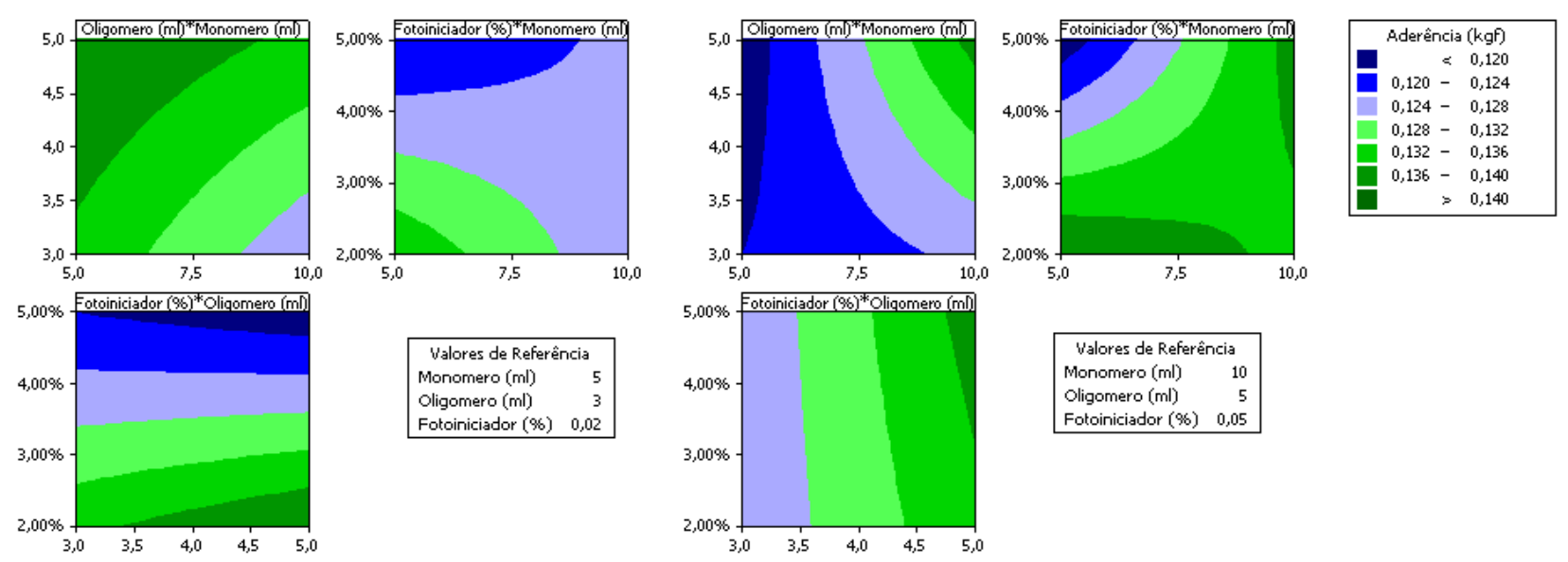

Valores de Referência Monomero (ml) Fotoiniciador $(\%) \quad 0,05$

Figura 6.40 - Diagramas de contorno de resistência de adesividade entre camadas em função de componentes de material

Adicionalmente, ao analisar a contribuição da proporção entre monômero e oligômero (M/O), conforme apresentado na Figura 6.41, pode ser observada uma maior adesividade para valores $\mathrm{M} / \mathrm{O}$ entre 1 e 2 , em paralelo à concentração de iniciador entre 2 e $2.5 \%$. 

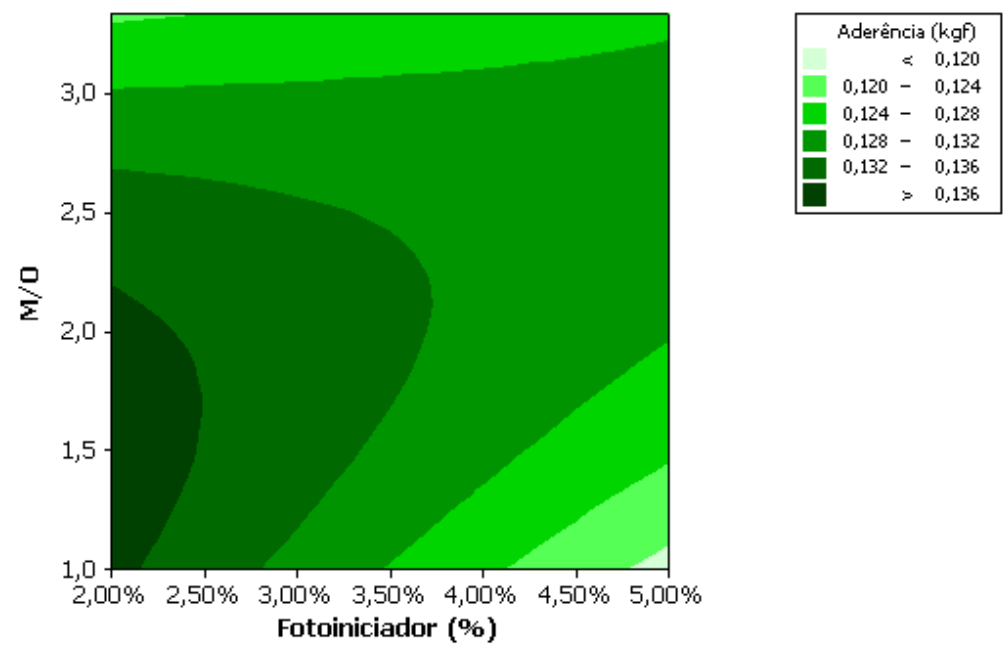

Figura 6.41 - Diagramas de contorno de resistência de adesividade entre camadas em função de proporção entre monômero por oligômero e concentração de fotoiniciador

\section{Otimização de material compósito}

Em função das diferentes respostas proporcionadas pelos componentes do material compósito, foi realizado um estudo de otimização com o objetivo de identificar a formulação de material mais indicada ser empregada neste projeto. Em contraste com o estudo de otimização realizado para o material polimérico, este estudo visa identificar as regiões onde são encontrados os maiores valores de resistência à tração em presença ou não de água aderência entre camadas.

A descrição deste problema de otimização pode ser observado nas Equações abaixo, tendo esta otimização o objetivo maximizar a tensão de ruptura em presença ou não de água e maximizar a adesividade entre camadas.

$$
\operatorname{Max} \rightarrow F_{\text {adesiv }}, \sigma_{\text {rup }}, \sigma_{\text {rup } a g u a}
$$

Submetido à: 


$$
\begin{aligned}
& 0 ., 13 \leq F_{\text {adesiv }}[k g f] \\
& 28 \leq \sigma_{\text {rup }}[M P a] \\
& 13 \leq \sigma_{\text {rup agua }}[M P a]
\end{aligned}
$$

Adicionalmente, a Figura 6.42 apresenta a faixa de viabilidade para as restrições do estudo de otimização. Para a identificação do valor ótimo do estudo, foram definidos como valores iniciais: $5 \mathrm{ml}$ para monômero; $3 \mathrm{ml}$ para oligômero e $2 \%$ para iniciador.

Como resultado, foi possível identificar como ótimo local a formulação de material: $10 \mathrm{ml}$ de monômero; 4,40 de oligômero e $2 \%$ de iniciador. Através desta formulação é possível observar como respostas: $0.132 \mathrm{kgf}$ de força de adesividade; $29 \mathrm{MPa}$ de tensão de ruptura e 13,60 MPa de tensão de ruptura em presença de água.
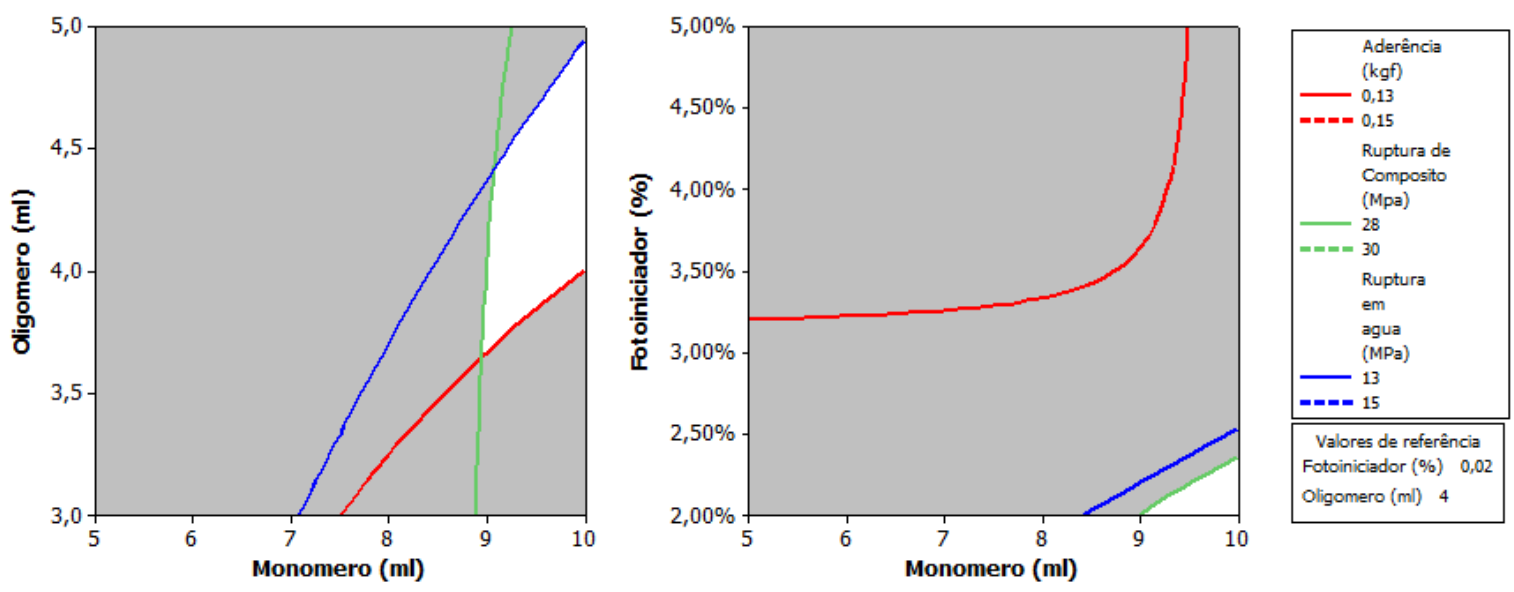

Figura 6.42 - Indicação de faixa de viabilidade às restrições do problema de otimização 


\subsubsection{Comportamento de microestrutura de compósito}

Com o objetivo de explicar o comportamento do material compósito, foram realizados estudos da microestrutura do material, sendo analisadas regiões de transição de deposição, vistas de transversais e frontais do compósito e seções transversais de material com múltiplas camadas de substrato.

$\mathrm{Na}$ Figura 6.43, podem ser observadas as imagens micrograficas de vistas frontais substrato e compósito. Nesta imagem, pode observar a influência do polímero para o compósito, visto que as porosidades do substrato são preenchidas pelo material polimérico.

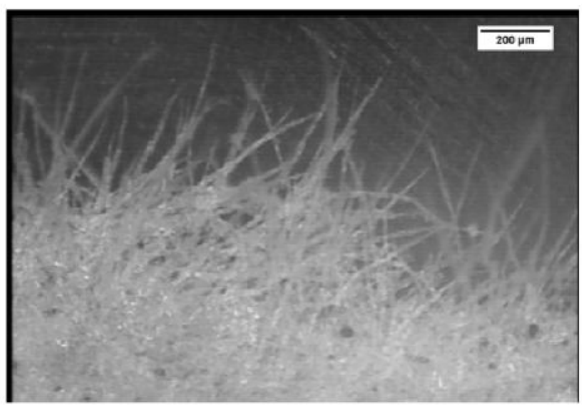

a)

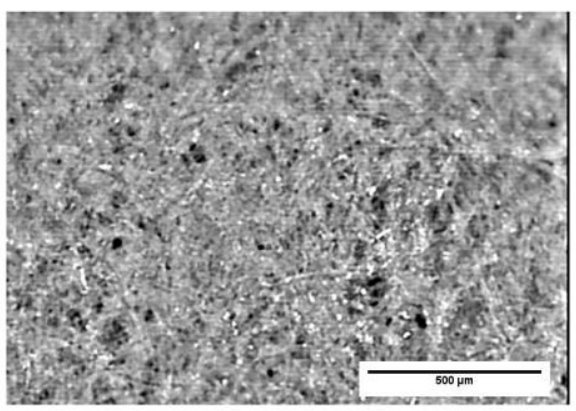

c)

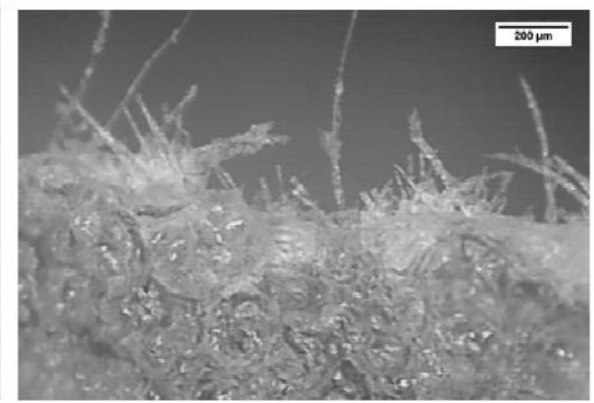

b)

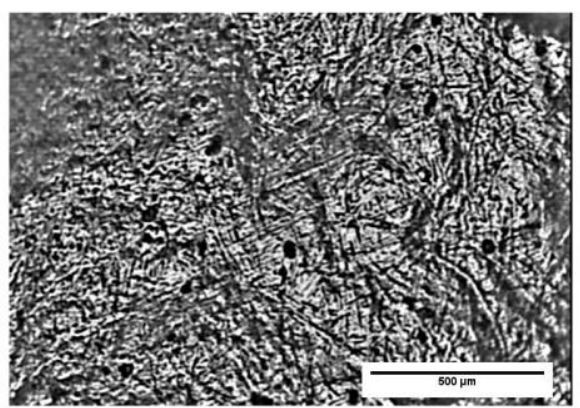

d)

Figura 6.43 - Imagens microscópicas de vista de topo de a) ruptura de substrato celulósico (papel seda); b) ruptura de material compósito com relação polímero/papel igual a 6,$5 ;$ c) região central de material celulósico (papel seda); e d) região central de compósito com relação polímero/papel igual a 6,5

Adicionalmente, a Figura 6.44 apresenta a micrografia da seção transversal de substrato e compósito, identificando o nível de penetração do material polimérico no substrato. Através desta figura, torna-se possível identificar a concentração do 
polímero em meio o substrato. Consequentemente, evidenciando o sentido de construção das camadas para baixo, em adição à polimerização ser realizado pelo topo.

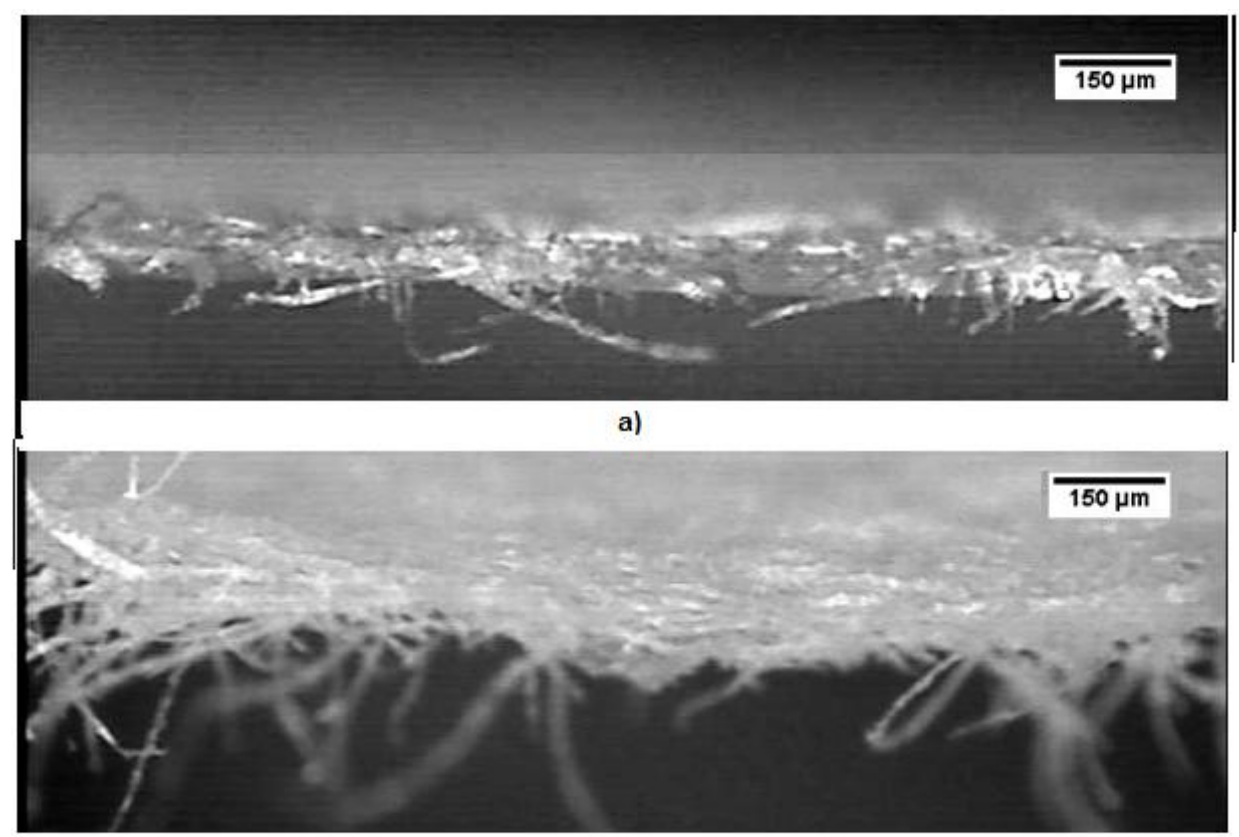

b)

Figura 6.44 - Imagens microscópicas de seção transversal de a) material compósito e b) substrato celulósico (papel seda)

Já a Figura 6.45 apresenta a seção transversal do material compósito com múltiplas camadas. Onde é evidenciada a interação entre material polimérico presente nas camadas. Adicionalmente, através desta figura, pode-se identificar o sobrematerial proveniente da adição de polímero no substrato. Consequentemente, sendo possível estimar fator de correção para dimensional da peça final no sentido de construção de camadas (z). Por fim, este fator de correção pode ser identificado como $6 \mu \mathrm{m}$ por camada.

Por outro lado, esta figura também permite identificar a relação entre camadas, evidenciando a formação de um material continuo e homogênio. Em adição, isto explica o comportamento encontrado na análise de modo de falha do ensaio de aderência entre camadas, visto que em todos os casos estudados foi observado rompimento no substrato. 


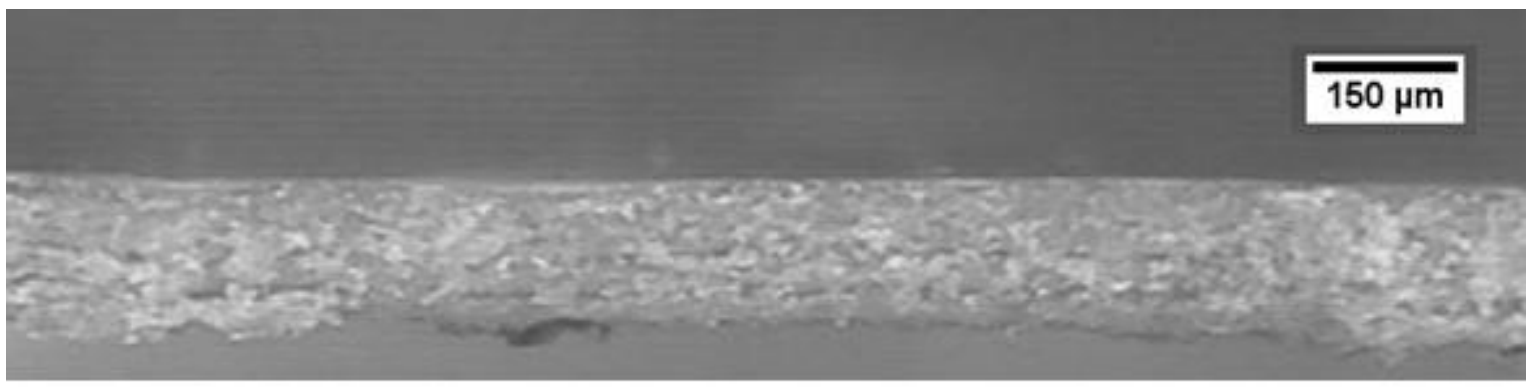

Figura 6.45 - Imagens microscópicas de seção transversal de material compósito com múltiplas camadas 


\section{PARTE II - VALIDAÇÃO DE PROPOSTA DE PROCESSO}

\section{PROJETO CONCEITUAL DO EQUIPAMENTO}

Após o desenvolvimento do material compósito a ser utilizado neste projeto, este capítulo apresenta os estudos que foram realizados para a determinação do layout de equipamento, assim como desenvolvimento do sistema de controle, sistema de alimentação e sistema de alimentação de material celulósico. Neste capítulo, é também apresentada uma proposta de equipamento protótipo para validação funcional da proposta de processo.

\subsection{Desenvolvimento Sistema de deposição}

Confome indicado em análise funcional, as funções de formação de compósito, alimentação e deposição de polímero foram estipuladas para compor o sistema de deposição, conforme apresentado na

Figura 7.1. Neste sistema, tem-se o material polimérico no estado líquido como uma de suas entradas, enquanto a deposição de mateiral recebe como entrada, comandos do sistema de controle e posicionamento. Neste caso, este interrelacionamento pode ser representado pela fixação do sistema de deposição nos eixos de posicionamento $x-y$. 


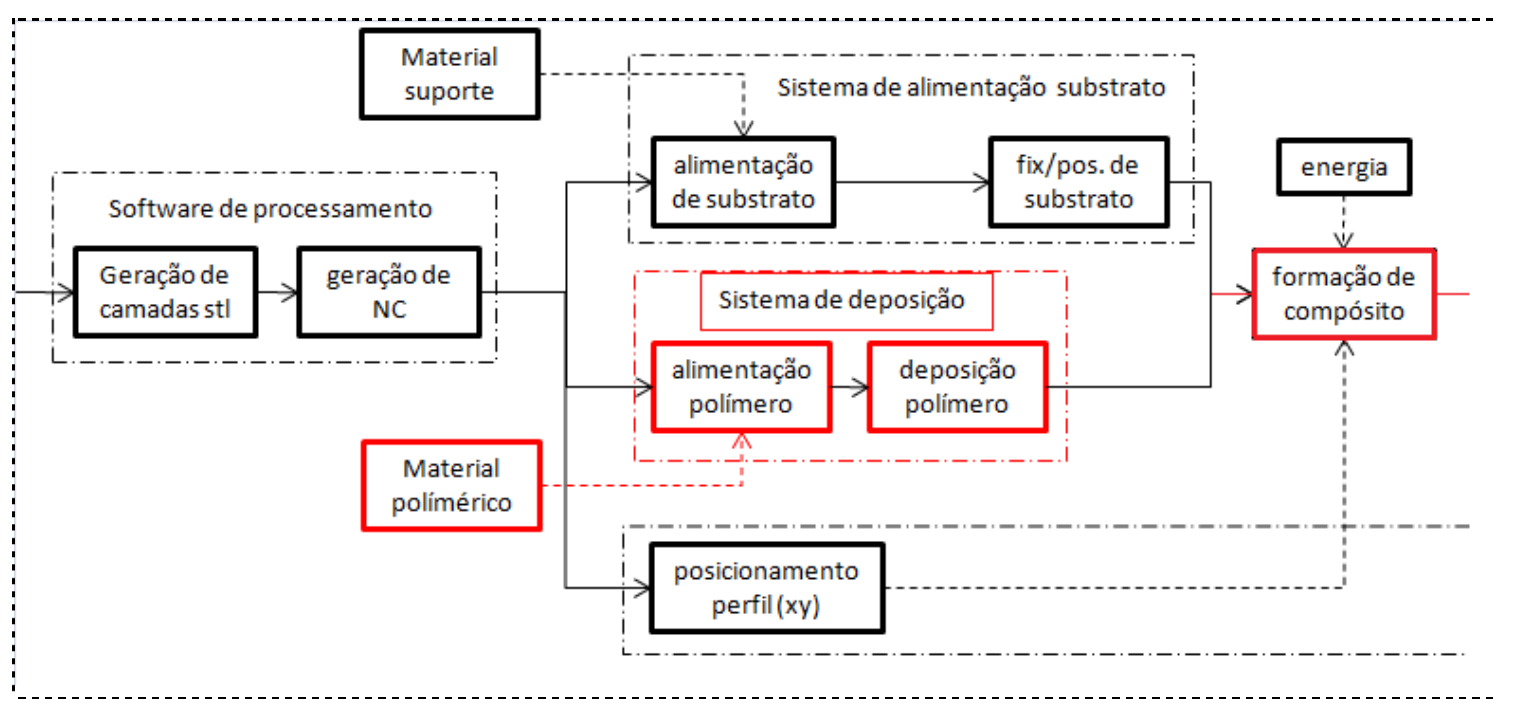

Figura 7.1 - Indicação de funções de sistema de deposição apresentado em análise funcional

Para o desenvolvimento do sistema de deposição, foi elaborada uma matriz morfológica a partir de levantamento de concepções identificadas no estado da arte, Seção 3.5. Nesta Matriz, Tabela 7.1, é apresentado um apanhado de requisitos de projeto e soluções possíveis para cada um destes. Adicionalmente, foram indicadas, nesta matriz, 4 concepções de sistema de deposição baseadas em sistemas identificados no levantamento do estado da arte. 
Tabela 7.1 - Matriz morfológica de sistema de deposição, indicando concepções e suas principais aplicações

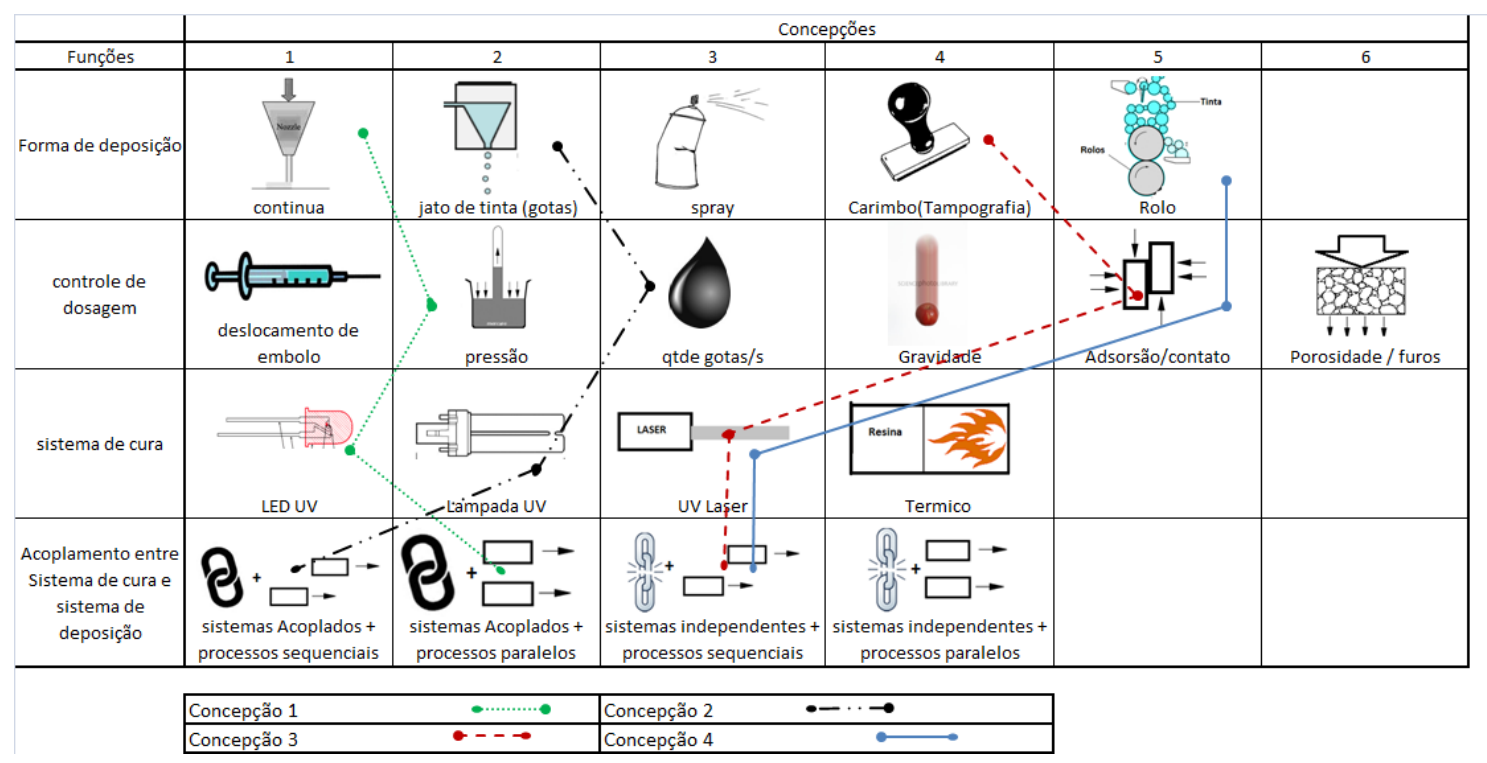

Na Figura 7.2 são apresentadas ilustrações das concepções encontradas na matriz morfológica acima apresentada. Nesta figura, "a" representa concepção 1; "b", concepção 2; "c", concepção 3; e "d", concepção 4.

A partir do levantamento destas concepções de sistema de deposição, foi elaborada uma matriz de seleção relativa (Tabela 7.2), com o objetivo de determinação da concepção a ser utilizada no projeto.

Nesta tabela, é especificada uma concepção como referência, sendo seus requisitos de projeto comparados com os das outras concepções. Nesta análise, os requisitos de projeto das concepções avaliadas são somente assinalados como melhores $(+1)$, piores $(-1)$ ou iguais (0) aos da concepção de referência. Desta forma, através da soma destes pesos, é possível determinar a concepção mais adequada para o projeto. 


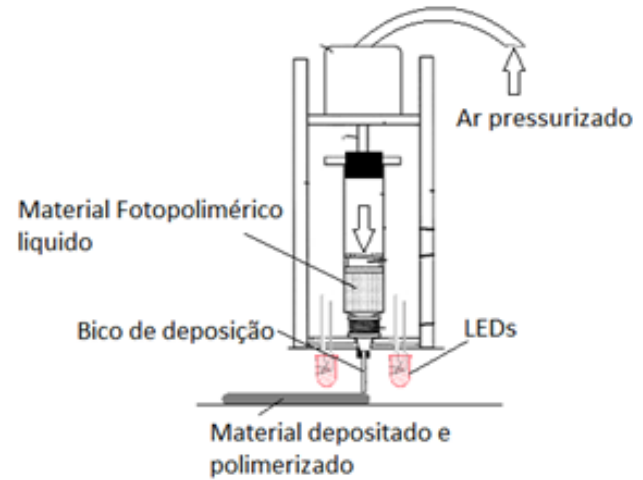

a)

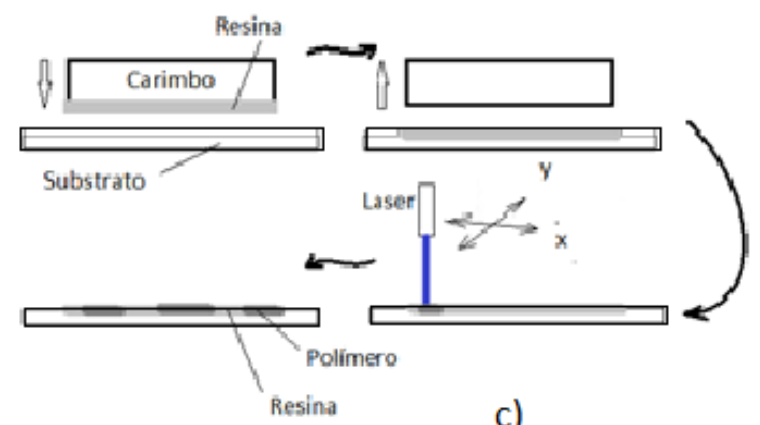

c)

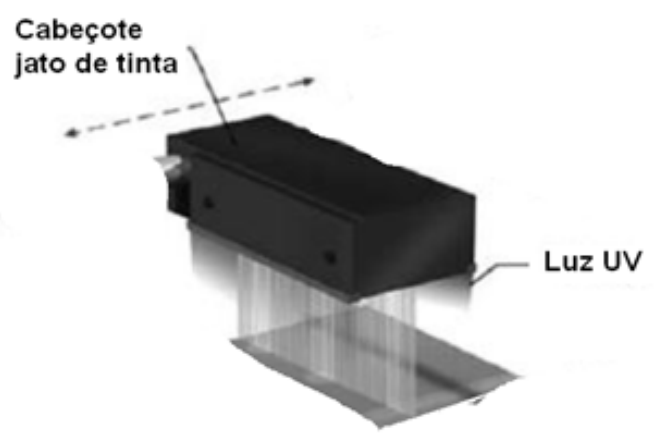

b)

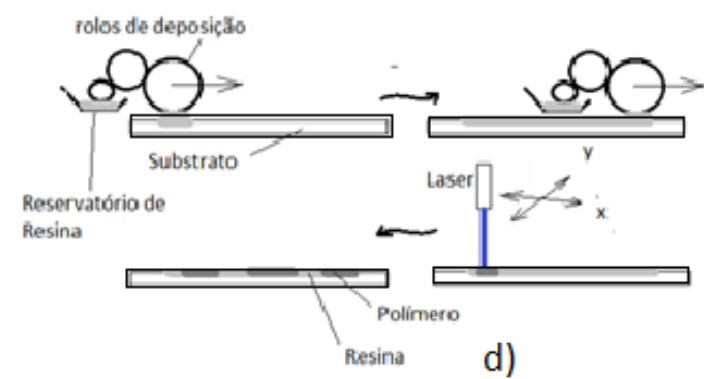

d)

Figura 7.2 - llustrações de concepções encontradas em matriz morfológica de sistema de deposição de material fotopolimérico, sendo: a) Concepção 1; b) Concepção 2; c) Concepção 3; d) Concepção 4

Neste caso, as concepções indicadas para serem empregadas no projeto foram a concepção 3 e concepção 4 . Em ambos os casos, o sistema de formação de compósito foi baseado em laser num processo posterior à deposição, enquanto ambas as formas de deposição foram do tipo de área: sendo tampografia (concepção 3) e litografia (concepção 4).

Logo, para a decisão de qual das duas concepções seriam utilizadas para validação funcional de processo proposto, a complexidade de implementação destas soluções foi empregada como critério de desempate. Assim, a tampografia (concepção 3) foi escolhida pelo fato de esta poder ser realizada de forma manual. 
Tabela 7.2 - Matriz de análise e seleção de concepções de sistema de deposição

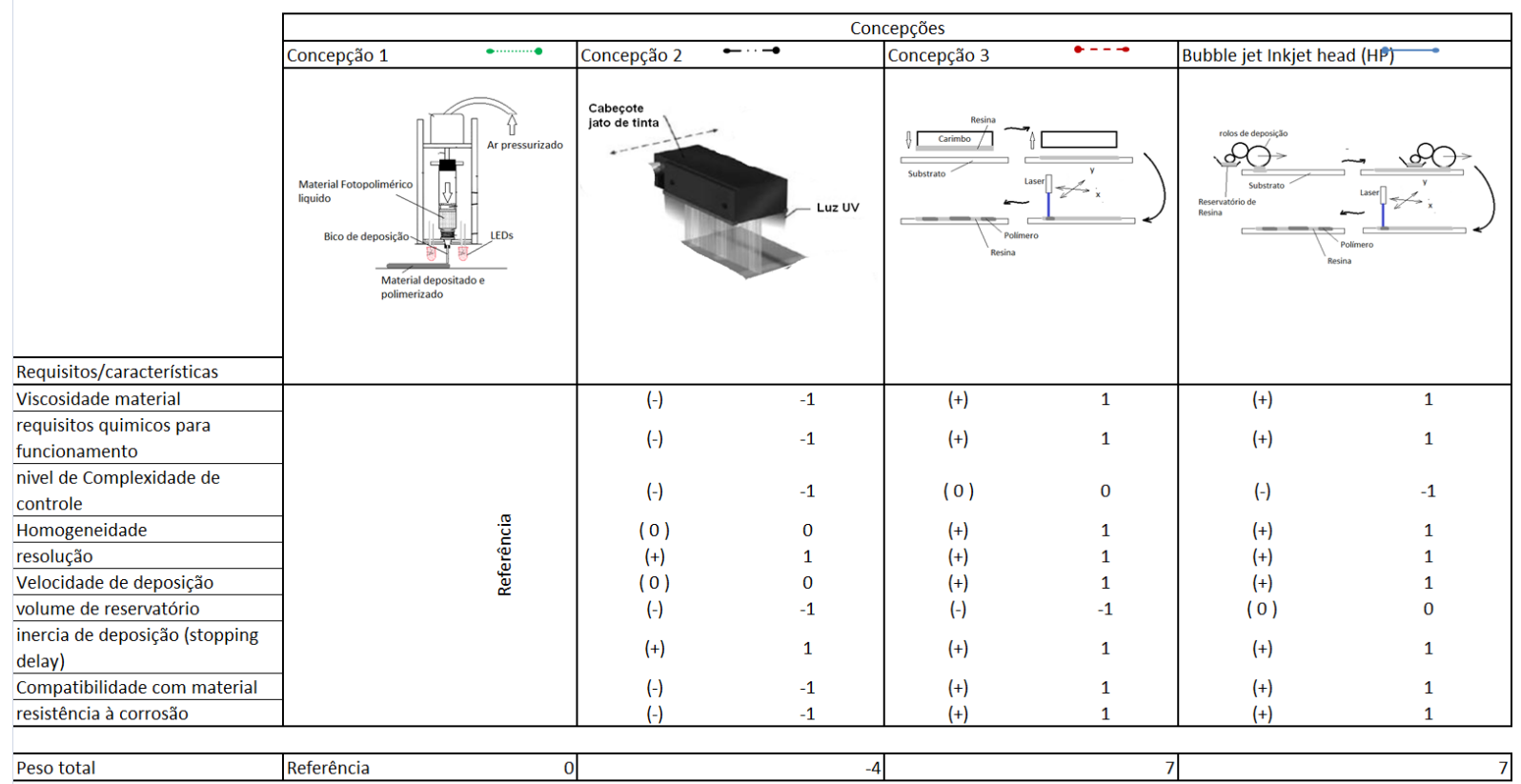

\subsection{Desenvolvimento de Sistema de alimentação de substrato}

Em relação ao sistema de alimentação de substrato, foram identificadas as funções de alimentação do substrato e fixação e posicionamento do substrato como componentes funcionais deste sistema, como pode ser observado na Figura 7.3.

Nesta figura, também é possível observar como funções de entrada, o material celulósico laminado, assim como o sinal vindo do sistema de posicionamento e controle.

Para o desenvolvimento do sistema de alimentação de substrato, foi utilizado a metodologia de criatividade chamada de matriz morfológica, tendo como conceito fundamental o levantamento de requisitos de projeto e possíveis concepções para implementação destes. 


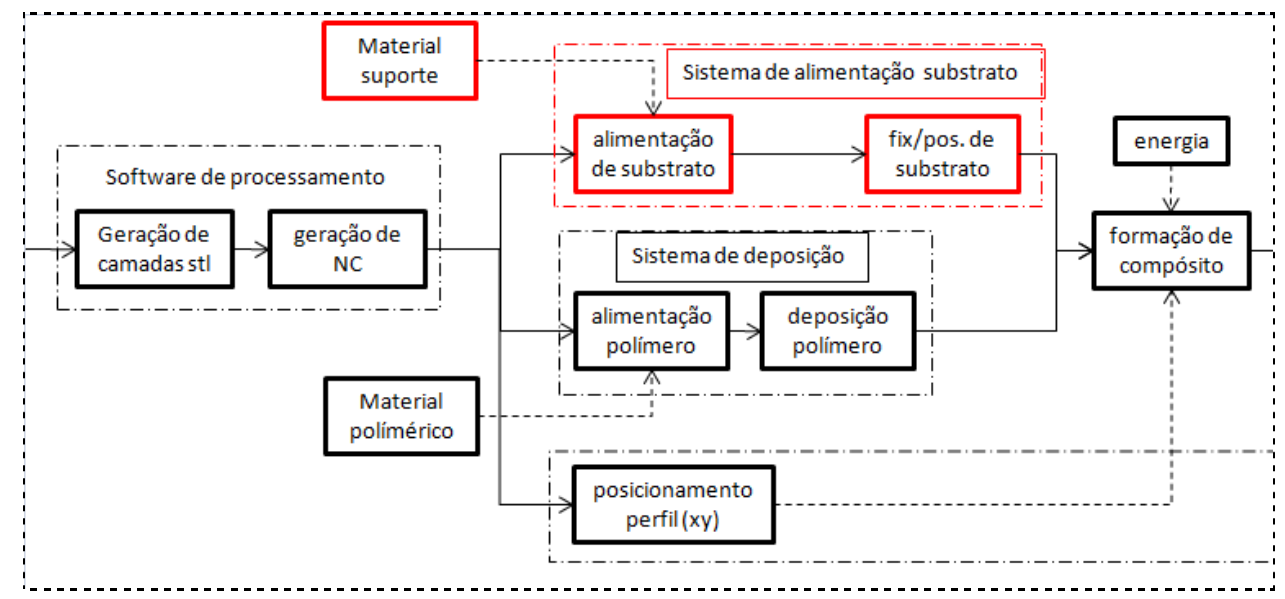

Figura 7.3 - Indicação de funções de sistema de alimentação de substrato celulósico apresentado em análise funcional

$\mathrm{Na}$ Tabela 7.3, pode-se observar a matriz morfológica do sistema de alimentação de material, onde são também indicadas concepções já empregadas em equipamentos comerciais.

Tabela 7.3 - Matriz morfológica de sistema de alimentação de substrato celulósico, indicando concepções e suas principais aplicações

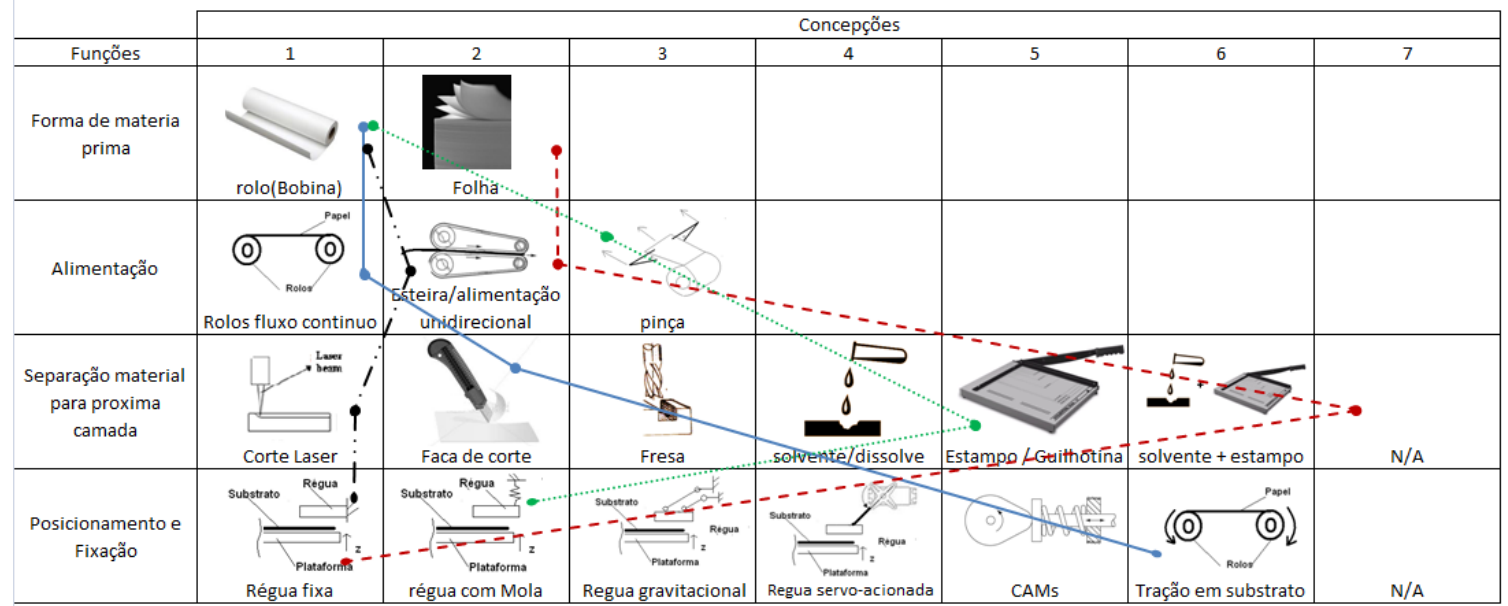

\begin{tabular}{|ll|lc|}
\hline Concepção 1 & $\bullet-$ & Concepção 2 & $\bullet \cdots \cdots \cdots \cdots \cdots \cdots$ \\
\hline Concepção 3 & $\bullet-\cdots--\bullet$ & Concepção 4 & $\bullet-\cdots-\cdots$ \\
\hline
\end{tabular}


Na Figura 7.4 são apresentadas ilustrações das concepções encontradas na matriz morfológica acima apresentada. Nesta figura, "a" representa concepção 1; "b", concepção 2; "c", concepção 3; e "d”, concepção 4.

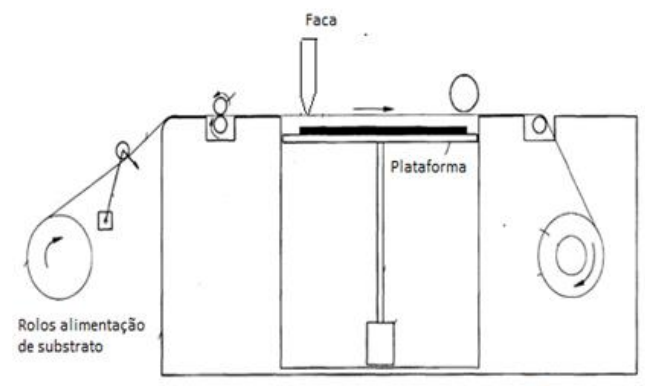

a)

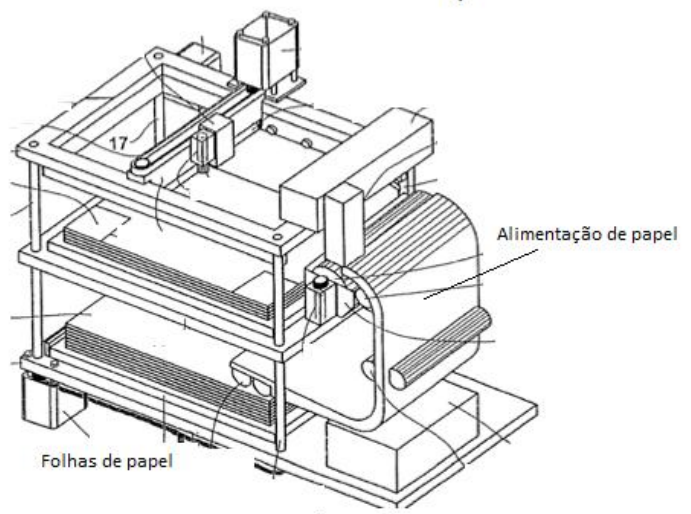

c)

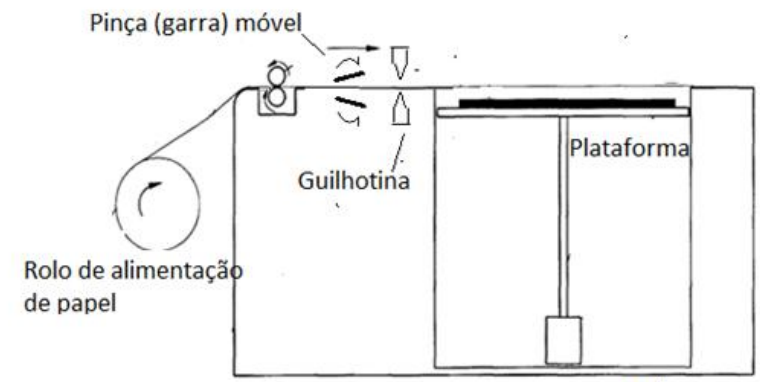

b)

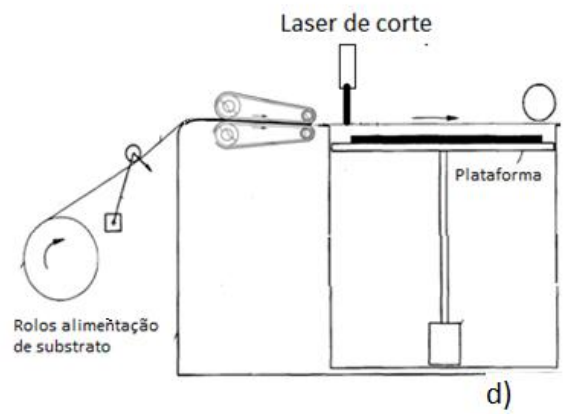

Figura 7.4 - llustrações de concepções encontradas em matriz morfológica de sistema de alimentação de substrato, sendo: a) Concepção 1; b) Concepção 2; c) Concepção 3; d) Concepção 4

A partir desta matriz morfológica, foi possível identificar 5 concepções de sistemas de alimentação de material. Sendo que para a avaliação destas concepções, foi empregada uma matriz de análise relativa, conforme apresentado na Tabela 7.4. 
Tabela 7.4 - Matriz de análise e seleção de concepções de sistema de alimentação de substrato celulósico, sendo apresentados os requisitos de projeto utilizados para seleção, assim como as ilustrações descritivas de concepções

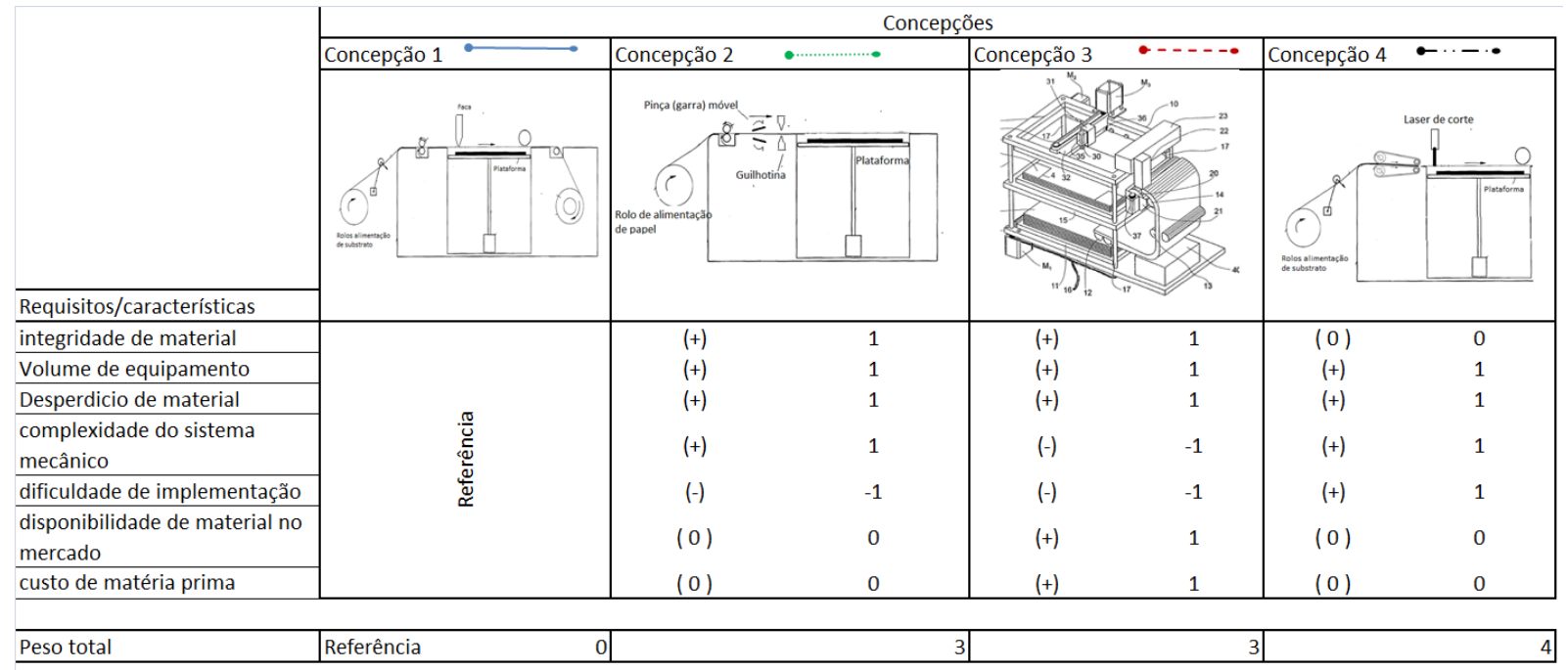

Como resposta desta análise, foi identificada a concepção 4 como a mais indicada para utilização no projeto. Esta concepção é caracterizada pelo fornecimento do material celulósico em rolo/bobina direto, enquanto a segregação do material para construção das próximas camadas é realizada por meio de corte a laser. Neste conceito, o posicionamento do substrato é garantido por régua fixa que comprime substrato em função da elevação da plataforma.

\subsection{Desenvolvimento de Sistema de posicionamento}

Com relação ao desenvolvimento do sistema de posicionamento, foram realizados estudos referentes à elaboração e seleção de concepções de equipamento, sendo, adicionalmente, determinados os elementos de máquina mais adequados para serem utilizados neste projeto. 


\subsubsection{Identificação de concepção de projeto}

Para o desenvolvimento de sistema de posicionamento, foram estabelecidas restrições de configuração de equipamento baseadas nas concepções de sistema de deposição de material fotopolimérico e sistema de alimentação de substrato.

Para manter alinhamento ortogonal de sistema de alimentação de substrato com plataforma de construção e manter distância com laser, foi definido que o deslocamento da plafaforma deve seguir o sentido de empilhamento das camadas (eixo z). Da mesma forma, a plataforma de construção deve ser fixa no sentido horizontal (eixos x e y). Com isto, permitindo que as réguas de fixação de substrato fossem fixas, de gravidade ou até mesmo de servo-acionados.

Logo, o deslocamento do laser para o processo de formação de compósito deve ser feito ao longo dos eixos x e y. Assim, foi escolhida para este projeto a concepção sistema de posicionamento apresentada na Figura 7.5. Esta concepção foi amplamente utilizada em primeiras gerações de FDM (CRUMP et al., 2009; GIBSON et al., 2010).

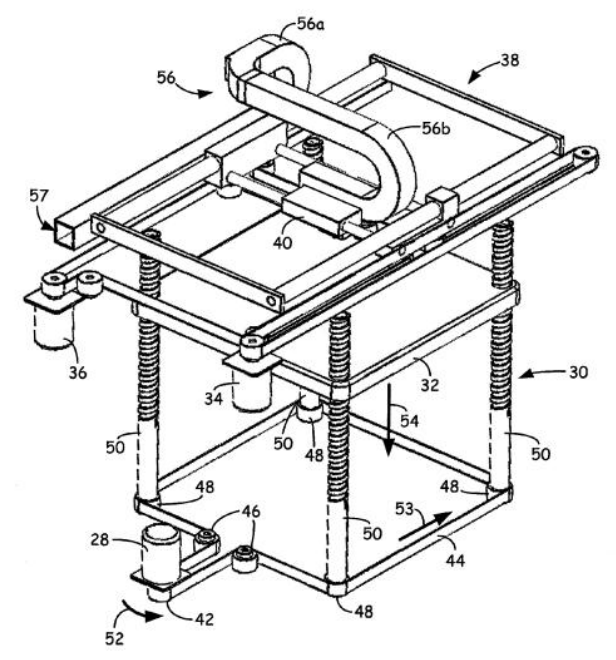

Figura 7.5 - Ilustração de concepção de sistema de posicionamento de primeiras gerações de processos FDM (CRUMP et al., 2009) 


\subsubsection{Levantamento de função de custo-tolerância}

Como critério de seleção de elementos de máquina para o sistema de posicionamento, foi realizado um estudo relacionando o tipo, custo e erro proporcionado por estes componentes. Adicionalmente, foi também identificado a relação entre custo e tolerâncias promovidas por processos de fabricação.

O objetivo principal deste estudo é de identificar as funções de custo-erro ou custo-tolerância para os principais elementos de um sistema de posicionamento, como guias de movimentação, transmissão de movimento e suportes (estrutura).

Em relação à determinação do custo dos componentes, foi realizada uma pesquisa de mercado sendo utilizado como referência o rolamento linear, para guias de movimentação, e fuso trapezoidal, para transmissão de movimento.

$\mathrm{Na}$ Tabela 7.5, pode ser observado um levantamento dos principais componentes utilizados em sistemas de posicionamento, assim como o erro geral proporcionado por estes. Adicionalmente; é também apresentada a grade de precisão destes componentes e o seu custo relativo, conforme (SLOCUM, 1992; GATES, 2006; HIWIN, 2006; 2008; THOMSON, 2009a; b; GATES, 2011). 
Tabela 7.5 - Relação de principais elementos de transmissão e guia, sendo apresentado a grade de precisão, erro geral e custo relativo proporcionado por componente

\begin{tabular}{|c|c|c|c|c|}
\hline & Elementos de Maquina & Grade de precisāo & Erro geral & Custo relativo \\
\hline \multirow{7}{*}{ 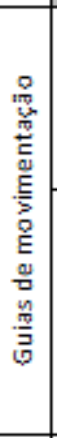 } & \multirow[b]{2}{*}{ Rolamento linear } & normal (c) & $38 \mu \mathrm{m}$ & 1 \\
\hline & & Alto $(\mathrm{H})$ & $29 \mu \mathrm{m}$ & 1.170731707 \\
\hline & \multirow[b]{5}{*}{ rfilado } & normal (c) & $17 \mu \mathrm{m}$ & 1.97597561 \\
\hline & & Alto $(\mathrm{H})$ & $12 \mu \mathrm{m}$ & 2.173658537 \\
\hline & & Precisāo (P) & $6 \mu \mathrm{m}$ & 2.498780488 \\
\hline & & Superprecisäo (SP) & $3 \mu \mathrm{m}$ & 2.999756098 \\
\hline & & Ultra precisāo(UP) & $2 \mu \mathrm{m}$ & 3.749634146 \\
\hline \multirow{6}{*}{ 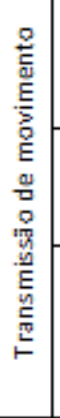 } & Fuso Trapezoidal & IT10 & $500 \mu \mathrm{m}$ & 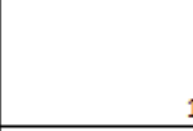 \\
\hline & Correia sincronizadora T10 + polia IT7 & ITO7 & $100 \mu \mathrm{m}$ & 1.291248207 \\
\hline & & C10 & $210 \mu \mathrm{m}$ & 1.552941176 \\
\hline & & $\mathrm{CO}$ & $52 \mu \mathrm{m}$ & 1.918425907 \\
\hline & & $\mathrm{CO5}$ & $23 \mu \mathrm{m}$ & 1.833572453 \\
\hline & Fuso de esferas recirculantes & $\mathrm{CO}$ & $12 \mu \mathrm{m}$ & 8.3 \\
\hline
\end{tabular}

Adicionalmente, foi identificada a curva de erro geral em função do custo do componente, apresentado na Figura 7.6 e Figura 7.7. A partir deste levantamento, foram determinadas as regressões exponenciais e de potência das guias de movimentação e elementos de transmissão de movimento, respectivamente. Podese observar que os mínimos quadrados destas regressões apresentaram valores superiores a 0.95 , indicando que estas curvas apresentam confiabilidade superior a $5 \%$. 


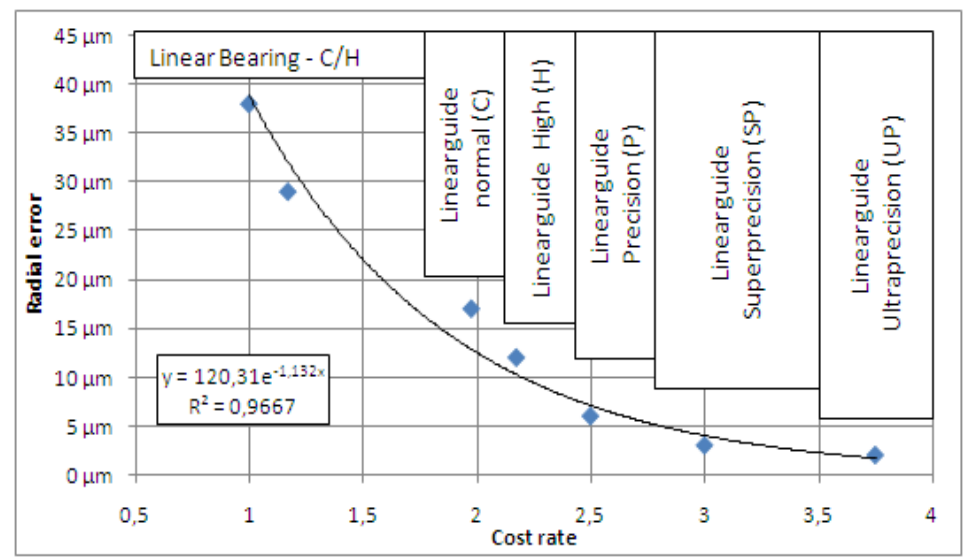

Figura 7.6 - Determinação de regressão exponencial de erro geral de guias de movimentação em função de custo de componente

Nestas figuras, podem ser também identificados os tipos de componentes em relação ao custo determinado. Desta forma, sendo possível especificar o componente conforme custo relativo.

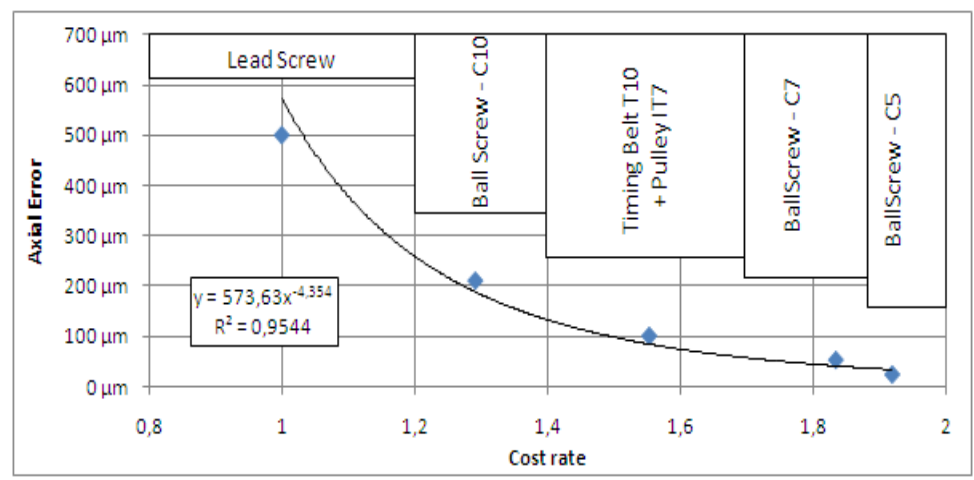

Figura 7.7 - Determinação de regressão potência de erro geral de elementos de transmissão de movimento em função de custo de componente

Por outro lado, para a determinação do custo em função da tolerância proporcionada pelo processo de fabricação, foi utilizado um modelo matemático conforme apresentado por (HU e XUE, 1994). Para este estudo, foi utilizado o modelo de reciprocidade, Equação (7.1), enquanto para a faixa de aplicação, foram estipuladas as grades de tolerância entre IT1 e IT7. 
Nesta equação, o custo é uma função da tolerância $(\delta)$, enquanto $c_{0}$ é um coeficiente de sensibilidade do modelo. Consequentemente, para a grade de tolerância de referência (IT7), este coeficiente foi determinado como $0.052 \mathrm{~mm}$. Desta forma, sendo atribuído o custo relativo de 1 para IT7.

Custo $=c_{0} \cdot \delta^{-1}$

Adicionalmente, a Figura 7.8 apresenta graficamente a curva desta função, sendo relacionada a tolerância proporcionada pelo processo de fabricação e o seu custo equivalente.

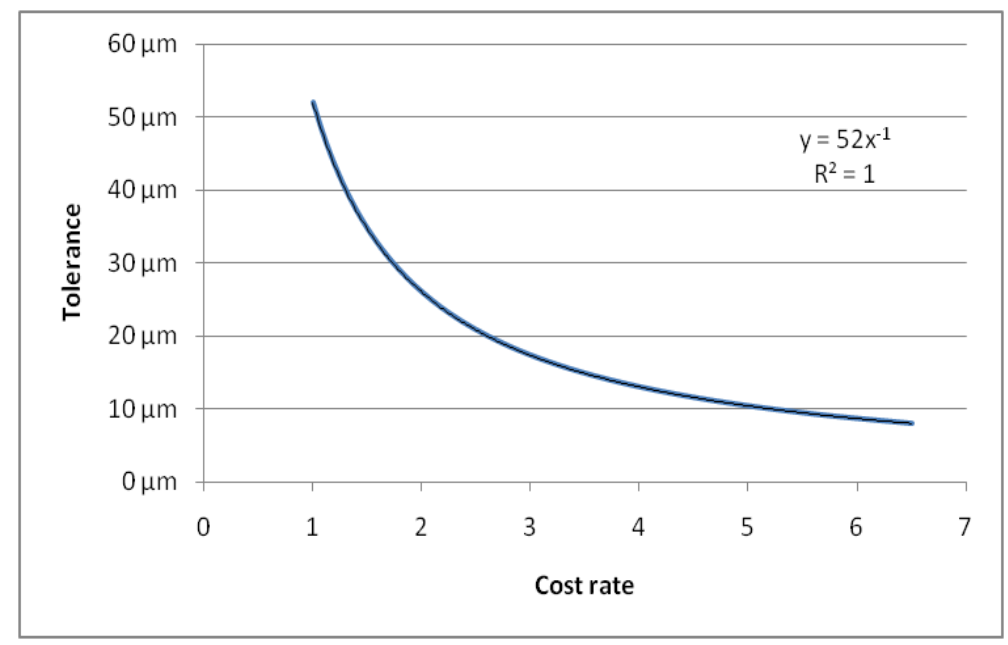

Figura 7.8 - Determinação de curva de tolerância em função do custo proporcional do processo de fabricação

Por fim, foi possível identificar um modelo matemático para a determinação do custo total do equipamento a partir dos elementos de máquina estudados. Neste modelo, apresentado na Equação (7.2), são considerados os custos referentes às guias de movimentação, componentes de transmissão de movimento e custo de fabricação de suportes e estruturas. 


$$
C_{\text {total }}=\left(C_{g_{x}} \cdot N_{a_{x}}+C_{g_{y}} \cdot N_{a_{y}}+C_{g_{z}} \cdot N_{a_{z}}\right) \cdot w_{1}+\left(C_{t_{x}} \cdot N_{b_{x}}+C_{t_{y}} \cdot N_{b_{y}}+C_{t_{z}} \cdot N_{b_{z}}\right) \cdot w_{2}+C_{m} \cdot w_{3}
$$

Sendo:

$C_{\text {total }}$ a somatória dos custo dos componentes e operações de fabricação (suportes e estrutura

$C_{g_{x}}, C_{g_{y}}$ e $C_{g_{z}}$ o custo das guias de movimentação, considerando os três eixos respectivamente

$C_{t_{x}}, C_{t_{y}}$ e $C_{t_{z}}$ o custo dos componentes de transmissão de movimento, considerando os três eixos respectivamente

$C_{m}$ o relativo às operações de fabricação

$w_{1}$ o peso relativo ao custo das guias de movimentação

$w_{2}$ o peso relativo ao custo dos componentes de transmissão de movimento

$w_{3}$ o peso relativo ao custo de fabricação

$N_{a_{x}}, N_{a_{y}}$ e $N_{a_{z}}$ a quantidade de guias de movimentação utilizadas no modelo

$N_{b_{x}}, N_{b_{y}}$ e $N_{b_{z}}$ a quantidade de componentes de transmissão de movimento utilizados no modelo

\subsubsection{Determinação de modelo matemático}

Para determinação do modelo matemático utilizado para determinação do erro final, foi empregado um modelo de estimativa de erros (SLOCUM, 1992). Neste modelo é determinado o erro final do equipamento através de transformações homogêneas (Homogeneous Transformation Matrix - HTM), conforme apresentado na Seção 3.6.3.

Para a elaboração deste modelo, foram determinados um sistema de coordenada relativo a cada eixo do equipamento, como pode ser observado na 
Figura 7.9. Nesta figura, é apresentado um esquemático dos eixos e dimensões principais de primeiras gerações de equipamentos FDM.

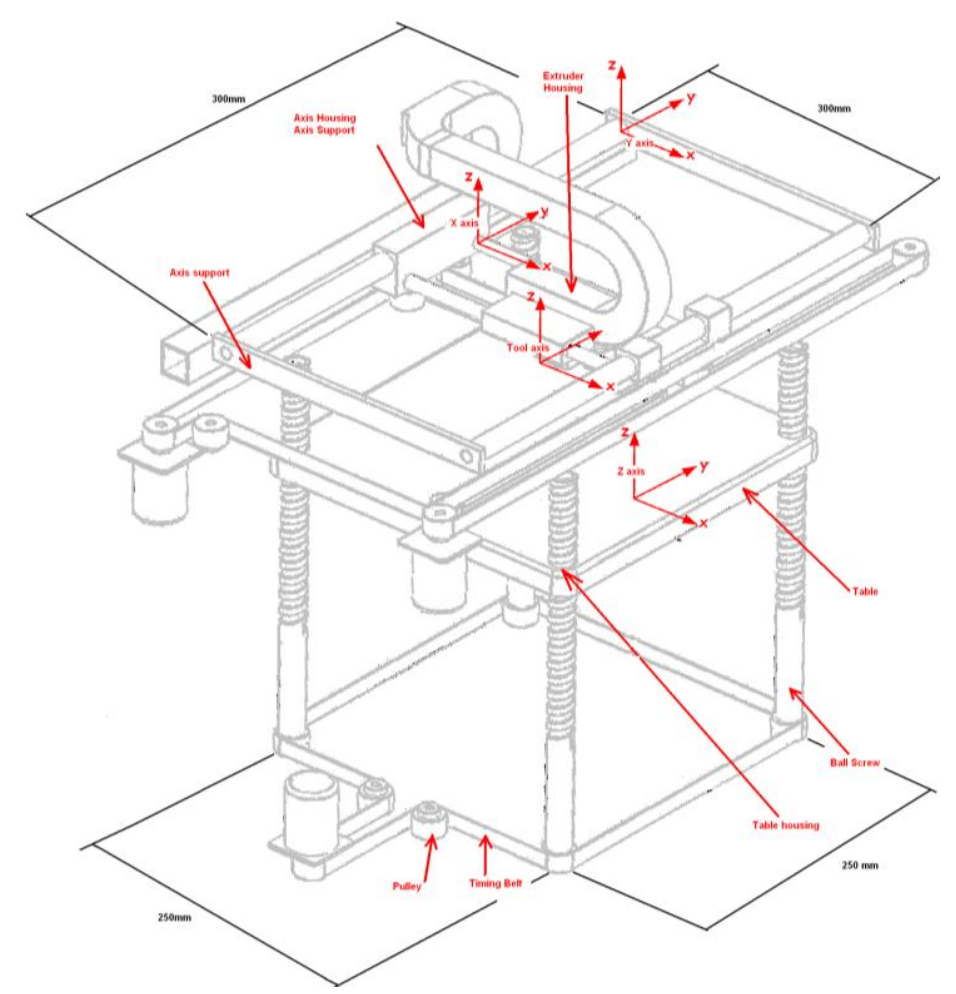

Figura 7.9 - Determinação de sistemas de coordenada para cada eixo de movimentação do equipamento de posicionamento, baseado em primeiras gerações de FDM.

Adicionalmente, esta figura também apresenta as dimensões principais do equipamento, assim como os componentes utilizados em primeiras gerações de FDM. Em adição, as dimensões apresentadas nesta figura foram inicialmente utilizadas na validação do modelo matemático, sendo equivalentes às dimensões principais do equipamento Fortus 250mc (STRATASYS, 2011).

Consequentemente, o modelo matemático obtido a partir destas determinações pode ser observado nas Equações (7.3), (7.4) e (7.5), onde são apresentadas as HTM de cada um dos eixos. 
${ }^{T} T_{x_{\text {error }}}=\left[\begin{array}{cccc}1 & -\varepsilon_{z_{1}} & \varepsilon_{y_{1}} & 150-X+\delta x_{1} \\ \varepsilon_{z_{1}} & 1 & -\varepsilon_{x_{1}} & 25+\delta y_{1} \\ -\varepsilon_{y_{1}} & \varepsilon_{x_{1}} & 1 & 50+\delta z_{1} \\ 0 & 0 & 0 & 1\end{array}\right]$

${ }^{x} T_{y_{\text {error }}}=\left[\begin{array}{cccc}1 & -\varepsilon_{z_{2}} & \varepsilon_{y_{2}} & \delta x_{2} \\ \varepsilon_{z_{2}} & 1 & -\varepsilon_{x_{2}} & 125-Y+\delta y_{2} \\ -\varepsilon_{y_{2}} & \varepsilon_{x_{2}} & 1 & -25+\delta z_{2} \\ 0 & 0 & 0 & 1\end{array}\right]$

${ }^{y} T_{z_{\text {error }}}=\left[\begin{array}{cccc}1 & -\varepsilon_{z_{3}} & \varepsilon_{y_{3}} & -150+\delta x_{3} \\ \varepsilon_{z_{3}} & 1 & -\varepsilon_{x_{3}} & -150+\delta y_{3} \\ -\varepsilon_{y_{3}} & \varepsilon_{x 3} & 1 & -25+Z+\delta z_{3} \\ 0 & 0 & 0 & 1\end{array}\right]$

Sendo, $X, Y, Z$ posições de deslocamento entre eixos; $\varepsilon_{\mathrm{X}}$, $\varepsilon_{\mathrm{y}}$ e $\varepsilon_{\mathrm{Z}}$ erros angulares e $\delta x, \delta y$ e $\delta z$ erros lineares nos sentidos $x, y, z$, respectivamente.

Adicionalmente, a Equação (7.6) apresenta a determinação do erro final do equimamento, considerando apenas erros mecânicos provenientes de problemas geométricos dos componentes.

$E_{R}={ }^{R} T_{z_{\text {error }}} \cdot{ }^{-1} T_{z} \rightarrow\left[\begin{array}{c}\delta x \\ \delta y \\ \delta z \\ 1\end{array}\right]=\left[\begin{array}{cccc}1 & 0 & 0 & X \\ 0 & 1 & 0 & Y \\ 0 & 0 & 1 & Z \\ 0 & 0 & 0 & 1\end{array}\right]^{-1}\left[\begin{array}{cccc}1 & -\varepsilon_{z} & \varepsilon_{y} & X+\delta x \\ \varepsilon_{z} & 1 & -\varepsilon_{x} & Y+\delta y \\ -\varepsilon_{y} & \varepsilon_{x} & 1 & Z+\delta z \\ 0 & 0 & 0 & 1\end{array}\right]$

\subsubsection{Validação de modelo numérico}

Com o objetivo de validação do modelo matemático, foi utilizado como referencial, o equipamento comercial Fortus $250 \mathrm{mc}$, fornecendo valores de precisão 
iguais a $\pm 127 \mu \mathrm{m}$ nos sentidos $\mathrm{x}$ e $\mathrm{y}$, e $250 \mu \mathrm{m}$ no sentido $\mathrm{z}$ (espessura de camada) (STRATASYS, 2011).

Para a determinação das tolerâncias e erros do modelo matemático, foram especificadas como componentes: Correia sincronizadora T10, polia sincronizadora IT7 com 30mm de diâmetro, fuso de esferas recirculantes de precisão C10, rolamentos lineares de precisão normal e grade de tolerância de fabricação igual a IT4. Adicionalmente, foi considerado para deterlinação do modelo matemático o ponto de zero máquina no centro da mesa de construção.

Como resultado deste estudo, foi obtido o erro geral do equipamento através do modelo matemático proposto, sendo apresentado na Tabela 7.6. Nesta tabela, torna-se possível validar o modelo matemático proposto, visto que a diferença entre os resultados obtidos e os anunciados pelo equipamento comercial é de $\pm 1 \mu \mathrm{m}$.

Tabela 7.6 - Comparativo entre erro final estimado por modelo matemático e precisão anunciado por fabricante de equipamento Fortus $250 \mathrm{mc}$ (STRATASYS, 2011).

\begin{tabular}{|c|c|c|}
\hline Direção & Erro do Modelo $(\mathrm{mm})$ & Precisão de FDM 250mc (mm) \\
\hline $\mathrm{x}$ & $-0,128$ & $\pm 0,127$ \\
\hline $\mathrm{y}$ & $-0,126$ & $\pm 0,127$ \\
\hline $\mathrm{z}$ & $-0,244$ & 0,250 \\
\hline Media & 0,166 & 0,168 \\
\hline
\end{tabular}

Desta forma, pode-se dizer que o modelo proposto é válido para a realização dos estudos apresentados neste projeto, como a determinação dos componentes do sistema de posicionamento e otimização numerica do sistema. 


\subsubsection{Otimização de sistema de posicionamento -"Cost and Error Budget"}

Com o objetivo de identificar a configuração de equipamento de posicionamento mais adequando para ser empregado neste projeto, foram realizados estudos de otimização relacionando o custo total do equipamento, assim como o seu erro final.

Para a realização destes estudos, foi empregada a metodologia de atribuição de pesos (Goal Attainment), visto que o problema de otimização pussuia múltiplos objetivos. Adicionalmente, a solução do problema foi realizado através de Newton modificado, tendo como pontos iniciais para as interações iguais aos valores de referência de guias de movimentação, componentes de transmissão de movimento e custo de fabricação (1).

Este estudo foi realizado através da ferramenta computacional Matlab, sendo o problema de otimização descrito como:

$$
\operatorname{Min} \rightarrow f(\cos t, \text { error })=C_{\text {total }} \cdot w+\text { Error } \cdot(1-w)
$$

Submetido à:

$$
\begin{aligned}
& 1 \leq C_{g} \leq 5 \\
& 1 \leq C_{t} \leq 3 \\
& 1 \leq C_{m} \leq 15
\end{aligned}
$$

Nesta otimização, foi atribuído o peso $w$ para as funções objetivo (custo e Erro), variando entre 0 e 1 . Desta forma, permitindo identificar a função de compromisso (Optimal Pareto) deste modelo matemático.

Esta otimização também considera como restrições, custo de 1 a 5 para guias de movimentação, 1 a 3 para componentes de transmissão de movimento e 1 a 15 para custo de fabricação. Adicionalmente, foi estipulado o peso de custo igual a 3 componentes de transmissão de movimento de forma a normalizar a função de custo. 
Como resultado deste estudo, foi encontrado uma media de erro final médio igual a $141.46 \mu \mathrm{m}$, considerando uma otimização balanceada. Ou seja, considerando o peso de funções objetivo iguais a 0.5 . Neste caso, o custo relativo encontrado foi de 1.59 vezes o custo mais baixo estudado, sendo possível identificar como componentes: rolamento linear de alta precisão para guias de movimentação em x e $\mathrm{y}$; fusos de esfera recirculante $\mathrm{C7}$, para componentes de transmissão de movimento em x e y; e fuso de esferas recirculantes C5 para movimentação em z. Cabe também ressaltar que esta solução proporciona um erro inferior ao erro encontrado no equipamento comercial estudado em $27 \mu \mathrm{m}$.

Adicionalmente, foi encontrada a função de compromisso deste modelo, onde são apresentados os valores de otimização conforme a variação do peso das funções objetivo. Esta curva é apresentada na Figura 7.10, sendo também apresentados os pontos de otimização balanceada $(w=0.5)$ e solução equivalente à Fortus 250mc.

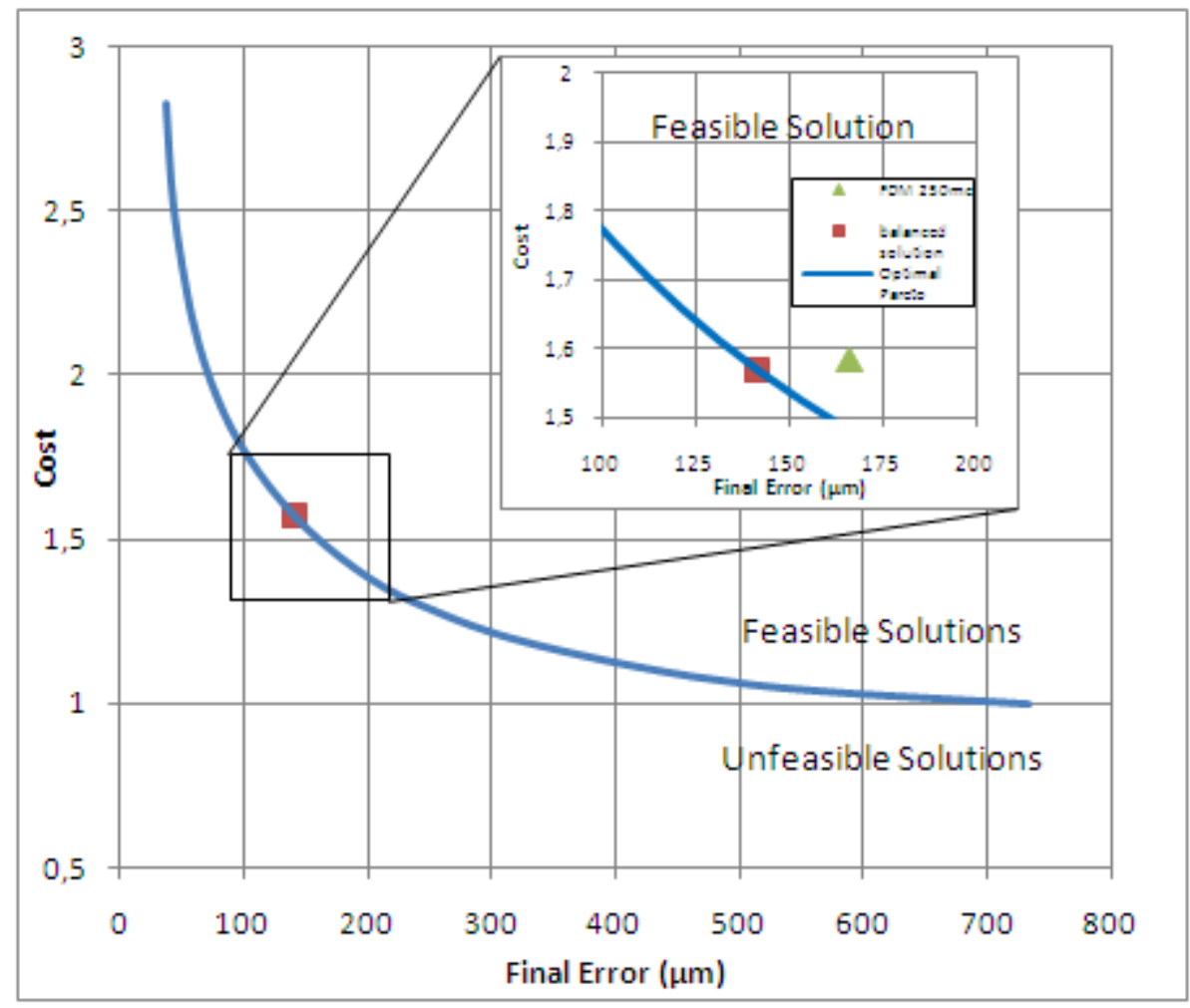

Figura 7.10 - Curva apresentando função de compromisso apresentando pontos de otimização balanceada e de concepção de Fortus 250mc 
Por outro lado, através deste estudo, foi possível identificar os componentes relativos a cada solução encontrada na função de compromisso, como pode ser observado na Tabela 7.7.

Neste caso, o erro mínimo encontrado em neste estudo é encontrado para o peso igual a 0 , onde é ignorado o custo do equipamento na otimização. Para este resultado, o valor de erro médio foi de $37.19 \mu \mathrm{m}$, proporcionando um custo de 2.83 vezes o custo da solução mais barata. A obtenção deste resultado se deve à utilização de grade de tolerância de fabricação igual a IT1, sendo utilizadas guias lineares de ultraprecisão e fusos de esfera recirculantes C5.

Tabela 7.7 - Relação de faixas de função de compromisso de estudo de otimização e elementos de máquina equivalentes

\begin{tabular}{|c|c|c|c|c|c|c|c|c|c|}
\hline Weight & \begin{tabular}{|l} 
X error \\
$(\mu \mathrm{m})$
\end{tabular} & $\begin{array}{l}\text { Y error } \\
(\mu \mathrm{m})\end{array}$ & $\begin{array}{l}\text { Z error } \\
(\mu \mathrm{m})\end{array}$ & $\begin{array}{l}\text { Average } \\
\text { Error }(\mu \mathrm{m})\end{array}$ & $\begin{array}{l}\text { Relative } \\
\text { Cost }\end{array}$ & $\begin{array}{l}\text { Manufacturing } \\
\text { Tolerance }\end{array}$ & Linear guide $x y$ & $\begin{array}{l}\text { Transmission } \\
\text { Element xy }\end{array}$ & $\begin{array}{l}\text { Transmission } \\
\text { Element } \mathrm{z}\end{array}$ \\
\hline 0 & \begin{tabular}{|l|}
$-37,38$ \\
\end{tabular} & $-36,62$ & $-37,58$ & 37,19 & 2,83 & IT1 & Linear guide (UP) & Ball screw - C5 & Ball screw - C5 \\
\hline 0,1 & $-43,09$ & $-41,94$ & $-44,45$ & 43,16 & 2,51 & IT2 & Linear guide (SP) & Ball screw - C5 & Ball screw - C5 \\
\hline 0,2 & \begin{tabular}{|l|}
$-52,85$ \\
\end{tabular} & $-51,13$ & $-71,66$ & 58,55 & 2,17 & IT2 & Linear guide $(P)$ & Ball screw - C5 & Ball screw - C7 \\
\hline 0,3 & $-63,24$ & $-60,99$ & $-109,5$ & 77,92 & 1,94 & IT3 & Linear guide $(\mathrm{C})$ & Ball screw - C5 & $\begin{array}{c}\text { Timing belt + } \\
\text { pulley IT7 }\end{array}$ \\
\hline 0,4 & $\mid-78,07$ & $\mid-75,22$ & -156 & 103,09 & 1,75 & IT4 & Linear Bearing $(\mathrm{H})$ & Ball screw - C7 & $\begin{array}{c}\text { Timing belt + } \\
\text { pulley IT7 }\end{array}$ \\
\hline 0,5 & $-105,6$ & $-102,1$ & $-216,6$ & 141,46 & 1,57 & IT4 & Linear Bearing $(\mathrm{H})$ & Ball screw - C7 & Ball screw - C10 \\
\hline 0,6 & $-140,1$ & $-135,8$ & $-294,5$ & 190,10 & 1,41 & IT5 & Linear Bearing $(\mathrm{C})$ & $\begin{array}{c}\text { Timing belt + } \\
\text { pulley IT7 }\end{array}$ & Ball screw - C10 \\
\hline 0,7 & $-176,6$ & $-171,2$ & -383 & 243,61 & 1,30 & IT5 & Linear Bearing $(\mathrm{C})$ & $\begin{array}{c}\text { Timing belt + } \\
\text { pulley IT7 }\end{array}$ & Lead Screw \\
\hline 0,8 & $-240,4$ & $-233,1$ & $-541,8$ & 338,48 & 1,18 & IT6 & Linear Bearing $(\mathrm{C})$ & $\begin{array}{c}\text { Timing belt + } \\
\text { pulley IT7 }\end{array}$ & Lead Screw \\
\hline 0,9 & $-399,3$ & $-388,3$ & $-740,9$ & 509,47 & 1,06 & IT6 & Linear Bearing $(\mathrm{C})$ & Ball screw - C10 & Lead Screw \\
\hline 1 & $|-730,8|$ & $-718,7$ & $|-751,6|$ & 733,69 & 1,00 & IT7 & Linear Bearing $(\mathrm{C})$ & Lead Screw & Lead Screw \\
\hline
\end{tabular}

A partir deste estudo, foi selecionada a concepção encontrada na otimização balanceada para ser utilizada neste estudo.

\subsection{Desenvolvimento de Sistema de Controle}

Com o objetivo de realizar o controle do sistema de posicionamento, sistema de deposição e sistema de alimentação de substrato, foram identificadas as 
principais características necessárias para atenter os requisitos levantados na especificação do projeto.

Em relação aos principais requisitos levantados, destaca-se a utilização de sistema de controle com arquitetura PC-NC, cuja forma de comunicação pode ser via porta USB ou LPT.

Desta forma, foi elaborada uma matriz morfológica de forma a relacionar os requisitos de projeto com possíveis soluções a serem implementadas. Esta matriz pode ser observada na Tabela 7.8, onde são apresentadas 3 concepções de sistemas de controle.

Tabela 7.8 - Matriz morfológica de sistema de controle, indicando concepções conforme combinações de funções exercidas pelo sistema

\begin{tabular}{|c|c|c|c|c|c|}
\hline \multirow[b]{2}{*}{ Function } & \multicolumn{5}{|c|}{ Conceitos de funções } \\
\hline & 1 & 2 & 3 & 4 & 5 \\
\hline Software de controle (PC-NC) & Turbo CNC &.$\ldots$ EMC $\ldots . \bullet$ & $\mathrm{MACH} 3$ & outros & $\ldots-\mathrm{N} / \mathrm{A}$ \\
\hline Interface de comunicação & ....... & USB.- $:=$ & $=$ irtual LPT (USB-LPT) & Ethernet-•- & $\mathrm{N} / \mathrm{A}$ \\
\hline Interface de controle & \multicolumn{2}{|c|}{ Fontrole direto (transistorespitrole indireto (PI) } & CNC Controler & $--\cdots$ & \\
\hline $\begin{array}{l}\text { Acionamento de sistema de } \\
\text { posicionamento }\end{array}$ & PWM (motores DC) & $\begin{array}{c}\text { Passo complete } \\
\text { (motores de } \\
\text { passo) }\end{array}$ & $\begin{array}{l}\text { Passo Fracionado } \\
\text { (motores de pasșo) }\end{array}$ & N/A & \\
\hline Realimentação & Encoder linear & Encōoder rangułaf & $\because \because$ - resolver & $\mathrm{N} / \mathrm{A}$ & \\
\hline onamento de sistema de deposiç & Relê/Solenoide & microcontrolador & $\ldots-P-\overline{M A}==0$ & cionamento manu & N/A \\
\hline Acionamento de lâmpada/LED & Relê & - $\cdots$-Tiristor $\cdots$ & manual & $\mathrm{N} / \mathrm{A}$ & \\
\hline namento de alimentação de subs & Selê+drives independentes & microcontrolador & 9, PWM & ciohamento manu & $\mathrm{N} / \mathrm{A}$ \\
\hline Sistema auxiliar de controle & Quadro eletrico/drives & crocontrolador (P) & $\bullet \bullet \quad C L P$ & $\therefore \quad N / A$ & \\
\hline $\mathrm{CP} 1$ & $\bullet \cdots \rightarrow$ & CP 2 & $\bullet--\bullet$ & CP 3 & $\bullet \cdots \cdots \cdots \cdot \bullet$ \\
\hline
\end{tabular}

Entre as opções apresentados nesta tabela, cabe destacar a dependência entre formas de acionamento, interfaces de comunicação, sistemas de realimentação e software de controle.

A partir da determinação de concepções de sistema de controle realizado por meio deste método de criatividade, foi possível analisar e identificar a solução mais adequada para ser empregada neste trabalho.

Esta análise foi realizada por meio de uma matriz de análise e seleção relativa, sendo escolhida como concepção de referência a concepção 1, como pode ser observado na Tabela 7.9. Nesta tabela, são também apresenta como requisitos de 
projeto, custo relacionados à implementação, robustez do sistema, presisão proporcionada, flexibilidade de alteração de parâmetros de processo e tipos de acionamento. Adicionalmente, esta matriz também utiliza como critério de seleção a velocidade máxima proporcionada pelo sistema e portabilidade do equipamento, assim como a função de monitoramento do processo em tempo real.

Tabela 7.9 - Matriz de análise e seleção de concepções de sistema de controle, sendo apresentados os requisitos de projeto utilizados para seleção, assim como as ilustrações descritivas de concepções

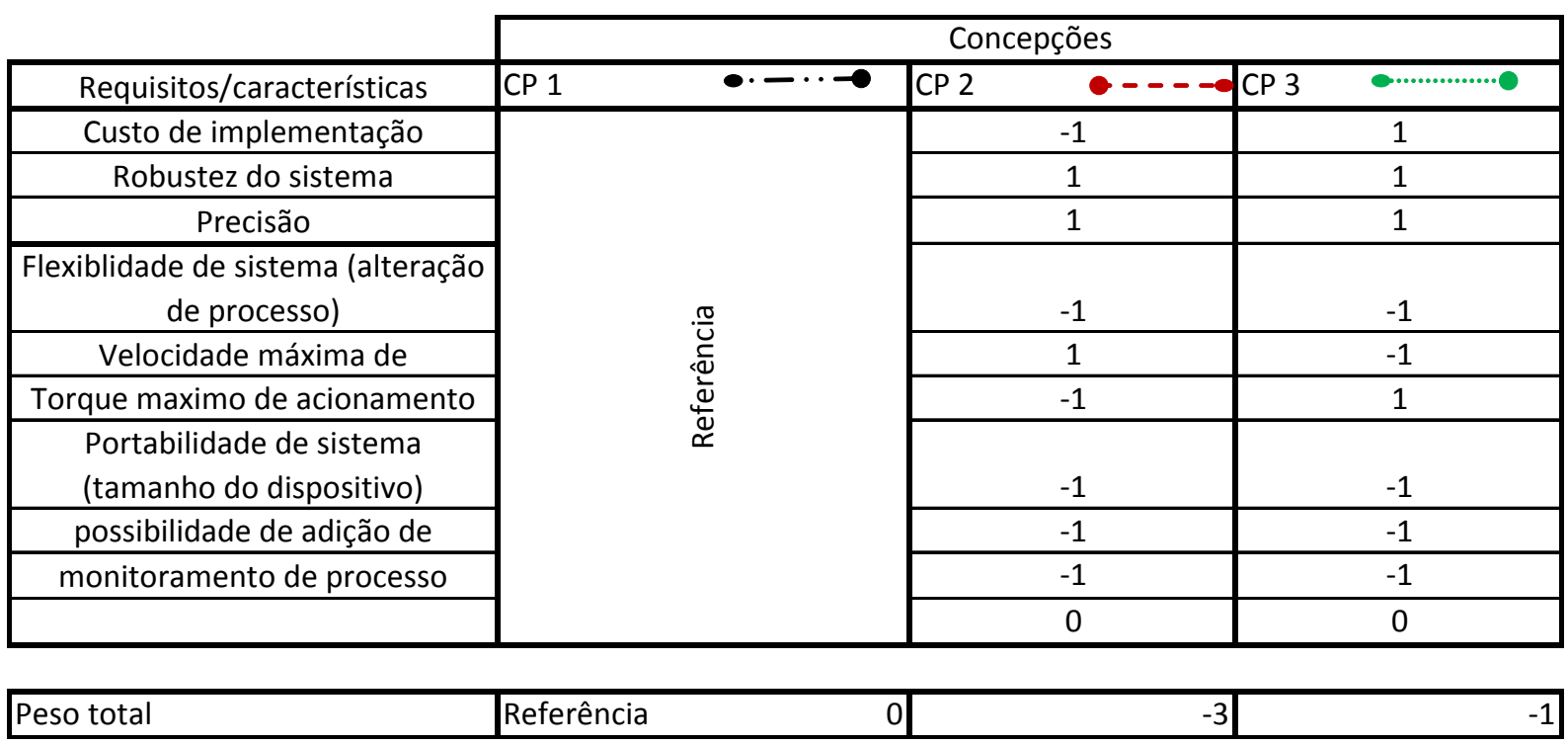

Como resultado desta análise, foi possível observar que, conforme critérios apresentados nesta tabela, a concepção de referência ( concepção 1) foi indicada como a mais adequada para ser utilizada neste projeto.

A partir da determinação desta concepção, foi possível desenvolver os principais sub-sistemas que compõem o controle do equipamento, como o controle do sistema de posicionamento e controle de processo.

Com relação ao controle do sistema de posicionamento, foi utilizado um drive virtual para simular a porta paralela do computador pessoal (porta LPT), proporcionando com que comunicação entre computador e interface de controle NC fosse realizada através de porta USB. 
Desta forma, sendo possível utilizar o programa TurboCNC como software de controle PC-NC do equipamento. Adicionalmente, este programa permite o controle de motores de passo de forma direta e fracionada, cujo acionamento é realizado através de drives de controle. Adicionalmente, foi utilizado um interface de controle que permitisse o acionamento de até 6 dispositivos através de relê, como pode ser observado na Figura 7.11.

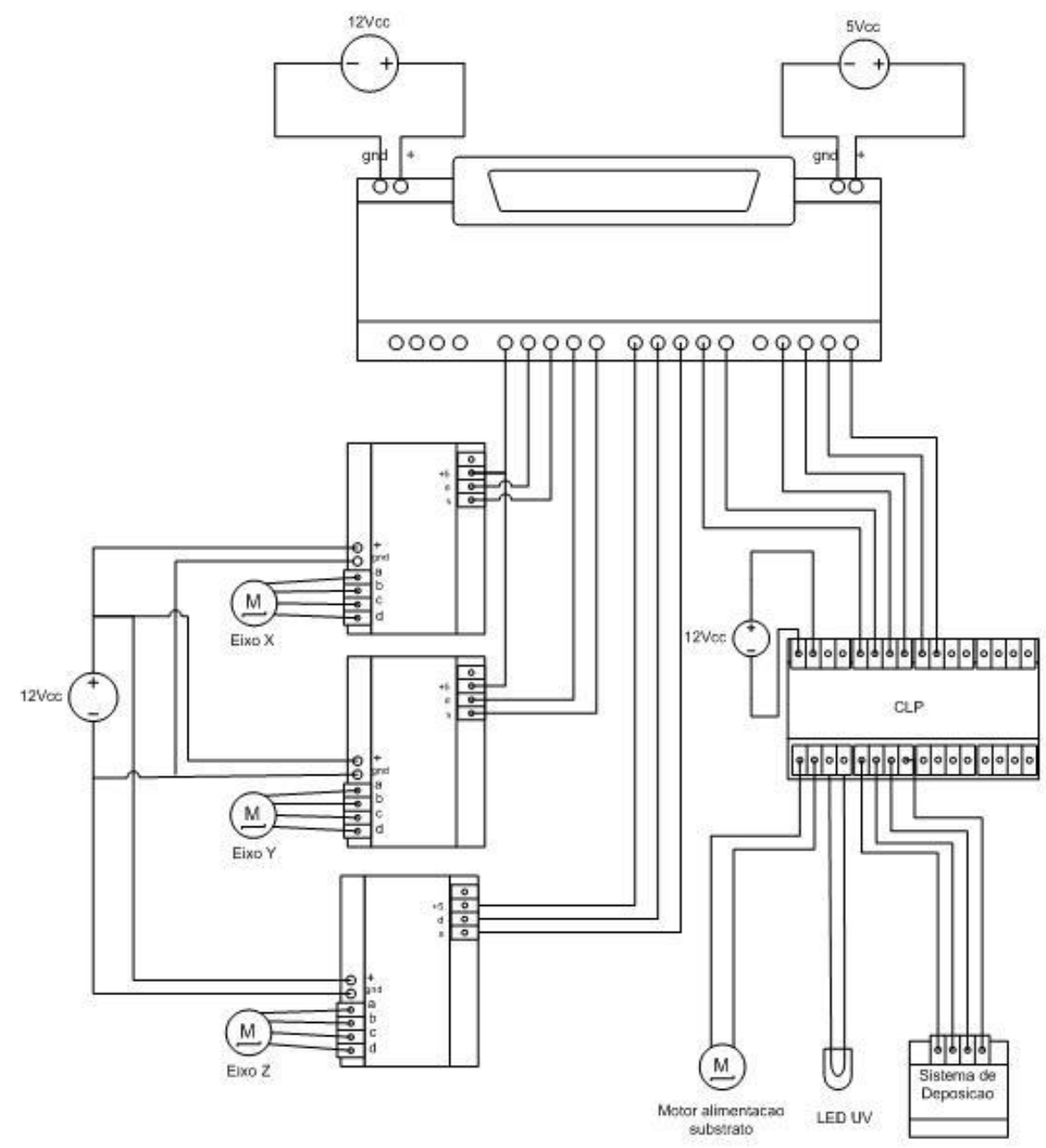

Figura 7.11 - Layout de interface de controle de sistema de posicionamento

Com o objetivo principal de permitir o monitoramento do processo, assim como a flexibilidade do processo, foi utilizado um CLP para realização do acionamento de sistema de alimentação de substrato e sistema de deposição, assim como controle temperatura, entre outros. 
Para a implementação deste projeto, foi escolhido um CLP com 12 entradas analógicas, 14 entradas digitais e 8 saidas digitais, (CLP APB 22MRDL) (ANNELECTRICS, 2011).

Com relação à linguagem de programação PC-NC, optou-se por modificar a linguagem ISO G de forma adequar a linguagem à aplicação em questão. Na Tabela 7.10, é apresentada uma relação de códigos e seu as respectivas funções na máquina.

Tabela 7.10 - Relação de comandos de acionamento de equipamento e suas funcionalidades

\begin{tabular}{|c|l|}
\hline G91 & Define deslocamento relativo \\
\hline G90 & Define deslocamento absoluto \\
\hline G71 & Define sistema métrico \\
\hline M03 & Liga fonte luminosa (Laser 20mW ou 100mW) \\
\hline M05 & Desliga fonte luminosa \\
\hline M70 & Desativa rotina do CLP deposição e alimentação de material) \\
\hline M71 & Aiva rotina do CLP (deposição e alimentação de material) \\
\hline G04 & Liga tempo de espera \\
\hline P & Determina tempo de espera em segundos \\
\hline G00 & Deslocamento em velocidade máxima \\
\hline G01 & Deslocamento de cabeçote \\
\hline F & Determina velocidade de deslocamento do laser mm/min \\
\hline
\end{tabular}

\subsection{Projeto Preliminar de Equipamento}

Para a validação do processo proposto neste trabalho, fez-se necessário o desenvimento e implementação de um projeto funcional preliminar (equipamento protótipo). Desta forma, sendo possível a identificação de viabilidade funcional e caracterização preliminar do processo. 
Com relação ao sistema de posicionamento, utilizou-se o os parâmetros de projeto encontrados no resultado ótimo balanceado do estudo de otimização de sistema de posicionamento (Secção 7.3.5).

Para a composição da estrutura do equipamento, foram empregados perfis extrudados de alumínio, permitindo a fixação dos mancais e suportes dos sistemas de forma rápida, modular e ainda mantendo tolerância geral inferior a $0,7 \mathrm{~mm}$ e de planicidade inferior a $0,3 \mathrm{~mm}$.

$\mathrm{Na}$ Figura 7.12, é apresentado o desenho isométrico de projeto preliminar que foi desenvolvido para a validação deste trabalho. Nesta figura, é apresentado o layout dos os principais elementos que constituem a proposta de equipamento, como por exemplo: a plataforma de construção, suporte de laser de polimerização, reservatório de material fotopolimérico, sistema de alimentação de substrato; rolo de substrato (papel) e régua de posicionamento e fixação de substrato.

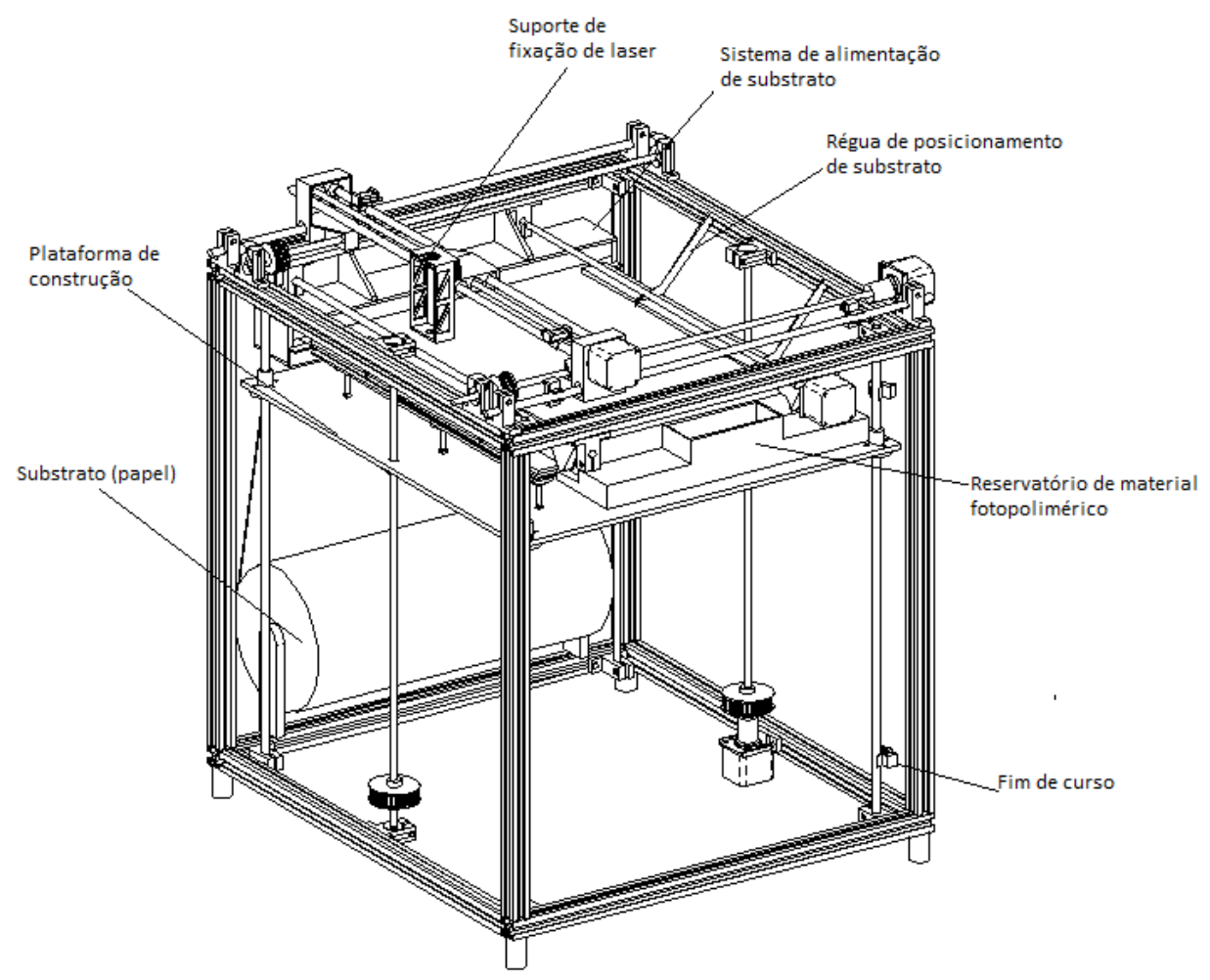

Figura 7.12 - Vista isométrica de projeto preliminar de equipamento protótipo 
Com relação às principais etapas deste processo, a Figura 7.13 apresenta um fluxograma relacionando o fluxo de operação do processo proposto. Cabe destacar que a cada camada, é utilizada uma trajetória especifica relativa à secção transversal do objeto. Adicionalmente, os processos relacionados à alimentação de substrato e deposição de material são controlados por CLP, enquanto a formação seletiva de compósito e o recuo de plataforma, por controlador PC-NC.

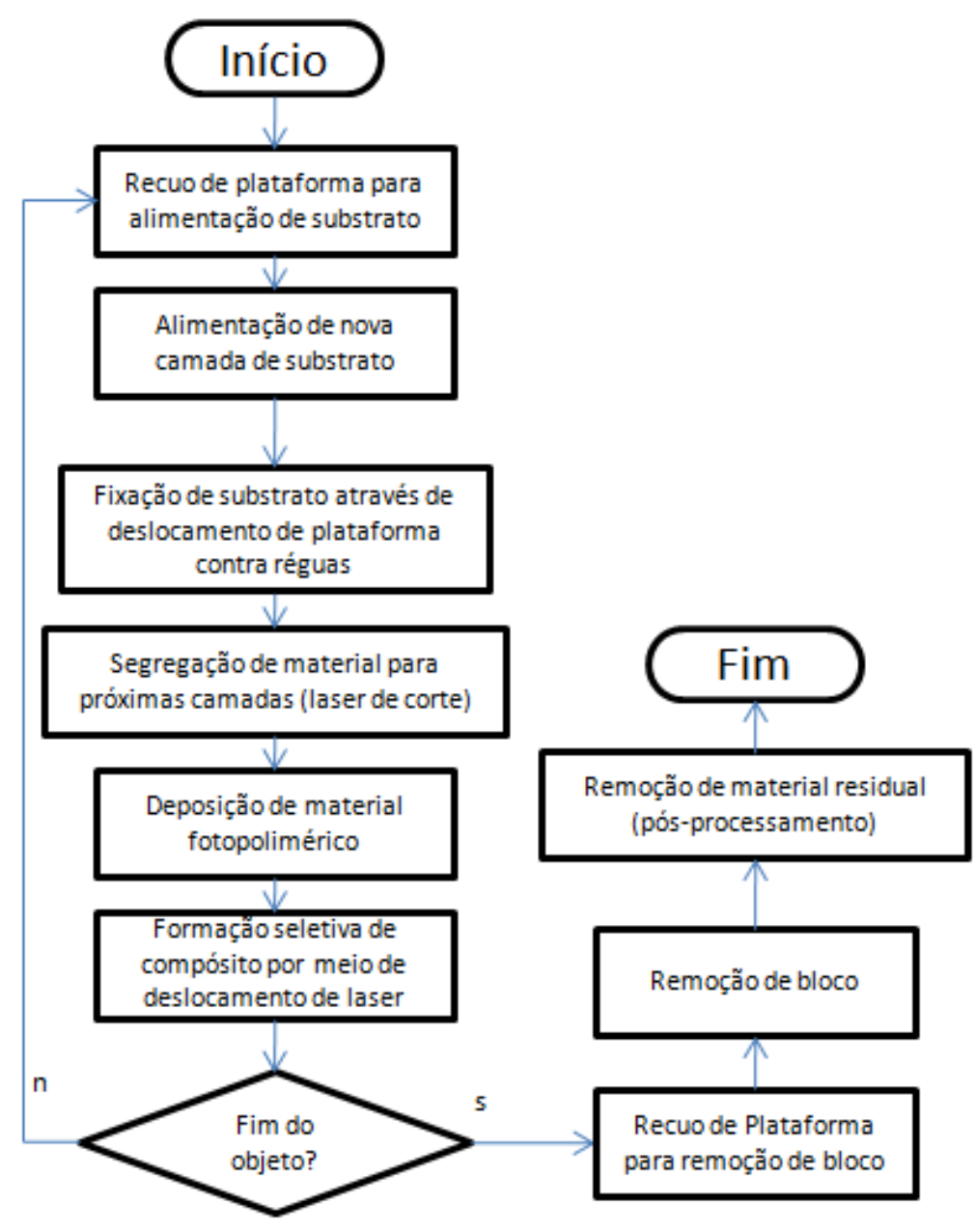

Figura 7.13 - Fluxograma de funcionamento de proposta de processo

\subsubsection{Sistema de Posicionamento}

Para implementação e validação do projeto, o sistema de posicionamento do projeto preliminar (equipamento protótipo) foi composto de um sistema de 
movimentação do laser dependente, linear e ortogonal nas direções X, Y. Enquanto ao longo do eixo Z, a plataforma de construção se movimenta independentemente aos outros eixos.

Adicionalmente; o desenho isométrico deste sistema, assim como suas principais medidas, pode ser observado na Figura 7.14.

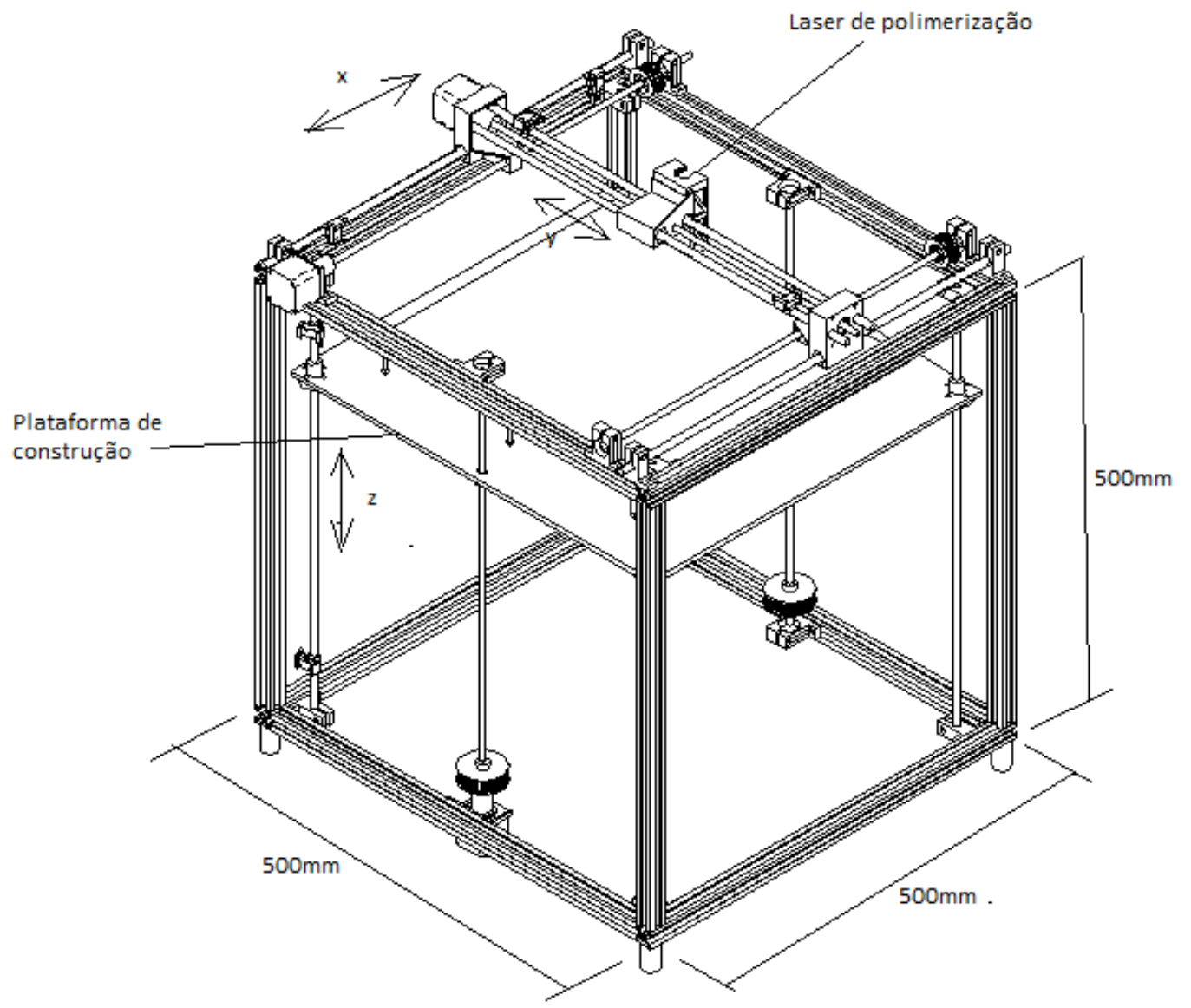

Figura 7.14 - Vista isométrica do sistema de posicionamento do projeto preliminar de equipamento protótipo

Para a movimentação no eixo X, foram empregados 2 fusos de esferas de C10 e 2 eixos lineares (IT 08), sendo utilizado um par de cada lado do eixo de movimentação em Y. O objetivo deste recurso é de diminuir o erro de ortogolalidade entre eixos $X$ e $Y$ dinâmicamente e quase-estaticamente, implicando 
consequentemente na redução dos erros lineares em $X(\delta x)$ e angulares em $Z(\Theta z)$. Neste caso, o sincronismo dos 2 fusos foi realizado por meio de correia sicronizadora T10.

Com relação à movimentação ao longo de $\mathrm{Y}$, foi foram utilizados 2 eixos lineares e 1 fuso de esferas de C10 centralizado, evitando a incidência de erros lineares em $Y(\delta y)$ e angulares em $Z(\Theta z)$. Desta forma, os erros de posicionamento do suporte de laser de polimerização são reduzidos, visto que este sistema de posicionamento em X e Y permite, adicionalmente; a calibração de ortogonalidade e linearidade.

Já o sistema movimentação ao longo de Z consiste no deslocamento da plataforma de construção por meio de 2 fusos de esferas de C10 e 4 eixos lineares (IT 08). Neste caso, o sistema de movimentação é composto por 2 sistemas de deslocamento linear, sendo cada sistema composto de 2 eixos posicionados nas extremidades da plataforma com 1 fuso centralizado. Desta forma, evita-se a incidência de erros de ortogonalidade entre $Z$ e $X Y$. Ou seja, erros angulares em $X$ (Өx) e $Y(\ominus y)$ e lineares em Z (סz).

Perante a ausência de forças resultantes do processo sobre os eixos, como forças de corte, foi optado por utilizar motores de passo híbridos, que são extremamente compactos que proporcionam torque 1.7N.m. Em adição, o acoplamento entre eixo de motor e fuso foi proporcionado por acoplamento flexível, permitindo a compensação de um possível desalinhamento entre eixo de motor e fuso.

\subsubsection{Plataforma de Construção}

Ao considerar que processos de manufatura aditiva se baseiam principalmente em sistema CNC de 2 eixos e meio, a planicidade da plataforma de construção se torna um dos pontos mais cruciais no projeto do equipamento.

Com objetivo de garantir esta planicidade, a plataforma de construção foi dividida em 2 níveis, sendo a movimentação realizada num nível e o empilhamento 
de camadas em outro. Este conceito pode ser observado na Figura 7.15, onde são expostos os principais elementos da plataforma de construção.

Neste caso, plataforma de construção é fixada na plataforma de movimentação por meio de um sistema de nivelamento constituído por 9 apoios. Cada um dos apoios é composto de: sapata de posicionamento, parafusos de nivelamento, porca de nivelamento e contraporca.

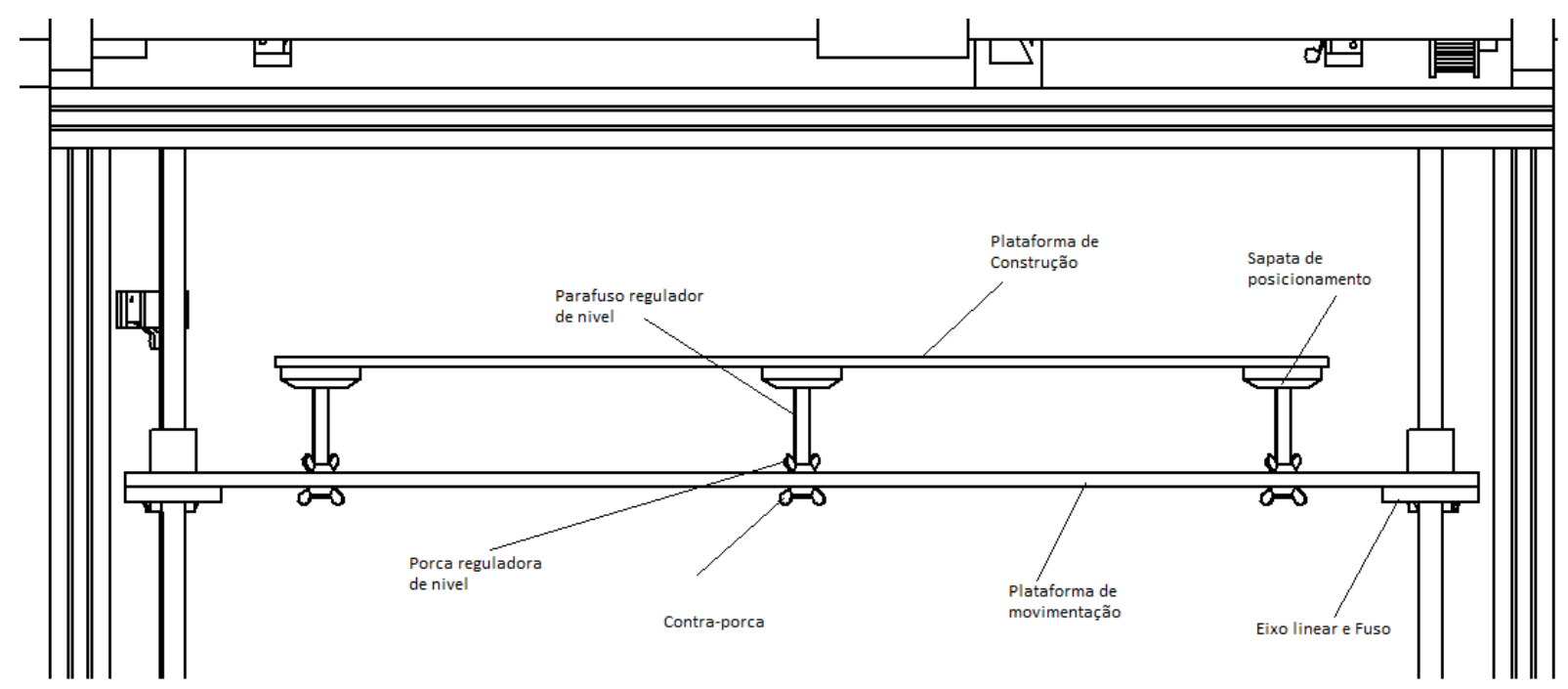

Figura 7.15 - Vista frontal de sistema de regulagem de nível e calibração de plataforma de construção do projeto preliminar de equipamento protótipo

Adicionalmente, este conceito permite que sistemas de deposição de material fotopolimérico, régua de fixação de substrato e sistema de alimentação de substrato sejam posicionados mais próximos da plataforma de construção. Da mesma forma, sensores de fim de curso são acionados pela plataforma de movimentação, não interferindo na plataforma de construção. 


\subsubsection{Suporte do laser de polimerização}

Com relação ao suporte do laser de polimerização, foi elaborado um conceito de suporte que permitisse o emprego em diversos lasers de diodo e vários diâmetros de feixe, conforme apresentado na Figura 7.16.
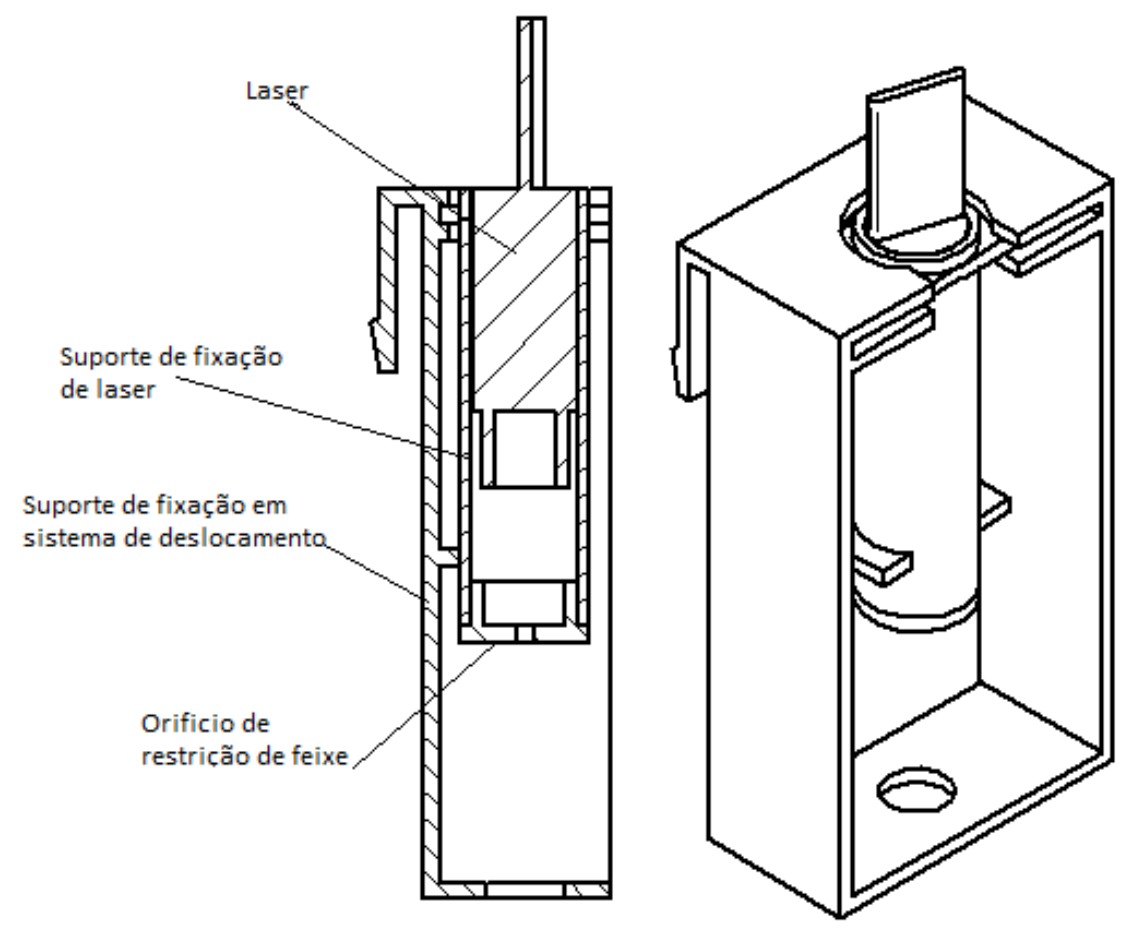

Figura 7.16 - Desenho esquemático de suporte de laser de polimerização do projeto preliminar de equipamento protótipo

Neste conceito, além de um suporte de fixação de laser de diodo, foi estabelecida a utilização de um elemento de restrição de feixe de laser por orifício para controle do diâmetro de feixe de laser de saída.

Nesta figura, são também apresentados os principais elementos deste sistema, podendo ser utilizados lasers de 20mW (SHARP, 2006) e 100mW (SHARP, 2007) e o orifícios de restrição de feixe de laser de $\varnothing 2 \mathrm{~mm}$ e $\varnothing 4 \mathrm{~mm}$. Desta forma, permitindo a realização de estudo de identificação dos efeitos de intensidade de laser (múltiplos lasers) e diâmetro de feixe de laser (restrição por orifício) para o processo. 


\subsubsection{Sistema de Alimentação de Substrato}

Com relação ao sistema de alimentação de substrato, este foi dividido em 3 funcionalidades principais: a alimentação de substrato; o posicionamento e fixação do substrato; e a segregação de substrato para futuras camadas.

Na Figura 7.17, pode-se observar um esquemático das réguas de fixação de substrato. Logo, para todas as camadas construídas, haverá margens sem material residual. As réguas são fixas na estrutura do equipamento, sendo compostas de acrílico, em sua maioria, e álcool polivinilico (PVA) na interface com substrato.

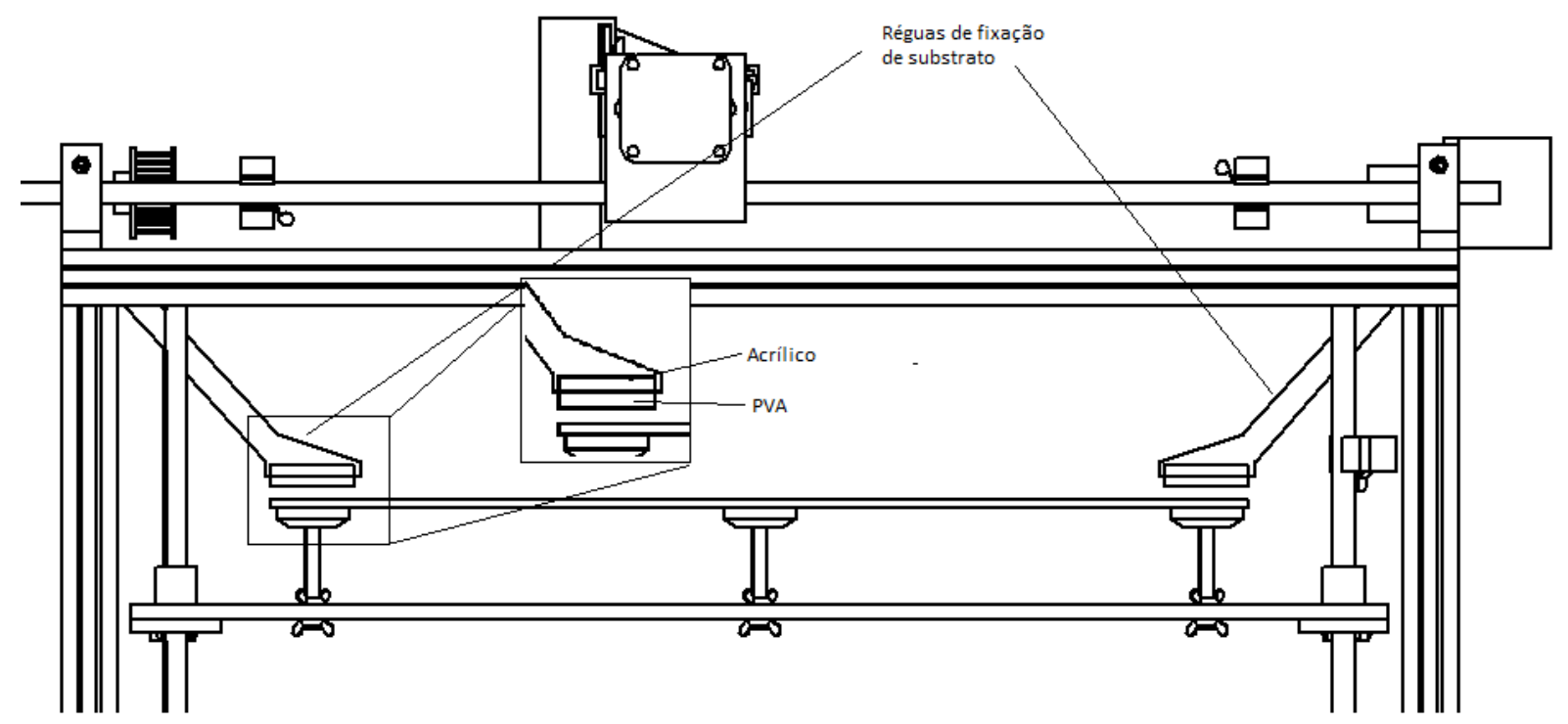

Figura 7.17 - Desenho esquemático de réguas de posicionamento e fixação de substrato do projeto preliminar de equipamento protótipo

O princípio de funcionamento deste sistema consiste na compressão do substrato contra as réguas e plataforma de construção devido à movimentação da plataforma. Logo, ao término de cada camada, a plataforma de construção recua, permitindo a alimentação da próxima camada. Da mesma forma, em cada começo 
de construção de camada, a plataforma se desloca comprimindo o substrato contra as réguas de fixação.

O sistema de alimentação, apresentado no esquemático da Figura 7.18, consiste em duas esteiras de borracha, que comprimem e movimentam o substrato vindo do rolo de papel (posicionado no inferior do equipamento) para a plataforma de construção.

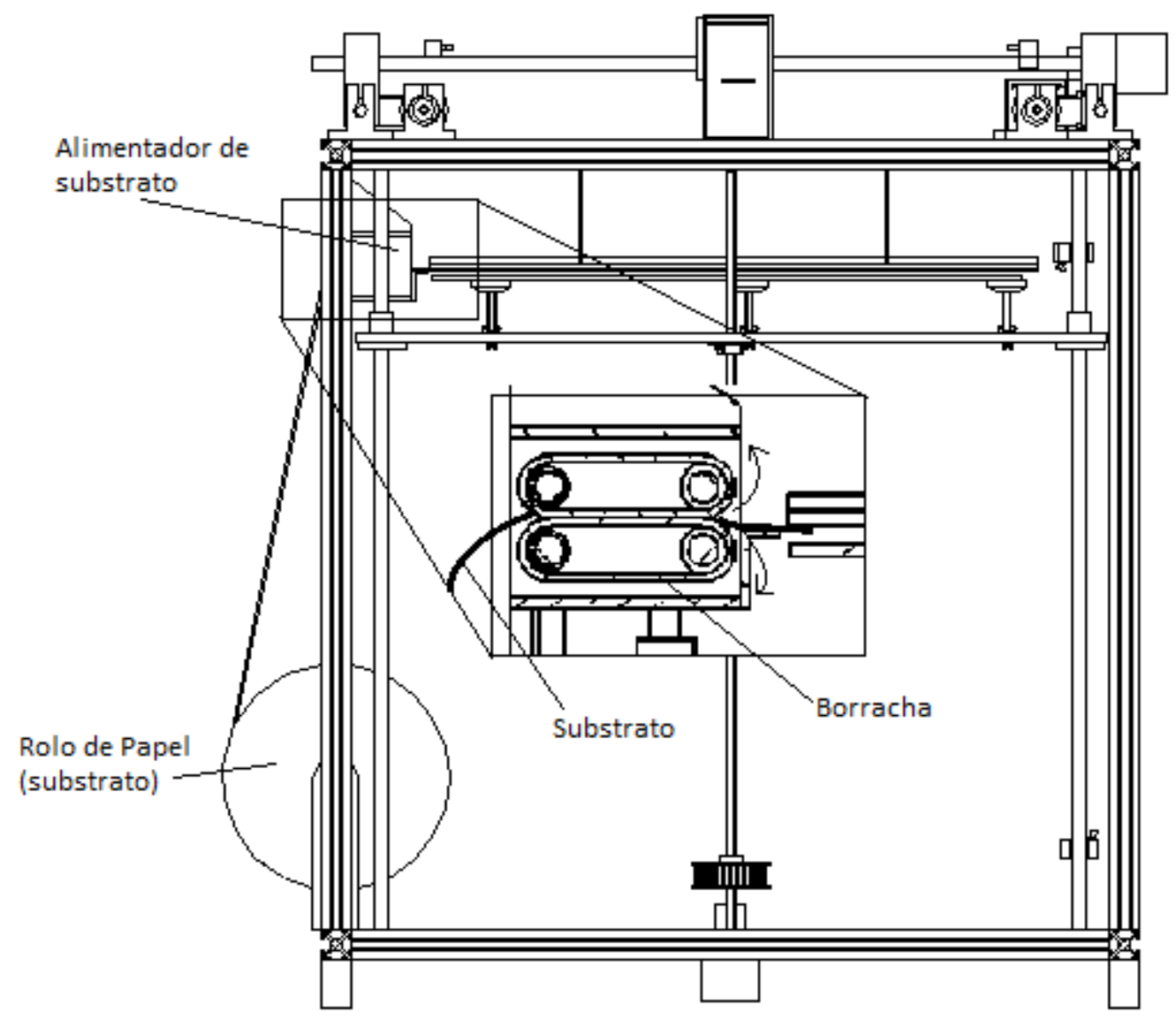

Figura 7.18 - Desenho esquemático de sistema de alimentação de substrato do projeto preliminar de equipamento protótipo

Neste caso, foi escolhido utilizar um sistema de correias ao invés de rolos de alimentação devido à simplicidade de construção e implementação, visto que o deslocamento do substrato é controlado inteiramente pelo sistema de alimentação. 
Já para a segregação de substrato para próximas camadas, foi optado por alocar um laser de corte no suporte de laser de polimerização de forma a realizar o corte do substrato no início da construção de cada camada

\subsubsection{Sistema de Deposição de Material Fotopolimérico}

Para a deposição de material fotopolimérico, foi empregado sistema semelhante à litografia (secção 7.1). Este sistema consiste no deslocamento de um rolo de deposição ao longo da camada de substrato após coletar material fotopolimérico líquido no reservatório. Um esquemático deste sistema é apresentado na Figura 7.19, onde é possível destacar que o revestimento do rolo de deposição é de PVA, permitindo a transferência do material para o substrato.

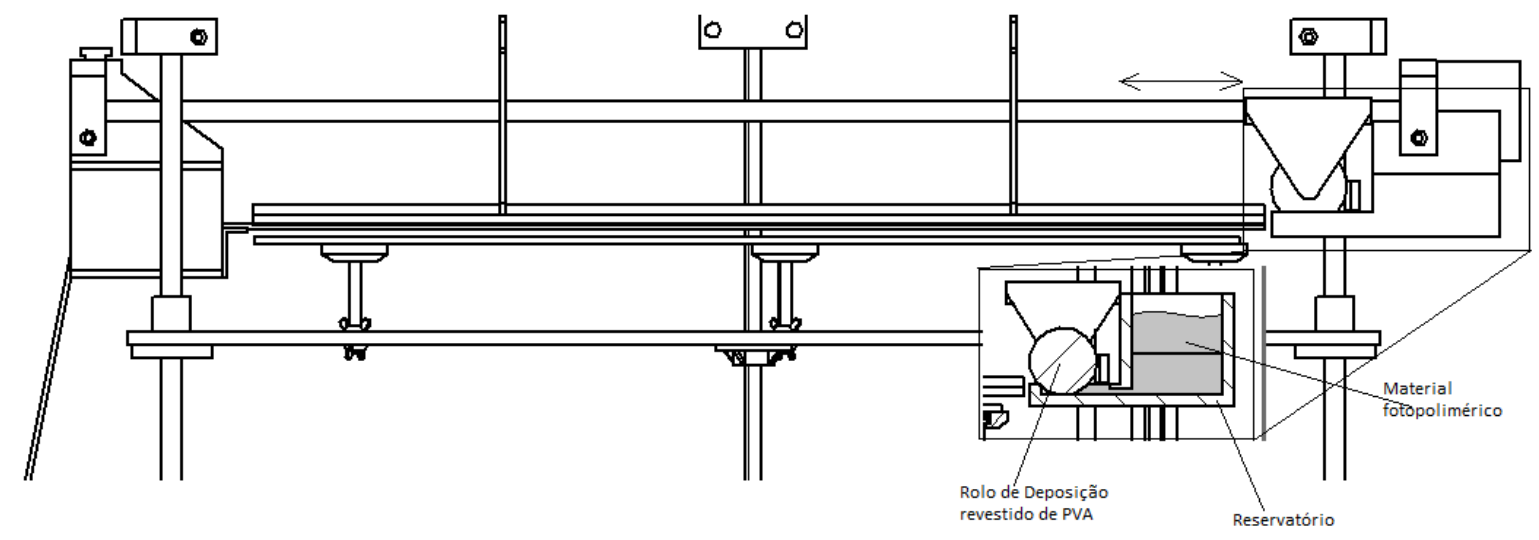

Figura 7.19 - Desenho esquemático de sistema de deposição de material fotopolimérico do projeto preliminar de equipamento protótipo 


\subsubsection{Calibração de Sistema de Posicionamento}

Para a calibração do sistema de posicionamento, inicialmente foi realizado o alinhamento da ortogonalidade dos eixos $X Y$ e Z, ajustando o erro Abbé $\left(\right.$ Abbé $\left.=d_{\text {exxo }} \cdot \sin \theta\right)$ em $\mathrm{X}$ e Z . Em relação à calibração de alinhamento ao longo do eixo $\mathrm{Y}$ este foi observado erro de Abbé ser inferior a $1 \mu \mathrm{m}$, devido à distância entre guias lineares (offset) ser muito pequena (inferior a $35 \mathrm{~mm}$ ).

Inicialmente, foi estabelecido o paralelismo inferior a $10 \mu \mathrm{m}$ entre os eixos lineares e fusos que proporcionam movimento $X$ através do posicionamento dos mancais. Para 0 ajuste da ortogonalidade entre eixos $X$ e $Y$, foram medidos os suportes de cada um dos lados, e regulado o deslocamlento dos fusos de forma a perpendicularidade entre $X$ e $Y$ fosse estabelecida num valor inferior a $20 \mu \mathrm{m}$, conforme apresentado na Figura 7.20. Neste caso, foi também analisada a resolução máxima do sistema, sendo obtido valor de $1 \mu \mathrm{m}$. 


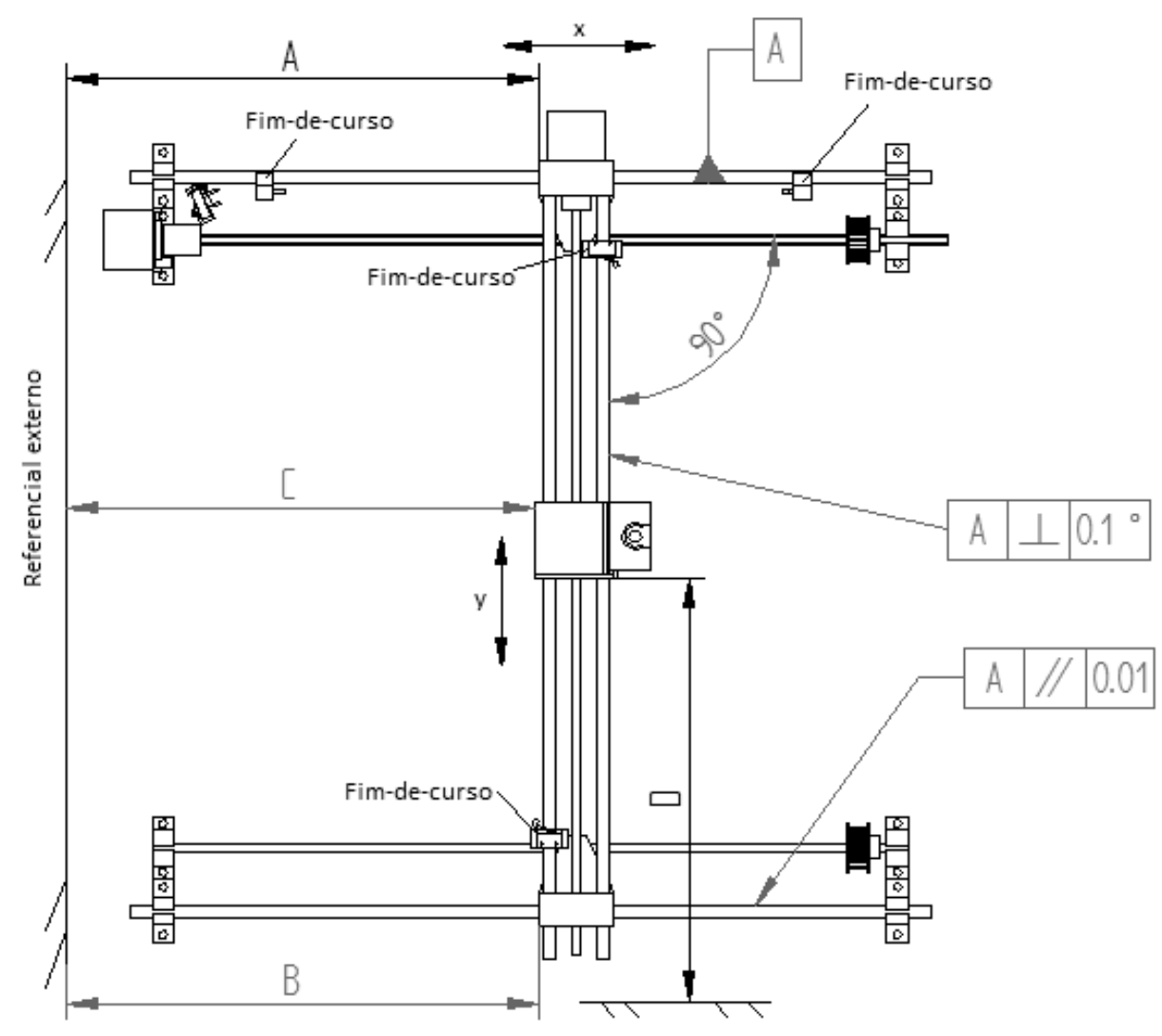

Figura 7.20 - Esquamático de calibração de ortogonalidade entre eixos X e Y de sistema de posicionamento

Esta figura também apresenta os pontos de medição do eixo $Y$ de acordo com referencial externo $(A, B, C$ e $D)$, onde foi realizada a aferição para que $A, B$ e $C$ apresentassem divergência de no máximo $50 \mu \mathrm{m}$ ao longo do deslocamento em $\mathrm{Xe}$ Y. Através desta aferição foi também possível definir, via controle NC-PC, a compensação de resolução mínima (deslocamento incremental mínimo). Adicionalmente, foi verificado através de goniômetro, a perpendicularidade entre $\mathrm{Xe}$ $\mathrm{Y}$, de forma que se apresentasse tolerância inferior a $0.01^{\circ}$.

Pode-se também destacar que estas medições foram realizadas com auxílio de paquímetro de $0.01 \mathrm{~mm}$ de precisão, relógio comparador digital de $1 \mu \mathrm{m}$ de precisão e sensor de distância infravermelho de $1 \mu \mathrm{m}$ de precisão.

Ao final do processo de calibração, foram posicionados os sensores fim-decurso, de forma a impedir a movimentação fora da área de interesse $(290$ × 390 mm) 
Para ajuste de ortogonalidade de eixo Z (plataforma de construção), os eixos lineares e fusos foram foi primeiramente alinhados paralelamente de forma a proporcionar perpendicularidade de $10 \mu \mathrm{m}$ com plano $\mathrm{XY}$, conforme apresentado na Figura 7.21.

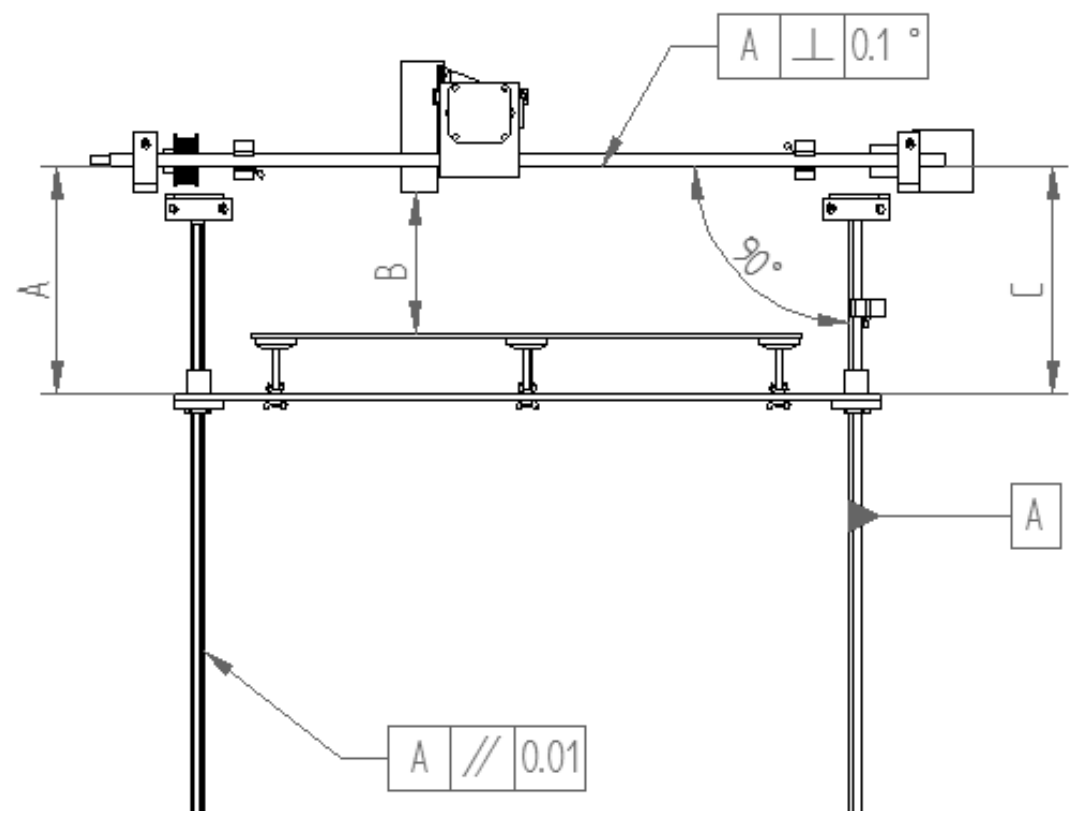

Figura 7.21 - Esquamático de calibração de ortogonalidade entre eixo $Z$ e plano $X Y$ de sistema de posicionamento e planicidade de plataforma de contrução

Em seguida, a plataforma de construção foi ajustada a partir de pontos A e C, posicionados nos fusos de deslocamento em Z. Este ajuste for realizado com referencial interno (eixos $\mathrm{X}$ e $\mathrm{Y}$ ) visto que no caso de equipamentos de fabricação aditiva o alinhamento entre $Z$ e $X Y$ se mostra como um dos fatores mais importantes. Para a identificação da resolução máxima de deslocamento da plataforma, foram também utilizados os pontos $\mathrm{A}$ e $\mathrm{C}$, sendo encontrado valor de $1 \mu \mathrm{m}$.

Adicionalmente, a plataforma de construção foi ajustada matricialmente com relação ao deslocamento do laser (ponto de medição $B$ ) com auxilio de relógio comparador de precisão igual a $1 \mu \mathrm{m}$, de forma a não ser observada divergência superior a $20 \mu \mathrm{m}$. 
Para realização deste ajuste, foi estabelecida uma matriz de medição com 25 pontos onde os apoios permitem nivelamento e correção de resultados obtidos nesta aferição (Figura 7.22).

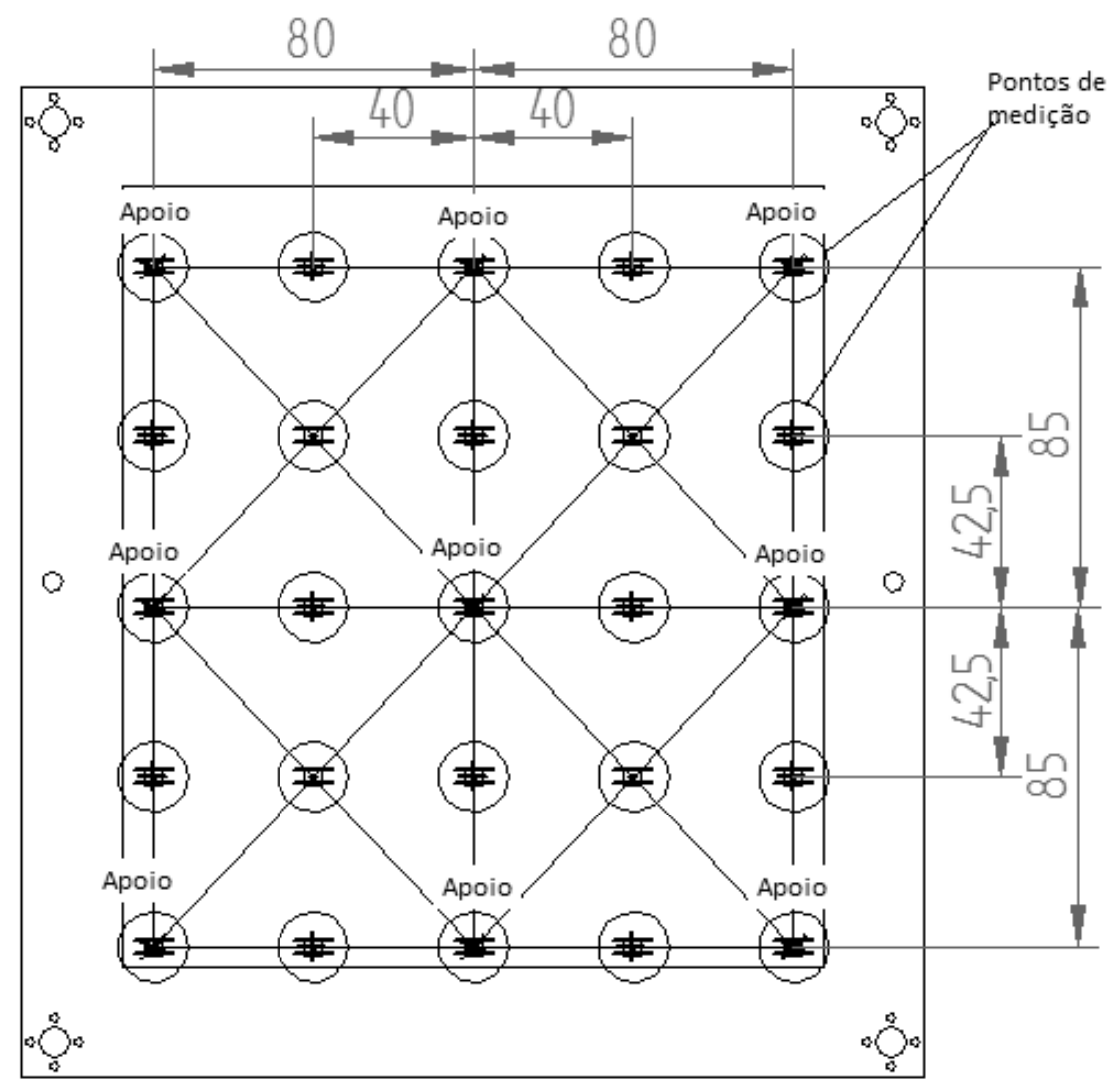

Figura 7.22 - Esquamático de calibração de planicidade de plataforma de construção em relação a suporte de laser (ferramenta)

O procedimento realizado neste ajuste inicia-se pela medição dos pontos localizados sobre os apoios, sendo estes ajustados para proporcionar valores inferiores a $10 \mu \mathrm{m}$. Em seguida, os outros pontos de medição foram aferidos de forma a identificar o erro de planicidade da plataforma de construção igual a $20 \mu \mathrm{m}$.

Por fim, foi observada a precisão do sistema através da análise do erro planar obtido através da medição de pontos provenientes de caneta hidrocolor de bico com diâmetro de $1 \mathrm{~mm}$ fixada em suporte de laser. Neste caso, foi estabelecido como padrão, uma matriz de $45 \times 25 \mathrm{~mm}$ sendo espaçada em células de $5 \mathrm{~mm}$ a ser gravado em papel fixado em plataforma de construção Figura 7.23. Adicionalmente, este 
padrão foi repetido 5 vezes de forma a ser observada a repetibilidade do sistema. Como resultado desta análise, não foi evidenciada divergência geral superior a $250 \mu \mathrm{m}$.

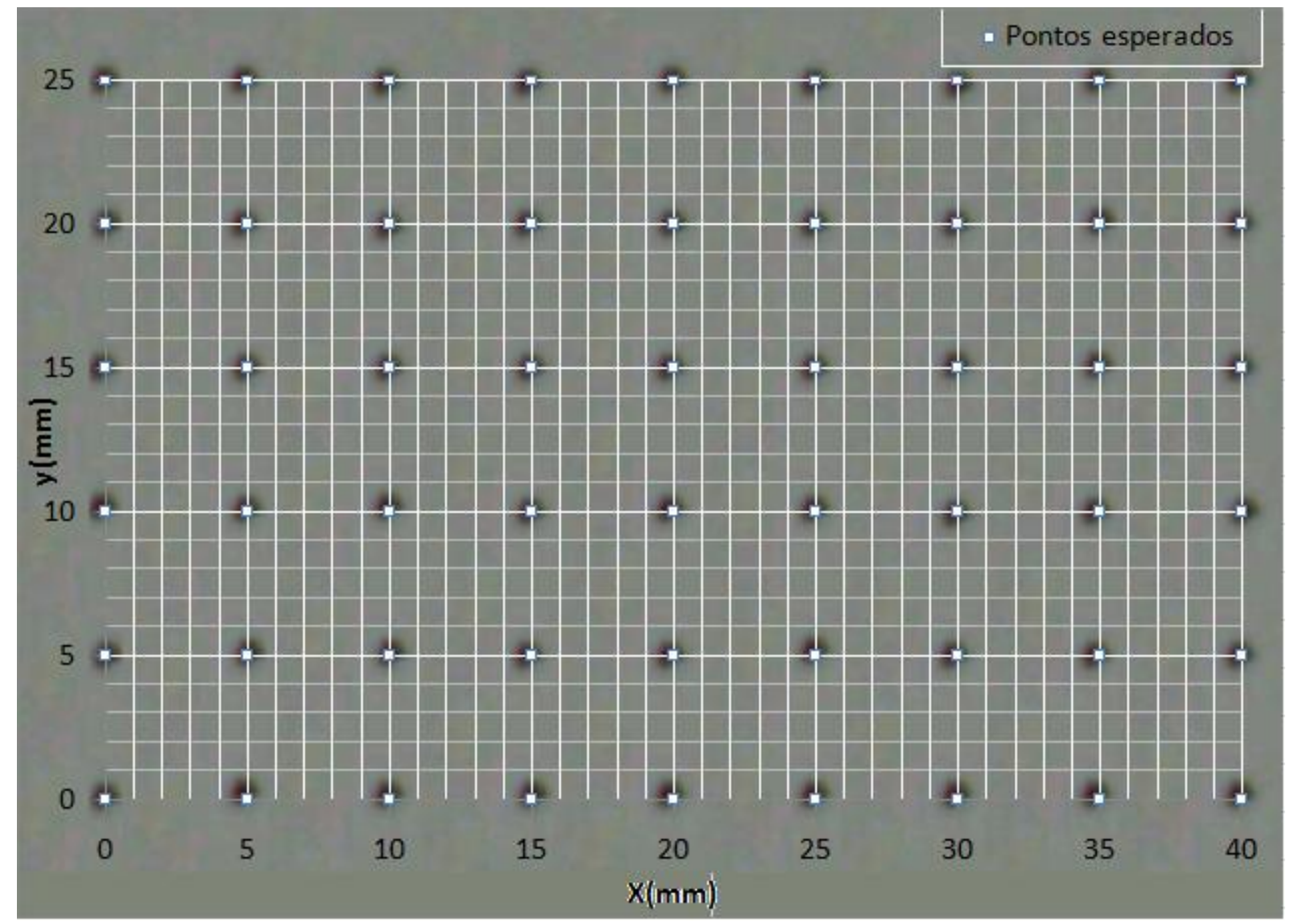

Figura 7.23 - Sobreposição de foto e Padrão 45×25mm utilizado para a análise de precisão e repetibilidade planar de sistema de posicionamento

\subsection{Sistema de pós-processamento}

Em função de este projeto apresentar caráter preliminar, tendo como objetivo principal a identificação da viabilidade funcional do processo proposto, foi optado em utilizar um sistema de pós-processamento e acabamento manual. Sendo, neste caso, utilizado jatos de água para remoção do material residual. 


\section{CARACTERICAÇÃO DA PROPOSTA}

Neste capítulo, são descritas as atividades relacionadas à implementação e caracterização do processo proposto, como sua validação funcional e identificação de faixas viáveis de operação do processo. São também apresentados os descritivos dos experimentos de caracterização do processo proposto, considerando as etapas de fabricação de camada única e múltiplas camadas, assim como a confecção de corpo de prova para identificação de viabilidade funcional de processo proposto.

\subsection{Materiais e Métodos de Caracterização}

Em adição aos materiais apresentados na Secção 4.1, foram utilizados recursos adicionais para a análise e caracterização do processo de manufatura aditiva proposto neste trabalho.

Para construção dos corpos de prova e caracterização do processo proposto, foi utilizado parcialmente o projeto preliminar de equipamento (Secção 7.5). Neste caso, os sistemas de posicionamento e de polimerização foram utilizados integralmente e de forma automatizada, enquanto os sistemas de deposição e de alimentação de substrato foram substituídos por operações manuais. Foi tomada esta decisão devido à automatização desses sistemas não contribuir ativamente para a validação do processo, mesmo apresentando grande complexidade de configuração. E consequentemente, por não ser foco principal deste trabalho, devem ser implementados em trabalhos futuros.

Para o estudo de caracterização, foram também utilizados dois lasers de diodo com intensidades diferentes e mesmo comprimento de onda $(405 \mathrm{~nm})$. Onde um proporciona potência de $20 \mathrm{~mW}$ (SHARP, 2006) e outro de 100mW (SHARP, 2007). Neste caso, estas potências podem ser representadas de acordo com área de incidência do feixe de laser, sendo $1,6 \mathrm{~mW} / \mathrm{mm}^{2}$ bpara o laser de $20 \mathrm{~mW}$, e $8 \mathrm{~mW} / \mathrm{mm}^{2}$ para o laser de $100 \mathrm{~mW}$. 
Para o processo de deposição, foi utilizado um dispositivo de tampografia com área de $5000 \mathrm{~mm}^{2}$ e revestimento de álcool polivinilico (PVA) (Figura 8.1). Assim, o dispositivo tampográfico realizada manualmente a coleta e transferência de material fotopolimérico contido em reservatório para o substrato.

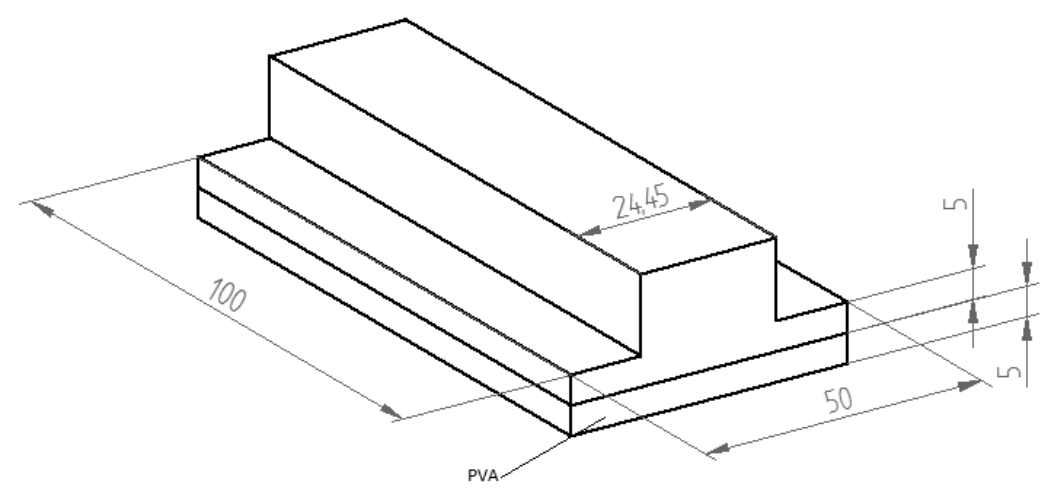

Figura 8.1 - Desenho esquemático de dispositivo de tampografia utilizado para deposição de material fotopolimérico em substrato

Adicionalmente, o substrato foi previamente preparado com formato de 100x100mm, de forma a existir regiões de fixação.

Com relação ao material fotopolimérico utilizado na validação e caracterização do processo, foi utilizada a formulação de material baseada no resultado de otimização do desenvolvimento de material (Capítulo 6). Neste caso, o teor de cada um dos componentes do material é de: $5 \mathrm{ml}$ de monômero (MMA), $5 \mathrm{ml}$ de oligômero (TMPTA) e 2\% no peso de fotoiniciador IGS CureALL 2500.

Para a identificação do comportamento microestrutural dos materiais, foi utilizado um Microscópio Ótico Digital Bresser LCD-Microscope $8.9 \mathrm{~cm}$. Este microscópio de bancada permite a amplificação de até 1600x de magnitude, sendo a aquisição e processamento das imagens micrograficas realizadas através do software MATLAB.

Para a remoção de material fotopolmérico residual e contraste de regiões polimerizadas em corpos de prova, foi utilizado álcool isopropílico (Secção 4.1.3), sendo o processo de secagem realizado em ambiente com temperatura controlada $\left(20^{\circ} \mathrm{C}\right)$. 


\subsection{Planejamento de Experimentos de Caracterização}

Em relação à fabricação do protótipo da concepção de equipamento concebido neste trabalho (Capítulo 7), foram determinados processos não definitivos ou não ferramentados para a fabricação destes componentes. Desta forma, foram empregadas técnicas de ferramental rápido e fabricação aditiva, assim como a utilização de estruturas modulares e componentes de prateleira (padronizados).

Para a caracterização do processo, foram identificadas características de sistema de deposição, formação seletiva de compósito, influência de formação de compósito em multiplas camadas e caracterização de funcionalidade da proposta de processo.

\subsubsection{Caracterização de sistema de deposição}

Para a caracterização da proposta, foi utilizado um sistema de tampografia manual para a deposição de material fotopolimérico em substrato celulósico. Contudo, para não haver divergências relacionadas à quantidade de material depositado por área, foi realizado um estudo para caracterizar a quantidade de material depositado por este processo manual.

O dispositivo de tampografia utilizado neste estudo (secção 8.1) é composto por camada de álcool polivinílico (PVA), proporcionando a transferência do material do reservatório para o substrato por meio da adsorsão de material por seus poros.

Nesse estudo, 30 amostras de substrato previamente pesadas foram submetidas à deposição (um passe de dispositivo de tampografia) e pesadas ao final do processo através de balança de precisão. Com isto, permitindo identificar a quantidade e repetibilidade do processo de deposição. Foi determinado que as amostras de substrato (papel seda $18 \mathrm{~g} / \mathrm{mm}^{2}$ ) deveriam ter dimensão de 150x80. 
Desta forma, permitindo a fixação de substrato, além de cobrir a área inteira do dispositivo de tampografia.

\subsubsection{Caracterização de Formação de Compósito em uma Camada}

Para análise de formação seletiva de compósito, foram inicialmente estudados os principais parâmetros de controle de deste processo em uma camada. Neste estudo, a intensidade luminosa (I), diâmetro de feixe de laser ( $\mathrm{Wd})$, velocidade de deslocamento $(\mathrm{Vd})$ foram consideradas variáveis, enquanto o comprimento de onda $(\lambda)$, espessura de substrato, tipo de substrato, e tipo de material fotopolimérico foram mantidos constantes. Como respostas as serem analisadas, foram definidos largura de linha de polimerização (Wp) e a definição de linha de polimerização, sendo que esse pode ser indefinido por ser apresentada polimerização em excesso ou em falta. Outra resposta que também foi analisada é a aderência à plataforma, onde foram submetidos testes sobre plataforma de Poli (metil metacrilato) (PMMA) e Polipropileno (PP).

Na Tabela 8.1, são apresentados os valores dos fatores de controle utilizados sendo aplicada metodologia univariável para identificação de repetibilidade, variabilidade e impacto de variáveis para o processo. 
Tabela 8.1 - Matriz de experimento de estudo de formação seletiva de compósito em uma camada

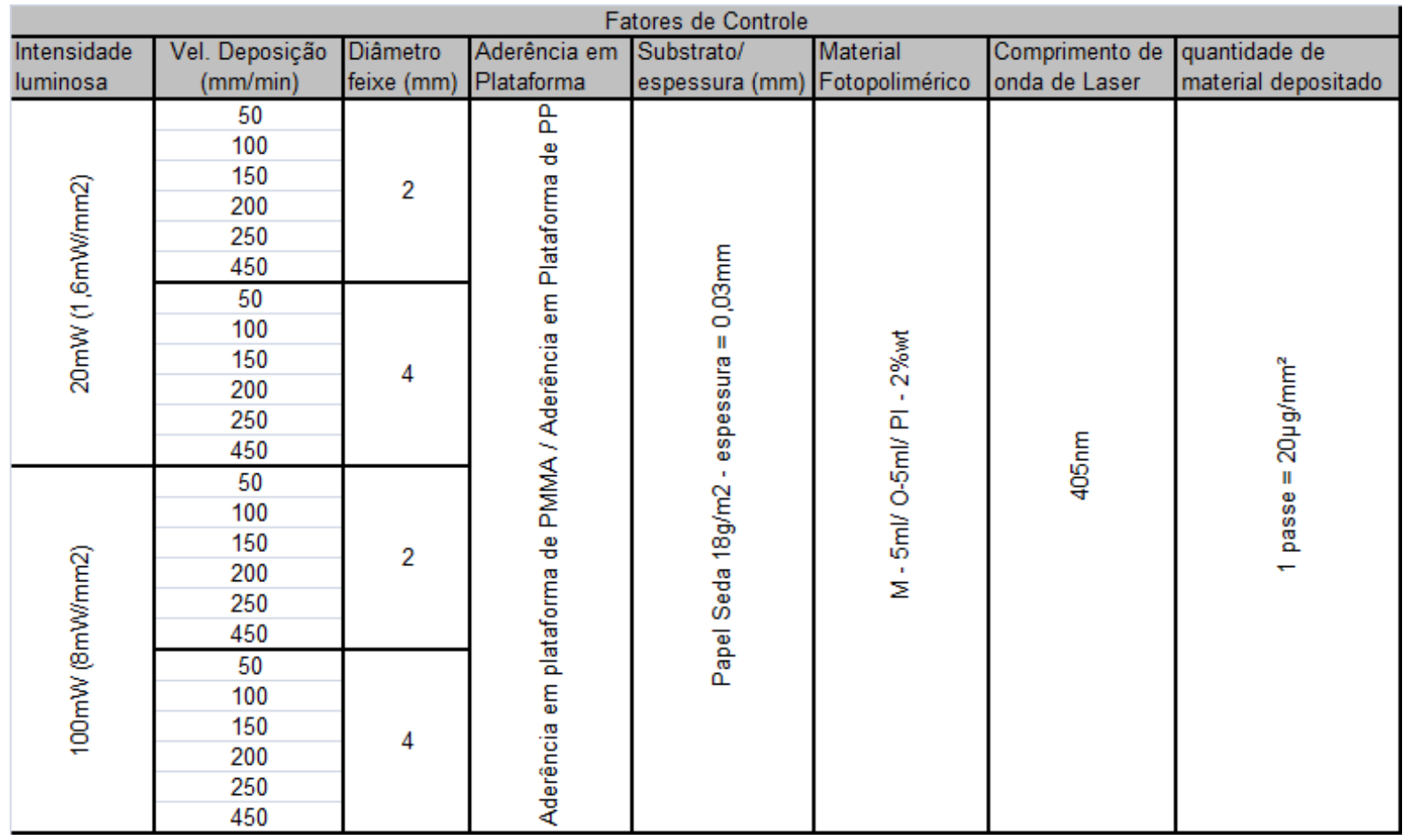

Para identificação das respostas, foram realizadas análises microscópicas para a identificação de homogeneidade e largura de linha de polimerização, assim como do nível de definição de linha de polimerização (definida ou indefinida).

O procedimento utilizado na realização deste estudo comprende o posicionamento do substrato na plataforma, deposição de material fotopolimérico por meio de dispositivo de tampografia, exposição seletiva de luz através de laser, análise de aderência em plataforma, remoção de material residual (não polimerizado) por meio de álcool, secagem de camada, análise microscópica de área polimerizada. Este procedimento pode ser também observado na Figura 8.2. 


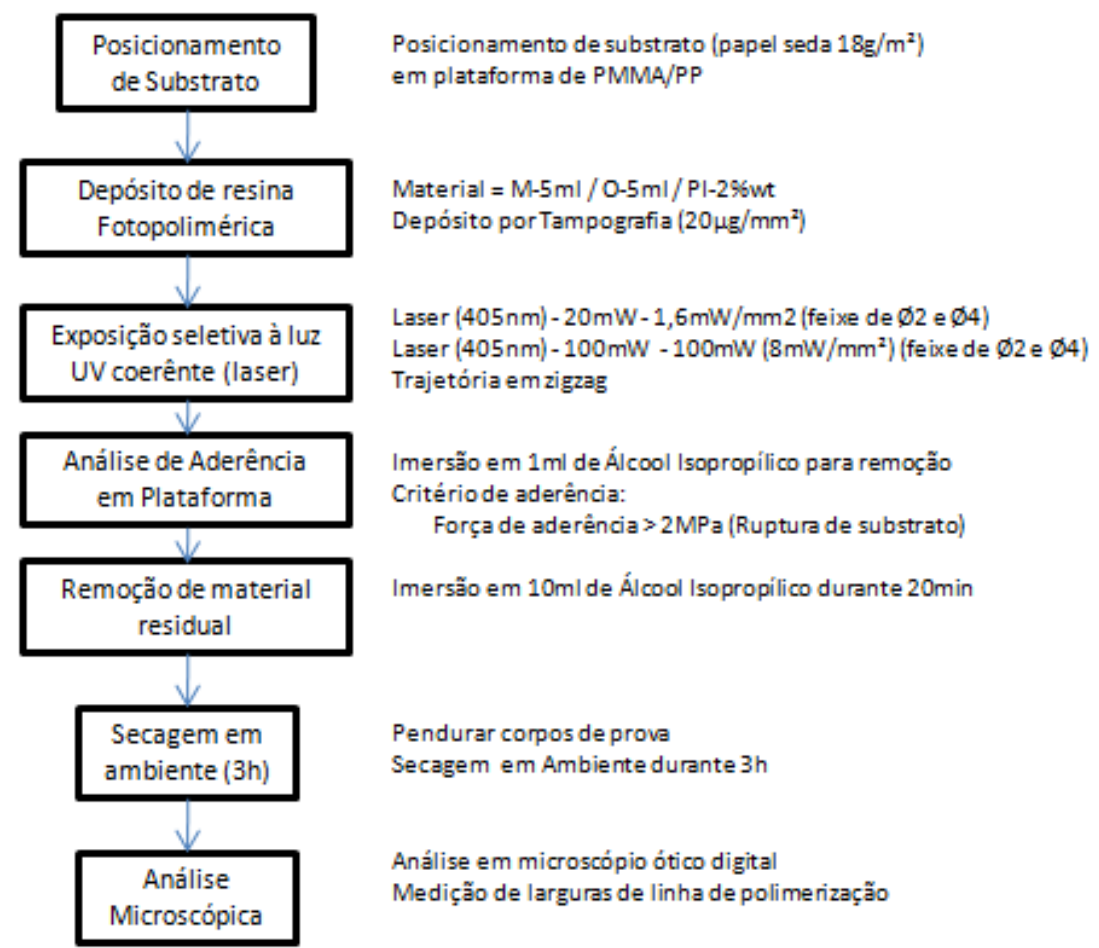

Figura 8.2 - Procedimento de fabricação de corpo de prova para estudo de formação seletiva de compósito em uma camada

Com relação à exposição seletiva à luz UV coerente, foram utilizados 2 lasers de comprimento de $405 \mathrm{~nm}$ e intensidades de $20 \mathrm{~mW}$ e $100 \mathrm{~mW}$, onde o diâmetro do feixe de laser foi delimitado por orifícios de 2 e $4 \mathrm{~mm}$.

Foi escolhido um caminho em zig-zag como trajetória de exposição do laser, permitindo a análise microscópica em 3 regiões distintas do trajeto. Para a análise da repetibilidade e normalidade do processo, foram coletadas 10 medidas de cada uma destas regiões totalizando 30 medidas por corpo de prova e 90 por experimento. A Figura 8.3 apresenta uma ilustração da trajetória percorida pelo laser, indicando, adicionalmente, as regiões analisadas microscópicamente. Como este estudo previu dois diâmetros distintos de feixe de laser, foi escolhida uma trajetória para cada dimensão. 


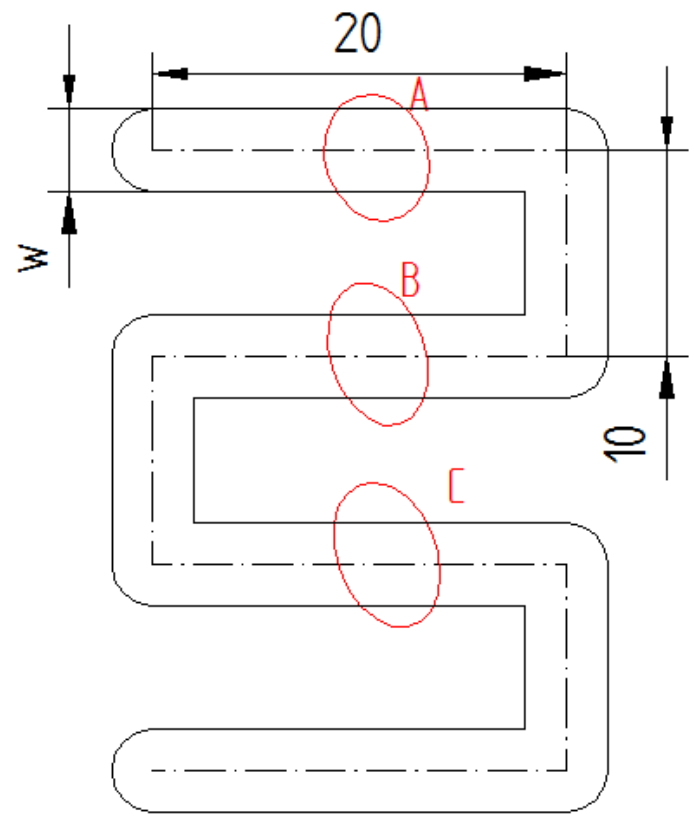

a)

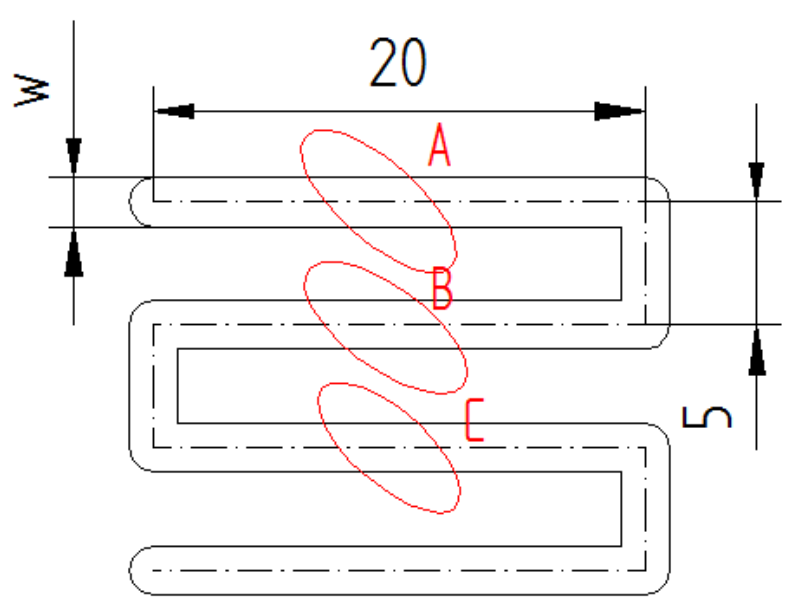

b)

Figura 8.3 - Ilustração e dimensionamento geral de trajetórias de deslocamento percorridas por laser de diâmetro de feixe $4 \mathrm{~mm}$ (a) e $2 \mathrm{~mm}$ (b), tipo de polimerização esperada (largura "w") e indicação de regiões de análise microscópica (marcações "A", "B" e "C")

Para remoção da camada de substrato, resina e compósito da plataforma, foi utilizado $1 \mathrm{ml}$ de álcool isopropílico. Foi também especificado que no caso de ruptura de substrato no ato da remoção da plataforma, a força para remoção do compósito da plataforma é superior à 2MPa, evidenciando a aderência entre componentes. Já no caso contrário, não foi possível observar aderência significativa.

A remoção do material (resina) residual da camada foi caracterizada pela imersão de camada de substrato impregnado de resina e com regiões polimerizadas em $10 \mathrm{ml}$ de álcool isopropílico durante 20 minutos. Com isso, buscou-se a solubilização de material não polimerizado ou com baixo grau de polimerização, e consequentemente, a separação deste resíduo no momento de secagem.

Este procedimento se mostra necessário para a visualização da região polimerizada, assim como para garantir a integridade dos corpos de prova ao longo do tempo. Sem o emprego deste procedimento, além das áreas dos corpos de prova que não foram expostas à luz UV do laser ficarem suscetíveis à polimerização, não seria possível distinguir áreas polimerizadas de não polimerizadas. 
Por outro lado, a utilização deste método não possibilita a identificação de níveis intermediários de polimerização. Logo, conversão superior à $50 \%$ são consideradas polimerizadas. Foi também definido que linha de polimerização é indefinida quando regiões não expostas diretamente exposta à luz apresentam valore de conversão inferior a $50 \%$ (falta de polimerização) ou superior a $50 \%$ (polimerização periférica excessiva).

\subsubsection{Caracterização de Formação de Compósito em para Múltiplas Camadas}

Continuando a caracterização do processo de formação seletiva de compósito, foi realizado um estudo com objetivo de identificar o grau de interferência da formação de compósito para camadas anteriores. Este estudo pode também ser chamado de profundidade de penetração em outras tecnologias, como SLA.

Neste estudo, foram identificados os efeitos dos parâmetros de processo para a profundidade de penetração. As variáveis de controle, como no estudo anterior, são intensidade luminosa (I), diâmetro de feixe de laser (Wd), velocidade de deslocamento $(\mathrm{Vd})$. O tipo de experimento é de dois niveis $\left(2^{3}\right)$, sem pontos centrados nas faces e nem corpo.

A Tabela 8.2 apresenta a matriz de experimentos deste estudo, onde são expostas as variáveis de controle e constantes utilizadas neste estudo.

Tabela 8.2 - Matriz de experimento de estudo de formação seletiva de compósito em múltiplas camadas

\begin{tabular}{|c|c|c|c|c|c|c|}
\hline Intensidade luminosa & $\begin{array}{l}\text { Vel. Deposição } \\
(\mathrm{mm} / \mathrm{min})\end{array}$ & $\begin{array}{l}\text { Diâmetro } \\
\text { feixe }(\mathrm{mm})\end{array}$ & \begin{tabular}{|l|} 
Substrato/ \\
espessura $(\mathrm{mm})$
\end{tabular} & \begin{tabular}{|l} 
Material \\
Fotopolimérico
\end{tabular} & $\begin{array}{l}\text { Comprimento de } \\
\text { onda de Laser }\end{array}$ & $\begin{array}{l}\text { quantidade de } \\
\text { material depositado }\end{array}$ \\
\hline$(-) 20 \mathrm{~mW}(1,6 \mathrm{~mW} / \mathrm{mm} 2)$ & $(-) 100$ & $(-) 2$ & \multirow{2}{*}{$\begin{array}{c}\text { Papel Seda } \\
18 \mathrm{~g} / \mathrm{m} 2 \text { - } \\
\text { espessura = } \\
0,03 \mathrm{~mm}\end{array}$} & \multirow{2}{*}{$\begin{array}{c}\mathrm{M}-5 \mathrm{ml} / \mathrm{O}-5 \mathrm{ml} / \\
\mathrm{PI}-2 \% \mathrm{wt}\end{array}$} & \multirow{2}{*}{$405 \mathrm{~nm}$} & \multirow{2}{*}{$\begin{array}{c}10 \text { camadas de } \\
\text { substrato com } \\
1 \text { passe }=20 \mu \mathrm{g} / \mathrm{mm}^{2}\end{array}$} \\
\hline (+) $100 \mathrm{~mW}(8 \mathrm{~mW} / \mathrm{mm} 2)$ & $(+) 450$ & $(+) 4$ & & & & \\
\hline
\end{tabular}

De maneira geral, o procedimento empregado consiste no empilhameto prévio de 10 camadas de substrato com material fotopolimérico depositado antes da 
exposição à luz e consequente formação de compósito. Como objetivo principal, destaca-se a identificação do número de camadas aderidas umas nas outras após exposição seletiva à luz e remoção de material residual.

Na Figura 8.4, é apresentado um fluxograma que descreve em detalhes as etapas realizadas neste procedimento. Cabe ressaltar que esta figura também apresenta um laço lógico com contador, indicando o processo empregado para empilhamento das camadas de substrato impregnado com resina fotopolimérica.

Neste estudo, foram utilizadas a mesmas trajetórias de deslocamento do laser que no estudo anterior (Figura 8.3), visto que o aumeto da proximidade entre trajetória do zig-zag poderia interferir no grau de conversão de percursos anteriores. Isto inviabilizaria a análise cruzada entre resultados dos dois estudos.

Como observado em resultados de estudo anterior (Secção 8.2.2), não foi observada a aderência entre a plataforma de PP e substrato. Logo, foi utilizado neste estudo apenas a plataforma de PP, eliminando a etata remoção de corpo de prova da plataforma. Já a remoção de material residual foi realizada pela imersão dos corpos de prova em $10 \mathrm{ml}$ de álcool isopropílico durante $20 \mathrm{~min}$, sendo os mesmos secos ao longo de 3 horas em ambiente.

Para a contagem de camadas com aderência, foi utilizado $1 \mathrm{ml}$ de alcool isopropílico para o início da remoção das camadas. Neste momento, buscou-se identificar o número de camadas que apresentavam aderência entre si superior à resistência do substrato molhado (2MPa). Ou seja, foi contado o número de camadas que apresentavam ruptura de qualquer tipo no substrato. 


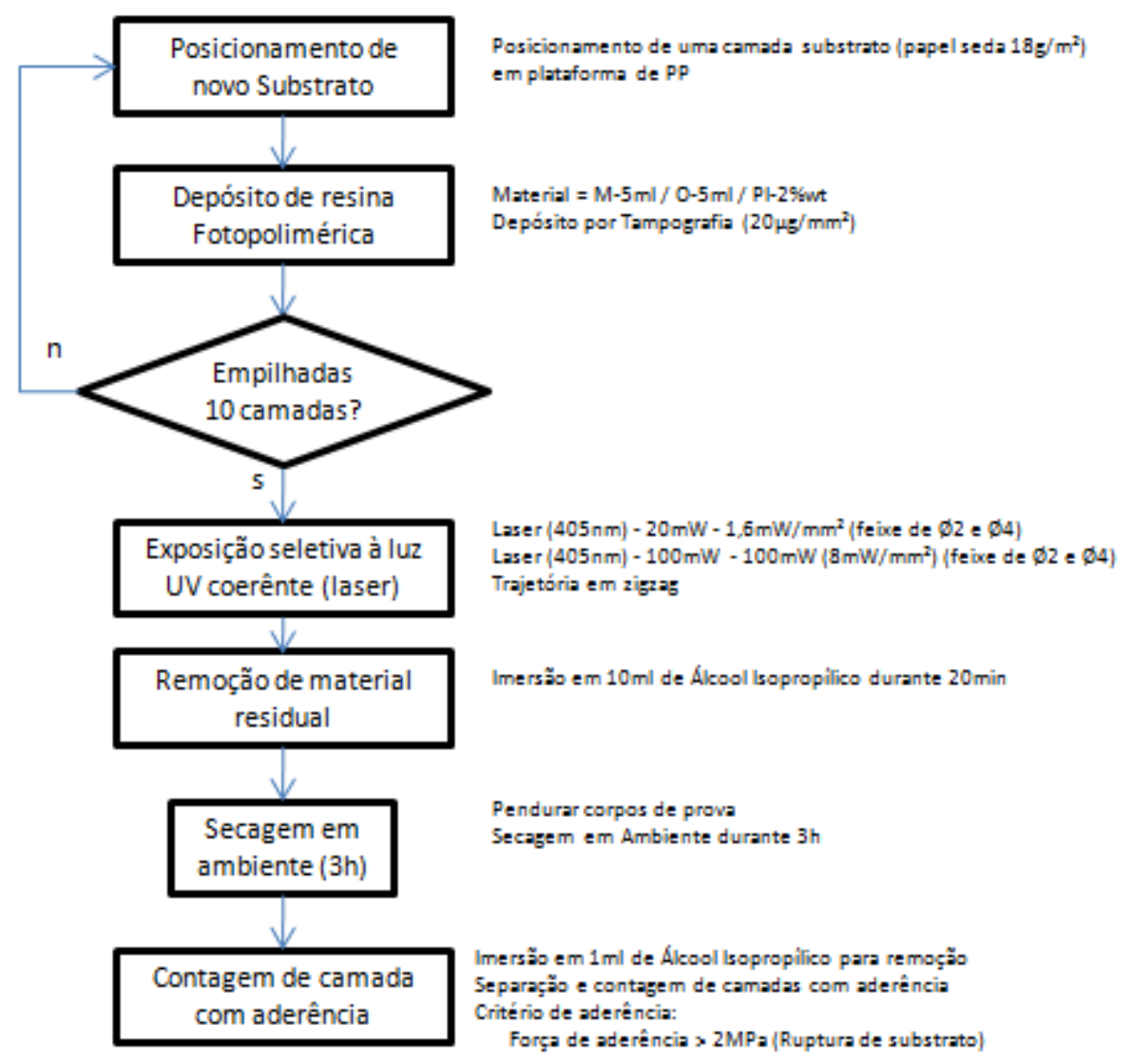

Figura 8.4 - Procedimento de fabricação de corpo de prova para estudo de formação seletiva de compósito múltiplas camadas

\subsubsection{Caracterização de Funcionalidade de Conceito}

Para a caracterização funcional do conceito de processo proposto, foram construídos corpos de prova retangulares com dimensões esperadas de $12 \times 62 \times 1,5 \mathrm{~mm}$. Neste estudo, foram consideradas como variáveis, velocidade de deslocamento de laser $(\mathrm{Vd})$, o ângulo de trajetória de varredura e intensidade luminosa. Como constantes, foram mantidos o diâmetro de feixe de laser, a distância entre linha de polimerização, número de camadas (50), tipo e espessura de substrato, e formulação de material fotopolimérico.

Neste estudo, foi aplicado um planejamento de experimentos completo de $2^{(3)} \mathrm{e}$ sem pontos centrais para investigar a viabilidade do processo. Na Tabela 8.3, é apresentado uma relação dos principais parâmetros utilizados para a construção dos 
corpos de prova, assim como a ilustração da trajetória utilizada em cada camada, número de camadas e dimensional final esperado. Neste caso, apesar da espessura de substrato ser de $30 \mu \mathrm{m}$, a espessura de camada esperada é de $36 \mu \mathrm{m}$, conforme observado na secção 6.3.3.

Tabela 8.3 - Relação de valores de parâmetros utilizados no estudo de caracterização de funcionalidade de processo

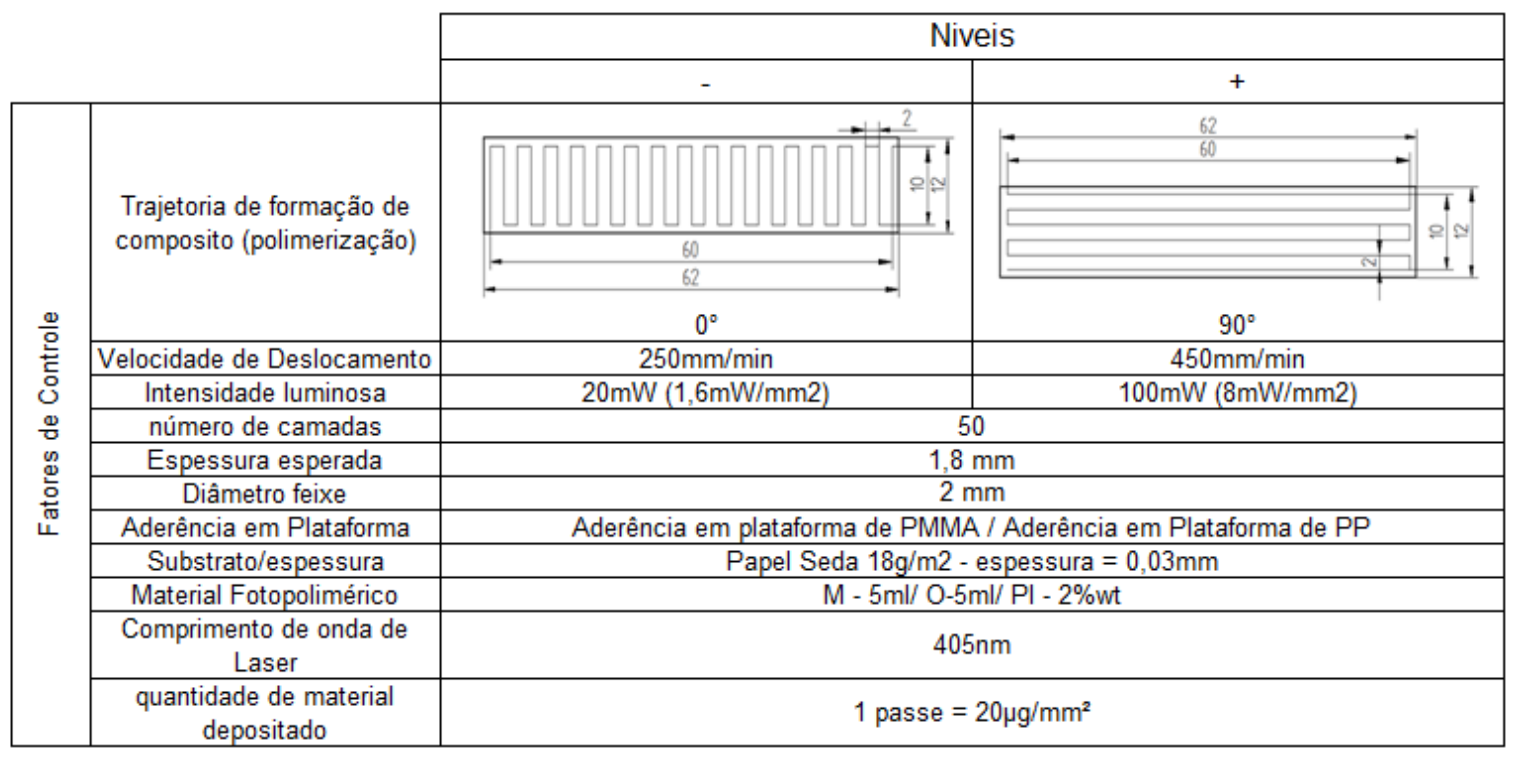

Adicionalmente, a matriz de experimento deste estudo é apresentada na Tabela 8.4, onde são apresentados os valores das variáveis utilizados em cada um dos experimentos. 
Tabela 8.4 - Matriz de experimentos utilizados no estudo de caracterização de funcionalidade de processo $\left(2^{3-1}\right)$

\begin{tabular}{|c|cc|cc|cr|}
\hline exp & \multicolumn{2}{|c|}{$\begin{array}{c}\text { Trajetoria de formação de } \\
\text { compósito (polimerização) }\end{array}$} & \multicolumn{2}{|c|}{$\begin{array}{c}\text { Velocidade de } \\
\text { Deslocamento }\end{array}$} & \multicolumn{2}{|c|}{ Intensidade luminosa } \\
\hline 1 & $(-)$ & $0^{\circ}$ & $(-)$ & $250 \mathrm{~mm} / \mathrm{min}$ & $(+)$ & $100 \mathrm{~mW}(8 \mathrm{~mW} / \mathrm{mm} 2)$ \\
\hline 2 & $(-)$ & $0^{\circ}$ & $(+)$ & $450 \mathrm{~mm} / \mathrm{min}$ & $(-)$ & $20 \mathrm{~mW}(1,6 \mathrm{~mW} / \mathrm{mm} 2)$ \\
\hline 3 & $(+)$ & $90^{\circ}$ & $(-)$ & $250 \mathrm{~mm} / \mathrm{min}$ & $(-)$ & $20 \mathrm{~mW}(1,6 \mathrm{~mW} / \mathrm{mm} 2)$ \\
\hline 4 & $(+)$ & $90^{\circ}$ & $(+)$ & $450 \mathrm{~mm} / \mathrm{min}$ & $(+)$ & $100 \mathrm{~mW}(8 \mathrm{~mW} / \mathrm{mm} 2)$ \\
\hline 5 & $(-)$ & $0^{\circ}$ & $(-)$ & $250 \mathrm{~mm} / \mathrm{min}$ & $(-)$ & $20 \mathrm{~mW}(1,6 \mathrm{~mW} / \mathrm{mm} 2)$ \\
\hline 6 & $(-)$ & $0^{\circ}$ & $(+)$ & $450 \mathrm{~mm} / \mathrm{min}$ & $(+)$ & $100 \mathrm{~mW}(8 \mathrm{~mW} / \mathrm{mm} 2)$ \\
\hline 7 & $(+)$ & $90^{\circ}$ & $(-)$ & $250 \mathrm{~mm} / \mathrm{min}$ & $(+)$ & $100 \mathrm{~mW}(8 \mathrm{~mW} / \mathrm{mm} 2)$ \\
\hline 8 & $(+)$ & $90^{\circ}$ & $(+)$ & $450 \mathrm{~mm} / \mathrm{min}$ & $(-)$ & $20 \mathrm{~mW}(1,6 \mathrm{~mW} / \mathrm{mm} 2)$ \\
\hline
\end{tabular}

Como respostas deste estudo, foram definidas as dimensões gerais do objeto final (altura, produndidade e largura) e resistência mecânica a tração. Desta forma, torna-se possível observar a anisotropia e resistência mecânica proporcionada por este novo processo em relação aos processos convencionais, além de evidenciar deficiências e dificuldades para implementação deste processo em escala comercial.

O procedimento utilizado para a obtenção destes corpos de prova pode ser observado na Figura 8.5. Nesta figura, são expostas tanto as etapas decorrentes do processo (formação seletiva de compósito) quanto do pós-processamento (remoção de material e substrato residual). 


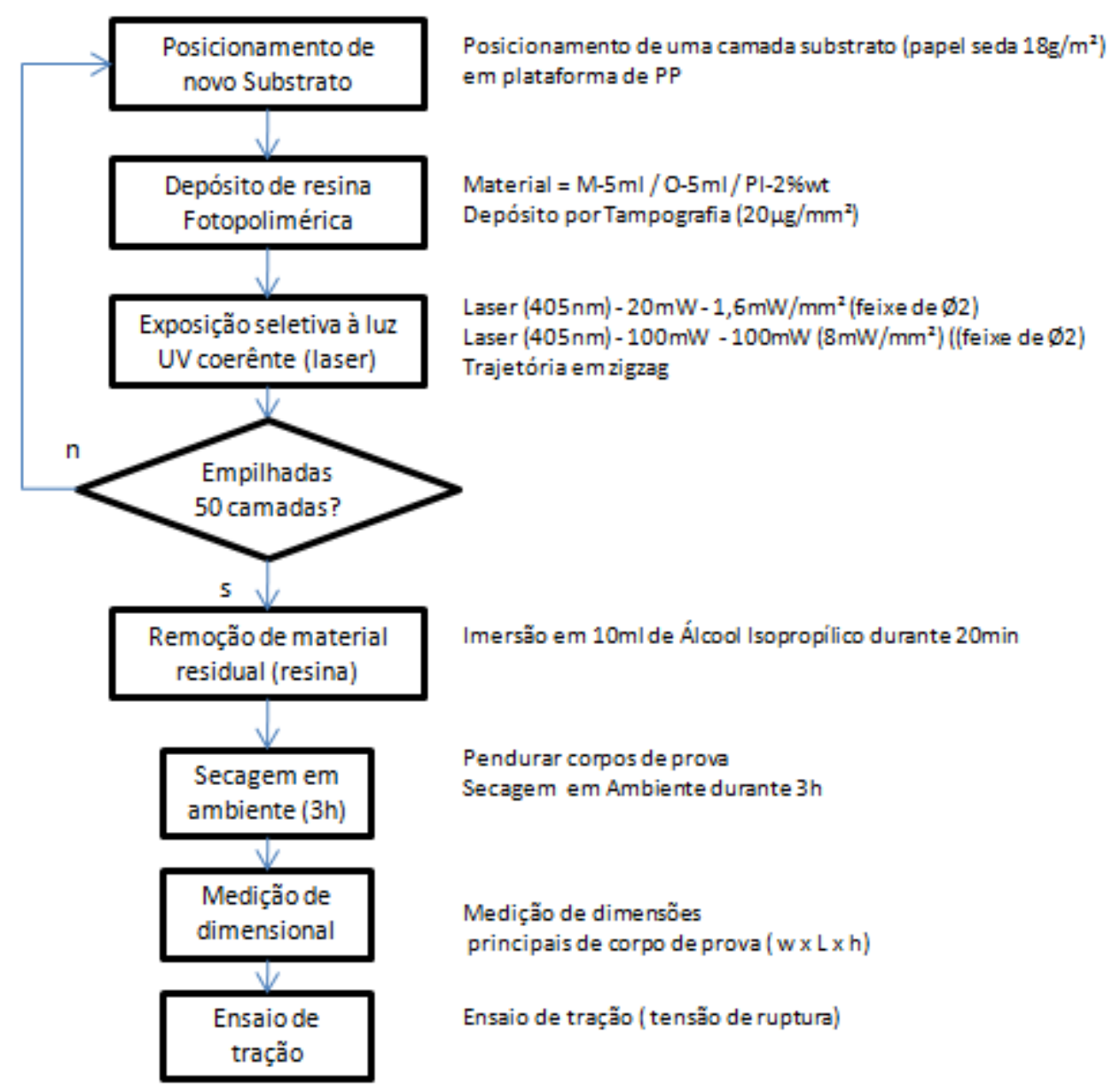

Figura 8.5 - Procedimento de fabricação de corpo de prova para estudo caracterização funcional de conceito

\subsection{Resultados e Discussões}

Nesta secção serão apresentados os resultados relacionados aos estudos de caracterização do processo de manufatura aditiva proposto neste trabalho, assim como os resultados relacionados à caracterização do processo de deposição tampográfico manual empregado nos estudos. Adicionalmente, serão discutidos aspectos do processo que indicam potenciais e dificuldades para implementação e viabilização do processo. 


\subsubsection{Caracterização de sistema de deposição}

Com relação à caracterização de sistema de deposição manual utilizado para a validação do processo, foi observado que o dispositivo tampográfico proporciona a transferência e deposição média total de aproximadamente $100 \mathrm{mg}$ de material fotopolimérico por passe. Isto é equivale a uma deposição de $20 \mu \mathrm{g} / \mathrm{mm}^{2}$ e a um percentual polímero/papel aproximado de 1.5.

Na Tabela 8.5, é apresentado a relação de resultados da estatística descritiva deste estudo, considerando número de amostras igual a 30.

Nesta tabela é possível observar que a um valor de desvio padrão baixo, de apenas $7 \mu \mathrm{g} / \mathrm{mm}^{2}$, enquanto os valores de curtose e assimetria se mostram próximos de 0 . Isto significa que a distribuição de valores tende levemente para esquerda da média, enquanto o formato da distribuição é semelhante a uma distribuição normal.

Pode-se também observar um intervalo de valores de $29 \mu \mathrm{g} / \mathrm{mm}^{2}$, indicando que o mínimo de material depositado por este método é de $84 \mu \mathrm{g} / \mathrm{mm}^{2}$ e máximo de $113 \mu \mathrm{g} / \mathrm{mm}^{2}$. Ou seja, pode-se indicar que este processo apresenta grande repetibilidade seguindo uma distribuição normal.

Tabela 8.5 - Relação de dados de estatística descritiva de estudo de caracterização de sistema de deposição manual (tampografia)

\begin{tabular}{|l|c|c|c|}
\cline { 2 - 4 } \multicolumn{1}{c|}{} & $\begin{array}{c}\text { Deposição de dispositivo } \\
\text { tampográfico }\left(\mu \mathrm{g} / \mathrm{mm}^{2}\right)\end{array}$ & $\begin{array}{c}\text { Deposição total de dispositivo } \\
\text { tampográfico }(\mathrm{mg})\end{array}$ & $\begin{array}{c}\text { Percentual de } \\
\text { polimero/papel }\end{array}$ \\
\hline Média & 97,87867049 & 19,5757341 & 1,453141993 \\
\hline Erro padrão & 1,403636128 & 0,280727226 & 0,006498315 \\
\hline Mediana & 96,85766736 & 19,37153347 & 1,448415127 \\
\hline Desvio padrão & 7,6880317 & 1,53760634 & 0,035592739 \\
\hline Variância & 59,10583143 & 2,364233257 & 0,001266843 \\
\hline Curtose & $-0,124811946$ & $-0,124811946$ & $-0,124811946$ \\
\hline Assimetria & 0,413288848 & 0,413288848 & 0,413288848 \\
\hline Intervalo & 29,69244116 & 5,938488231 & 0,137465005 \\
\hline Mínimo & 84,14277407 & 16,82855481 & 1,38954988 \\
\hline Máximo & 113,8352152 & 22,76704304 & 1,527014885 \\
\hline Soma & 2936,360115 & 587,2720229 & 43,59425979 \\
\hline
\end{tabular}




\subsubsection{Caracterização de Formação de Compósito em uma Camada}

Como resultado dos experimentos realizados para caracterização de formação de compósito em uma camada, foi realizado uma análise microscópica em três regiões de cada uma das três amostras.

Na Figura 8.6, é apresentada imagens microscópicas do experimento 3, tendo como variáveis de processo: Laser -- $20 \mathrm{~mW}-1,591549 \mathrm{~mW} / \mathrm{mm}^{2}$, feixe $\varnothing 2 \mathrm{~mm}, \mathrm{Vd}$ $150 \mathrm{~mm} / \mathrm{min}$. Nesta figura, a imagem "a" apresenta uma foto sem contraste, enquanto a "b" apresenta com contraste. Este recurso foi empregado de forma a facilitar a identificação de limites entre partes polimerizadas e não polimerizadas.

Pode-se observar que o perfil de aresta de linha polimerização não é inteiramente constante devida a distribuição de fibras de celulose. Contudo, foi identificado que, em sua maioria, a largura da linha de polimerização segue uma distribuição normal. Pode-se também destacar que não foram identificadas zonas de transição (média polimerização), visto que para identificação desta linha de polimerização, os corpos de prova foram imersos em não-solvente. Com isto, solubilizando qualquer indicativo de zona de transição. 


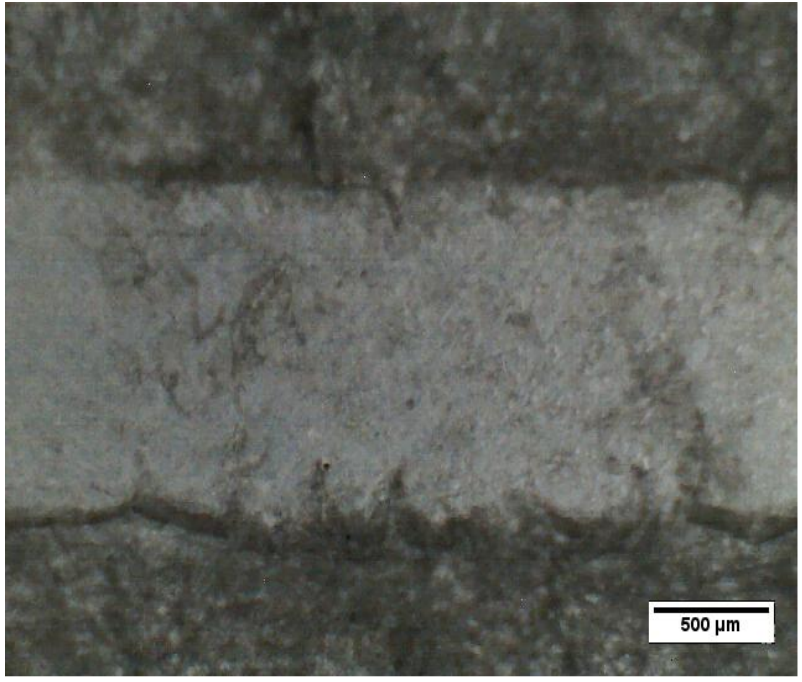

a)

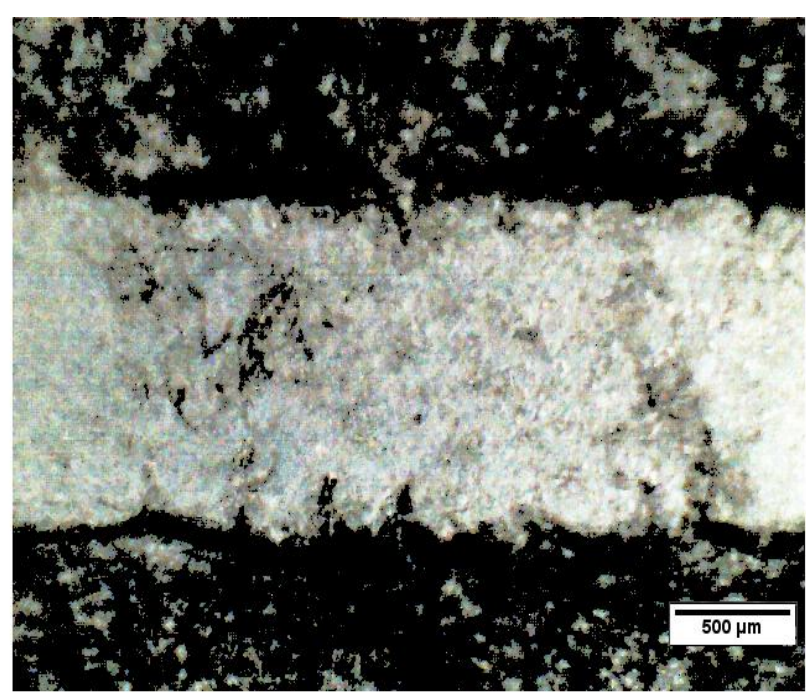

b)

Figura 8.6 - Imagem microscópica de linha de deposição de experimento 3 (Laser $20 \mathrm{~mW}-1,591549 \mathrm{~mW} / \mathrm{mm}^{2}$, feixe $\left.\varnothing 2 \mathrm{~mm}, \mathrm{Vd}-150 \mathrm{~mm} / \mathrm{min}\right)$, onde a) é a imagem microscópica sem contraste e b) é a imagem microscópica com contraste

Os resultados estatísticos deste estudo são apresentados na Tabela 8.6. Nesta tabela, são expostos valores de largura média de linha de polimerização, assim como desvio padrão e variância. Como os dados de cada um dos experimentos foram submetidos a teste de normalidade (teste de Shapiro Wilk ou Teste W), são apresentadas as conclusões sobre o teste, assim como o p-value dos mesmos. Para resultados de teste $\mathrm{W}$ que não apresentaram evidências estatísticas contra a hipótese nula (amostras seguem distribuição normal), foi atribuído, em tabela, a descrição igual a "normal". Por outro lado, para resultados de teste W que apresentaram evidências estatísticas contra a hipótese nula, foi atribuída descrição igual a "Anormal".

Neste estudo, foram identificados poucos casos de anormalidade, contudo, estas indicam uma tendência de limite de janela de operação. Ao analisar os experimentos de 7 a 12 (intensidade de laser $20 \mathrm{~mW}$, diâmetro de feixe de $4 \mathrm{~mm}$ ) a anormalidade foi identificada para velocidades de deslocamento próximas das que resultaram em linha de polimerização indeterminada. Adicionalmente, para estas mesmas velocidades, foram observados os maiores valores de variância de largura. 
Por outro lado, foi também evidenciada uma quantidade grande de anormalidades para alto nível de intensidade de laser.

Com relação à indeterminação de linha de deposição, foi observada sua ocorrência em todas as condições que apresentavam velocidade de deslocamento igual ou inferior a $50 \mathrm{~mm} / \mathrm{min}$. Neste casos, não foi possível observar uma linha de polimerização em função da polimerização periférica ser muito acentuada.

Tabela 8.6 - Relação de variáveis e resultados de estudos de formação de compósito em uma camada

\begin{tabular}{|c|c|c|c|c|c|c|c|c|c|c|}
\hline Exp & Intensity & $\operatorname{Lw}(\mathrm{mm})$ & $\mathrm{Vd}(\mathrm{mm} / \mathrm{min})$ & Média $(\mu \mathrm{m})$ & Desvio Padrão & Variância & $\begin{array}{l}\text { Aderência } \\
\text { em PMMA }\end{array}$ & $\begin{array}{l}\text { Aderência } \\
\text { em Pp }\end{array}$ & $\begin{array}{l}\text { Teste W- } \\
\text { p-value }\end{array}$ & $\begin{array}{l}\text { Teste W- } \\
\text { resultado }\end{array}$ \\
\hline 1 & \multirow{12}{*}{ 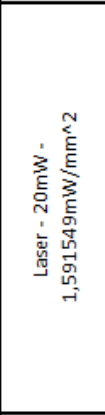 } & \multirow{6}{*}{2} & 50 & \multicolumn{7}{|c|}{ Indeterminated polymerization line -excess of periferical polymerization } \\
\hline 2 & & & 100 & 1.505 & 45 & 245.709 & Sim & Não & 0,0311308 & Normal \\
\hline 3 & & & 150 & 1.459 & 35 & 149.496 & Sim & Não & 0,0992441 & Normal \\
\hline 4 & & & 200 & 1.438 & 43 & 219.465 & Sim & Não & 0,077947 & anormal \\
\hline 5 & & & 250 & \multirow{2}{*}{\multicolumn{7}{|c|}{ Indeterminated polymerization line -lack of polymerization }} \\
\hline 6 & & & 450 & & & & & & & \\
\hline 7 & & \multirow{6}{*}{4} & 50 & \multicolumn{7}{|c|}{ Indeterminated polymerization line -excess of periferical polymerization } \\
\hline 8 & & & 100 & 3.416 & 37 & 165.056 & Sim & Não & 0,0050183 & Anormal \\
\hline 9 & & & 150 & 3.416 & 74 & 648.934 & Sim & Não & 0,0992441 & Normal \\
\hline 10 & & & 200 & 3.442 & 16 & 29.068 & Sim & Não & 0,077947 & Normal \\
\hline 11 & & & 250 & 2.969 & 140 & 2.346 .187 & Sim & Não & 0,0001694 & anormal \\
\hline 12 & & & 450 & & & & & Não & & \\
\hline 13 & \multirow{11}{*}{ 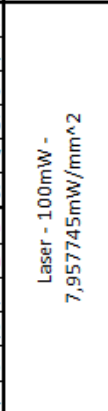 } & \multirow{6}{*}{2} & 50 & \multicolumn{7}{|c|}{ Indeterminated polymerization line -excess of periferical polymerization } \\
\hline 14 & & & 100 & 1.613 & 44 & 228.865 & Sim & Não & 0,6706644 & Normal \\
\hline 15 & & & 150 & 1.687 & 22 & 59.344 & Sim & Não & 0,1172899 & Normal \\
\hline 16 & & & 200 & 1.635 & 35 & 143.612 & Sim & Não & 0,1604423 & Normal \\
\hline 17 & & & 250 & 1.540 & 23 & 64.880 & Sim & Não & 0,8880507 & Normal \\
\hline 18 & & & 450 & 1.517 & 35 & 149.054 & Sim & Não & 0,7880507 & Normal \\
\hline$\frac{19}{20}$ & & \multirow{5}{*}{4} & $\begin{array}{r}50 \\
100\end{array}$ & \multicolumn{7}{|c|}{ Indeterminated polymerization line -excess of periferical polymerization } \\
\hline 21 & & & 150 & 3.356 & 188 & 1.063 .887 & Sim & Não & 0,1957074 & Normal \\
\hline 22 & & & 200 & 3.224 & 77 & 177.219 & Sim & Não & 0,0016628 & anormal \\
\hline 23 & & & 250 & 3.168 & 123 & 456.861 & Sim & Não & $1,861 \mathrm{E}-05$ & anormal \\
\hline 24 & & & 450 & 2.715 & 188 & 1.056 .357 & Sim & Não & $3,861 \mathrm{E}-05$ & anormal \\
\hline
\end{tabular}

A variação de larguras médias observadas para diâmetro de feixe de laser de 2 $\mathrm{mm}$ foi de: 1438 a $1505 \mu \mathrm{m}$ para intensidade de laser de $20 \mathrm{~mW}$ e 1540 a $1687 \mu \mathrm{m}$ para intensidade de laser de $100 \mathrm{~mW}$. Enquanto para diâmetro de feixe de laser de $4 \mathrm{~mm}$, foi de 2969 a $3442 \mu \mathrm{m}$ para intensidade de laser de $20 \mathrm{~mW}$ e 3168 a $3356 \mu \mathrm{m}$ para intensidade de laser de $100 \mathrm{~mW}$.

Apesar da possibilidade de identificação de linha de polimerização, os experimentos que utilizaram laser de intensidade maior apresentaram maior nível de 
polimerização periférica (regiões não expostas diretamento ao laser), assim como maior incidência de anormalidades.

Este tipo de comportamento pode ser observado na Figura 8.7, onde são apresentadas imagens microscópicas a) experimento 16 (Laser - 100mW 7,957745mW/mm2, feixe $\varnothing 2 \mathrm{~mm}$, Vd $-200 \mathrm{~mm} / \mathrm{min}$ ), e b) experimento 3 (Laser $20 \mathrm{~mW}$ - 1,591549mW/mm2, feixe $\varnothing 2 \mathrm{~mm}, \mathrm{Vd}-150 \mathrm{~mm} / \mathrm{min})$. Visto que foram aplicados os mesmos filtros de contraste em ambas as imagens, pode-se observar claramente a acentuação de polimerização periférica para o experimento 16 . E consequentemente, interferindo na homogeneidade da linha de polimerização.

Cabe ressaltar que este comportamento foi observado para todas as intensidades e diâmetros de feixe de laser estudados neste trabalho ao considerar velocidade de deslocamento igual ou inferior a $50 \mathrm{~mm} / \mathrm{min}$.

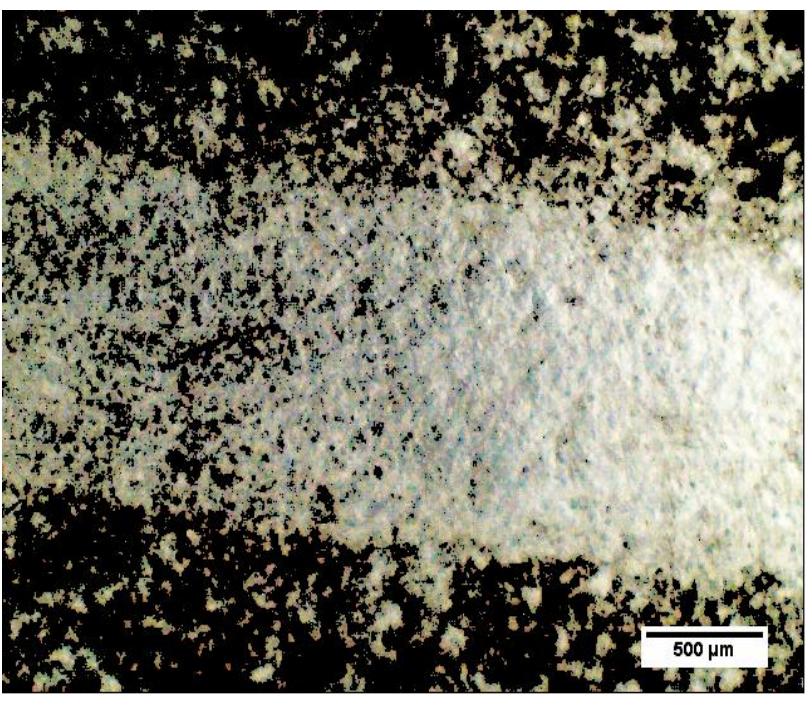

a)

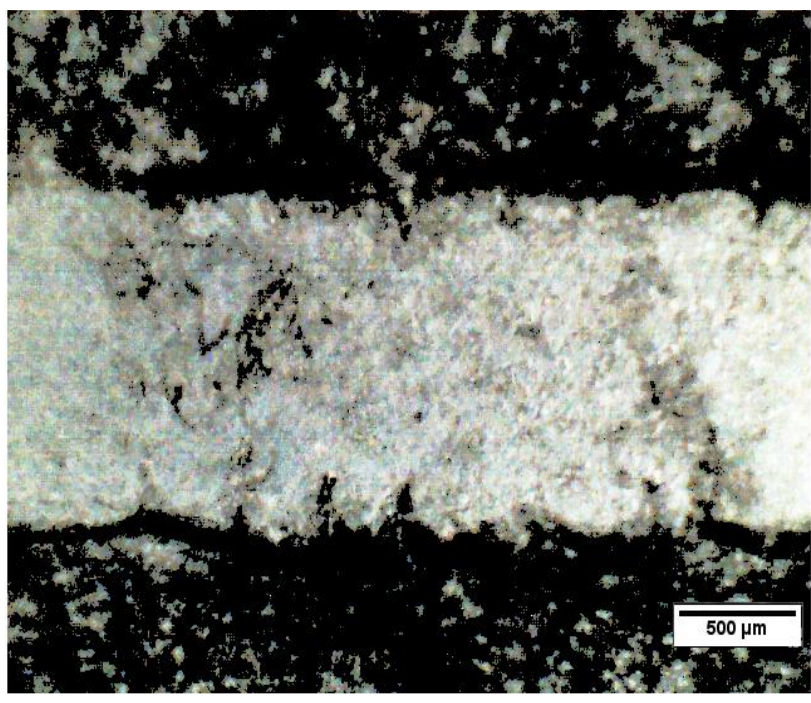

b)

Figura 8.7 - Imagens microscópica de linhas de deposição de: a) experimento 16 (Laser - 100mW - 7,957745mW/mm², feixe $\varnothing 2 \mathrm{~mm}, \mathrm{Vd}-200 \mathrm{~mm} / \mathrm{min})$, e b) experimento 3 (Laser - 20mW - 1,591549mW/mm², feixe $\varnothing 2 \mathrm{~mm}, \mathrm{Vd}$ $150 \mathrm{~mm} / \mathrm{min}$ ), sendo que ambos apresentam mesmo grau de contraste

Como conseqüência deste comportamento, pode-se indicar um comportamento diferente de tecnologias com princípio funcional semelhantes, como estereolitografia (SLA). Ao contrário da SLA, cujo perfil de linha de polimerização é parabólico, o 
processo proposto apresenta uma propagação de luminosidade ortogonal ao feixe de laser. Isto pode ser explicado ao considerar que o substrato é composto por fibras orientadas aleatoriamente, proporcionando a difração dos raios de luz e, conseqüentemente, a propagação da polimerização em zonas periféricas (regiões não expostas diretamente à luz).

Adicionalmente, a incidência de polimerização periférica não pode ser observada devido à intensidade luminosa ser inferior. Com isto, a taxa de propagação ortogonal da luz é reduzida, assim como a energia de iniciação da polimerização. Logo, considerando que esta energia é reduzida ao ponto do iniciador não alcançar o estado triplo de excitação, o material não é polimerizado.

Como conseqüência de tal comportamento, pode-se observar um indicativo problema em potencial para o processo de formação seletiva de compósito a ser analisado. Entre os diversos problemas que resultariam deste comportamento, destaca-se a redução de controle dimensional. Contudo, este comportamento poderia ser minimizado ou solucionado através da redução do tempo de exposição do laser (aumento de velocidade de deslocamento). Sobretudo, este tipo de estudo de otimização do processo deve ser realizado em estudos futuros.

Por outro lado, pode-se utilizar este tipo de técnica aliada a utilização de fonte de luz extensa para a fabricação de chapas de compósito de acríllico celulose em múltiplas camadas.

Com relação à aderência com plataforma, esta tabela apresenta o resultado positivo ou negativo obtido para plataforma de PMMA e de PP. Em todos os expeirmentos foi observada aderência de compósito recém polimerizado com plataforma de PMMA, sendo também observada a situação oposta para a plataforma de PP.

Adicionalmente, o comportamento de largura de polimerização em relação à velocidade de deslocamento, intensidade de laser e diâmetro de feixe de laser pode ser observado graficamente na Figura 8.8.

Pode-se observar que para diâmetro feixe de laser de $2 \mathrm{~mm}$, a diferença de intensidade de laser proporcionou o aumento da largura de linha de deposição. Contudo, para diâmetro de $4 \mathrm{~mm}$, isto não pode ser evidenciado. 
Para ambos os casos onde foi utilizada uma intensidade de laser igual a $20 \mathrm{~mW}$, foi observada uma tendência de queda da largura da linha de polimerização em função da velocidade de deslocamento. Adicionalmente, foi observado que para o diâmetro de feixe de $2 \mathrm{~mm}$ a velocidades inferiores a $50 \mathrm{~mm} / \mathrm{min}$ e superiores a $250 \mathrm{~mm} / \mathrm{min}$ proporcionaram indeterminação de linha de polimerização. Para valores superiores a $250 \mathrm{~mm} / \mathrm{min}$, a indeterminação da linha de polimerização se deve pelo baixo nível de conversão resultante da baixa intensidade luminosa por área por tempo. Adicionalmente, estes baixos níveis de polimerização não puderam ser observados pois foram removidos junto com material residual na imersão dos corpos de prova em não solvente. 

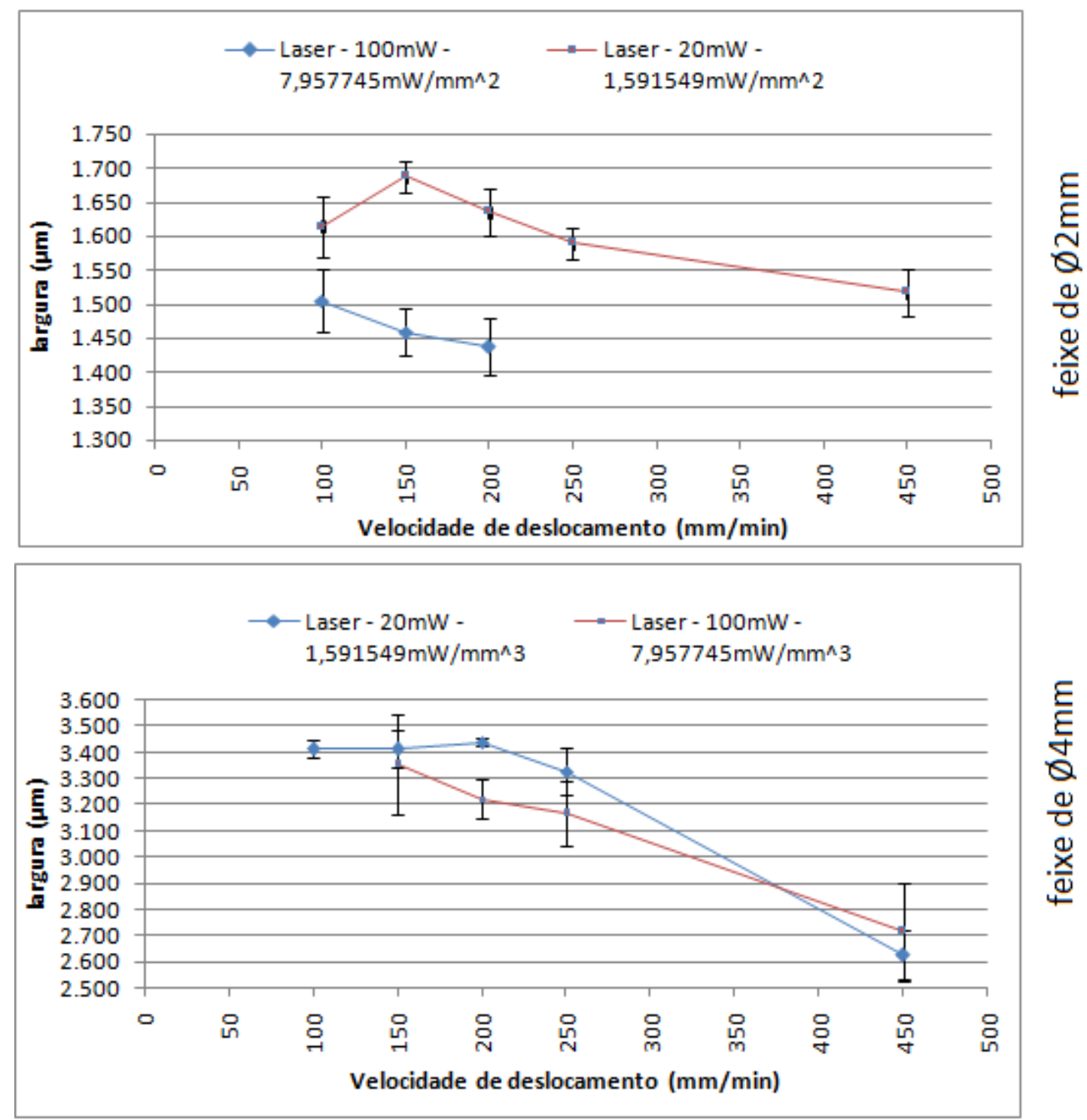

Figura 8.8 - Relação de largura de linha de polimerização em função de velocidade de deslocamento, intensidade de laser e diâmetro de feixe de laser

Para os casos onde o diâmetro de feixe de laser foi de $\varnothing 4 \mathrm{~mm}$, foi realizado um teste T (student test), que permite identificar estatisticamente se duas condições experimentais apresentam as mesmas médias e variâncias. Como resultado, foi identificando que os lasers de 20 e 100mW apresentaram a média e variância.

Sobretudo, este estudo apresentou um indicativo de viabilidade do processo, visto que foram encontrados diversos resultados com comportamento normal, repetibilidade, baixa polimerização periférica e controle dimensional de linhas de polimerização. 


\subsubsection{Caracterização de Formação de Compósito em Múltiplas Camadas}

Com relação ao estudo de formação de compósito em múltiplas camadas, foi realizado um levantamento do número máximo de camadas aderidas em função de velocidade de deslocamento, intensidade de laser e diâmetro de feixe de laser.

$\mathrm{Na}$ Tabela 8.7, são expostos os resultados de profundidade de penetração (número de camadas com aderência superior a $2 \mathrm{MPa}$ ), assim como os valores de variáveis: intensidade de laser, diâmetro de feixe de laser (Lw) e velocidade de deslocamento.

Tabela 8.7 - Matriz de variáveis e resultado de número de camadas aderidas em passe único (profundidade de penetração)

\begin{tabular}{|c|c|c|c|c|}
\hline Exp & \begin{tabular}{|l|} 
Potência/ \\
Intensitade \\
\end{tabular} & $\mathrm{Lw}(\mathrm{mm})$ & $\mathrm{Vd}(\mathrm{mm} / \mathrm{min})$ & $\mathrm{N}^{\circ}$ de camadas \\
\hline 1 & \multirow{4}{*}{ 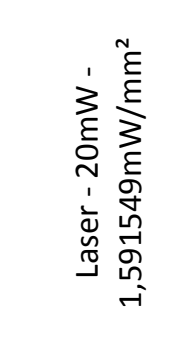 } & 2 & 100 & 1 \\
\hline 4 & & 4 & 100 & 1 \\
\hline 5 & & 2 & 450 & 0 \\
\hline 6 & & 4 & 450 & 0 \\
\hline 1 & \multirow{4}{*}{ 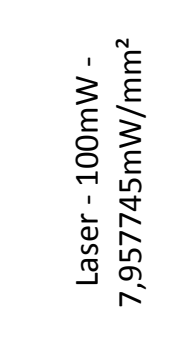 } & 2 & 100 & 4 \\
\hline 4 & & 4 & 100 & 4 \\
\hline 5 & & 2 & 450 & 0 \\
\hline 6 & & 4 & 450 & 0 \\
\hline
\end{tabular}

Pode-se observar que para a faixa de valores estudada, o diâmetro de feixe de laser não apresentou efeito sobre o número de camadas aderidas (profundidade de penetração). Já o aumento da velocidade de deslocamento proporcionou a falta de aderência entre camadas anteriores. Outra variável que também apresentou efeito sobre a profundidade de penetração é a intensidade de laser. Contudo, deve-se ressaltar que apesar desta aderência estar em torno de 4 camadas para laser de 100mW, pode-se observar a incidência de polimerização periférica. 
Através destes resultados, pode-se ressaltar que a profundidade de penetração esta ligada à intensidade luminosa por área, sendo que o tempo de exposição contribui para o aumento do nível de conversão, e não da profundidade. Consequentemente, pode-se atribuir uma taxa de número de camadas por intensidade igual a $(\mathrm{n}=0.471239 \cdot I+0,25)$, onde, $\mathrm{n}$ é o número de camadas e a intensidade ( $\left(\right.$ ) é expressa em $\left[\mathrm{mW} / \mathrm{mm}^{2}\right]$.

Este tipo de comportamento se mostra semelhante ao da estereolitografia, que indica a profundidade de penetração Dp como a nível máximo de espessura que efetivamente é possível polimerizar com um nível de conversão superior a $30 \%$ (GIBSON et al., 2010). Logo, mesmo que se reduza a velocidade de deslocamento do laser, a espessura polimerizada continuará constante.

\subsubsection{Caracterização de Funcionalidade de Conceito}

Com relação à caracterização de funcionalidade do conceito de processo proposto neste trabalho, foi realizado um estudo com objetivo de identificar a possibilidade de fabricação de objetos. Neste estudo, foram conceccionados 4 corpos de prova conforme planejamento de experimentos apresentado na secção 8.2.4.

Foi observado que entre a faixa de valores de parâmetros de processo estudados, o laser de intensidade $100 \mathrm{~mW}$ proporcionou distorção dimensional muito grande, inviabilizando o processo nas faixas de valores de parâmetros estudados.

Na Figura 8.9 são apresentadas imagens de corpo de prova confeccionado com Intensidade de laser $100 \mathrm{~mW}$, diâmetro de feixe de laser $2 \mathrm{~mm}$, velocidade de deslocamento $700 \mathrm{~mm} / \mathrm{min}$ e ângulo de orientação de varredura $90^{\circ}$. 


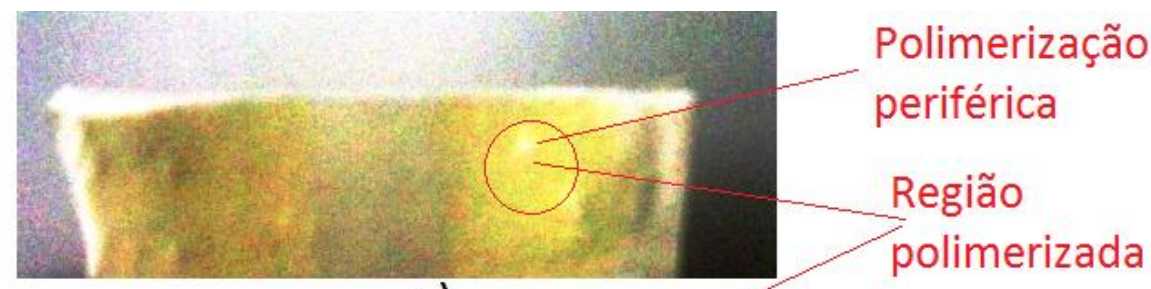

a)

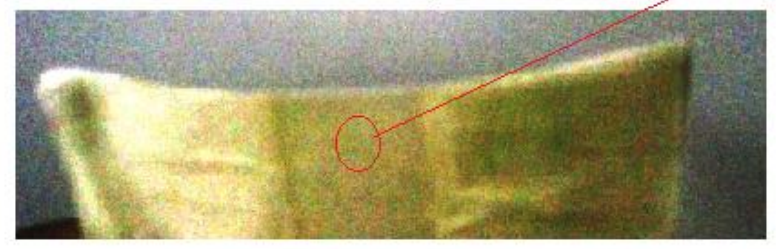

b)

Figura 8.9 - Fotos de secção transversão de corpo de prova confeccionado com Intensidade $100 \mathrm{~mW}$, diâmetro de feixe de laser $2 \mathrm{~mm}$, velocidade de deslocamento $700 \mathrm{~mm} / \mathrm{min}$ e ângulo de orientação de varredura $90^{\circ}$ antes de remoção de material residual, onde a) parte interior do corpo deprova e b) parte superior do corpo de prova

Por este motivo, os experimentos que apresentavam intensidade de laser de $100 \mathrm{~mW}$ como variável não foram realizados. Contudo, cabe ressaltar que esta intensidade de laser somente inviabiliza o processo para a faixa de valores estudados, devendo ser estudado futuramente faixas diferentes.

Uma explicação para a ocorrência deste problema pode ser relacionado ao perfil de polimerização gerado por este processo. Ao contrario da SLA, cujo perfil de polimerização é parabólico, foi observado que o processo proposto apresenta uma dispersão luminosa lateral proveniente da incidência dos raios de luz nas fibras de celulose. Consequentemente, pode ser observada uma polimerização periférica à área de incidência do laser (linha de polimerização).

Uma comparação entre o perfil de polimerização observado no processo proposto e a SLA é ilustrado na Figura 8.10. Contudo, esta figura apresenta uma estimafiva deste perfil, devendo este ser apurado em trabalhos futuros. 


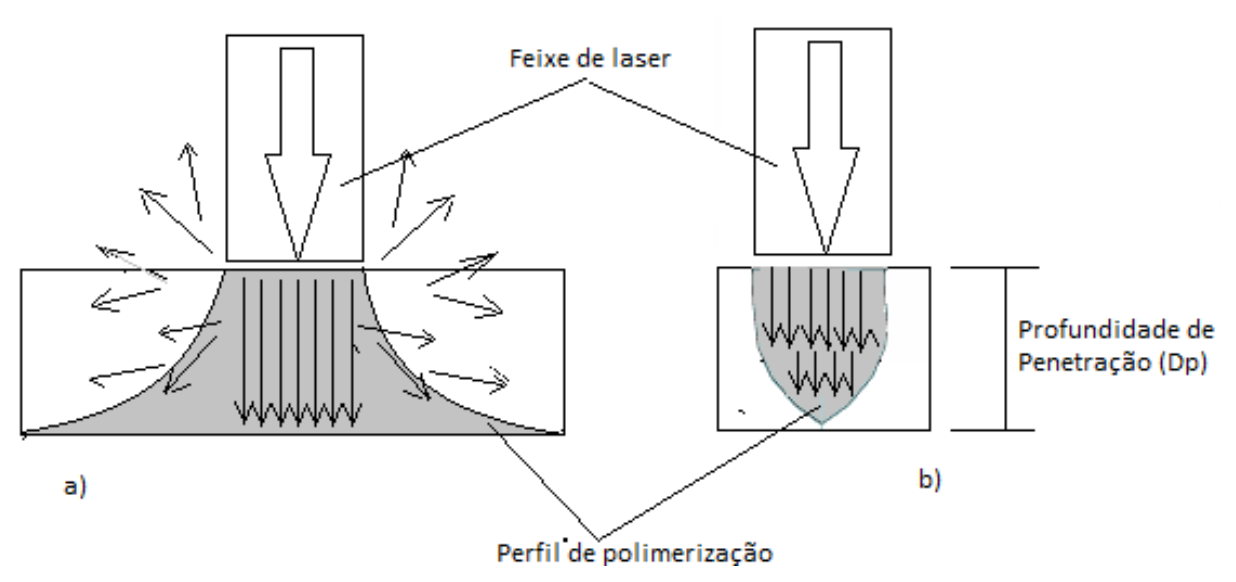

Figura 8.10 - Representação genérica de perfil de cura gerados por deslocamento de laser em a) processo de formação seletiva de compósito (proposta do trabalho) e b) estereolitografia (SLA)

Sobretudo, ao analisar os corpos de prova confeccionados com valores intensidade de laser inferiores $(20 \mathrm{~mW})$, torna-se possível observar a viabilidade funcional do processo. A Figura 8.11 apresenta imagens de corpos de prova confeccionados com Intensidade de laser igual a $20 \mathrm{~mW}$, diâmetro de feixe de laser igual a $2 \mathrm{~mm}$, velocidade de deslocamento $250 \mathrm{~mm} / \mathrm{min}$ e ângulo de orientação de varredura igual a $90^{\circ}$ (a) e $0^{\circ}(\mathrm{b})$. 


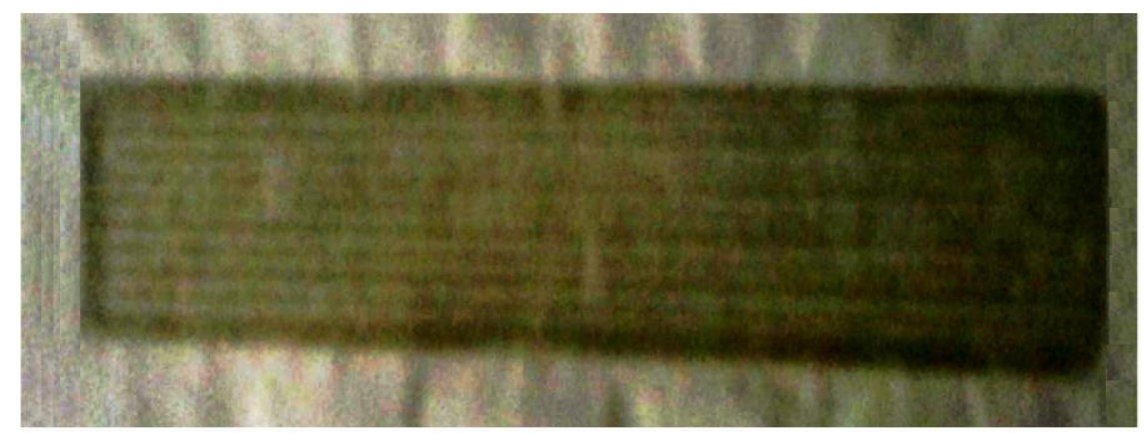

a)

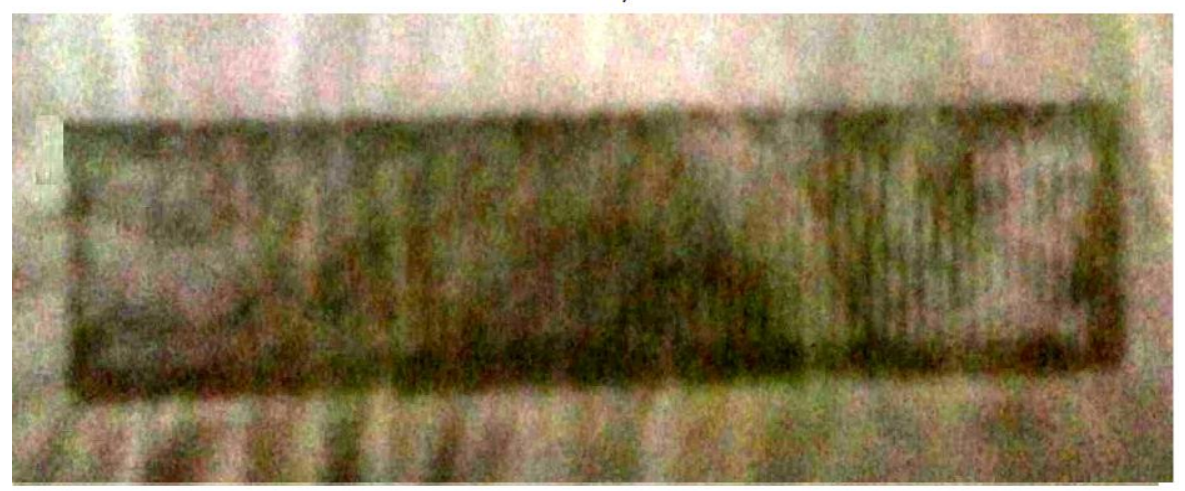

b)

Figura 8.11 - Imagens de corpos de provas confeccionados com Intensidade $20 \mathrm{~mW}$, diâmetro de feixe de laser $2 \mathrm{~mm}$, velocidade de deslocamento $250 \mathrm{~mm} / \mathrm{min}$ e a) ângulo de orientação de varredura $90^{\circ}$; b) ângulo de orientação de varredura $0^{\circ}$; antes de remoção de material residual

Em contraste com a viabilidade funcional observada, cabe também ressaltar a dificuldade encontrada no início do processo de exposição de laser. Devido ao circuito eletrônico de controle do laser, o início direto (via relê) proporciona um pico de corrente, e, consequentemente, um pico de intensidade luminosa. Desta forma, foi ocasionado um foco de formação periférica de polímero na região de início de fabricação de camada, como pode ser observado na Figura 8.12.

Para solucionar este problema, foi incluído um circuito de amortecimento eletrônico resistivo-capacitivo $(R C)$ após o acionamento do relê. Desta forma, fazendo com que o laser aumente e diminua sua intensidade gradativamente após acionamento do relê do CLP. 


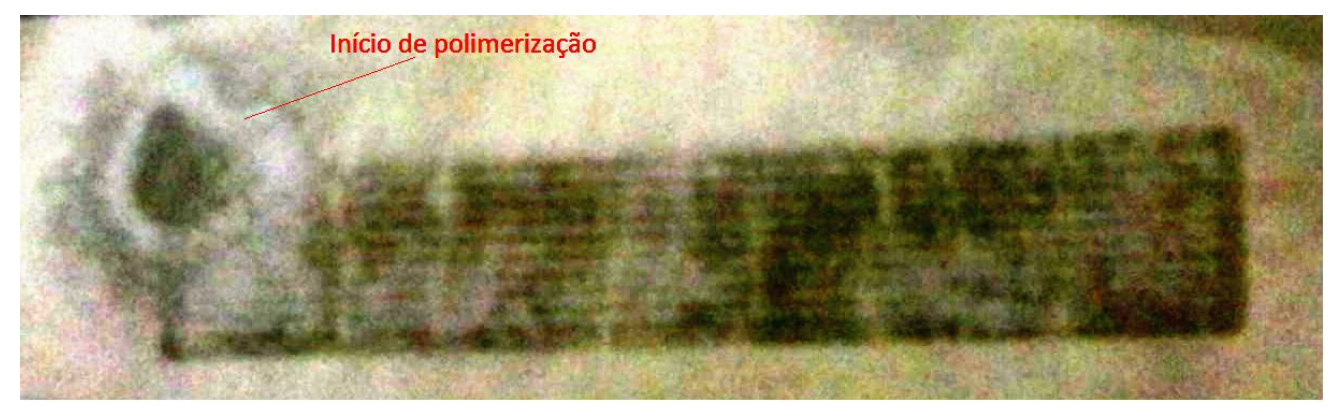

Figura 8.12 - Imagens de foco de polimerização periférica em início de polimerização de corpos de provas confeccionados com Intensidade $20 \mathrm{~mW}$, diâmetro de feixe de laser $2 \mathrm{~mm}$, velocidade de deslocamento $250 \mathrm{~mm} / \mathrm{min}$ e ângulo de orientação de varredura $90^{\circ}$; antes de remoção de material residual

A Tabela 8.8 apresenta a relação dos resultados encontrados no estudo de caracterização de funcionalidade do conceito. Nesta tabela, pode-se observar a variação dimensional dos corpos de prova, assim como os valores de tensão de ruptura obtidos por esforço de tração.

Foi possível observar que a para velocidades de $450 \mathrm{~mm} / \mathrm{min}$, foi evidenciada a falta de aderência entre camadas, inviabilizando a funcionalidade do processo para construção de objetos 3d.

Da mesma forma, foi observada a inviabilidade do processo em função de altos valores de intensidade de laser $(100 \mathrm{~mW})$. Neste caso, foi observada uma deformação excessida provocada por polimerização periférica.

Tabela 8.8 - Relação de valores de respostas do estudo de caracterização de funcionalidade de conceito

\begin{tabular}{|c|c|c|c|c|c|c|c|c|c|}
\hline $\exp$ & $\begin{array}{c}\text { Orientação de } \\
\text { varredura }\end{array}$ & & $\begin{array}{l}\text { ocidade de } \\
\text { slocamento }\end{array}$ & & ensidade lumino & $W(\mathrm{~mm})$ & $\mathrm{L}(\mathrm{mm})$ & $h(\mathrm{~mm})$ & Tensão (Mpa) \\
\hline & $(-) 0^{\circ}$ & $(-)$ & $250 \mathrm{~mm} / \mathrm{min}$ & $(+)$ & $100 \mathrm{~mW}(8 \mathrm{~mW}$ & \multirow{2}{*}{\multicolumn{4}{|c|}{$\begin{array}{c}\text { Distorção dimensional excessiva } \\
\text { Falta de aderência entre camadas }\end{array}$}} \\
\hline & $(-) 0^{\circ}$ & $(+)$ & $450 \mathrm{~mm} / \mathrm{min}$ & $(-)$ & $20 \mathrm{~mW}\left(1,6 \mathrm{~mW} / \mathrm{mm}^{2}\right)$ & & & & \\
\hline 3 & $(+) 90^{\circ}$ & $(-)$ & /min & $(-)$ & $20 \mathrm{~mW}\left(1,6 \mathrm{~mW} / \mathrm{mm}^{2}\right)$ & 12 & 62,5 & 1,83 & 31,67 \\
\hline 4 & $(+) 90^{\circ}$ & $(+)$ & $450 \mathrm{~mm} / \mathrm{min}$ & $(+)$ & $100 \mathrm{~mW}\left(8 \mathrm{~mW} / \mathrm{mm}^{2}\right)$ & \multicolumn{4}{|c|}{ Distorção dimensional excessiva } \\
\hline 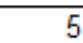 & $(-) 0^{\circ}$ & $(-)$ & $250 \mathrm{~mm} / \mathrm{min}$ & $(-)$ & $20 \mathrm{~mW}\left(1,6 \mathrm{~mW} / \mathrm{mm}^{2}\right)$ & 12 & 61,5 & 1,8 & 15,46 \\
\hline 6 & $(-) 0^{\circ}$ & $(+)$ & hin & $(+)$ & $\left.\mathrm{mW} / \mathrm{mm}^{2}\right)$ & \multicolumn{4}{|c|}{ Distorção dimensional excessiva } \\
\hline 7 & $(+) 90^{\circ}$ & $(-)$ & $250 \mathrm{~mm} / \mathrm{min}$ & $(+)$ & $100 \mathrm{~mW}\left(8 \mathrm{~mW} / \mathrm{mm}^{2}\right)$ & \multicolumn{4}{|c|}{ Distorção dimensional excessiva } \\
\hline 8 & $(+) 90^{\circ}$ & $(+)$ & $450 \mathrm{~mm} / \mathrm{min}$ & $(-)$ & $20 \mathrm{~mW}\left(1,6 \mathrm{~mW} / \mathrm{mm}^{2}\right)$ & \multicolumn{4}{|c|}{ Falta de aderência entre camadas } \\
\hline
\end{tabular}


Neste estudo, foi possível observar apenas uma combinação de intensidade de laser e velocidade de deslocamento que torna o processo viável, onde: a velocidade de deslocamento é igual a $250 \mathrm{~mm} / \mathrm{min}$ e a potência do laser é de $20 \mathrm{~mW}$.

Com relação às respostas do planejamento de experimentos, foi possível encontrar valores dimensionais de corpo de prova com variação dimensional máxima de $0.5 \mathrm{nmm}$, enquanto os valores máximos e mínimos de resistência mecânica à tração foram de 31,67 e 15,46 MPa, respectivamente. Em adição, as curvas de tensão-deformação destas duas combinações de parâmetros de processo são apresentadas na Figura 8.13.

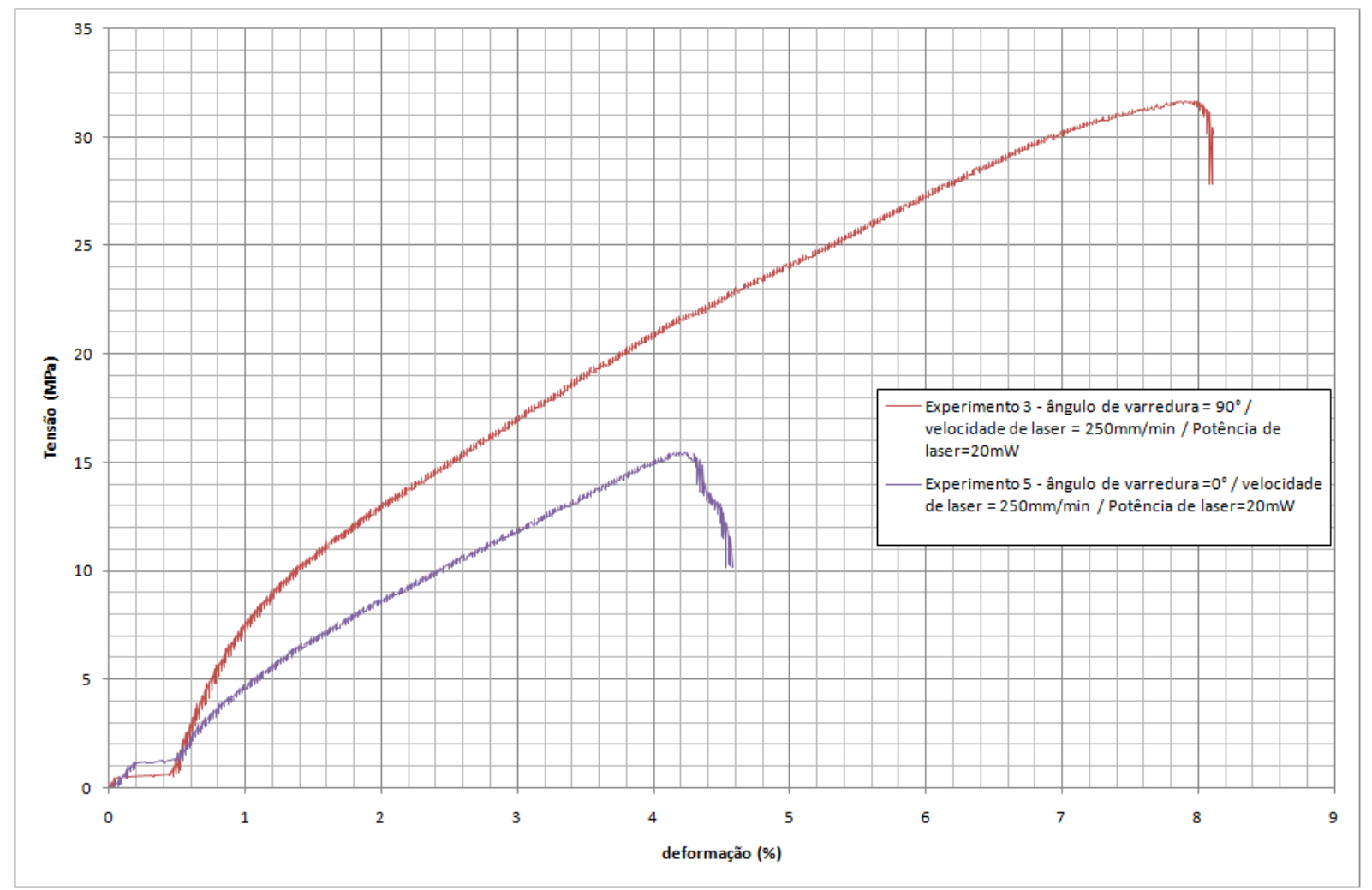

Figura 8.13 - Curva de tensão-deformação de corpos de provas fabricados nos experimentos 3 e 5, sendo a variável de processo avaliada igual ao ângulo de varredura da trajetória do laser.

Com relação à variação da resistência mecânica à tração encontrada em função da angulação da estratégia de varredura do laser, foi possível observar que a 
anisotropia do material ao longo do plano $X Y$ pode ser controlada através de um parâmetro de processo.

Foi também observada variação dimensional em função do ângulo de varredura da trajetória de deslocamento, sendo o desvio padrão do comprimento $(L)$ igual a $0.5 \mathrm{~mm}$. Outra variação dimensional observada esta relacionada à altura $(\mathrm{h})$ do objeto. Neste caso, um dos corpos de prova apresentou variação de $0.03 \mathrm{~mm}$.

Sobretudo, através desta investigação, foi possível identificar a viabilidade funcional da proposta de processo apresentada neste trabalho.

Outro aspecto que também foi observado na contrução dos corpos de prova é a ocorrência de bolhas e micro-bolhas de ar provenientes de espaços vazios entre as fibras. Estas bolhas podem ser observadas na Figura 8.14.

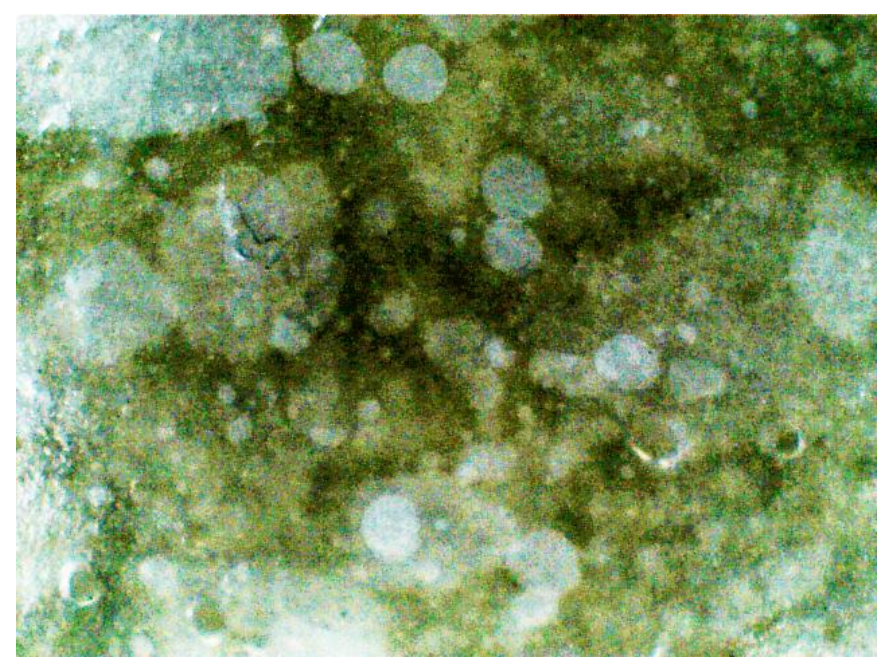

Figura 8.14 - Imagens de micro-bolhas observadas em corpos de prova

Logo, a redução de incidência de bolhas é um ponto importante a ser estudado em trabalhos futuros, visto que estas bolhas acentuam a heteregeneidade do material, e assim, a perda de resistência mecânica. 


\section{ANÁLISE DE VIABILIDADE E FUNCIONALIDADE}

Neste capítulo são apresentadas discussões sobre a viabilidade funcional e posicionamento tecnológico do processo de manufatura aditiva proposto neste trabalho. São expostas características que mostram a funcionalidade e potencialidade da proposta, assim como problemas intrísecos da concepção. São adicionalmente comparadas estes características com as de outras tecnologias como Estereolitografia (SLA), Modelagem por Fusão e deposição (FDM), Modelagem de objeto laminado (LOM) e Sinterização seletiva por laser (SLS). Desta forma, é permitida a identificação da aplicabilidade do processo proposto, assim como do posicionamento de mercado.

É também apresentado o posicionamento tecnológico da proposta, indicando os pontos a serem desenvolvidos para que esta proposta seja efetivamento um produto. Como por exemplo, a automatização do sistema de alimentação de substrato e sistema de alimentação.

\subsection{Análise de Viabilidade Funcional}

Com relação ao estudo de viabilidade do processo proposto, teve-se como objetivo principal a caracterização básica do processo de forma a identificar a possibilidade de fabricação de um objeto de forma simples.

Como observado na secção 8.3.4, foi possível confeccionar corpos de prova com precisão equivalente a processos convencionais, assim como processos de manufatura aditiva. Com relação ao controle dimensional, foi obtida distorção máxima de $0,5 \mathrm{~mm}$ no processo proposto, enquanto para SLA, esta distorção podese chegar a até $0.4 \mathrm{~mm}$ (MAHESH et al., 2004). Adicionalmente, a divergência encontrada em processos SLS e FDM pode chegar a até $0.9 \mathrm{~mm}$ e $0.5 \mathrm{~mm}$, respectivamente (MAHESH et al., 2004). Já para LOM, esta distorção pode chegar a 0.97mm (MAHESH et al., 2004), evidenciando a equivalência da proposta com tecnologias correntes em estágios iniciais de desenvolvimento. 
Com relação à linha de forma de geração de camadas, foi identificado que o processo proposto gera linhas de polimerização mínima de aproximadamente $1.5 \mathrm{~mm}$. Apesar de este valor aparentar ser alto, fases iniciais de desenvolvimento de tecnologias FDM apresentam valores de largura de filamento entre 0,254 de 2,54mm (NG et al., 2002). Estes valores também se apresentam próximo da faixa recomendada pelo fabricande do equipamento FDM 1650, onde é recomenda faixa de largura de filamento entre 0,254 e 1,47mm (COMB et al., 2003; GIBSON et al., 2010).

Já, ao comparar com tecnologias de SLA atuais, onde o diâmetro de feixe de laser varia de 80 a 760 $\mathrm{mm}$ (GIBSON et al., 2010), a proposta de processo se mostra mais bruta. Contudo, ao considerar que a largura de linha de polimerização é dependente do diâmetro de feixe de laser, a aplicação direta de diâmetro de orifício de restricção inferior proporcionaria um valor de largura de polimerização menor.

Com relação à resolução de camadas, a proposta de processo apresenta valor de camada de $33 \mu \mathrm{m}$, sendo um valor inferior ao padrão de FDM $(254 \mu \mathrm{m})$, SLA $(50 \mu \mathrm{m})$, SLS $(150 \mu \mathrm{m})$ e LOM $(200 \mu \mathrm{m})$ (GIBSON et al., 2010).

Pode-se ressaltar que ao contrário de tecnologias de SLA e FDM, a proposta apresentada neste trabalho não necessita de material suporte, e desta forma, assemelhando-se de processos de SLS, LOM e 3D Printing. Por outro lado, é evidenciada a incidência de material residual não reutilizável, assim como LOM. No caso de em Processos SLS e 3D Printing, este material é reaproveitado, visto que o substrato empregado é à base de pó.

Ao comparar esta proposta de processo com processo LOM, torna-se também possível identificar que a forma de remoção de material residual (água) é mais ágil e tende a causar menor dano aos objetos. É também possível observar que, ao contrário de processos LOM a base de papel, esta proposta de processo também proporciona peças com resistência à água. Foi também observada uma resistência mecânica pelo menos duas vezes superior às resistências encontradas em tecnologias LOM.

Ao comparar a velocidade de fabricação obtida nesta proposta, até o momento, com concepções comerciais, pode-se observar que o processo proposto $(250 \mathrm{~mm} / \mathrm{min})$ é quase 10 vezes mais lento que os valores baixos da SLA ou FDM 
(2000mm/min) (3DSYSTEMS, 2010b; GIBSON et al., 2010; 3DSYSTEMS, 2011b; a). Desta forma, faz-se ainda necessária a otimização e aumento da velocidade de varredura para viabilizar a tecnologia a nível comercial.

Por outro lado, esta proposta de processo apresentou a ocorrência de bolhas de ar provenientes de espaços vazios entre as fibras de celulose, indicando a falta potencial de homogeneidade de objetos fabricados por esta tecnologia. Logo, devem-se investigar formas de deposição de resina que proporcionem o escape de ar retido e a conseqüente eliminação de bolhas de ar.

Ao considerar os valores de resistência à tração encontrados neste estudo (entre 15,46 e 37,67MPa), foi possível identificar valores proximos aos de processos convensionais, como molde de injeção (20 e $60 \mathrm{MPa}$ ), ou mesmo processos aditivos, como FDM (entre 22 e $71 \mathrm{MPa}$ ) (REDEYE, 2011) e SLA (entre 28 a $78 \mathrm{MPa}$ ) (JACOBS et al., 1992; COOPER, 2001; LIOU, 2007; 3DSYSTEMS, 2008e; d; b; c; a; f; 2009; 2010b; a; GIBSON et al., 2010).

Outro aspecto que também deve ser ressaltado é a tendência de melhoria de comportamento mecânica do material devido às fibras de celulose. Entre estas características está o aumento a resistência a impacto e o aumento de resistência à temperatura, contudo, estas propriedades, entre outras, devem ser analisadas em estudos futuros.

\subsection{Análise de Posicionamento Tecnológico}

A proposta de processo apresentada neste trabalho se encontra ainda em fase preliminar, sendo apenas avalidada a funcionalidade desta nova concepção. Desta forma, para que esta proposta se torne um produto, faz-se ainda necessário que sejam implementados e automatizados os sistemas de deposição e sistema de alimentação de substrato.

Adicionalmente, após a implementação destes sistemas, torna-se possível analisar a potencialidade do processo, assim como suas restrições. Neste caso, é necessário que seja avaliada a capabilidade de construção de geometrias 
complexas, geometrias suspensas, geometrias formadas por cascas, espessura mínima de parede e degraus formados por em superfíces rasas.

Para identificar a aplicabilidade do processo, é também importante que seja realizada uma caracterização detalhada das propriedades físico-mecânicas do material compósito. Desta forma, é possível observar a contribuição desta tecnologia para uma aplicação ou indústria especifica. E da mesma forma, o aumento da velocidade de construção de camada é necessário para viabilização da aplicabilidade do conceito.

Outro aspecto que deve ser também observado em estudos futuros é a viabilidade econômica do processo e da matéria prima. Cabe ressaltar que não há tecnologia de manufatura aditiva nacional, sendo apenas fabricados nacionalmente FDM de baixo custo e baixa precisão. Sobretudo, o lançamento de um processo industrial nacional baseado em compósitos visa um novo nicho de mercado ainda não explorado. 


\section{CONCLUSÕES}

Neste capítulo são apresentadas as conclusões obtidas nos estudos de pesquisas de fundamentação desenvolvidas ao longo deste trabalho, assim como das atividades experimentais referentes à validação da concepção de processo aditivo proposto.

Adicionalmente, são apresentados alguns estudos em potencial a serem desenvolvidos no futuro, dando, desta forma,continuidade a este projeto.

\subsection{Desenvolvimento de Material}

\subsubsection{Material Celulósico}

Em relação ao desenvolvimento de material, pode ser observada a indicação de materiais celulósicos apropriados para ser utilizado no processo de fabricação aditivo proposto, papel tipo seda, sendo seguido de papel vegetal.

Para a determinação deste material, foram identificadas as propriedades dos papéis: Vegetal, Sulfite, Sulfurizé e seda. Sendo identificada a menor opacidade para o papel vegetal. Neste caso, foi identificado o papel tipo seda como o segundo menos opaco. Em adição, os valores de opacidade deste material molhado se aproximaram dos valores do papel vegetal seco, sendo estes inferiores a $65 \%$.

Em relação à opacidade dos papéis sulfurizé e sulfite, ambos apresentaram valores superiores à 85\% mesmo em presença de água, implicando na utilização de fonte luminosa 2.3 vezes mais potente para implementação do projeto proposto.

Já em relação dos valores de resistência à tração, foram encontradosos maiores valores de tensão de ruptura para o papel vegetal (27.32MPa), sendo seguido do papel tipo seda (15.22MPa). Contudo ao considerar os materiais em presença de água, pode-se indicar o papel sulfurizé como o mais resistente, sendo encontrado valor de tensão de ruptura em presença de água igual aproximadamente 
$2 \mathrm{MPa}$. Isto se deve ao fato deste material apresentar baixos valores de absorção devido ao tratamento químico e branqueamento do processo de fabricação do papel.

Em contraste com estes resultados, a taxa de absorção do papel seda se mostrou muito superior aos outros papéis, indicando o maior nível de porosidade deste papel. Isto pode ser conseqüência da utilização de processo mecânico para a geração de polpa de celulose.

No papel seda, também pode ser observada através de análise micrografica a abstinência de tratamento químico e branqueamento em adição a apresentar a menor espessura e gramatura entre os materiais celulósicos estudados. Através deste estudo, foi possível também observar que o papel do tipo seda mostra o maior comprimento de fibras entre os quatro materiais celulósicos analisados.

\subsubsection{Material Polimérico}

Com referência ao desenvolvimento do material polimérico, foi possível observar a influência dos teores dos componentes químicos constituintes do material fotopolimérico para a viscosidade, taxa de polimerização, resistência mecânica à tração, módulo de elasticidade por flexão e temperatura de trabalho do material. Em adição, foi identificada a formulação de material mais adequada para ser utilizada neste trabalho apartir de estudo de otimização estatístico.

Foi possível observar menores valores de viscosidade para formulações cuja relação entre monômero e oligômero $(\mathrm{M} / \mathrm{O})$ é igual a 3.34. Neste estudo, foi também identificado um baixo efeito proporcionado pelo iniciador, enquanto o maior valor de viscosidade foi obtido para formulações com $\mathrm{M} / \mathrm{O}$ igual a 1 . Para este caso, os valores de viscosidade encontrados variaram entre 1.525 e $2.959 \mathrm{cP}$, contendo nesta faixa, valores de viscosidade adequados para serem utilizados em sistemas de deposição por jato de tinta.

Em relação à taxa de polimerização, foi observada conversão dos materiais através de análise fotométrica, sendo encontrados valores de polimerização superiores a $60 \%$ em 30 segundos de exposição em luz UV de intensidade luminosa igual a $120 \mathrm{~mW}$. Adicionalmente, ao considerar fontes luminosas de maior potência, 
pode-se observar que este material apresenta valores de conversão similares em tempos muito inferiores, como por exemplo, 3 segundos para lâmpadas UV de 9W.

Para o início de polimerização, pode-se observar o maior efeito proporcionado pelo iniciador em conjunto ao monômero, enquanto para a terminação da polimerização, a combinação entre iniciador e oligômero apresentou maior efeito.

Contudo, para ambos os casos, o aumento da concentração de iniciador proporcionou a redução da taxa de polimerização. Este comportamento pode ser explicado pelo aumento excessivo da taxa de absorção da solução, inibindo a chegada do iniciador ao estado de excitação triplo.

Este comportamento pode ser observado mais claramente ao analisar as curvas de conversão, onde foi identificada a estagnação da polimerização para as formulações de materiais com relação M/O igual a 1.

Foi também possível identificar diagramas de contorno de valores de polimerização em 30 e 60 segundos em função do teor de monômero, oligômero e fotoiniciador. Através destes diagramas, foi possível identificar o aumento da taxa de polimerização para concentrações de iniciador próximas a $2 \%$, sendo que altos niveis de monômero proporcionaram maiores valores em fases iniciais de polimerização. Em contrapartida, altos valores de oligômero proporcionaram maiores valores de conversão para fases finais de polimerização.

Em relação à resistência mecânica à tração, foi observada a maior influência do iniciador tanto para a tensão de ruptura quanto para o elongamento na ruptura. Adicionalmente, os materiais apresentaram comportamento frágil, não sendo observada região de deformação hookeana.

Foi possível também ser observado o aumento da fragilidade do material para níveis altos de oligômero e iniciador, sendo este efeito provavelmente proporcionado pelo grande gradiente de polimerização do material ao longo da espessura. Em conjunto, pode-se também indicar a grande acumulo de tensão superficial e a grafitização e interamarração de cadeias polimericas do material devido aos múltiplos grupos funcionais presentes no oligômero. 
O maior valor de tensão de ruptura encontrado neste estudo foi de aproximadamente $48 \mathrm{MPa}$, obtido para a formulação que apresentava $10 \mathrm{ml}$ de monômero, $3 \mathrm{ml}$ de oligômero e $2 \%$ de fotoiniciador.

Em relação ao módulo de elasticidade, foram encontrados valores médios entre 1.62 e $5.84 \mathrm{GPa}$, sendo que os maiores valores foram encontrados para concentrações altas de iniciador e relação entre monômero e oligômero (M/O) igual a 1.

Por outro lado, ao analisar os valores de temperatura de trabalho (HDT) do material, foi observado o maior efeito proporcionado pela interação entre os três componentes formuladores do material, sendo o segundo maior efeito proporcionado pelo iniciador.

Neste estudo, foram encontrados valores de temperatura de amolecimento do material (HDT - 30\% do valor inicial do módulo de elasticidade) entre 37 e $81^{\circ} \mathrm{C}$, onde o maior valor foi encontrado para formulação de $5 \mathrm{ml}$ de monômero, $3 \mathrm{ml} \mathrm{de}$ oligômero e $5 \%$ de fotoiniciador. Esta tendência de resultados pode ser explicado pelo menor grau de cristalinização obtida por esta formulação de material, visto que são encontrados baixos valores de interamarrações (crosslinking) proporcionadas pelo oligômero, assim como maior homogeneidade do material devido às baixas taxas de polimerização.

Adicionalmente, foram encontrados altos níveis de cristalinidade para formulação de materiais cuja relação entre monômero e oligômero próxima de 1 , como por exemplo os materiais $\mathrm{C}$ e $\mathrm{G}$.

Com o objetivo de identificar uma formulação de material adequada para ser utilizada neste projeto, foi realizada uma otimização desta formulação, sendo encontrado como valor otimizado, $10 \mathrm{ml}$ de monômero, 4,38 $\mathrm{ml}$ de oligômero e $2 \%$ de iniciador. Para esta formulação, foram encontrados como valores de resposta: viscosidade de $1,53 \mathrm{cP}$, conversão em 60 segundos de $79,92 \%$, resistência mecânica à tração de 43,39 MPa, Módulo de flexão de 4,55 GPa e Temperatura de HDT $(30 \%)$ de $49,79^{\circ} \mathrm{C}$. 


\subsubsection{Material compósito}

Em relação ao desenvolvimento do material compósito, foram identificadas a resistência mecânica à tração do material em presença ou não de água, assim como identificada a influência da quantidade de polímero impregnado em substrato celulósico para esta resistência. Em adição, foi identificada uma das características essenciais para a viabilização deste projeto, a aderência entre camadas.

Inicialmente, foi identificada a contribuição da quantidade de polímero por material celulósico. Os resultados deste estudo foram encontrados entre $15 \mathrm{e}$ $30 \mathrm{MPa}$, conforme quantidade percentual de polímero impregnado em papel. Como resultado, foi obtida uma curva de segundo grau como regressão polinomial desta função, sendo obtido mínimo quadrado igual a 0.981 . Através deste estudo, foi possível estabelecer como parâmetro a relação entre polímero e papel de 5 para realização dos estudos de identificação de formulação de material compósito.

Para a resistência mecânica média à tração, foi identificado o iniciador como o principal componente que contribui para a resistência do compósito, sendo encontrados valores de tensão de ruptura superiores a 28MPa para concentrações baixas de iniciador. Adicionalmente, este valor é obtido para valores baixos de oligômero e altos de monômero. Em outras palavras, estas tensões de ruptura são observadas para índices de relação entre monômero e oligômero entre 2 e 3 , indicando a maior contribuição do monômero para a resistência mecânica à tração do compósito. Cabe ressaltar que a formulação de polímero utilizada neste compósito proporcionou o maior valor de resistência à tração entre os polímeros estudados.

Em contrapartida, quando em presença de água, os maiores valores de tensão de ruptura foram encontrados para concentrações baixas de iniciador. Isto pode ser facilmente evidenciado em função do maior efeito ser proporcionado pelo iniciador.

Uma das explicações para isto é relacionado ao grau de conversão do polímero, visto que estes níveis baixos de iniciador proporcionaram os maiores valores de conversão. Adicionalmente, cabe ressaltar que apesar da água ser um 
não solvente do polimetacrilado de metila (PMMA), esta é um solvente do monômero e oligômero que geram este polímero.

Em relação à adesividade entre camadas de compósito, foram encontrados valores entre 0.117 e $0.140 \mathrm{kgf}$. O maior efeito foi encontrado para interação entre monômero e iniciador, sendo seguido pelo iniciador. Adicionalmente, foram analisados os modos de ruptura desta junta adesiva, sendo encontrada a falha no substrato para todos os materiais estudados. Contudo, foram também observadas diferenças de homogeneidade de romprimento devido ao gradiente de polimerização proporcionado pela fonte luminosa.

Por fim, foi identificada através de estudo de otimização a formulação de compósito mais adequada para ser empregada na implementação deste projeto. Neste resultado, foi encontrado para a formulação otimizada: $0.132 \mathrm{kgf}$ de força de adesividade; 29 MPa de tensão de ruptura e 13,60 MPa de tensão de ruptura em presença de água. Esta formulação é composta por 10ml de monômero; 4,40 de oligômero e $2 \%$ de iniciador, sendo impregnado em papel do tipo seda numa relação de polímero por papel igual a 5.

\subsection{Análise de Viabilidade e Funcionalidade}

Com relação à validação da concepção do projeto, foi possível observar a viabilidade funcional da concepção através do processo de geração e transformação do material, conforme apresentado nos estudos de apoio.

Ao longo deste trabalho, foi possível realizar o desenvolvimento e a implementação do sistema de posicionamento, sistema de polimerização e sistema de controle PC-NC, enquanto o sistema de deposição, sistema de alimentação de material celulósico foi desenvolvido conceitualmente e implementado manualmente.

Em relação ao densenvolvimento do sistema de posicionamento, foram analisadas concepções de sistemas através de matriz morfológica e matriz de análise relativa. A partir de layout identificado neste estudo, foi elaborado modelo matemático para estimativa de erros assim como de custo relativo total do equipamento. Neste estudo, foi também validado este modelo matemático através 
da comparação com a precisão de um equipamento FDM equivalente (Fortus $250 \mathrm{mc}$ ), sendo encontrado um desvio de $1 \mu \mathrm{m}$.

Adicionalmente, foi realizado um estudo de otimização numérica empregando a função de custo e de erro do modelo matemático encontrado, sendo identificada a função de compromisso (Optimal Pareto) das soluções ótimas deste problema. Para a solução balanceada (mesma importância para função de custo e de erro) foi encontrada a configuração de equipamento cujos parâmetros de projeto são: fabricação de suportes e componentes com tolerância IT4, utilização de rolamentos lineares, fusos de esfera de $\mathrm{C} 7$ para eixos $\mathrm{X}$ e $\mathrm{Y}$; e fuso de esferas $\mathrm{C} 10$ para eixo $\mathrm{Z}$.

Esta configuração de equipamento proporcionou um custo 1.57 vezes superior ao custo da opção mais barata estudada, sendo encontrado um erro médio de $141.46 \mu \mathrm{m}$.

Em relação ao sistema de controle PC-NC, foi desenvolvido um sistema que contempla a utilização de interface de comunicação USB, tendo interface de controle e para acionamento de drives de controle de motores de passo assim como de CLP.

Por fim, foi elaborado e construído um projeto preliminar do protótipo do equipamento a ser validado, sendo agrupados os sistemas desenvolvidos neste trabalho.

Para a análise da viabilidade do processo proposto, foi caracterizada a forma de geração seletiva de compósito, sendo observada uma linha de polimerização com largura entre 1438 e $3442 \mu \mathrm{m}$. Foi possível identificar que a potência de laser de $100 \mathrm{~mW}$ implica em polimerização periférica. Adicionalmente, foi observado que a linha de polimerização apresenta comportamento normal para algumas faixas de parâmetros de processo.

Para diâmetro de feixe de laser de $2 \mathrm{~mm}$ e potência de laser de $20 \mathrm{~mW}$, a faixa entre 100 e 200mm/min ocasionou linha de polimerização determinada, sendo os limites inferiores implicam em indeterminação de linha de polimerização devido ao excesso de polimerização e polimerização periférica, enquanto a indeterminação observada nos limites superiores, pela falta de polimerização (baixo grau de conversão). 
Foi também observada a diminuição da largura de linha de polimerização em função da velocidade de polimerização. Contudo,

Com relação à interferência do processo formação de perfil de camadas para camadas anteriores, foi observado que a intensidade de laser de $1,591549 \mathrm{~mW} / \mathrm{mm}^{2}$ e velocidade de laser entre 100 e $250 \mathrm{~mm} / \mathrm{min}$ implica em aderência de 1 camada anterior. Já para intensidade de laser de 7,957745 mW/mm² implica em aderência de 4 camadas. Foi também visto que para velocidade de laser de $450 \mathrm{~mm} / \mathrm{min}$, não houve aderência entre camadas.

Para validação da funcionalidade do conceito de processo proposto, foram avaliadas faixas de parâmetro de processo através de um planejamento de experimentos. O objetivo deste estudo foi de investigar faixas viáveis de processo, sendo encontradas 2 faixas onde o desvio dimensional é de $0.5 \mathrm{~mm}$ do valor esperado. Foi também observado que para laser de potência de $100 \mathrm{~mm} / \mathrm{min}$, houve excesso de distorção dimensional ocasionada por polimerização periférica.

Para valores de velocidade de laser de $450 \mathrm{~mm} / \mathrm{min}$ e potência de laser de $20 \mathrm{~mW}$, o processo não se apresentou viável devido à falta de aderência entre camadas.

Com relação ao ângulo de varredura do laser, foi observado que este ocasiona uma variação da anisotropia do objeto. A resistência mecânica à tração observada nos corpos de prova (15,46 e 31,67MPa) indicou que o processo proposto permite a construção de objetos com resistência similar à de processos convensionais, como molde de injeção, e processos de manufatura aditiva, como FDM e SLA.

Por fim, foi possível identificar a viabilidade funcional do conceito de processo proposto, sendo necessário estudo mais aprofundado do processo, da caracterização do material, da viabilidade econômica e do potencial de geração de geometrias complexas em trabalhos futuros.

\subsection{Pesquisas Futuras}

Visto que esta pesquisa tem caráter pioneiro na área, tem-se ainda muitos desafios para serem superados. Sendo possível o desenvolvimento e 
aperfeiçoamento de material, caracterização do material, projeto e otimização do equipamento e caracterização e otimização do processo proposto.

Entre os principais assuntos a serem abordados futuramente, cabe ressaltar:

- Desenvolvimento de novas formulações de material polimérico;

- Identificação de material compatível com tecnologias jato de tinta;

- Desenvolvimento de novos substratos;

- Caracterização e desenvolvimento de material compósito;

- Implementação de sistema de alimentação automatizado;

- Implementação de sistema de deposição de material automatizado;

- Desenvolvimento de novas concepções de sistemas de posicionamento;

- Desenvolvimento de novas concepções de sistemas de deposição;

- Desenvolvimento de novas concepções de sistema de alimentação de substrato;

- Desenvolvimento de processo de acabamento e remoção de material residual automatizado;

- Caracterização e otimização de processo;

- Análise de capabilidade de geração de geometrias complexas;

- Caracterização dimensional, mecânica, térmica e química do objeto final;

- Determinação de nicho de aplicação de peça final. 


\section{PRODUÇÃo CIENTÍFICA NO PERÍODO (FEV 2010 - FEV 2014)}

CUNICO, M. W. M. . Development of New Rapid Prototyping Process. Rapid Prototyping Journal, v. 17, p. 138-147, 2011.

CUNICO, M. W. M. . Estudo de caracterização de deposição aérea em tecnologias de prototipagem rápida suprimindo necessidade de material suporte. In: VII edição do Plastshow 2012, 2012, São Paulo. Anais da VII edição do Plastshow 2012. São Paulo: Aranda Eventos, 2012.

CUNICO, M. W. M. . ESTUDO DE CARACTERIZAÇÃO DE DEPOSIÇÃO AÉREA EM TECNOLOGIAS DE PROTOTIPAGEM RÁPIDA SUPRIMINDO NECESSIDADE DE MATERIAL SUPORTE. In: CONEM 2012 - VII Congresso Nacional de Engenharia Mecânica, 2012, São Luis. Anais do VII Congresso Nacional de Engenharia Mecânica. São Paulo: ABCM, 2012.

CUNICO, M. W. M. . STUDY OF FDM PROCESS PARAMETER FOR DEPOSITION OF FILLAMENT IN AREA WITH NO SUPPORT MATERIAL. In: European Forum on Rapid Prototyping and Manufacturing, 2012, Paris. Proceedings of AEPR 12, 17th European Forum on Rapid Prototyping and Manufacturing. Paris: AFPR - Association Française de Prototypage Rapide, 2012.

CUNICO, M. W. M. ; CARVALHO, J. . OPTIMIZATION OF RAPID PROTOTYPING PROCESS BASED ON SIMULTANEOUS DEPOSITION AND PHOTOPOLYMERIZATION USING ANALYTIC APPROACH. In: COBEM 2011 - 21st INTERNATIONAL CONGRESS OF MECHANICAL ENGINEERING, 2011, Natal. Green Mechanical Engineering, 2011. 
CUNICO, M. W. M. ; CARVALHO, J. . DETERMINATION OF DEGREE OF PHOTOPOLYMERIZATION RATE BY PHOTOMETRIC METHOD BASED ON UV LED AND PHOTODIODE. In: COBEM 2011 - 21st INTERNATIONAL CONGRESS OF MECHANICAL ENGINEERING, 2011, Natal. Green Mechanical Engineering, 2011.

CUNICO, M. W. M. ; CARVALHO, J. . OPTIMIZATION OF POSITIONING SYSTEM OF FDM MACHINE DESIGN USING ANALYTICAL APROACH. Rapid Prototyping Journal, 2013. (In press)

CUNICO, M. W. M. ; CARVALHO, J. . Optimization of thick layers photopolymerization systems and analytical aproach. Rapid Prototyping Journal, 2013. (In press)

CUNICO, M. W. M. ; CARVALHO, J. . DESIGN OF AN FDM POSITIONING SYSTEM AND APPLICATION OF AN ERROR-COST MULTIOBJECTIVE OPTIMIZATION APPROACH. Rapid Prototyping Journal, 2013. (In press)

CUNICO, M. W. M. ; CARVALHO, J. . Desenvolvimento de um novo critério para a caracterização da temperatura de amolecimento de termoplásticos por meio de deflexão sob carga (HDT). Plástico Industrial, 2013. (In press)

CUNICO, M. W. M. ; CARVALHO, J. . Development of acrylate-based material using a multivariable approach: additive manufacturing applications. Rapid Prototyping Journal, 2013. (In press)

CUNICO, M. W. M. . STUDY AND OPTIMIZATION OF FDM PROCESS PARAMETER FOR DEPOSITION OF FILLAMENT IN AREA WITH NO SUPPORT 
MATERIAL AND INCREASE OF LAYER. Virtual and Physical Prototyping (Print), 2013. (In press)

CUNICO, M. W. M. .Otimização resistência mecânica de peças fabricadas por processo de fabricação aditivo por planejamento de experimentos (DoE) In: 7 Congresso Brasileiro de Engenharia de Fabricação, 2013, Itatiaia. VII CONGRESSO BRASILEIRO DE ENGENHARIA DE FABRICAÇÃO, 2013 (In press) 


\section{REFERÊNCIAS}

3DSYSTEMS. Accura® 25 Plastic. 3D Systems. 2008a. Disponível em: $<$ http://production3dprinters.com/sites/production3dprinters.com/files/downloads/DS Accura 25 US.pdf>. Acesso em: setembro de 2011.

3DSYSTEMS. Accura® 48HTR Plastic. 3D Systems. 2008b. Disponível em: $<$ http://production3dprinters.com/sites/production3dprinters.com/files/downloads/DS Accura 48HTR US.pdf>. Acesso em: setembro de 2011.

3DSYSTEMS. Accura® 55 Plastic. 3D Systems. 2008c. Disponível em: $<$ http://production3dprinters.com/sites/production3dprinters.com/files/downloads/DS Accura 55 US.pdf>. Acesso em: setembro de 2011.

3DSYSTEMS. Accura® 60 Plastic. 3D Systems. 2008d. Disponível em: $<$ http://production3dprinters.com/sites/production3dprinters.com/files/downloads/DS Accura 60 US.pdf>. Acesso em: setembro de 2011.

3DSYSTEMS. Accura® Amethyst Plastic. 3D Systems. 2008e. Disponível em: $<$ http://production3dprinters.com/sites/production3dprinters.com/files/downloads/DS Accura Amethyst US.pdf>. Acesso em: setembro de 2011.

3DSYSTEMS. Accura ${ }^{\circledR}$ Bluestone ${ }^{\mathrm{TM}}$ Plastic. 3D Systems. 2008f. Disponível em: $<$ http://production3dprinters.com/sites/production3dprinters.com/files/downloads/DS Accura Bluestone US.pdf>. Acesso em: setembro de 2011.

3DSYSTEMS. Accura ${ }^{\circledR}$ e-Stone ${ }^{\mathrm{TM}}$ Material. 3D Systems. 2009. Disponível em: $<$ http://production3dprinters.com/sites/production3dprinters.com/files/downloads/DS Accura estone US.pdf $>$. Acesso em: setembro de 2011.

3DSYSTEMS. Accura ${ }^{\circledR}$ CeraMAX ${ }^{\text {TM }}$ Composite. 3D Systems. 2010a. Disponível em: $<$ http://production3dprinters.com/sites/production3dprinters.com/files/downloads/DS Accura CeraMAX US.pdf>. Acesso em: setembro de 2011.

3DSYSTEMS. Accura ${ }^{\circledR}$ PEAK ${ }^{\mathrm{TM}}$ Plastic. 3D Systems. 2010b. Disponível em: $<$ http://production3dprinters.com/sites/production3dprinters.com/files/downloads/DS Accura PEAK US.pdf>. Acesso em: setembro de 2011.

3DSYSTEMS. iPro ${ }^{\mathrm{TM}} 8000$ \& 9000. 3D Systems. 2011a. Disponível em: $<$ http://production3dprinters.com/sites/production3dprinters.com/files/downloads/iProFamily-USEN.pdf>. Acesso em: setembro de 2011.

3DSYSTEMS. ProJet ${ }^{\mathrm{TM}}$ 6000. 3D Systems. 2011b. Disponível em: $<$ http://printin3d.com/sites/printin3d.com/files/downloads/Projet 6000 brochure USE N.pdf>. Acesso em: setembro de 2011. 
3DSYSTEMS. V-Flash. 3D Systems. 2011c. Disponível em: $<$ http://printin3d.com/sites/printin3d.com/files/downloads/V-

Flash Brochure USEN.pdf>. Acesso em: setembro de 2011.

ALBERT, A. Understanding CNC Routers. Vancouver: FPInnovations. 2008. 116 p.

ANDREAJEWSKA, E. Photopolymerization Kynetics of Multifuntional Monomers. Progress in Polymer Science, v.22, p.6. 2001.

ANDRZEJEWSKA, E. Photopolymerization kinetics of multifunctional monomers. Progress in Polymer Science, v.26, n.4, p.605-665. 2001.

ANNELECTRICS. Analog PLC APB 22MRDL - datasheet. Ann Electric Co. 2011. Disponível em: <www.annelectric.com/>. Acesso em: agosto de 2011.

ARCHER, R. D. Inorganic and Organometallic Polymers: Wiley-VCH, Inc. 2001

ASTM, D. 5573-99. Standard practice for classifying failure modes in fiber-reinforcedplastic (FRP) joints. Annual Book of ASTM Standards, v.15. 2002.

ATHANI, V. V. Stepper motors: fundamentals, applications and design: New Age International (P) Ltd., Publishers. 2007. 214 p.

ATTOH-OKINE, N. O. e B. M. AYYUB. Applied research in uncertainty modeling and analysis: Springer Verlag, v.20. 2005. 545 p.

BANEA, M. e L. DA SILVA. Adhesively bonded joints in composite materials: an overview. Proceedings of the Institution of Mechanical Engineers, Part L: Journal of Materials: Design and Applications, v.223, n.1, p.1-18. 2009.

BARTON, J. M. D. e M. C. FULTON. Mechanical properties of a typical stereolithography resin. Journal of Strain, v.36, p.6. 2000.

BATCHELDER, J. S. SYRINGE TIP ASSEMBLY AND LAYERED DEPOSITION SYSTEMS UTILIZING THE SAME. PCT: Stratasys 2008.

BEAMAN, J. J. e C. R. DECKARD. Selective laser sintering with assisted powder handling. United States: Board of Regents, The University of Texas System (Austin, TX) 1990.

BERG, W. M. The theory and application of precision mechanical components: a guide for engineers, designers, draftsmen, and technicians: R. Sacken. 1965. $166 \mathrm{p}$.

BEY-OUESLATI, R., S. PALM, et al. High speed direct-write for rapid fabrication of three dimensional microfluidic devices. International Journal of Heat and Technology, v.26, n.1, p.125-131. 2008. 
BIBB, R., D. EGGBEER, et al. Rapid manufacture of removable partial denture frameworks. Rapid Prototyping Journal, v.12, n.2, p.95-99. 2006.

BITSFROMBYTES. BFB 3000 Plus Brochure. 3D System. 2011. Disponível em: <http://www.bitsfrombytes.com/>. Acesso em: agosto de 2011.

BLAYO, A. Formulation des Encres Pour l'impression Techniques de l'ingénieur. Génie des procédés, v.JC1, n.J2290, p.1-17. 2007.

BODDAPATI, A., S. B. RAHANE, et al. Gel time prediction of multifunctional acrylates using a kinetics model. Polymer, v.52, n.3, p.866-873. 2011.

BRACELPA. Relatorio estatistico anual de 2009/2010. Associação Brasileira de Celulose e 2010.2 Dapel. <http://www.bracelpa.org.br/bra2/index.php>. Acesso em: agosto de 2011.

BRANDRUP, J., E. H. IMMERGUT, et al., Eds. Polymer Handbook: John Wiley \& Sons, Inc., p.2370 ed. 1999.

BURWASH, W., W. FINLAY, et al. Deposition of Particles by a Confined Impinging Jet onto a Flat Surface at $R e=10$ 4. Aerosol Science and Technology, v.40, n.3, p.147-156. 2006.

CALLISTER, W. D. Materials Science and Engineering: an Introduction: John Wiley \& Sons, Inc. 2003

CIBA. Photoinitiators for UV Curing: Key Products Selection Guide. Ciba Specialty Chemicals Inc. 2003. Disponível em: $<$ http://www.ciba.com/pf/docMDMS.asp?targetlibrary=CHBS CE MADS\&docnumber $=1803>$. Acesso em: 10 jul 2008.

COMB, J. W., W. R. J. PRIEDEMAN, et al. High Precision Modeling Filament. World Intelectual Property Organization S. Inc. USA: 39 p. 2003.

CONDIT, R. e D. W. JONES. Stepping motors fundamentals. Microchip Technology Inc. 2004. Disponível em: <www. microchip. com>. Acesso em: agosto de 2011.

COOPER, K. G. Rapid Prototyping Technology Selection and Application. NY: CRC Press 2001.

COYLE, J. D. Introduction to Organic Photochemistry: John Wiley \& Sons Lld. 1986. $190 \mathrm{p}$.

CRUMP, S., S. BATCHELDER J, et al. SYSTEM AND METHOD FOR BUILDING THREE-DIMENSIONAL OBJECTS WITH METAL-BASED ALLOYS. US: Stratasys, Inc. : 22 p. 2009.

CRUMP, S. S. Apparatus and method for creating three-dimensional objects. US: Stratasys, Inc. : 15 p. 1989. 
CUNICO, M. M. W. M. Development of New Rapid Prototyping Process. Rapid Prototyping Journal, v.17, n.2, p.6-6. 2011.

CUNICO, M. W. M. e J. D. CARVALHO. DETERMINATION OF DEGREE OF POLYMERIZATION BY LOW COST PHOTOMETRIC SYSTEM: APPLICATION OF UV LED AND PHOTODIODE. 21st Brazilian Congress of Mechanical Engineering. Natal: ABCM, 2011. p.

D'ALMEIDA, M. L. O. e C. T. E. C. E. PAPEL. Celulose e papel: SENAI, Departamento Regional de São Paulo, Escola Theobaldo De Nigris, v.2. 1981. 964 p.

DATAQ. DI-158 Datasheet. Dataq Instruments. 2011. Disponível em: $<$ http://www.dataq.com/support/documentation/pdf/datasheets/158ds.pdf>. Acesso em: agosto de 2011.

DECKER, C., T. NGUYEN THI VIET, et al. UV-radiation curing of acrylate/epoxide systems. Polymer, v.42, n.13, p.5531-5541. 2001.

DECKER, C., T. N. T. VIET, et al. UV-radiation curing of acrylate/epoxide systems. Polymer, v.42, p.11. 2001.

DEVONALD, D. P. M., GB) Inks for ink jet printing comprising a tris-azo dye United States Patent. USA: Fujifilm Imaging Colorants Limited (Manchester, GB) US7153351: 6 p. 2006

DONG, H. DROP-ON-DEMAND INKJET DROP FORMATION AND DEPOSITION. School of POLYMER, TEXTILE AND FIBER ENGINEERING, Georgia Institute of Technology, 2006. $136 \mathrm{p}$.

DORNFELD, D. e D. E. LEE. Precision Manufacturing: Springer. 2007. 775 p.

DROBNY, J. G. Radiation Technology for Polymers: Taylor and Francis. 2010. $283 \mathrm{p}$.

DRURY, B. e I. O. E. ENGINEERS. The Control Techniques drives and controls handbook: Institution of Electrical Engineers. 2001. 373 p.

EDGAR. Stock chart - Stratasys. 2011. Disponível em: <http://www.stratasys.com/>. Acesso em: agosto de 2011.

EEKELS, J. e N. F. M. ROOZENBURG. A methodological comparison of the structures of scientific research and engineering design: their similarities and differences. Design Studies, v.12, n.4, p.197-203. 1991.

EMIC. Especificação técnica de maquina de ensaio universal DL10000. EMIC. 2011. Disponível em: <http://www.emic.com.br/>. Acesso em: agosto de 2011. 
ENVISIONTEC. Desktop Digital Shell Printer (DDSP). EnvisionTec. 2009a. Disponível em: $<$ http://www.envisiontec.com/fileadmin/pdf/MachineDatasheet_DDSP.pdf>. Acesso em: setembro de 2011.

ENVISIONTEC. Perfactory DSP. EnvisionTec. 2009b. Disponível em: $<$ http://www.envisiontec.com/fileadmin/pdf/Prod.Folder_DSP_en_DIN.pdf $>$. Acesso em: setembro de 2011.

ENVISIONTEC. envisionTEC e-Shell 200 Series. EnvisionTec. 2011a. Disponível em: <http://www.envisiontec.com/fileadmin/pdf/MatSheet_eShell200_en_s.pdf>. Acesso em: setembro de 2011.

ENVISIONTEC. envisionTEC e-Shell 300 Series. EnvisionTec. 2011b. Disponível em: <http://www.envisiontec.com/fileadmin/pdf/MatSheet_eShell300_en_s.pdf>. Acesso em: setembro de 2011.

ENVISIONTEC. envisionTEC PIC 100 Series. EnvisionTec. 2011c. Disponível em: $<$ http://www.envisiontec.com/fileadmin/pdf/MatSheet_PIC100_en_DIN.pdf>. Acesso em: setembro de 2011.

ENVISIONTEC. envisionTEC RC 25 (NanoCure). EnvisionTec. 2011d. Disponível em:

<http://www.envisiontec.com/fileadmin/pdf/MatSheet_NanoCureRC25_en_DIN.pdf>. Acesso em: setembro de 2011.

ENVISIONTEC. envisionTEC WIC 100 G Series. EnvisionTec. 2011e. Disponível em: <http://www.envisiontec.com/fileadmin/pdf/MatSheet_WIC100_en.pdf>. Acesso em: setembro de 2011.

ENVISIONTEC. Perfactory DDP. EnvisionTec. 2011f. Disponível em: $<$ http://www.envisiontec.com/fileadmin/pdf/DigitalDentalPrinting.pdf>. Acesso em: setembro de 2011.

EOS. Material Overview. EOS e-manufacturing solutions. 2011. Disponível em: <http://eos.materialdatacenter.com/eo/standard/main/compare/?mdc5=rg22u1 mdi92 599lrjdl8111b00 >. Acesso em: agosto de 2011.

EXONE. Material Overview. Exone. 2011. Disponível em: $<$ http://www.exone.com/eng/technology/x1-prometal/materials_prometal.html>. Acesso em: agosto de 2011.

FOGGIATTO, J. A., C. H. AHRENS, et al. Moldes de ABS Construídos pelo Processo de Modelagem por Fusão e Deposição para Injeção de PP e PEBD. Polímeros: Ciência e Tecnologia. 2004.

FOUASSIER, J., X. ALLONAS, et al. Photopolymerization reactions under visible lights: principle, mechanisms and examples of applications. Progress in Organic Coatings, v.47, n.1, p.16-36. 2003. 
FOUASSIER, J. P., X. ALLONAS, et al. Photopolymerization reactions under visible lights: principle, mechanisms and examples of applications. Progress in Organic Coating, v.47, p.20. 2003.

FOUASSIER, J. P. e J. RABEK. Radiation Curing in Polymer Science and Technology: Fundamentals and Methods. London: Springer. 1993. 563 p.

GATES. Timing Bet Theory. Gates Mectrol. 2006. Disponível em: < http://www.gates.com/ >. Acesso em: junho de 2011.

GATES. Urethane Timing Belts and Pulley. Gates Mectrol. 2011. Disponível em: $<$ http://www.gates.com/ >. Acesso em: junho de 2011.

GIBSON, I., Ed. Advanced manufacturing technology for medical applications: Reverse Engineering, Software Conversion and Rapid Prototyping. Chichester: John Wiley \& Sons Ltd, p.257 ed. 2005.

GIBSON, I., L. CHEUNG, et al. The use of rapid prototyping to assist medical applications. Rapid Prototyping Journal, v.12, n.1, p.53-58. 2006.

GIBSON, I., D. W. ROSEN, et al. Additive Manufacturing Technologies: Rapid Prototyping to Direct Digital Manufacturing: Springer. 2010. 473 p.

GOTHAIT, H. APPARATUS AND METHOD FOR THREE DIMENSIONAL PRINTING World International Patent Office: Objet Geometries Inc. 2000.

HALE, L. C. Principles and techniques for designing precision machines. (Ph.D Thesis). Department of Mechanical Engineering, Massachusetts Institute of Technology, 1999. 493 p.

HEVNER, A. R., S. T. MARCH, et al. Design science in information systems research. Mis Quarterly, v.28, n.1, p.75-105. 2004.

HIWIN. Linear Bearing Technical Information. HIWIN Linear Motion Products \& Technology. 2006. Disponível em: <http://www.hiwin.com/ >. Acesso em: junho de 2011.

HIWIN. Ball Screw Technical Information. HIWIN Linear Motion Products \& Technology. 2008. Disponível em: <http://www.hiwin.com/ >. Acesso em: junho de 2011.

HOCKING, M. B. Production of Pulp and Paper. In: (Ed.). Handbook of Chemical Technology and Pollution Control (Third Edition). San Diego: Academic Press, 2005. Production of Pulp and Paper, p.453-504

HOUTMANN, Y., B. DELEBECQUE, et al. Adaptive local slicing in Stratoconception by using critical points. Advances in Production Engineering \& Management $\mathbf{J}$, v.4, p.59-68. 2009. 
HU, W. e D. XUE. New production cost-tolerance models for tolerance synthesis. Journal of engineering for industry, v.116, p.199. 1994.

HUDGIN, D. E., Ed. PLASTICS TECHNOLOGY HANDBOOK: TAYLOR \& FRANCIS USA, p.866 ed. 2006.

HULL, C. W. A., CA). Apparatus for production of three-dimensional objects by stereolithography. United States: UVP, Inc. (San Gabriel, CA) 1986.

IGM. Omnirad CureAll 2500 Photo-initiator Compound. IGM Resins - UV Radcure Specialities. 2005. Disponível em: <www.igmresins.com/>. Acesso em: agosto de 2011.

IMF. World Economic Outlook (setember 2011) - Nominal GDP. International Monetary Fund. 2011. Disponível em: <http://www.imf.org/>. Acesso em: setembro de 2011.

INTERNATIONALPAPERS. Chamequinho White. International Papers do Brasil. $2011 . \quad$ Disponível em: <http://www.internationalpaper.com/BRAZIL/EN/Products/Chamequinho/WhiteA4.ht $\mathrm{ml}$. Acesso em: agosto de 2011.

JACOBS, P. F., D. T. REID, et al. Rapid prototyping \& manufacturing: fundamentals of stereolithography: Society of Manufacturing Engineers. 1992

JASTY, S. Aldrich Polymer Products Application and Reference Information. SigmaAldrich. $1999 . \quad$ Disponível em: $<$ http://www.sigmaaldrich.com/aldrich/brochure/al_pp_applications.pdf>. Acesso em: 10 jul. 2008.

JONSSON, S., P. SUNDELL, et al. Radiation chemistry aspects of polymerization and crosslinking. A review and future environmental trends in [] nonacrylate'chemistry. Progress in Organic Coatings, v.27, n.1-4, p.107-122. 1996.

JUNIOR, A. P. D. C., V. D. P. P. D. CUNHA, et al. Modelo de Calibração da Concentração de Metilmetacrilato em Solução Aquosa Utilizando Espectroscopia de Absorção no Ultravioleta. Quimica Nova, v.26, n.6, p.4. 2003.

KABATC, J. e J. PACZKOWSKI. Acceleration of the free radical polymerization by using $\mathrm{N}$-alkoxypyridinium salt as co-initiator in hemicyanine dye/borate salt photoinitiating system. Journal of Photochemistry and Photobiology A: Chemistry, v.184, p.9. 2006.

KELLY, A. e C. H. ZWEBEN. Comprehensive Composite Materials: Polymer matrix composites: Elsevier. 2000. 1152 p.

KELLY, A. E. Theme issue: The role of design in educational research. Educational Researcher, v.32, n.1, p.3. 2003. 
KIPPHAN, H. Handbook of Print Media: Technologies and Production Methods: Springer. 2001. 1206 p.

KIRWAN, M. J. Paper and paperboard packaging technology: Blackwell Pub. 2005. $453 \mathrm{p}$.

KLANG, J. e J. BALCERSKI. UV Curing Technology: Issues for Inkjet Formulations, 2002. p.

KLANG, J. A. e J. S. BALCERSKI. New Developments in the Commercialization of UV Curable Inkjet Inks. Sartomer. 2002. Disponível em: <www.sartomer.com/>. Acesso em: agosto de 2011.

KRICHELDORF, H. R., O. NUYKEN, et al., Eds. Handbook of polymer Synthesis: Marcel Dekker Inc, p.945 ed. 2005.

KRUNIĆ, S., M. PERINIĆ, et al. NA INI BRZE IZRADE PREDSERIJSKIH PROIZVODA - RAPID PROTOTYPING APPLICATION. Eng. Rev, v.30, n.2, p.91100. 2010.

LEE, T. Y., T. M. ROPER, et al. The kinetics of vinyl acrylate photopolymerization. Polymer, v.44, p.7. 2003.

LEMEE, V., J. P. FOUASSIER, et al. Structure/properties relationships in photoinitiators of polymerization: 10. The behaviour of bichromophoric derivatives. European Polymer Journal, v.35, p.12. 1999.

LIGHT, G. M. e H. KWUN. Nondestructive Evaluation of Adhesive Bond Quality: State of the Art Review. DTIC Document. 1989. Disponivel em: <http://handle.dtic.mil/100.2/ADA210051 >. Acesso em: agosto de 2011.

LINDQVIST, U., K. ANDERSEN, et al. Innovations in Ink-Jet Technology. VTT Information Technology. Metallimiehenkuja, Finland. 2003

LIOU, F. W., Ed. Rapid prototyping and engineering applications: a toolbox for prototype development: CRC Press ed. 2007.

LOVESTEAD, T. M., A. K. O'BRIEN, et al. Models of multivinyl free radical photopolymerization kinetics. Journal of Photochemistry and Photobiology A: Chemistry, v.159, n.2, p.135-143. 2003.

MAGDASSI, S. The Chemistry of Inkjet Inks: WORLD SCIENTIFIC PUB CO (2009. $345 \mathrm{p}$.

MAHESH, M., Y. WONG, et al. Benchmarking for comparative evaluation of RP systems and processes. Rapid Prototyping Journal, v.10, n.2, p.123-135. 2004. 
MALMSTRIJM, E., P. E. SUNDELL, et al. Mechanisms of radiation induced cationic polymerization in the presence of onium salts. Nuclear Instruments and Methods in Physics Research B, v.105, p.7. 1995.

MALONE, E. e H. LIPSON. Fab@ Home: the personal desktop fabricator kit. Rapid Prototyping Journal, v.13, n.4, p.245-255. 2007.

MARGOLIN, L. Ultrasonic droplet generation jetting technology for additive manufacturing: an initial investigation. School of Mechanical Engineering Georgia Institute of Technology, 2006. $185 \mathrm{p}$.

MATYJASZEWSKI, K. e T. P. DAVIS, Eds. Handbook of Radical Polymerization: John Wiley and Sons, Inc., Hoboken., p.935 ed. 2002.

MEZAKI, R. e G.-H. MA. Rate Equations of Polymerization Reactions: ChemTec Publishing. 1997. $334 \mathrm{p}$.

MILLER, C. Perspectives in Chemistry: Searching for the Cure. RADTECH. 2005. Disponível em: $<$ http://radtech.org/members/member_documents/Perspectives\%20in\%20Chemistry $\% 20-\% 20$ Searching\%20for\%20the\%20Cure.pdf>. Acesso em: 01 de dezembro de 2010.

MINIPA. Fonte de Alimentação regulavel MPL-1305M. Minipa. 2011. Disponível em: <http://www.minipa.com.br/>. Acesso em: agosto de 2011.

MIYASAKA, H., S. R. KHAN, et al. Photoinduced electron transfer dynamics in aromatic vinyl polymers and related systems: time-resolved detection of primary events. Journal of Photochemistry and Photobiology C: Photochemistry Reviews, v.4, p.20. 2003.

MORITA, S. e K. SUGIYAMA. Sheet lamination modeling method and sheet lamination modeling apparatus: Kira Corporation: 27 p. 2000.

MORTARA, L., J. HUGHES, et al. Proposed classification scheme for direct writing technologies. Rapid Prototyping Journal, v.15, n.4, p.299-309. 2009.

MUELLER, T. Truly functional testing; selecting rapid prototyping materials so that prototypes predict the performance of injection molded plastic parts. 3d Systems. 2004. Disponível em: <www.3dsystems.com/>. Acesso em: janeiro de 2011.

MUKHERJEE, K. K. R. Fundamentals of photochemistry Wiley. 1978. 347 p.

NAOMI LUFT, C. Ink-Jet Printing. In: (Ed.). Coatings Technology Handbook, Third Edition: CRC Press, 2005. Ink-Jet Printing, p.25-1-25-4

NG, P., P. S. V. LEE, et al. Prosthetic sockets fabrication using rapid prototyping technology. Rapid Prototyping Journal, v.8, n.1, p.6. 2002. 
OBJET. Products Overview. OBJET. 2011. Disponível em: $<$ http://www.objet.com/3D-Printer/Products_Overview/>. Acesso em: setembro de 2011.

ODIAN, G. Principles of Polymerization: John Wiley \& Sons, Inc. 2004. 840 p.

OHTA, N. e M. ROSEN. Color desktop printer technology: CRC Press/Taylor \& Francis Group. 2006. 279 p.

PACKHAM, D. E. Handbook of adhesion: John Wiley. 2005. 677 p.

PAHL, G., W. BEITZ, et al. Engineering design: a systematic approach. London: Springer-Verlag London Limited. 2007. 617 p.

PHAM, D. e R. GAULT. A comparison of rapid prototyping technologies. International Journal of Machine Tools and Manufacture, v.38, n.10-11, p.12571287. 1998.

PHILIPS. Ultraviolet purification application information. Philips. 2006. Disponível em: <www.philips.com/>. Acesso em: agosto de 2011.

PHILIPS. Product family description: Compact single-ended low-pressure mercury vapour fluorescent lamps. Philips Electronics UK Ltd. 2008. Disponível em: $<$ http://www.prismaecat.lighting.philips.com/FredhopperPDFWebServicelnter/docts/1 e81c91d-bab9-460a-bba9-890752fed984/product.pdf>. Acesso em: 09 jul. 2008.

PIZZI, A. e K. L. MITTAL, Eds. Handbook of Adhesive Technology, Revised and Expanded: CRC Press, p.1024 ed. 2003.

POLYSCIENCES. Methyl Methacrylate Casting \& Embedding Kit for making hard, clear castings. Polysciences, Inc. 2009. Disponível em: <www.polysciences.com/>. Acesso em: agosto de 2011.

PRINZ, F. B., C. L. ATWOOD, et al. Rapid Prototyping in Europe and Japan. Center for Advanced Technology, v.102. 1997.

RADTECH. Membership directory. Radtech Europe. 2008. Disponível em: <http://www.radtech-europe.com/>. Acesso em: 10 jul. 2008.

RAMESH, R., M. A. MANNAN, et al. Error compensation in machine tools -- a review: Part I: geometric, cutting-force induced and fixture-dependent errors. International Journal of Machine Tools and Manufacture, v.40, n.9, p.1235-1256. 2000.

REDEYE. Prototype \& Production Materials Comparison Chart. Stratasys. 2011. Disponível em: <http://www.redeyeondemand.com/downloads/chart-horizontal.pdf>. Acesso em: setembro de 2011.

RODRIGUES, M. R. e G. M. NEUMANN. Fotopolimerização: Princípios e Métodos. . Polímeros: Ciência e Tecnologia, v.13, p.10. 2003. 
SACHS, E. M., J. S. HAGGERTY, et al. Three-dimensional printing techniques. US Patent Office. USA: Massachusetts Institute of Technology 1989.

SANDERS, R. C., J. L. FORSYTH, et al. 3-D model Making. US Patent Office: Sanders Prototypes Inc. 1998.

SARTOMER. Product Bulletin: ESACURE KIP100F. Sartomer Company. 1998. Disponível em: <http://www.sartomer.com/wpapers/2708.pdf>. Acesso em: 09 jul. 2008.

SARTOMER. Product Catalog. Sartomer Company. 2004. Disponível em: <http://www.sartomer.com/TechLit/3000.pdf>. Acesso em: 09 jul. 2008.

SARTOMER. Technical Data Sheet: CN501. Sartomer Company. 2007. Disponível em: <http://www.sartomer.com/wpapers/2717.pdf>. Acesso em: 09 jul. 2008.

SARTOMER. Material Safety Data Sheet: CN501. Sartomer Company. 2008. Disponível em: <http://www.sartomer.com/msds/0000FD28.pdf>. Acesso em: 09 jul. 2008.

SCHMIDT, K. A. SELECTIVE DEPOSITION MODELING WITH CURABLE PHASE CHANGE MATERIALS. World Intellectual Property Office. Pct: 3D SYSTEMS, INC. 2004.

SCIMAGO. Country Comparison. 2011. Disponível em: <http://www.scimagojr.com/>. Acesso em: setembro de 2011.

SEEDSSTUDIO. DSO Nano Manual. Seeds Studio Works. 2009. Disponível em: $<$ http://www.seeedstudio.com/depot/images/product/dsomanual.pdf>. Acesso em: 01 de dezembro de 2010.

SHARP. Laser Diode GH04020A2GE. Sharp Corporation. 2006. Disponível em: <http://combinlasers.com/3Sharp/Sharp_Blue_Laser_Diode_GH04020A2GE_405nm _20mW.pdf>. Acesso em: 01 de dezembro de 2011.

SHARP. Laser Diode GH04P21A2GE. Sharp Corporation. 2007. Disponível em: <http://combinlasers.com/3Sharp/Sharp_Blue_Laser_Diode_GH04P21A2GE_405nm _105mW.pdf>. Acesso em: 01 de dezembro de $201 \overline{1}$.

SIGLENT. Datasheet SDS1000CM serial. Siglent. 2011. Disponível em: $<$ http://www.siglent.com/en/product_show.asp?articleid=159>. Acesso em: agosto de 2011.

SIGMA-ALDRICH. Methyl Methacrylate, 99\%. Sigma-Aldrich Co. 2008a. Disponível em:

<http://www.sigmaaldrich.com/catalog/search/ProductDetail/ALDRICH/M55909>.

Acesso em: agosto de 2011. 
SIGMA-ALDRICH. Trimethylolpropane triacrylate. Sigma-Aldrich Co. $2008 \mathrm{~b}$. Disponível em: <http://www.sigmaaldrich.com/catalog/search/ProductDetail/ALDRICH/246808>. Acesso em: agosto de 2011.

SIGMA-ALDRICH. Isopropyl alcohol - 19030 - meets USP testing specifications. SIGMA-ALDRICH. 2011. Disponível em: <http://www.sigmaaldrich.com/>. Acesso em: agosto de 2011.

SLOCUM, A. H. Precision machine design: Society of Manufacturing Engineers. 1992. $750 \mathrm{p}$.

SMOOK, G. A. Handbook for pulp \& paper technologists: Angus Wilde Publications. 2002. 419 p.

SPERLING, L. H. Introduction to Physical Poylmer Science: John Wiley \& Sons, Inc. 2006. 866 p.

STRATASYS. FORTUS 250mcTM System Specifications. Stratasys. 2011. Disponível em: <http://www.fortus.com/Fortus900mc.aspx >. Acesso em: junho de 2011.

STRONG, W. N., M. A. VIDAL, et al. Liquid dispensing apparatus. US Patent office. USA: Nordson Corporation. US 2007/0287965 A1 2007.

SUH, S. H., S. K. KANG, et al. Theory and Design of CNC Systems: Springer. 2008. $455 \mathrm{p}$.

TAN, K. K., T. H. LEE, et al. Precision motion control: design and implementation: Springer. 2008. 272 p.

TEXAS. OPT-101 Monolithic Photodiode and Single-Supply Transimpedance Amplifier. 1994. Disponível em: <www.ti.com>. Acesso em: 01 de dezembro de 2010.

THABOUREY, J., C. BARLIER, et al. STRATOCONCEPTION CONTRIBUTION FOR RAPID TOOLING IN DIE CASTING: FROM THE DESIGN TO EXPERIMENTS. Advances in Production Engineering \& Management, p.121. 2010.

THOMSON. Lead Screws, Ball Screws and Ball Splines. Thomson Linear. 2009a. Disponível em: <http://www.thomsonlinear.com/>. Acesso em: junho de 2011.

THOMSON. Thomson RoundRail Linear Guides and Components. Thomson Linear. 2009b. Disponível em: <http://www.thomsonlinear.com/s. Acesso em: junho de 2011.

TONG, K., S. JOSHI, et al. Error compensation for fused deposition modeling (FDM) machine by correcting slice files. Rapid Prototyping Journal, v.14, n.1, p.4-14. 2008. 
TONG, K., E. A. LEHTIHET, et al. Parametric error modeling and software error compensation for rapid prototyping. Rapid Prototyping Journal, v.9, n.5, p.301-313. 2003.

TONG, K., E. A. LEHTIHET, et al. Software compensation of rapid prototyping machines. Precision Engineering, v.28, n.3, p.280-292. 2004.

TRACTON, A. A., Ed. Coatings Technology Handbook: CRC Press, p.936, third ed. 2005.

UEC. UEC -1005 A TENSILE STRENGTH TESTER (Electro-Mechanical). Universal Engineering Corporation (UEC). 2011. Disponível em: <http://www.uecin.com/>. Acesso em: agosto de 2011.

VANDRESEN, M. Aplicação da técnica do núcleo perdido na injeção de peças complexas, em moldes de ferramental rápido, a partir da estereolitografia. Engenharia Mecânica, Universidade Federal de Santa Catarina, Florianópolis/SC, 2004.

VCC, O. UV LED LAMP - VAOL-5EUV0T4. VCC, Optoelectronics. 2009. Disponível em: <http://vcclite.com/wp-content/files/VAOL-5EUV0T4-LED-5mm-UV.pdf>. Acesso em: 01 de dezembro de 2010.

VENKATESH, V. C. e S. IZMAN. Precision Engineering: McGraw-Hill. 2008. 418 p.

VESELOVSKIII, R. A. e V. N. KESTEL'MAN. Adhesion of polymers: McGraw-Hill. 2002. $404 \mathrm{p}$.

VISWANATH, D. S. Viscosity of liquids: theory, estimation, experiment, and data: Springer. 2007. $660 \mathrm{p}$.

VOLPATO, N., Ed. Prototipagem Rápida : Tecnologias e Aplicações: EDGARD BLUCHER, p.272, 1st ed. 2007.

VOZZI, G., A. PREVITI, et al. Microsyringe-based deposition of two-dimensional and three-dimensional polymer scaffolds with a well-defined geometry for application to tissue engineering. Tissue Engineering, v.8, n.6, p.1089-1098. 2002.

WEBSTER, J. G. The measurement, instrumentation, and sensors handbook: CRC Press. 1999. 1500 p.

WEI, T., S. CHOI, et al. Development of a sheet-based material handling system for layered manufacturing. Robotics and Automation, 2001. Proceedings 2001 ICRA. IEEE International Conference on. 2001, 2001. 1352-1357 vol.2 p.

WESTON, C. K. Liquid dispensing apparatus. US Patent office. USA: Nordson Corporation. 53485851993. 
WILLIAMS, C. B. Design and development of a layer-based additive manufacturing process for the realization of metal parts of designed mesostructure. (Dissertation). Mechanical Engineering, Georgia Institute of Technology, 2008. $421 \mathrm{p}$.

WILLIAMS, G. CNC robotics: build your own workshop bot: McGraw-Hill. 2003. $311 \mathrm{p}$.

WIPO. International Patent Classification (IPC). 2011. Disponível em: <http://www.wipo.int/>. Acesso em: julho de 2011.

WU, M., W. ZHAO, et al. A novel stereolithography technology with conventional UV light. Rapid Prototyping Journal, v.7, n.5, p.268-275. 2001.

YURTERI, S., A. ONEN, et al. Benzophenone based addition fragmentation agent for photoinitiated cationic polymerization. European Polymer Journal, v.38, p.6. 2002.

YURTERI, S., A. ONEN, et al. Yurteri, S.; Onen, A.; Yagci, Y. European Polymer Journal, v.38, p.5. 2002. 